Beiträge aus der Nordwestdeutschen Forstlichen Versuchsanstalt Band 10

\title{
Waldentwicklungsszenarien für das Hessische Ried
} Entscheidungsunterstützung vor dem Hintergrund sich beschleunigt ändernder Wasserhaushalts - und Klimabedingungen und den Anforderungen aus dem europäischen Schutzgebietssystem Natura 2000

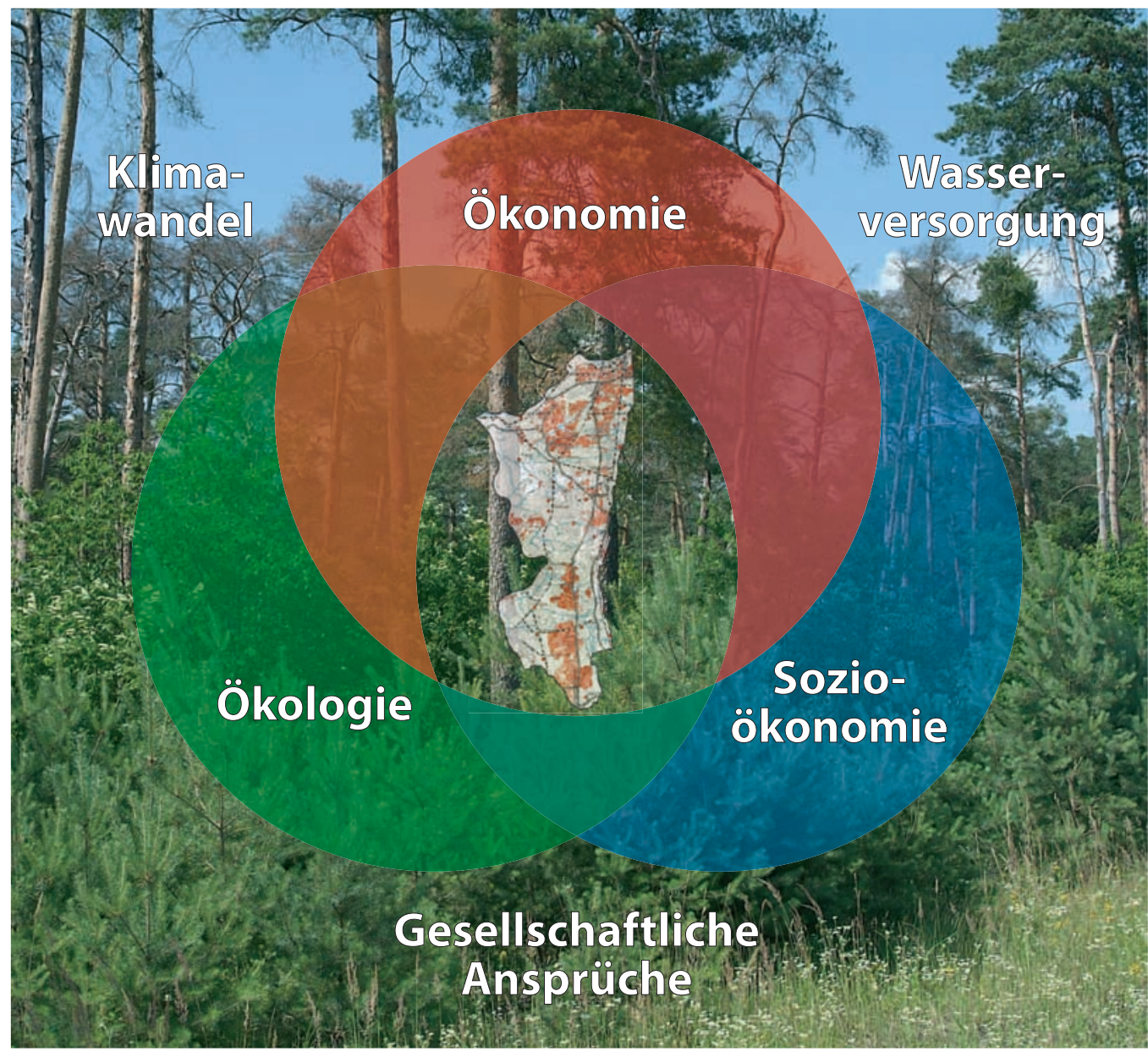

\section{@ Universitätsdrucke Göttingen}

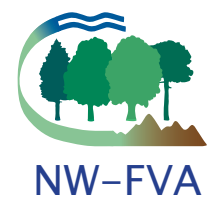



Nordwestdeutsche Forstliche Versuchsanstalt (Hrsg.)

Waldentwicklungsszenarien für das Hessische Ried

This work is licensed under the

Creative Commons License 3.0 "by-nd", allowing you to download, distribute and print the document in a few copies for private or educational use, given that the document stays unchanged and the creator is mentioned.

You are not allowed to sell copies of the free version.

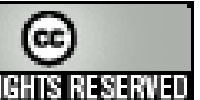


erschienen als Band 10 der Reihe „Beiträge aus der Nordwestdeutschen Forstlichen Versuchsanstalt“ in den Universitätsdrucken im Universitätsverlag Göttingen 2013 
Nordwestdeutsche

Forstliche Versuchsanstalt (Hrsg.)

\section{Waldentwicklungsszenarien für das Hessische Ried}

Entscheidungsunterstützung vor dem Hintergrund sich beschleunigt ändernder Wasserhaushalts- und Klimabedingungen und den Anforderungen aus dem europäischen Schutzgebietssystem Natura 2000

Beiträge aus der

Nordwestdeutschen

Forstlichen Versuchsanstalt

Band 10

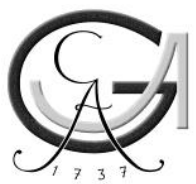

Universitätsverlag Göttingen 2013 


\section{Bibliographische Information der Deutschen Nationalbibliothek}

Die Deutsche Nationalbibliothek verzeichnet diese Publikation in der Deutschen Nationalbibliographie; detaillierte bibliographische Daten sind im Internet über $<$ http://dnb.ddb.de> abrufbar.

Global Forest Decimal Classification: 11; 116; 121; 2; 25; 4; 65

\section{Herausgeber der Reibe:}

Nordwestdeutsche Forstliche Versuchsanstalt (NW-FVA)

Grätzelstr. 2, D-37079 Göttingen

Tel.: +49 (0)551-69401-0, Fax: +49 (0)551-69401-160

E-Mail: zentrale@nw-fva.de

www.nw-fva.de

Schriftleitung der Reihe: Prof. Dr. Hermann Spellmann

Redaktion der Reibe: Inge Kehr, Ulrike Gaertner

Redaktion: Dr. Martin Rohde, Prof. Dr. Hermannn Spellmann

Autoren: Jörg Ahner, Dr. Bernd Ahrends, Falko Engel, Dr. Jan Hansen, Dr. Swen Hentschel, Dr. Rainer Hurling, Dr. Henning Meesenburg, Uwe Mestemacher, Dr. Peter Meyer, Prof. Dr. Bernhard Möhring, Prof. Dr. Jürgen Nagel, Ralf Nagel, Bianca Pape, Dr. Martin Rohde, Dr. Hendrik Rumpf, Dr. Marcus Schmidt, Dr. Matthias Schmidt, Prof. Dr. Hermann Spellmann, Johannes Sutmöller

Das Projekt „Waldentwicklungsszenarien für das Hessische Ried“ wurde von dem Hessischen Ministerium für Umwelt, Energie, Landwirtschaft und Verbraucherschutz finanziert.

Antragsteller: Nordwestdeutsche Forstliche Versuchsanstalt

Projektlaufzeit: März 2008 bis Dezember 2011

\section{Titelgrafik: Etta Paar}

Dieses Buch ist auch als freie Onlineversion über die Homepage der NW-FVA, des Verlages sowie über den OPAC der Niedersächsischen Staats- und Universitätsbibliothek (http://www.sub.uni-goettingen.de) erreichbar und darf gelesen, heruntergeladen sowie als Privatkopie ausgedruckt werden. Es gelten die Lizenzbestimmungen der Onlineversion. Es ist nicht gestattet, Kopien oder gedruckte Fassungen der freien Onlineversion zu veräußern.

(C) 2013 Universitätsverlag Göttingen

http://univerlag.uni-goettingen.de

ISBN: 978-3-86395-110-8

ISSN: $1865-6994$ 


\section{Inhaltsverzeichnis}

Zusammenfassung $\quad 1$

Abstract

1 Einleitung 11

1.1 Rahmenbedingungen, Rückblick, Begründung für das Projekt 11

1.2 Abgrenzung und Kurzbeschreibung des Projektgebietes 12

1.3 Untersuchungsansatz und Projektpartner 14

2 Material und Methoden $\quad 17$

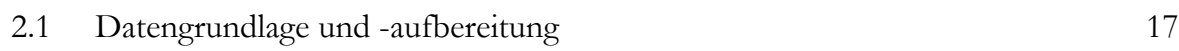

2.1.1 Forsteinrichtungsdaten / Waldbestandsdaten 18

$\begin{array}{ll}\text { 2.1.1.1 Ausgangssituation } & 18\end{array}$

2.1.1.2 Verknüpfung der Geometrie- und Sachdaten 19

2.1.1.3 Aufbereitung der Daten für den Waldwachstumssimulator und Aufbau der Modellbestände $\quad 20$

$\begin{array}{ll}2.1 .2 \text { Standortsdaten } & 20\end{array}$

2.1.2.1 Klima 20

2.1.2.2 Boden 25

2.1.2.3 Hydrologie $\quad 30$

2.1.3 Naturschutz $\quad 32$

2.1.3.1 Bestehende Naturschutzauflagen $\quad 32$

2.1.3.2 Habitatmodellierung / Hotspots 34

2.2 Beschreibung der Szenarien und. Modellansätze 37

2.2.1 Grundwasserszenarien $\quad 37$

2.2.2 Klimaszenarien 40

2.2.3 Untersuchungsansätze 43

2.2.4 Stoffhaushaltsmodellierung 43

2.2.4.1 Einfübrung 43

2.2.4.2 Modellierungsansatz. $\quad 45$

2.2.4.3 Modellauswabl und Anpassungen 46

2.2.4.4 Atmosphärische Stoffeinträge 49

2.2.4.5 Basenfreisetzung durch Verwitterung $\quad 55$

2.2.4.6 Nährstoffentnabme $\quad 56$

2.2.4.7 Koblenstoff- und Stickstoffhaushalt $\quad 58$

2.2.4.8 Dynamische Modellierung der Trophie $\quad 59$

2.2.4.9 Anfangs- und Randbedingungen der Modellrechnungen 64 
2.2.5 Wasserhaushaltsmodellierung 64

2.2.5.1 Modellbeschreibung 64

2.2.5.2 Regeln und Modellparametrisierung 66

2.2.5.3 Modellkalibrierung $\quad 68$

$\begin{array}{lll}\text { 2.2.6 Standort-Leistungs-Modell } & 70\end{array}$

2.2.6.1 Datengrundlage $\quad 71$

2.2.6.2 Modellierungsansatz. $\quad 73$

2.2.6.3 Modellierung des Standort-Leistungs-Bezuges $\quad 74$

$\begin{array}{lll}2.2 .7 & \text { Mortalitätsmodell } & 79\end{array}$

2.2.7.1 Allgemeines Mortalitätsmodell $\quad 79$

2.2.7.2 Maikeäfer-Mortalitäts-Modell $\quad 97$

2.2.8 Waldwachstumsmodell 106

2.2.8.1 Verjüngungsschichten und Einwuchs $\quad 111$

2.2.8.2 Ausscheidender Bestand, Holzentnabme und Totholz. 112

2.2.8.3 Totholzmodell 116

2.2.9 Habitatmodellierung und Identifikation von Hotspots 117

2.2.10 Naturschutzfachliche Regeln 122

2.2.10.1 Flächenhafter Nutzungsverzicht $\quad 123$

2.2.10.2 Erhalt der Waldgesellschaft $\quad 123$

2.2.10.3 Erbalt Altholz $\quad 125$

2.2.10.4 Mindestanzabl Habitatbäume $\quad 125$

$\begin{array}{ll}2.2 .11 \text { Waldbauregeln } & 125\end{array}$

2.2.11.1 Erfahrungswissen der Forstämter $\quad 125$

2.2.11.2 Ableitung der Waldbauregeln $\quad 126$

$\begin{array}{ll}\text { 2.2.12 Modellkopplung } & 134\end{array}$

2.2.12.1 Simulationsvorbereitung 136

2.2.12.2 Szenariosimulation 136

2.2.13 Ökologische Bewertung der Ergebnisse der Modellläufe 138

2.2.13.1 Buchen- und Eichen Lebensraumtypen der FFH-Richtlinie $\quad 138$

2.2.13.2 Hotspots 140

2.2.14 Ökonomische Bewertung 141

2.2.14.1 Modell- und Kalamitätsbetrieb 1967-2007 141

2.2.14.2 Bewertung der prognostizierten Waldentwicklung $\quad 150$

3 Ergebnisse $\quad 157$

3.1 Klimatische Verhältnisse 157

3.2 Auswirkungen der Klima- und Grundwasserstandszenarien auf den

3.2.1 Gebietswasserhaushalt 162

3.2.2 Einfluss des Grundwassers auf die Bestandesverdunstung 166 
3.2.3 Auswirkung eines extremen Trockenjahres auf den Wasserhaushalt 168

3.2.4 Wasserhaushalt ausgesuchter Einzelbestände $\quad 170$

$\begin{array}{ll}\text { 3.2.5 Bewertung des Trockenstressrisikos } & 174\end{array}$

3.3 Auswirkungen der Klima- und Grundwasserszenarien auf den Stoffhaushalt der Bestände

3.3.1 Atmosphärische Stoffeinträge

3.3.2 Versauerungs- und Nährstoffsituation

3.3.2.1 Zustand und Dynamik

3.3.2.2 Auswirkungen der Szenarioannabmen

185

3.3.3 Stickstoffhaushalt

3.3.3.1 Denitrifikation

3.3.3.2 Koblenstoff- und Stickstoffdynamik

3.3.3.3 N-Austräge mit dem Sickerwasser

3.3.4 Evaluierung und Diskussion der Modellansätze

3.3.5 Bewertung der Standortsbedingungen 200

3.4 Erfahrungswissen der Forstämter 201

3.4.1 Waldbestandsverhältnisse 201

3.4.2 Waldverjüngung 203

3.5 Auswirkungen auf die waldbaulichen Potenziale 204

3.5.1 Veränderung der Standortstypen 204

3.5.1.1 Ausgangssituation $2007 \quad 204$

3.5.1.2 Veränderung der Frischestufen $\quad 207$

3.5.2 Veränderungen der Waldstruktur 211

3.5.2.1 Baumartenverteilung 211

3.5.2.2 Horizontale und vertikale Waldstruktur 222

3.5.2.3 Potenziale der nachbaltigen Holzproduktion 229

3.5.2.4 Entwicklung des Schadholzaufkommens 233

3.5.2.5 Walderneuerung 237

$\begin{array}{ll}3.6 \text { Waldschutz } & 241\end{array}$

3.6.1 Populationsdichte der Waldmaikäfer im Hessischen Ried 243

3.6.1.1 Vergleich der realen und der geschätzten Populationsdichte 243

3.6.1.2 Vergleich der modellierten Populationsdichten 244

3.6.1.3 Einfluss der Bodenartengruppe auf die modellierte Engerlingsdichte 249

3.6.1.4 Einfluss des Grundwasseranschlusses auf die modellierte

Populationsdichte der Waldmaikäfer

3.6.2 Einfluss der Populationsdichte der Waldmaikäfer auf die Mortalität der Waldbäume

3.6.2.1 Gefäbrdung von Kulturen und natürlicher Verjüngung 254

3.6.2.2 Gefäbrdung älterer Bäume 256 
3.7 Naturschutz

3.7.1 Entwicklung der Waldlandschaft „Hessisches Ried“ von 1800 bis heute

3.7.2 Schutzgüter im Wald

260

3.7.2.1 Lebensräume

260

3.7.2.2 Arten

262

$\begin{array}{lll}\text { 3.7.3 Schutzgebiete } & 264\end{array}$

3.7.3.1 Räumliche Überlagerungen 264

3.7.3.2 Vergleich geschützter und nicht geschützter Wälder 265

3.7.3.3 Schutzgüter innerhalb und außerbalb von Schutzgebieten 269

3.7.4 Forstliche Nutzungsbeschränkungen durch Naturschutzauflagen 270

3.7.5 Hotspots der xylobionten Artenvielfalt 272

3.7.5.1 Ausgangszustand 272

3.7.5.2 Entwicklung der Habitateignung 277

3.7.6 Naturschutzfachliche Entwicklung der Buchen- und Eichenwälder im Simulationszeitraum 282

3.7.6.1 Simulierte Bestandesentwicklung in den Szenarien 282

3.7.6.2 Flächenentwicklung der Eichen-und Buchenbestände 283

3.7.6.3 Entwicklung der Eichen- und Buchen-Lebensraumtypen in den FFH-Gebieten 284

3.8 Ökonomische Bewertung 290

3.8.1 Modell- und Kalamitätsbetrieb 290

3.8.1.1 Bestandesklassenentwicklung 290

3.8.1.2 Ökonomische Kenngrößen 293

3.8.1.3 Baumartensperifische Betrachtung 296

3.8.2 Bewertung der Szenarien der prognostizierten Waldentwicklung 303

3.8.2.1 Holzerlöse 303

3.8.2.2 Wertentwicklung der Bestände $\quad 305$

3.8.2.3 Kulturkosten 306

3.8.2.4 Ertragswerte $\quad 307$

3.8.3 Baumartenspezifische Betrachtung 308

$\begin{array}{lll}\text { 3.8.3.1 Buche } & 308\end{array}$

3.8.3.2 Eiche 310

3.8.3.3 Kiefer $\quad 311$

3.8.3.4 Vergleich der Baumarten 313

3.8.4 Naturschutzbedingte Bewirtschaftungsbeschränkungen 314 
4 Diskussion und Schlussfolgerungen $\quad 315$

4.1 Material und Methoden 315

4.2 Wasserhaushalt im Klimawandel 318

$\begin{array}{lll}4.3 & \text { Stoffhaushalt } & 319\end{array}$

$\begin{array}{lll}4.4 & \text { Waldschutz } & 320\end{array}$

4.5 Waldbau 322

4.5.1 Baumartenwahl und Waldentwicklungstypen (WET)-Planung auf standörtlicher Grundlage $\quad 323$

4.5.2 Waldbauliche Maßnahmen 325

4.5.2.1 Kultur-/Jungwuchsstadium $\quad 325$

4.5.2.2 Differenqierungsstadium 326

4.5.2.3 Auslese- und Ausreifungsstadium $\quad 327$

4.5.2.4 Reife- und Regenerationsstadium 328

$\begin{array}{lll}\text { 4.6 Naturschutz } & 328\end{array}$

4.6.1 Schutzgebietsüberlagerungen und Nutzungseinschränkungen 328

4.6.2 Habitateignung 329

4.6.3 FFH-Gebiete und Lebensraumtypen 329

4.7 Ökonomie 331

4.7.1 Ertragswerte 331

4.7.2 Baumartenvergleich 332

$\begin{array}{ll}\text { Literatur } & 335\end{array}$

Autoren $\quad 355$

Anhang $\quad 359$

Anhang 1: Niederschlags- und Klimastationen $\quad 359$

Anhang 2: Stoffhaushaltsmodell $\quad 361$

Anhang 3: Fragebogen Waldbewirschaftung 390

Anhang 4: Sortimentierungsschlüssel $\quad 391$

Anhang 5: Ertagswertdifferenzen 396 



\section{Waldentwicklungsszenarien für das Hessische Ried}

Entscheidungsunterstützung vor dem Hintergrund sich beschleunigt ändernder Wasserhaushalts- und Klimabedingungen und den Anforderungen aus dem europäischen Schutzgebietssystem Natura 2000

\section{Forest development scenarios for the Hessian Ried}

Decision support in view of accelerated change in the water budget and climatic conditions, and requirements of the European network of protected areas Natura 2000

\section{Zusammenfassung}

Im November 2006 verabschiedeten alle Fraktionen des Hessischen Landtages eine gemeinsame Entschließung zur langfristigen Sanierung der bereits stark geschädigten südhessischen Wälder. Dieser Parlamentsbeschluss war der Anlass für das Projekt „Waldentwicklungsszenarien für das Hessische Ried“, das von Anfang 2008 bis Ende 2011 an der Nordwestdeutschen Forstlichen Versuchsanstalt in Zusammenarbeit mit dem Servicezentrum Forsteinrichtung und Naturschutz (FENA) des Landesbetriebes HESSEN-FORST und Instituten der Universität Göttingen bearbeitet wurde.

Ziel des Verbundprojektes war es, mit einem modellorientierten Ansatz die Auswirkungen der sich ändernden Umweltbedingungen auf die Leistungen und Wirkungen der Wälder sowie auf die Handlungsspielräume der Forstbetriebe im Hessischen Ried für einen 30-jährigen Prognosezeitraum abzubilden. Hierdurch 
sollte eine raumbezogene Wissens- und Entscheidungsbasis für die Politik, Fachverwaltungen und Waldbesitzer erarbeitet werden, um die Waldfunktionen bzw. die gesellschaftlichen Ansprüche an den Wald in der Fläche neu zu gewichten, Vermeidungs- bzw. Anpassungsstrategien zu entwickeln und gezielte Maßnahmen zur Sanierung der bereits stark geschädigten Waldgebiete einzuleiten.

Das Untersuchungsgebiet wird im Norden durch die Stadt Frankfurt, im Osten durch die Bundesstraße B3 und im Süden und Westen durch die Landesgrenze begrenzt. Die Waldfläche beträgt ca. 30.000 Hektar, die sich auf etwa $51 \%$ Landes-, $44 \%$ Kommunal- und ca. $5 \%$ Privat- und Bundeswald verteilen. Im öffentlichen Wald überwiegen die Baumarten Eiche (26\%), Rotbuche $(31 \%)$ und Kiefer (39 \%). Die Mehrzahl der Flächen ist mit Wasserschutz-, NaturschutzKlimaschutz- und Erholungsfunktionen belegt. Das Hessische Ried ist durch ungünstige Waldstandorte und ein bereits heute trocken-warmes Klima gekennzeichnet. Im Zusammenwirken von Grundwasserabsenkungen ab Mitte der sechziger Jahre, biotischen und abiotischen Schadereignissen sowie Einträgen aus der Luft sind die Waldökosysteme des Projektgebiets stark destabilisiert und die Forstbetriebe in ihrem waldbaulichen Handeln stark eingeschränkt.

Der Untersuchungsansatz ist stark modellorientiert. Im Zentrum steht ein flächendifferenziertes, GIS-basiertes, multiskaliges Gebietsmodell. Es stützt sich auf eine GIS-Datenbasis, in der die aufbereiteten Informationen zur Landnutzungsform, zum Standort, zum Lokalklima, zum Wassermanagement, zu den Beständen, zum Schutzgebietsstatus (wasser-, forst- und naturschutzrechtliche Schutzgebiete), zum Arteninventar und zum Waldzustand verwaltet werden. Die Waldbehandlung wird unter Beachtung naturschutzrechtlicher Auflagen regelbasiert gesteuert. Die erfassten Ist-Zustände im Hessischen Ried liefern die Grundlage für die betrachteten Waldentwicklungsszenarien bis zum Jahr 2039, die von folgenden Annahmen ausgehen:

\section{Grundwasser:}

- Status quo (GW0): Die Grundwasserstände werden auf dem Niveau des Grundwasserbewirtschaftungsplans Hessisches Ried (RP DARMSTADT 1999) festgeschrieben.

- Weitere Absenkung der Grundwasserstände (GW-): Die Grundwasserstände sinken auf allen Flächen unter ein von den Baumwurzeln noch erreichbares Niveau.

- Anhebung der Grundwasserstände (GW+): Die Grundwasserstände werden wieder auf das Niveau vor Beginn der industriellen Grundwasserentnahmen angehobe

\section{Klima:}

- Referenz, (Ref): unveränderte Klimaentwicklung bezogen auf die Klimanormalperiode 1961 bis 1990 
- Feuchtes Klimaszenario (A1Bf): 20 feuchteste Läufe des mit dem statistischen

Modell WETTREG regionalisierten Klimaszenarios A1B

- Trockenes Klimaszenario (A1Bt): 20 trockenste Läufe des mit dem statistischen Modell WETTREG regionalisierten Klimaszenarios A1B

Der modulare Projektansatz erlaubte durch die Kopplung von GIS, Wasserhaushaltsmodell, Waldwachstumssimulator und Expertenwissen sowohl die regelbasierte Umsetzung der verschiedenen waldbaulichen Entwicklungsszenarien, deren Modifikation, flexible Entwicklung, Anwendung und Bewertung, als auch eine Kombination der Varianten in der Fläche. Zentrales Prognosewerkzeug war das waldbauliche Entscheidungsunterstützungssystem WaldPlaner der Nordwestdeutschen Forstlichen Versuchsanstalt. Mit ihm war es möglich, folgende, z. T. regelbasierte Teilmodelle zu einem Gesamtsimulationssystem zu kombinieren:

- Grundwasserstände

- Atmosphärische Stickstoffeinträge

- Wasserhaushalt

- Standort-Leistung

- Allgemeines Mortalitätsmodell

- Maikäfermortalitätsmodell

- Waldwachstumsmodell (TreeGrOSS)

- Naturschutzregeln / Naturschutzfachliche Vorgaben

- Waldbauregeln / Waldbaustrategien

Auf diesem Wege gelang es, nicht nur die Waldentwicklung seit Mitte der sechziger Jahre bis zum Stichjahr 2007 nachzuzeichnen und eine Zustandsanalyse zu ermöglichen, sondern auch die Auswirkungen unterschiedlicher Grundwasserverhältnisse und klimatischer Bedingungen bis zum Jahr 2039 erfolgreich zu simulieren und zu quantifizieren.

Die Ergebnisse bestätigen, dass die Wälder im Ballungsraum Rhein-Main zu den forstlichen Brennpunkten in Mitteleuropa gehören. Flächenverbrauch, Zerschneidung, Stoffeinträge aus der Luft, steigender Wasserbedarf und Erholungsdruck führen zu einer schleichenden Destabilisierung der Wälder.

Die abiotischen Belastungen, und hier insbesondere der Trockenstress sowie die gravierenden Grundwasserabsenkungen seit Anfang der 70er-Jahre, haben mittlerweile auf großen Flächen die Waldökosysteme soweit geschwächt, dass massive biotische Schäden vor allem durch Maikäfer und Kiefernmisteln hinzukommen, die zu Waldauflösungserscheinungen führen. Ein geordneter Forstbetrieb ist vielerorts nicht mehr möglich. Die betriebswirtschaftlichen Verluste der letzten 40 Jahre belaufen sich bei vorsichtigen Annahmen auf ca. 70 Millionen Euro.

Die ökologischen Rahmenbedingungen werden sich in Zukunft durch den Klimawandel weiter verschlechtern. Die reale Verdunstung wird zunehmen, die Grundwasserspende sinken und der Infiltrationsbedarf zum Aufrechterhalten der bisherigen Grundwasserstände steigen. 
Die simulierten Grundwasserszenarien (weitere Absenkung [GW-], Anhebung $[\mathrm{GW}+])$ führen zu einer Halbierung bzw. Verdoppelung der Flächenanteile mit sicherem Grundwasseranschluss. Heute beträgt ihr Anteil nach dem Grundwasserbewirtschaftungsplan Hessisches Ried (Referenz [GW0]) noch $18 \%$.

Die Mehrzahl der grundwasserfernen Standorte (> $60 \%$ der Fläche) wird auf die Klimaänderungen sehr sensitiv reagieren. Die Wasserversorgung wird sich verschlechtern und der Trockenstress wird sich für die Waldbestände erhöhen. Hierdurch werden die waldbaulichen Entwicklungsmöglichkeiten weiter eingeschränkt. Das Hauptaugenmerk der waldbaulichen Maßnahmen muss auf die Stabilisierung der vorhandenen Bestände, die Senkung bzw. Verteilung der Risiken und den Umbau der heute bzw. künftig nicht mehr standortsgemäßen Bestockungen gerichtet werden.

Zur Stabilisierung der Bestände und zur Verteilung der Risiken sind gestaffelte Durchforstungen, die Förderung von Mischbaumarten, erhöhte Z-Baumzahlen, variable Zielstärken in Abhängigkeit von Vitalität, Qualität und Entwertungsgefahr sowie ein konsequenter Waldschutz besonders wichtige Maßnahmen.

Für den standortsgemäßen Waldumbau stehen der forstlichen Praxis mit den im Projekt aufbereiteten Standortsinformationen und neu entwickelten Matrizen für Waldentwicklungstypen (WET) jetzt bestandesbezogen Informationen zur Verfügung, die eine Beurteilung der heutigen bzw. künftigen Standortseignung der vorhandenen Bestockungen sowie die Auswahl standortsgemäßer Baumarten bei Verjüngungsmaßnahmen erlauben. Ökonomisch verspricht auch unter den Bedingungen des trockenen Klimaszenarios der Anbau der Kiefer, der Edellaubbaumarten und der Douglasie relativ stabile Ertragswerte.

Der Erfolg von Verjüngungsmaßnahmen hängt in weiten Bereichen des Hessischen Rieds entscheidend von der lokalen Maikäfersituation ab. In den Gradationsgebieten ist eine wirksame Reduzierung der Engerlingsdichten ökologisch wie ökonomisch dringend geboten.

Angesichts der gravierenden ökologischen Veränderungen sind statische Ansätze für die Waldsanierung im Hessischen Ried nicht zielführend. Auch in Zukunft wird es dort Wald geben, aber er wird vielerorts anders zusammengesetzt und aufgebaut sein und nicht mehr die gleichen Funktionen in derselben Güte erfüllen. Insbesondere die Perspektiven für die Eichen- und Buchen-Waldgesellschaften sind ungünstig und erfordern eine naturschutzfachliche Auseinandersetzung mit diesem Sachverhalt. Im Rahmen des Vorhabens wurden die Vorrangflächen für den Erhalt von Eichenwäldern im Sinne von Hotspots identifiziert.

Das Projekt stellt der Politik, den Fachverwaltungen und den Waldbesitzern eine raumberogene Wissens- und Entscheidungsbasis zur Verfügung, um die Waldfunktionen bzw. die gesellschaftlichen Ansprüche an den Wald in der Fläche neu zu gewichten, Vermeidungs- bzw. Anpassungsstrategien zu entwickeln und gezielte Maßnahmen zur Sanierung der bereits stark geschädigten Waldgebiete einzuleiten. 
Zur Dokumentation der Vitalitätsentwicklung und zur Bereitstellung zuverlässiger Planungsdaten erscheint es notwendig, eine eigene Betriebsklasse „Hessisches Ried“ für die von HESSEN-FORST bewirtschafteten bzw. betreuten Wälder zu schaffen und deren Naturalausstattung durch eine permanente, systematische Stichprobe zu erfassen.

Fazit:

Im Hessischen Ried sind die Wälder und mit ihnen eine nachhaltige, multifunktionale Forstwirtschaft stark gefährdet. Es ist höchste Zeit, die vielfältigen Ansprüche an die Forstbetriebe besser mit den Eigentümerinteressen abzustimmen. Hierzu ist die Vielzahl der Sachziele neu zu ordnen, in einem Zielsystem hierarchisch zu strukturieren und entsprechend ihrer raumbezogenen Bedeutung neu zu gewichten. Zur Sicherung der Waldfunktionen müssen bisher aufgeschobene Entscheidungen zeitnah getroffen werden. Die möglichen Sanierungsmaßnahmen sind an ihrer Wirksamkeit und ihren Gesamtkosten zu messen.

Stichworte: Hessisches Ried, Grundwasser, Klimawandel, Waldentwicklungsszenarien, Wasserhaushalt, Stoffhaushalt, Waldbau, Waldschutz, Naturschutz, ökonomische Bewertung

\section{Abstract}

In November 2006 all fractions of the state parliament of Hesse, Germany, ratified a joint resolution for the long-term rehabilitation of the degraded forests in southern Hesse. This parliamentary decision was the impetus for the project "Forest Development Scenarios for the Hessian Ried", conducted between the beginning of 2008 to the end of 2011 by the Northwest German Forest Research Station in cooperation with the Forest Survey and Conservation Service (FENA) of the Hesse State Forest Enterprise, HESSEN-FORST, and institutes at the Göttingen University.

The aim of the joint project was to model the effects of the changing environmental conditions (climate change, groundwater condition) on the productivity and properties of forests as well as on the range of management options available to the forest enterprise in the Hessian Ried for a 30-year prediction period. With a compilation of different models, a spatial database for knowledge and decision making was developed to assist politicians, forest managers, and forest owners to re-assess the forest functions and community expectations of the forest in the area. Furthermore it would assist the development of avoidance or adaptation strategies and the introduction of specific measures for the rehabilitation of the areas of severely degraded forest. 
The research area is bounded by the City of Frankfurt to the north, the highway B3 to the east and the state borders to the south and west. The forest area covers about $30000 \mathrm{ha}$, comprising approximately $51 \%$ state forest, $44 \%$ communal forests, and about $5 \%$ private and national forest. In the public forests, the predominant tree species are oak (26\%), European beech $(31 \%)$ and Scots pine $(39 \%)$. Much of area serves water catchment protection, nature conservation, climate protection and recreation functions. The Hessian Ried is characterised by forest sites with low productivity and the current climate is typically dry and warm. The combined effects of the reduction in the water table in the mid-1960s, the occurrence of biotic and abiotic damage and atmospheric inputs have led to severe destabilisation of the forest ecosystems, imposing tight constraints on the silvicultural options available to the forest enterprises.

The research approach adopted was very much a model-based one. A spatial, multi-scale area model was used. The model was supported by a GIS database which managed data collated on land use types, site characteristics, local climate, water management, stand data, the legal protection status (water, forest, and nature conservation protection areas), plant species surveys and forest condition. Under consideration of the protection regulations, forest management options were devised in a rules-based system. The current status of the Hessian Ried provided the basis for the forest development scenarios up until 2039. In the scenarios, the following assumptions were made.

\section{Groundwater}

- Status quo (GWO): the groundwater levels are set to the levels specified in the groundwater management plan for the Hessian Ried (RP DARMSTADT 1999).

- Further reduction in the groundwater table ( $G W$-): the groundwater table falls to a level below that which can be reached by tree roots in all areas.

- Rise in the groundwater table $(G W+)$ : the groundwater levels are raised to the level prevalent before commencement of industrial groundwater extraction.

\section{Climate}

- Reference (Ref): unchanged climatic conditions based on the climatological standard normals between 1961 and 1990.

- Wet climate scenario (A1Bf): 20 of the wettest regional climate scenarios A1B run in the statistical model WETTREG.

- Dry climate scenario (A1Bt): 20 of the driest regional climate scenarios A1B run in the statistical model WETTREG.

By linking the GIS, the water budget model and the forest growth simulator and by incorporating expert knowledge, the module approach enabled both the rulesbased implementation of the different silvicultural development scenarios, their modification, flexible development, use and assessment as well as a combination of the variants in the area. WaldPlaner, the silvicultural decision support system 
developed by the Northwest German Forest Research Station, was the central prediction tool in this process. It made it possible to combine the following models, some of which are rule-based, into an entire simulation system:

- Groundwater levels

- Atmospheric nitrogen inputs

- Water budget

- Site productivity

- General mortality model

- Cockchafer mortality model

- Forest growth model (TreeGrOSS)

- Conservation regulations/conservation prescriptions

- Silvicultural rules/silvicultural strategies

In this way it was possible, not only to model the forest development from the mid-1960s up to the year 2007 and analyse current status, but also to simulate and quantify successfully the effects of various groundwater and climatic conditions up to the year 2039.

The results confirm that the Rhine-Main conurbation is one of the regions in Central Europe in which forest management faces major challenges. Land acquisition, forest fragmentation, deposition from the atmosphere, increasing demand for water and pressure for recreational areas destabilize the forests.

The abiotic impacts, in particular drought stress and a marked lowering of the groundwater table since the beginning of the 1970s, have gradually weakened large areas of the forest ecosystems to the extent that massive biological damage, predominantly from cockchafer and Scots pine mistletoe infestations, have also affected the forests such that forest dieback is now evident. A regular forest management is no longer possible in many locations. The economic losses of enterprises in the last 40 years amount, for conservative estimates, to about 70 million Euros

The ecological conditions will deteriorate further in the future due to climate change. The actual evaporation will increase, the groundwater discharge will decrease, and the infiltration needed to maintain the groundwater table at the same level will increase.

The simulated groundwater scenarios (further drop [GW-], rise $[G W+]$ ) lead to a halving or doubling of the areas assured of access to groundwater respectively. Today, according to the groundwater management plan for the Hessian Ried, this area still amounts to $18 \%$. (Reference [GW0]).

Most of the sites without access to groundwater ( $>60 \%$ of the area) will be very sensitive to climate change. The water supply will worsen and drought stress will increase in the forest stands. As a result, the silvicultural development options will become increasingly limited. The silvicultural measures must focus on the stabili- 
sation of existing stands, the reduction or distribution of risks and the conversion of the stands that neither today nor tomorrow are suitable for the site.

To stabilise stands and distribute the risks, graduated thinnings, the promotion of mixed species, increased number of future crop trees, variable target diameters in relation to vitality, quality and risk of devaluation and sound forest protection are particularly important measures.

For site-specific forest conversion, which takes the given site conditions into consideration, the forest management now have access to site-specific information through the site data collated in the project and the newly developed matrices for forest development types (WET). This information will facilitate an assessment of current or future site suitability of the existing stands and the selection of tree species for regeneration that are appropriate for the site. The planting of Scots pine, Maple, Ash, and Douglas fir promise relatively stable economic yields even if the dry climate scenario eventuates.

The success of regeneration measures over much of the Hessian Ried area depends largely on the local cockchafer populations. In the infestation areas, an effective reduction in the larvae density is urgently needed from an ecological and economic perspective.

In view of the serious ecological changes, static approaches for the forest rehabilitation in the Hessian Ried would not achieve the desired objectives. While forests will also exist there in the future, they will have a different composition and structure over much of the area, and will no longer be able to fulfil the same functions at the same quality. In particular, given the unfavourable outlook for oak and for beech forest communities, a review of the conservation situation of these forest communities is required. As part of this project, the identified hotspots of biodiversity will become the priority areas for the maintenance of oak forest.

The project provides politicians, forest managers and forest owners with a spatial knowledge and decision tool for assessing the forest functions and community expectations of forests in this area, for developing avoidance or adaptations strategies and for introducing specific measures for the rehabilitation of the already severely degraded forest areas.

For the documentation of vitality development and the provision of reliable planning data, a management category "Hessian Ried" for the forests managed or supervised by HESSEN-FORST should be created and the natural resources of these forests should be monitored via a permanent systematic sampling.

\section{Conclusion:}

In the Hessian Ried, the forests and, with them, sustainable, multipurpose forestry are in danger of failing. It is high time the multiple demands on forest enterprises were brought into better agreement with the owners interests. Here, the many objectives need to be reappraised, restructured into a hierarchical system, and 
assessed in terms of their spatial importance. To ensure the forest functions, decisions which have been postponed in the past must be made soon. The possible rehabilitation measures need to be evaluated in terms of their effectiveness and overall costs.

Keywords: Hessian Ried, groundwater, climate change, forest development scenarios, water budget, nutrient budget, silviculture, forest protection, nature conservation, economic assessment 



\section{Einleitung}

\subsection{Rahmenbedingungen, Rückblick, Begründung für das Projekt}

Die Wälder im Ballungsraum Rhein-Main gehören zu den forstlichen Brennpunkten in Mitteleuropa. Auf engsten Raum werden hier außergewöhnliche Ansprüche an den Wald und die Forstbetriebe gestellt, die sich aus der hohen Bevölkerungsdichte, der starken Industrialisierung und dem engen Verkehrswegenetz ergeben. Flächenverbrauch, Zerschneidung, Stoffeinträge aus der Luft, stetig steigender Wasserbedarf und Erholungsdruck sind die Folgen. Die abiotischen Belastungen, und hier insbesondere die gravierenden Grundwasserabsenkungen, haben mittlerweile auf großen Flächen die Waldökosysteme soweit geschwächt, dass massive biotische Schäden durch Maikäfer, Borkenkäfer und Schwammspinner hinzukommen, die zu Waldauflösungserscheinungen führen. Die Lage wird sich in Zukunft weiter zuspitzen, wenn die Grundwasserentnahmemengen weiter erhöht werden sollen und die prognostizierten Klimaveränderungen für die Vegetationszeit höhere Temperaturen und geringere Niederschläge bewirken. Bereits heute gehört das Hessische Ried zu den trockensten und wärmsten Gebieten in Hessen.

Mit der Verlichtung der Bestände geht eine zunehmende Vergrasung der Bestände einher, die die Wasserbilanzen verschlechtert und die waldbaulichen Handlungsspielräume der Forstbetriebe stark einschränkt. Dies kollidiert gleichzeitig mit den naturschutzfachlichen Anforderungen, die sich aus dem europäischen Schutzgebietssystem NATURA 2000 ergeben, dessen Gebietskulisse im Hessischen Ried rund 15.000 ha Wald umfasst. Für die Waldbesitzer wird es zunehmend schwieriger, die Grundpflichten gemäß \6 des Hessischen Forstgesetzes (HFORSTG 2002) zu erfüllen. Dies gilt vor allem in den ausgewiesenen forstrechtlichen Schutzgebieten. Zusätzliche Ansprüche ergeben sich außerdem aus der Umsetzung der Wasserrahmenrichtlinie (EG WRRL) der Europäischen Gemeinschaft (EUROPÄISCHES PARLARMENT u. EUROPÄISCHER RAT 2000)

Bereits in den Jahren 1996 bis 1999 hat die damalige Hessische Landesforstverwaltung eine umfassende Analyse der Situation der Wälder im Rhein-MainGebiet vorgenommen und ein differenziertes Konzept zur Stabilisierung und Erhaltung dieser gefährdeten Waldbestände erarbeitet (PRIES et al. 1999). Die hieraus abgeleiteten Sanierungsmaßnahmen hatten für eine Sanierungsfläche von knapp 1.900 Hektar innerhalb eines Vier-Jahres-Zeitraums ein Gesamtvolumen von über 23 Millionen DM. Trotz der Umsetzung vieler der konkret geplanten Maßnahmen konnte keine grundlegende Verbesserung der Situation erreicht werden, insbesondere deswegen, weil sich die belastenden Rahmenbedingungen (Grundwasserent- 
nahme, Insektenbefall, Witterungsverhältnisse, ...) eher weiter verschlechtert als gebessert haben.

Vor diesem Hintergrund haben die Fraktionen des Hessischen Landtages im Jahr 2006 eine gemeinsame Entschließung zur langfristigen Sanierung der südhessischen Wälder verabschiedet (HESS. LANDTAG 2006). Deren Erhaltung und Entwicklung soll durch das Projekt „Waldentwicklungsszenarien für das Hessische Ried" unterstützt werden.

Ziel des Verbundprojektes ist der Aufbau eines Entscheidungsunterstützungssystems, mit dem sich die Auswirkungen der sich ändernden Umweltbedingungen auf die Leistungen und Wirkungen der Wälder sowie auf die Handlungsspielräume der Forstbetriebe im Hessischen Ried abbilden lassen. Diese Prognosen bilden eine raumbezogene Wissens- und Entscheidungsbasis für die Politik, Fachverwaltungen und Waldbesitzer, um die Waldfunktionen bzw. die gesellschaftlichen Ansprüche an den Wald in der Fläche neu zu gewichten, Vermeidungs- bzw. Anpassungsstrategien zu entwickeln und gezielte Maßnahmen einzuleiten um den Gesamtnutzen zu optimieren.

\subsection{Abgrenzung und Kurzbeschreibung des Projektgebietes}

Das Untersuchungsgebiet wird im Norden begrenzt durch die Stadt Frankfurt, im Osten durch die Bundesstraße B3 und im Süden und Westen durch die Landesgrenze. Das gesamte Untersuchungsgebiet ist rund 106.000 Hektar groß, bei einer maximalen Nord-Süd-Ausdehnung von etwa $55 \mathrm{~km}$ und einer maximalen OstWest-Ausdehnung von knapp $30 \mathrm{~km}$.

Das Projektgebiet umfasst die Wälder des Hessischen Rieds (s. Abb. 1). Die Waldfläche beträgt ca. 30.000 Hektar, die sich auf etwa 51 \% Landes-, 44 \% Kommunal- und ca. $5 \%$ Privat- und Bundeswald verteilen. Sie werden von den hessischen Forstämtern Darmstadt, Groß-Gerau, Lampertheim und Langen sowie dem Stadtforstamt Frankfurt bewirtschaftet und betreut. Im öffentlichen Wald überwiegen die Baumarten Eiche (26\%), Rotbuche (31 \%) und Kiefer (39\%). Die Mehrzahl der Flächen ist mit Wasserschutz-, Naturschutz- Klimaschutz- und Erholungsfunktionen belegt. Knapp 15.000 ha gehören zur Natura 2000-Gebietskulisse, die mehrere Buchen- und Eichen-Lebensraumtypen einschließt, und in der zahlreiche prioritäre Waldarten leben.

Bei einer Höhenlage von 80 bis $100 \mathrm{~m}$ ü. NN liegt der bearbeitete Bereich in der planaren Höhenstufe und damit in der zentralen Eichen-Mischwald-Zone mit schwach subkontinentaler Klimaprägung. Schon heute ist das Regionalklima durch eine überdurchschnittlich hohe Temperatur von über $16^{\circ} \mathrm{C}$ in der Vegetationszeit, einer Jahresmitteltemperatur von über $10{ }^{\circ} \mathrm{C}$ und von geringen Jahresniederschlägen um $660 \mathrm{~mm}$, in besonders ungünstigen Teilbereichen im Westen auch darunter, charakterisiert. Ca. $340 \mathrm{~mm}$ der Jahresniederschlagsmenge fallen in der Vegetationszeit, wobei es sich häufig um Niederschläge mit geringer Intensität handelt. 
Die klimatische Wasserbilanz in der Vegetationszeit gestaltet sich damit bereits heute deutlich negativ. Verschärft wird dieses Problem durch die geringe Speicherkapazität der Böden und die zuweilen geringen Niederschläge im Spätwinter, die den Bodenwasserspeicher nicht wieder auffüllen.

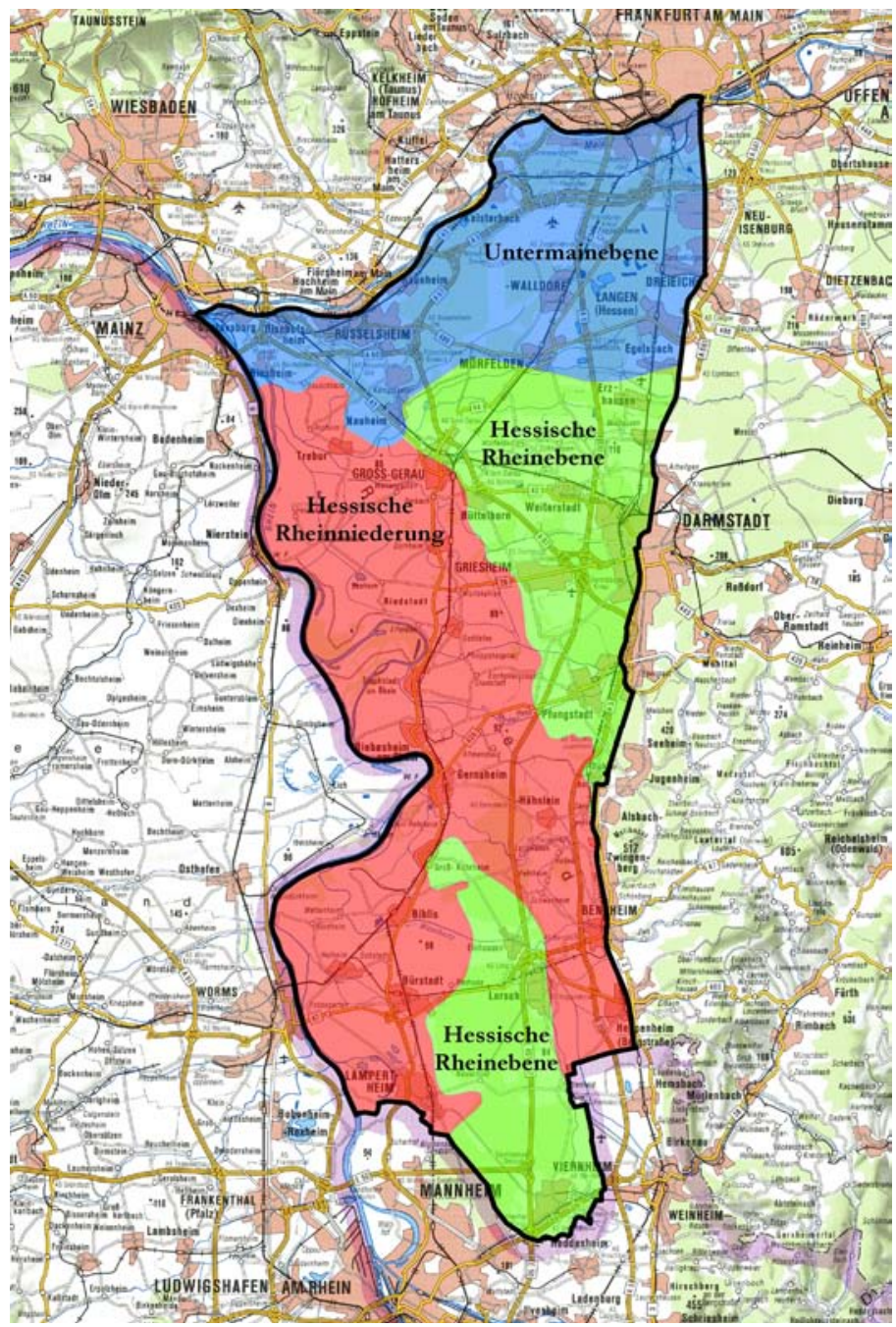

Abbildung 1: Abgrenzung des Projektgebietes

Bei den Ausgangssubstraten der Bodenbildung handelt es sich meistens um Terrassensande und -kiese bzw. Flugsande, auf einem deutlich geringeren Flächenanteil sind es Hochflutlehme, die, häufig als strenge Tone zum Teil unterlagert mit einer kaum durchwurzelbaren Kalkschicht (Rhein-Weiß) ausgeprägt, ebenfalls schwierige Waldstandorte darstellen. 
Unter waldökologisch-naturräumlichen Aspekten handelt es sich in etwa um das Wuchsgebiet Hessische Rhein-Main-Ebene mit den Wuchsbezirken Hessische Rheinniederung (ca. 45 Prozent der Gesamtfläche des Untersuchungsgebietes), Hessische Rheinebene (ca. 30 Prozent der Gesamtfläche des Untersuchungsgebietes) und dem westlichen Teil des Wuchsbezirks Untermainebene (ca. 25 Prozent der Gesamtfläche des Untersuchungsgebietes).

Bis zur Wende vom 19. zum 20. Jahrhundert prägte das auf großer Fläche im Mittel nur ein bis drei Meter unter Flur anstehende, häufig nährstoffreiche Grundwasser die forstlichen Standorte. Grundwasserabsenkungen im 20. Jahrhundert, die sich besonders seit den 60er-Jahren rasant verstärkten, haben hier zu einer drastischen Verschlechterung vieler Standorte geführt. Derzeit ist das Grundwasser auf dem größten Teil ehemals grundwasserbeeinflusster Standorte nicht mehr wurzelerreichbar.

Das Hessische Ried ist somit gekennzeichnet durch ungünstige Waldstandorte und ein bereits heute trocken-warmes Klima. Im Zusammenwirken mit den prognostizierten Klimaänderungen, weiteren anthropogenen Schadeinflüssen wie Stoffeinträgen, Ozonbelastung und Waldzerschneidung, in jüngerer Vergangenheit auftretenden Insektenkalamitäten (Maikäfer, Kiefern- und Eichenprachtkäfer, Eichenblatt-Fraßgesellschaft) und den Sturmschäden von 1990 führte das zu einer starken Destabilisierung der Waldökosysteme des Projektgebiets. Die Folgen sind teils dramatische Zuwachsverluste, Vitalitätseinbußen bis zu erhöhten Absterberaten verbunden mit einer Verlichtung, Vergrasung und Verwilderung der Bestände, dem Ausbleiben natürlicher Verjüngung sowie enorme Hindernisse für die künstliche Bestandesbegründung. Die Forstbetriebe der Region stellt das vor große waldbauliche Probleme, die ihre wirtschaftliche Situation stark belasten, die Einhaltung der Grundpflichten nach $\ 6$ des Hessischen Forstgesetzes zunehmend erschweren, vor allem aber die Erfüllung der Waldfunktionen und in Teilbereichen sogar die Existenz des Waldes bedrohen.

\subsection{Untersuchungsansatz und Projektpartner}

Das Verbundprojekt ist stark modellorientiert. Im Zentrum steht ein flächendifferenziertes, GIS-basiertes, multiskaliges Gebietsmodell. Es stützt sich auf eine GIS-Datenbasis, in der die aufbereiteten Informationen zur Landnutzungsform, zum Standort, zum Lokalklima, zum Wassermanagement, zu den Beständen, zum Schutzgebietsstatus (wasser-, forst- und naturschutzrechtliche Schutzgebiete), zum Arteninventar und zum Waldzustand verwaltet werden. Parallel dazu wurden mit Hilfe von Literaturrecherchen, Weiserflächenauswertungen und der Analyse vorliegender Forsteinrichtungsergebnisse und forstbetrieblicher Erfahrungen die Erfolge bzw. Misserfolge verschiedener Bewirtschaftungsstrategien bei unterschiedlichen standörtlichen und waldbaulichen Ausgangssituationen abgeschätzt und in Regeln für die Waldbehandlung überführt. 
Die erfassten Ist-Zustände im Hessischen Ried liefern die Grundlage für die betrachteten Waldentwicklungsszenarien bis zum Jahr 2030 (s. Abb. 2). Diese bilden die Waldentwicklung unter folgenden Grundannahmen ab:

(1) Status quo (GW0):

Die Grundwasserstände werden auf dem Niveau des Grundwasserbewirtschaftungsplans Hessisches Ried (RP DARMSTADT 1999) festgeschrieben.

(2) Weitere Absenkung der Grundwasserstände (GW-):

Die Grundwasserstände sinken auf allen Flächen unter ein von den Baumwurzeln noch erreichbares Niveau.

(3) Anbebung der Grundwasserstände (GW+):

Die Grundwasserstände werden wieder auf das Niveau vor Beginn der industriellen Grundwasserentnahmen angehoben (Bezugsjahr: 1951).

Diese drei Grundwasserszenarien werden jeweils mit drei Klimaszenarien kombiniert, nämlich zum einen unter der Annahme einer unveränderten Klimaentwicklung bezogen auf die Klimanormalperiode 1961 bis 1990 als Referenz (Ref) und zum anderen mit der feuchten sowie der trockenen Variante des mit dem Modell WETTREG regionalisierten Klimaszenarios A1B (A1Bf bzw. A1Bt)

Das Gesamtprojekt ist in acht Teilprojekte (TP) untergliedert, die von der Nordwestdeutschen Forstlichen Versuchsanstalt (NW-FVA), der Forstwissenschaftlichen Fakultät der Universität Göttingen sowie HESSEN-FORST, Forsteinrichtung und Naturschutz (FENA) bearbeitet wurden:

TP 1: Bereitstellung von Basisdaten, Datenerfassung, -aufbereitung u. Interpretation

FENA, Fachbereiche Forsteinrichtung, Geo-Informationen, Naturschutz

TP 2: Wasserhaushaltsmodellierung

NW-FVA, Abt. Umweltkontrolle

TP 3: Stoffhaushaltsmodellierung

Universität Göttingen (Forst), Abt. Ökopedologie der gemäßigten

Zonen;

NW-FVA, Abt. Umweltkontrolle

TP 4: GIS und Waldentwicklungsszenarien

NW-FVA, Abt. Waldwachstum

TP 5: Waldbau

NW-FVA, Abt. Waldwachstum

TP 6: Waldschutr.

NW-FVA, Abt. Waldschutz 
TP 7: Waldnaturschutr.

NW-FVA, Abt. Waldwachstum;

FENA, Fachbereich Naturschutz

TP 8: Ökonomische Bewertung

Universität Göttingen (Forst), Abt. Forstökonomie und

Forsteinrichtung;

NW-FVA, Abt. Waldwachstum

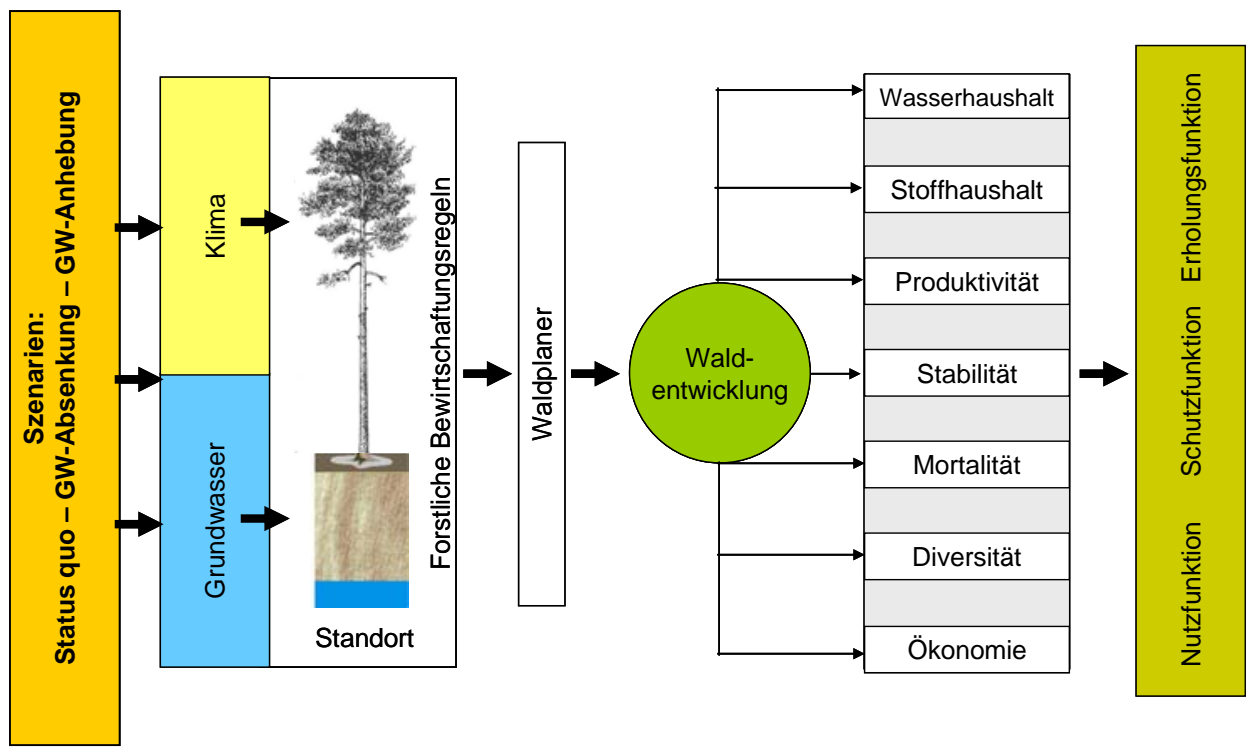

Abbildung 2: Schematische Darstellung des Projektansatzes

Der modulare Projektansatz erlaubt durch die Kopplung von GIS, Wasserhaushaltsmodell, Waldwachstumssimulator und Expertenwissen sowohl die regelbasierte Umsetzung der verschiedenen waldbaulichen Entwicklungsszenarien, deren Modifikation, flexible Anpassung, Anwendung und Bewertung, als auch eine Kombination der Varianten in der Fläche. Auf diesem Wege werden schließlich Optimierungsansätze auf der Ebene von hydrologisch abgrenzbaren Waldgebieten erarbeitet, die in einen Maßnahmenkatalog münden, der Handlungsalternativen für die Forstwirtschaft aufzeigt, die dem vom Hessischen Landtag formulierten Ziel einer langfristigen Sanierung der südhessischen Wälder am besten gerecht werden. 


\section{Material und Methoden}

\subsection{Datengrundlage und -aufbereitung}

Die Grundlage für die Beschreibung des Ausgangszustandes sowie die Eingangsgrößen für die verschiedenen Modelle und die Simulationen bildeten die von der Servicestelle FENA ${ }^{1}$ bereitgestellten Geo- sowie Standorts- und Forsteinrichtungsdaten der im Untersuchungsgebiet liegenden Forstbetriebe, soweit sie ihre Zustimmung zur Verwendung im Projekt erklärt hatten. Darüber hinaus wurden analog vorliegende Bodenprofilbeschreibungen und -bohrungen der ehemaligen hessischen Forsteinrichtungsanstalt, die Bodenübersichtskarte (BÜK 50), die Grunddatenerhebung der Natura 2000-Lebensräume sowie Informationen des Büros BGS Umwelt Darmstadt zu den Grundwasserständen im Hessischen Ried aufbereitet und mit in die Untersuchungen einbezogen.

Da sich die Forsteinrichtungsdaten je nach Betrieb auf unterschiedliche Stichjahre zwischen 1998 und 2002 bezogen, wurden sie von der NW-FVA mit Hilfe des computergestützten Prognosewerkzeugs „WaldPlaner“ (HANSEN 2006, Albert u. HANSEN 2007, HANSEN u. NAgel 2011) der Nordwestdeutschen Forstlichen Versuchsanstalt auf das einheitliche Bezugsjahr 2007 fortgeschrieben.

Die analog vorliegenden Bodendaten wurden an der NW-FVA digitalisiert und für die weiteren Auswertungen aufbereitet. Die Beschreibung der Bodensubstrate erfolgte dabei in Anlehnung an die Kartierung von LEHMANN (1981), sodass einheitliche Bezugs- und Beschreibungsgrößen für das gesamte Gebiet erarbeitet wurden. Zur Berechnung der nutzbaren Feldkapazität (nFK) wurden den einzelnen Substraten Wasserspeicherkapazitäten gemäß der aktuellen bodenkundlichen Kartierungsanleitung (KA5) der Bundesanstalt für Geowissenschaften und Rohstoffe (AG BODEN 2005) zugewiesen.

Ein zentrales Werkzeug sowohl für die Erfassung, Verarbeitung, Organisation und Verwaltung von Geodaten, als auch für die räumlichen Analysen sowie für die Präsentation von Ergebnissen sind Geographische Informationssysteme (GIS). Innerhalb der einzelnen Teilprojekte wurden verschiedene Hardwaresysteme und Softwarepakete eingesetzt.

Die für die gesamte Projektgruppe verbindliche Abgrenzung des Untersuchungsgebietes sowie sämtliche Geometriedaten basieren auf einem von der FENA bereitgestellten Geodatensatz im ESRI ${ }^{2}$-Shapefile-Format (prm_abgr.shp). Alle Geodaten beziehen sich auf das Gauß-Krüger-Koordinatensystem mit

\footnotetext{
${ }^{1}$ HeSSEN-Forst, Servicezentrum für Forsteinrichtung und Naturschutz in Gießen

${ }^{2}$ Environmental Systems Research Institute (ESRI) Inc., Redlands, Kalifornien (USA)
} 
$3^{\circ}$ breiten Meridianstreifen (Streifen 3: Mittelmeridian bei $9^{\circ}$ ) und das Kartenbezugssystem DHDN (Deutsches Hauptdreiecksnetz), oft auch „Potsdam Datum“ oder „Rauenberg Datum“ genannt.

Für die vorliegende Untersuchung sind zunächst alle Waldflächen innerhalb des Untersuchungsgebietes relevant. Betrachtet man die Objektart 4107 Wald, Forst der aktuellen ATKIS3-Geodaten als Referenz, dann handelt es sich hierbei um eine Gesamtwaldfläche von 30.109,20 Hektar, was einem Bewaldungsprozent von 28,4 Prozent entspricht. Diese ATKIS-Waldfläche verteilt sich auf die Attribute der Kategorie Vegetationsmerkmal wie folgt:

- Laubholz

$$
\begin{array}{rr}
7.769,24 \mathrm{ha} & 25,8 \% \\
9.505,61 \mathrm{ha} & 31,6 \% \\
12.834,35 \mathrm{ha} & 42,6 \%
\end{array}
$$

- Nadelholz

- Laub- und Nadelholz

Letztlich konnten davon 27.659 Hektar Baumbestandsfläche (ohne Nebenflächen) in ein Geographisches Informationssystem integriert werden, da nur für dieses Territorium die notwendigen Basisinformationen (Geometrie- und Sachdaten) verfügbar waren. Insgesamt 7.201 Waldbestände teilen sich die o. g. Gesamtfläche, sodass eine durchschnittliche Bestandesgröße von 3,84 Hektar angenommen werden kann.

Die gegenüber der Anzahl an Einzelbeständen deutlich höhere Anzahl der im GIS verwalteten Polygone (7.201 Einzelbestände entfallen auf 9.357 Polygone) kommt dadurch zustande, dass sich ein und derselbe Bestand häufig aus mehreren Polygonen zusammensetzt (z. B. infolge der Zerschneidung durch Verkehrswege, Wasserläufe o. ä.).

\subsubsection{Forsteinrichtungsdaten / Waldbestandsdaten}

Dem Projekt liegt ein flächenbasierter Ansatz zugrunde, d. h. jeder einzelne Waldbestand im Untersuchungsgebiet war zu einem definierten Zeitpunkt mit seinen wichtigsten Charakteristika flächenscharf und möglichst realitätsnah abzubilden. Dieser Ist-Zustand (Status quo) des Waldes im Hessischen Ried bildete die Grundlage für weitere Untersuchungen in den verschiedenen Teilprojekten.

\subsubsection{Ausgangssituation}

Verwertbare Forsteinrichtungsdaten (digitale Karten mit den dazu gehörigen Sachdaten) konnten für insgesamt 27.659 Hektar Waldfläche (7.201 Bestände) innerhalb des Untersuchungsgebietes beschafft werden. Allerdings stammten vor allem die Sachdaten nicht nur aus unterschiedlichen Inventurverfahren (unter anderem in Abhängigkeit von der jeweiligen Waldbesitzart, z. B. kommunaler Wald der Stadt Frankfurt am Main vs. Landes- und Betreuungswald von HESSEN-FORST),

\footnotetext{
${ }^{3}$ Amtliches Topographisch-Kartographisches Informationssystem
} 
sondern es gab auch hinsichtlich ihrer Aktualität (Forsteinrichtungs-Stichjahr) große Unterschiede. Hierzu ergab eine Analyse der Daten, dass nach der Lieferung eines Updates für Teilbereiche des Untersuchungsgebietes durch die FENA etwa 90 Prozent der Waldfläche mit einer als ausreichend aktuell einzuschätzenden Forsteinrichtung (Stichjahr 2002 und jünger) ausgestattet waren. Die Heterogenität in den Roh(Sach-)daten erforderte eine aufwändige Nachbearbeitung. Demgegenüber verlief der Aufbau der digitalen Karte der Waldbestände des Untersuchungsgebietes aufgrund der auf ATKIS abgestimmten Geometrien der Forstflächen in der Form von GIS-Polygonen ohne größere Probleme.

Im Rahmen des Projektes wurde das Stichjahr 2007 als einheitliches Startdatum für die Modellierung der Zukunftsszenarien festgelegt. Dies hatte zur Folge, dass die Inventurdaten aus insgesamt 13 verschiedenen Stichjahren auf das Jahr 2007 anzupassen waren. Dazu wurden alle Inventurdatensätze mit einem Stichjahr der Forsteinrichtung älter als 2007 mit Hilfe des Waldwachstumssimulators „,WaldPlaner“ unter Berücksichtigung der Holzeinschlagstatistiken der FENA (HEKAS) bis zum Jahr 2007 fortgeschrieben. Für die Datensätze jüngeren Datums (Forsteinrichtungs-Stichjahre 2008 und 2009) wurden diese vereinfachend ohne Änderungen auf 2007 zurückdatiert. Durch den Vergleich einfach abzuleitender Bestandesparameter (z. B. Laub-/Nadelholz, Schlussgrad/Überschirmung) der mit dem „WaldPlaner" fortgeschriebenen Waldbestände mit digitalen Orthofotos einer Befliegung aus dem Jahr 2007 erfolgte eine stichprobenhafte Verifizierung der Sachdaten.

\subsubsection{Verknüpfung der Geometrie- und Sachdaten}

Alle bestandesbeschreibenden Sachdaten der Forsteinrichtung wurden zunächst in einer Microsoft Access-Datenbank strukturiert zusammengeführt, und die digitale Karte mit den Bestandespolygonen wurde im Geografischen Informationssystem ArcGIS in der Version 9.3.1 aufgearbeitet.

In beiden Informationslagen (Attributtabellen des Geometrielayers und Sachdatentabellen) wurde ein eindeutiges Schlüsselfeld angelegt, über das eine korrekte und eindeutige Verknüpfung erfolgen konnte. Für die von der FENA bereitgestellten Originaldaten des Landes- bzw. Betreuungswaldes im Untersuchungsgebiet bildete die Waldeinteilungsflächenkennziffer (WEFLKZ) die Basis für die Generierung eines solchen Schlüssels, für die Waldbestände der Stadt Frankfurt am Main wurde der entsprechende Schlüssel aus den Originaldaten (Abteilungsnummer, Unterabteilungsnummer und Nummer der Betriebseinheit) zusammengesetzt. Diese vorläufigen Schlüsselfelder vom Datentyp Text wurden für alle Waldbesitzarten in einen einheitlichen, nummerischen Schlüssel „ID“ konvertiert, welcher schließlich für beide Informationslagen (Geometrie- und Sachdaten) ein korrektes Verknüpfen sicherstellte. 


\subsubsection{Aufbereitung der Daten für den Waldwachstumssimulator und Aufbau der Modellbestände}

Die digitalen Datensätze der Forsteinrichtung beschreiben Waldbestände als kleinste zusammenhängende Einheit eines Forstbetriebes im Ganzen. Demgegenüber arbeitet der Waldwachstumssimulator „WaldPlaner“ auf der Grundlage des einzelbaumorientierten, statistischen Wuchsmodells „BWinPro“. Für das Generieren von Modellbeständen auf Einzelbaumbasis stellt der „WaldPlaner“ eine integrierte Plugin-Einleseroutine bereit, für die grundlegende, bestandesbeschreibende Parameter aus den Sachdatentabellen der Forsteinrichtung extrahiert und in einer Datenbank mit fest definierter Struktur aufbereitet werden müssen. Zwingend notwendig sind insbesondere die folgenden Angaben:

- ID (eindeutiger Identifikationsschlüssel des Waldbestandes)

- Stichjahr der Forsteinrichtung

- Baumart

- Alter

- Ertragsklasse

- Mischungsanteil

- Bestockungsgrad

- Bestandesschicht

- Bestandesfläche

Der Aufbau der Modellbestände erfolgt für eine vorher definierte Modellbestandsgröße, die wiederum abhängig ist von der erforderlichen Genauigkeit der Bestandesparameter, des EDV-technischen Ressourcenverbrauchs (Rechenzeiten, Speicherplatz usw.) und weiterer Aspekte. Für das Generieren der hier im Projekt relevanten 7.201 Waldbestände zeigte sich unter Berücksichtigung dieser Restriktionen, dass eine Modellbestandsgröße von 0,33 Hektar den Anforderungen genügt.

Die Ergebnisse der Modellbestandsgenerierung (Einzelbaumdaten, Bestandesdaten, Metadaten) wurden in die zentrale Projektdatenbank eingespeist. Dabei handelte es sich um eine PostgreSQL-Datenbank, auf die alle Teilprojekte mit jeweils angepassten Nutzerrechten Zugriff hatten.

\subsubsection{Standortsdaten}

\subsubsection{Klima}

Das Untersuchungsgebiet Hessisches Ried ist Teil der Oberrheinischen Tiefebene. Klimatisch ist das Gebiet aufgrund seiner Höhenlage von ca. 80 bis $150 \mathrm{~m}$ über NN der planaren Höhenstufe zuzuordnen. Die Rhein-Main-Ebene liegt im Übergangsbereich zwischen dem ozeanisch geprägtem Klima Westeuropas und dem kontinentalem Klima Osteuropas. Ganzjährig dominieren Westwindwetterlagen. Der Winter ist allgemein mild und feucht, der Sommer ist mäßig warm, ausge- 
sprochene Trockenperioden treten jedoch selten auf. Infolge konvektiver Niederschläge weisen die Sommermonate (Juni bis August) ein leichtes Niederschlagsmaximum auf.

Grundlage für die Erfassung der Witterung und für die Berechnung der klimatischen Verhältnisse bildet das Messnetz des Deutschen Wetterdienstes (DWD). Der DWD betreibt unterschiedlich ausgestattete Messnetze zur Erfassung wichtiger klimatischer Messgrößen. Das umfangreichste Messnetz umfasst die Stationen, die ausschließlich den Niederschlag erfassen. Im Untersuchungsgebiet sind dies insgesamt 25 Stationen, die teilweise außerhalb des eigentlichen Projektgebietes liegen (s. Abb. 3 und Tab. A1 im Anhang). Lufttemperatur und Luftfeuchte sowie Sonnenscheindauer und Windgeschwindigkeit werden an Klimastationen und synoptischen Stationen gemessen. Dieses Messnetz weist eine deutlich geringere räumliche Dichte auf als das Niederschlagsmessnetz. Für die Regionalisierung dieser meteorologischen Kenngrößen wurden für das Projektgebiet Hessisches Ried 6 Stationen verwendet (s. Abb. 3 und Tab. A1 im Anhang).

Die Stationsdaten des DWD wurden mit einem kombinierten Verfahren aus IDW (Inverse Distance Weighting) und Höhenregression in die Fläche auf ein Raster mit einer Auflösung von $100 \mathrm{~m}$ regionalisiert. Die abstandsgewichtete Interpolation nach dem IDW-Verfahren berücksichtigt alle Stationen, die innerhalb eines definierten Suchradius liegen. Bei der höhenabhängigen Regression wurde die Interpolation anhand von mindestens drei Messstationen in Abhängigkeit von der Geländehöhe durchgeführt. Beide Verfahren wurden gleich gewichtet bei der Regionalisierung der Niederschlags- und Temperaturwerte angewendet.

Die Jahresmitteltemperatur liegt im Mittel der Klimanormalperiode (1961 1990) zwischen rund $9,7^{\circ} \mathrm{C}$ und $10,3^{\circ} \mathrm{C}$. Trotz der relativ geringen Unterschiede zeigt die räumliche Verteilung einen Abnahme der Temperatur von Südwest nach Nordost (s. Abb. 3). Die langjährige mittlere Jahresniederschlagssumme weist im Untersuchungsgebiet eine deutlich höhere räumliche Variabilität auf. Die niedrigsten Werte werden mit rund $600 \mathrm{~mm}$ im Westen an der Landesgrenze zu Rheinland-Pfalz erreicht, mit zunehmender Geländehöhe steigt die Jahresniederschlagssumme in Richtung Odenwaldrand auf über $750 \mathrm{~mm}$ an.

Für wasserwirtschaftliche Fragestellungen und Modellrechnungen wird häufig mit korrigierten Niederschlagswerten gearbeitet (FIEBIGER et al. 2009). Die Korrektur von Niederschlagsmesswerten stellt kein triviales Problem dar, da der Fehler von der Art des Niederschlags, dem verwendeten Messgerät und den Standortverhältnissen am Messpunkt beeinflusst wird (RICHTER 1995). Die Trennung zwischen flüssigem und festem Niederschlag erfolgt mittels einer Grenztemperatur. Diese liegt bei $+0,5^{\circ} \mathrm{C}$. Die Korrektur der Niederschläge erfolgt in Abhängigkeit von der Windgeschwindigkeit und wird für Regen und Schnee mit spezifischen Korrekturparametern berechnet.

Im Projektgebiet Hessisches Ried wird das mittlere jährliche Niederschlagsangebot durch die Korrektur um ungefähr 100 mm erhöht. Die Niederschlagssumme 
reicht im Mittel von $680 \mathrm{~mm}$ bis $860 \mathrm{~mm}$, wobei die räumliche Variabilität wie bei den unkorrigierten Werten eine Zunahme von West nach Ost aufweist (s. Abb. 3). Die Validierung der Niederschlagsinterpolation erfolgte mit Hilfe der Karten 2.2 und 2.5 des Hydrologischen Atlas (BUNDESMINISTERIUM FÜr UMWELT, NATURSCHUTZ UND REAKTORSICHERHEIT 2000).

Über die Verdunstung wird ein Großteil des Niederschlags wieder der Atmosphäre zugeführt. Die Evapotranspiration (Verdunstung) fasst die Prozesse der Evaporation (Verdunstung von der vegetationslosen Landoberfläche), Transpiration (Verdunstung der Pflanzen) und Interzeption (Verdunstung von der Pflanzenoberfläche) zusammen. Steht ein unbegrenztes Wasserangebot zur Verfügung, entspricht die tatsächliche Verdunstung der maximal möglichen Evapotranspiration (potenzielle Verdunstung).

Um den Einfluss des Klimas auf die Verdunstung flächenhaft zu beschreiben, wird standardmäßig mit einer Grasvegetation als einheitlicher Bodenbedeckung gerechnet (Grasreferenzverdunstung). Die Berechnung der potenziellen Verdunstung erfolgt nach der Methode von Penman-Monteith (MONTEITH 1985, PENMAN 1948). Im Untersuchungsgebiet variiert die potenzielle Verdunstung zwischen $580 \mathrm{~mm}$ am Odenwaldrand und rund $650 \mathrm{~mm}$ im Südwesten des Gebietes (s. Abb. 3). Der hydrologische Atlas (Karte 2.12) weist für die Rhein-MainRegion eine potenzielle Evapotranspiration von 600 bis $650 \mathrm{~mm}$ aus (BUNDESMINISTERIUM für UMWELT, NATURSCHUTZ u. REAKTORSICHERHEIT 2000).

Die klimatische Wasserbilanz (KWB) ist eine einfache Methode, um die Wasserversorgung von Vegetationsbeständen abzuschätzen (MÜLLER 2006, SPELLMANN et al. 2007). Die KWB ist die Differenz aus dem gefallenen Niederschlag und der potenziellen Verdunstung. Die KWB wurde auf Grundlage der korrigierten Niederschlagssumme berechnet. Weist ein Standort einen Niederschlagsüberschuss auf, so wird dieser als Abfluss aus dem Gebiet abgeführt, er füllt den Bodenwasserspeicher auf oder er trägt zur Grundwasserneubildung bei. 

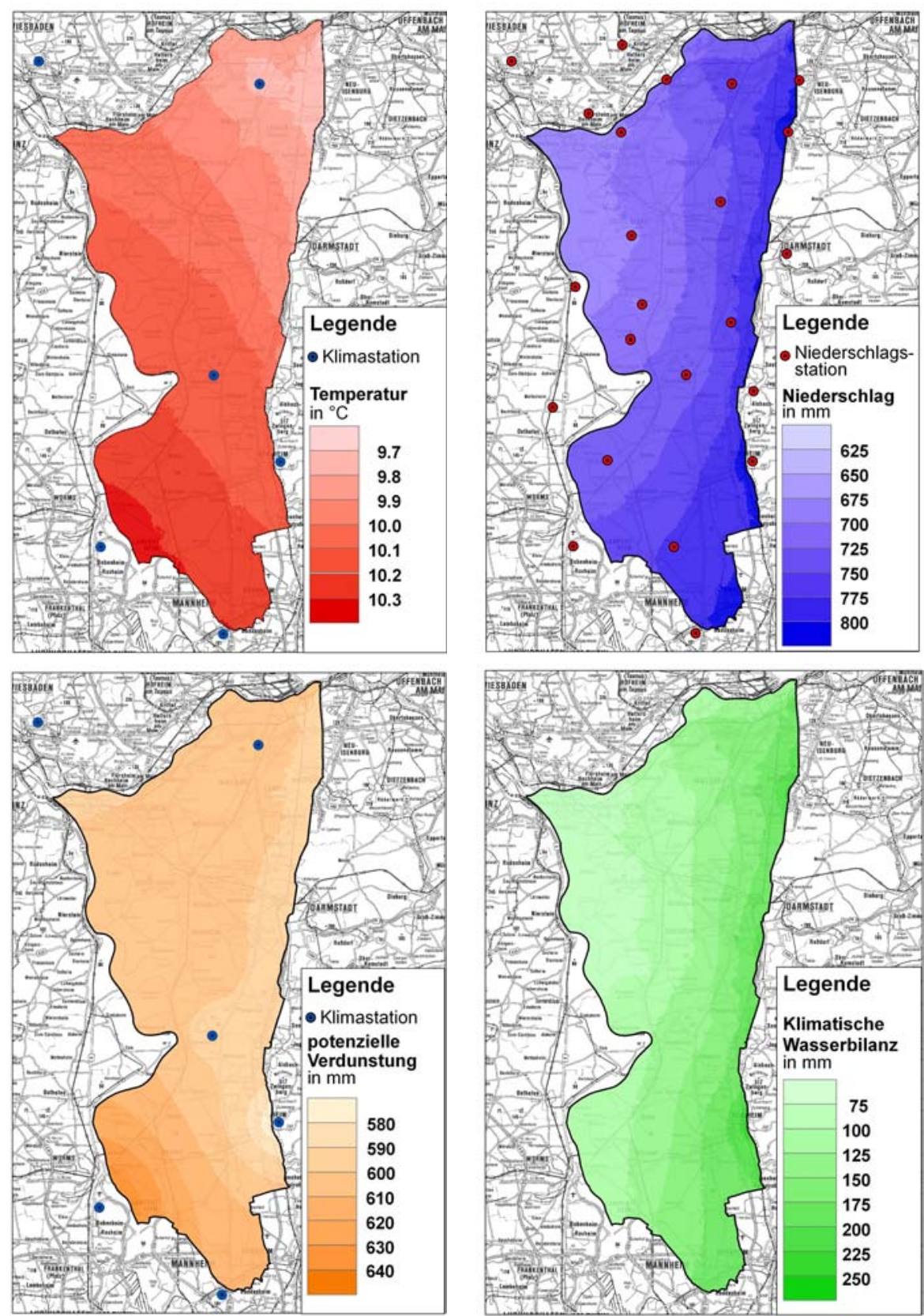

Abbildung 3: Jahresmitteltemperatur $\left[{ }^{\circ} \mathrm{C}\right]$ (oben links), mittlere jährliche Niederschlagssumme [mm] (oben rechts), potenzielle Verdunstung [mm] (unten links) und Klimatische Wasserbilanz. [mm] (unten rechts) im Untersuchungsgebiet für die Klimanormalperiode 1961 - 1990 
Im Projektgebiet Hessisches Ried betrug der Überschuss in der KWB im Jahresmittel der Klimanormalperiode 70 bis $270 \mathrm{~mm}$ (s. Abb. 3). Ein Großteil dieser Wassermenge trägt zur Grundwasserneubildung bei und wird über die Vorfluter (Grundwasserabfluss) abgeführt oder für die Trinkwasserversorgung und Beregnung genutzt. Allerdings muss berücksichtigt werden, dass insbesondere auf den Waldstandorten in Abhängigkeit vom Bestandesalter, der Bestandeszusammensetzung und -dichte die potenzielle Verdunstung deutlich über der Verdunstungsleistung einer reinen Grasvegetation liegt und folglich der Überschuss in der KWB geringer ausfällt.

In der Tabelle 1 sind die Klimakennwerte als Gebietsmittel der Klimanormalperiode 1961 bis 1990 für das Projektgebiet Hessisches Ried aufgelistet. Die Vegetationsperiode (s. Kap. 2.2.5.2) umfasst den Zeitraum von ungefähr Mitte April bis Anfang Oktober mit der längsten Dauer im Südwesten des Gebietes und einer leichten Abnahme Richtung Odenwaldrand. Während der Vegetationsperiode weist die klimatische Wasserbilanz ein deutliches Defizit von knapp $100 \mathrm{~mm}$ auf. In klimatisch normalen Jahren kann dieses Defizit durch den Wasserüberschuss während der Vegetationsruhe ausgeglichen werden. In niederschlagsarmen Jahren kann auch ein zu Beginn der Vegetationsperiode aufgefüllter Bodenwasserspeicher das Defizit nicht kompensieren. So betrug im Jahr 1976 das KWB-Defizit in der Vegetationsperiode knapp $450 \mathrm{~mm}$ im Gebietsmittel (Grundlage Grasreferenzverdunstung) und auch für das gesamte Jahr 1976 betrug das Defizit noch rund $300 \mathrm{~mm}$.

Tabelle 1: $\quad$ Mittlere Klimakennwerte für die Klimanormalperiode für das Hessische Ried

\begin{tabular}{lccc}
\hline Klimakennwert & Jahr & $\begin{array}{c}\text { Vegetations- } \\
\text { periode }\end{array}$ & Vegetationsruhe \\
\hline Niederschlag, gemessen & $659 \mathrm{~mm}$ & $341 \mathrm{~mm}$ & $318 \mathrm{~mm}$ \\
Niederschlag, korrigiert & $745 \mathrm{~mm}$ & $371 \mathrm{~mm}$ & $374 \mathrm{~mm}$ \\
potenzielle Verdunstung & $606 \mathrm{~mm}$ & $470 \mathrm{~mm}$ & $136 \mathrm{~mm}$ \\
klimatische & $139 \mathrm{~mm}$ & $-99 \mathrm{~mm}$ & $238 \mathrm{~mm}$ \\
Wasserbilanz & $10,1^{\circ} \mathrm{C}$ & $16,6^{\circ} \mathrm{C}$ & $4,4^{\circ} \mathrm{C}$ \\
Temperatur & & & \\
\hline
\end{tabular}

Die Vitalität der Bestände im Hessischen Ried hängt dementsprechend maßgeblich von der Wasserversorgung ab. Infolge großflächiger Grundwasserabsenkungen sind die meisten Bestände insbesondere im südlichen Untersuchungsraum darauf angewiesen, dass in den Wintermonaten der Bodenwasserspeicher aufgefüllt wird. In ausgesprochenen Trockenjahren, wie 1962 bis 1964, 1971, 1973, 1976, traten vermehrt Trockenstressbedingungen auf, die die Vitalität und Produktivität der 
Bestände massiv beeinträchtigt haben (PRIES et al. 1999). In Zukunft ist damit zu rechnen, dass es infolge des erwarteten Klimawandels vermehrt zu Trockenstressbedingungen kommt (SPEKAT et al. 2007).

\subsubsection{Boden}

\subsection{Flächenhafte Bodeninformationen}

Obwohl die Rhein-Main-Ebene das wohl am intensivsten boden- wie standortskundlich untersuchte Gebiet Hessens ist, liegt für die Waldflächen im Untersuchungsgebiet außer der Bodenübersichtskarte im Maßstab $1: 50.000$ (BÜK50) keine hoch auflösende Bodenkarte vor. Die Bodenübersichtskarte im Maßstab $1: 25.000$ stand für die Modellierung noch nicht zur Verfügung. Das Hauptproblem bei der Anwendung und Entwicklung der Modelle liegt somit nicht bei den Modellen selbst, sondern in den zu gering aufgelösten Bodeneingangsdaten. Entsprechend werden in der Bodenkunde häufig mittels Disaggregierung aus mittelmaßstäbigen Bodendaten unter Berücksichtigung weiterer Geodaten (z. B. Gesteinsuntergrund, Relief usw.) höher aufgelöste Daten abgeleitet (MEER 2007). Somit war es auch in diesem Projekt das Ziel, die BÜK50 für die Waldgebiete im Hessischen Ried durch eine Reliefanalyse auf Basis eines DGM mit 10 m Rasterweite höher räumlich zu differenzieren. Die Qualität des DGM10 erwies sich jedoch in der durchgeführten Reliefanalyse als unzureichend, um damit eine Disaggregierung der BÜK50 vorzunehmen.

Das DGM10 des Hessischen Rieds basiert im Wesentlichen auf dem DGM20 (20 m Rasterweite) der Hessischen Landesvermessung. Das DGM20 von Hessen weist viele unterschiedliche Qualitätsmängel und Fehlertypen auf. Ursache hierfür ist vor allem die räumlich sehr heterogene Datenbasis des DGM (z. B. Isohypsen, photogrammetrische Messungen). Außerhalb des Gebietes mit Höheninformationen aus Laserbefliegungen gibt es nur entlang des Rheins wenige Gebiete, die bodenkundlich relevante Kleinformen des Reliefs (z. B. Flutrinnen, Uferwälle und Dünen) abbilden.

Aufgrund der vorab angeführten Probleme wurde im Projekt ein anderer Weg beschritten. Hierbei wurde versucht, die vorhandenen Informationen aus vorangegangenen Standortskartierungen, der Substratkartierung nach LEHMANN (1981) und den Standortsformenkarten (Kelsterbach, Lampertheim, Lorsch, Mörfelden) zu nutzen, um höher aufgelöste Bodeninformationen für die Modellentwicklungen und -anwendungen bereitzustellen. Die für die Arbeiten verwendeten Datengrundlagen sind in der Tabelle 2 zusammenfassend dargestellt.

Anhand der vorab angeführten Datenquellen wurden für das Untersuchungsgebiet 184 Substrateinheiten für die Waldflächen ausgeschieden. Die Substrattypen sind in Horizonte untergliedert, die durch folgende Merkmale charakterisiert werden: 
- Horizontsymbol,

- Horizonttiefe,

- Feinbodenart,

- Lagerungsdichte,

- Bodenskelettgehalt,

- Humusgehalt,

- Karbonatgehalt sowie

- Substratzuordnung.

Tabelle 2: $\quad$ Datengrundlage Geologie und Boden im Untersuchungsgebiet

\begin{tabular}{|c|c|c|c|}
\hline Quelle & $\begin{array}{l}\text { Flächenab- } \\
\text { deckung }\end{array}$ & Format & Bemerkungen \\
\hline Standortskartierung & betreuter Wald & digital & nFK und Trophiestufen \\
\hline $\begin{array}{l}\text { Forsteinrichtungs- } \\
\text { sachdatenbestand }\end{array}$ & betreuter Wald & digital & $\begin{array}{l}\text { Bodenparameter, an Waldorte } \\
\text { gebunden }\end{array}$ \\
\hline $\begin{array}{l}\text { Standortsformen- } \\
\text { karte ZIMMERMANN } \\
(1953 / 54)\end{array}$ & $\begin{array}{l}\text { im Norden voll- } \\
\text { ständig, im Süden } \\
\text { vereinzelt }\end{array}$ & analog & $\begin{array}{l}\text { substratbezogene Abgrenzung, } \\
\text { Profilangaben }(565+1340 \\
\text { Datensätze })\end{array}$ \\
\hline $\begin{array}{l}\text { Substratkartierung } \\
\text { LEHMANN (1981) }\end{array}$ & $\begin{array}{l}\text { Gernsheimer } \\
\text { Stadtwald, Jägers- } \\
\text { buger Wald }\end{array}$ & analog & $\begin{array}{l}\text { substratbezogene Abgrenzung, } \\
\text { Profilangaben ( } 993 \text { Datensätze) }\end{array}$ \\
\hline BÜK 50 & vollständig & digital & $\begin{array}{l}77 \text { Leitprofile für das Unter- } \\
\text { suchungsgebiet, Humusformen } \\
\text { vorhanden }\end{array}$ \\
\hline BÜK 25 & $\begin{array}{l}\text { in Bearbeitung, } \\
\text { für das Projekt } \\
\text { nicht verfügbar }\end{array}$ & digital & \\
\hline GÜK 25 & $\begin{array}{l}\text { flächendeckend, } \\
\text { auf der Basis } \\
\text { einzelner Karten- } \\
\text { blätter }\end{array}$ & digital & \\
\hline
\end{tabular}

Anhand der so erstellten Bodenkarte wurden z. B. die nutzbaren Feldkapazitäten (nFK) für unterschiedliche Bodentiefen (entsprechend verschiedener Durchwurzelungstiefen und Altersklassen) ermittelt. Beispielhaft zeigt Abbildung 4 die nFK für eine Durchwurzelungstiefe von $140 \mathrm{~cm}$. Die höchsten Werte der Wasserverfügbarkeit werden für die Böden der Altarme von Rhein, Main und Neckar sowie auf einigen Flächen im Norden des Untersuchungsgebietes berechnet. Hier liegt die nFK teilweise über $250 \mathrm{~mm}$. Im Gegensatz dazu weisen Böden mit einem hohen Sandanteil geringe nFK-Werte von teilweise unter $100 \mathrm{~mm}$ auf. Auf einem Großteil der Waldböden liegt die nutzbare Feldkapazität bei ungefähr 150 mm, da hier mehr oder weniger mächtige Schluff- und Tonhorizonte die Wasserspeicherkapazi- 
tät erhöhen. Dabei ist zu beachten, dass ggf. die schwach lehmigen und schwach tonigen Sande überschätzt werden. Aus diesem Grund wurden die Wasserspeicherkapazitäten für diese Substratgruppen nach bestem Expertenwissen reduziert. Sie erscheinen dennoch im Vergleich zu dem vorgefundenen Zustand der Vegetation in manchen Regionen nicht immer nachvollziehbar. In diesem Zusammenhang stellt sich die Frage, inwieweit die potenziell mögliche Bodenwasserspeicherkapazität durch die Winterniederschläge aufgefüllt wird.
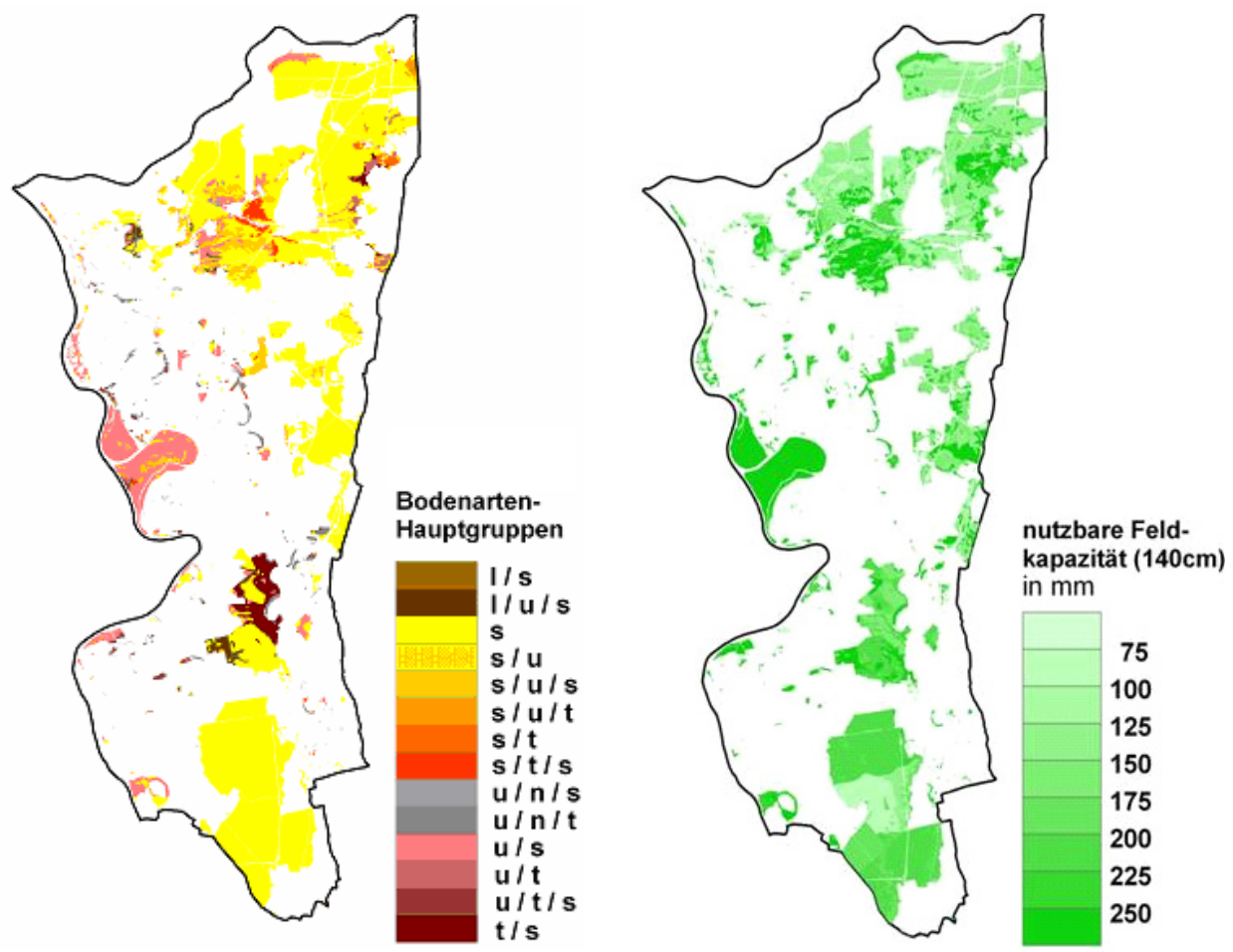

Abbildung 4: Bodenarten-Hauptgruppen (nach KA5) (links) und nutz̧bare Feldkapazität [mm] (rechts) für die Waldflächen im Projektgebiet Hessisches Ried; $s=$ Sand, $u=$ Schluff, $l=$ Lehm, $t=$ Ton, $n=$ Niedermoor

Für statistische Auswertungen wurden die Leitprofile zu 14 Bodenarten-Hauptgruppen zusammengefasst (s. Abb. 4). Die Vorgehensweise bei der Substrattypenbildung erfolgte nach der hessischen Anweisung für Forsteinrichtungsarbeiten (HAFEA) (HMULF 2002). Aus den vorliegenden Bodenausgangsgesteinen, vornehmlich quartäre Lockergesteine, wurden erst Substratarten und daraus im nächsten Arbeitsschritt Substrattypen generiert. Die Substrattypen wurden auf wesentliche Merkmale reduziert, sodass sie zu einer Anzahl von 30 aggregiert werden 
konnten. Die Substrattypen wurden abschließend nach der KA5 (AG BODEN 2005, Seite 142) zu 14 Bodenarten-Hauptgruppen zusammengefasst.

Die Böden im Hessischen Ried weisen aufgrund ihrer Genese überwiegend geschichtete Strukturen auf. Die Schichtung wurde bei der Aggregierung zu den Bodenarten-Hauptgruppen berücksichtigt. Die Legende zur Bodenkarte bildet die Schichtung der Böden ab. Die Bodenarten-Hauptgruppe „, $\mathrm{s} / \mathrm{u} / \mathrm{t}$ “ fasst Substrattypen zusammen, deren Schichtung Sande über Schluffe über Tone aufweist.

Auf weiten Flächen des Hessischen Rieds kam es im letzten Glazial/Postglazial zu ausgedehnten Flugsandverwehungen (PRIES et al. 1999). Dabei entstanden gebietsweise Dünengürtel, die unregelmäßig über das Untersuchungsgebiet verteilt sind. In weiten Bereichen des nördlichen Projektgebietes (Frankfurter Stadtwald, Mörfelden) und im Darmstädter Westwald dominieren Sande, als Reinsande oder geschichtet als Lehm- oder Schluffsande. Dies trifft ebenso auf Teile des Gernsheimer/Jägersburger Waldes zu sowie flächendeckend auf den Lorscher und Viernheimer Wald im Süden des Untersuchungsgebietes. Hochflutlehme treten besonders in den Altarmen des Rheins und Neckars auf (Kühkopf, Gernsheimer/ Jägersburger Wald). In einigen Altarmen des Neckars sind Niedermoorablagerungen zu finden (Gernsheimer/Jägersburger Wald). Detaillierte Informationen zu den bodenbildenden Substraten, der Bodenbildung und den Nährstoffverhältnissen sind bei PrIES et al. (1999) und ZIMMERMANN (1956) nachzulesen.

Die Daten der Substratkartierung dienten im Projekt als Eingangsgrößen für Wasser- und Stoffhaushaltsmodellierungen. Weiterhin beeinflusst die Substratausprägung die Baumarteneignung und die Entwicklung von Schadorganismen. Die Substratkartierung enthält jedoch keine Angaben zur Humusform und -mächtigkeit. Entsprechende Informationen werden jedoch für die Wasser- und Stoffhaushaltsmodellierung benötigt. Wegen ihrer günstigen physikalischen und chemischen Verhältnisse sind Humusauflagen häufig sehr intensiv durchwurzelt (GODBOLD et al. 2003), sodass eine Vernachlässigung der Humusauflage nur bei geringer Mächtigkeit und schwacher Durchwurzelung gerechtfertigt ist (z. B. Humusform Mull) (HÖRMANN et al. 2003).

Abbildung 5 und Tabelle A2 (s. Anhang) geben einen Überblick über den Zusammenhang zwischen Humusform und Humusmächtigkeit für 747 hessische Bodenprofile. Bei den Angaben zum typischen Moder (mot) und typischen Rohhumus (rot) sind die geringen Stichprobenumfänge zu beachten. Auf Grundlage dieser Informationen wurde anhand der in der Standortskartierung ausgewiesenen Nährstoffstufen mit Hilfe der „Einstufungshilfe Trophie“ der HAFEA (HMULF 2002) zunächst die Humusform abgeleitet und diese anschließend in eine Auflagehumusmächtigkeit überführt. 


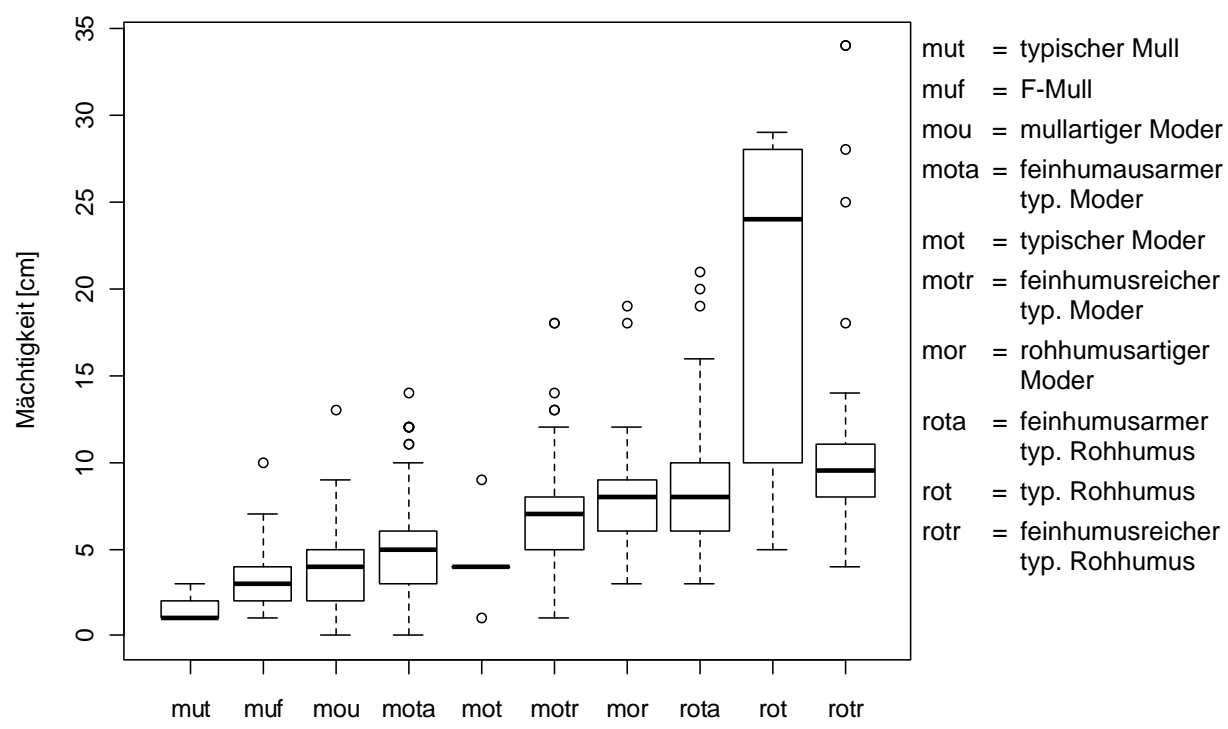

Abbildung 5: Verteilung (Box-Plots mit 10., 25. Perzentil, Median, 75., 90. Perzentil und Ausreißer) der Mächtigkeiten des Auflagehumus [cm] für verschiedene Humusformen in bessischen Waldböden (Hessisches W aldbodeninformationssystem WABIS)

\subsection{Punkthafte Bodeninformationen}

Verfügbare bodenkundliche Profil- und Bohrinformationen bilden eine wichtige Grundlage zur Validierung der Modellsimulationen. Zudem werden Informationen zur Heterogenität der Kartiereinheiten benötigt, um die Unsicherheiten auf dieser Maßstabsebene bei Modellanwendungen besser quantifizieren zu können.

Eine umfangreiche Datengrundlage für bodenphysikalische und -chemische Bodenparameter bietet das WABIS (Waldbodeninformationssystem). In diesem waren die Bodenprofile der BZE I schon vorhanden, sodass noch die Profile aus der BZE II ergänzt werden mussten. Insgesamt standen so für das Untersuchungsgebiet 62 Profile zur Verfügung. Hiervon entfallen 19 Profile auf eutrophe, 38 auf mesotrophe und 5 auf oligotrophe Standorte. Zeitlich decken sie ein Fenster von über 20 Jahren (1985 - 2008) ab, was insbesondere für die dynamische Modellierung von bodenchemischen Kenngrößen von Bedeutung ist.

Für ganz Hessen stehen aus dem WABIS zwischen 500-750 (je nach Fragestellung) Profile zur Verfügung. Letztgenannte Profile wurden für verschiedenste statistische Auswertungen herangezogen (s. z. B. Modell der Humusmächtigkeiten). Bei den jeweiligen Auswertungen sind die genauen Stichprobenumfänge angegeben.

Neben diesem Profilbestand lagen für das Untersuchungsgebiet zahlreiche bodenphysikalische Profil- und Bohrinformationen analog vor. Diese wurden 
digitalisiert und anhand der Ortsangaben bzw. anhand der Karten georeferenziert. Im Rahmen des Projektes wurden mehr als 2.500 Profilangaben/Bohransprachen digitalisiert und damit dauerhaft archiviert. Für die räumlichen Analysen der nutzbaren Feldkapazität standen etwa 500 Profile zur Verfügung. Trotz der großen Profilanzahl ist eine räumliche Repräsentanz nur z. T. gewährleistet. Einige Bereiche des Untersuchungsgebietes (z. B. der Jägersburger Wald) werden durch vorhandene Profilansprachen sehr gut repräsentiert. In anderen Bereichen (z. B. Darmstädter Westwald) liegen dagegen nur wenige Einzelerhebungen vor.

\subsubsection{Hydrologie}

Das Hessische Ried ist durch sehr geringe Reliefunterschiede und einen natürlicherweise geringen Grundwasserflurabstand gekennzeichnet. Bis auf die Dünenbereiche und die Wälder am Odenwaldrand verfügten daher große Teile der Wälder ursprünglich über einen sicheren Anschluss an das Grundwasser (Grundwasserflurabstand $<2,50 \mathrm{~m}$ ). Im Laufe des letzten Jahrhunderts erfuhr das Hessische Ried jedoch durch vielfältige anthropogene Eingriffe eine massive Veränderung des natürlichen Wasserregimes (PRIES et al.1999).

Die Begradigung bzw. Verlegung der Flussverläufe von Rhein, Main und Neckar sowie deren Eindeichung hat dazu geführt, dass weite Bereiche des Hessischen Rieds als natürliches Überschwemmungsgebiet entfallen und durch Entwässerungsmaßnahmen der landwirtschaftlichen Nutzung zugeführt wurden. Insbesondere im Nahbereich der Flüsse und Entwässerungssysteme waren deutliche Grundwasserabsenkungen die Folge. Mit dem Bau zahlreicher Wasserwerke zur Trink- und Nutzwassergewinnung wurde um 1900 und verstärkt seit den 60erJahren des letzten Jahrhunderts das Grundwasserregime einer weiteren nachhaltigen Veränderung unterzogen. Da die Anlagen fast ausschließlich in Waldgebieten errichtet wurden, sank dort der Grundwasserspiegel vielfach flächendeckend stark $\mathrm{ab}$, sodass ehemals grundwassernahe Waldstandorte heute nicht mehr über einen sicheren Anschluss an das Grundwasser verfügen. Von den flächendeckenden Grundwasserabsenkungen sind besonders der Darmstädter Westwald, der Gernsheimer und der Jägersburger Wald sowie im Süden des Untersuchungsgebietes der Lorscher/Bürstädter Wald und der Viernheimer Wald betroffen. Durch zurückgehende Grundwasserentnahme zu Beginn der 1990er-Jahre und das Inkrafttreten des Grundwasserbewirtschaftungsplans Hessisches Ried im Jahr 1999 (RP DARMSTADT 1999) konnten nur lokal Verbesserungen in der Wasserversorgung der Bestände erzielt werden.

Am Beispiel des Grundwasserpegels Groß-Rohrheim (Nr. 544002) im Jägersburger Wald kann die zeitliche Entwicklung der Grundwasserstände nachvollzogen werden (s. Abb. 6). In den 1950er-Jahren schwankte der Flurabstand um 2 Meter. Mit einsetzender Grundwasserentnahme Ende der 60er-Jahre des letzten Jahrhunderts sank der Grundwasserstand am Pegel um annähernd 5 Meter. Die Bestände, die ursprünglich über einen Grundwasseranschluss verfügten, sind seitdem darauf 
angewiesen, dass während längerer Trockenperioden der Bodenwasserspeicher ausreichend gefüllt ist. Dies ist auf den weit verbreiteten Sandböden (s. Abb. 4) jedoch nicht der Fall, besonders wenn, wie in der ersten Hälfte der 1970er-Jahre und zu Beginn der 1990er-Jahre, mehrere Trockenjahre aufeinander folgen. Vitalitäts- und Produktionseinbußen bis zu Totalausfällen der betroffenen Bestände waren die Folge (PRIES et al. 1999). Seit Inkrafttreten des Grundwasserbewirtschaftungsplans Hessisches Ried im Jahr 1999, der sogenannte Grenzgrundwasserstände definiert, die nicht unterschritten werden dürfen, ist ein leichter Anstieg der Grundwasserstände zu verzeichnen (HMULV 2005). Allerdings sind die Flurabstände häufig noch so groß, dass auch weiterhin viele Bestände in den betroffenen Waldgebieten nicht über einen Grundwasseranschluss verfügen. Am Pegel 544002 im Jägersburger Wald beträgt der Flurabstand gegenwärtig noch über vier Meter. Erst eine Anhebung des Grundwasserstands um weitere ein bis zwei Meter würde an diesem Standort wieder den sicheren Grundwasseranschluss herstellen.

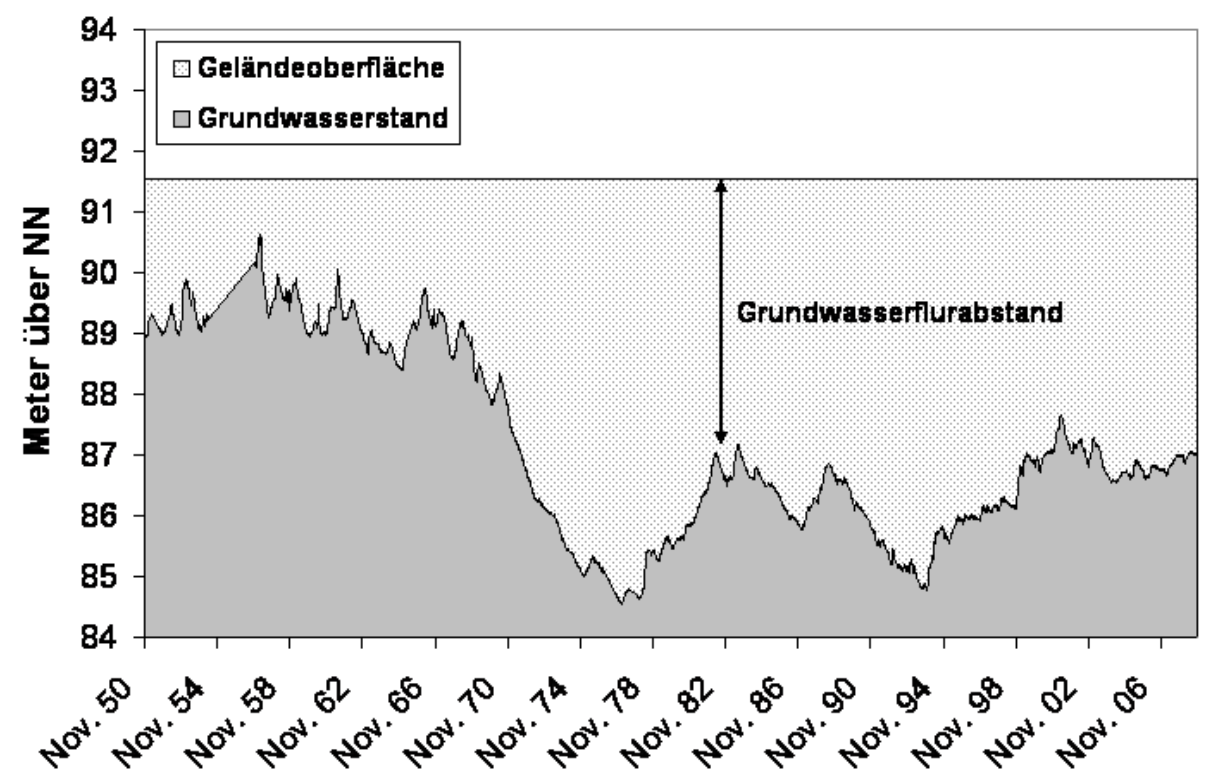

Abbildung 6: Verlauf des Grundwasserstands [m ̈̈. NN] am Pegel Groß-Robrheim (Nr. 544002) im Jägersburger $W$ ald

In Kapitel 2.2.1 werden die verwendeten Grundwasserstandsszenarien (Stichtagsmessung und Grundwasserbewirtschaftungsplan) flächenhaft differenziert beschrieben und vergleichend ausgewertet. 


\subsubsection{Naturschutz}

Die für das Vorhaben zusammengestellten und aufbereiteten Naturschutzdaten (s. Tab. 3) dienten zum einen dazu, die im Hessischen Ried für die Forstwirtschaft bestehenden naturschutzfachlichen Auflagen mit konkreter rechtlicher Grundlage möglichst flächengenau abzubilden. Zum anderen wurden auf ihrer Grundlage der derzeitige Zustand und die zu erwartende Entwicklung der Buchen- und Eichenlebensräume aus naturschutzfachlicher Sicht bewertet. Dies geschah anhand einer Habitatmodellierung zur Identifikation von Hotspots für die Lebensgemeinschaften der Alters- und Zerfallsphase von Buchen- und Eichenwäldern und des Weiteren durch die Betrachtung relevanter Größen zur Bewertung von FFH-Lebensraumtypen.

\subsubsection{Bestehende Naturschutzauflagen}

Einschränkungen für die Forstwirtschaft ergeben sich im Hessischen Ried in öffentlich-rechtlich ausgewiesenen Schutzgebieten (Naturschutzgebiete, FFHGebiete, EU-Vogelschutzgebiete), auf Flächen gesetzlich geschützter Biotope, durch Selbstbindung oder durch vertragliche Bindung - letzteres vor allem durch die Bereitstellung von Waldflächen für naturschutzrechtliche Kompensationsmaßnahmen. Diese Einschränkungen wurden als Naturschutzauflage gewertet, wenn in der entsprechenden Rechtsgrundlage konkrete Vorgaben für die forstliche Bewirtschaftung vorzufinden waren. Nach der Art der Einschränkung konnten der Verzicht auf die forstliche Nutzung ganzer Bestände oder Bestandesteile und qualitative Auflagen, beispielsweise bezüglich der Baumartenwahl, voneinander unterschieden werden.

Auf der Grundlage der folgenden Datensätze wurden diese verschiedenen Auflagen einschließlich ihrer räumlichen Überlagerung flächenscharf in den WaldPlaner implementiert (weitere Informationen zu den Daten s. Tab. 3):

- Geo- und Sachdaten der Schutzgebietskulisse

- Schutzgebietsverordnungen: Die jeweiligen Auflagen wurden gutachtlich in Regelsets für den WaldPlaner übersetzt.

- Tabellarische Daten zu Waldflächen für Kompensationsmaßnahmen 
Tabelle 3: Datengrundlage: Auflistung aller Datensätze, die zur Abbildung des naturschutə̃fachlichen Schutzstatus, zur Ableitung von Naturschutzauflagen (s. Kap. 2.2.10) und zur naturschutzfachlichen Bewertung von Eichen- und Buchenwäldern (Alters- und Zerfallsphase, s. Kap. 2.2.13) herangezogen wurden. Die Datensätze lagen in digitaler Form vor (GIS-Daten), soweit nichts anderes vermerk.t ist.

\begin{tabular}{|c|c|}
\hline Datensatz & Definition/Arbeitsschritt \\
\hline \multicolumn{2}{|l|}{ Schutzstatus } \\
\hline FFH-Gebiete & Gebietsgrenzen \\
\hline Vogelschutz-Gebiete & Gebietsgrenzen \\
\hline Lebensraumtypen (LRT) & $\begin{array}{l}\text { Hainsimsen-Buchenwald (9110), Waldmeister- } \\
\text { Buchenwald (9130), Sternmieren-Eichen-Hainbuchenwald } \\
\text { (9160), Alte bodensaure Eichenwälder (9190), } \\
\text { Hartholzauenwälder (91F0), Weichholzauenwälder und } \\
\text { Erlen-Eschen-Wälder an Fließgewässern }(* 91 E 0)\end{array}$ \\
\hline Naturschutzgebiete (NSG) & Gebietsgrenzen \\
\hline NSG-Verordnungen & textliche Beschreibung \\
\hline Naturwaldreservat & Gebietsgrenze \\
\hline $\begin{array}{l}\text { Kompensationsmaßnahmen } \\
\text { Flughafen Frankfurt }\end{array}$ & $\begin{array}{l}\text { tabellarische Zusammenstellung der Maßnahmen mit } \\
\text { Angaben zur räumlichen Lage (Abteilungen) }\end{array}$ \\
\hline $\begin{array}{l}\text { Kleinflächige } \\
\text { Eigenbindungen }\end{array}$ & $\begin{array}{l}\text { persönliche Mitteilungen über die betroffenen Flächen } \\
\text { im Stadtwald Frankfurt und Gemeindewald Gernsheim }\end{array}$ \\
\hline \multicolumn{2}{|l|}{ Naturschutzfachliche Bewertung } \\
\hline Forsteinrichtung & $\begin{array}{l}\text { Beschreibung in Kapitel 2.1.1; u. a. Identifizierung von } \\
\text { Wald außer regelmäßigem Betrieb (WarB-Flächen) }\end{array}$ \\
\hline $\begin{array}{l}\text { Biotoptypen } \\
\text { Grunddatenerhebung }\end{array}$ & $\begin{array}{l}\text { flächige Biotoptypen innerhalb von FFH-Gebieten } \\
\text { nach HB }\end{array}$ \\
\hline \multirow[t]{2}{*}{$\begin{array}{l}\text { Hessische Biotopkartierung } \\
\text { (HB) }\end{array}$} & $\begin{array}{l}\text { verwendete Biotoptypen: Buchenwälder mittlerer und } \\
\text { basenreicher Standorte (01.110), Bodensaure } \\
\text { Buchenwälder (01.120), Sonstige Eichen- } \\
\text { Hainbuchenwälder (01.142), Eichenwälder (01.150), } \\
\text { Hartholzauenwälder (01.172), Übrige stark forstlich } \\
\text { geprägte Laubwälder (01.183) }\end{array}$ \\
\hline & $\begin{array}{l}\text { u. a. Identifizierung von möglichen Vorkommen } \\
\text { gesetzlich geschützter Biotope ( } \$ 30 \text { BNatschG) }\end{array}$ \\
\hline $\begin{array}{l}\text { natis-Artdaten } \\
\text { (Hessische Zentrale Artdatenbank) }\end{array}$ & Indikatorarten der Alters- und Zerfallsphase (s. Tab. 4) \\
\hline Haas'sche Karte 1800 & Digitalisierung der analogen Karte \\
\hline $\begin{array}{l}\text { Preußische Landesauf- } \\
\text { nahme } 1900\end{array}$ & Digitale Karte lag vor \\
\hline
\end{tabular}




\subsubsection{Habitatmodellierung / Hotspots}

Die Habitatmodellierung erfolgte summarisch für eine Auswahl von Indikatorarten der Alters- und Zerfallsphase in Buchen- und Eichenwäldern aus den Anhängen II und IV der FFH-Richtlinie (s. Tab. 4). Um die Habitateignung aller Waldflächen im Untersuchungsgebiet für diese Arten zu bestimmen, wurden die Geodaten der Artenfunde mit flächig vorliegenden Informationen zur Bestockung, Habitatkontinuität und Biotopausstattung (s. Tab. 5) verschnitten und einer statistischen Analyse, der sog. „Ecological-Niche Factor Analysis“ (ENFA) (HIRZEL et al. 2002) unterzogen. Eine genauere Beschreibung der Methodik findet sich in Kapitel 2.2.9. Die Methode ENFA wurde bereits in anderen Projekten erfolgreich angewendet (LACHAT u. BÜTLER 2009, BRAUNISCH u. SUCHANT 2007). Flächen mit einer besonders hohen Habitateignung werden in der vorliegenden Studie als Hotspots bezeichnet.

Tabelle 4: $\quad$ Übersicht über die in der Habitatmodellierung verwendeten Indikatorarten der Altersund Zerfallsphase, Nachweise Arten aus natis und Grunddatenerbebung

\begin{tabular}{llcc}
\hline Deutscher Name & Wissenschaftlicher Name & $\begin{array}{c}\text { Anzahl } \\
\text { Nachweise }\end{array}$ & $\begin{array}{c}\text { Anhang } \\
\text { FFH }\end{array}$ \\
\hline Heldbock & Cerambyx cerdo & 194 & II/IV \\
Eremit & Osmoderma eremita & 22 & II/IV \\
Veilchenblauer & Limoniscus violaceus & 4 & II \\
Wurzelhalsschnellkäfer & Myotis bechsteinii & 23 & II/IV \\
Bechsteinfledermaus & Plecotus auritus & 34 & IV \\
Braunes Langohr & Myotis natterei & 16 & IV \\
Fransenfledermaus & Myotis brandtii & 2 & IV \\
Große Bartfledermaus & Nyctalus noctula & 7 & IV \\
Großer Abendsegler & Pipistrellus nathusii & 2 & IV \\
Rauhautfledermaus & & 304 & \\
\hline Summe & & & \\
\hline
\end{tabular}

Die Artdaten entstammten einem von der FENA bereitgestellten Auszug aus der natis-Datenbank (HESSEN-FORST FENA 2007) und der Grunddatenerhebung im Rahmen der FFH-Gebietsausweisung.

Der natis-Datensatz enthält detaillierte Informationen zu Artenvorkommen aus verschiedenen Quellen. Diese reichen von Artgutachten, die vom Land Hessen in Auftrag gegeben worden sind, über Datensammlungen von Naturschutzverbänden bis hin zu Quellen ehrenamtlicher Akteure. Die Daten lagen im Vektorformat als Punktdaten vor. Sie enthielten für jeden Fundort einer Art eine Unschärfeangabe, die die mögliche Abweichung des tatsächlichen Fundorts von der in der 
Vektordatei angegebenen Koordinate in Metern quantifiziert. Punkte mit einer Unschärfe > $200 \mathrm{~m}$ wurden von den weiteren Auswertungen ausgeschlossen.

Ergänzt wurden die natis-Daten durch die im Rahmen der FFH-Grunddatenerhebung erfassten Artdaten des Regierungspräsidiums Darmstadt. Diese Funde stammen aus dem Zeitraum zwischen 2001 und 2004.

Die ausgewählten Arten unterscheiden sich maßgeblich hinsichtlich ihrer Mobilität: Während die xylobionten Käfer nur wenig mobil sind, ist die Gruppe der Fledermäuse äußerst mobil. Bei letzteren wurden deshalb ausschließlich Sommer-, Winter- und Wochenstubenquartiere im Wald verwendet, um den unmittelbaren Bezug zu Altbeständen mit geeigneten Habitatstrukturen zu gewährleisten.

Ein wesentlicher Anteil der Habitatvariablen wurde aus den Forsteinrichtungsdaten abgeleitet. Da die betrachteten Arten indikatorisch für die Alters- und Zerfallsphase in Buchen- und Eichenwäldern stehen, stellt das Bestandesalter eine Schlüsselvariable dar.

Die Bewaldungskontinuität ist eine weitere wichtige Habitatvariable bei der Betrachtung wenig mobiler Arten wie den xylobionten Käfern. Per Definition wird zwischen historisch alten, d. h. mindestens seit Ende des 18. Jahrhunderts bestehenden, und historisch jungen Wäldern unterschieden, die erst später auf unbewaldeten Standorten entstanden sind. (Wulf 1994, GLASER u. HAUKE 2004)

Die Lage der Waldflächen um 1800 wurde der Haas'schen Karte entnommen, wobei die einzelnen Kartenblätter auf die Jahre zwischen 1789 und 1801 datiert sind. Die Haas'sche Karte liegt im Original im Maßstab 1:30.380 vor und weist unterschiedliche Signaturen für Laub-, Nadel- und Mischwälder auf. Dieser Quelle wird eine vergleichsweise hohe Verlässlichkeit bezüglich der topographischen Details zugesprochen (BLESSON 2006).

Anhand der Karten der Preußischen Landesaufnahme wurde die Ausdehnung des Waldes im Jahr 1900 abgegrenzt. Die Preußische Landesaufnahme liegt im Maßstab 1 : 25.000 vor und ist deckungsgleich mit dem heutigen Blattschnitt der Topographischen Karten. Im Unterschied zur Haas'schen Karte differenziert die Preußische Landesaufnahme im Untersuchungsgebiet nicht zwischen Laub-, Nadel- und Mischwald.

Die aktuellen Waldflächen wurden dem ATKIS Basis-DLM (digitales Landschaftsmodell) entnommen. Sie basieren auf digitalen Orthophotos und unterscheiden zwischen Laub-, Nadel- und Mischwald. Auf Grund der feinen Auflösung der Orthophotos kann die Genauigkeit der aktuellen Waldflächen als hoch eingestuft werden. 
Tabelle 5: $\quad$ Erklärende Variablen des Habitatmodells und deren Datengrundlagen

\begin{tabular}{|c|c|}
\hline $\begin{array}{l}\text { Habitatvariable } \\
\text { Forsteinrichtung }\end{array}$ & Definition \\
\hline Alter Laubholz-Altbestand & Maximales Alter aller Laubbaumarten je Fläche \\
\hline natürlicher Bestockungsgrad & nat. Bestockungsgrad des Gesamtbestandes \\
\hline $\begin{array}{l}\text { Flächenanteil Laubholz- } \\
\text { Altbestand }\end{array}$ & Flächenanteil des Bestandes mit dem maximalen Alter \\
\hline Anteil Laubholz & $\begin{array}{l}\text { Anteil Laubbäume (Baumartengruppen Eiche und Buche } \\
\text { der Forsteinrichtung) }\end{array}$ \\
\hline Anteil Eiche & Anteil Baumarten Eiche (ohne Roteiche) \\
\hline Anteil Buche & Anteil Baumart Buche \\
\hline $\begin{array}{l}\text { Anteil nicht- } \\
\text { standortheimische } \\
\text { Baumarten }\end{array}$ & $\begin{array}{l}\text { Anteil nicht-standortheimischer Nadel- und Laubbaum- } \\
\text { arten (Nadelholz ohne Kiefer, Roteiche, Robinie, Hybrid- } \\
\text { Pappel) }\end{array}$ \\
\hline Flächengröße & Fläche der Beschreibungseinheit \\
\hline \multicolumn{2}{|l|}{ Weitere Datenquellen } \\
\hline $\begin{array}{l}\text { Bewaldungskontinuität } \\
\text { Laub- und Mischwald }\end{array}$ & $\begin{array}{l}\text { Seit mind. } 200 \text { Jahren mit Laub- oder Mischwald bestockt } \\
\text { (Haas'sche Karte und Preußische Landesaufnahme) }\end{array}$ \\
\hline $\begin{array}{l}\text { Distanz zu Flächen der } \\
\text { Hessischen Biotop- } \\
\text { kartierung (HB) }\end{array}$ & Distanz zu eichen- und buchendominierten Flächen der HB \\
\hline $\begin{array}{l}\text { Distanz zu } \\
\text { Referenzflächen }\end{array}$ & $\begin{array}{l}\text { Distanz zu überregional bekannten Flächen mit hoher } \\
\text { Habitatqualität: Schwanheimer Eichen, Naturschutzgebiet } \\
\text { Sauergrund, Naturwaldreservat Karlswörth, Reliktwald } \\
\text { Lampertheim (eine Abteilung), Stieleichenwald Gernsheim } \\
\text { (eine Abteilung) und Flächen aus eigener Bereisung mit } \\
\text { hoher Habitatqualität }\end{array}$ \\
\hline
\end{tabular}

Aufgrund des größeren Maßstabes und der Verfügbarkeit von Laub-, Nadel- und Mischwaldsignaturen in der Haas'schen Karte im Vergleich zu Auswertungen der historischen Datengrundlage von GLASER u. HAUKE (2004) wurde eine eigene Auswertung der Bewaldungskontinuität vorgezogen.

Eine weitere Datenquelle zur Einschätzung der Habitateignung war die Hessische Biotopkartierung. Es handelt sich hierbei um eine selektive Kartierung der aus naturschutzfachlicher Sicht besonders wertvollen Biotope (HMULF 1995). Im Rahmen der Habitatmodellierung wurden die Flächen mit den Biotoptypen Buchenwälder mittlerer und basenreicher Standorte (01.110), bodensaure Buchenwälder (01.120), sonstige Eichen-Hainbuchenwälder (01.142), Eichenwälder (01.150), Hartholzauenwälder (01.172), und übrige stark forstlich geprägte Laubwälder (01.183) verwendet. In die Habitatmodellierung ging die Entfernung zu diesen besonders wertvollen Flächen ein. 


\subsection{Beschreibung der Szenarien und Modellansätze}

\subsubsection{Grundwasserszenarien}

Die Waldentwicklung im Hessischen Ried wird maßgeblich von den Grundwasserverhältnissen beeinflusst. Durch anthropogene Maßnahmen kam es in der Vergangenheit in weiten Bereichen des Untersuchungsraumes zu starken Grundwasserabsenkungen (s. Kap. 2.1.2.3). Besonders die Bestände im Süden des Projektgebietes verfügen gegenwärtig nicht mehr über einen gesicherten Grundwasseranschluss. Um den Einfluss des Grundwassers auf die Waldentwicklung im Hessischen Ried zu untersuchen, wurden drei Grundwasserstandsszenarien mit dem gekoppelten Modellsystem gerechnet:

(1) Status quo (GW0):

Die Grundwasserstände werden auf dem mittleren Niveau des Grundwasserbewirtschaftungsplans Hessisches Ried (RP DARMSTADT 1999) festgeschrieben. Die aktuellen Grundwasserverhältnisse bilden die Grundlage für die unterstellten Waldentwicklungsszenarien. Wie aus Abbildung 6 ersichtlich, unterlagen die Grundwasserstände in den letzten Jahren relativ geringen Schwankungen. Der Grundwassergleichenplan für den Oktober 2007 kann deshalb als repräsentativ für dieses Szenario angesehen werden.

(2) Weitere Absenkung der Grundwasserstände (GW-):

Die Grundwasserstände sinken auf allen Flächen unter ein von den Baumwurzeln noch erreichbares Niveau. Die maximale Absenkung darf jedoch die im Grundwasserbewirtschaftungsplan festgeschriebenen unteren Grenzgrundwasserstände nicht unterschreiten. Da die Grenzgrundwasserstände des Grundwasserbewirtschaftungsplans nicht das gesamte Untersuchungsgebiet abdecken, wurde der nördliche Bereich (Frankfurter Stadtwald bis zum Main) mit den Grundwasserständen aus dem Oktober 1991 ergänzt. Die Verhältnisse im Oktober 1991 zeigen im Vergleich zu den Grenzgrundwasserständen die geringsten Abweichungen.

(3) Anbebung der Grundwasserstände (GW+):

Die Grundwasserstände werden wieder auf das Niveau vor Beginn der industriellen Grundwasserentnahmen angehoben. Als Referenz werden die Grundwasserstände aus dem Juli 1951 herangezogen. Für die Zukunft würde dies bedeuten, dass die Grundwasserentnahmen überall dort, wo möglich, soweit zurückgefahren werden, dass die Bestände wieder Anschluss an das Grundwasser erhalten. Die Anhebung des Grundwasserspiegels kann lokal auch durch Wiederaufspiegelung mit Hilfe von Infiltrationsbrunnen erfolgen. 
In Abbildung 7 sind die Flurabstände für die Grundwasserszenarien Status quo (GW0), erhöhte Grundwasserstände $(\mathrm{GW}+)$ und weiter sinkende Grundwasserstände (GW-) dargestellt.
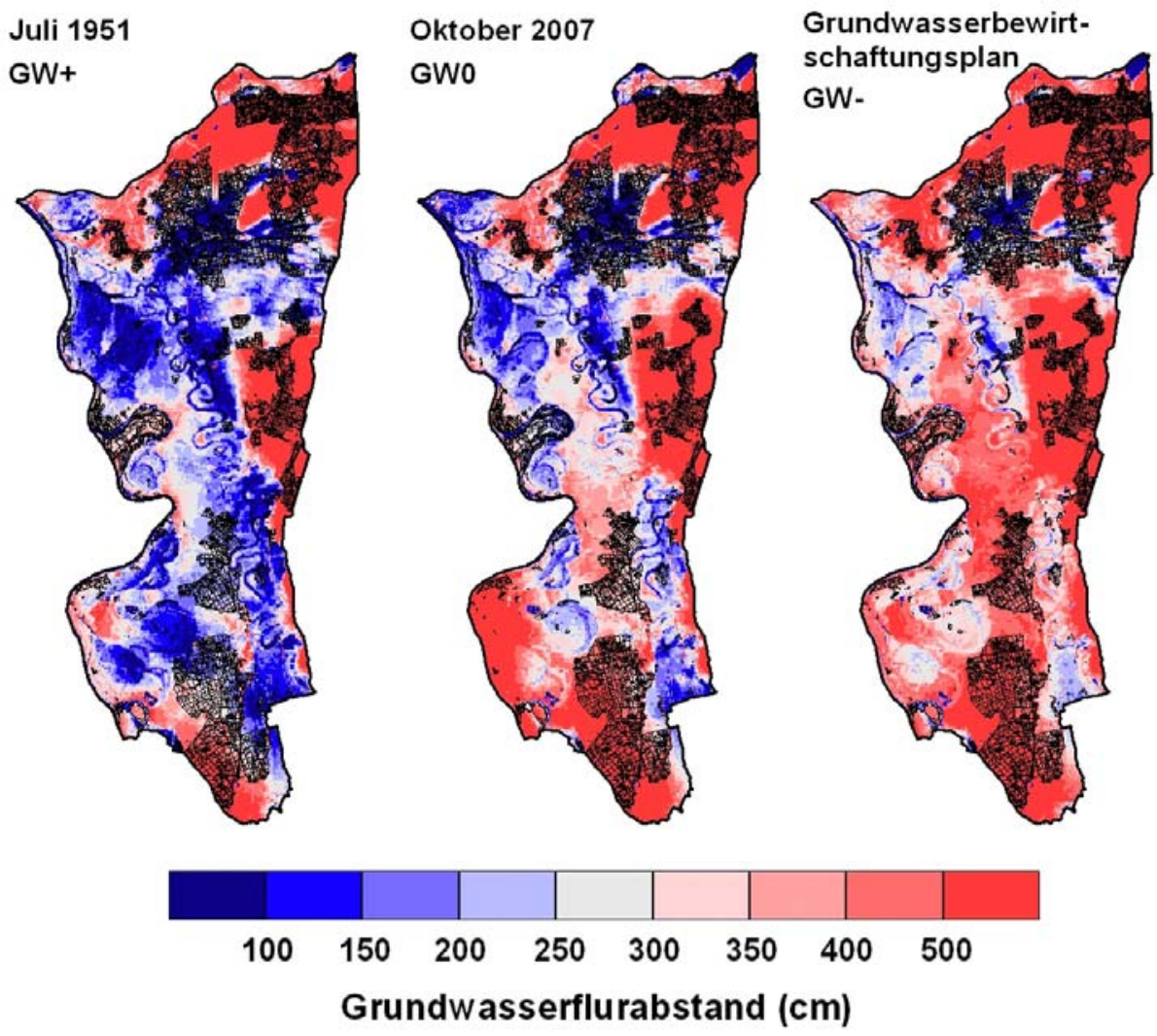

Abbildung 7: Grundwasserstandsszenarien für das Hessische Ried

Vor der Grundwasserabsenkung verfügten viele Waldflächen im Hessischen Ried über einen sicheren Grundwasseranschluss. Erkennbar sind die Flächen in Abbildung 7 durch ihre hell- bis dunkelblaue Einfärbung. Ab einem Flurabstand von weniger als etwa 2,50 Metern Tiefe ist eine Wasserversorgung der Bäume über das Grundwasser weitgehend gewährleistet (ZIMMERMANN 1956). Der gesamte Gernsheimer/Jägersburger Wald und die meisten Bestände des Lorscher, Bürstädter und Viernheimer Waldes verfügten ehemals über einen sicheren Grundwasseranschluss. Auch viele Bestände der Forstämter Groß-Gerau und Langen im Norden des Untersuchungsgebietes zeichneten sich durch geringe Flurabstände aus. Im Frankfurter Stadtwald und in Teilen des Darmstädter Westwaldes (außer dem 
nördlichen Bereich) betrugen bereits vor der Grundwasserabsenkung in den 60erJahren die Flurabstände mehr als fünf Meter. Insgesamt wiesen im Juli 1951 knapp 40 Prozent aller Bestände im Hessischen Ried einen Grundwasserflurabstand von weniger als 2,50 m auf. Gut 30 Prozent der Waldflächen waren dagegen mit Flurabständen von über $5 \mathrm{~m}$ schon damals weit von einem Grundwasseranschluss entfernt (s. Abb. 8). Bei Grundwasserflurabständen zwischen etwa 2,50 und $5 \mathrm{~m}$ kann in Abhängigkeit von der Baumart, dem Bestandesalter und dem Bodensubstrat davon ausgegangen werden, dass die Durchwurzelung einzelner Bäume bis zum Kapillarsaum hinabreicht (positiver Grundwassereinfluss).

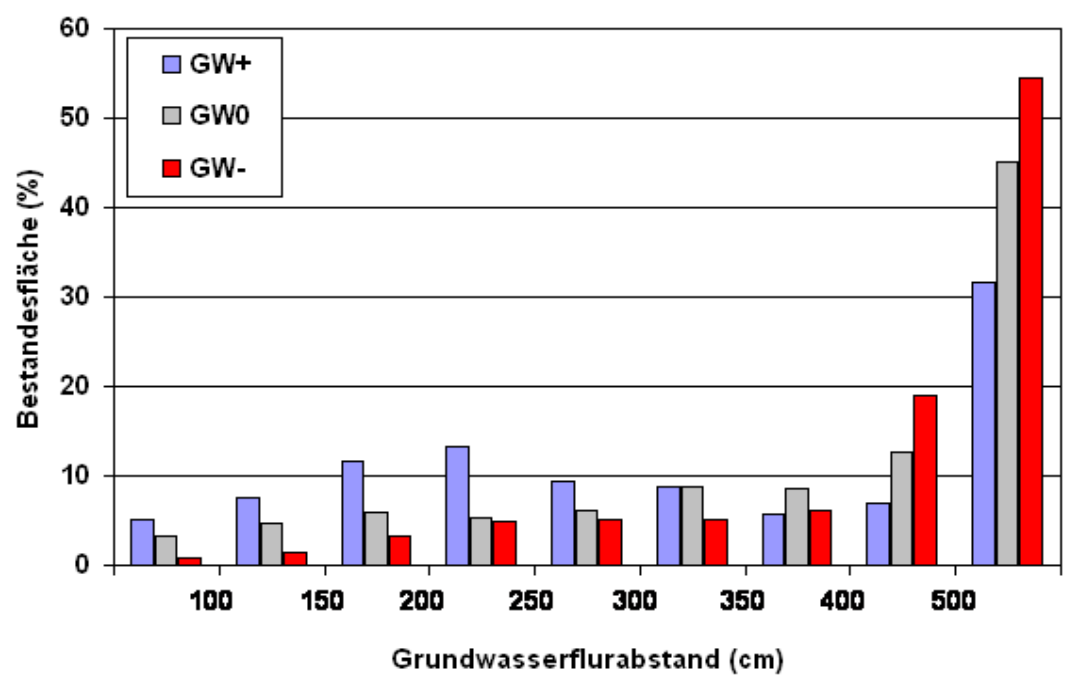

Abbildung 8: Häufigkeitsverteilung der Bestandesfläche an den Flurabstandsklassen

Unter heutigen Grundwasserverhältnissen (Szenario GW0) stocken bereits 45 Prozent der Bestände auf grundwasserfernen ( $>5 \mathrm{~m}$ Flurabstand) Standorten, während nur noch 19 Prozent der Waldflächen Flurabstände von weniger als 2,50 Metern aufweisen (s. Abb. 8). Von den Grundwasserabsenkungen sind besonders der Gernsheimer/Jägersburger Wald, der Lorscher, Bürstadter und Viernheimer Wald sowie Teile des Darmstädter Westtwaldes betroffen (s. Abb. 7). Sollten in Zukunft die Entnahmemengen weiter ansteigen, verfügten in Anlehnung an die Grenzgrundwasserstände des Grundwasserbewirtschaftungsplans nur noch neun Prozent der Waldflächen über einen sicheren Grundwasseranschluss, während mindestens 55 Prozent der Bestände ihren Wasserbedarf ausschließlich aus dem Bodenwasser decken müssten (s. Abb. 8). Bei diesem Szenario würden besonders Bestände in den Forstämtern Groß-Gerau und Langen ihren Grundwasseranschluss verlieren (s. Abb. 7). 
Die Grundwasserstände bilden die untere Randbedingung im hydrologischen Modell. Außerdem beeinflusst der Grundwasserflurabstand die Bonität eines Bestandes, indem im Standort-Leistungsmodell das Wuchspotenzial bei Grundwasseranschluss erhöht und bei fehlendem Grundwasseranschluss herabgesetzt wird. Auch die gesamte waldbauliche Behandlung, das Pflege-Nutzungs-Regime und die Zuweisung des Waldentwicklungstyps werden in Abhängigkeit von den Grundwasserverhältnissen regelbasiert gesteuert.

\subsubsection{Klimaszenarien}

Die Klimaszenarien des Intergovernmental Panel on Climate Change (IPCC 2007) basieren auf verschiedenen Annahmen zum globalen Ausstoß von Treibhausgasen bis zum Jahr 2100. In allen Szenarien wird für die Zukunft ein mehr oder weniger starkes Wirtschaftswachstum angenommen. Die Szenarien unterscheiden sich jedoch dahingehend, wie der Verbrauch natürlicher Ressourcen, insbesondere fossiler Energieträger, ansteigt und wie der globale Wissens- und Techniktransfer ein umweltschonendes Wirtschaften begünstigt. Bei den moderaten B-Emisionsszenarien nimmt langfristig der Ausstoß von Treibhausgasen ab bzw. stagniert auf einem im Vergleich zur Gegenwart leicht erhöhtem Niveau. Die Temperaturerhöhung fällt bei den weniger umweltbewussten A-Szenarien deutlich stärker aus, da mit einem weiteren Anstieg der Treibhausgasemissionen gerechnet wird. Derzeit wird das Klimaszenario A1B als die wahrscheinlichste Projektion des Klimas angesehen. Bei diesem Szenario steigt die globale Jahresmitteltemperatur bis zum Ende des Jahrhunderts um ca. 3,5 K. Für das Hessische Ried fällt der projizierte Anstieg mit knapp 2,5 K etwas moderater aus.

Die Emissionsszenarien des IPCC bilden die Grundlage globaler Klimamodelle. Die Globalmodelle bilden die zukünftige Entwicklung des Klimas auf einem relativ groben Raster ab. Das Modell ECHAM5/MPI-OM des Hamburger Max-Planck-Instituts beispielsweise verwendet eine horizontale Auflösung von $200 \times 200 \mathrm{~km}$ (ROECKNER et al. 2003). Für viele Fragestellungen und Untersuchungsgebiete ist diese räumliche Auflösung allerdings zu grob. Um die Ergebnisse der globalen Klimamodelle mit einer höheren räumlichen Auflösung darzustellen, werden regionale Klimamodelle eingesetzt.

Dynamische Regionalmodelle rechnen - vergleichbar mit den Globalmodellen - die zukünftige Klimaentwicklung physikalisch basiert für einen begrenzten Raum mit hoher räumlicher Auflösung. Bei dem genesteten Verfahren kommen an den Modellrändern des Regionalmodells die Antriebsdaten des Globalmodells zum Einsatz. Statistische Regionalmodelle gehen davon aus, dass die globalen Modelle die großräumigen Zirkulationsmuster (Wetterlagen) treffend beschreiben. Über die Kausalkette von sich veränderten Häufigkeitsverteilungen der Großraumwetterlagen werden tägliche Werte für meteorologische Variablen (Temperatur, Niederschlag etc.) ermittelt. Die Werte werden nicht wie bei den dynamischen Modellen 
für ein definiertes Raster berechnet, sondern als Zeitreihen für Klima- und Niederschlagsstationen des Deutschen Wetterdienstes.

Für das Untersuchungsgebiet liegen die Daten der dynamischen Regionalmodelle REMO (JACOB et al. 2008) und CLM (ROCKEL et al. 2008) sowie des statistischen Modells WETTREG vor. Die Modellsimulationen im Hessischen Ried wurden mit dem Modell WETTREG durchgeführt, da die dynamischen Regionalmodelle einen teilweise starken Niederschlagsbias (Verzerrung) aufweisen. Dieser äußert sich dahin gehend, dass Niederschlagsmaxima im Vorland von Mittelgebirgen vorausgesagt werden und nicht in den Hochlagen. Dieser Fehler tritt bei den statistischen Modellen nicht auf.

Für jedes Klimaszenario wurden verschiedene Varianten gerechnet, die sich hinsichtlich des Niederschlagsregimes stark unterscheiden, während die Temperaturvarianz relativ gering ist. Um die Spannweite in der Niederschlagsprojektion zu erfassen, wurden die jeweils trockenste und feuchteste Variante des A1B-Szenarios für die gekoppelte Modellsimulation verwendet (SPELLMANN et al. 2007). Zur Regionalisierung wurden die Stationsdaten des WETTREG-Modells mit dem gleichen Verfahren wie bei den Messdaten auf das Modellgitter von 100 m-Rasterweite interpoliert (s. Kap. 2.1.2.1).

Am Beispiel der Station Mannheim wird die klimatische Entwicklung für die Jahresmitteltemperatur und die Jahresniederschlagssumme aufgezeigt (s. Abb. 9). Für die Klimanormalperiode 1961 bis 1990 beträgt die gemessene Jahresmitteltemperatur $10,3{ }^{\circ} \mathrm{C}$. Die verwendeten A1B-Varianten des WET'TREG-Modells bilden den Messwert mit 10,2 ${ }^{\circ} \mathrm{C}$ (trockene Variante) und 10,6 ${ }^{\circ} \mathrm{C}$ (feuchte Variante) sehr gut ab. Bis zum Jahr 2040 soll die Temperaturerhöhung relativ moderat ausfallen. Für den Zeitraum 2011 bis 2040 wird eine Jahresmitteltemperatur von $10,9^{\circ} \mathrm{C}$ (trocken) und $11,0^{\circ} \mathrm{C}$ (feucht) berechnet. Betrachtet man allerdings nur die letzte Dekade (2031 bis 2040) des Simulationszeitraumes, so beschleunigt sich die Erwärmung deutlich. Die berechnete Jahresmitteltemperatur liegt mit $11,6{ }^{\circ} \mathrm{C}$ bzw. $11,7^{\circ} \mathrm{C}$ fast $1,5^{\circ} \mathrm{C}$ über dem Mittelwert der Klimanormalperiode.

Die Niederschlagsentwicklung an der Station Mannheim zeigt keinen eindeutigen Trend. In der Periode 1961 bis 1990 beträgt die mittlere Jahressumme des gemessenen Niederschlags $667 \mathrm{~mm}$. Hier liegt die feuchte Variante der WETTREG-Simulation mit $698 \mathrm{~mm}$ deutlich näher an den Messwerten als die trockene Variante mit $560 \mathrm{~mm}$. Zukünftig wird sich die Niederschlagsentwicklung nicht wesentlich verändern. Für den Zeitraum von 2011 bis 2040 werden $576 \mathrm{~mm}$ (trockene Variante) und $692 \mathrm{~mm}$ (feuchte Variante) berechnet. Allerdings fällt die Periode 2031 bis 2040 im Vergleich mit den mittleren Jahressummen von 614 mm bzw. $752 \mathrm{~mm}$ überdurchschnittlich feucht aus. 

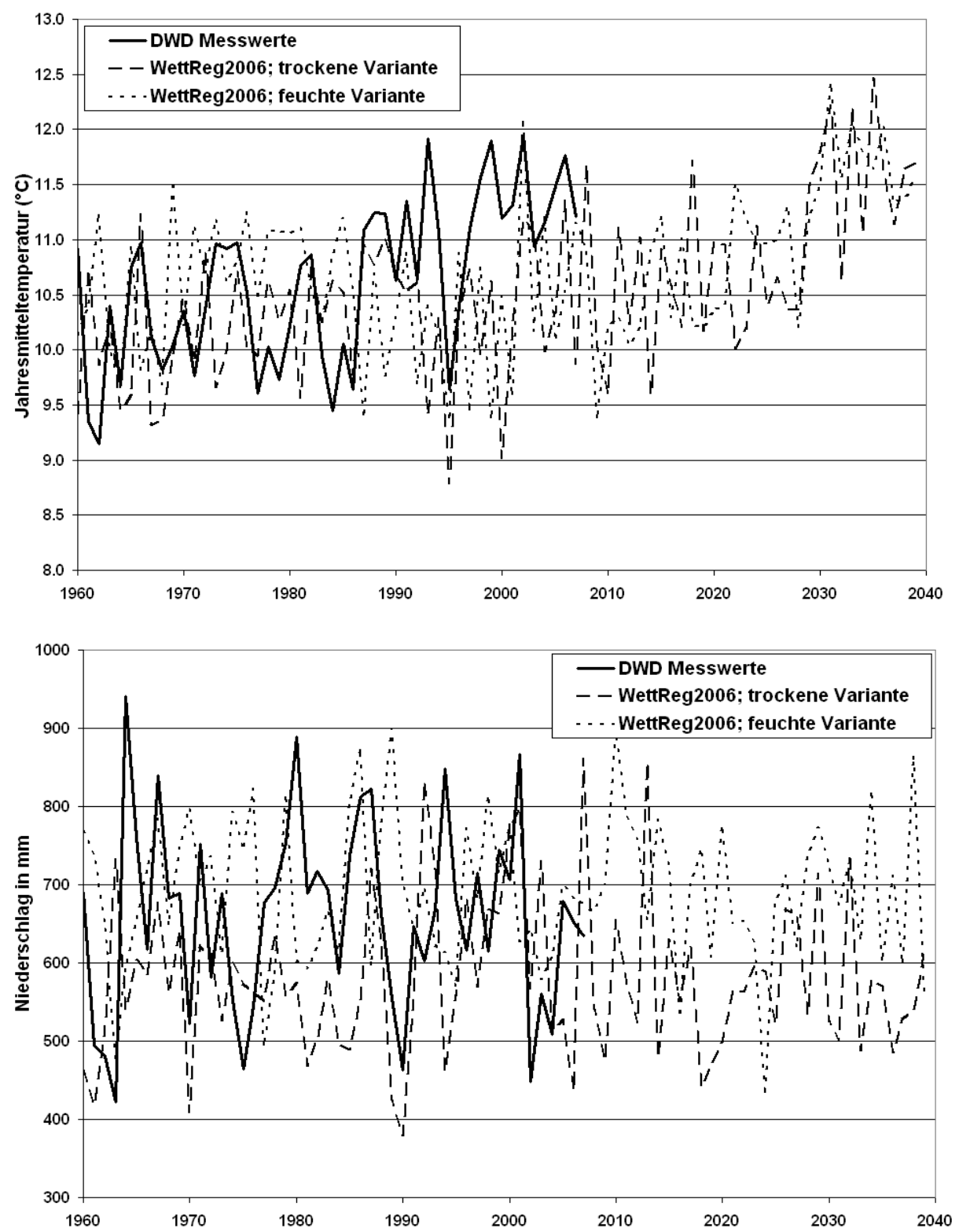

Abbildung 9: Gemessene (DWD) und simulierte (WETTREG) Jabresmitteltemperaturen $\left[{ }^{\circ} \mathrm{C}\right]$ (oben) und Jahresniederschlagssummen [mm] (unten) für die Station Mannheim 
Der Klimawandel wird sich vielfältig auf die Wälder im Hessischen Ried auswirken. Der erwartete Temperaturanstieg wird den Verdunstungsanspruch der Bäume insbesondere in der Vegetationsperiode deutlich erhöhen. Bei gleichzeitig abnehmendem Niederschlagsangebot im Sommer werden die Bestände zunehmend unter Wasserstress leiden.

Eine flächendifferenzierte Beschreibung der klimatischen Verhältnisse unter der Verwendung der WETTREG-Varianten erfolgt in Kapitel 3.1.

\subsubsection{Untersuchungsansätz̧e}

Zentrales Prognosewerkzeug war das waldbauliche Entscheidungsunterstützungssystem WaldPlaner (HANSEN 2006, ALBERT u. HANSEN 2007, HANSEN u. NAGEL 2011) der Nordwestdeutschen Forstlichen Versuchsanstalt. Es ist in der Lage, verschiedene, z. T. regelbasierte Teilmodelle zu einem Gesamtsimulationssystem zu kombinieren.

Für die vorliegende Studie wurden folgende Eingangsgrößen, Teilmodelle und Regeln kombiniert:

- Grundwasserstände (Büro BGS Umwelt)

- Stoffhaushaltsmodell (dynamischer Stoffhaushalt)

- Wasserhaushalt (WaSim/ETH, SCHULLA 1997)

- Standort-Leistung (AlbERT u. SCHMIDT 2010a, AlBERT u. SCHMidT 2010b)

- Allgemeines Mortalitätsmodell

- Maikäfermortalitätsmodell

- Waldwachstumsmodell (TreeGrOSS)

- Naturschutzregeln / Naturschutzfachliche Vorgaben

- Waldbauregeln / Waldbaustrategien

Die einzelnen Teilmodelle und der Ablauf der Simulation werden in den folgenden Unterkapiteln beschrieben.

\subsubsection{Stoffhaushaltsmodellierung}

\subsubsection{Einfübrung}

Die Nährstoffversorgung ist neben dem Wasserhaushalt die wichtigste lokale Standortskomponente. Entsprechend ist die Erfassung aller für das Waldwachstum wichtigen natürlichen Bedingungen das Ziel der forstlichen Standortskartierung. Ohne diese Informationen ist weder eine umweltbewusste und rationelle Bewirtschaftung des Waldes (ARBEITSKREIS STANDORTSKARTIERUNG 2003) noch eine ausreichende Bewertung der Wirkung von Klimaänderungen möglich (PUHE u. ULRICH 2001, BYTNEROWICZ et al. 2007). In Hessen, wie auch in den anderen Bundesländern, gehen die länderspezifischen Verfahren der Standortskartierung von einer statischen Betrachtung der Standortsfaktoren Boden, Klima und Relief 
aus. Dieses ist darauf zurückzuführen, dass die Verfahren der Bundesländer in der Mitte des letzten Jahrhunderts entwickelt wurden, als die Dynamik der forstlichen Standorte hinsichtlich der atmosphärischen Stickstoffeinträge, der Bodenversauerung und der Klimaveränderungen noch weitgehend unbekannt war. Vor dem Hintergrund der derzeitigen Projektionen über die globalen Klimaentwicklungen (TEBALDI et al. 2006, SCHÄr et al. 2004) und der hohen Dynamik der regionalen Stoffeinträge (SCHÖPP et al. 2003) ist es dringend geboten, diese Veränderungen in die Planungen für eine nachhaltige Waldnutzung zu integrieren.

Unsere Waldökosysteme sind seit mehreren Jahrzehnten hohen atmosphärischen Stoffeinträgen ausgesetzt. Durch Maßnahmen zur Luftreinhaltung sind zwar die Säureeinträge in den letzten Jahren stark zurückgegangen (FOWLER et al. 2007). Gleichzeitig sind jedoch auch die Depositionen von $\mathrm{K}, \mathrm{Mg}$ und $\mathrm{Ca}$ gesunken (GAUGER et al. 2002), sodass die Basensättigung weiter absinkt oder sich weiterhin auf einem kritischen Niveau befindet. Anders als die Säureeinträge verbleiben die atmosphärischen Einträge von reduzierten und oxidierten Stickstoffverbindungen nach wie vor auf einem sehr hohen Stand, da die Zielvorgaben zur Reduzierung der Stickoxid- und Ammoniak-Emissionen nicht erreicht werden konnten (s. Kap. 2.2.4.5.4). Somit sind die atmosphärischen Stickstoffdepositionen mittlerweile neben dem Klimawandel zu einer der Hauptgefährdungen für die Funktionalität und Stabilität der Waldökosysteme geworden (MATSON et al. 2002, NiLSEN 1990, GLATZEL et al. 1987). Als weitere unerwünschte Effekte sind die Verschiebung des Artenspektrums der Bodenvegetation (ANDERS et al. 2002) und besonders die Austräge von Nitrat mit dem Sickerwasser (Gewässereutrophierung und -versauerung) (AHRENDS et al. 2010a, DISE u. WRIGHT 1995) zu nennen.

Neben Störungen und Schädigungen der Waldökosysteme berichten zahlreiche Untersuchungen von Wachstumssteigerungen durch die atmosphärischen Stickstoffeinträge (AlBERT u. SCHMIDT 2010a, KENK u. FISCHER 1988, LAUBHANN et al. 2009, NiLSSON u. WiKLund 1992). Vor dem Hintergrund der Dynamik der letzten Jahrzehnte (SCHÖPP et al. 2003, FOWLER et al. 2007) und der regionalen Unterschiede der Einträge (GAUGER et al. 2008) ist es notwendig, sowohl die zeitlichen als auch die räumlichen Unterschiede in die Modellierung des Waldwachstums, als auch in die Abschätzung der Grundwasserbelastung unter sich ändernden klimatischen Bedingungen zu integrieren.

Aus den dargestellten Herausforderungen der Zukunft und Problemen der Vergangenheit lässt sich die Notwendigkeit der Entwicklung eines dynamischen Stoffhaushalt-Modells für das Entscheidungsunterstützungssystem ableiten. Mit diesem Modul soll sich die Dynamik bodenchemischer Kennwerte aufgrund veränderter Stoffeinträge und Standortsbedingungen beschreiben lassen. Des Weiteren sollen sich mit diesem Modul die Auswirkungen der unterschiedlichen Waldentwicklungsszenarien auf Kenngrößen und Indikatoren des Stoffhaushaltes abbilden lassen. Der Vergleich und die Analyse unterschiedlicher Szenarien bilden die Grundlage für die Ableitung räumlich optimierter Bewirtschaftungsstrategien. 
Schließlich sollen die durchzuführenden Modellierungen auch einen Beitrag zur Diskussion über die Schadenskausalitäten liefern. Aus den Zielsetzungen resultiert bei der planerischen Umsetzung ein hoher Anspruch an die räumliche Differenzierung. Hieraus ergibt sich eine erhebliche Anforderung an die Qualität und die räumliche Auflösung der für die Modellierung notwendigen flächenhaften Eingangsdaten. Weiter sollen die zukünftigen waldbaulichen Strategien die Veränderungen integrieren, die aus der globalen Klimaentwicklung und den regional differenzierten atmosphärischen Stoffeinträgen resultieren.

Im Einzelnen ergeben sich folgende Arbeitsbereiche der Modellierung und Regionalisierung stoffhaushaltlicher Kenngrößen:

- Modellierung der vergangenen und der zukünftigen Belastungssituation durch Säure und Stickstoffdeposition für die unterschiedlichen waldbaulichen Bewirtschaftungseinheiten.

- Regionalisierung ausgewählter Kenngrößen des Stickstoffhaushaltes (Immobilisation, Aufnahme, Denitrifikation, Deposition) und sickerwassergebundener Stickstoffaustrag bei unterschiedlichen waldbaulichen Bewirtschaftungsszenarien.

- Modellhafte Abbildung der Versauerungs- und Nährstoffsituation im Boden

\subsubsection{Modellierungsansatz}

Entsprechend der Vorgaben sind die Zielgrößen der flächenhaften Modellierungsarbeiten messbare Kenngrößen, mit denen der Veränderungsumfang, die Veränderungsgeschwindigkeit und -richtung von bodenchemischen und waldwachstumskundlichen Entwicklungen bewertet und Zielerreichungen überprüft werden können. In Anlehnung an RIEK u. WOLFF (2007) sind die folgenden Leitindikatoren geeignet, um den Versauerungszustand des Bodens und seiner Veränderung infolge natürlicher und anthropogener Versauerungsprozesse zu beschreiben:

- pH-Wert: Der pH-Wert beeinflusst direkt oder indirekt eine Vielzahl von Prozessen, die in unseren Böden ablaufen (PENNE et al. 2010, WALSE et al. 1998, SVERDRUP u. WARFVINGE 1993).

- Basensättigung: Die Basensättigung ist zusammen mit der effektiven Kationenaustauschkapazität (KAKeff) ein relativ guter Indikator für die Ausstattung eines Standortes mit wichtigen Makronährelementen wie Calcium, Magnesium oder Kalium (SCHULTE-BISPING et al. 2001, STOCK 2004, Meiwes u. Meesenburg 2007). Des Weiteren sind die Basenvorräte entscheidend, um zuverlässige Aussagen zu den Versauerungsvorgängen zu treffen (RIEK u. WOLFF 2007).

- Pufferfähigkeit: Ein Boden ist umso besser gepuffert, desto geringer die pHAbnahme bei konstanter Säurezufuhr ist. Entsprechend ergeben sich aus den unterschiedlichen Silikatverwitterungsraten der Böden unterschiedliche Empfindlichkeiten hinsichtlich der Bodenversauerung. 
Geeignete Leitindikatoren, die den Stickstoffstatus und seine Dynamik als Folge von atmosphärischen Stickstoffeinträgen und internen Umsetzungsprozessen beschreiben, sind:

- Stickstoffaustrag: Erhöhte Stickstoffausträge mit dem Sickerwasser sind ein wichtiger Indikator für eine zunehmende Stickstoffsättigung des Bodens (ABER et al. 1989).

- Umsatzbedingungen (C/N-Verhältnis): Das C/N-Verhältnis im Auflagehumus bzw. bei mullartigen Humusformen im Ah-Horizont ist eine häufig verwendete Kenngröße, um die Umsatzbedingungen zu beschreiben (ARBEITSKREIS STANDORTSKARTIERUNG 2003) und die Austragsgefährdung von Stickstoff einzuschätzen (MACDONALD et al. 2002).

- Akkumulierte Stickstoffmenge: Die im Boden akkumulierte Stickstoffmenge und insbesondere ihre Dynamik gibt wichtige Hinweise auf den aktuellen Stand der N-Akkumulation im Ökosystem.

Bei einer integrierten Bewertung der Auswirkungen von atmosphärischen Stoffeinträgen, Grundwasserabsenkungen, Klimaänderungen und waldbaulichen Maßnahmen sollten daher alle diese Indikatoren als Zielgrößen der Modellierungsarbeiten berücksichtigt werden, bzw. sollten die quantitativen Kenngrößen in Modellen sinnvoll miteinander verknüpft werden.

\subsubsection{Modellauswabl und Anpassungen}

Aufgrund seiner großen Bedeutung ist der Stoffhaushalt von Waldökosystemen seit mehr als einem Jahrhundert Gegenstand zahlreicher Modellierungsaktivitäten (CHERTOV u. KOMAROV 1997). Im Zusammenhang mit den hohen atmosphärischen Stoffeinträgen in den 80er- und 90er-Jahren sind zahlreiche Modelle zur Rekonstruktion und Vorhersage von Zeitreihen bodenchemischer Parameter und Stoffausträgen mit dem Sickerwasser entwickelt worden (TIKTAK u. VAN GRINSVEN 1995). Diejenigen Modelle, die den Stickstoffkreislauf mehr oder weniger prozessorientiert abbilden, wie z. B. PnET-CN (ABER et al. 1997), Forest-DNDC (LI et al. 2000) oder Century (KeLLY et al. 1997), vernachlässigen jedoch die Kopplung vieler biochemischer Prozesse an den Kationenkreislauf (GAUGER et al. 2008).

Dynamische Modelle, die mit ihren zahlreichen Modifikationen in der Vergangenheit häufig in regionalen Studien angewendet wurden (POSCH et al. 2003), sind u. a. die Modelle VSD (PosCH u. ReINDS 2009), Smart (DE VRIES et al. 1989, Safe (Alveteg u. Sverdrup 2002) und Magic (COSBY et al. 1985). Die Anwendbarkeit dieser Modelle wurde von GAUGER et al. (2008) getestet. Das entscheidende Auswahlkriterium für das am besten geeignete dynamische Modell war die Verfügbarkeit über die notwendigen Eingangsdaten in einer Auflösung von $1 \times 1 \mathrm{~km}$ für die gesamte Waldfläche Deutschlands. Bei diesem Test mussten das SAFE- und das ForSAFE-Modell leider als nicht anwendbar ausgeschlossen werden, während sich das VSD-Modell auf einer Reihe von Level-II-Plots als anwendbar erwies 
(GAUGER et al. 2008). Hierbei zeigt das dynamische bodenchemische Modell VSD einen plausiblen zeitlichen Verlauf der Wirkung von Säureeinträgen und forstlichen Maßnahmen auf die Elementkonzentrationen in der Bodenlösung. Vom Modell werden alle wesentlichen Schlüsselprozesse wie die atmosphärischen Stoffeinträge, die Silikatverwitterung, die Nährstoffaufnahme durch die Bäume, der Kationenaustausch, die N-Immobilisation sowie die Auswaschung von Elementen aus dem Wurzelraum abgebildet (s. Abb. 10).

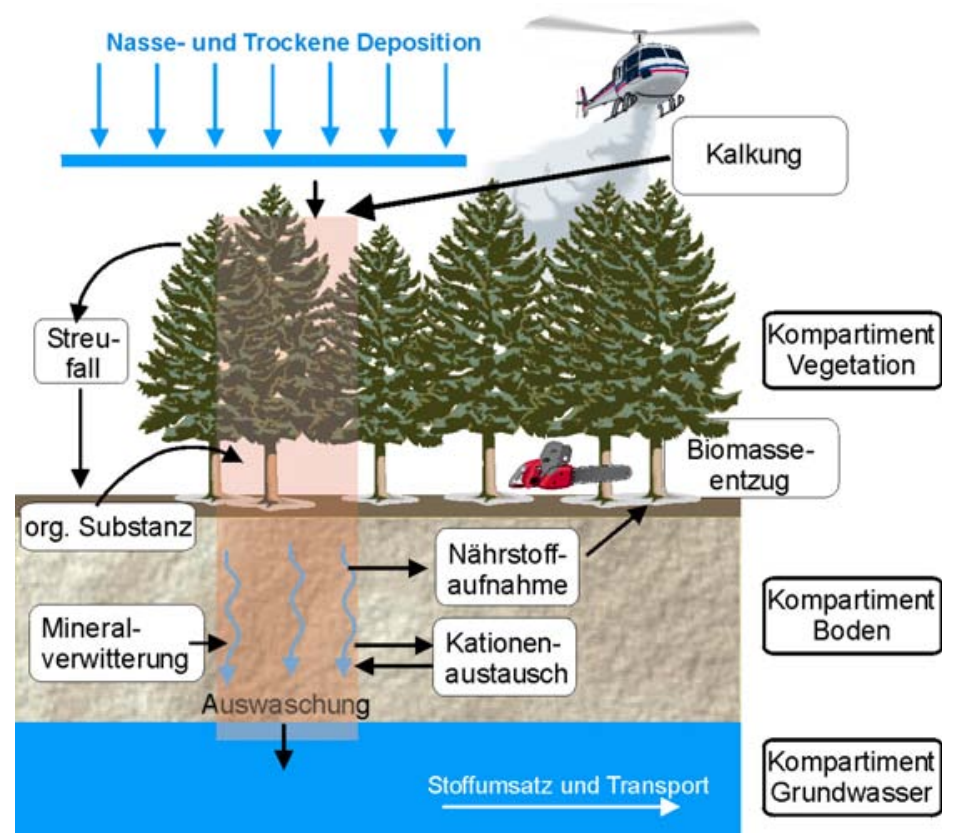

Abbildung 10: Schematische Darstellung der einbezogenen Bilanøgrößen (AHRENDS et al. 2008)

Für großflächige Anwendungen des vorab beschriebenen Modells VSD wurde dieses in VisualBasic 2008 nachprogrammiert. So bestehen keine Schnittstellen zu den anderen Modellkomponenten und der Programmdurchlauf kann mit einer einzigen Konsolenanwendung für alle Flächen aus dem GIS gestartet werden. Um die korrekte Implementierung der Gleichungen und ihrer Parametrisierung zu prüfen, wurden DSS-RM und VSD miteinander verglichen. Beide Programme lösen im Kern exakt dasselbe Problem. Daher können unterschiedliche Ergebnisse nur aufgrund von Programmierfehlern oder der Diskretisierung der Differentialgleichungen auftreten. Für den Vergleich wurde ein Bodenprofil von $1 \mathrm{~m}$ Tiefe mit extrem unterschiedlichen Eintragssituationen betrachtet. Insgesamt betrug der Simulationszeitraum 200 Jahre.

Die exakte Übereinstimmung zwischen beiden Modellen zeigt (s. Abb. 11), dass die Massenbilanzgleichungen mit ihren dynamischen Erweiterungen korrekt 
implementiert wurden. Auf Grundlage dieser Modellversion wurden Modellanpassungen durchgeführt. Eine detaillierte Beschreibung befindet sich im Anhang 2. Dort sind ebenfalls die Parametrisierung der Modelle und die Transferfunktionen beschrieben.
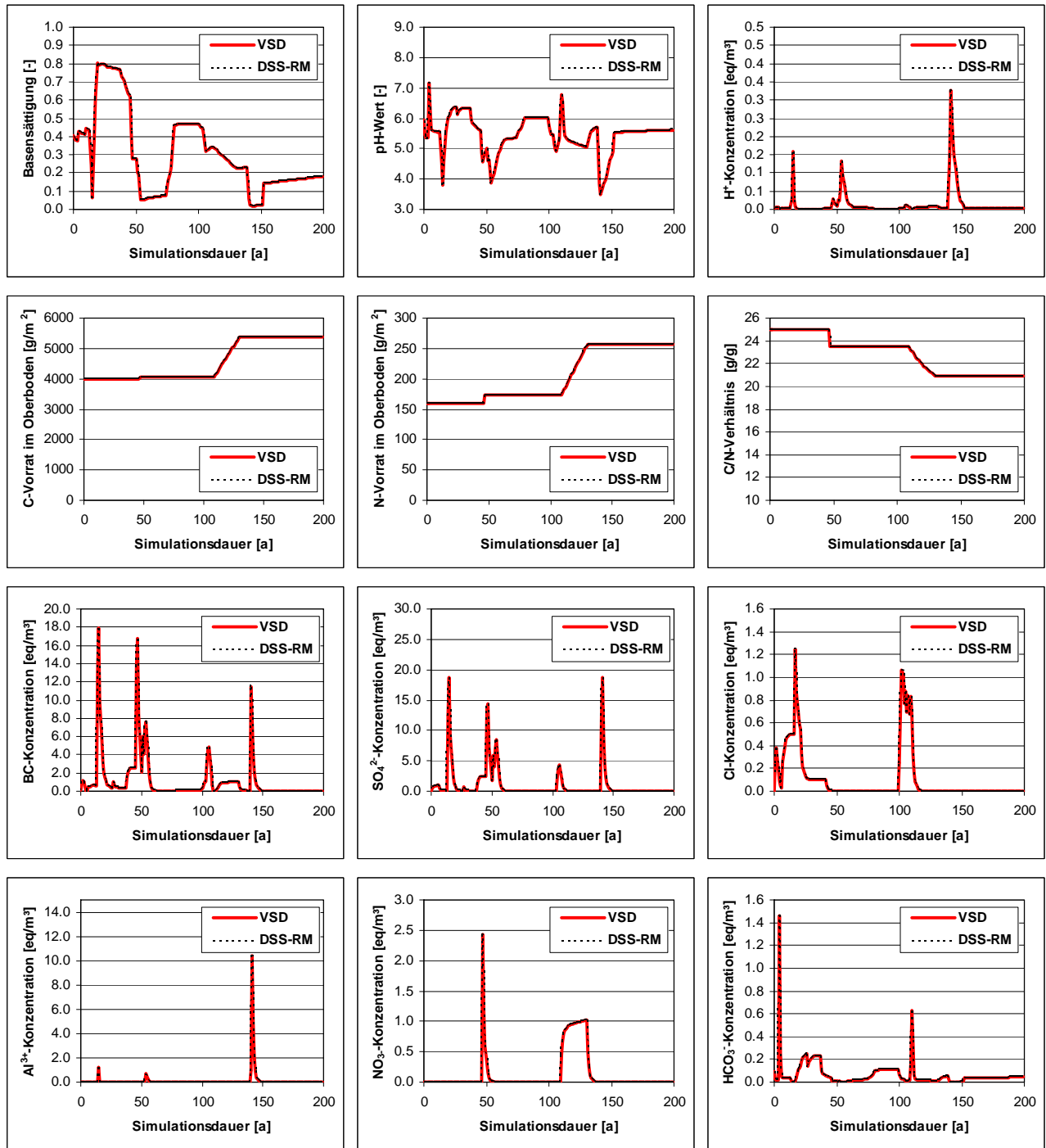

Abbildung 11: Vergleich modellierter bodenchemischer Kennwerte. Die dicken roten Linien stellen die Simulationen mit VSD 3.1.2 und die gestrichelten schwarzen die Simulationen mit dem für das Projekt entwickelten GIS-Modell (DSS-RM) dar. 


\subsubsection{Atmosphärische Stoffeinträge}

\subsection{Grundlagen und Modellierungsansatz}

Bei der Modellierung des Stoffhaushaltes sind die Stoffeinträge durch die atmosphärische Deposition von zentraler Bedeutung. Der Stoffeintrag in Ökosysteme mit der Feuchtdeposition gibt im Wesentlichen nur den von der Landnutzung unabhängigen Anteil der Gesamtdeposition wieder. Demgegenüber ist der zusätzliche Eintrag von Gasen und Partikeln mit der Trockendeposition von der Landnutzung abhängig. Besonders bei Waldökosystemen ist die Trockendeposition für einen erheblichen Teil des Nähr- und Schadstoffeintrags veantwortlich. Dieser Eintrag ist jedoch nur unter hohem Aufwand direkt messbar und muss daher flächenhaft modelliert werden. Hierfür kommen grundsätzlich zahlreiche unterschiedliche Methoden in Betracht (PETERS 1995), wovon am häufigsten die Kronenbilanzmodelle oder die Widerstandsmodelle verwendet werden (SPRANGER 2000). Die Kronenraumbilanzmodelle lassen streng genommen keine Extrapolation und auch keine Prognosen zu und sind somit nur lokal einsetzbar (GEHRMANN et al. 2001). Kronenraumbilanzmodelle beruhen auf den für jeden betrachteten Bestand (Waldökosystemzelle) gemessenen Freiland- und Bestandesniederschlägen und sind nur begrenzt regionalisierbar. Demgegenüber betrachten Widerstandsmodelle die Depositionsprozesse einzelner Stoffe und eignen sich für die Extrapolation und die Prognose der Depositionsverhältnisse unter anderen Rahmenbedingungen (Immission, Baumarten, Baumhöhen, Windgeschwindigkeiten usw.). Darüber hinaus werden generell Widerstandsmodelle gegenüber Kronenraumbilanzmodellen für die Ableitung von Depositionsraten für Stickstoffverbindungen als überlegen angesehen (GEHRMANN et al. 2001).

Flächendeckende und räumlich detaillierte Eingangsdaten von atmosphärischen Stickstoffeinträgen in Deutschland liefern die Daten des Umweltbundesamtes (BUilTJES et al. 2011, GAUGER et al. 2008). Diese Daten werden mit einer modifizierten Version (AHrENDS et al. 2007, 2010) des Modells MAKEDEP von Alveteg (1998) gekoppelt. Beispiele für die Anwendung dieses gekoppelten Modellsystems sind bei AHRENDS et al. (2007, 2008, 2009, 2010a), AlBERT u. SCHMiDT (2010a, 2010b) und JANSEN et al. (2007) zu finden. Der genaue Ablauf wird im Folgenden beschrieben.

Durch Verbesserungen der Methode zur Berechnung der trockenen Deposition (Erhaltung der Massenbilanz, veränderte Parametrisierung der atmosphärischen Widerstände) unterscheiden sich die Depositionsfrachten der Datensatze von BuitjEs et al. (2011) und GAUGER et al. (2008). Da das empirische Waldwachstumsmodell von ALBERT u. SCHMIDT (2010b) mit den Daten von GAUGER et al. (2008) parametrisiert wurde, wurden entsprechend auch diese Depositionsdaten verwendet, um den Effekt der Stickstoffdeposition auf das Waldwachstum abzubilden. Für die Quantifizierung des ökosysteminternen Stickstoffkreislaufes wurde auf den aktuelleren Datensatz von BuILTjES et al. (2011) zurückgegriffen. 
Dieses Vorgehen erscheint deshalb gerechtfertigt, da im Unterschied zur Höhe die Werte die Flächenverteilung der trockenen Deposition in beiden Projekten sehr ähnlich sind (BUILTJES et al. 2011). Ein weiterer Grund für dieses Vorgehen lag darin, dass im Datensatz von GAUGER at al. (2008) für die basischen Kationen keine elementspezifischen und keine landnutzungsspezifischen Trockendepositionen vorliegen, sondern nur die gewichteten Mittelwerte der basischen Kationen für alle Landnutzungsklassen in der jeweiligen CORINE-Rasterzelle.

\subsection{Landnutzungsspezifische Ermittlung der Trockendeposition}

Der Datensatz von BuILTJES et al. (2011) enthält für jedes 1 x $1 \mathrm{~km}$ Raster die berechnete Trockendepositionen für 9 unterschiedliche Landnutzungsklassen. Da die Trockendeposition für diese 9 unterschiedlichen Landnutzungen innerhalb eines 1 x $1 \mathrm{~km}$ Rasters vorliegt, kann mit Hilfe von großmaßstäblichen Landnutzungskarten die Datenübertragung von der Rasterfläche auf die kleineren Landnutzungseinheiten erfolgen. Für die Kopplung dieser Landnutzungsklassen mit Waldwachstumsmodellen ist es notwendig, die jeweiligen Bestandestypen den hier dargestellten Landnutzungsklassen zuzuordnen. Der Übersetzungsschlüssel ist im Anhang (s. Tab. A7) zusammengestellt. Die Ziffern sind der nummerische Schlüssel der Bestandestypen im WaldPlaner.

\subsection{Korrekturfunktionen für die Trockendeposition in Abhängigkeit von der Baumhöhe}

Die Berechnung der Trockendeposition wird bei BUITJES et al. (2011) für eine mittlere Baumhöhe in Deutschland durchgeführt. Für die Berechnung bei GAUGER et al. (2008) mit dem Modell IDEM (Integrated DEposition Model) (BLEEKER et al. 2004, ERISMAN et al. 1994) wurde die notwendige Rauhigkeitslänge noch unter Berücksichtigung der Baumhöhe geschätzt. Hierbei wurde die durchschnittliche Baumhöhe (getrennt nach Nadel-, Laub- und Mischwald) des jeweiligen Bundeslandes verwendet. Folglich ergeben sich an den Grenzen der Bundesländer „Datensprünge“ der modellierten Trockendeposition, die nur aus den verwendeten Baumhöhen resultieren können (Ausnahme: Gittersprünge anderer Eingangdaten). Da Hessen an sechs weitere Flächenbundesländer grenzt, ergibt sich hieraus die Möglichkeit, den Einfluss der Baumhöhe auf die Trockendeposition mit Hilfe einer Regressionsanalyse zu quantifizieren.

Für die Auswertung wurden die Karten der Trockendeposition (GAUGER et al. 2008) in eine Datenbank importiert. Die Depositionen von angrenzenden Rasterzellen in unterschiedlichen Bundesländern können dann in einer linearen Regressionsanalyse zueinander in Beziehung gesetzt werden. Aus den unterschiedlichen Baumhöhen in den jeweiligen Bundesländern ergeben sich Differenzen in der Trockendeposition, die über die Steigung der Regressionsgleichung beschrieben werden können. Setzt man nun die Steigungen der Regressionsgleichungen aller 6 angrenzenden Bundesländer (für jeweils ein Element, eine Waldklasse und Jahr) 
zur Baumhöhe in Beziehung, dann erhält man den erwarteten (vgl. ERISMAN u. DrAAIJERS 2003, MOHR et al. 2005, SCHrIJVER et al. 2008) linearen Zusammenhang. Hieraus ergibt sich die Steigung [m] und der Achsenabschnitt [b] für die Normalform der Geradengleichung (1) für alle Elemente und Waldtypen auf Jahresbasis.

$$
f(x)=m \cdot x+b
$$

Mit Hilfe dieser Funktion kann die Berechnung der Trockendeposition in Abhängigkeit von der Baumhöhe erfolgen (AHRENDS et al. 2010a).

$$
T D X^{B K}=(m \cdot H+b) \cdot T D X
$$

mit:

$$
\begin{array}{ll}
\mathrm{X} & =\mathrm{Cl}, \mathrm{SO} \\
\mathrm{H} & =\mathrm{Ca}, \mathrm{K}, \mathrm{Mg}, \mathrm{NO}_{\mathrm{Y}}, \mathrm{NH}_{\mathrm{X}}, \mathrm{Na} \\
\mathrm{m} & =\text { Gestandeshöhe }[\mathrm{m}] \\
\mathrm{b} & =\text { Achsenabschnitt in Abhängigkeit vom Jahr und Landnutzung } \\
\text { TDX } & \left.=\text { Trockendeposition nach GAUGER et al. (2008) [eq ha } \mathrm{a}^{-1}\right] \\
\text { TDX }^{\mathrm{BK}} & \left.=\text { um die Baumhöhe korrigierte Trockendeposition [eq ha } \mathrm{ha}^{-1} \mathrm{a}^{-1}\right]
\end{array}
$$

Durch diese einfachen Funktionen ist es möglich, ein Downscaling der Deposition innerhalb einer $1 \times 1 \mathrm{~km}$-Rasterzelle auf Bestandesebene durchzuführen (s. Abb. 12). Da die Datensätze von GAUGER et al. (2008) und BUITJES et al. (2011) sowohl zeitlich als auch methodisch nicht direkt miteinander vergleichbar sind, wurden aus den ermittelten Parametern mittlere Werte für alle Elemente und Jahre berechnet $(\mathrm{m}=0,007, \mathrm{~b}=0,86)$. Bei der Anwendung dieser Korrekturfaktoren ergibt sich bei einer Verringerung der Baumhöhe von 20 auf $15 \mathrm{~m}$ eine Reduzierung der Deposition um 3,5 Prozent. Ein vergleichbarer Einfluss wurden auch bei den Sensitivitätsanalysen von BUITJES et al. (2011) ermittelt (2-3 Prozent). Als oberste Grenze der Korrekturfunktion wurde eine Bestandeshöhe von $30 \mathrm{~m}$ angesetzt (AHRENDS et al. 2010). Hiermit soll ein ungebremster Anstieg der Deposition mit Erhöhung der Baumhöhe im Modell abgefangen werden. Dieses kann damit erklärt werden, dass selbst bei einer Erhöhung des turbulenten Luftmassenaustausches, insbesondere in sehr lichten Beständen, die Nadel-/Blattmasse nicht mehr für derart hohe Depositionsraten ausreicht (IVENS 1990). Entsprechende Zusammenhänge sind auch bei dem Durchforstungsversuch von EINERT (2000) für Kiefernbestände beschrieben worden. 

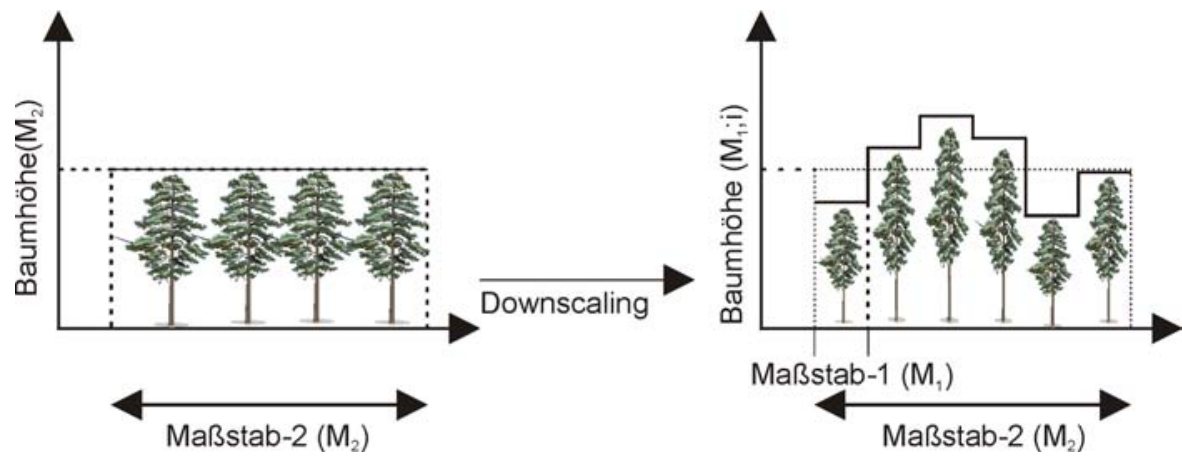

Abbildung 12: Disaggregierung der Trockendeposition über die Baumböhe (verändert nach BIERKENS et al. 2000)

\subsection{Depositionsszenarien}

Da die Depositionsdaten von GAUGER et al. (2008) und BUITJES et al. (2011) nur relative geringe Zeiträume abdecken, ist es notwendig, zeitliche Extrapolationsverfahren für die Stoffdeposition in das Stoffhaushaltsmodell zu integrieren. Dieses umfasst sowohl die Rekonstruktion der historischen Inputkurven, als auch die Entwicklung von Zukunftsszenarien für die wichtigsten Elemente.

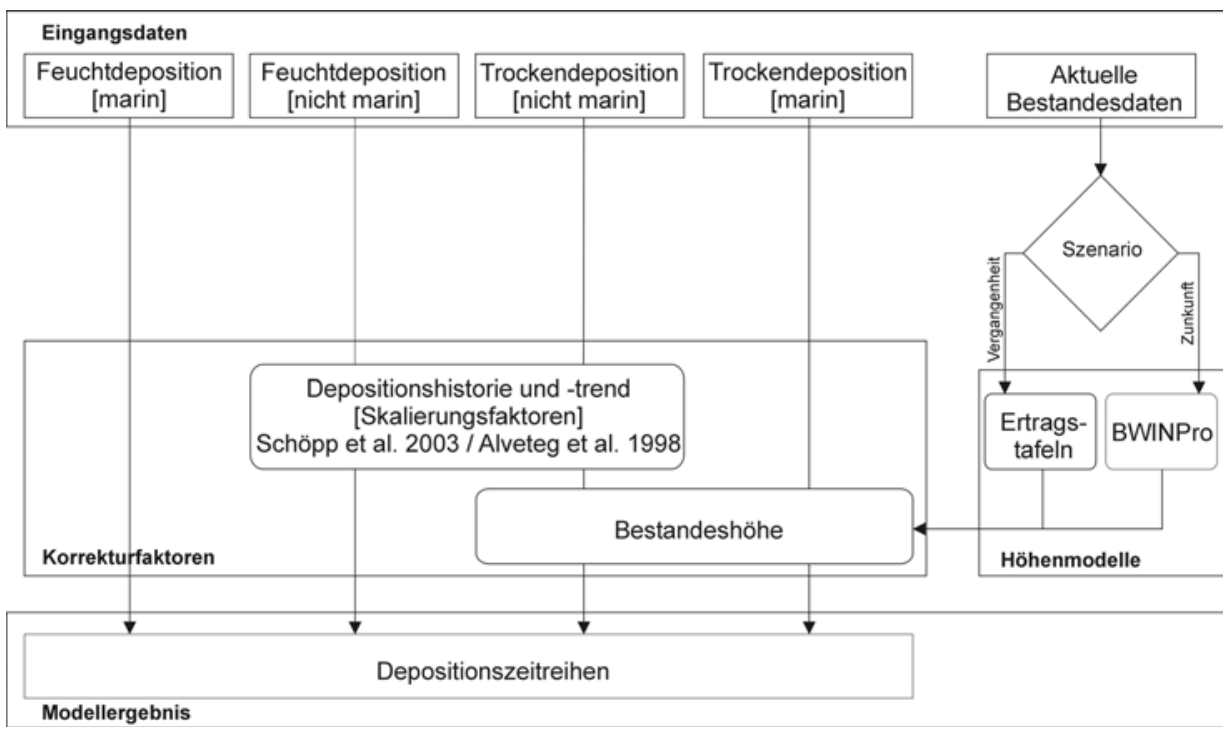

Abbildung 13: Flussdiagramm des modifizierten Modells MAKEDEP qur Entwicklung von Depositionszeitreihen (verändert nach ALVETEG 1998) 
Die Rekonstruktion der historischen atmosphärischen Stoffeinträge und die Prognoseberechnungen erfolgten mit einer modifizierten Version des Modells MAKEDEP (s. Abb. 13) von ALVETEG (1998). Das Modell MAKEDEP berechnet Depositionszeitreihen unter Berücksichtigung von am Standort gemessenen Depositionsraten und der Nadelbiomasse (AlveTEG 1998). Die Berücksichtigung der Nadelbiomasse bei der Berechnung der Trockendeposition wurde bei dieser modifizierten Version durch die Höhenkorrekturfunktionen ersetzt (s. Kap. 2.2.5.5.3).

Für die Konstruktion von einheitlichen Depositionszeitreihen wurde für den Zeitraum von 1980 bis 2006 auf die EMEP-Daten (Cooperative Programme for Monitoring and Evaluation of the Long-range Transmission of Air pollutions in Europe) zurückgegriffen (http://www.emep.int) und aus ihnen Kurven der relativen Deposition berechnet. Zur Berechnung der Deposition vor 1980 wurden historische Zeitreihen herangezogen (ALVETEG 1998, SCHÖPP et al. 2003). Die Verwendung dieser einheitlichen Rekonstruktionsgrundlage ist von Bedeutung, da mit Hilfe dieser Methodik auch das klimasensitive Waldwachstumsmodell (ALBERT u. SCHMIDT 2010a) für ganz Deutschland parametrisiert wurde. Die Berechnung der relativen Deposition wurde wie folgt durchgeführt:

$$
D E P_{t}=D E P_{R J} \cdot\left(\frac{E M E P_{t}}{E M E P_{R J}}\right)
$$

mit:

$$
\begin{array}{ll}
\operatorname{DEP}_{\mathrm{t}} & =\text { Deposition zum Zeitpunkt } \mathrm{t}\left[\text { eq } \mathrm{m}^{-2} \mathrm{a}^{-1}\right] \\
\operatorname{DEP}_{\mathrm{RJ}} & =\text { Deposition im Referenzjahr }\left[\text { eq m} \mathrm{m}^{-2} \mathrm{a}^{-1}\right] \\
\text { EMEP }_{\mathrm{t}} & \left.=\text { EMEP Deposition zum Zeitpunkt } \mathrm{eq} \mathrm{em}^{-2} \mathrm{a}^{-1}\right] \\
\text { EMEP }_{\mathrm{RJ}}: & =\text { EMEP Deposition im Referenzjahr }\left[\text { eq m } \mathrm{m}^{-2} \mathrm{a}^{-1}\right]
\end{array}
$$

Diese Art der Skalierung von gemessenen Daten mit dem Verhältnis (oder der Differenz) von modellierten Daten wird häufig in der Meteorologie zur Korrektur von Klimadaten angewendet, um Konsistenz mit den gemessenen Daten zu erzeugen (PIANi et al. 2010, MUDELSEE et al. 2010). Als Referenzjahr wurde für den Datensatz von GAUGER et al. (2008) (Zeitraum 1995 - 2004) das Jahr 2000 und für den Datensatz von BUITJES et al. (2011) das Jahr 2005 ausgewählt und für diese Jahre eine mittlere Deposition berechnet. Dieser Berechnungsansatz macht die Skalierung robuster gegenüber einzelnen jährlichen Schwankungen in den modellierten Depositionsdaten.

Die angenommene zukünftige Entwicklung der Deposition beruht auf internationalen Vereinbarungen im Rahmen der UN/ECE Convention on Long Range Transboundary Air Pollution (CLRTAP, Göteborg-Protokoll 1999). Die nach den Vereinbarungen des Göteborg-Protokolls projizierten Entwicklungen der wichtigsten Stoffeintragskomponenten geben den Rahmen für die zukünftige Eintragssituation vor. Das Göteborg-Protokoll ist ein international rechtsverbindliches Instrument zur Verringerung der Luftschadstoffe. Es wurde 1999 von den meisten 
europäischen Staaten, den USA und Kanada beschlossen, trat 2005 in Kraft und legt Grenzen für die jährlichen Emissionen der Schadstoffe Schwefeldioxid $\left(\mathrm{SO}_{2}\right)$, Stickoxide $\left(\mathrm{NO}_{\mathrm{X}}\right)$, Ammoniak $\left(\mathrm{NH}_{3}\right)$ und Flüchtige, organische Verbindungen (VOC) für das Jahr 2010 fest (UN/ECE 2004). Das Bezugsjahr für die prozentuale Reduktion ist 1990 (s. Tab. 6).

Tabelle 6: Länderspezifische Reduktionswerte [\%] für jährliche Emissionsmengen gemäß dem Göteborg-Protokoll, die bis zum Jahr 2010 erreicht werden müssen (UN/ECE 2004)

\begin{tabular}{lcccc}
\hline Land & Schwefeldioxid & Stickoxide & Ammoniak & VOC \\
\hline Deutschland & $-90 \%$ & $-60 \%$ & $-28 \%$ & $-69 \%$ \\
Österreich & $-57 \%$ & $-45 \%$ & $-19 \%$ & $-55 \%$ \\
Schweiz & $-40 \%$ & $-52 \%$ & $-13 \%$ & $-51 \%$ \\
Europa & $-75 \%$ & $-49 \%$ & $-15 \%$ & $-57 \%$ \\
\hline
\end{tabular}

Aktuelle Ergebnisse (UN/ECE 2006) weisen darauf hin, dass die Zielvorgaben für einige Elemente nicht erreicht werden können. Während nach der Referenzprognose die Vorgaben für die Emisssionshöchstmengen für $\mathrm{SO}_{2}$ und VOC im Jahre 2010 eingehalten wurden, reichten die eingeleiteten Maßnahmen dagegen nicht aus, um beim Stickstoff unterhalb der Emissionshöchstmengen für das Jahr $2010 \mathrm{zu}$ bleiben (UMWELTBUNDESAMT 2010). Entsprechend erfolgt für Stickoxide eine Reduktion um 52 Prozent und für Ammoniak um 12 Prozent (s. Abb. 14). Bei der Reduktion der Schwefeldioxid-Emissionen zeigt ein Vergleich mit den Depositionsdaten nach GAUGER et al. (2008), dass eine Depositionsreduktion um 90 Prozent in verhältnismäßig geringer belasteten Gebieten zu stark ausfällt. Entsprechend wurden sie nur um 80 Prozent reduziert.

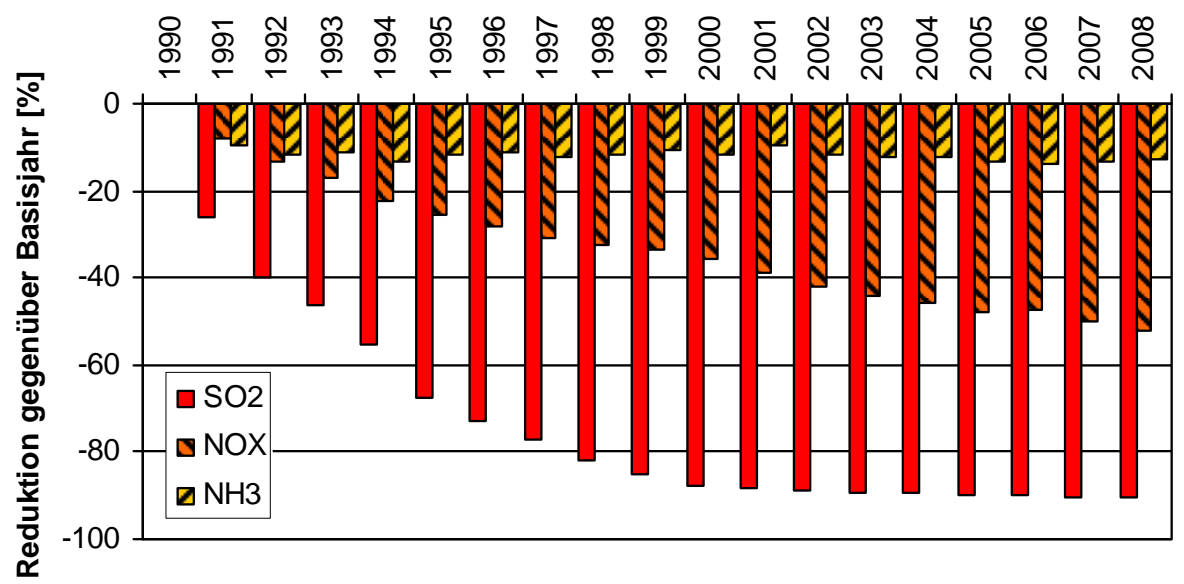

Abbildung 14: Emissionsentwicklung in Deutschland gegenüber dem Basisjabr 1990 von $\mathrm{NO}_{\mathrm{X}}, \mathrm{NH}_{3}$ und $\mathrm{SO}_{2}$ (UMWELTBUNDESAMT 2010) 
Über die langfristige Entwicklung der Emission und Deposition von Calcium, Magnesium, Kalium und Chlorid liegen nur sehr wenige Informationen vor. Da die Deposition dieser Elemente jedoch die Säure-/Basenbilanz der Waldökosysteme mit beeinflusst, ist es notwendig, eine Abschätzung ihrer Zeitreihen durchzuführen (s. Tab. 7).

Tabelle 7: Berechnung von Depositionszeitreiben für die verschiedenen Depositionskategorien und Elemente nach ALVETEG (1998)

\begin{tabular}{|c|c|c|}
\hline Depositionskategorie & Element & $\begin{array}{l}\text { Proportional zur } \\
\text { Standardkurve }\end{array}$ \\
\hline trockene marine & $\mathrm{BC}^{\mathrm{a}}, \mathrm{Na}^{+\mathrm{b}}, \mathrm{Cl}, \mathrm{SO}_{4}^{2-}$ & konstant \\
\hline feuchte marine & $\mathrm{BC}^{\mathrm{a}}, \mathrm{Na}^{+\mathrm{b}}, \mathrm{Cl}^{-}, \mathrm{SO}_{4}{ }^{2-}$ & konstant \\
\hline \multirow[t]{3}{*}{ trockene nicht-marine } & $\mathrm{BC}^{\mathrm{a}}, \mathrm{Cl}^{-}, \mathrm{SO}_{4}^{2-}$ & $\mathrm{SO}_{4}^{2-}$ \\
\hline & $\mathrm{NO}_{3}^{-}$ & $\mathrm{NO}_{3}^{-}$ \\
\hline & $\mathrm{NH}_{4}^{+}$ & $\mathrm{NH}_{4}^{+}$ \\
\hline \multirow[t]{3}{*}{ feuchte nicht-marine } & $\mathrm{BC}^{\mathrm{a}}, \mathrm{Cl}^{-}, \mathrm{SO}_{4}^{2-}$ & $\mathrm{SO}_{4}^{2-}$ \\
\hline & $\mathrm{NO}_{3}^{-}$ & $\mathrm{NO}_{3}^{-}$ \\
\hline & $\mathrm{NH}_{4}{ }^{+}$ & $\mathrm{NH}_{4}{ }^{+}$ \\
\hline
\end{tabular}

a : $\mathrm{BC}$ (basische Kationen) $=\mathrm{Ca}^{2+}, \mathrm{Mg}^{2+}$ und $\mathrm{K}^{+}$

b : Für Nord- und Westeuropa kann angenommen werden, dass $\mathrm{Na}^{+}$kaum bzw. nur sehr lokal aus anthropogenen Quellen stammt und deshalb zumindest in küstennahen Gebieten zu 100 Prozent meeresbürtig ist (GAUGER et al. 1997).

Es gibt allerdings eine Vielzahl unterschiedlicher lokaler Emissionsquellen, die zur Deposition dieser Elemente beitragen können. Diese Quellen können sich in Abhängigkeit von lokalen und regionalen Faktoren sehr unterschiedlich entwickeln (z. B. Waldbrände, Emission aus dem Straßenverkehr, Wüstenstaub oder Kalkungen, s. Alveteg 1998). Daher wird vereinfacht angenommen, dass der nichtmarine Anteil der Deposition dieser Elemente zumindest zum Teil mit den menschlichen Aktivitäten in Verbindung gebracht werden kann (JOHANSSON et al. 1996) und ihre Deposition dem Trend der Schwefeldeposition folgt (s. Abb. 14). Langjährige Depositionsmessungen auf den Level II-Messflächen der NW-FVA zeigen jedoch, dass die Depositionsreduktion seit den 90er-Jahren für basische Kationen nicht so stark auffällt wie für Sulfat. Entsprechend wurden diese bei den zukünftigen Szenarien nur um 70 Prozent gegenüber dem Bezugsjahr reduziert.

\subsubsection{Basenfreisetzung durch Verwitterung}

In Waldökosystemen sind aufgrund des intensiven Säureinputs mit der trockenen Deposition in Kombination mit der ökosysteminternen Säureproduktion (VAN BREEMEN et al. 1983, LIKENS et al. 1977) erhöhte Verwitterungsraten zu erwarten. $\mathrm{Zu}$ entsprechenden Ergebnissen kamen auch LELONG et al. (1990) und FÖLSTER (1985) bei Untersuchungen in verschiedenen Wassereinzugsgebieten. Die Quanti- 
fizierung der Verwitterungsrate von $\mathrm{M}_{\mathrm{b}}$-Kationen ist somit bestimmend für die Prognose weiterer Versauerungsentwicklungen (FEGER 1989) und für die Einschätzung der Nachhaltigkeit von forstlichen Bewirtschaftungsmaßnahmen, da die Freisetzung der Kationen aus den Silikaten zu einem äquivalenten Verbrauch an Protonen führt und entscheidend für die Nährstoffversorgung der Standorte ist.

Zur Bestimmung der Silikatverwitterungsraten für Wassereinzugsgebiete sind in der Literatur zahlreiche Verfahren und Modelle beschrieben worden. Zusammenstellungen und Kurzbeschreibungen finden sich bei JÖNSSON et al. (1995), SVERDRUP $(1990,1996)$ und VELBEL (1986). Von diesen Modellen ist besonders das Simulationsmodell Profile von Sverdrup u. WARfVINGe (1995) für eine Einbindung in das Entscheidungsunterstützungssystem geeignet. Neue Arbeiten zeigen die Möglichkeiten von PROFILE für flächenhafte Anwendungen (AHRENDS et al. 2008, AKSELSSON et al. 2005). PROFILE hat seine Praxistauglichkeit in zahlreichen verschiedenen Einzugsgebieten Europas und Nordamerikas bewiesen. Bei den in diesen Einzugsgebieten durchgeführten Testanwendungen reproduzierte es die gemessenen Verwitterungsraten unter sehr verschiedenen Bedingungen (Raten von 0,007-18,6 $\mathrm{kmol}_{\mathrm{c}}$ je Hektar und Jahr) und dieses in einem vertretbaren Fehlerrahmen ( \pm 15 Prozent, SVERDRUP 1996). Weiterhin liegt das Modell in einer auf die deutschen Verhältnisse (Mineral-Kinetik) angepassten Version (CL- PROFILE) mit Dokumentation (BECKER 1999) vor.

In Profile kann der Boden sowohl über ein Bodenprofil als auch über ein gesamtes Einzugsgebiet repräsentiert werden. Eine der Hauptkomponenten in PROFILE ist die quantitative Beschreibung der Freisetzung von basischen Kationen durch Silikatverwitterung sowie deren Wechselwirkungen mit den Ionengehalten der Bodenlösung. Daher wurden die Gleichungen zur Berechungen der Verwitterung direkt mit der Bodenlösung des VSD-Modells gekoppelt, wie es auch in dem dynamischen Modell SAFe (WARFVINGE et al. 1993) der Fall ist. Die für die Verwitterung betrachteten Prozesse sind im Anhang detaillierter beschrieben.

\subsubsection{Näbrstoffentnabme}

Eine weitere wichtige Bilanzgröße (s. Abb. 10) bei der stoffhaushaltlichen Bilanzierung ist neben der Berücksichtigung der Einträge durch die Deposition und der Silikatverwitterung auch die Quantifizierung der Nährstoffspeicherung in den jeweiligen Holzkomponenten des Bestandes und deren Entzug durch Ernte.

Für die quantitative Bilanzierung mit den Bilanzgrößen des Eintrages und des Austrages sind Aufnahmeraten von Stickstoff und basischen Kationen von entscheidender Bedeutung. Nach DE VRIES (1991) kann die Stoffaufnahme als Funktion von Wachstumsrate und Elementgehalt in den unterschiedlichen Baumkompartimenten quantifiziert werden. 


$$
X_{A}=Z W_{K} \cdot p_{K} \cdot c t X_{K}
$$

mit:

$$
\begin{aligned}
& \mathrm{X}_{\mathrm{A}}=\text { Aufnahme für das Element X }\left[\mathrm{kg} \cdot \mathrm{ha}^{-1} \cdot \mathrm{a}^{-1}\right] \\
& \mathrm{ZW}_{\mathrm{K}}=\text { Zuwachs des Kompartiments }\left[\mathrm{m}^{3} \cdot \mathrm{ha}^{-1} \cdot \mathrm{a}^{-1}\right] \\
& \mathrm{p}_{\mathrm{K}}=\text { Dichte des Kompartiments }\left[\mathrm{kg} \mathrm{m}^{-3}\right] \\
& \mathrm{ctX}_{\mathrm{K}}=\text { Gehalt von Element X im jeweiligen Kompartiment }\left[\mathrm{kg} \cdot \mathrm{kg}^{-1}\right]
\end{aligned}
$$

Je nach Nutzungsvariante des Bestandes müssen die Raten der einzelnen Baumkompartimente addiert werden. Die hiermit zu ermittelnden Netto-Aufnahmeraten beziehen sich auf die folgenden drei Nutzungsvarianten:

- Derbholz ohne Rinde (o. R.)

- Derbholz mit Rinde (m. R.)

- Vollbaum (alle oberirdischen Baumkompartimente)

Die Unterteilung in Derbholz $(\mathrm{d} \geq 7 \mathrm{~cm})$ und Reisholz $(\mathrm{d}<7 \mathrm{~cm})$ bietet sich zum einen durch die Verwendung des WaldPlaners als Wachstumssimulator an. Zum anderen ist auf diese Weise mit der Nutzungsvariante 2 (Derbholz m. R.) die wirtschaftlich bedeutendste Variante der Entnahme von Schaftholz mit Rinde und Ästen erster Ordnung gut zu beschreiben (NEBE u. HERRMANN 1987). Sie umfasst die industriell gut verwertbaren Rohstoffe. Diese Variante wird auch gegenwärtig am meisten praktiziert, da ein Verzicht der Rindennutzung aus erntetechnischen Gründen kaum möglich ist (FEGER 1993). Dieses gilt besonders für Laubhölzer (BLFW 1997). Auf eine Berücksichtigung der Ganzbaumernte ist verzichtet worden. Hierbei wird zusätzlich zum Vollbaum das Wurzelwerk entnommen. Die Entnahme des Wurzelstockes und die Streunutzung gehören zur historischen Waldnutzung und spielen bei der heute üblichen forstlichen Praxis keine Rolle mehr.

Bei den Berechnungen ergibt sich die Wachstumsrate aus dem laufenden jährlichen Zuwachs an Derbholz. Um den laufenden jährlichen Zuwachs an Rindenmasse zu berechnen, wurden die Schätzfunktionen nach JACOBSEN et al. (2003) verwendet. Der Anteil an Reisholz wird mit Hilfe der Funktion von DAUBER u. KREUTZER (1979) berechnet. Die Elementgehalte in den unterschiedlichen Baumkompartimenten (Derbholz, Derbrinde, Zweige) wurden nach den Angaben und mit den Funktionen aus JACOBSEN et al. (2003) in Abhängigkeit vom Baumalter ermittelt.

Alle Biomassekomponenten werden im Modell auf $\mathrm{kg}$ bezogen, sodass die Festmeterangaben zunächst in kg umgerechnet werden müssen. Dieses geschieht über die Holzdichte. Verwendet wurde die Darrdichte, also die Rohdichte von trockenem Holz. Für die Umrechnung von Festmeter in $\mathrm{kg}$ dienen die Angaben aus dem Holzatlas von WAGENFÜHR (2000). Diese Dichteangaben beziehen sich auf das Derbholz mit Rinde. Für die Rinde wurden die Angaben nach KRAMER (1988) verwendet (s. Anhang Tab. A14). 
Material und Methoden

\subsubsection{Koblenstoff- und Stickstoffhaushalt}

Die Waldbewirtschaftung kann sich auf den organischen Kohlenstoffgehalt im Boden durch eine Verringerung der Einträge (Streufall) oder durch eine Erhöhung der Abbauraten auswirken (JURGENSEN et al 1997, PENNE et al. 2010, WORRELL u. HAMPSON 1997). Neben der Bewirtschaftung bestehen große Unterschiede zwischen den Bodentypen. So haben insbesondere Podsole sehr große Vorräte an Kohlenstoff (BATJES 2002). Dieses wird auf die langsamen Zersetzungsprozesse und damit verbundene Akkumulation von Kohlenstoff im Waldboden zurückgeführt (SCHULZE et al. 2009). Als anthropogene Ursachen einer reduzierten Streumineralisierung kommen eine zunehmende Oberbodenversauerung, erhöhte Schwermetallgehalte und/oder erhöhte N-Gehalte in Frage (BERG u. LASKOWSKI 2006, DijKSTRA et al. 2009, MeIWES et al. 2002). Aufgrund des letztgenannten Einflussfaktors und weil die Stickstoffdynamik an den Kohlenstoffkreislauf gekoppelt ist (GUNDERSEN et al. 2006), sollten diese beiden Kreisläufe nicht getrennt voneinander betrachtet werden.

Die hohe zeitliche Dynamik während einer Umtriebszeit (BÖTTCHER u. SPRINGOB 2001, BrinKMANN u. Nieder 2002, EMmer u. SEVINK 1994, HeINSDORF et al. 1986, TIETEMA 2004) und die hohe räumliche Variabilität (LISKI 1995, PENNE et al. 2010, RomAnYÀ et al. 2000, SCHulP et al. 2008) von Kohlenstoffvorräten in der Humusauflage und im Oberboden macht es schwierig zeitliche Veränderungen messtechnisch nachzuweisen. Daher können Veränderungen der Kohlenstoff- und Stickstoffvorräte häufig nur mit Hilfe von Modellen beschrieben werden. Zwei sehr häufig verwendete Modelle sind die ursprünglich für landwirtschaftliche Oberböden entwickelten Modelle CENTURY (KELLY et al. 1997) und RothC (COLEMAN u. JENKINSON 1996). Beides sind technisch sehr umfangreiche Modelle (WALLman et al. 2006). Nicht weniger komplex sind die Modelle SOMM von CHERTOv u. KOMAROv (1997) bzw. dessen Nachfolger ROMUL (CHERTOV et al. 2001), DECOMP (WALLMAN et al. 2006), FOREST-DNDC (LI et al. 2000), NUCSAM (GROENENBERG et al. 1995) und YASSO (LISKI et al. 2005). Alle diese Modelle sind zumeist mit der Zielsetzung entwickelt worden, die am Streuabbau beteiligten Prozesse möglichst detailliert zu beschreiben. Für die allgemeine Anwendbarkeit und Übertragbarkeit eines Modells ist aber das Vorhandensein von übermäßig vielen, einflussreichen, kalibrierungsbedürftigen Parametern nachteilig. Die für den Modelloutput entscheidenden Größen sind nur mit erheblichem Aufwand (Sensitivitätsanalyse) zu identifizieren. Die äußerst hohen Datenanforderungen werden i.d. R. nur für intensiv erforschte Untersuchungsgebiete erreicht oder bedürfen noch zusätzlicher Untersuchungen. Somit sind sie nur bedingt für ein GIS-gestütztes Modellsystem geeignet. Daher wurde die von BONTEN et al. (2009) entwickelte und dokumentierte vereinfachte Version des Modells DNDC (LI et al. 1994) verwendet, die auch in die Modelle SMARTml (BONTEN et al. 2011a) und VSD+ (BONTEN et al. 2011b) implementiert ist. In dieser Modellversion sind die wesentlichen Prozesse des C- und N-Kreislaufes (Immobilisation, 
Denitrifikation, Nitrifikation, Stickstoffausträge) berücksichtigt und eng miteinander verknüpft. Dieses Modell wurde mit seiner Standardparametrisierung z. B. in unkalibrierter Form an den langen Zeitreihen im Solling getestet (BONTEN et al. 2011b). Hier konnte die gemessene C- und N-Dynamik des Standortes sehr gut abgebildet werden. Detaillierte Beschreibungen der Prozesse und der Parametrisierung sind im Anhang zusammengestellt.

\subsubsection{Dynamische Modellierung der Trophie}

\subsection{Einführung}

Der Nährstoffstatus von Waldböden kann mit Hilfe verschiedener Standortseigenschaften oder -parametern charakterisiert werden. Parameter, die häufig zur Bewertung der Standortsqualität herangezogen werden, sind das C/N-Verhältnis, die Basensättigung im Wurzelraum, die effektive Kationenaustauschkapazität, die Humusform oder die Nährstoffvorräte (AHRENDS et al. 2008, ARBEITSKREIS STANDORTSKARTIERUNG 2003, JANSEN et al. 2002, KOPP 2004, ULRICH u. SHRIVASTAVA 1978). Diese Kenngrößen sind häufig von internen Bodenfaktoren wie Bodenart, Lagerungsdichte, Skelettgehalt oder der organischen Substanz abhängig (EBERL 1998, SCHUlte-BISPING et al. 2001). In der Praxis werden i. d. R. all diese Faktoren in einer integrativen Zahl (Nährstoffziffer) zusammengeführt.

Tabelle 8: $\quad$ Einstufungshilfe der Trophiestufen (verändert nach: GLOGNER et al. 2009)

\begin{tabular}{|c|c|c|}
\hline Stufe & Schlüssel & $\begin{array}{l}\text { Hinweise aus Boden- und Geländesituation, } \\
\text { Bestockung }\end{array}$ \\
\hline carbonat-eutroph & 7 & $\begin{array}{l}\text { i. W. Kalkstandorte; Mull-Rendzinen bis Braun- } \\
\text { erden; sehr artenreiche Waldgesellschaften }\end{array}$ \\
\hline eutroph & 6 & $\begin{array}{l}\text { i. W. Basalt- und Diabasstandorte, Hochflutlehme; } \\
\text { Mull-Bodenformen; sehr artenreiche Waldgesell- } \\
\text { schaften }\end{array}$ \\
\hline schwach eutroph & 5 & $\begin{array}{l}\text { i. W. lösslehmreichere Basalt- und Diabasstandorte, } \\
\text { Odenwaldkristallin etc. }\end{array}$ \\
\hline gut mesotroph & 4 & $\begin{array}{l}\text { i. W. Lösslehm- und z. T. Grauwackenstandorte } \\
\text { (geprägt von Flattergras) }\end{array}$ \\
\hline mesotroph & 3 & $\begin{array}{l}\text { i. W. Schiefer- und Buntsandsteinstandorte (geprägt } \\
\text { von Hainsimse), auch Flug- und Terrassensand- } \\
\text { standorte, soweit nicht karbonatisch }\end{array}$ \\
\hline schwach mesotroph & 2 & wie vor, im Bodenprofil deutliche Podsoligkeit \\
\hline oligotroph & 1 & $\begin{array}{l}\text { i. W. Buntsandsteinstandorte, Quarzitstandorte, } \\
\text { Sandstandorte mit deutlich ausgeprägtem Podsol- } \\
\text { profil (Summe Mächtigkeit der Bodenhorizonte } \\
\text { Ahe, Ae, Bsh } \geq 15 \mathrm{~cm} \text { ); Rohhumus-Bodenformen }\end{array}$ \\
\hline
\end{tabular}


Für die integrative Bewertung liegen länderspezifische Verfahren vor, die unterschiedliche Gewichtungen der jeweiligen Faktoren und auch Klassifikationen vornehmen. In Hessen wird zur Kennzeichnung der Nährstoffverhältnisse des Bodens der in der Vegetationskunde entwickelte Trophiebegriff verwendet. Unterschieden werden hierbei sieben Stufen (s. Tab. 8).

Eine solche Einstufung liefert jedoch keine Hinweise auf die Nährstoffvorräte oder bodenchemischen Zustände. Solche Beziehungen sind jedoch die Vorraussetzung für eine flächendeckende und dynamische Kartierung der Nährstoffversorgung anhand von flächenhaft verfügbaren Eingangsdaten. Daher war es Ziel dieser Untersuchungen, die Beziehungen zwischen der Trophieeinstufung und bodenphysikalischen und bodenchemischen Kennwerten anhand des Hessischen Waldbodeninformationssystems (WABIS) abzuleiten.

\subsection{Datengrundlage und Aufbereitung}

Die Parametrisierung der formulierten Regressionsmodelle (s. Kap. 2.2.5.9.3) erfolgt auf der Grundlage der WABIS-Profile und den zugehörigen Profilbeschreibungen. In die Analyse wurden die wesentlichen bodenchemischen und -physikalischen Variablen aufgenommen. Die ordinal skalierte Trophiestufe wurde mit Hilfe der Tabelle 8 übersetzt. Die Datensätze des WABIS enthalten jedoch keine Zwischenstufen, sondern nur die Gruppen oligotroph, mesotroph und eutroph, sodass sich die Auswertungen im ersten Schritt auf diese drei Gruppen konzentrieren.

Für die Berechnung von mittleren bodenphysikalischen und -chemischen Profileigenschaften ist die gewählte Profiltiefe von entscheidender Bedeutung. So fand z. B. ZIRLEWAGEN (2009) den höchsten Erklärungswert für die räumliche Verteilung der Basensättigung für eine Profiltiefe von $60 \mathrm{~cm}$. Der Tiefenbereich zwischen 0-60 cm wird auch häufig als Hauptwurzelraum angesprochen (GASSER et al. 2009). Demgegenüber wird in Bodenbewertungssystemen häufig die Bewertung für eine standardisierte Tiefe von $1 \mathrm{~m}$ durchgeführt (HENNINGS 2000, FALK et al. 2008). Die Substratkartierung in Hessen erfolgt in der Regel bis $1,20 \mathrm{~m}$ (HMULF 2002). Des Weiteren enthalten viele Profile des WABIS nur AnalyseErgebnisse für $120 \mathrm{~cm}$ bzw. $90 \mathrm{~cm}$ Bodentiefe. Daher erfolgte die tiefengewichtete Mittelwertbildung für eine Bezugstiefe von $100 \mathrm{~cm}$. Die Mittelwertbildung der jeweiligen Bodenparameter erfolgte nach folgender Gleichung:

$$
X=\frac{1}{T} \sum_{h=1}^{n} T_{h} \cdot X_{h}
$$

mit:

$$
\begin{aligned}
& \mathrm{X}=\text { Bodeneigenschaft }(\mathrm{z} . \text { B. Sandgehalt, Skelettgehalt, Basensättigung) } \\
& \mathrm{T}=\text { Profiltiefe }[\mathrm{cm}] \\
& \mathrm{h}=\text { Horizont }
\end{aligned}
$$


Eine Ausnahme bildet das C/N-Verhältnis. Dieses wird bei den Auflagehumusformen aus dem Oh abgeleitet und bei L-Mull, F-Mull und mullartigem Moder aus dem Ah-Horizont (s. ARBEITSKREIS STANDORTSKARTIERUNG 2003). In Einzelfällen musste z. B. auf das C/N-Verhältnis aus einem anderen Horizont (Of-Horizont) zurückgegriffen werden, wenn für den Oh-Horizont keine Analysen vorlagen.

Bei der Datenanalyse wurden neben linearen Regressionsmodellen

$$
Y=b_{0}+b_{1} \cdot X_{1}+b_{2} \cdot X_{2}+\ldots+b_{n} \cdot X_{n}+\varepsilon
$$

auch generalisierte additive Modelle (LANE 2002, HASTIE u. TIBSHIRANI 1990)

$$
\begin{aligned}
& Y=b_{0}+f_{1}\left(X_{1}\right)+f_{2}\left(X_{2}\right)+\ldots+f_{n}\left(X_{n}\right)+\varepsilon \\
& \text { mit } \\
& \mathrm{b}_{0}, \mathrm{~b}_{1}, \mathrm{~b}_{\mathrm{n}}=\text { Regressionskoeffizienten } \\
& \mathrm{f}_{1}, \mathrm{f}_{2}, \mathrm{f}_{\mathrm{n}} \quad=\text { glättende Funktionen } \\
& \varepsilon \quad=\text { Residuen }
\end{aligned}
$$

eingesetzt.

\subsection{Modellentwicklung}

Bei der Modellierung lag der Fokus auf der Entwicklung von Modellen, die durch die Standortskartierung begründbar sind und nicht unnötig viele Parameter enthalten. Des Weiteren sollten die einleitend angeführten Indikatoren zur Beschreibung des Versauerungsprozesse und des Stickstoffstatus Berücksichtigung finden. Solche einfachen und interpretierbaren Modellansätze sind eine wichtige Voraussetzung für die spätere Verwendbarkeit und Akzeptanz bei der Regionalisierung und der Übertragung der Ergebnisse auf beliebige Regionen. Entsprechend wurden z. B. signifikante Beziehungen zu klimatischen Parametern nicht im Modell berücksichtigt. Das Ziel war eine möglichst gute Anpassung an die Daten, aber kein „Überfit“ an zufälligen Abweichungen. Die Analyse der Daten zeigt, dass sowohl oligotrophe Standorte mit Basensättigungen $<10$ Prozent als auch eutrophe Standorte mit Basensättigungen $>45$ Prozent vorlagen. Desweiteren sind im Auflagehumus bzw. Ah-Horizonten bei Mull-Humusformen C/N-Verhältnisse von $<7$ anzutreffen. Da C/N-Verhältnisse unter $10 \mathrm{im} \mathrm{Auflagehumus} \mathrm{nur} \mathrm{sehr}$ selten vorkommen (ZEZSCHWITZ 1980, 1985) resultieren solche C/N-Verhältnisse häufig aus anthropogenen Störungen (z. B. Tiefpflügen). In der Statistik wird bei einem begründeten Verdacht auf Ausreißer in der Regel das gestutzte arithmetische Mittel berechnet (SACHS u. HEDDERICH 2006). Entsprechend wurden bei der folgenden Modellentwicklung alles Datensätze oberhalb des 0,95- und unterhalb des 0,05-Quantils in der jeweiligen Eutrophiestufe ausgeschlossen. Entsprechend dieser Vorgaben wurde das folgende Regressionsmodell an den Datensatz $(\mathrm{n}=471)$ angepasst:

$$
N Z=b_{0}+f_{1}(B S)+f_{2}(C N)+f_{3}\left(K A K_{e f f}\right)+\varepsilon\left(\mathrm{r}^{2} \text { adj. }=0,67\right)
$$


Die Regressionsanalyse zeigt die Abhängigkeiten der Nährstoffziffer von den schon vorab beschriebenen Parametern wie $\mathrm{C} / \mathrm{N}-$ Verhältnis, Basensättigung und $\mathrm{KAK}_{\text {eff }}$ (s. Tab. 9). Da die $\mathrm{KAK}_{\text {eff }}$ und die austauschbaren Kationen (H, Na, K, Ca, $\mathrm{Mg}, \mathrm{Fe}, \mathrm{Mn}, \mathrm{Al}$ ) bei jeder forstlichen Standortskartierung als Standard analysiert werden sollten (ARBEITSKREIS STANDORTSKARTIERUNG 2003), sind die Beziehungen als erwartungsgemäß anzusprechen. In der Abbildung 15 sind die partiellen Effekte beispielhaft für die Prädiktoren Basensättigung, C/N-Verhältnis und $\mathrm{KAK}_{\text {eff }}$ dargestellt. Der starke Effekt des C/N-Verhältnisses im Oberboden ist aus vielerlei Hinsicht begründbar. Zum einen erfolgt bei der Hessischen Standortskartierung eine starke Berücksichtigung der Humusform (Einstufungshilfe s. ARBEITSKREIS STANDORTSKARTIERUNG 2003) und diese steht in enger Beziehung zum C/N-Verhältnis (SCHLUTOW et al. 2009). Des Weiteren unterstreicht die Beziehung zum C/N-Verhältnis die herausragende Bedeutung der Stickstoffversorgung für das Baumwachstum. So war z. B. bei den europaweiten Untersuchungen von LAUBHANN et al. (2009) das C/N-Verhältnis der einzige bodenchemische Parameter, der signifikante Beziehung zum Grundflächenzuwachs aufwies. Aber auch der Effektplot der Basensättigung zeigt eine bemerkenswerte Übereinstimmung mit experimentellen Befunden aus der Literatur. So wurden bei den Untersuchungen von BRAUN et al. (1999) signifikante Effekte hinsichtlich des Dickenzuwachses von Bäumen zwischen den Gruppen $\leq 40$ und $>40$ Prozent Basensättigung (Mittelwert 0 bis $40 \mathrm{~cm}$ Tiefe) festgestellt. Die Ergebnisse zeigen, dass insbesondere in den Randbereichen die Unsicherheit sehr stark ansteigt. Dieses liegt zum einen darin begründet, dass die Extrembereiche durch die Klassifizierung in 3 Stufen nur sehr schlecht abgedeckt werden.

Tabelle 9: $\quad$ Parameterschätzungen des ausgewählten generalisierten additiven Modells (GAM) zur Abschätzung der ,nummerischen "Nährstoffziffer

\begin{tabular}{lccccc}
\hline Parameter & Effekt & Ref.df & $\mathrm{F}$ & $\mathrm{p}$ & Sig. \\
\hline $\mathrm{b}_{0}$ & 2,098 & 0,014 & 149,2 & $<2^{\mathrm{e}-16}$ & $* * *$ \\
$\mathrm{BS}$ & 4,399 & 5,405 & 5,156 & $7,91^{\mathrm{e}-05}$ & $* * *$ \\
$\mathrm{C} / \mathrm{N}$ & 6,019 & 7,189 & 7,821 & $3,98^{\mathrm{e}-09}$ & $* * *$ \\
KAK $_{\text {eff }}$ & 6,784 & 7,891 & 8,220 & $2,62^{\mathrm{e}-10}$ & $* * *$ \\
\hline & & $\mathrm{F}$ = Freiheitsgrade & \\
& & Pig. = Signifikanzniveau & \\
& & &
\end{tabular}



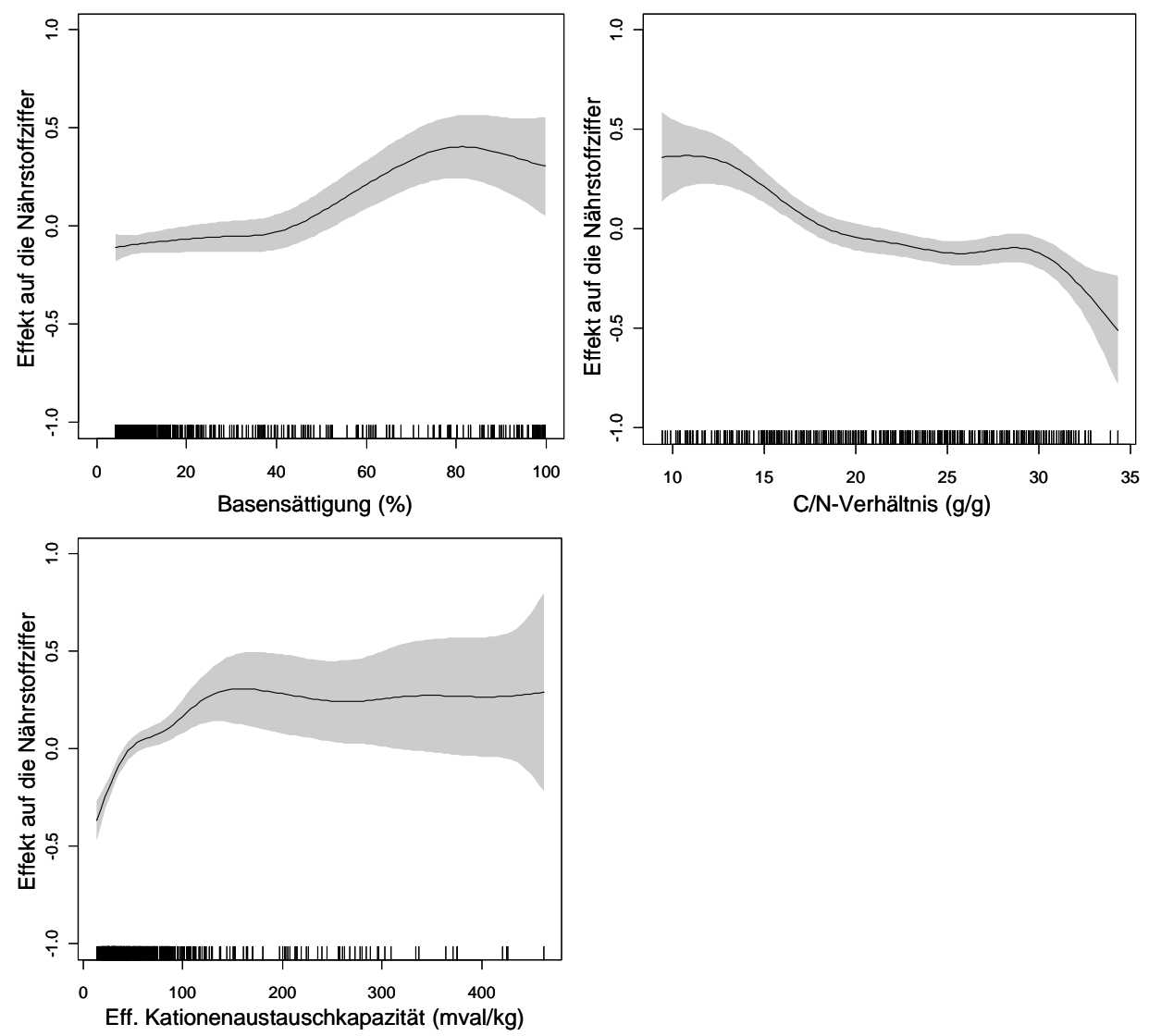

Abbildung 15: Partielle Effekte der Prädiktoren Basensättigung (oben links), C/N-Verbältnis (oben rechts) und effektive Kationenaustauschkapazität (unten) auf den Mittelwert der Verteilung der Nährstoffieiffer. Das graue Band beschreibt das $95 \%$-Konfidenzintervall.

Tabelle 10 zeigt beispielhaft die Variabilität der tiefengewichteten Basensättigung innerhalb der jeweiligen Trophiestufen. Daher wurden die partiellen Effekte für die Modellanwendung in den Randbereichen wissensbasiert (ARBEITSKREIS STANDORTKARTIERUNG 2003, KONOPATZKI u. KIRSCHNER 1997, NFP 2002) angepasst.

Tabelle 10: Deskriptive Statistik der tiefengewichteten Basensättigung (in Prozent) für $1 \mathrm{~m}$ Profiltiefe für hessische Waldböden

\begin{tabular}{lccccccc}
\hline & $\overline{\mathrm{x}}$ & $10 \%-$ & $25 \%-$ & $\begin{array}{c}50 \%- \\
\text { Perzentil }\end{array}$ & $75 \%-$ & $90 \%-$ & Anzahl \\
\hline oligotroph & 11,2 & 5,0 & 6,1 & 8,8 & 13,8 & 18,5 & 73 \\
mesotroph & 18,5 & 5,2 & 6,9 & 10,8 & 23,3 & 43,9 & 508 \\
eutroph & 75,9 & 38,1 & 64,6 & 82,2 & 95,2 & 98,3 & 144 \\
\hline
\end{tabular}


Bei der Beurteilung der Modellgüte und Modelldiagnose des generalisierten additiven Modells (GAM) zeigen sich jedoch einige Probleme hinsichtlich der Normalverteilung der Residuen. Entsprechend sollte insbesondere bei der Übertragung auf andere Gebiete die Anwendbarkeit zunächst anhand von ausgewählten Standorten geprüft werden.

\subsubsection{Anfangs- und Randbedingungen der Modellrechnungen}

Die Simulationen wurden 1900 gestartet und bis 2040 durchgeführt. Die Lösung der Modellgleichungen erfordert initiale Angaben zur Basensättigung, dem C/NVerhältnis und den Kohlenstoffvorräten. Zur Abschätzung der Basensättigung nach der Transferfunktionen von SPRANGER et al. (2004) wird neben dem Bodentyp auch die Baumart, die Höhe über NN, das Bestandesalter, die Temperatur, der Niederschlag und die Depositionsverhältnisse berücksichtigt, um die initiale Basensättigung abzuschätzen. Dieser Ansatz wurde durch die direkte Berücksichtigung des Carbonatgehaltes und Informationen über das Ausgangsgestein erweitert.

Unter der Annahme, dass die initiale Basensättigung relativ sicher abgeschätzt werden kann, wurde anschließend das initiale $\mathrm{C} / \mathrm{N}-$ Verhältnis anhand des sog. harmonischen Gleichgewichtes (KONOPATZKI u. KIRSCHNER 1997) zwischen Basensättigung und $\mathrm{C} / \mathrm{N}-$ Verhältnis abgeschätzt. Hierfür wurden die oberen Grenzen der C/N-Bereiche verwendet. Der initiale Kohlenstoffvorrat im Oberboden $(20 \mathrm{~cm})$ wurde einheitlich für alle Standorte auf $2000 \mathrm{~g} / \mathrm{m}^{2}$ gesetzt. Die initiale Poolaufteilung wurde wie in BONTEN et al. (2011a) beschrieben durchgeführt. Die vergangene Bestandesentwicklung wurde auf Grundlage der Forsteinrichtung mit dem bei RÜPING (2009) beschriebenen Verfahren rekonstruiert.

\subsubsection{Wasserhaushaltsmodellierung}

\subsubsection{Modellbeschreibung}

Die Wasserhaushaltsmodellierung erfolgte mit Hilfe des gebietsdifferenzierten hydrologischen Einzugsgebietsmodells WaSiM-ETH (Version 8.8.0).

WaSiM-ETH ist in verschiedenen Einzugsgebieten von der Mikro- $\left(<1 \mathrm{~km}^{2}\right)$ bis zur Mesoskala $\left( \pm 10.000 \mathrm{~km}^{2}\right)$ bereits erfolgreich getestet und angewendet worden. Durch die modulare Struktur und das GIS-basierte Einleseformat der Geodatenbasis werden eine einfache Handhabung und die Kopplung mit anderen Modellen gewährleistet. WaSiM-ETH weist zahlreiche Modellbausteine wie Module für Schneeschmelze und -akkumulation, Grundwasser und Abflussrouting auf, die bei Bedarf aktiviert werden können (s. Abb. 16). Die räumliche und zeitliche Auflösung der Eingabe- und Ausgabeparameter ist frei wählbar.

Der meteorologische Antrieb der Klima- und Niederschlagsstationen wird mit Hilfe verschiedener Verfahren (IDW, höhenabhängige Regression), die vom Anwender ausgewählt und kombiniert werden können, auf das Flächenraster des 
Modells interpoliert. Weiterhin besteht die Möglichkeit einer topographiebedingten Strahlungskorrektur und Temperaturmodifikation sowie einer windabhängigen Niederschlagskorrektur.

Hauptgrößen der Modellierung sind die Verdunstung, der Bodenwasserhaushalt und die Abflussbildung. Die Evapotranspiration beschreibt die Verdunstungsprozesse Transpiration, Interzeption und Evaporation. Die Interzeption wird von WaSiM-ETH über einen einfachen Speicheransatz ermittelt. Die potenzielle Evapotranspiration wird nach der Methode von Penman-Monteith (MONTEITH 1965, PENMAN 1948) berechnet. Zur Simulation der Bodenwasserflüsse wird der Richards-Ansatz (RICHARDS 1931) in eindimensionaler vertikaler Form (SCHULLA u. JASPER 2007) verwendet, der eine detaillierte Beschreibung des Bodenprofilaufbaus erlaubt. Die Parametrisierung der verwendeten $\mathrm{pF}-$ Kurven erfolgt nach Mualem / van Genuchten (VAN GENUCHTEN 1980).

Anhand der Ergebnisparameter können Änderungen der Wasserhaushaltskenngrößen (Interzeption, Evapotranspiration, Infiltration, Abfluss) für die Vergangenheit und die Zukunft abgeschätzt werden. Im konkreten Beispiel kann auf die Entwicklung der Wasserbilanz bei sich änderndem Klima und den Einfluss verschiedener Baumarten und forstlicher Behandlung auf die Grundwasserneubildungsrate geschlossen werden. Eine detaillierte Modellbeschreibung ist bei SCHULLA u. JASPER (2007) zu finden.

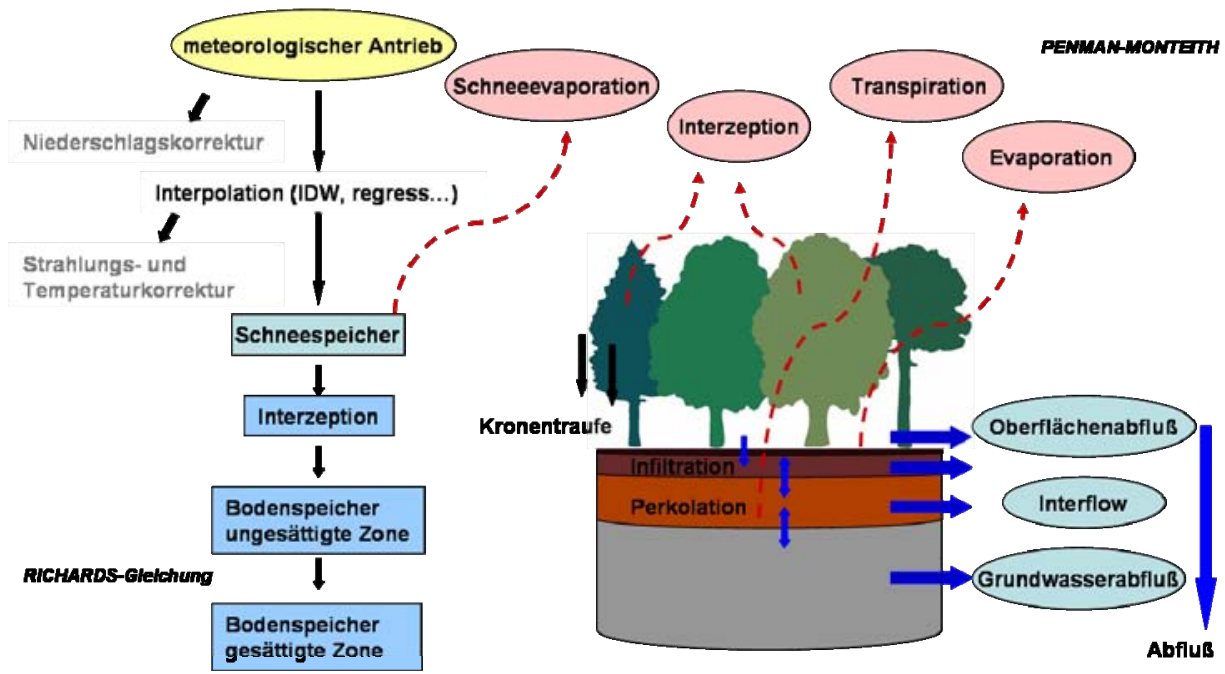

Abbildung 16: Modellschema WaSiM-ETH (verändert nach SCHULLA u. JASPER 2007) 


\subsubsection{Regeln und Modellparametrisierung}

Die Parametrisierung des hydrologischen Modells erfolgte anhand allgemein gültiger Ableitungsvorschriften und Regeln. 7.201 Bestände im Hessischen Ried wurden dabei mit einem spezifischen Parametersatz zum Blattflächenindex, Bedeckungsgrad, zur Bestandeshöhe, Durchwurzelung und zur Vergrasung belegt. Die Vegetationsparameter wurden nach jedem Simulationszyklus (4 Jahre) neu bestimmt, um die Dynamik der Waldentwicklung in Abhängigkeit von den Grundwasser- und Klimaszenarien im hydrologischen Modell abzubilden. Die Modellierung der Wasserbewegung im Boden ist primär von den bodenphysikalischen Eigenschaften des Substrates abhängig. Für jedes der 182 Leitprofile der Bodenkarte lagen horizontbezogene Angaben zum Substrat, Skelettgehalt und zur Lagerungsdichte vor. Anhand dieser Angaben wurden die Mualem / van GenuchtenParameter sowie die gesättigte hydraulische Leitfähigkeit abgeleitet. Die Bodenparameter änderten sich während der Simulationsperiode nicht, da unterstellt wurde, dass auch unter veränderten Klimabedingungen die Bodengenese zeitlich längeren Entwicklungsprozessen unterliegt.

Die Ableitungsvorschriften zur Parametrisierung der Bestände wurden im WaldPlaner implementiert (ALBERT u. HANSEN 2007). So wurde anhand des Brusthöhendurchmessers (BHD) und der Stammzahl die langfristige Veränderung des Blattflächenindex (LAI) auf der Basis der Einzelbaumdaten baumartenabhängig berechnet (HAMMEL u. KENNEL 2001). Um die Variabilität des LAI während eines Vegetationszyklus nachzubilden, war es notwendig, den Beginn und das Ende der Vegetationsperiode zu bestimmen. Der Vegetationsbeginn (Blattaustrieb) wurde nach dem phänologischen Modell von MENZEL (1997) und MENZEL u. FABIAN (1999) für verschiedene Hauptbaumarten berechnet. Das Ende der Vegetationsperiode (Laubfall) wurde nach dem empirischen Ansatz von WILPERT (1990) bestimmt. Beide Modelle wurden in WaSiM/ETH integriert, sodass für jedes Jahr in Abhängigkeit von der Witterung die Vegetationsperiode berechnet wurde. Für die Zeit der Vegetationsruhe wurde der LAI für Laubbäume auf 50 Prozent des maximalen LAI gesetzt (ELEND 2000), da über die Äste und den Stamm der Bäume auch im Winter Haftwasser verdunstet (Interzeption). Der LAI für Nadelbäume wurde nach HAMMEL u. KENNEL (2001) für die Vegetationsruhe mit 80 Prozent des maximalen LAI im Sommer angenommen.

Eine weitere wichtige Größe zur Parametrisierung der Landnutzung im Wasserhaushaltsmodell stellt der Bedeckungsgrad dar. Dieser wird direkt im WaldPlaner berechnet und an das hydrologische Modell übergeben. Bei einem Bedeckungsgrad von unter 0,85 wurde die Annahme getroffen, dass sich auf den Freiflächen eine Gras- und Strauchvegetation entwickelt. Unterschritt der Bedeckungsgrad einen Wert von 0,30, wurde eine flächendeckende Vergrasung unterstellt. Die „Vergrasungsregeln“ wurden für die Kiefer in Abhängigkeit vom Bestandesalter leicht modifiziert. Bei einem Bedeckungsgrad von über 70 Prozent wurde bei jungen Kieferbeständen (Alter $\leq 40$ Jahre) keine Sekundärvegetation 
angenommen. Bei mittelalten Beständen (41- $\leq 60$ Jahre) betrug der Vergrasungsanteil 50 Prozent der Fläche und bei älteren Kiefernbeständen (> 60 Jahre) 100 Prozent.

Trat eine Sekundärvegetation auf, wurden die Vegetationsparameter mit denen der Bestände addiert. Da die Auswirkungen einer Sekundärvegetation auf den Wasserhaushalt nicht explizit in diesem Projekt untersucht wurden, wurde auf eine Modellierung mit mehrschichtigen Vegetationslayern verzichtet.

Neben dem Bedeckungsgrad wurde auch die Bestandeshöhe für die Parametrisierung der sogenannten Verschiebungs- bzw. Rauhigkeitshöhe, die 1/3 der Bestandeshöhe beträgt, verwendet.

Die Durchwurzelungstiefe der Bestände wurde in Anlehnung an RAISSI et al. (2009) substrat- und altersabhängig abgeleitet (s. Tab. 11). Eine weitere Differenzierung der Durchwurzelungstiefe nach Baumarten wurde nicht vorgenommen. In Tabelle 11 werden Spannweiten der Durchwurzelungstiefe genannt. Aufgrund der Tiefgründigkeit der Böden im Hessischen Ried und der Ergebnisse lokaler Erhebungen (Intensivmessflächen) wurde der maximale Wert für die Tiefenerstreckung der Wurzeln verwendet. Die höchste Durchwurzelungstiefe mit $250 \mathrm{~cm}$ wird auf schluffigen Böden erreicht, während auf tonreichen Böden die Wurzeln bis maximal $150 \mathrm{~cm}$ Tiefe wurzeln. Bei geringen Grundwasserflurabständen entspricht der effektive Wurzelraum der Tiefe des anstehenden Grundwasserkörpers.

Über den kapillaren Aufstieg aus dem Grundwasser erschließen die Bestände noch aus größeren Tiefen pflanzenverfügbares Bodenwasser. Nach Tabelle 78 der Kartieranleitung 5 (AG BODEN 2005) kann der Abstand zwischen der Grundwasseroberfläche und dem effektiven Wurzelraum in Abhängigkeit vom Substrat bis zu 2,5 m betragen. Allerdings nimmt die kapillare Aufstiegsrate mit zunehmendem Abstand zum Grundwasser deutlich ab.

Tabelle 11: $\quad$ Alters- und substratabhängige effektive Durchwurzelungstiefe (nach RAISSI et al. 2009)

\begin{tabular}{lcccc}
\hline $\begin{array}{l}\text { Bestandesalter } \\
\text { Jahre] }\end{array}$ & $\begin{array}{c}\text { Sande } \\
{[\mathrm{cm}]}\end{array}$ & $\begin{array}{c}\text { Lehme } \\
{[\mathrm{cm}]}\end{array}$ & $\begin{array}{c}\text { Schluffe } \\
{[\mathrm{cm}]}\end{array}$ & $\begin{array}{c}\text { Tone } \\
{[\mathrm{cm}]}\end{array}$ \\
\hline$<15$ & $70-100$ & $80-110$ & $120-150$ & $80-100$ \\
$15-45$ & $110-150$ & $120-160$ & $160-200$ & $100-120$ \\
$>45$ & $150-200$ & $160-210$ & $200-250$ & $120-150$ \\
\hline
\end{tabular}

Eine zentrale Bedeutung in der hydrologischen Modellierung haben die hydraulischen Eigenschaften der ungesättigten Bodenzone. Die pF-Kurve beschreibt das Verhältnis zwischen Wassergehalt und Matrixpotenzial als stetige Funktion. Die Schätzung der Funktionsparameter (van Genuchten-Parameter) wurde über Pedotransferfunktionen in Abhängigkeit von Bodenart oder Korngrößenzusammen- 
setzung durchgeführt (WESSOLEK et al. 2009). Diese Pedotransferfunktion bietet gegenüber anderen gebräuchlichen Verfahren (AG BODEN 2005, TEEPE et al. 2003) den Vorteil, dass eine Differenzierung der hydraulischen Eigenschaften für die im Hessischen Ried verbreitet auftretenden Sandböden in Reinsande, Fein-, Mittel- und Grobsande möglich ist. Die gesättigte hydraulische Leitfähigkeit wurde ebenfalls WeSSOLEK et al. (2009) entnommen.

Die ausgewiesenen Leitprofile beinhalten keine Information zur Humusauflage. In Anlehnung an Abbildung 5 und Tabelle A2 (s. Kap. 2.1.2.2) wurden die Leitprofile mit Hilfe der regionalisierten Humusformen mit einer $5 \mathrm{~cm}$ mächtigen Humusauflage versehen. Flächen (Profile) mit einer mullartigen Humusform erhielten keine Humusauflage, da diese in der Regel nicht durchwurzelt ist und somit nicht als zusätzlicher Wasserspeicher für die Bestände zur Verfügung steht. Die Parametrisierung der Humusauflage erfolgte nach HAMMEL u. KENNEL (2001).

\subsubsection{Modellkalibrierung}

In der hydrologischen Modellierung nimmt die Kalibrierung einen hohen Stellenwert ein. Sie ist bei komplexen, hochgradig nichtlinearen Modellen kein triviales Problem, da nicht alle Parameter eindeutig aus den Gebietseigenschaften abgeleitet werden können. Die Kalibrierung eines hydrologischen Modells erfolgt standardmäßig anhand von gemessenen Abflusszeitreihen. Im Hessischen Ried ist das natürliche Wasserregime infolge der vielfältigen anthropogenen Eingriffe (s. Kap. 2.1.2.3) so überprägt, dass aufgrund der fehlenden räumlichen und zeitlichen Kenntnis der erfolgten Maßnahmen eine Kalibrierung des hydrologischen Modells anhand von Abflussdaten nicht möglich ist.

Die Anpassung der Antriebsdaten sowie der potenziellen Verdunstung (Grasreferenz) wurde bereits in Kapitel 2.1.2.1 kurz beschrieben. Daten zum Bodenwasserhaushalt konnten aufgrund fehlender bzw. zu weniger Messungen nicht als Kalibriergrößen herangezogen werden.

Im Rahmen der Waldökosystemstudie Hessen (WÖSSH) wurden im Jahr 1998 im Hessischen Ried (Jägersburger Wald) drei Intensiv-Monitoringflächen eingerichtet (EICHHORN 1992). Unterschieden werden je eine Buchen-, Eichen- und Kiefernfläche. Für die Waldflächen wurden bereits ab 1974 in einem Abstand von rund 5 Jahren wachstumskundliche Daten erhoben. Der Buchen- und Eichenbestand wiesen im Jahr 1998 ein mittleres Alter von gut 90 Jahren auf. Die mittlere Bestandeshöhe betrug bei der Buche $27 \mathrm{~m}$ und bei der Eiche $24 \mathrm{~m}$. Der mittlere Brusthöhendurchmesser (BHD) lag bei beiden Beständen zwischen $31-32 \mathrm{~cm}$. Die Kiefernfläche wurde dagegen erst in den 1960er-Jahren begründet. Folglich liegen die wachstumskundlichen Kenndaten mit einer mittleren Höhe von rund $20 \mathrm{~m}$ und einem BHD von $18 \mathrm{~cm}$ deutlich unter denen der anderen Intensivmessflächen. Der effektive Wurzelraum der drei Bestände reicht bis in eine Tiefe von ca. $200 \mathrm{~cm}$. 
Das forstliche Umweltmonitoring beinhaltet die Erfassung von Freiland- und Bestandesniederschlag. Diese Daten wurden zur Kalibrierung des Wasserhaushaltes herangezogen, indem das Interzeptionsmodell anhand des gemessenen Bestandesniederschlags kalibriert wurde. Die Feinkalibrierung erfolgte über den freien Parameter zur spezifischen Speicherkapazität.

Aufgrund ihrer räumlichen Nähe sind die klimatischen Verhältnisse an allen drei Standorten ähnlich. Im Bilanzierungszeitraum (1998 bis 2006) betrug die mittlere Niederschlagshöhe rund $720 \mathrm{~mm}$ pro Jahr. Der gemessene Bestandesniederschlag unterscheidet sich auf allen drei Intensiv-Monitoringflächen nur geringfügig (s. Tab. 12). Dies überrascht zunächst, da die Bestandeseigenschaften sehr unterschiedlich sind. Die Höhe der Interzeption bzw. des Bestandesniederschlages wird jedoch maßgeblich durch den Bedeckungsgrad und den Blattflächenindex gesteuert. Der Bedeckungsgrad liegt mit 0,60 bei der Kiefer und 0,67 bei der Buche deutlich unter dem Wert der Eichenfläche mit 0,85. Der Blattflächenindex wiederum ist auf dem Buchenstandort mit 5,6 (2,8 im Winter) signifikant höher als bei der Kiefer mit 4,5 (3,8 im Winter) und der Eichenintensivfläche mit 4,2 (2,1 im Winter). Infolge der unterschiedlichen Bestandesparameterkombination von hohem Bedeckungsgrad und geringem Blattflächenindex bei der Eiche sowie niedrigem Bedeckungsgrad und höherem Blattflächenindex bei Kiefer und Buche weist die Interzeption auf allen drei Intensivmessflächen mit ca. $170 \mathrm{~mm}$ bzw. der Bestandesniederschlag mit ca. $550 \mathrm{~mm}$ sehr ähnliche Werte auf (s. Tab. 12).

Die Kalibrierung der Interzeption erfolgte für den Zeitraum 1998 bis 2006. Der simulierte Bestandesniederschlag wird auf dem Buchenstandort mit $541 \mathrm{~mm}$ (550 mm gemessen) leicht unterschätzt, auf der Eichenfläche mit $554 \mathrm{~mm}$ (545 mm gemessen) leicht überschätzt und auf der Kiefernintensivfläche beträgt die Abweichung zum Messwert nur $1 \mathrm{~mm}$ (s. Tab. 12). Eine Analyse der mittleren Monatssummen zeigt teilweise deutlichere Abweichungen. Dies liegt darin begründet, dass die Bestandesniederschläge nur in einem Zyklus von 14 Tagen oder länger erfasst werden. Je nach Messtermin wird dadurch der Niederschlag aus dem Vormonat in den Folgemonat übertragen. Dies zeigt exemplarisch der Vergleich zwischen den gemessen und simulierten Bestandesniederschlägen für die Monate Juli und August. Während im Juli die Messwerte deutlich über der Simulation liegen, kehrt sich das Verhältnis im August um (s. Tab. 12). Der spezifische Speicherkoeffizient zur Quantifizierung des maximalen Interzeptionsspeichervermögens wurde für alle Baumarten auf 0,55 gesetzt.

Die Regionalisierung der Antriebsdaten, die Anpassung der potenziellen Verdunstung und der klimatischen Wasserbilanz sowie die Kalibrierung der Bestandesniederschläge wird als gut bewertet. Die Anwendbarkeit des hydrologischen Modells für Prognosezwecke bei verschiedenen Grundwasser- und Klimaszenarien ist damit gewährleistet. 
Material und Methoden

Tabelle 12: Vergleich gemessener (gem) und simulierter (sim) Bestandesniederschläge [mm] auf den Intensiv-Monitoringflächen Buche, Eiche und Kiefer im Jägersburger Wald, Erhebungszeitraum: 01.01.1998 - 31.12.2006

\begin{tabular}{lcccccc}
\hline $\begin{array}{l}\text { Monats- } \\
\text { mittel }\end{array}$ & $\begin{array}{c}\text { Buche } \\
\text { gem }\end{array}$ & $\begin{array}{c}\text { Buche } \\
\text { sim }\end{array}$ & $\begin{array}{c}\text { Eiche } \\
\text { gem }\end{array}$ & $\begin{array}{c}\text { Eiche } \\
\text { sim }\end{array}$ & $\begin{array}{c}\text { Kiefer } \\
\text { gem }\end{array}$ & $\begin{array}{c}\text { Kiefer } \\
\text { sim }\end{array}$ \\
\hline Jan & 44 & 41 & 43 & 41 & 41 & 40 \\
Feb & 38 & 41 & 37 & 41 & 35 & 40 \\
Mrz & 47 & 54 & 46 & 54 & 43 & 53 \\
Apr & 33 & 39 & 32 & 40 & 30 & 38 \\
Mai & 41 & 54 & 42 & 54 & 45 & 55 \\
Jun & 36 & 28 & 36 & 29 & 40 & 31 \\
Jul & 69 & 49 & 69 & 51 & 77 & 53 \\
Aug & 39 & 50 & 42 & 52 & 42 & 53 \\
Sep & 53 & 37 & 53 & 39 & 56 & 41 \\
Okt & 52 & 55 & 52 & 57 & 55 & 58 \\
Nov & 54 & 50 & 51 & 51 & 52 & 51 \\
Dez & 44 & 44 & 42 & 44 & 41 & 44 \\
\hline Jahr & 550 & 541 & 545 & 554 & 557 & 556 \\
\hline
\end{tabular}

\subsubsection{Standort-Leistungs-Modell}

In der vorliegenden Studie wurde ein klimasensitives Standort-Leistungsmodell nach AlBERT und SCHMIDT (2008, 2010a) eingesetzt. Mit Hilfe dieses Modells kann die aktuelle und zukünftige Leistungsfähigkeit jedes beliebigen Standortes für die fünf Baumarten Eiche, Buche, Kiefer, Fichte und Douglasie in Deutschland geschätzt werden. Die neben diesen Hauptbaumarten im Untersuchungsgebiet vorkommenden Nebenbaumarten wurden entsprechend ihrem Wachstumsgang den Hauptbaumarten zugeordnet.

Aufgrund der sich u. a. durch den Klimawandel bereits mittelfristig verändernden Standortsbedingungen müssen dynamische Bonitierungssysteme in der Waldwachstumsmodellierung und der Forstplanung eingesetzt werden. Ziel ist es, mit Hilfe von verallgemeinerten additiven Modellen die aktuelle und zukünftige baumartspezifische Leistungsfähigkeit eines Standortes auf Grundlage von Boden- und Klimavariablen zu schätzen. Dabei wird die Leistungsfähigkeit eines Standortes über die Mittelhöhenbonität beschrieben, die ein Bestand hypothetisch nach 100 Jahren unter konstanten aktuellen oder zukünftigen Standortsbedingungen erreichen würde. Die klimasensitiven Standort-Leistungs-Modelle dienen dazu, das 
Wuchspotenzial verschiedener Baumarten für waldbauliche Entscheidungen zu vergleichen. Gleichzeitig liefern die Modelle Eingangswerte für den im WaldPlaner eingesetzten Waldwachstumssimulator TreeGROSS.

\subsubsection{Datengrundlage}

Der Parametrisierungsdatensatz für die klimasensitiven Standort-LeistungsModelle besteht aus Inventurpunkten der Bundeswaldinventur I und II sowie der Betriebsinventur der Niedersächsischen Landesforsten, an denen die entsprechende Baumart in Rein- oder Mischform vorkommt und mindestens eine Baumhöhe gemessen wurde. Für die Baumart Buche sind dies 35.864 Beobachtungen, für die Eiche 20.666, für die Fichte 57.100, für die Kiefer 35.104 und für die Douglasie 4.586. An jedem Inventurpunkt wird baumartspezifisch die Mittelhöhenbonität im Alter 100 mit Hilfe des longitudinalen Höhen-Durchmesser-Bonitierungsansatzes von SCHMIDT $(2008,2009)$ als Funktion von Bestandesparametern und der Seehöhe sowie der geografischen Lage geschätzt (vgl. auch ALBERT u. SCHMIDT 2008). Diese Bonitierungsmethode auf Basis der Arbeit von MEHTÄTALO (2004) erfordert im Gegensatz zu herkömmlichen Bonitierungssystemen keine Konstanz der Standortsbedingungen, die aufgrund des nachgewiesenen Wachstumstrends schon in den letzten Jahrzehnten nicht mehr gegeben war (vgl. z. B. RÖHLE 1995, STERBA 1995, ElFVING u. NYSTRÖM 1996, SPIEKER et al. 1996, SCHADAUER 1999). Tabelle 13 gibt einen Überblick über die verwendeten erklärenden Variablen und die Methodik ihrer Herleitung.

Als erklärende Variablen werden die Bodennährstoffversorgung (Nähr), die nutzbare Feldkapazität (nFK), die Stickstoffdepositionsrate (Ndep) sowie die Temperatursumme in der Vegetationszeit (Temp) und die klimatische Wasserbilanz in der Vegetationszeit (kWB) herangezogen. Ein räumlicher Trend quantifiziert den Einfluss der geografischen Lage auf die Standortleistungsfähigkeit und subsummiert sämtliche Effekte, wie z. B. den Windeinfluss, die nicht explizit von den anderen Modellvariablen beschrieben werden. Weitere Variablen wurden im Rahmen der Modellbildung durch Modellvergleiche auf Basis des Bayesian Information Criterion (BIC) ausgeschlossen. Im Einzelnen werden jedem BWI- und BIInventurpunkt die entsprechenden Parameterwerte zugeordnet. Die Bodenparameter werden ausgehend vom diesem Punkt zugeordneten Leitprofil der flächendeckenden Wald-Bodenübersichtskarte (Wald-BÜK) über Transferfunktionen hergeleitet (AHRENDS 2010) Die mit dem regionalen Klimamodell WETTREG (SPEKAT et al. 2007) projizierten Klimaparameter werden mit Hilfe des Modells WASIM-ETH (vgl. SCHULLA 1997, SCHULlA u. JASPER 2007) auf $200 \times 200 \mathrm{~m}$ Teilflächen regionalisiert und den Inventurpunkten über deren Mittelpunktkoordinaten zugeordnet. 
Tabelle 13: Verwendete Modellvariablen und die zu ihrer Herleitung verwendete Methodik

\begin{tabular}{|c|c|c|}
\hline Variable & Einheit & Datenquelle \\
\hline Bodennährstoffe & $\begin{array}{l}\text { in } 4 \text { Stufen gruppierte } \\
\text { Bodennährstoffversorgung }\end{array}$ & $\begin{array}{l}\text { abgeleitet aus Leitprofilen } \\
\text { entsprechend der Wald- } \\
\text { BÜK; modifiziert von } \\
\text { AHRENDS (2010) }\end{array}$ \\
\hline $\begin{array}{l}\text { nutzbare } \\
\text { Feldkapazität }\end{array}$ & $\begin{array}{l}\text { auf } 1,4 \mathrm{~m} \text { Bodentiefe bilanziert } \\
\text { [mm] }\end{array}$ & $\begin{array}{l}\text { abgeleitet aus Leitprofilen } \\
\text { entsprechend der Wald- } \\
\text { BÜK; modifiziert von } \\
\text { AHRENDS (2010) }\end{array}$ \\
\hline $\begin{array}{l}\text { Stickstoffdeposi- } \\
\text { tion }\end{array}$ & $\begin{array}{l}\text { über das Bestandesleben gemittelte } \\
\text { jährliche Stickstoffdepositionsrate } \\
{[\mathrm{eq} / \mathrm{ha} / \mathrm{a}]}\end{array}$ & $\begin{array}{l}\text { modelliert mit } \\
\text { modifizierter Version von } \\
\text { MAKEDEP (ALVETEG et } \\
\text { al. 1997, AHRENDS et al. } \\
\text { 2008) }\end{array}$ \\
\hline Temperatursumme & $\begin{array}{l}\text { Summe der täglichen Mittel- } \\
\text { temperatur in der Vegetationszeit } \\
{\left[{ }^{\circ} \mathrm{C}\right] \text {, wobei die Vegetationszeit }} \\
\text { dynamisch und baumartspezifisch } \\
\text { berechnet wird (vgl. MENZEL 1997, } \\
\text { WILPERT 1990) }\end{array}$ & $\begin{array}{l}\text { modelliert mit } \\
\text { WETTREG für die } \\
\text { Klimanormalperiode } 1961 \\
\text { bis 1990; regionalisiert auf } \\
200 \times 200 \text { m mit WASIM- } \\
\text { ETH (vgl. SCHULLA 1997; } \\
\text { SPEKAT et al. 2007) }\end{array}$ \\
\hline $\begin{array}{l}\text { klimatische } \\
\text { Wasserbilanz }\end{array}$ & $\begin{array}{l}\text { Differenz aus der Niederschlags- } \\
\text { summe und der potenziellen Eva- } \\
\text { potranspiration (vgl. MONTEITH } \\
1985 \text { ) in der Vegetationszeit [mm] }\end{array}$ & $\begin{array}{l}\text { modelliert mit } \\
\text { WETTREG für die } \\
\text { Klimanormalperiode } 1961 \\
\text { bis } 1990 \text {; regionalisiert auf } \\
200 \times 200 \text { m mit WASIM- } \\
\text { ETH (vgl. SCHULLA 1997, } \\
\text { SPEKAT et al. 2007) }\end{array}$ \\
\hline
\end{tabular}

Tabelle 14 beschreibt die Verteilung der erklärenden Variablen anhand von Mittelwert und Standardabweichung bzw. von Klassenbesetzungen für die kategorischen Variablen. Die Bodennährstoffversorgung wurde in vier Stufen klassifiziert. Eine Differenzierung zwischen Bergland- und Tieflandstandorten ist aufgrund unterschiedlicher Effekte gleicher Klassen auf das Wachstum notwendig. Diese Unterschiede liegen im Kartierschema begründet, das zwischen Bergland und Tiefland unterscheidet (vgl. AHRENDS 2010).

Da die effektive Durchwurzelungstiefe auf vielen Böden des Tieflandes bei mindestens 1,4 m liegt (CZAJKOWSKI et al. 2009), wurde die nutzbare Feldkapazität einheitlich für alle Standorte auf 1,4 $\mathrm{m}$ bilanziert. 
Tabelle 14: Mittelwert $[\overline{\mathrm{x}}]$ und Standardabweichung [sd] der verwendeten kontinuierlichen Variablen biw. Anzabl der Beobachtungen je Nährstoffstufe (von $1=$ arm bis $4=$ reich, getrennt nach Bergland und Tiefland; \} kennzeichnet Klassen, die aufgrund von nicht signifikanten Modelleffekten bei der Modellselektion zusammengefasst wurden)

\begin{tabular}{|c|c|c|c|c|c|c|c|}
\hline & & & Buche & Eiche & Fichte & Kiefer & Douglasie \\
\hline \multirow{8}{*}{$\begin{array}{l}\text { Nährstoffstufe } \\
\text { [n] }\end{array}$} & \multirow{4}{*}{ Bergl. } & 1 & 487 & \multirow{2}{*}{ \} 1.229} & 1.898 & \multirow{2}{*}{ \} 6.724} & \multirow{2}{*}{ \} 781} \\
\hline & & 2 & 1.841 & & 6.668 & & \\
\hline & & 3 & \multirow{2}{*}{ \} 4549} & \multirow{2}{*}{\} 12.642} & 22.693 & \multirow{2}{*}{\} 15.987} & 1.583 \\
\hline & & 4 & & & 13.196 & & 1.128 \\
\hline & \multirow{4}{*}{ Tiefl. } & 1 & 1.346 & 1.965 & 22145 & $x+7223$ & $x, 421$ \\
\hline & & 2 & 101 & \multirow{2}{*}{ \} 3.239} & $\{2.145$ & $1.22 J$ & $\{4 \angle 1$ \\
\hline & & 3 & \multirow{2}{*}{7.540} & & 6.150 & 3.983 & \multirow{2}{*}{ \} 673} \\
\hline & & 4 & & 1.591 & 4.350 & 1.187 & \\
\hline \multirow{2}{*}{\multicolumn{2}{|c|}{$\begin{array}{l}\text { nutzbare Feldkapazität } \\
(\mathrm{nFK})[\mathrm{mm}]\end{array}$}} & $\bar{x}$ & 157 & 173 & 158 & 187 & 178 \\
\hline & & sd & 48 & 52 & 43 & 44 & 47 \\
\hline \multirow{2}{*}{\multicolumn{2}{|c|}{$\begin{array}{l}\text { Stickstoffdeposition } \\
\text { (Ndep) [eq/ha/a] }\end{array}$}} & $\overline{\mathrm{x}}$ & 2.163 & 2.202 & 2.635 & 2.728 & 3.622 \\
\hline & & sd & 862 & 1.149 & 1.043 & 1.351 & 1.701 \\
\hline \multirow{2}{*}{\multicolumn{2}{|c|}{$\begin{array}{l}\text { Temperatursumme in } \\
\text { der Vegetationszeit } \\
{\left[{ }^{\circ} \mathrm{C}\right]}\end{array}$}} & $\bar{x}$ & 2.117 & 2.215 & 2.048 & 2.070 & 2.205 \\
\hline & & sd & 140 & 92 & 183 & 92 & 107 \\
\hline \multirow{2}{*}{\multicolumn{2}{|c|}{$\begin{array}{l}\text { klimatische Wasser- } \\
\text { bilanz (KWB) [mm] }\end{array}$}} & $\bar{x}$ & -188 & -234 & -157 & -237 & -265 \\
\hline & & sd & 109 & 69 & 127 & 81 & 87 \\
\hline
\end{tabular}

Im Gegensatz zur mittleren Temperatur in der Vegetationszeit, die in den oben beschriebenen klimasensitiven Standort-Leistungs-Modellen verwendet wurde (ALBERT u. SCHMIDT 2008, 2010b), wurde als erklärende Variable die Temperatursumme in der Vegetationszeit herangezogen. Dies hat den Vorteil, dass sich nicht nur der durch Klimawandel hervorgerufene absolute Temperaturanstieg, sondern auch eine mögliche Verlängerung der Vegetationszeit im Parameterwert widerspiegelt. Grundsätzlich beschreibt die Temperatursumme die zur Verfügung stehende Energiemenge besser als die Mitteltemperatur, da sich die letztere auf unterschiedliche Bilanzierungszeiträume beziehen kann.

\subsubsection{Modellierungsansatz}

Der verwendete statistische Modellierungsansatz zur Beschreibung des StandortLeistungs-Bezugs der Baumarten Fichte, Buche, Kiefer, Eiche und Douglasie ist ein verallgemeinertes additives Modell (vgl. HASTIE u. TIBSHIRANI 1990), das im 
Statistikpaket R 2.10.0 (R DEVELOPMENT CORE TEAM 2010) unter Verwendung der Bibliothek mgcv 1.6-0 (WOOD 2006) parametrisiert wurde. Additive Modelle erlauben es, nichtlineare Effekte der Prädiktorvariablen auf die Antwortvariable zu identifizieren, ohne dass Annahmen über eine bestimmte Funktionsform vorgegeben werden müssen. In der Methodik von WOOD (2006) werden dazu penalisierte Regressionssplines verwendet. Dabei wird die Flexibilität der Anpassung fast ausschließlich über einen Glättungsparameter gesteuert, der über verallgemeinerte Kreuzvalidierung optimiert wird. Die allgemeine Form eines verallgemeinerten additiven Modells (GAM) lautet für normal- und homogen verteilte Beobachtungen wie folgt:

$$
\begin{aligned}
& Y_{i}=a+f\left(X_{\mathrm{i}}\right)+\varepsilon_{i} ; \varepsilon_{i} \sim N\left(0, \sigma^{2}\right) \\
& \text { mit } \\
& Y_{i} \quad=\text { Response Variable } \\
& X_{i} \quad=\text { erklärende Variable } \\
& f \quad=\text { glättende Funktion. }
\end{aligned}
$$

Im Gegensatz zum einfachen linearen Regressionsmodell, in dem die Beziehung zwischen $Y_{i}$ und $X_{i}$ durch einen konstanten Regressionsparameter beschrieben wird, werden im GAM glättende Funktionen zur Beschreibung potenzieller nichtlinearer Effekte verwendet. Zur Darstellung nichtlinearer Modelleffekte bietet sich die graphische Darstellung der glättenden Funktion als Kurve inklusive eines punktweisen Prognoseintervalls an.

\subsubsection{Modellierung des Standort-Leistungs-Bezuges}

Das Modell für die Baumarten Buche, Eiche, Fichte und Kiefer lässt sich wie folgt spezifizieren:

$$
\begin{aligned}
\operatorname{hg} 100_{i}= & \alpha_{1}+\mathrm{Nähr}_{i}^{\mathrm{T} \beta}+\mathrm{f}_{1}\left(\mathrm{Temp}_{i}\right)+\mathrm{f}_{2}\left(\mathrm{KWB}_{i}\right)+\mathrm{f}_{3}\left(\mathrm{nFK}_{i}\right)+\mathrm{f}_{4}\left(\mathrm{Ndep}_{i}\right) \\
& +\mathrm{f}_{5}\left(\mathrm{RW}_{i}, \mathrm{HW}_{i}\right)+\varepsilon_{i}
\end{aligned}
$$

mit

$$
\begin{aligned}
& \text { hg100 }{ }_{i}=\text { Mittelhöhenbonität im Alter } 100 \text { an Stichprobenpunkt } i[\mathrm{~m}] \\
& \mathrm{Nähr}_{i}^{\mathrm{T}}=\text { Indikatorenvektor für klassifizierte Bodennährstoffe } \\
& \beta=\text { zu Nähr gehörender Parametervektor } \\
& \mathrm{KWB}_{i}=\text { klimatische Wasserbilanz in der Vegetationszeit (VZ) [mm] } \\
& \mathrm{Temp}_{i}=\text { Temperatursumme in } \operatorname{der} \mathrm{VZ}\left[{ }^{\circ} \mathrm{C}\right] \\
& \mathrm{Ndep}_{i}=\text { mittlere Stickstoffdeposition }[\mathrm{eq} / \mathrm{ha} / \mathrm{a}] \\
& \mathrm{nFK}_{i}=\text { nutzbare Feldkapazität [mm] } \\
& \mathrm{RW}_{i}, \mathrm{HW}_{i}=\text { Gauss-Krüger-Lagekoordinaten } \\
& \alpha_{1} \quad=\text { Regressionskoeffizient (Interzept) } \\
& \mathrm{f}_{1}, \mathrm{f}_{2}, \mathrm{f}_{3}, \mathrm{f}_{4}=\text { eindimensionale glättende Funktionen } \\
& \mathrm{f}_{5} \quad=\text { zweidimensionale glättende Funktion zur Beschreibung des räumlichen } \\
& \text { Trends }
\end{aligned}
$$


Bei der Baumart Douglasie ist es für die Gewährleistung eines biologisch plausiblen Modellverhaltens notwendig, die Modelleffekte der verschiedenen Einflussgrößen in zwei Modellierungsschritten zu schätzen. Diese Vorgehensweise ist erforderlich, da die untereinander korrelierten Prädiktoren bei gleichzeitig deutlich geringerer Datengrundlage für die Douglasie dazu führen, dass sich die Modelleffekte nicht voneinander trennen lassen. Darüber hinaus ist die Variable nutzbare Feldkapazität im Douglasienmodell nicht signifikant.

Vormodell:

$$
\operatorname{hg} 100_{i}=\alpha_{1}+\mathrm{f}_{1}\left(\text { Temp }_{i}\right)+\mathrm{f}_{2}\left(\mathrm{KWB}_{i}\right)+\varepsilon_{i}
$$

Hauptmodell:

$$
\operatorname{hg} 100_{i}=\alpha_{1}+\mathrm{Nähr}_{i}^{\mathrm{T} \beta}+\hat{\mathrm{f}}_{1}\left(\mathrm{Temp}_{\mathrm{i}}\right)+\hat{\mathrm{f}}_{2}\left(\mathrm{KWB}_{\mathrm{i}}\right)+\mathrm{f}_{4}\left(\mathrm{Ndep}_{i}\right)+\mathrm{f}_{5}\left(\mathrm{RW}_{i}, \mathrm{HW}_{i}\right)+\varepsilon_{i}
$$

mit

$\hat{f}_{1}, \hat{f}_{2}=$ die im Modell (11) parametrisierten und in (12) übernommenen Effekte

Bei allen Modellen gehen die erklärenden Variablen entweder als lineare Terme oder als nicht-lineare Effekte, die mit Hilfe von ein- bzw. zweidimensionalen glättenden Splines modelliert werden, in das Standort-Leistungs-Modell ein. Die aggregierten Kenngrößen der Modellgüte sind wie folgt:

$\begin{array}{lll}\text { Baumart: } & \mathrm{R}^{2}: & \text { Standardfehler }[\mathrm{m}] \text { : } \\ \text { Fichte } & 0,44 & 3,1 \\ \text { Buche } & 0,31 & 3,4 \\ \text { Kiefer } & 0,45 & 2,6 \\ \text { Eiche } & 0,33 & 3,1\end{array}$

Die linearen und nicht-linearen Effekte sind in allen Modellen hochsignifikant. Die Koeffizienten der kategorischen Variablen und linearen Terme sind bezüglich ihrer Wirkungsrichtung aus biologischer Sicht als plausibel zu beurteilen: Je besser die Nährstoffversorgung und je höher die nutzbare Feldkapazität (linear im Buchenmodell) ist, desto besser ist die Mittelhöhenbonität. Die nicht-linearen Effekte inklusive der punktweisen Prognoseintervalle (5 Prozent Irrtumswahrscheinlichkeit) sind in den Abbildungen 17 bis 20 dargestellt.

Bei der Interpretation der partiellen Effekte muss die Korrelation der Prädiktorvariablen untereinander beachtet werden. Da beispielsweise Temperaturveränderungen fast immer mit Veränderungen der klimatischen Wasserbilanz einhergehen, darf nicht vom Temperatureffekt direkt auf die Veränderung der Standortleistungsfähigkeit geschlossen werden. Des Weiteren dürfen die Effekte in den Randbereichen der Beobachtungswerte nicht überinterpretiert werden, da sie mit nur wenigen Daten belegt sind. 
In Abbildung 17 sind die unterschiedlichen Temperaturbereiche, in denen Datensätze der einzelnen Baumarten vorliegen, gut erkennbar. Fichte und Buche zeigen im unteren Temperaturbereich nur geringe Reaktionen der Leistungsfähigkeit, während die übrigen Baumarten auch vom Temperaturanstieg im unteren Wertebereich ihrer jetzigen Vorkommen profitieren. Ab einer Temperatursumme von ca. $1500{ }^{\circ} \mathrm{C}$ in der Vegetationszeit reagiert die Fichte stark, die Buche ab ca. $1800{ }^{\circ} \mathrm{C}$. Für alle Baumarten zeigt der Temperatureffekt im oberen Bereich ein Abflachen, d. h. steigende Temperatursummen scheinen sich hier nicht mehr leistungssteigernd auszuwirken.

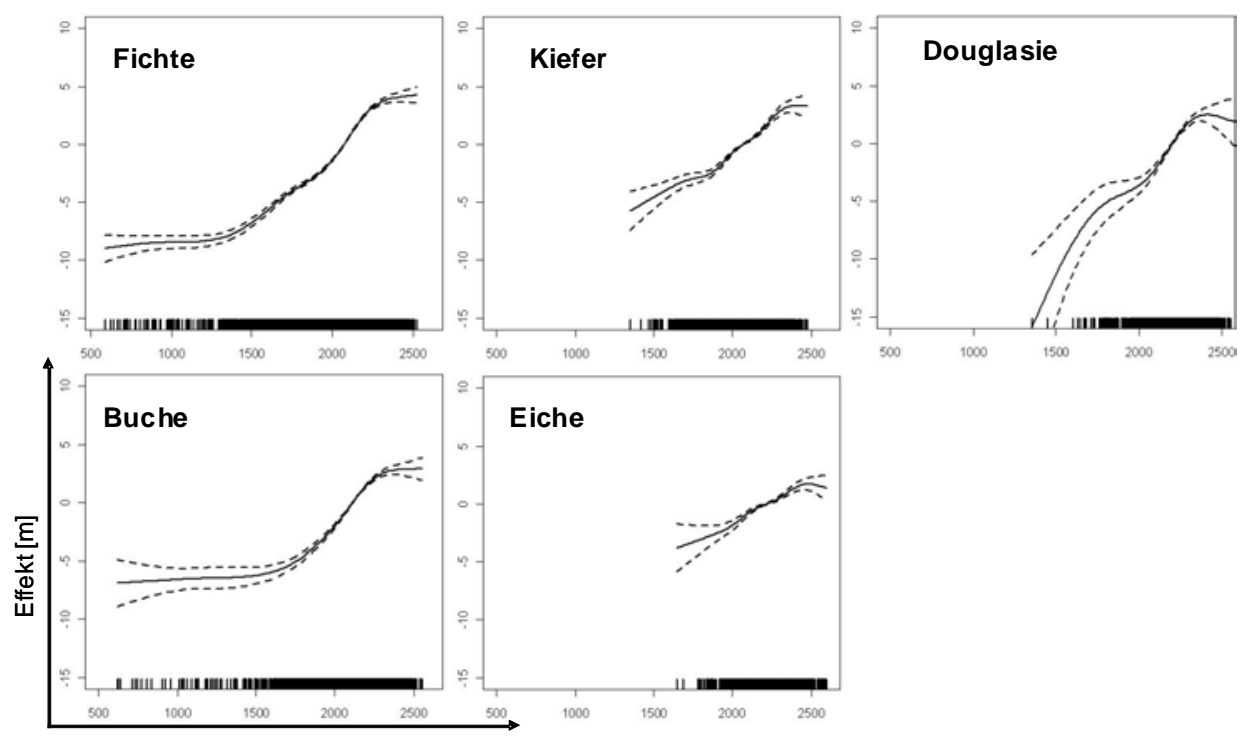

Temperatursummme in der $\mathrm{VZ}\left[{ }^{\circ} \mathrm{C}\right]$

Abbildung 17: Nicht-linearer Effekt der Temperatursumme in der Vegetationszeit [ $\left.{ }^{\circ} \mathrm{C}\right]$ auf die Mittelböhenbonität $[\mathrm{m}]$ der fünf Baumarten. Die gestrichelten Linien beschreiben punktweise Prognoseintervalle (5\% Irrtumswahrscheinlichkeit). Die Striche auf der Abszisse markieren Datensätze mit der entsprechenden Ausprägung.

Der Effekt der klimatischen Wasserbilanz ist für die Baumart Buche über den gesamten Wertebereich fast gleichmäßig ansteigend und erst im oberen Bereich abflachend (s. Abb. 18). Die Effekte bei den anderen Baumarten zeigen bereits bei ca. $-200 \mathrm{~mm}$ ein deutliches Abflachen. Der nicht monoton steigende Effekt der klimatischen Wasserbilanz bei der Baumart Kiefer erscheint biologisch nicht sinnvoll, ist jedoch durch die vorliegenden (unbalancierten) Kombinationen der einzelnen Einflussfaktoren im Parametrisierungsdatensatz erklärbar. Unter den Kiefernbeständen mit einer klimatischen Wasserbilanz größer $-100 \mathrm{~mm}$ verbirgt sich ein höherer Anteil an Hochlagenstandorten, die im Mittel eine geringere Bonität auf- 
weisen. Diese geringere Leistungsfähigkeit trotz besserer Wasserversorgung als im Tiefland wird im Modell eben auch durch das Absinken des Effektes der klimatischen Wasserbilanz beschrieben und nicht ausschließlich über den Temperatureffekt. Abhilfe könnte hier der Einsatz neuer Modellierungsmethoden mit monoton steigenden Effekten bieten und für Prognosen eine bessere biologische Plausibilität gewährleisten (BREZGER 2005).

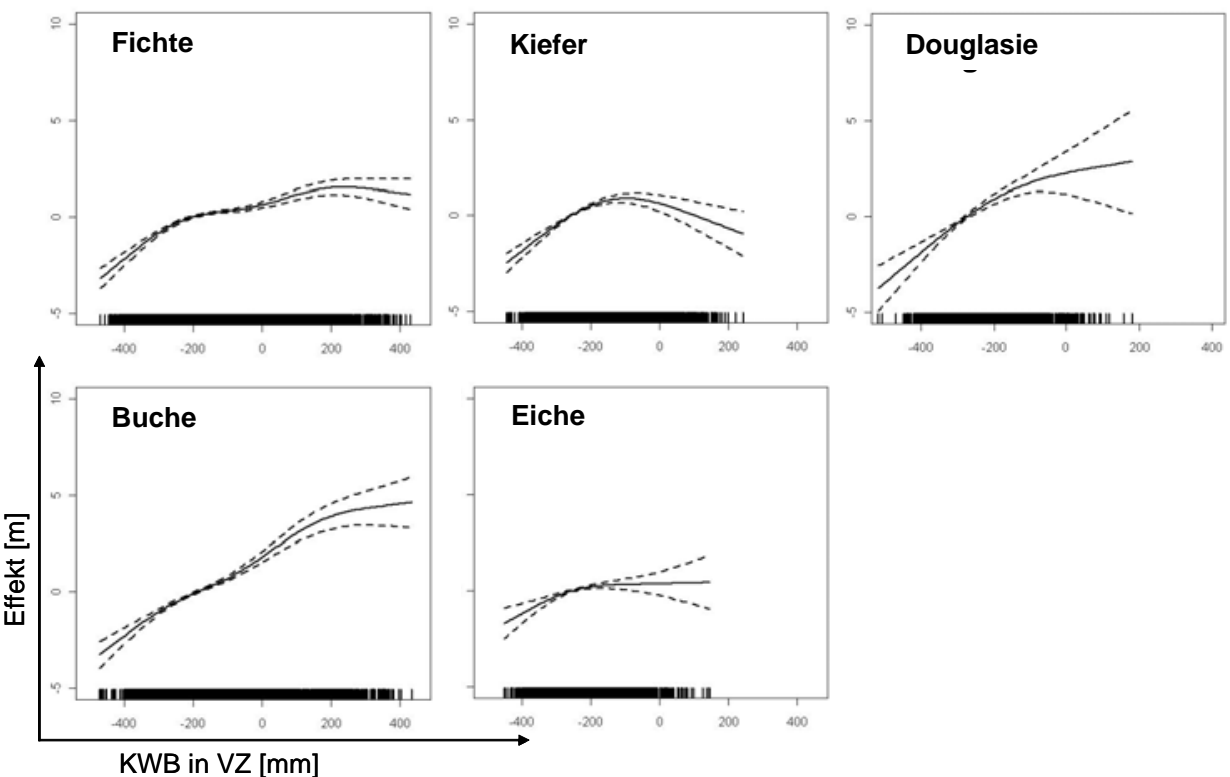

Abbildung 18: Nicht-linearer Effekt der klimatischen $W$ asserbilanz in der Vegetationszeit [mm] auf die Mittelhöbenbonität $[\mathrm{m}]$ der fünf Baumarten

Der Effekt der nutzbaren Feldkapazität auf die Standortleistungsfähigkeit ist im Vergleich zum Effekt der Temperatursumme und der klimatischen Wasserbilanz recht gering (s. Abb. 19). Die nutzbare Feldkapazität ist dennoch eine wichtige Kenngröße, da sie hilft, zwischen Standorten mit ähnlichen Niederschlags- und Temperaturverhältnissen, aber unterschiedlichen Bodenarten zu differenzieren. 

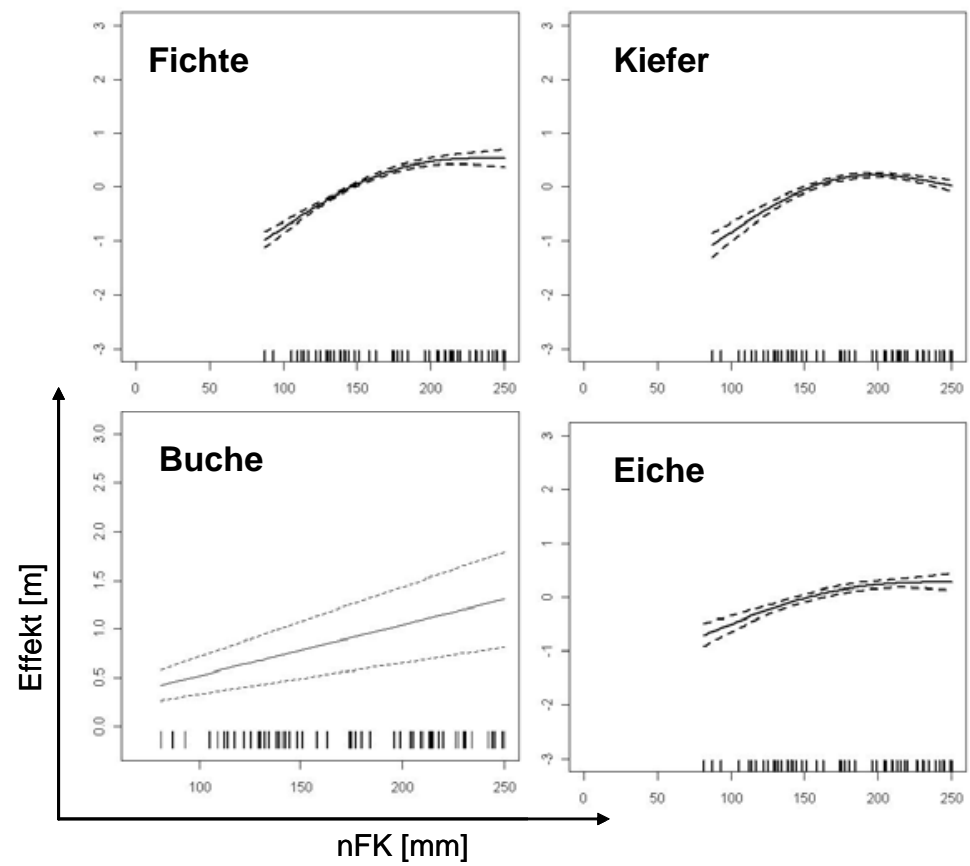

Abbildung 19: Nicht-linearer bzw. linearer (Buche) Effekt der nutzbaren Feldkapazität [mm] auf die Mittelhöhenbonität $[\mathrm{m}]$ der vier Baumarten

Die Stickstoffdepositionsrate hat einen großen Effekt auf die Standortleistungsfähigkeit (s. Abb. 20). Allerdings weist sie eine starke räumliche Abhängigkeit auf, mit Werten in Nordwestdeutschland zwischen 6000 und $8000 \mathrm{eq} / \mathrm{ha} / \mathrm{a}$ und Werten zwischen 700 u. 5000 eq/ha/a im übrigen Bundesgebiet (AHRENDS 2010).

In den Szenariosimulationen wird die mögliche Dynamik der Standortleistungsfähigkeit unter Klimawandel untersucht. Dabei werden die Klimabedingungen für zukünftige Perioden unter Annahme von Klimaszenarien mit dem regionalen Klimamodell WETTREG (SPEKAT et al. 2007) projiziert. Während sich somit die Temperatursummen und klimatischen Wasserbilanzen der Standorte in der Szenariosimulation verändern, werden die übrigen erklärenden Modellvariablen als konstant angenommen.

Der Boden wird zu Beginn der Vegetationszeit als wassergesättigt angesehen, die nutzbare Feldkapazität steht somit in vollem Umfang zur Verfügung. Die Stickstoffdeposition wird analog zum Vorgehen bei der Modellparametrisierung als mittlere jährliche Rate über das Bestandesleben bilanziert. Zukünftige jährliche Stickstoffdepositionswerte werden mit einem Modell von AHRENDS (2010) projiziert. Die Verfügbarkeit der Bodennnährstoffe wird sich unter Klimawandel verändern (vgl. AHRENDS 2010). Im Modell wird diese aber vorerst als konstant angenommen. 


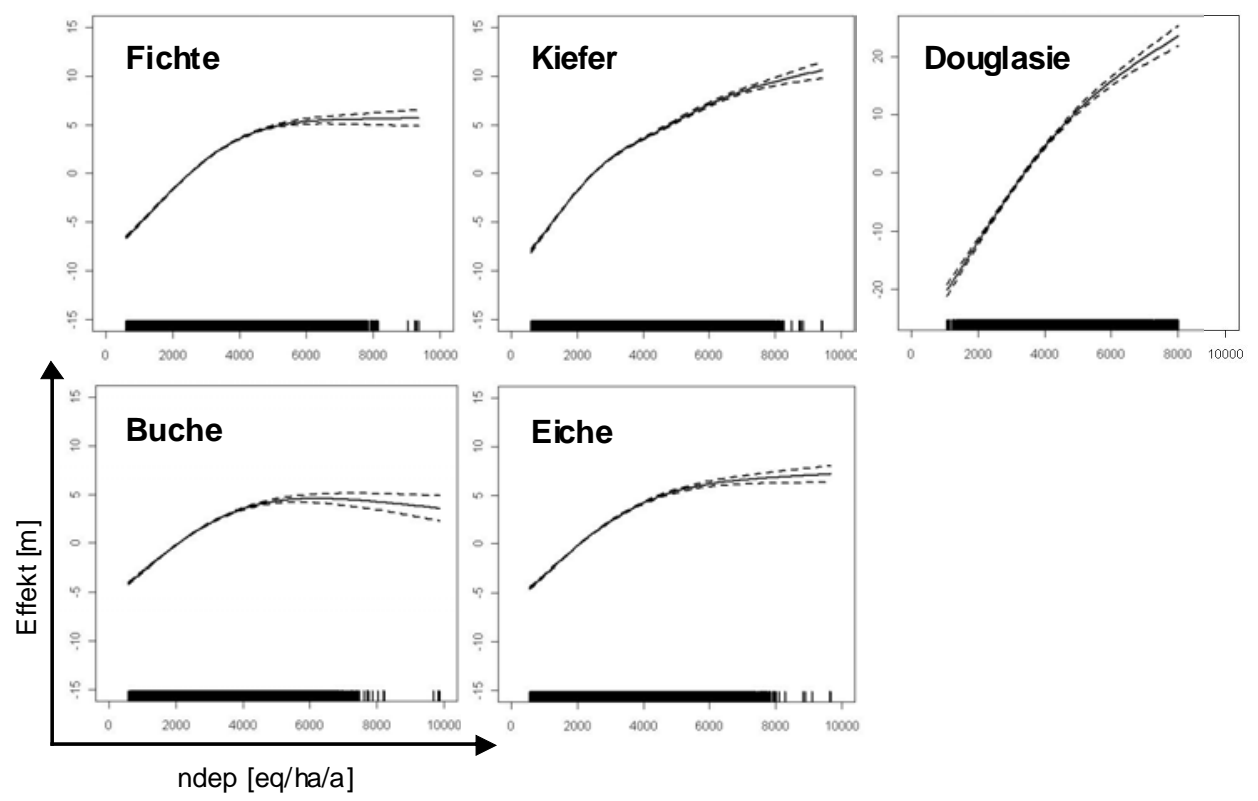

Abbildung 20: Nicht-linearer Effekt der Stickstoffdepositionsrate [eq/ha/a] auf die Mittelhöhenbonität $[\mathrm{m}]$ der fünf Baumarten

\subsubsection{Mortalitätsmodell}

\subsubsection{Allgemeines Mortalitätsmodell}

Zu den Kernproblemen der Waldwachstumssimulation zählt die Beschreibung von Absterbeprozessen. In ungestörten bzw. unbewirtschafteten Wäldern wirkt hauptsächlich eine dichtebedingte Mortalität. Zur Beschreibung dieser dichtebedingten Mortalität sind bereits verschiedene Modellansätze entwickelt und in Waldwachstumssimulatoren implementiert worden (KAHN u. PRETZSCH 1997). Grundsätzlich sind dabei Ansätze mit Einzelbaumbezug (ĎURSKÝ 1997) und Bestandesmodelle zu unterscheiden (STERBA 1987). Einzelbaummodelle prognostizieren die Wahrscheinlichkeit, dass einzelne Bäume absterben, in Abhängigkeit von Einzelbaum-, Bestandes- und Standortsvariablen. Bestandesmodelle beschreiben die Entwicklung von maximalen Bestandesdichten in Abhängigkeit von Bestandes- und Standortsparametern. Basierend auf der Arbeit von STERBA (1987) modellierten DÖBBELER u. SPELLMANN (2002) die maximale Grundfläche/ha in Abhängigkeit vom Grundflächenmittelstamm für Deutschland für die vier Hauptbaumarten (Eiche, Buche, Fichte und Kiefer), wobei großräumige Standortsunterschiede durch eine Stratifizierung in 5 Regionen erfasst wurden. Der Ansatz diente in diesem Fall allerdings der Definition von Eingriffsstärken in Relation zur maximal erreichbaren Bestandesgrundfläche. ĎURSKÝ (2000) verwandte ebenfalls den Ansatz von STERBA (1987), um regionalspezifische maximale Bestandesdichten für 
Bayern zu schätzen, wobei die Auflösung hier bis zur Wuchsbezirksebene reicht. ĎURSKÝ (2000) kombinierte anschließend das einzelbaumbezogene Mortalitätsmodell mit dem regionalspezifischen Bestandesmodell, um eine größere Prognosestabilität $\mathrm{zu}$ erreichen und um regionalspezifische Unterschiede abbilden $\mathrm{zu}$ können.

Neben der dichtebedingten Sterblichkeit spricht HASENAUER (1994) von einer unspezifischen Sterblichkeit nach Erreichen eines baumartenspezifischen kritischen Alters und von einer zufälligen Mortalität, deren praktische Bedeutung er jedoch als verhältnismäßig gering einstuft. Gegenüber dieser unspezifischen Mortalität hat die Mortalität, die konkreten Faktoren wie Winterstürmen und Insektenkalamitäten zugeordnet werden kann, eine sehr viel größere Bedeutung (HANEWINKEL et al. 2010). Grundsätzlich erscheint die Erfassung der störungsbedingten Mortalität komplizierter als die der dichtebedingten Mortalität, da sie durch schwer quantifizierbare zufällige Ereignisse bestimmt wird. Eine modellhafte Erfassung dieser Mortalität ist dennoch möglich, wenn geeignete Datengrundlagen zur Verfügung stehen (ALBRECHT 2009, SCHMIDT et al. 2010) und Einschränkungen bei der Anwendung der Modelle unter geänderten Rahmenbedingungen beachtet werden.

Die erhöhte Mortalität von Bäumen im Hessischen Ried, die seit dem Ende der 1960er-Jahre vor allem im Zusammenhang mit Grundwasserabsenkungen beobachtet wird, ist in ihrer Intensität ein regional begrenztes Problem. Statistische Modelle, die sich für die Beschreibung dieser Absterbeprozesse und für die Implementierung in Waldwachstumssimulatoren eignen, sind bisher nicht entwickelt worden. Die einfache Beschreibung der Mortalität über prozentuale Absterberaten, wie sie JACOBSEN (2010) verwendet, muss dabei für einzelbaumorientierte Modelle als unzureichend erachtet werden. Nur die Entwicklung statistischer Modelle ermöglicht es, Einflussgrößen und ihre Effekte auf die Mortalität $\mathrm{zu}$ identifizieren und zu quantifizieren. Realistische waldwachstumskundliche Szenariosimulationen setzen aber voraus, dass die Zusammenhänge realitätsnah beschrieben werden können, da ansonsten eine zu geringe Sensitivität gegenüber Managementmaßnahmen wie z. B. der Regulierung der Grundwasserflurabstände resultiert.

Ein Modellansatz, der in forstlichen Anwendungen häufig zur Modellierung unterschiedlicher Mortalitätsereignisse verwendet wird, ist der Regressionsansatz mit binärer Antwortvariable, d. h. ein Regressionsansatz bei dem die abhängige Variable nur die kategoriellen Ausprägungen „überlebend“ oder „gestorben“ annimmt. Dieser Ansatz eignet sich vor allem dann, wenn es darum geht, die Mortalität während eines konkreten Schadereignisses wie einem Wintersturm zu beschreiben (SCHMIDT et al. 2010). Der Ansatz ist weniger gut dazu geeignet, Zeitreihendaten wie sie z. B. in der WZE erhoben werden, zu beschreiben, da die Beobachtungen über der Zeit an ein und demselben Objekt nicht unabhängig voneinander sind. Grundsätzlich bestehen zwar Möglichkeiten, die zeitliche Abhängig- 
keit auch in binären Regressionsmodellen zu berücksichtigen, die Modellansätze sind dann allerdings deutlich komplizierter. Ein weiteres Problem bei der Modellierung von Zeitreihendaten tritt dadurch auf, dass in einem binären Regressionsmodell ein einheitliches Zeitintervall vorliegen muss, auf das sich die Beobachtungen „überlebend“ bzw. „gestorben“ beziehen. Diese Voraussetzung ist jedoch bezüglich forstlicher Datengrundlagen selten erfüllt.

Eine adäquate Methode zur Beschreibung von Mortalitätsereignissen, die in Zeitreihenuntersuchungen erfasst werden, ist die Überlebenszeitanalyse. Die in dieser Untersuchung verwendeten Weiserflächen und WZE-Punkte sind wiederholt aufgenommen worden, sodass es sich um Zeitreihendaten handelt, wenn auch die Aufnahmeintervalle sehr stark variieren. Durch die stark variierenden Aufnahmeintervalle kommen binäre Regressionsmodelle auch bei Berücksichtigung zeitlicher Abhängigkeiten für eine Modellierung nicht in Frage. Ein Modell zur Überlebenszeitanalyse auf der Basis der WZE in Rheinland-Pfalz wurde von STAUPENDAHL (2011) entwickelt. Allerdings standen in diesem Fall für die Modellbildung ausschließlich konstante Standortsparameter zur Verfügung, sodass ein parametrischer Modellansatz verwendet werden konnte, in dem angenommen wird, dass die Dichteverteilung der Überlebenszeiten einer Weibull-Verteilung folgt.

In der vorliegenden Untersuchung beinhalten die erfassten Zeitreihen unabhängige Variablen, die zeitabhängig sind. Beispielsweise verändern sich sowohl die BHD der erfassten Bäume als Folge des Dickenwachstums als auch die Flurabstände infolge unterschiedlicher Fördermengen, Niederschläge und Evapotranspirationsraten über der Zeit. Parametrische Modellansätze der Überlebenszeitanalyse kommen aber für die Modellierung nicht in Frage, wenn die Effekte zeitabhängiger Kovariablen geschätzt werden sollen.

Eine geeignete Methode zur Berücksichtigung zeitabhängiger Kovariablen in der Überlebenszeitanalyse basiert auf dem Cox-Proportional-Hazard-Regressionsmodell (COX 1972). Dieser Ansatz wird in der vorliegenden Untersuchung verwendet, wobei zusätzlich mit Hilfe penalisierter Regressionssplines überprüft wurde, ob die Effekte der unabhängigen Variablen nicht-linear sind.

Die Datengrundlage für die Ableitung des Mortalitätsmodells lieferten die Beobachtungsergebnisse der im Hessischen Ried im Rahmen der Forstökologischen Beweissicherung angelegten Weiserflächen der ehemaligen Hessischen Forsteinrichtungsanstalt, heute HESSEN-FORST FENA, die Beobachtungsflächen der jährlichen Waldzustandserhebung sowie die Versuchsflächen der NW-FVA im Hessischen Ried (s. Abb. 21). 


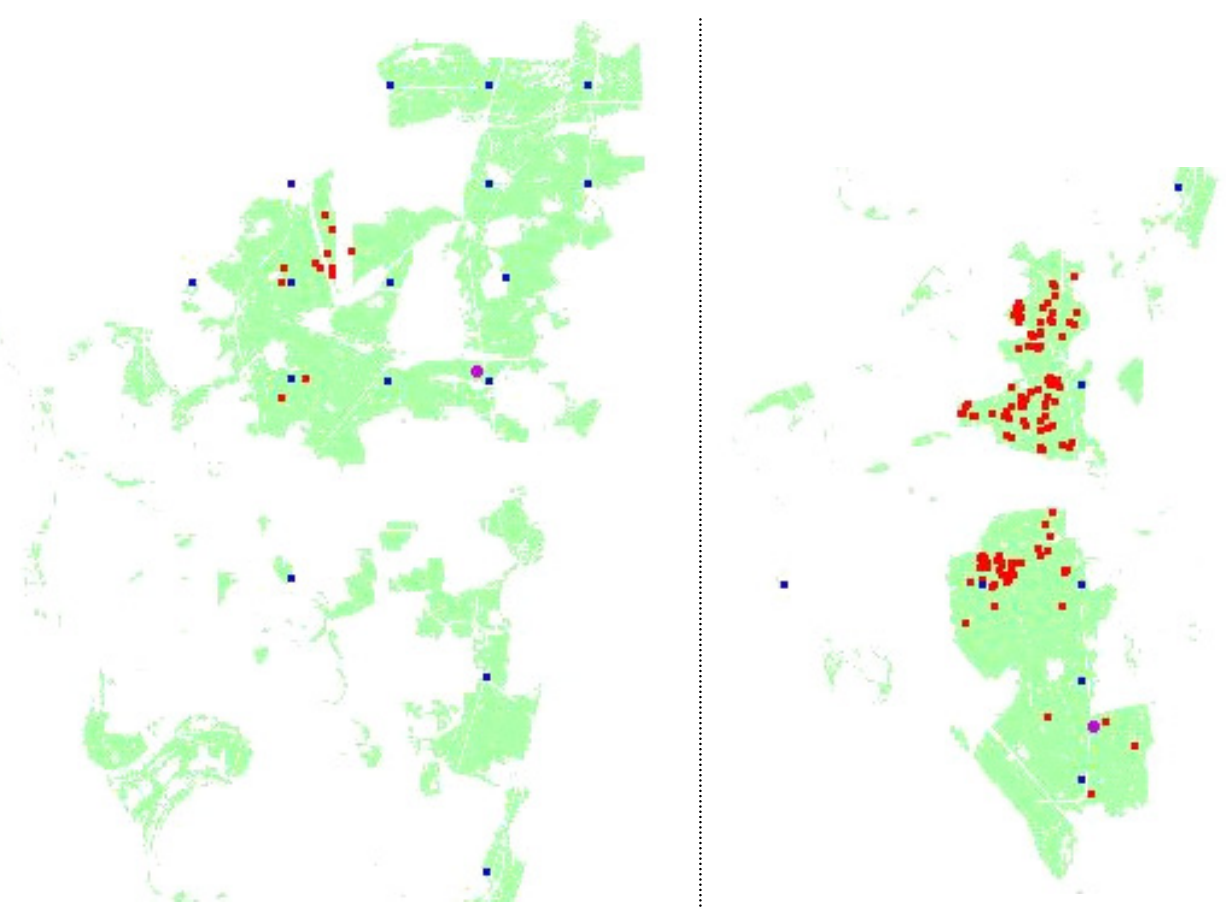

Abbildung 21: Lage der zur Parametrisierung des Mortalitätsmodells herangezogenen Untersuchungsflächen im Hessischen Ried (links: nördlicher Teil, rechts: südlicher Teil)

Die Datenaufbereitung für zeitabhängige Einflussgrößen erfolgte analog der Form, wie sie von FOX (2002) im Rahmen soziologischer Untersuchungen zur Rückfälligkeit von Häftlingen beschrieben wurde. Es wurde somit pro Baum und Beobachtungsintervall ein Datensatz mit allen potenziellen Kovariablen und seinem binären Status (lebendig bzw. tot) generiert.

Alle Bäume wurden als „lebend“ gekennzeichnet, sofern sie nicht wie folgt gekennzeichnet waren:

1. Den Status „,tot“ erhielten die Bäume, die in den Wiederholungsaufnahmen als tot bzw. abgestorben angesprochen wurden bzw. die in den WZE-Aufnahmen einen Nadelblattverlust von 100 Prozent aufwiesen.

2. Fehlende Bäume erhielten den Status „,tot“", wenn je Weiserfläche und Aufnahme nicht mehr als 5 Bäume fehlten. Diese Vorgehensweise basiert auf den örtlichen Erfahrungen, dass auf den Weiserflächen keine regulären Nutzungen, sondern nur noch Kalamitätsnutzungen stattfanden.

3. Bäume, die bei Durchforstungen entnommen wurden oder nach der Totastansprache mit der Klasse 5 (,abgestorben“ bzw. „zwischenzeitlich entnommen") belegt waren, wurden ebenfalls als „,tot" eingestuft. 
Als Zeitpunkt des Absterbens der Bäume wurde die Mitte der jeweiligen Beobachtungsperiode angenommen. Fehlten mehrere Bäume, konnte ein Nutzungseingriff nicht ausgeschlossen werden und diese Bäume behielten den Status „lebend“. Auch potenziell abgestorbene Bäume, die im Zuge von forstlichen Nutzungen auf den Weiserflächen ohne Vermerk ihres Status entnommen wurden, konnten nicht berücksichtigt werden und wurden weiterhin als „lebend“ gekennzeichnet. Einschläge auf den Weiserflächen und dabei vor allem die Entnahme stark geschädigter Bäume sind aus wissenschaftlicher Sicht als äußerst ungünstig zu bewerten, da dadurch Informationen (Absterben oder Erholung der Bäume in den nächsten Jahren) verloren gehen. Ebenfalls negativ einzuschätzen ist die Praxis, dass Flächen teilweise zu früh aus der Beobachtung entlassen wurden, wenn sie sich in Auflösung befunden haben. Aufgrund der forstlichen Eingriffe, der frühen Aufgabe einiger Flächen und der Unsicherheit bei der Zuordnung vieler fehlender Bäume kann davon ausgegangen werden, dass die Anzahl der beobachteten Ausfälle unterschätzt wird. Bäume, die fehlen, entnommen wurden oder von Windwurf betroffen sind, sind rechtszensierte Beobachtungen, d. h. sie werden bis zum Zeitpunkt ihres Ausscheidens mit dem Status „lebend“ geführt und führen anschließend lediglich zu einer Reduktion der Risikomenge. Wenn aber absterbende Bäume aufgrund von mangelnder Versuchssteuerung als rechtszensiert beschrieben werden müssen, weil ihre weitere Entwicklung nicht beobachtet wurde, führt das zu verzerrten, d. h. gerichtet falschen Schätzungen. Die genannten Gründe führen insgesamt zu einer wahrscheinlich eher konservativen Schätzung des Mortalitätsniveaus im Modell.

Für die Auswertungen wurde die Programmbibliothek survival (THERNEAU u. LUMLEY 2009) innerhalb des Statistik-Softwarepaketes $R$ genutzt (R DEVELOPMENT CORE TEAM 2010). Eine genaue Beschreibung der verschiedenen Analysemethoden von Überlebensdaten sowie die Möglichkeiten der Modellbewertung finden sich bei THERNEAU u. GRAMBSCH (2000).

Für die Baumarten Eiche, Buche und Kiefer wurden folgende baumartenspezifische Modelle entwickelt. Diese drei baumartenspezifischen Modelle beinhalten entsprechend der Modellselektion unterschiedliche Vektoren von unabhängigen Variablen (Formeln 13, 14 und 15). Einige der nicht-linearen Effekte wurden in einem zweiten Schritt durch Funktionen approximiert, die bestimmte Monotoniebedingungen gewährleisten, die aus Expertenwissen resultieren. Hierbei handelt es sich überwiegend um die Datenbereiche an den Rändern der Verteilungen der unabhängigen Variablen, die geringere Anzahlen von Beobachtungen umfassen. 


$$
\begin{aligned}
& \text { Kiefer: } S\left(t \mid x_{i j}\right)=f\left(B H D_{i j}, B H D_{\text {rel_ij }}, G_{j}, G W_{\text {ref_ii }}\right) \\
& \text { Eiche: } \mathrm{S}\left(\mathrm{t} \mid \mathrm{x}_{\mathrm{ij}}\right)=\mathrm{f}\left(\mathrm{BHD}_{\mathrm{ij}}, \mathrm{BHD}_{\text {rel_ij }}, \mathrm{GW}_{\mathrm{j}}, \mathrm{GW}_{\text {ref_ij }}, \mathrm{nFK}_{\mathrm{j}}, \mathrm{BS}_{\mathrm{j}}\right) \\
& \text { Buche: } \mathrm{S}\left(\mathrm{t} \mid \mathrm{x}_{\mathrm{ij}}\right)=\mathrm{f}\left(\mathrm{BHD}_{\text {rel_ij }}, \mathrm{GW}_{\mathrm{i}}, \mathrm{BS}_{\mathrm{j}}\right) \\
& \text { mit: } \\
& \mathrm{S}\left(\mathrm{t} \mid \mathrm{x}_{\mathrm{ij}}\right)=\text { Bedingte Überlebenswahrscheinlichkeit, dass ein Baum } i \text { auf der Weiser- } \\
& \text { fläche (WZE-Punkt) } j \text { mit dem Kovariablenvektor } \mathrm{x}_{\mathrm{ij}} \text { das Alter t erreicht } \\
& \mathrm{BHD}_{\mathrm{i}}=\text { Entwicklung des Brusthöhendurchmessers [mm] von Baum } i \text { auf der } \\
& \text { Weiserfläche (WZE-Punkt) } j \text { über dem Alter bis zum Alter t } \\
& \text { BHD }_{\text {rel_ } \mathrm{i}}=\text { Entwicklung des relativen Brusthöhendurchmessers von Baum } i \text { auf der } \\
& \text { Weiserfläche (WZE-Punkt) } j \text { über dem Alter bis zum Alter t } \\
& \mathrm{GW}_{\mathrm{ij}}=\text { Entwicklung des mittleren Grundwasserflurabstandes }[\mathrm{cm}] \text { auf der } \\
& \text { Weiserfläche (WZE-Punkt) } j \text { über dem Alter von Baum } i \text { bis zum Alter } \mathrm{t} \\
& \mathrm{GW}_{\text {ref_ij }}=\text { Referenzgrundwasserflurabstand [cm] auf der Weiserfläche (WZE-Punkt) } \\
& j \text { zum Zeitpunkt 1951. Liegt das Keimjahr des Baumes } i \text { nach 1921, so } \\
& \text { wird stattdessen der Flurabstand des Jahres verwendet, in dem der Baum } \\
& i \text { ein Alter von } 30 \text { erreicht. } \\
& \mathrm{nFK}_{\mathrm{j}}=\text { Nutzbare Feldkapazität [mm] für die Bezugstiefe } 140 \mathrm{~cm} \text { auf der Weiser- } \\
& \text { fläche (WZE-Punkt) } j \\
& \mathrm{BS}_{\mathrm{j}}=\text { Bodensubstratklasse [,Sand“, „Ton“, „lehmige Standorte“] auf der } \\
& \text { Weiserfläche (WZE-Punkt) } j
\end{aligned}
$$

Die soziale Stellung eines Baumes wird im Modell über das Verhältnis vom BHD zum Grundflächenmittelstamm $\left(\mathrm{BHD}_{\text {rel }}\right)$ erfasst. Die Altersentwicklung des Grundflächenmittelstammes wird mit einem Regressionsmodell beschrieben, dass anhand der Durchmessermessungen auf den Weiserflächen und WZE-Punkten parametrisiert wurde. Die Verteilung der unabhängigen Variablen $\mathrm{BHD}_{\text {rel }}$ weist für alle drei Baumarten eine große Spreitung auf (s. Tab. 15), sodass es bezüglich dieser Variablen nur selten zu Schätzungen im Extrapolationsbereich kommt, wenn die Modelle in Simulationen auf den gesamten Forsteinrichtungsdatensatz des Hessischen Rieds angewendet werden. Gleiches gilt für die Variable BHD in den Datensätzen für Eiche und Kiefer. 
Tabelle 15: Verteilungen der unabhängigen Variablen, die einen signifikanten Effekt auf die Überlebenswabrscheinlichkeiten von Kiefern, Eichen und Buchen im Hessischen Ried aufweisen

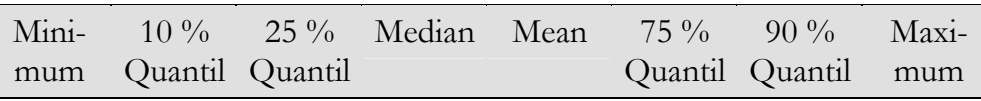

\section{Kiefer:}

Datensätze $=21.428$, Bäume $=6.655$, Flächenaufnahmen $=656$, Flächen $=75$

\begin{tabular}{lrrrrrrrr}
\hline BHD $[\mathrm{mm}]$ & 45 & 133 & 175 & 239 & 263 & 328 & 437 & 856 \\
BHD $_{\text {rel }}$ & 0,28 & 0,70 & 0,83 & 0,97 & 0,97 & 1,12 & 1,26 & 2,43 \\
GW $[\mathrm{cm}]$ & 40,0 & 147,8 & 175,7 & 442,2 & 497,0 & 555,5 & 1046 & 2313,0 \\
GW $_{\text {ref }}[\mathrm{cm}]$ & 107,0 & 145 & 309,0 & 674,0 & 562,2 & 674,0 & 862 & 1609,0 \\
\hline
\end{tabular}

\section{Eiche:}

Datensätze $=24.952$, Bäume $=6.014$, Flächenaufnahmen $=800$, Flächen $=122$

Substrat: Ton: $\mathrm{n}=178(5 \%)$, Sand: $\mathrm{n}=134(9 \%)$, lehmige Standorte: $\mathrm{n}=19.904(86 \%)$

\begin{tabular}{lrrrrrrrr}
\hline BHD [mm] & 60 & 177 & 233 & 307 & 325 & 400 & 500 & 961 \\
BHD $_{\text {rel }}$ & 0,35 & 0,75 & 0,86 & 1,01 & 1,04 & 1,18 & 1,39 & 2,75 \\
GW [cm] & 80,0 & 332,4 & 409,3 & 473,1 & 496,1 & 548,0 & 649,5 & 2313,0 \\
GW $_{\text {ref }}[\mathrm{cm}]$ & 79,0 & 144 & 184,0 & 218,0 & 250,5 & 254,0 & 279 & 1609,0 \\
nFK [mm] & 71 & 160 & 173 & 187 & 184 & 190 & 238 & 281 \\
\hline
\end{tabular}

\section{Buche:}

Datensätze $=7.386$, Bäume $=2.159$, Flächenaufnahmen $=532$, Flächen $=78$

Substrat: Ton: $\mathrm{n}=507(7 \%)$, Sand: $\mathrm{n}=1.047(14 \%)$, lehmige Standorte: $\mathrm{n}=5.832(79 \%)$

\begin{tabular}{lrrrrrrrr}
\hline BHD $_{\text {rel }}$ & 0,19 & 0,45 & 0,63 & 0,84 & 0,85 & 1,05 & 1,25 & 2,12 \\
GW [cm] & 40,0 & 303,3 & 406,6 & 496,2 & 589,8 & 587,0 & 1152,0 & 2313,0 \\
\hline
\end{tabular}

Die regionalisierten Grundwasserflurabstände wurden von der Firma BGS Umwelt, Darmstadt übernommen. Im Zeitraum von 1970 bis 2007, in dem die meisten Aufnahmen der Weiserflächen lagen, standen für 23 Jahre flächendeckende Grundwasserstände zur Verfügung, darunter für alle Jahre dieses Zeitraums mit besonders niedrigen (1976, 1993) oder besonders hohen Grundwasserständen (1988). Die Werte für fehlende Jahre (maximal zwei aufeinanderfolgende Jahre) wurden durch lineare Interpolation hergeleitet. Für jede Beobachtungsfläche wurde für den Zeitraum zwischen zwei Aufnahmen ein mittlerer Grundwasserstand berechnet.

Bei der Kiefer decken die Flurabstände GW einen großen Wertebereich ab, der auch oberflächennahe Flurabstände umfasst, während bei Eiche und Buche nur 10 Prozent der Datensätze Flurabstände von weniger als 3,5 bzw. 3,0 m aufweisen. Beim Referenzflurabstand $\mathrm{GW}_{\text {ref }}$ weisen dagegen sowohl bei der Kiefer als auch bei der Eiche immerhin 10 Prozent der Datensätze Flurabstände von weniger als 1,4 $\mathrm{m}$ auf. Die Variablen BHD und $\mathrm{GW}_{\text {ref }}$ weisen keinen zusätzlichen signifikanten 
Effekt auf die Überlebenswahrscheinlichkeit der Buche auf. Im Modell der Eiche weisen zusätzlich die nutzbare Feldkapazität (nFK) bis zu einer Bezugstiefe von 1,4 $\mathrm{m}$ und die Bodensubstratklasse BS signifikante Effekte auf. Im Buchenmodell ist zusätzlich die Bodensubstratklasse signifikant. Die Variable BS wird sowohl bei der Buche, vor allem aber bei der Eiche von der Klasse „lehmige Standorte“ dominiert, während auf „Sand“ und vor allem „Ton“ nur relative wenige Beobachtungen entfallen.

Bei der Beurteilung der umfangreichen Datengrundlage muss beachtet werden, dass die Beobachtungen geklumpt von relativ wenigen Flächen stammen, die nicht systematisch über das Ried verteilt sind (s. Abb. 21 u. Tab. 15). Somit sind trotz der breiten Spreitung der Datenbereiche bestimmte Variablenkombinationen nur schwach oder überhaupt nicht mit Beobachtungen belegt, sodass es bei der Anwendung auf das gesamte Ried in Simulationen zu Schätzungen im Extrapolationsbereich kommen kann.

Die Mischbaumarten, für die keine ausreichende Datenbasis für eine eigene Modellparametrisierung existiert, wurden gutachtlich der Kiefer, Eiche oder Buche zugeordnet (s. Tab. 16). Zusätzlich wurde vorhandenes Expertenwissen über die Robustheit der Baumarten dafür genutzt, die zugeordneten Überlebenswahrscheinlichkeiten mit gutachtlichen Korrekturfaktoren proportional zu verändern bzw. anzupassen.

Tabelle 16: Zuordnung der Baumarten, für die keine Modelle zur Beschreibung der Überlebenswabrscheinlichkeit parametrisiert werden Konnten, zu Kiefer, Eiche oder Buche und gutachtlich definierte Faktoren zur Modifikation der Überlebenswahrscheinlichkeiten

\begin{tabular}{lcc}
\hline Modell & Baumart & $\begin{array}{c}\text { Faktor für die Überlebenswahr- } \\
\text { scheinlichkeit }\end{array}$ \\
\hline Eiche & Robinie u. Birke & 1,2 \\
& Roteiche & 1,1 \\
\hline Buche & Linde u. Hainbuche & 1,5 \\
& Wal-, Schwarznuss u. Elsbeere & 1,4 \\
& Aspe, Eberesche u. Wildobst & 1,3 \\
& Ulme, Kirsche u. Esche & 1,2 \\
& Ahorn u. Kastanie & 1,1 \\
& Erle u. sonstige Laubhölzer & 0,8 \\
Piefer & Pappel u. Weide & 0,7 \\
& Schwarzkiefer & 1,0 \\
& Douglasie, Strobe u. Küstentanne & 0,9 \\
& Thuja, Tsuga u. Chamaecyparis & 0,8 \\
Lärche & 0,7 \\
& Fichte & 0,5 \\
\hline
\end{tabular}


Zur Darstellung der Modellsensitivität werden die Effekte der unabhängigen Variablen auf die Überlebenswahrscheinlichkeit graphisch beschrieben, die in der Modellselektion als signifikant identifiziert wurden. Der Identifikation und Quantifizierung des Effektes von Grundwasserabsenkungen kommt im Hessischen Ried eine besondere Bedeutung zu. Letztlich quantifiziert der vorgestellte Modellansatz jedoch die Überlebenswahrscheinlichkeit von Einzelbäumen in bewirtschafteten Beständen als Funktion der Gesamtrisikodisposition im Betrachtungszeitraum. Der Modellansatz beschreibt dabei die Effekte einiger im Datensatz zur Verfügung stehender Variablen, während die Effekte anderer nicht beobachteter Faktoren lediglich über das Gesamtrisikoniveau, das für die Baumart im Hessischen Ried typisch ist, erfasst werden.

Im Untersuchungsgebiet treten weitere Einflussfaktoren auf, für die negative Auswirkungen auf die Vitalität von Bäumen beschrieben wurden. Zu nennen sind hier abiotische Ursachen wie die Deposition von Ozon und Kerosin oder die Störung des Waldinnenklimas durch Zerschneidung der Waldkomplexe bei Baumaßnahmen. Zu den negativen biotischen Einflüssen, die im Hessischen Ried eine größere Rolle spielen, sind u. a. die Fraßschäden durch diverse Insekten (z. B. Schwammspinner, „Eichen-Fraßgesellschaft“, Kiefernspinner, Engerlinge der Blatthornkäfer) sowie der Befall mit Misteln und diversen Pilzen zu zählen (SCHWERDTFEGER 1981). Diese in der Praxis durchaus relevanten Risikofaktoren konnten aufgrund fehlender Daten nicht für die Modellparametrisierung berücksichtigt werden.

Neben den abstrakten Modelleffekten, die eine qualitative Interpretation zulassen, werden exemplarische Modellschätzungen dargestellt. Um den Einfluss der einzelnen unabhängigen Variablen zu verdeutlichen, gehen die weiteren im Modell enthaltenen Variablen mit konstanten Werten in die Schätzung ein. Bei der Interpretation muss beachtet werden, dass die Effekte auf die Mortalität immer gleichzeitig mit den Effekten der übrigen unabhängigen Variablen wirken.

\subsection{BHD und $\mathrm{BHD}_{\text {rel }}$}

Der Durchmesser eines Baumes, gemessen in Brusthöhe $(1,3 \mathrm{~m})$, stellt u. a. ein $\mathrm{Maß}$ für die ertragsgeschichtliche Verfügbarkeit wachstumsrelevanter Ressourcen dar und ist zusätzlich ein Maß für die genetisch bestimmte Konkurrenzkraft des Baumes. Mit der Zunahme des Alters ist auch eine Zunahme des BHD bei gleichzeitig abnehmender Stammzahl verbunden, was zu veränderten Risikodispositionen (Vulnerabilität) und damit Überlebensraten führt. Beispielsweise nimmt die Sturmschadensgefährdung mit steigendem BHD bzw. steigender Baumhöhe im Mittel zu. Die BHD-Entwicklung eines Baumes kann dabei nicht unabhängig von der sozialen Stellung eines Baumes im Bestandeskollektiv betrachtet werden. Beide Variablen sind untereinander korreliert und in der Modellselektion stellte sich heraus, dass der $\mathrm{BHD}_{\text {rel }}$ einen größeren Effekt auf die Mortalität als der BHD aufweist. Die BHD-Entwicklung über dem Alter wurde daher in Relation zur 
mittleren Altersentwicklung des Grundflächenmittelstammes im Hessischen Ried beschrieben (s. Abb. 22). Die schwarze Linie bildet dabei die erwartete Überlebenswahrscheinlichkeit für einen Baum ab, dessen BHD-Entwicklung exakt derjenigen des Grundflächenmittelstammes folgt. Die grüne Linie beschreibt die Überlebenswahrscheinlichkeit für einen Baum, dessen BHD-Entwicklung 130 Prozent, und die rote Linie für einen Baum, dessen BHD-Entwicklung 70 Prozent der Entwicklung des Grundflächenmittelstammes beträgt. Für die weiteren Einflussgrößen wurden die Bodensubstratklasse „lehmige Standorte“, eine nutzbare Feldkapazität von $190 \mathrm{~mm}$ bei einer Bezugstiefe von $140 \mathrm{~cm}$ und ein Flurabstand von jeweils $2 \mathrm{~m}$ für den Referenzzustand $\mathrm{GW}_{\text {ref }}$ und die Zeitreihe der Flurabstände GW unterstellt. Anhand der prognostizierten Überlebensfunktionen wird deutlich, dass die Mortalität mit sinkendem BHD rel bzw. abnehmender sozialer Stellung zunimmt. Die Schichtung der Überlebensfunktionen verdeutlicht die Nicht-Linearität

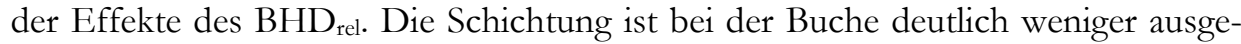
prägt als bei den Lichtbaumarten Kiefer und vor allem Eiche.

Die abstrakten Modelleffekte des $\mathrm{BHD}_{\text {rel }}$ sind für alle drei Baumarten über den gesamten Wertebreich monoton fallend, wenn man von dem Bereich unterhalb von 0,5 bei der Kiefer absieht (s. Abb. 23). Zusätzlich zu den originalen Effekten (rote Linie) sind die zugehörigen 95-Prozent Konfidenzintervalle sowie die Verläufe der Approximierungen der originalen Effekte dargestellt, sofern eine Approximierung erfolgte. Der Effekt des BHD ist für die Eiche ebenfalls monoton fallend (s. Abb. 8), sodass die Überlebenswahrscheinlichkeit bei gleichbleibender sozialer Stellung, d. h. konstantem BHD rel mit steigendem BHD stetig ansteigt. Dagegen weist der Verlauf für die Kiefer ein Minimum bei ca. $25 \mathrm{~cm}$ auf (s. Abb. 23). Eventuell kann die erhöhte Mortalität starker Kiefern auch als Effekt des starken Mistelbefalls im Hessischen Ried interpretiert werden. 
Kiefer

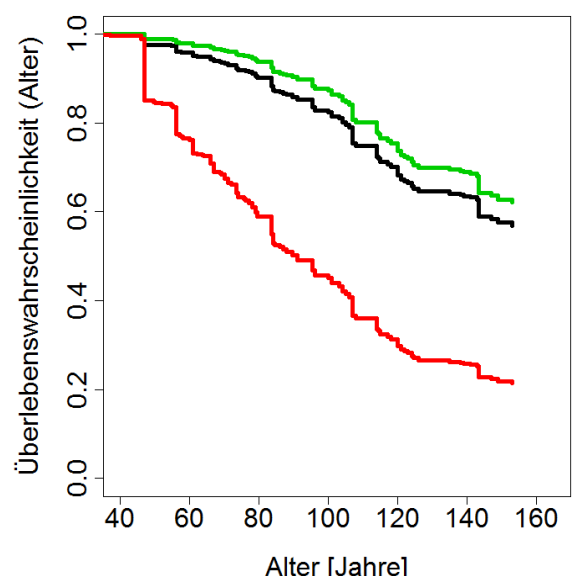

Buche

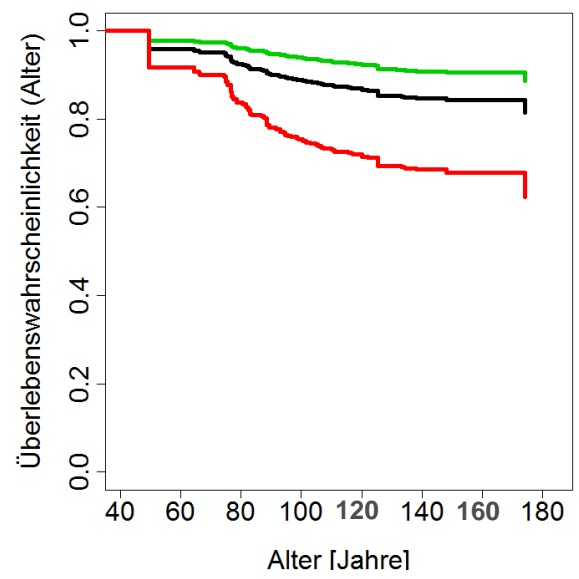

Eiche

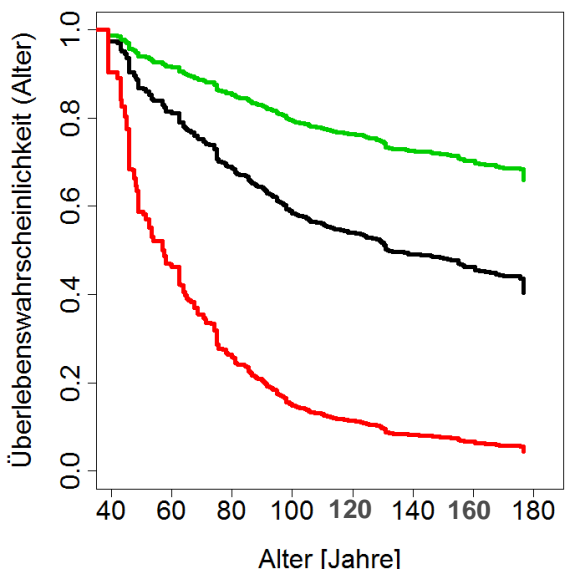

Abbildung 22: Mittlere Überlebenswahrscheinlichkeit von Kiefer, Eiche und Buche im Hessischen Ried bei durchschnittlicher BHD-Entwicklung entsprechend der mittleren Altersentwicklung des Grundflächenmittelstammes im Hessischen Ried (schwarze Linie). Zusätzlich sind die prognostizierten Verläufe von Bäumen dargestellt, deren BHD-Entwicklung $130 \%$ (grüne Linie) bzw. $70 \%$ (rote Linie) des mittleren Verlaufes entspricht. Für die weiteren Einflussgrößßen wurde die Bodensubstratklasse „lebmige Standorte", eine nutz̨bare Feldkapazität von 190 mm und ein Flurabstand von jeweils 2 m für den Referenzzustand GW ref und die Zeitreibe der Flurabstände GW unterstellt, wobei je nach Baumart unterschiedlich viele Variablen in die Modellschätrung eingehen. 


\section{Kiefer}
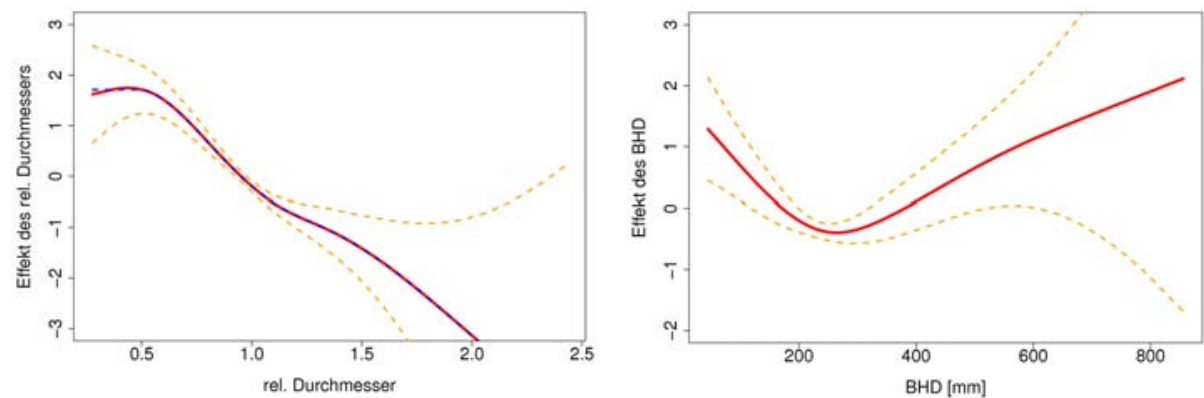

Eiche
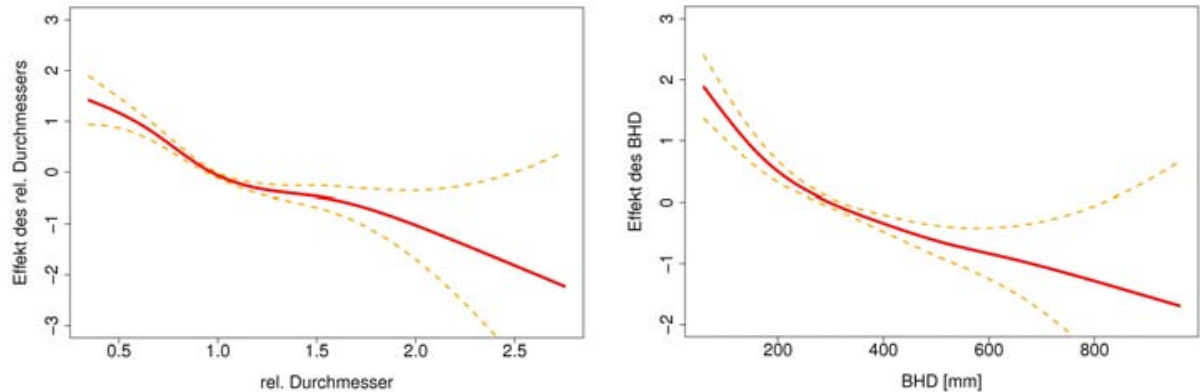

Buche

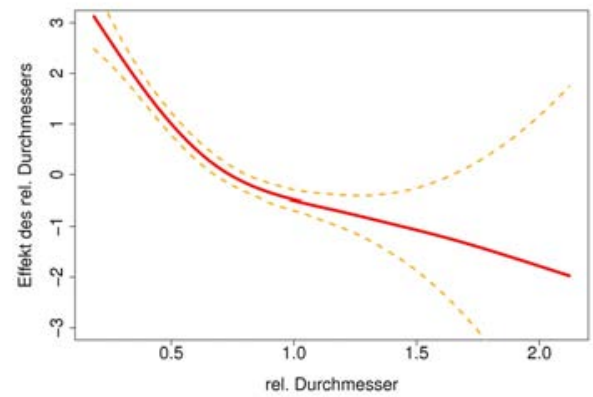

Abbildung 23: Abstrakte Modelleffekte des BHDrel und des BHD (Kiefer und Eiche) auf die Überlebenswahrscheinlichkeit von Kiefer, Eiche und Buche. $95 \%$-Konfidenzintervalle sind durch orange-gestrichelte Linien dargestellt.

\subsection{Bodensubstratklasse}

Eine Charakterisierung des Bodens wurde, in Anlehnung an das StandortsLeistungs-Modell, anhand der Profilbeschreibungen der Feinsubstratkartierung für die oberen $140 \mathrm{~cm}$ eines Standortes vorgenommen. Als geeignet stellte sich die Einteilung in die Bodesubstratklassen reine Sande, Standorte mit hohem Tonanteil und lehmige Standorte heraus. Für die Kiefer, die in den Beobachtungsflächen der Datengrundlage fast ausschließlich auf Sandstandorten stockt, ließ sich kein Effekt 
des Bodensubstrats nachweisen. Die Eiche reagierte auf schweren tonigen Böden mit der höchsten und auf leichten sandigen Böden mit der geringsten Mortalität (s. Abb. 24 und 25). Dagegen ist die Buche auf den Sandstandorten am anfälligsten. Auf den tonigen Substraten weist die Buche eine mittlere und auf den lehmigen Standorten die geringste Sterblichkeit auf (s. Abb. 24), wobei sich diese Effekte nicht signifikant unterscheiden (s. Abb. 25).

Eiche

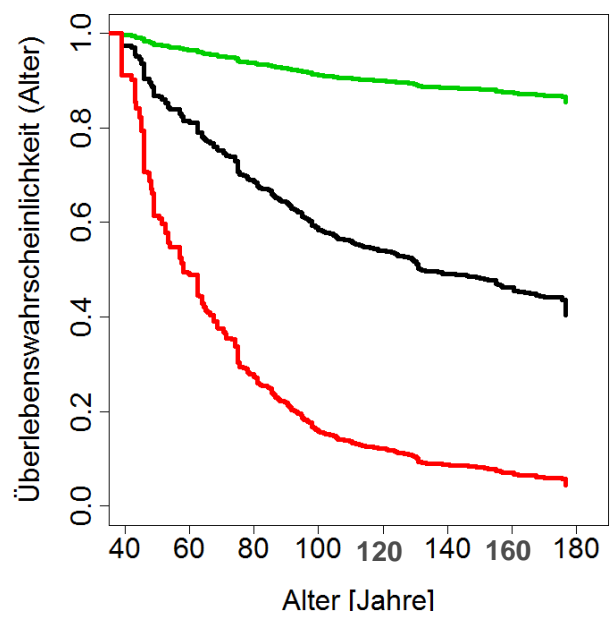

Buche

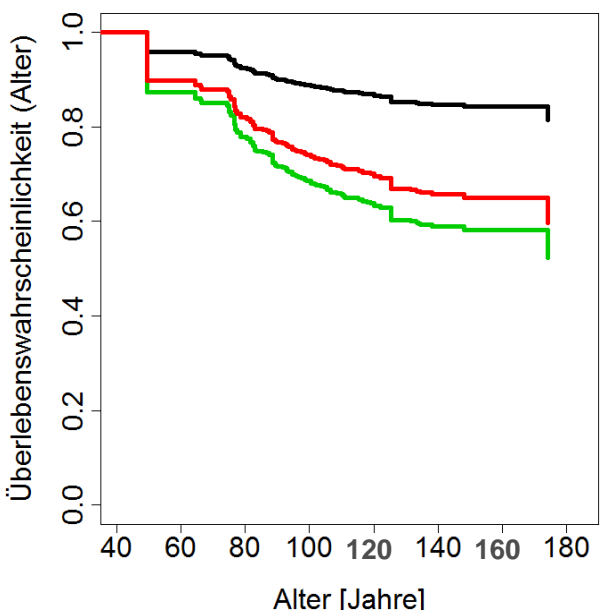

Abbildung 24: Mittlere Überlebenswahrscheinlichkeit von Eiche und Buche im Hessischen Ried bei durchschnittlicher BHD-Entwicklung auf lehmigen Standorten (schwarze Linie), auf tonigen Standorten (rote Linie) mit einer $n F K$ von jeweils $190 \mathrm{~mm}$ und auf reinen Sanden (grüne Linie) mit einer $n F K$ von $100 \mathrm{~mm}$. Die Flurabstände weisen einheitlich Werte von 2 m für die Referenz GWref und die Zeitreihe der Flurabstände GW auf.

\section{Eiche}

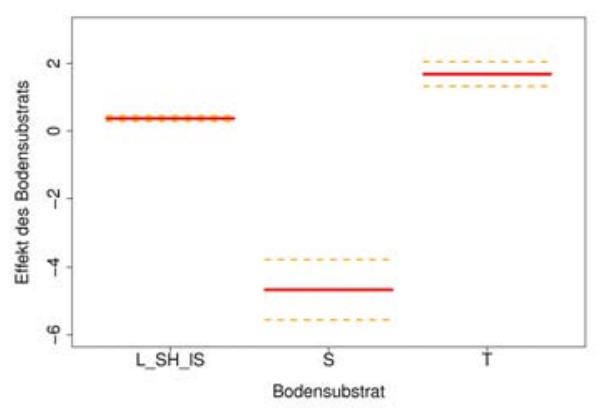

Buche

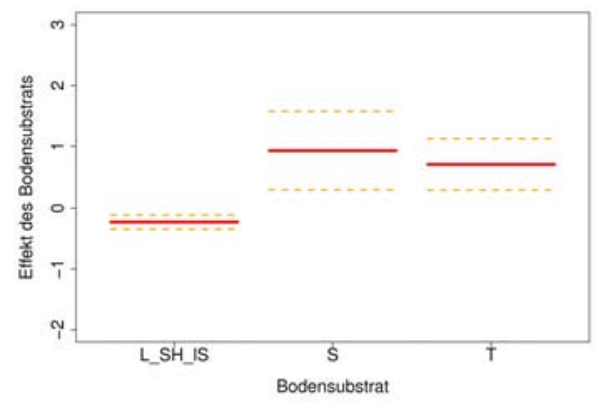

Abbildung 25: Abstrakte Modelleffekte der Bodensubstratklassen auf die Überlebenswahrscheinlichkeit von Eiche und Buche. $95 \%$-Konfidenzintervalle sind durch orange-gestrichelte Linien dargestellt. 


\subsection{Nutzbare Feldkapazität (nFK)}

Die nFK kennzeichnet die Wasserspeicherfähigkeit eines Bodens. Die Berechnung der nFK erfolgte in Anlehnung an die Charakterisierung des Bodens ebenfalls bis zu einer Tiefe von $140 \mathrm{~cm}$. Da die Werte der nFK für die sandigen Böden um den Wert $100 \mathrm{~mm}$ und für die tonigen Böden um den Wert $190 \mathrm{~mm}$ relativ schwach variieren, führt der Effekt der nFK hauptsächlich zu einer Abstufung der lehmigen Standorte. Die nFK wies nur für die Eiche einen signifikanten Effekt auf. Je höher die $\mathrm{nFK}$ ist, umso geringer ist die prognostizierte Mortalität der Eichen bei ansonsten konstanten Einflussgrößen (s. Abb. 26).
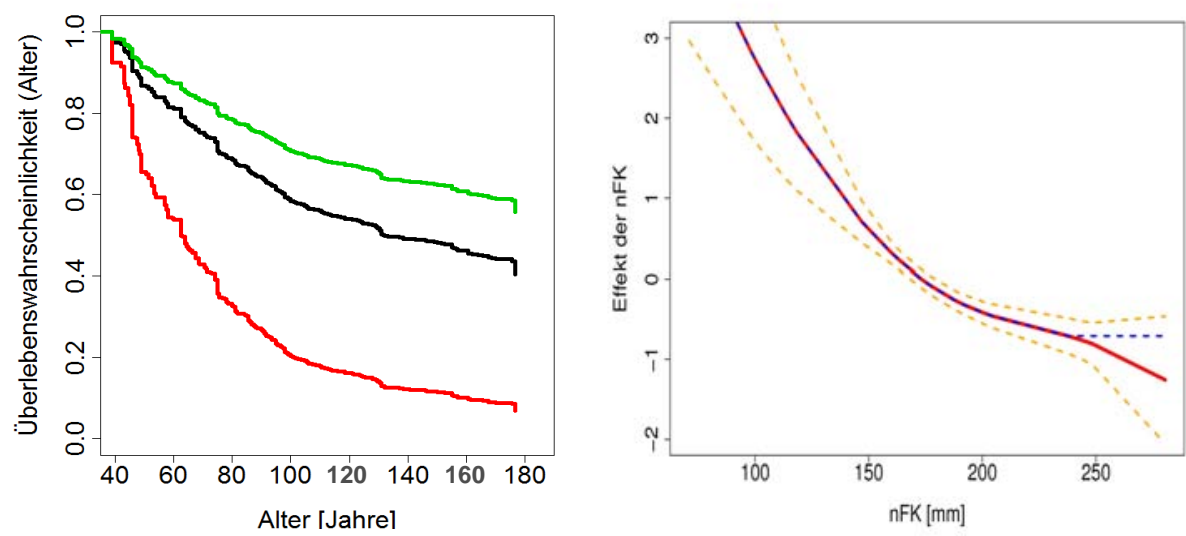

Abbildung 26: Links: Mittlere Überlebenswabrscheinlichkeit der Eiche im Hessischen Ried bei durchschnittlicher BHD-Entwicklung auf lehmigen Standorten und Flurabständen von 2 m für die Referenz GWref und die Zeitreihe der Flurabstände GW bei einer nFK von $140 \mathrm{~mm}$ (rote Linie), von 190 mm (schwarze Linie) und von 240 mm (grüne Linie).

Rechts: Abstrakter Modelleffekt der $n F K$ auf die Überlebenswahrscheinlichkeit der Eiche im Hessischen Ried. Das $95 \%$-Konfidenzintervall ist durch orange-gestrichelte Linien dargestellt.

\subsection{Grundwasserstand}

Die stark erhöhte Mortalität im Hessischen Ried wurde immer wieder mit der Absenkung der Grundwasserstände in Zusammenhang gebracht, ohne dass diese Hypothese bisher mit Hilfe quantitativer Methoden überprüft worden wäre. In den Überlebenszeitanalysen wurde jetzt erstmals ein signifikanter Effekt des Flurabstandes, der als zeitveränderliche Kovariable bzw. als Zeitreihe in die Parametrisierung eingeht, identifiziert (s. Abb. 27). 
Kiefer

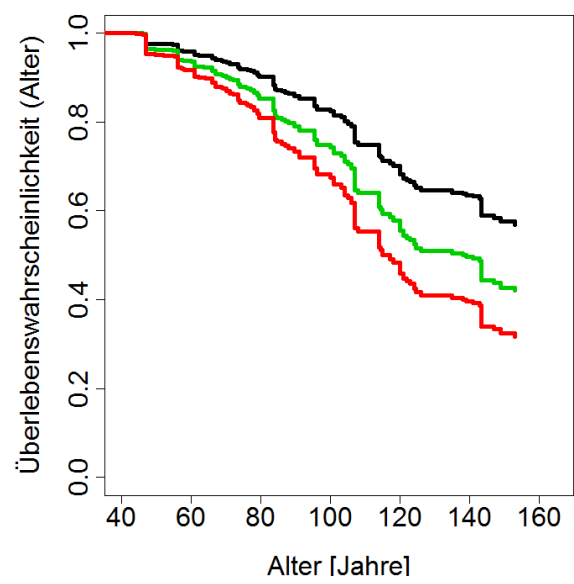

Buche

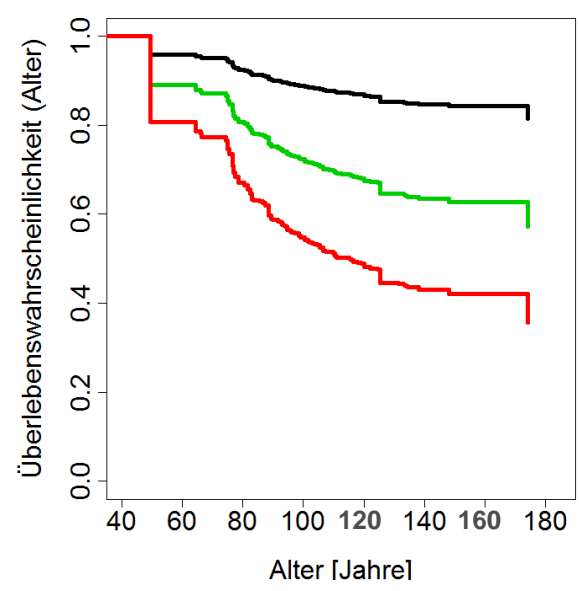

Eiche

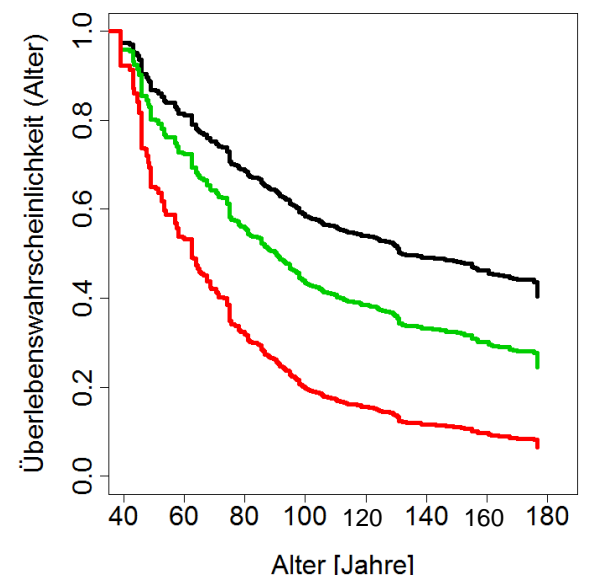

Abbildung 27: Mittlere Überlebenswahrscheinlichkeit von Kiefer, Eiche und Buche im Hessischen Ried bei durchschnittlicher BHD-Entwicklung und variierenden Zeitreihen der Flurabstände von $2 m$ (schwarze Linie), $4 m$ (grüne Linie) und $6 m$ (rote Linie). Für die weiteren Einflussgrößen wurde die Bodensubstratklasse „lehmige Standorte", eine nutzbare Feldkapazität von 190 mm und ein Flurabstand von 2 m für den Referenzzustand GW ref unterstellt, wobei je nach Baumart unterschiedliche V ariablen in die Modellschätrung eingehen.

Bei Kiefer und Eiche steigt die Mortalität aufgrund des nicht-linearen Effektes bis zu etwa 6-7 m unter Flur deutlich an, wobei die Steigung des Effektes ab ca. $5 \mathrm{~m}$ unter Flur bei beiden Baumarten degressiv nachlässt (s. Abb. 28). Abgesehen vom Bereich extrem geringer Flurabstände ist das Konfidenzintervall in diesem Bereich sehr eng, sodass der Effektverlauf als hochsignifikant beurteilt werden kann. Letzt- 
lich können aber Störeffekte nicht erfasster Einflussgrößen wie bei allen übrigen Modelleffekten nicht ausgeschlossen werden. Die Buche weist bis zu einem Flurabstand von ca. $8 \mathrm{~m}$ einen grundsätzlich ähnlichen Effektverlauf auf, wobei die Unsicherheit der Schätzung aufgrund der geringeren Datengrundlage deutlich höher ist (s. Abb. 28). Die sinkenden Verläufe im Bereich extrem großer Flurabstände für alle Baumarten weisen aufgrund der geringen Datenumfänge sehr große Unsicherheiten auf, sodass die unplausiblen Verläufe als Artefakte bzw. als Resultat von Störeffekten interpretiert werden. Für alle drei Baumarten wurden daher die originalen Effekte so approximiert, dass die Effekte ab bestimmten Grenzwerten konstant auf dem erreichten Niveau verlaufen (s. Abb. 28).

Kiefer

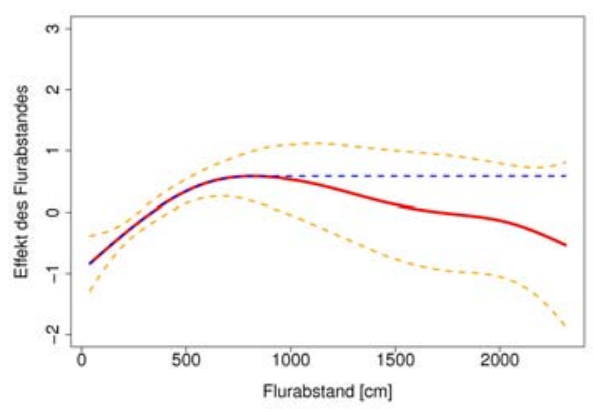

Buche

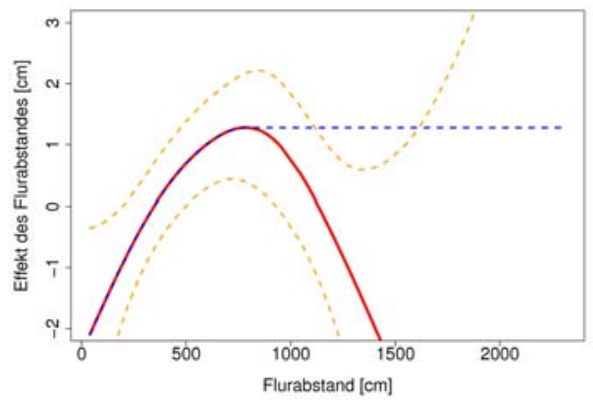

Eiche

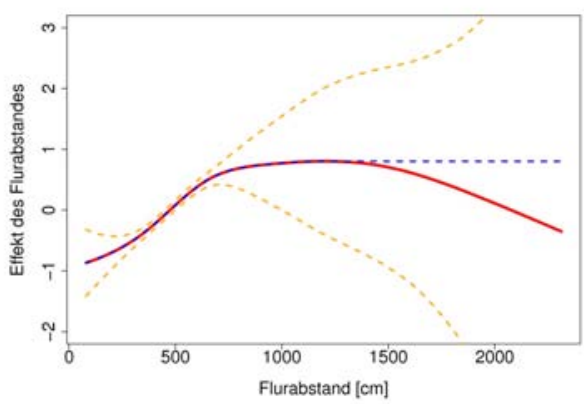

Abbildung 28: Abstrakte Modelleffekte des Flurabstandes auf die Überlebenswahrscheinlichkeit von Kiefer, Eiche und Buche. $95 \%$-Konfidenzintervalle sind durch orange-gestrichelte Linien und Approximierungen der originalen Effekte durch blau-gestrichelte Linien dargestellt.

\subsection{Grundwasserstand zum Referenzzeitpunkt}

Für Kiefer und Eiche wird die Mortalität nicht nur durch die Zeitreihe der Flurabstände im Beobachtungszeitraum bestimmt, sondern auch durch den Flurabstand zu einem Referenzzeitpunkt. Dieser Effekt kann dahingehend interpretiert werden, dass Grundwasserabsenkungen besonders in den Bereichen zu einer erhöhten 
Mortalität führen, die durch ehemals geringe Flurabstände gekennzeichnet waren. Den Ausführungen von ZANGER (1998) ist zu entnehmen, dass es im Hessischen Ried immer wieder Bemühungen zur Entwässerung gab. Die ersten nennenswerten Grundwasserabsenkungen erfolgten Mitte der 1960er-Jahre. Daher wurden die Grundwasserstände des Jahres 1951 als Referenzwert für alle Bestände festgelegt, deren Hauptbaumart zu diesem Zeitpunkt 30 Jahre oder älter war. Für jüngere Bestände ist anzunehmen, dass sie sich teilweise an geänderte Umweltbedingungen anpassen können und ihnen wurde daher als Referenzwert der Grundwasserstand des Jahres zugeordnet, indem sie 30 Jahre alt waren. Die Festlegung der Altersgrenze von 30 Jahren beruht auf Beobachtungen der Praktiker vor Ort. Sie beschreiben, dass viele Bestände im Alter zwischen 20 und 30 Jahren in ihrer juvenilen Wachstumsdynamik nachlassen und sich dann standörtliche Differenzen in Wachstum und Mortalität bemerkbar machen (GRÜNEKLEE, mündl. Mitteilung).

Der Effekt des Referenzflurabstandes führt bei der Kiefer dazu, dass sowohl Standorte mit ehemals geringen Flurabständen als auch Standorte, die schon immer grundwasserfern waren, eine erhöhte Mortalität aufweisen (s. Abb. 29 und 30).
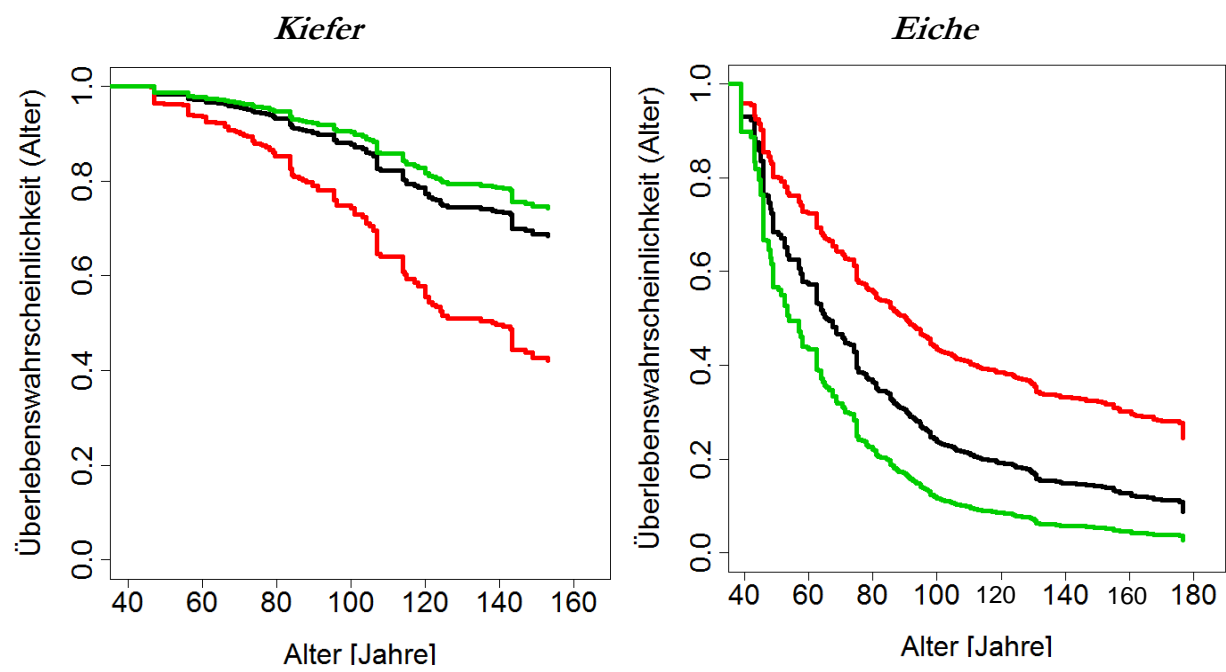

Abbildung 29: Mittlere Überlebenswahrscheinlichkeit von Kiefer und Eiche im Hessischen Ried bei durchschnittlicher BHD-Entwicklung auf lebmigen Standorten mit einer $n F K$ von 190 mm, einem aktuellen Grundwasserstand von $4 \mathrm{~m}$ unter Flur und einem Grundwasserstand im Referenzjabr von $2 m$ (rote Linie), von 4 m (schwarze Linie) sowie von 6 m (grïne Linie) unter Flur

Die geringste Mortalität tritt etwa im Bereich von 5-6 m auf (s. Abb. 30). Für die Kiefer scheint sich damit die Hypothese zu bestätigen, dass ältere Bestände auf grundwassernahen Standorten nicht mehr auf eine Grundwasserabsenkung reagie- 
ren können, während Bestände mit mittleren Referenzflurabständen weniger betroffen sind. Der erneute Anstieg der Mortalität für Standorte, die schon immer grundwasserfern waren (s. Abb. 30), lässt sich mit diesem Interpretationsansatz allerdings nicht erklären. Vielmehr muss angenommen werden, dass diese grundwasserfernen Standorte aufgrund anderer unbekannter Einflüsse eine erhöhte Mortalität aufweisen. Bei der Eiche lässt sich die Hypothese der größeren Anfälligkeit auf ehemals grundwassernahen Standorten kaum bestätigen. Zwar weisen ehemals sehr grundwassernahe Standorte eine höhere Mortalität auf als Standorte mit einem Referenzflurabstand von $2 \mathrm{~m}$. Aber bereits ab einem Referenzflurabstand von 2,20 m steigt die Mortalität in Richtung grundwasserferner Standorte bereits wieder an (s. Abb. 29 und 30).

Kiefer

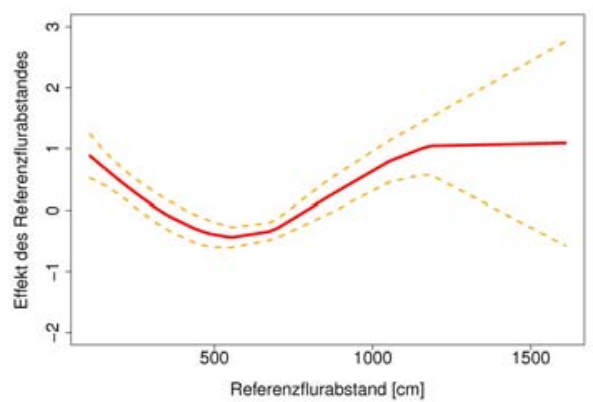

Eiche

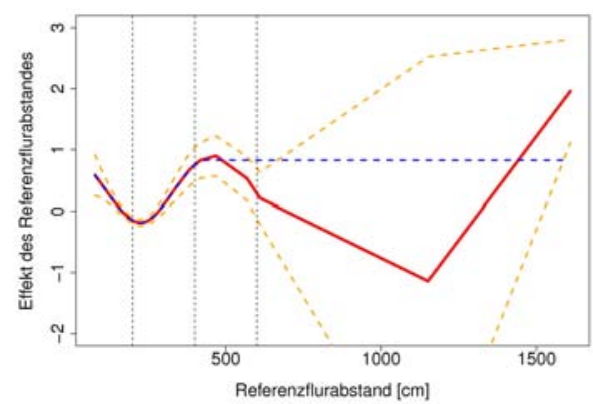

Abbildung 30: Abstrakte Modelleffekte des Flurabstandes im Referenzjahr auf die Überlebenswahrscheinlichkeit von Kiefer und Eiche. $95 \%$-Konfidenzintervalle sind durch orangegestrichelte Linien und Approximierungen der originalen Effekte durch blau-gestrichelte Linien dargestellt.

\subsection{Witterung}

Die Überprüfung, inwieweit die jährliche Witterung einen Effekt auf die Mortalität hat, erfolgte mit einem reduzierten Datensatz, in dem nur Aufnahmen mit einem Aufnahmeintervall von maximal drei Jahren berücksichtigt wurden. Diese Einschränkung stellt einen Kompromiss dar, da für derartige Untersuchungen eigentlich eine jährliche Auflösung notwendig erscheint. Die ausschließliche Verwendung von Daten mit einjährigem Aufnahmeintervall hätte jedoch zu einer sehr starken Reduktion des Datenumfanges geführt. Bei mehrjährigen Aufnahmeintervallen müssen die Jahreswerte, die die jährliche Witterung beschreiben, gemittelt werden, sodass es zu einer Nivellierung kommt. Diese Nivellierung erscheint bei einer sehr variablen Einflussgröße wie der jährlichen Witterung deutlich problematischer als bei den ebenfalls zeitabhängigen Größen BHD, BHD ${ }_{\text {rel }}$ und Flurabstand GW. Zusätzlich treten Probleme bei der Verwendung von zeitlich versetzten Berechnungszeiträumen auf, wenn die Effekte der Vorjahreswitterung auf die aktuelle Mortalität überprüft werden sollen. 
Für die Analyse der Effekte der Witterung wurde zunächst der Ariditätsindex nach DE MARTONNE (1926) für die Vegetationszeit berechnet (HMULF 2002). In einer zweiten Variante erfolgte die Berechnung des Indexes für das ganze Jahr, um darüber hinaus zu berücksichtigen, wie weit der Bodenwasserspeicher zum Beginn der Vegetationszeit aufgefüllt war. Als dritte Variante wurden die Werte von drei aufeinanderfolgenden Jahren gemittelt, um zeitlich versetzte Effekte auf die Mortalität zu überprüfen. Bei der dritten Variante wurden für einjährige Aufnahmeintervalle die zwei vorhergehenden Jahre und für zweijährige Aufnahmeintervalle ein zusätzliches vorhergehendes Jahr berücksichtigt. Bei dreijährigen Aufnahmeintervallen wurde über die drei Bezugsjahre gemittelt.

Die Schätzungen aus den Modellen ohne Witterungseinfluss (Formeln 13, 14 und 15) gingen als sogenanntes „offset“ in die Parametrisierung ein, um die Modelleffekte aus diesen Modellen zu berücksichtigen. Keine der geprüften Varianten führte zu einer signifikanten Verbesserung des Mortalitätsmodells.

\subsection{Maikäferdichte}

Eine Datengrundlage, die das Vorkommen und die Dichte von Maikäferengerlingen auf den einzelnen Beobachtungsflächen im zeitlichen Verlauf der letzten 30 Jahre quantitativ beschreibt, war nicht verfügbar. Geprüft wurde deshalb die Annahme, dass auf Flächen, auf denen nach Regionalisierung der Ergebnisse der Engerlingsgrabung 2009 hohe Maikäferdichten geschätzt wurden, auch zu früheren Zeitpunkten hohe Engerlingsdichten vorlagen und zu einer erhöhten Mortalität führten. Diese Hypothese konnte nicht bestätigt werden.

\subsubsection{Bestandesdichte}

Es wurde der Hypothese nachgegangen, dass die Bestandesdichte bzw. der Bestockungsgrad einen Effekt auf die Mortalität hat. Für geringe Bestockungsgrade als Ergebnis vorhergehender Absterbeereignisse, starker Durchforstungseingriffe oder von Windwurf wurde eine erhöhte Mortalität aufgrund eines gestörten Waldgefüges und Waldinnenklimas angenommen. Auch in überbestockten Beständen wurde eine höhere Mortalität insbesondere des Unterstandes angenommen, wobei die Trennung zwischen einer dichtebedingten Mortalität und anderen Schadursachen schwierig erscheint. Die Auswertungen ergaben keinen signifikanten Zusammenhang zwischen dem Bestockungsgrad und der Überlebenswahrscheinlichkeit der Bäume.

\subsubsection{Maikeäfer-Mortalitäts-Modell}

Grundlage für die Entwicklung eines Maikäfer-Mortalitäts-Modells bildeten die im Jahr 2009 auf einem 500 x 500 Meter-Raster durchgeführten Engerlingsgrabungen der NW-FVA. Insgesamt erfolgte die Feldaufnahme an 1.222 Rasterpunkten, wobei von jedem Rasterpunkt ausgehend in zehn Metern Abstand in den Haupthimmelsrichtungen je eine Grabung durchgeführt wurde (s. Abb. 31). In der 
Summe ergaben sich somit 4.888 Einzelgrabungen. Da aufgrund von Bebauungen, Verkehrsinseln, Mooren usw. einige Grabungen nicht durchgeführt werden konnten, verblieben letztendlich 4.871 Erhebungen. Jede Grabung hatte eine Fläche von 50 mal 50 Zentimetern und wurde mindestens bis zu einer Tiefe von 70 Zentimetern ausgehoben. Der gesamte Bodenaushub wurde sorgfältig nach Waldmaikäfern durchsucht. Je Waldmaikäferfund wurde das Entwicklungsstadium (Engerlingsstadium eins bis drei, Puppe, Imago), der Gesundheitszustand und die Tiefe des ersten Fundes protokolliert.

Die dabei erhaltenen Dichtewerte für das dritte Engerlingsstadium (E3-Stadium) wurden über ein generalisiertes additives Modell (GAM) flächenhaft interpoliert und unter Berücksichtigung von Grundwasserständen und Bodensubstraten in einer Auflösung von $100 \times 100$ Metern regionalisiert. Die regionalisierten Engerlingsdichten wurden in ein GridASCII-Format überführt. Im WaldPlaner wurden die Rasterzellenwerte (Engerlingsdichten) dieser Grids mit den Bestandespolygonen verschnitten und die mittlere Dichte je Bestand berechnet. Die räumliche Verteilung und Dichte der Maikäfer während der Laufzeit der Simulation war statisch, da eine flächige Grabungszeitreihe als Grundlage für eine Dynamisierung nicht vorlag.
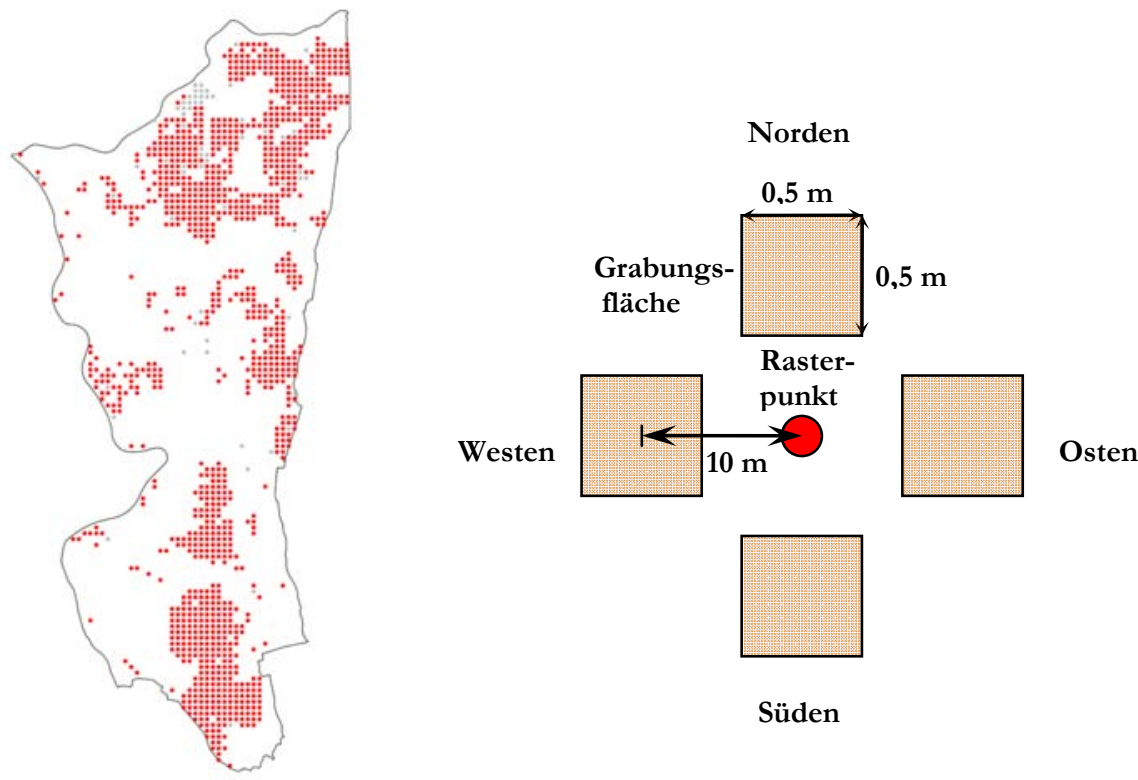

Süden

Abbildung 31: Links: Lage der Rasterpunkte der Engerlingsgrabungen 2009 im Untersuchungsgebiet (rot: Grabung erfolgt, grau: keine Grabung erfolgt); rechts: Systematik der Grabung an den Rasterpunkten 


\subsection{Modellierung der Engerlingsdichten}

Bei den Engerlingsdichten handelt es sich um Zähldaten, die nur ganzzahlige positive Werte annehmen können. In der Regel sind diskrete Verteilungsfunktionen, die spezielle Eigenschaften von Zähldaten berücksichtigen, am besten für die Modellierung geeignet. Nur in Fällen, in denen geringe Anzahlen mit wenigen Ausprägungen auftreten, können mehrkategoriale Regressionsmodelle eine Alternative sein (FAHRMEIR et al. 2007).

Bei der Modellselektion wurde deutlich, dass die Engerlingsdichten eine hohe räumliche Autokorrelation aufweisen, sodass spezielle Methoden der räumlichen Statistik verwendet werden müssen. Eine Nichtberücksichtigung dieser Abhängigkeiten würde einerseits elementare Annahmen der Regressionsanalyse verletzen und gleichzeitig in einer deutlich geringeren Prognosegüte resultieren.

Verallgemeinerte additive Modelle unter Verwendung der speziellen Methodik von WOOD (2006) bieten die Möglichkeit, räumlich korrelierte Daten zu modellieren, auch wenn die abhängige Variable, wie in diesem Fall, nicht normalverteilt ist. Die Methodik von WOOD steht innerhalb der Statistiksprache zur Verfügung. Die Methodik erlaubt als Verteilungsannahme sowohl die Verteilungsfunktionen der Exponentialfamilie (FAHRMEIR et al. 2007) als auch die negative Binomialverteilung, wobei in diesem Fall auch die Möglichkeit besteht, den Dispersionsparameter $\phi$ zu schätzen. Die räumlichen Abhängigkeiten werden dabei über 2-dimensionale glättende Splinefunktionen, d. h. über eine räumliche Trendfunktion beschrieben. Für die weiteren Kovariableneffekte wurden univariate glättende Splinefunktionen parametrisiert, wobei es sich in allen Fällen um penalisierte Regressionssplines handelt.

Die abhängige Variable ist die Summe der Engerlinge der vier $0,25 \mathrm{~m}^{2}$-Grabungen eines Stichprobenpunktes, sodass direkt die Dichte der Engerlinge pro $\mathrm{m}^{2}$ beschrieben wird. Die Grabungstiefe betrug je nach mechanischem Widerstand des Substrats maximal einen Meter. Neben der geographischen Lage der Stichprobenpunkte standen als unabhängige Variablen die Tonmächtigkeit [\%] bis zu einem Meter Tiefe und der Grundwasserstand unter Flur im Oktober 2007 [m] zur Verfügung. Die Tonmächtigkeit wurde dabei durch die Regionalisierung der Feinsubstratkartierung geschätzt und der Grundwasserstand entsprechend modelliert.

Das spezifische Poisson-Regressionsmodell zur Modellierung der Engerlingsdichte pro $\mathrm{m}^{2}$ unter Verwendung aller Kovariablen lässt sich wie folgt beschreiben: 


$$
g\left(\lambda_{i}\right)=\beta_{0}+f_{1}\left(G W_{i}\right)+f_{2}\left(\text { Ton }_{i}\right)+f_{3}\left(R W_{i}, H W_{i}\right) \text { wobei } \lambda_{i}=\mathrm{E}\left(E D_{i}\right)
$$

mit $E D_{i} \sim$ Poisson $\left(\lambda_{i}\right) ; E D_{i}=0,1,2, \ldots$

$$
\begin{array}{ll}
G W_{i} & \begin{array}{l}
\text { Grundwasserstand im Okt. } 2007 \text { am Stichprobenpunkt } i \text { ausgedrückt } \\
\text { als Flurabstand }[-1 \mathrm{~m}]
\end{array} \\
T_{0} n_{i} & \text { Tonmächtigkeit am Stichprobenpunkt } i[\%] \\
R W_{i}, H W_{i}= & \begin{array}{l}
\text { Rechts- und Hochwert im Gauß-Krüger-Koordinatensystem bezo- } \\
\text { gen auf den 3.-Meridian am Stichprobenpunkt } i
\end{array} \\
f_{1}, f_{2} & \text { 1-dimensionale glättende Splinefunktionen } \\
f_{3} & \text { 2-dimensionale glättende Splinefunktion }
\end{array}
$$

Ausgehend von einem Mittelwertmodell wurde in der Modellselektion getestet, inwieweit die schrittweise Integration der Kovariablen signifikante Effekte auf die Engerlingsdichte aufweist bzw. zur Modellverbesserung beiträgt. Dabei wurde deutlich, dass die räumliche Lage der Beobachtungen einen sehr viel stärkeren Effekt auf die Engerlingsdichte hat, als die Kovariablen, die einen kausalen Zusammenhang zur Engerlingsdichte aufweisen.

Die Effekte des Flurabstandes und der Tonmächtigkeit führen zu signifikanten Modellverbesserungen, wobei für den Effekt des Flurabstandes ein nicht-linearer Effekt deutlich wird (s. Abb. 32, links). Für die Tonmächtigkeit deutet sich ebenfalls ein nicht-linearer Effekt an (s. Abb. 32, rechts), der allerdings gegenüber einem linearen Effekt nicht signifikant unterschiedlich ist. Hierbei ist zu beachten, dass nur an vier Prozent $(n=51)$ der Grabungen überhaupt Tonschichten vorkamen. Eine weitere Untergliederung nach Substratgruppen wie Lehm oder Löss erbrachte keine Modellverbesserungen, sodass unterstellt werden kann, dass nur das Vorkommen und die Mächtigkeit kompakter Tonschichten zu einer Reduktion der Engerlingsdichte führt.
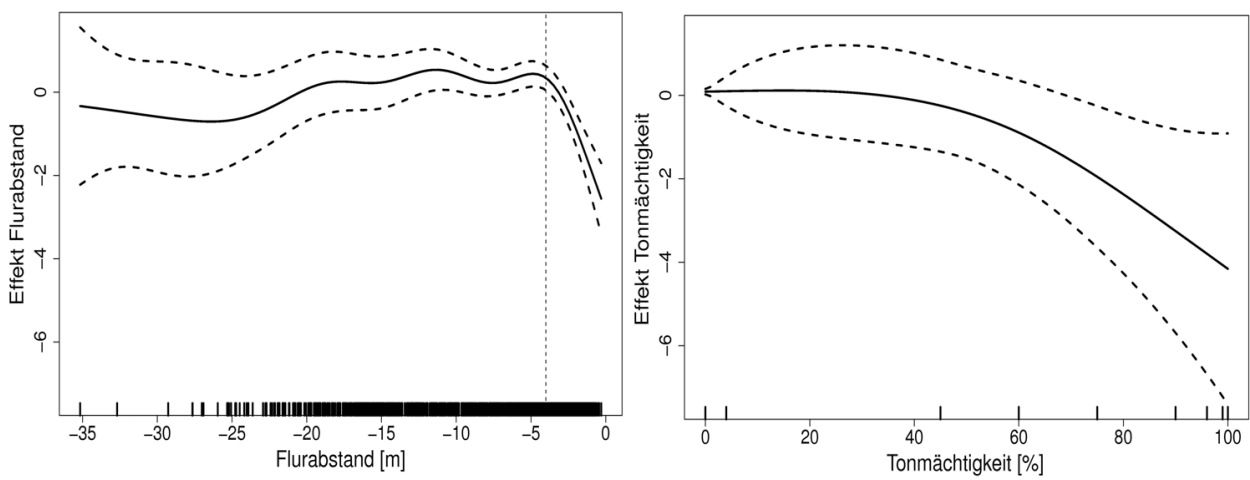

Abbildung 32: Modelleffekte (Formel 16) des Flurabstandes und der Tonmächtigkeit auf die Engerlingsdichte 
Zwischen ca. 4 und $0 \mathrm{~m}$ unter Flur ist ein abnehmender Effekt des Flurabstandes zu beobachten (s. Abb. 32, links). Somit nimmt die Engerlingsdichte mit geringer werdendem Flurabstand ab. Ab einem Flurabstand von mehr als ca. $4 \mathrm{~m}$ tritt ein annähernd asymptotischer Verlauf auf, der dahingehend interpretiert werden kann, dass eine weitere Grundwasserabsenkung keinen zusätzlichen Effekt mehr auf die Engerlingsdichte hat. Die Abnahme des Effektes bei sehr großen Flurabständen kann ebenso wie die leichten Schwankungen als zufällig angesehen werden, da das Konfidenzintervall in diesem Bereich sehr breit ist (s. Abb. 32, links). Der Effekt im Bereich zwischen 4 und $1 \mathrm{~m}$ unter Flur auf die Engerlingsdichte kann dahingehend interpretiert werden, dass auch einzelne Hochwasserereignisse die Engerlingsdichte beeinflussen, selbst wenn mittlere Flurabstände deutlich unterhalb von $1 \mathrm{~m}$ aber nicht tiefer als $4 \mathrm{~m}$ liegen. Weiterhin ist $\mathrm{zu}$ beachten, dass es sich um modellierte Flurabstände handelt und somit gewisse Unschärfen auftreten können. Im Bereich großer Flurabstände muss aus biologischer Sicht ein konstanter Effekt angenommen werden, da es für die Engerlingsdichten unerheblich sein dürfte, ob das Grundwasser 10, 20 oder 30 m unter Flur ansteht.

Das Modell wurde daher erneut parametrisiert, wobei der Effekt des Flurabstandes durch einen segmentierten linearen Term und der Effekt der Tonmächtigkeit durch einen einfachen linearen Term approximiert wurden (s. Formel 17, Tab. 17 und Abb. 33):

$$
\begin{aligned}
& g\left(\lambda_{i}\right)=\beta_{0}+f_{1}\left(G W_{i}\right)+\beta_{2} \operatorname{Ton}_{i}+f_{3}\left(R W_{i} H W_{i}\right) \\
& \text { mit } f_{1}(\mathrm{GW}) \quad\left\{\beta_{1} \cdot(\mathrm{GW}+4) \text {, für } \mathrm{GW}>-4 \mathrm{~m}, 0\right. \text { anderenfalls; } \\
& \text { wobei } \lambda_{i}=\mathrm{E}\left(E D_{i}\right) \text { mit } E D_{i} \sim \operatorname{NegBin}\left(\mu_{i} \phi\right) ; E D_{i}=0,1,2, \ldots \text {. }
\end{aligned}
$$

Tabelle 17: $\quad$ Statistische Kennwerte des verallgemeinerten additiven Modells (Formel 17) zur Schätzung der Engerlingsdichte

\begin{tabular}{ccccc}
\hline & Parameter & Standardfehler & z-Wert & $\operatorname{Pr}(>|\mathrm{z}|)$ \\
\hline$\beta_{0}$ & 0,042049 & 0,116573 & 0,361 & 0,71831 \\
$\beta_{1}$ & $-0,701963$ & 0,108724 & $-6,456$ & $1,07^{\mathrm{e}-10^{* * *}}$ \\
$\beta_{2}$ & $-0,023599$ & 0,007537 & $-3,131$ & $0,00174^{* *}$ \\
\hline$f_{3}(\mathrm{RW}, \mathrm{HW})$, edf $=91,95$ & & & p-Wert $<2^{\mathrm{e}-16^{* * *}}$ \\
$\mathrm{R}$-sq, $($ adj $)=0,467$ & Deviance explained $=71,4 \%$ &
\end{tabular}


Material und Methoden
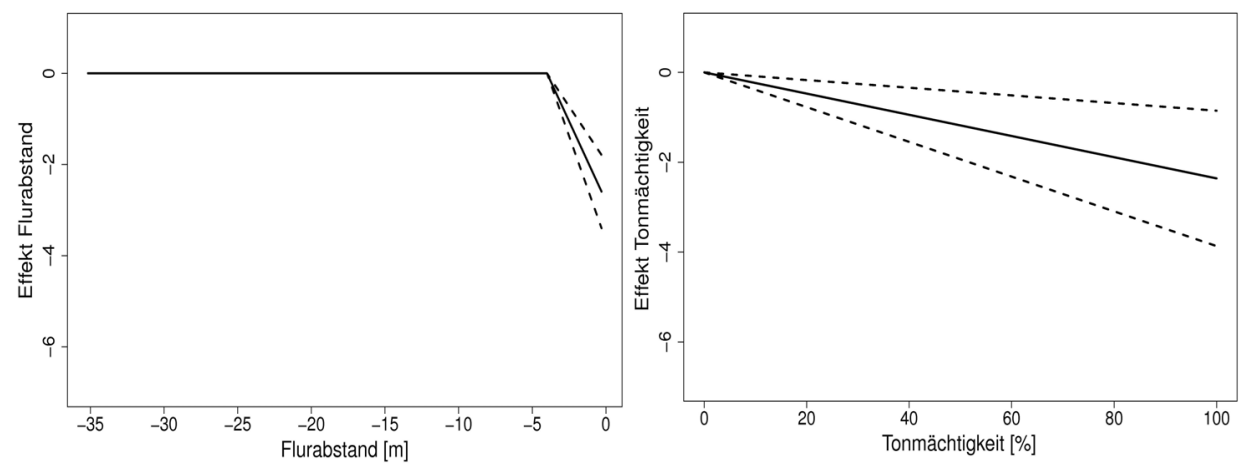

Abbildung 33: Linear approximierte Modelleffekte (Formel 17) des Flurabstandes und der Tonmächtigkeit auf die Engerlingsdichte

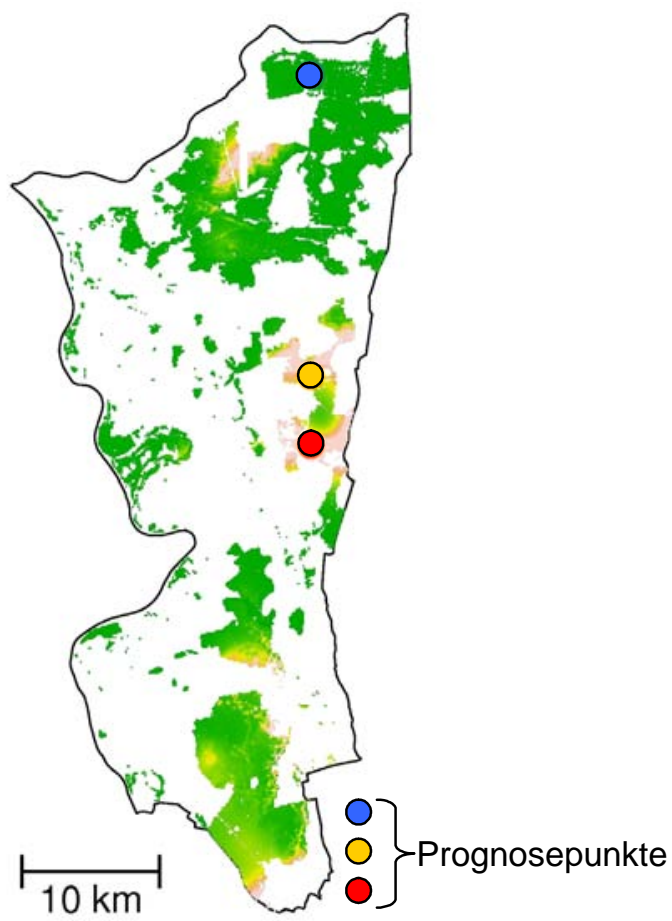

Abbildung 34: Konturplot zur Visualisierung einer Modellschätzung für das Szenario GW0, wobei die kausalen Variablen Flurabstand 2007 und Tonmächtigkeit mit den Ausprägungen des jeweiligen Rasterpunktes in die Schätzung eingehen. Zusätzlich ist die räumliche Lage der drei Standpunkte dargestellt, für die eine Prognose (Formel 17) durchgeführt wird (Abb. 35). 
Das Modellverhalten und die Sensitivität kann durch Modellschätzungen verdeutlicht werden, wobei der Flurabstand oder die Tonmächtigkeit unabhängig von den konkreten Ausprägungen am Stichprobenpunkt variiert werden und die jeweils andere kausale Variable mit einem konstanten Wert eingeht (s. Abb. 35). Hier wird die Engerlingsdichte beispielhaft für drei unterschiedliche Bezugspunkte im Hessischen Ried (s. Abb. 34) prognostiziert, die sich bezüglich des Effektes des räumlichen Trends deutlich unterscheiden.

Die unterschiedlichen Verläufe innerhalb einer Graphik (s. Abb. 35) resultieren einzig aus der unterschiedlichen regionalen Lage der Bezugspunkte (s. Abb. 34). Deutlich sind die großen regionalen Unterschiede zu erkennen, die sich nicht über kausale Variablen erklären lassen. Der Einfluss der Tonmächtigkeit ist ebenfalls deutlich zu erkennen (s. Abb. 35), wobei das Modell einen negativen aber mit steigender Tonmächtigkeit nachlassenden Einfluss beinhaltet: Die Engerlingsdichte nimmt mit steigender Tonmächtigkeit ab, wobei sich die Abnahmerate verringert. Der Einfluss des Flurabstandes ist ebenfalls deutlich (s. Abb. 35). Hier tritt zwischen 4 und $0 \mathrm{~m}$ unter Flur ein negativer und mit abnehmendem Flurabstand nachlassender Einfluss auf: Aufgrund des negativen Vorzeichens des Flurabstandes (Formel 17) nimmt die Engerlingsdichte von 4,0 auf 0,5 m unter Flur ab, wobei sich auch hier die Abnahmerate verringert. 

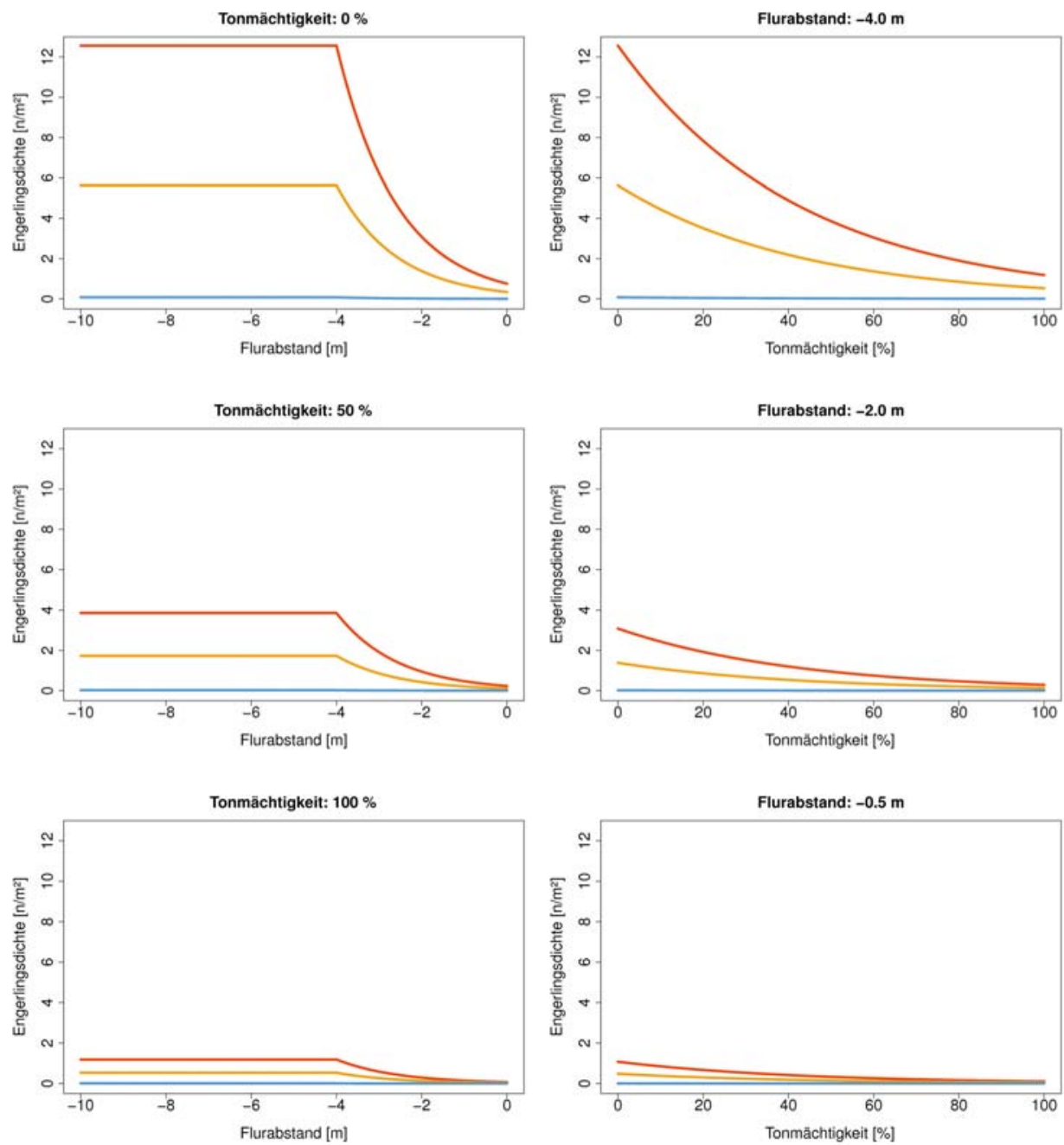

Abbildung 35: Prognose der Engerlingsdichte (Formel 17) an drei ausgewäblten Bezugspunkten im Hessischen Ried bei variierender Tonmächtigkeit (links) und variierenden Flurabständen (rechts). Die Funktionsverläufe sind in den gleichen Farben dargestellt wie die korrespondierenden Bezugspunkte in der Karte (Abb. 34). Der konstante Wert der zweiten, nicht variierten kausalen Kovariablen ist jeweils in der Abbildungsüberschrift angegeben. 


\subsection{Ableitung des Mortalitätsmodells}

Auf der Basis von Erfahrungs- und Expertenwissen sowie Literaturangaben wurde eine baumartenunabhängige, altersspezifische Schädigungsmatrix in Abhängigkeit der Engerlingsdichte erstellt (s. Tab. 18). Aus der regionalisierten Engerlingsdichte und dieser Vitalitätsmatrix wurde für jeden Einzelbaum ein Vitalitätswert geschätzt, wobei baumartenunabhängig in Abhängigkeit vom Baumalter und der Engerlingsdichte die Einzelbaumvitalität herabgesetzt wurde. Unterschreitet die Vitalität eines Modellbaums den Schwellenwert von 0,6, kann der Baum absterben. Ob ein Baum abstirbt, wurde über eine Zufallszahl bestimmt. Als Grundregeln zur Aufstellung der Matrix dienten folgende Erfahrungswerte:

- Bei Kulturen wirken Dichten von fünf oder mehr Engerlingen je Quadratmeter letal.

- Für mittelalte Bäume wird von einer höheren Widerstandskraft (größere Elastizität) ausgegangen.

- Bei Altbäumen können sich Dichten von zehn bis zwanzig Engerlingen je Quadratmeter nach mehreren Maikäfer-Generationen letal auswirken.

Zu Beginn des Simulationszeitraumes im Jahr 2007 gingen alle Bäume zu 100 Prozent vital, d. h. ohne Einbußen ihrer Vitalität in die Simulation ein. Diese vereinfachende Annahme war notwendig, da keine Daten über tatsächlich bereits vorliegende, teilweise erhebliche Vitaliätsverluste vorlagen. Modellbedingt kann ein Baum seine Vitalität nicht wieder verbessern, er kann nur das Niveau beibehalten oder sich verschlechtern (s. Abb. 36).

Tabelle 18: Baumartenunabhängige altersspezifische Matrix zur Schätzung der Vitalitätsminderung eines Einzelbaumes in Abhängigkeit von der Engerlingsdichte (3. Engerlingstadium, E3) (Ausschnitt)

\begin{tabular}{ccccccccccc}
\hline & \multicolumn{1}{c}{ Alter } \\
$\mathrm{E} 3 / \mathrm{m}^{2}$ & 1 & 2 & 3 & 4 & $\ldots$ & 126 & 137 & 138 & 139 & 140 \\
\hline 1 & 0,27 & 0,25 & 0,23 & 0,18 & $\ldots$ & 0,00 & 0,00 & 0,00 & 0,00 & 0,00 \\
2 & 0,30 & 0,27 & 0,25 & 0,21 & $\ldots$ & 0,00 & 0,00 & 0,00 & 0,00 & 0,00 \\
3 & 0,33 & 0,30 & 0,28 & 0,24 & $\ldots$ & 0,00 & 0,00 & 0,00 & 0,00 & 0,00 \\
4 & 0,35 & 0,33 & 0,31 & 0,26 & $\ldots$ & 0,00 & 0,00 & 0,00 & 0,00 & 0,01 \\
5 & 0,38 & 0,35 & 0,33 & 0,28 & $\ldots$ & 0,00 & 0,00 & 0,01 & 0,02 & 0,02 \\
$\ldots$ & $\ldots$ & $\ldots$ & $\ldots$ & $\ldots$ & $\ldots$ & $\ldots$ & $\ldots$ & $\ldots$ & $\ldots$ & $\ldots$ \\
97 & 1,00 & 1,00 & 1,00 & 1,00 & $\ldots$ & 1,00 & 1,00 & 1,00 & 1,00 & 1,00 \\
98 & 1,00 & 1,00 & 1,00 & 1,00 & $\ldots$ & 1,00 & 1,00 & 1,00 & 1,00 & 1,00 \\
99 & 1,00 & 1,00 & 1,00 & 1,00 & $\ldots$ & 1,00 & 1,00 & 1,00 & 1,00 & 1,00 \\
100 & 1,00 & 1,00 & 1,00 & 1,00 & $\ldots$ & 1,00 & 1,00 & 1,00 & 1,00 & 1,00 \\
\hline
\end{tabular}




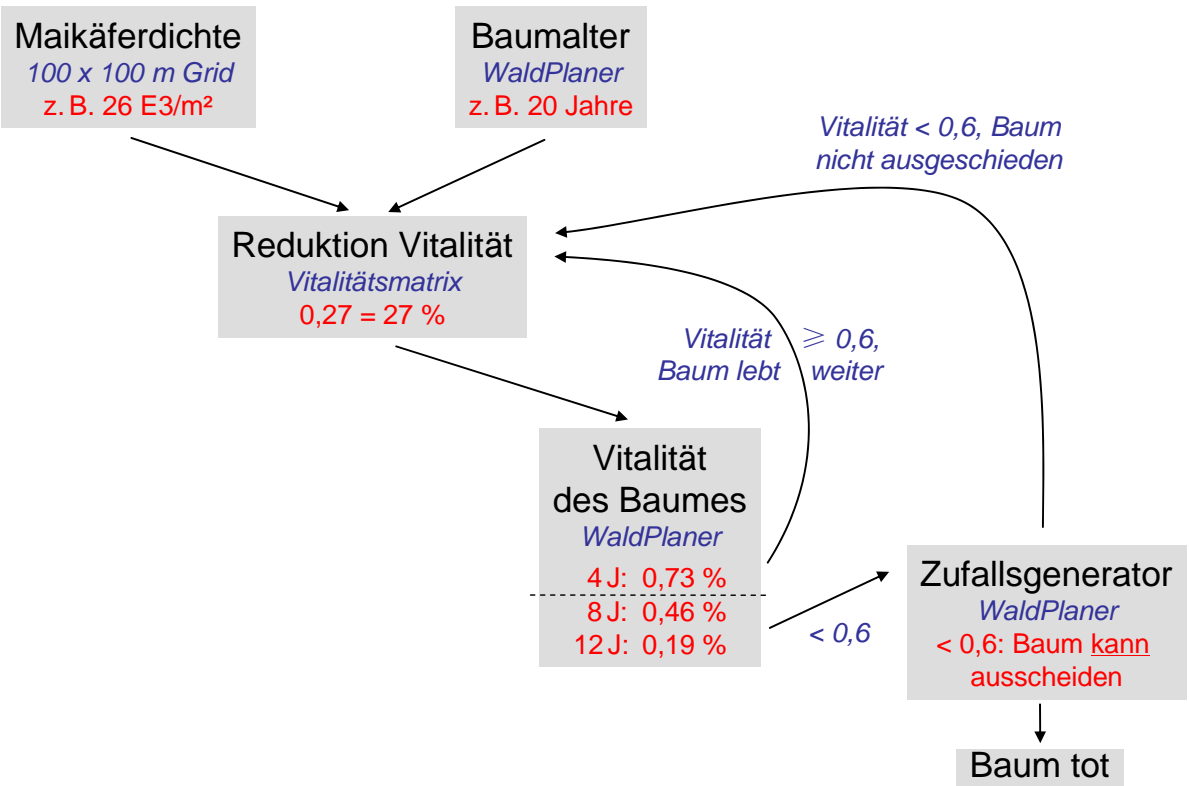

Abbildung 36: Schematische Darstellung des Maikeäfer-Mortalitätsmodells

\subsubsection{Waldwachstumsmodell}

Für die Modellierung des Waldwachstums wurde das an der NW-FVA entwickelte positionsunabhängige Einzelbaumwachstumsmodell BWINPro verwendet (NAGEL 1999, NAGEL et al. 2006). Dieses basiert auf der Simulationssoftware TreeGrOSS (Tree Growth Open Source Software), die in der Programmiersprache Java (Sun 2 Plattform, Standard Edition 1.5.0, 2009) unter der Entwicklungsoberfläche NetBeans 6.5 programmiert wurde (NAGEL 2002).

Es handelt sich um ein statistisches Modell, bei dem jeder einzelne Baum eines Bestandes in seiner Entwicklung beschrieben wird. Dieser sogenannte Einzelbaumansatz ermöglicht es, nahezu jede Bestandesstruktur und -zusammensetzung zu simulieren. In BWINPro wird das Baumwachstum stark abstrahiert und ist auf den BHD- und Höhenzuwachs reduziert. Die Funktionen zur Zuwachsschätzung wurden mit Hilfe umfangreicher Versuchsflächendaten baumartenweise parametrisiert. Als den Zuwachs beeinflussende Größen werden das Alter, die Kronenmantelfläche, der Kronenkonkurrenzindex und dessen Veränderung bei Durchforstungen verwendet. Über den spezifischen Standraumbedarf der Baumarten, welcher sich hauptsächlich aus der Kronengröße ergibt, werden die Mischbestandseffekte im Modell realisiert. Die Kronengröße wird im Modell aus der Höhe, dem Kronenansatz und der Kronenbreite für einen unterstellten Paraboloiden berechnet, wobei die für die Kronenmantelfläche und den Kronenkonkurrenzindex notwendigen Kroneninformationen über statische Funktionen aus dem 
BHD, der Höhe und der Bestandesoberhöhe geschätzt werden. Eine weitere wichtige Funktion des Wachstumsmodells ist die dichtebedingte Mortalität. Ob ein Baum stirbt, hängt letztendlich von dem minimalen Standraumbedarf der Art ab. Der minimale Standraumbedarf wird anhand der Funktionen von DöBBELER (2004) zur maximalen Dichteschätzung in Verbindung mit den Kronenbreitenfunktionen bestimmt.

Neben diesen grundlegenden Funktionen benötigt man für einen vollständigen Waldwachstumssimulator eine Vielzahl weiterer Funktionen. Im Rahmen der Studie wurde hauptsächlich auf die folgenden Funktionen zurückgegriffen:

- Generierung von Beständen (Durchmesserverteilungen, Baumhöhen, Stammfußkoordinaten)

- Bestandesbehandlung (Durchforstungen, Nutzung, Habitat- und Z-BaumAuswahl, Pflanzung)

- Einwuchs oder Verjüngung

- Visualisierung

- Analyse (Sortimentsaushaltung, Totholzentwicklung)

Für die waldwachstumskundliche Modellierung im Projekt Hessisches Ried wurde die Version 7.7 verwendet, in der eine Trennung zwischen Waldwachstumsmodell und Simulator so weit wie möglich umgesetzt wurde. Nahezu alle baumartenspezifischen Funktionen, Parameter und Einstellungen werden in einer XML-Einstellungsdatei gespeichert. Dadurch kann der Simulator mit Hilfe eines einfachen Texteditors verändert und auch für andere Modellregionen eingestellt werden. Alle Baumarten, die simuliert werden sollen, müssen in der XML-Einstellungsdatei definiert sein.

Das Waldwachstumsmodell BWINPro wurde ursprünglich für 5-jährige Zeitschritte parametrisiert. Um dem Entwicklungszyklus des Maikäfers Rechnung zu tragen, wurde in dieser Studie in 4-jährigen Zeitschritten simuliert. Je Zeitschritt werden die folgenden Schritte durchlaufen:

1. Überprüfung der altersbedingten Mortalität

2. Überprüfung der konkurrenzbedingten Mortalität

3. Schätzung des Höhen- und Grundflächenzuwachses

4. Erhöhung des Alters um 4 Jahre

5. Bestimmung des BHD und der Höhe nach 4 Jahren

6. Anpassung von Kronenansatz und -breite an die neuen Dimensionen

7. Update der ertragskundlichen Werte, Datenergänzung

Der Simulator lässt sich nur verwenden, wenn ein kompletter Datensatz für einen Bestand zur Verfügung steht. Hierzu zählen: 
- Flächengröße

- Jahr der Aufnahme (z. B. Stichjahr der Forsteinrichtung)

- Koordinaten der Eckpunkte

- Einzelbaumdaten (Baumart, Alter, BHD, Höhe, Kronenansatz, Kronenbreite, Koordinaten)

Aus den aufbereiteten Forsteinrichtungsdaten wurden 0,33 ha große Modellbestände erzeugt. Die Flächengröße von 0,33 ha wurde mit Rücksicht auf das Habitatbaumkonzept von HESSEN-FORST gewählt.

Aus den Daten der Forsteinrichtung wurden mit einer Durchmesserverteilungsfunktion, welche die baumartenspezifischen Parameter mit den übrigen Einstellungswerten zu Beginn der Simulation einliest, nach dem Ansatz von NAGEL und BIgING (1995) Bäume generiert. Dazu wurden aus den Angaben des maximalen Durchmessers (Dmax), der Höhe und des Durchmessers des Kreisflächenmittelstammes (dg) die Parameter einer Weibullverteilung geschätzt. Mit Hilfe von Zufallszahlen werden über die Weibullfunktion so lange Durchmesser erzeugt, bis die gewünschte Grundfläche erreicht ist.

$$
b h d=b \cdot\left[\left(\frac{T}{b}\right)^{c}-\log _{e}\left(1-F_{T}(x)\right)\right]^{\frac{1}{c}}
$$

Die Baumhöhe erhält jeder Baum bei der Generierung über eine Einheitshöhenkurve mit baumartenspezifischen Koeffizienten nach Sloboda (GAFFREY 1988).

$$
h_{i}=1,3+(h g-1,3) \cdot e^{-\left(a_{0} \cdot d g+a_{1}\right) \cdot\left(\frac{1}{d_{i}}-\frac{1}{d g}\right)}
$$

Die Funktionen für die Einheitshöhenkurve und die Höhenkurven liefern für die Bäume einer Baumart mit gleichem Durchmesser dieselbe Höhe. Damit in der Simulation die Höhen bei gleichem Durchmesser variieren, wird baumartenweise der Höhenvariationswert nach ALBERT (2000) hergeleitet, welcher je nach Baumart die Standardabweichung als lineare Regression des Kreisflächenmittelstamms oder der Durchmesserstandardabweichung schätzt. Dieser wird auf den Höhenwert addiert.

Für die Berechnung der Höhen des Kreisflächenmittel- und der Oberhöhenstämme wird je nach Baumart eine der folgenden Höhenkurven verwendet:

- Parabel $h=a_{0}+a_{1} \cdot d+a_{2} \cdot d^{2}$

- Prodan

$$
h-1.3=\frac{d^{2}}{a_{0}+a_{1} \cdot d+a_{2} \cdot d^{2}}
$$


- Petterson

$$
h=1,3+\left(\frac{d}{a_{0}+a_{1} \cdot d}\right)^{3,0}
$$

- Korsun

$$
h=e^{\left[a_{0}+a_{1} \cdot \ln (d)+a_{2} \cdot \ln ^{2}\left(d^{2}\right)\right]}
$$

- logarithmisch

$$
h=a_{0}+a_{1} \cdot \ln (d)
$$

Fehlende Kronenansatz- und Kronenbreitenwerte werden baumartenweise über Funktionen geschätzt, die in einer XML-Einstellungsdatei vorliegen. Die fehlenden Baumkoordinaten werden mit einem einfachen und schnellen Algorithmus über zwei Zufallszahlen erzeugt. Einem Baum wird eine zufällige Koordinate zugewiesen, wenn sich seine Krone nicht mit Kronen von anderen Bäumen überschneidet. Sollte diese Bedingung nicht erfüllt sein, wird eine neue Koordinate gezogen. Wenn nach 25 Versuchen noch keine Koordinate gefunden wurde, wird eine gewisse Überschneidung toleriert und der Toleranzwert mit jedem neuen Versuch erhöht, bis dem Baum eine Koordinate zugewiesen werden konnte. Durch die Angabe einer Gruppierungsgröße können neben einzelstammweisen Baumverteilungen auch gruppen-, horst- und truppweise Strukturen erzeugt werden.

In der TreeGrOSS Software wird die dichte- und die altersbedingte Mortalität berücksichtigt. Der Ausfall von Bäumen durch Trockenstress und Maikäfer wurde mit externen Routinen realisiert.

Die dichtebedingte Mortalität wurde über die maximale Dichte ermittelt. Dazu muss im Element Maximum Density der XML-Einstellungsdatei eine Funktion angegeben werden, mit der die maximale Dichte (Grundfläche) in $\mathrm{m}^{2} /$ ha berechnet werden kann. Für die Hauptbaumarten Deutschlands hat DOEBBELER (2004) Funktionen für verschiedene Regionen vorgestellt. Bei diesen wird die maximale Dichte mit der erweiterten Competition-Density-Rule (C-D-Regel) nach STERBA (1981) geschätzt, wobei sich die Stammzahlen bei der maximalen Grundfläche aus der hyperbelartigen Beziehung zwischen dem Mitteldurchmesser und der Stammzahl von Beständen bei gleicher Oberhöhe ableiten lassen. Dazu wird aus den Versuchsflächendaten von undurchforsteten und schwach durchforsteten Parzellen die Funktion

$$
d g=\frac{1}{a_{0} h 100^{a_{1}} N h a+b_{0} h 100^{b_{1}}}
$$

mit dem Verfahren der nicht linearen Regression angepasst. Bei konstanter Oberhöhe errechnet sich aus der Formel die Bestandesgrundfläche wie folgt: 


$$
\begin{gathered}
G=d g^{2} \cdot \frac{\pi}{4} \cdot N h a=\frac{1}{\left(A^{\prime} \cdot N+B^{\prime}\right)^{2}} \cdot \frac{\pi}{4} \cdot N=\frac{N \cdot \pi}{4 \cdot\left(A^{\prime} \cdot N+B^{\prime}\right)^{2}} \\
\text { wobei } A^{\prime}=a_{0} \cdot h 100^{a_{1}} \text { und } \quad B^{\prime}=b_{0} \cdot h 100^{b_{1}}
\end{gathered}
$$

Durch Nullsetzen der ersten Ableitung erhält man für die Stammzahl bei maximaler Grundfläche:

$$
N h a_{G \max }=\frac{B^{\prime}}{A^{\prime}}
$$

und durch Einsetzen der Stammzahl

$$
d g_{\text {gmax }}=1 / 2 \cdot B^{\prime}
$$

Mit Hilfe der geschätzten Koeffizienten lässt sich die maximale Grundfläche für eine gegebene Oberhöhe bestimmen:

$$
G_{\text {max }}=a_{0} \cdot b_{0} \cdot h 100^{\left(a_{1}+b_{1}\right)}
$$

Für die übrigen Baumarten wurde die maximale Dichte grob aus Versuchsflächen geschätzt (NAGEL et al. 2002). Dazu wurde der maximale Kronenschlussgrad mit Hilfe eines Konkurrenz-Indexes (C66) für alle vorhandenen Bäume bestimmt und anschließend der Kronenschlussgrad ermittelt, bei dem noch 95 bzw. 99 Prozent der Bäume überleben können. Der Kronenschlussgrad kann mit der Kronenbreitenfunktion bei den beobachteten Durchmessern in die maximale Grundfläche umgerechnet werden.

Der standardmäßige Mortalitätsalgorithmus arbeitet positionsabhängig, das heißt, dass er die Koordinaten der Bäume berücksichtigt. Er ermittelt aus allen Bäumen denjenigen, bei dem in seiner Einflusszone der aus der maximalen Dichte hergeleitete Kronenschlussgrad für seine Art am meisten von seinem C66xy-Wert überschritten wird. Dieser Baum wird als ,,absterbend“ markiert und es werden die positionsabhängigen Kronenkonkurrenzwerte C66xy für alle Bäume neu berechnet. Der Vorgang wiederholt sich so oft, bis kein C66xy-Wert mehr den hergeleiteten kritischen Kronenschlussgrad überschreitet. Die Einflusszone ist in der Standardversion auf die zweifache Kronenbreite begrenzt. Für eine schnelle Ausführung des Algorithmus werden nach der ersten Ausführung nur noch jene Bäume für eine eventuelle Mortalitätsauswahl berücksichtigt, deren C66xy-Wert bei der Berechnung größer als der kritische Kronenschlussgrad war. Der kritische Kronenschlussgrad (kritKS) wird aus dem Wert der maximalen Dichte $\left(G_{\max }\right)$ und der Kronenbreite (cw) des Bezugsbaumes berechnet:

$$
\text { kritKS }=\frac{G_{\max }}{d_{i^{2}}} \cdot c w_{i^{2}}
$$


Die altersbedingte Mortalität setzt ein, wenn Bäume ein vorgegebenes maximales Alter überschritten haben. Die Bäume unterliegen dabei einer mit zunehmendem Alter abnehmenden Überlebenswahrscheinlichkeit. Die Überlebenswahrscheinlich-

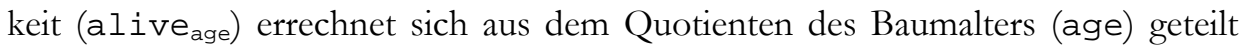
durch das maximale Alter (age $\mathbf{m a x}_{\max }$ ) der Baumart minus 1.

$$
\text { alive }_{\text {age }}=\left(\frac{\text { age }}{\text { age }_{\max }}-1\right)
$$

Ist der Wert alive age größer als eine Zufallszahl zwischen 1 und 0, so überlebt der Baum. Das maximale Alter ist baumartenweise in der XML-Einstellungsdatei abgelegt.

Der Höhenzuwachs wird in vielen statistischen Waldwachstumssimulatoren über zwei Teilmodelle berechnet. Das erste Teilmodell schätzt den potenziellen Höhenzuwachs. Das zweite Teilmodell schätzt einen Faktor, der den maximalen Höhenzuwachs auf den des Einzelbaumes reduziert (HASENAUER 2006). Im Modell BWINPro wird der Durchmesserzuwachs aus der Schätzung des Grundflächenzuwachses errechnet. Der Grundflächenzuwachs wird über die Variablen Alter, Kronenmantelfläche, Kronenkonkurrenzindex und die Veränderung des Kronenkonkurrenzindexes bestimmt. Die Kronenmantelfläche wird aus dem Kronenansatz und der Kronenbreite nach der Formel eines quadratischen Paraboloiden hergeleitet. Die baumartenweisen Regressionsfunktionen für den Höhenund Durchmesserzuwachs sind ebenfalls in der Einstellungsdatei hinterlegt.

Die Kronenveränderung wird in BWINPro über statische Funktionen für den Kronenansatz und die Kronenbreite ermittelt. Für den Kronenansatz gilt die Nebenbedingung, dass der Kronenansatz nicht kleiner werden kann.

\subsubsection{Verjüngungsschichten und Einwuchs}

Der Einwuchs von neuen Bäumen wird im Modell über Verjüngungsschichten geregelt. Die Verjüngungsschichten können entweder direkt in das Modell eingegeben oder automatisch generiert werden. Eine Verjüngungsschicht besteht im Modell aus kleinen Bäumen, die als Platzhalter genutzt werden. Jeder dieser kleinen Bäume hat aus rein modelltechnischen Erwägungen eine Kronenbreite von 2,52 m und einen Kronenansatz in halber Baumhöhe. Die Höhe dieser Verjüngungsschichtplatzhalter ergibt sich aus der Höhe im Alter 30. Der Durchmesser wird über ein vorgegebenes $\mathrm{h} / \mathrm{d}$-Verhältnis abgeleitet. Das dichtebedingte Mortalitätsmodell regelt, ob die Verjüngungsschichtplatzhalter gegebenenfalls bei zu starker Überschirmung absterben. Überschreitet der Durchmesser den Wert der Derbholzgrenze $(7 \mathrm{~cm})$, wird aus dem Verjüngungsplatzhalter ein zu berücksichtigender Baum, wobei die Eigenschaften Art, Alter, BHD, Höhe, Bonität und die Koordinaten übernommen werden. Alle anderen Werte werden bei der Übernahme neu generiert. Eine konstante Kronenbreite von 2,52 m wurde gewählt, da die beiden 
wichtigsten Baumarten, Buche und Fichte, an der Derbholzgrenze von $7 \mathrm{~cm}$ in etwa eine solche Kronenbreite aufweisen und so die Anzahl von Verjüngungsbäumen im Modell in einem vertretbaren Rahmen gehalten werden kann.

Die standardmäßige Verjüngungsroutine des Wachstumssimulators wurde für den Bereich Nordwestdeutschland mit den Betriebsinventurdaten der Niedersächsischen Landesforsten erstellt. Diese schätzt den Einwuchs von Verjüngungsbäumen in Abhängigkeit von der Bestockung und einer Kronenschlussgradklasse (C66Kl). Da die Daten von $500 \mathrm{~m}^{2}$ großen Probekreisen stammen und auch heterogene Bestandesverhältnisse in der Simulation berücksichtigt werden sollen, wird der Einwuchs an Verjüngungsbäumen für $500 \mathrm{~m}^{2}$ große Teilflächen eines Bestandes geschätzt. Dazu wird die Bestandesfläche zunächst mit einem Gitter von $500 \mathrm{~m}^{2}$ großen, quadratischen Rasterflächen überzogen. Danach wird für jede Rasterfläche geschätzt, ob eine Wahrscheinlichkeit (pE) besteht, dass Verjüngung vorkommt. Die Wahrscheinlichkeit wird in Abhängigkeit von der führenden Hauptbaumart und der C66-Klasse (C66Kl) - dem Lichtangebot - geschätzt. Für die Berechnung der C66-Klasse wird die Kronenschirmfläche aller Bäume, welche die Rasterfläche bedecken, berücksichtigt. Die Klassenbreite der C66Kl-Werte beträgt 0,2 und der höchste Klassenwert beträgt 2,5.

$$
p E=p 0 \cdot c 66 K l^{p 1}
$$

Ist eine gezogene Zufallszahl zwischen 0 und 1 größer als pE, so wird die Anzahl der einwachsenden Bäume geschätzt. Im anderen Falle wird die Einwuchsroutine für die spezielle Rasterzelle abgebrochen.

Die Anzahl der einwachsenden Bäume (nE) wird für jede $500 \mathrm{~m}^{2}$ große Rasterfläche in Abhängigkeit vom Lichtangebot berechnet. Das Lichtangebot wird durch die C66-Klasse ausgedrückt. Im Programm wird nE in eine ganze Zahl (Integer) konvertiert. Die Funktion gibt damit ganze Bäume zurück.

$$
n E=e^{p 0+p 1 \cdot c 66 K l}
$$

Im nächsten Schritt werden nun $\mathrm{nE}$ Verjüngungsschichtplatzhalter für die $500 \mathrm{~m}^{2}$ große Rasterfläche erzeugt. Dabei wird für jeden Baum die Baumart in Abhängigkeit von der führenden Baumart und des C66Kl, zufällig festgelegt. Es wird eine Zufallszahl $\mathrm{p}$ zwischen 0 und 1 gezogen und die Baumart gewählt, die mit der kumulierten Wahrscheinlichkeit aller möglichen Arten den Zufallswert überschreitet. Dem Verjüngungsplatzhalter werden anschließend die Werte: Alter 5 Jahre, BHD 0,5 cm, Höhe 0,5 m, Kronenansatz 0,25 $\mathrm{m}$ und Kronenbreite 2,52 m zugewiesen.

\subsubsection{Ausscheidender Bestand, Holzentnahme und Tothol:}

Die entnommenen und absterbenden Stämme werden in der TreeGrOSS Software langfristig protokolliert. Aus diesen Angaben lässt sich der ausscheidende Bestand 
für verschiedene Fragestellungen untersuchen. Zur Betrachtung der standörtlichen Nachhaltigkeit kann aus der gesamten Entnahmemenge und den verbleibenden Baumkompartimenten für verschiedene Nutzungsszenarien auch die verbleibende sowie die entnommene Biomasse und deren Nährstoffvorrat berechnet werden. Unter dem Begriff Nutzungsszenario wird in diesem Fall die Aushaltung und Sortierung der genutzten Stämme verstanden. Darüber hinaus lassen sich auch für die Belange des Naturschutzes spezielle Vorgaben definieren, die von besonderem naturschutzfachlichem Interesse sind (NAGEL 2008).

Der Vorrat, die Biomasse, die Nährstoffe des verbleibenden Bestandes und das Totholz werden in Verbindung mit dem Sortiermodul berechnet. Ein Nutzungsszenario wird durch die zu entnehmenden Sortimente definiert.

Jeder entnommene Stamm des Bestandes wird vom Programm in die vorgegebenen Sortimente zerlegt. Dabei wird jeweils für das Sortiment, welches eine höhere Wertigkeit als das nächste besitzt, geprüft, ob dieses im Stamm enthalten ist. Ist es im Stamm vorhanden, wird es virtuell aus dem Stamm geschnitten und dem Pool der Holzentnahme oder dem Totholzpool zugerechnet, je nachdem, welche Angabe für das Sortiment über den Verbleib im Bestand gemacht wurde. Darüber hinaus wird für alle im Bestand verbleibenden Totholzstücke geprüft, ob diese den Naturschutzvorgaben entsprechen und diese in den Pool des naturschutzrelevanten Totholzes gehören. Die Sortimente der Nutzung und die Definition des naturschutzrelevanten Totholzes sind in Einstellungsdateien hinterlegt.

Die Wuchsleistung der Bäume und des gesamten Bestandes kann durch forstliche Eingriffe erheblich beeinflusst werden. Aus diesem Grund muss ein Waldwachstumssimulator auch über Eingriffsmöglichkeiten verfügen. Die Eingriffe können entweder interaktiv oder automatisiert erfolgen. An dieser Stelle werden die automatisierten Routinen beschrieben, die im Wesentlichen auf die Ansätze von DUDA (2006) zurückgehen und die Lage der Bäume im Bestand berücksichtigen. Daher müssen für alle Bäume die Koordinaten bekannt sein. Für die modellhafte Abbildung von waldbaulichen Behandlungen hat DUDA (2006) verschiedene waldbaulichen Behandlungen in einzelne Behandlungselemente (Treatment elements) aufgeteilt und programmiert. Durch eine Aneinanderreihung der Behandlungselemente lassen sich fast alle derzeit gängigen waldbaulichen Behandlungen abbilden.

Ein Behandlungsprogramm definiert sich durch:

- Die Auswabl und Markierung von Bäumen: In der TreeGrOSS-Software kann jeder Baum der Klasse Tree mit den drei Attributen crop (Z-Baum), tempcrop (temporärer Z-Baum) und habitat (Habitatbaum) markiert werden. Die Attribute lassen sich mit den Werten true oder false (wahr oder falsch) belegen. Habitatbäume sind von allen weiteren waldbaulichen Maßnahmen ausgenommen. Sie bleiben in der Simulation solange erhalten, bis sie entweder durch dichte- oder altersbedingte Mortalität absterben. Bei langfristigen Simulationen wird empfohlen, auf Habitatbäume zu verzichten, 
da dem Waldwachstumsmodell kaum Daten von sehr alten und großen Bäumen zugrunde liegen. Die Z-Bäume sind in der Regel von Durchforstungsmaßnahmen ausgenommen, es sei denn, es kommt zu einer direkten, dichtebedingten Konkurrenz zwischen den Z-Bäumen, wenn beispielsweise mehr Z-Bäume ausgewählt sind, als beim Erreichen der Zielstärke auf der Fläche Platz finden könnten. Z-Bäume werden mit dem Erreichen der Zielstärke, mit der Aktivierung des Schirmschlags und des Kahlschlags geerntet. Die Auswahl von temporären Z-Bäumen gilt jeweils nur für einen Durchforstungszeitpunkt und wird aus programmiertechnischer Sicht für die Hochdurchforstung verwendet.

- Die Anlage von Rückegassen: Es kann der Abstand zwischen den Rückegassen und die Rückegassenbreite flexibel eingestellt werden.

- Das Endnutzungsverfahren: Bei der Zielstärkennutzung werden einzelne Bäume selektiv genutzt, wenn sie einen, für die jeweilige Baumart vorgegebenen Zielstärkendurchmesser überschritten haben. Weiterhin lassen sich die minimale und die maximale Nutzungsmenge vorgeben. Beide Vorgaben sollen verhindern, dass Nutzungen durchgeführt werden, die sich entweder nicht lohnen oder dass unrealistisch starke Eingriffe simuliert werden. Darüber hinaus lässt sich ein Schlussgrad für den Oberstand vorgeben, bei dessen Unterschreitung der restliche Oberstand abgenutzt wird. Beim Schirmschlag wird der Bestand mit Hilfe einer Verjüngungsgangzahl aufgelichtet und abgenutzt. Die Verjüngungsgangzahl gibt den Bestockungsgrad für die aufeinander folgenden 5-Jahresperioden an (KRAMER 1982). Die Bäume unterhalb eines Durchmessers von $7 \mathrm{~cm}$ bleiben davon unberücksichtigt. Beim Kablschlag wird der gesamte Bestand mit dem Erreichen einer gewissen Stärke auf einmal genutzt. Die Bäume mit einem Durchmesser kleiner als $7 \mathrm{~cm}$ verbleiben zunächst im Bestand.

- Das Durchforstungsverfahren: Eine Durchforstung erfolgt bei allen Durchforstungsverfahren, sofern der Bestand zu dicht sein sollte und die vorgegebenen Nutzungsmengen noch nicht erreicht sind. Wie viel Grundfläche $\left(G_{\text {aus }}\right)$ im Rahmen einer Durchforstung entnommen werden soll, wird über die Differenz der tatsächlichen Grundfläche $\left(G_{\text {real }}\right)$ und der gewünschten Grundfläche hergeleitet. Die gewünschte Grundfläche ergibt sich, baumartenweise gewichtet, aus der maximalen Grundfläche, welche mit Hilfe der Höhe des Grundflächenmittelstammes $\left(\mathrm{H}_{\mathrm{G}}\right)$ aus der maximalen Dichtefunktion $\left(G_{\max }\right)$ bestimmt wird. Die maximale Grundfläche wird über den vorgegebenen natürlichen Bestockungsgrad $\left(\mathrm{nB}^{\circ}\right)$ und die vorgegebene Durchforstungsintensität (Dfin) reduziert. Der natürliche Bestockungsgrad, das Verhältnis von angestrebter Grundfläche zur maximalen Grundfläche, kann in der XML-Einstellungsdatei in dem Element Moderate Thinning Factor für drei Höhenbereiche vorgegeben werden. Diese Einstellung lässt sich darüber hinaus in der Software über den Faktor Durchforstungsintensität (Klasse stand.trule, Eigenschaft thinningIntensity) variieren. Bei einer Durch- 
forstungsintensität von 1,0 wird der vorgegebene natürliche Bestockungsgrad eingehalten.

$$
\begin{aligned}
& G_{\text {max }}=a_{0} \cdot b_{0} \cdot h 100^{\left(a_{1}+b_{1}\right)} \\
& G_{\text {aus }}=G_{\text {max }} \cdot n B^{\circ} \cdot \text { Dfin }-G_{\text {real }}
\end{aligned}
$$

- Bei der Auslesedurchforstung werden zunächst die Z-Bäume so lange freigestellt, bis alle Z-Bäume keinen Kronenkontakt mehr aufweisen oder die angestrebte Zielgrundfläche erreicht ist. Sind alle Z-Bäume freigestellt und ist die tatsächliche Bestandesgrundfläche höher als die angestrebte Grundfläche, so werden schrittweise diejenigen Bäume entfernt, die den höchsten Konkurrenzdruck auf die übrigen Bäume ausüben. Mit anderen Worten, es werden starke Bäume im Sinne einer Hochdurchforstung entnommen. Bei der einfachen Hochdurchforstung werden temporäre Z-Bäume gewählt. Die Anzahl richtet sich in diesem Fall nach dem Platzbedarf der Kronen der temporär gewählten Z-Bäume. Es werden solange Bäume entnommen, bis die angestrebte Zielgrundfläche erreicht ist. Bei der Niederdurchforstung werden die Bäume vom schwachen Ende bis zum Erreichen der angestrebten Grundfläche entnommen. Für alle Durchforstungsarten kann die Durchforstungsintensität festgelegt werden. Eine Durchforstungsintensität von beispielsweise 0,9 führt zu einer Grundflächenabsenkung auf 90 Prozent. Die Durchforstung lässt sich schließlich auch mit der Vorgabe der minimalen und maximalen Eingriffsmengen begrenzen.

- Die Naturschutzrestriktionen haben einen Einfluss auf die Durchforstungen und die Endnutzung. Es kann festgelegt werden, wie viele Habitatbäume pro Hektar ausgewählt werden sollen. Zudem kann eingestellt werden, ob die Habitatbäume aus allen Bäumen, nur den Laubbäumen oder aus den Buchen und Eichen gewählt werden sollen. Habitatbäume sind im Programm von jeglichen Durchforstungs- und Erntemaßnahmen ausgenommen. Ein Baum kann frühestens dann zum Habitatbaum erklärt werden, wenn sein BHD 80 Prozent der Zielstärke erreicht hat. Die Aktivierung der Einstellung Minderheitenschutz, bewirkt, dass im Bestand selten vorkommende Arten einem gewissen Schutz unterliegen und gefördert werden. Darüber hinaus lässt sich festlegen, ob ab dem Unterschreiten eines gewissen Kronenschlussgrades des Oberstands keine Nutzungen mehr durchgeführt werden sollen und Bäume, die einen vorgegebenen BHD überschritten haben, nicht genutzt werden.

- Die Option der Pflanzung gehört ebenfalls zu einem waldbaulichen Behandlungskonzept. Diese kann notwendig sein, wenn der Bestand umgebaut werden soll oder die vorhandene Verjüngung keine ausreichende Aussicht auf Erfolg aufweist. Generell muss die Option zu pflanzen aktiviert sein. Es kann eingestellt werden, ob vor der Pflanzung der Unterstand entfernt und 
ab welchem Kronenschlussgrad des Oberstandes mit der Pflanzung automatisch begonnen werden soll. Darüber hinaus lassen sich der Deckungsgrad und die zu pflanzende Baumart bzw. Baumarten vorgeben. Im Modell werden keine Bäume, sondern sogenannte Verjüngungsplatzhalter gepflanzt, die gewissermaßen jeweils einen Baum zum Zeitpunkt des Einwuchses (BHD $\geq 7 \mathrm{~cm}$ ) darstellen. Das Wachstum der Verjüngungsplatzhalter folgt einer exponentiellen Funktion, die im Alter 30 die Höhe der Bonitätskurve schneidet. Der dazugehörige BHD wird mit Hilfe vorgegebener $\mathrm{h} / \mathrm{d}$ - Werte bestimmt. Ist der Konkurrenzindex C66 eines Verjüngungsplatzhalters größer als der kritische Kronenschlussgrad der Baumart, stirbt der Verjüngungsplatzhalter und wird aus der Baumliste entfernt. Erreicht der BHD einen Wert von $7 \mathrm{~cm}$, so wird der Verjüngungsplatzhalter in einen Baum umgewandelt.

Für die Definition einer Bestandesbehandlung wurden die Parameterwerte im Modell mit Hilfe der waldbaulichen Regelsets definiert.

\subsubsection{Totholzmodell}

Da mit dem ausgewählten Wuchsmodell TreeGrOSS Bestände einzelbaumweise modelliert werden, ist es in Kombination mit der Sortierroutine und dem ausgewählten Behandlungsprogramm möglich, die Auswirkungen verschiedener Sortierungsvorgaben und Bestandesbehandlungen auf die Entwicklung des Totholzes (stehend und liegend) abzubilden.

Das Modell kann Totholz aus natürlicher Mortalität abbilden. Darüber hinaus kann Totholz „aktiv“ angereichert werden. Dies wird erreicht, indem definierte Abschnitte eines Stammes, welcher im Rahmen eines modellierten Eingriffs entnommen und sortiert wurde, im Modellbestand belassen werden. Die Zersetzung des liegenden Totholzes wird baumartengruppenspezifisch nach dem von MEYER et al. (2009) vorgestellten Verfahren modelliert. Dieses Verfahren schätzt den Volumenabbau ähnlich, wie das bisher in BWINPro verwendete Modell von MÜLLER-USING (2005). Es wurde jedoch auf einer breiteren Datengrundlage parametrisiert und kann zusätzlich die Bruchwahrscheinlichkeiten von stehenden Bäumen oder Hochstümpfen abschätzen. Die Zersetzung bzw. Volumenreduktion wird dabei mittels folgender linearer Abbaufunktion geschätzt:

$$
V_{t}=\left\{\begin{array}{lll}
V_{0} & V_{t}>V_{0} & \text { wobei: } \\
V_{0}-k \cdot t & \text { sonst } & \mathrm{V}_{\mathrm{t}}=\text { Volumen zum Zeitpunkt } \mathrm{t} \\
& \mathrm{V}=\text { Ausgangsvolumen } \\
& \mathrm{k}=\text { Abbaurate (baumartengruppenspezifisch) } \\
& \mathrm{t}=\text { Zeit in Jahren }
\end{array}\right.
$$

Aufgrund des Modelltyps (linear) kann $V_{t}$ für kleine $t$ geringfügig größer als $V_{0}$ werden. In diesen Fällen wird $V_{t}$ gleich $V_{0}$ gesetzt.

Durch eine entsprechende Definition der Sortierungsvorgaben kann gezielt Totholz mit gewünschter Dimension angereichert werden. Dies kann zum einen öko- 
logisch bedeutsam sein, zum anderen aber auch einen finanziellen Hintergrund haben.

Neben der Zersetzung liegenden Totholzes kann das Modul auch stehendes Totholz abbilden. Dieses entsteht z. B. durch konkurrenzbedingte Mortalität und vor allem durch Extremereignisse (Stürme, Kalamitäten). Wobei letztere in dem gewählten Wuchsmodell noch nicht umgesetzt sind. In diesem System fällt stehendes Totholz lediglich durch die konkurrenz- bzw. altersbedingte Mortalität an. Für das stehende Totholz wird nach jedem Wachstumszyklus eine Bruchwahrscheinlichkeit wie folgt berechnet:

$$
\begin{aligned}
& P_{\text {Bruch }}=1-e^{\left(-\left(\frac{t-\theta}{\sigma}\right)^{c}\right)} \quad \begin{array}{l}
\text { wobei: } \\
P_{\text {Bruch }}=\text { Bruchwahrscheinlichkeit } \\
\theta \quad \text { Schwellenwert Parameter } \\
\sigma \quad=\text { Maßstabs-Parameter (charakteristische }
\end{array} \\
& \text { Lebensdauer) } \\
& \text { c = Form-Parameter } \\
& \mathrm{t}=\text { Zeit in Jahren }
\end{aligned}
$$

Dieser Wert gibt an, wie hoch die Wahrscheinlichkeit ist, dass der jeweilige stehende Stamm oder Stumpf umbricht. Stehendes Totholz wird nicht wie das liegende Totholz modellhaft zersetzt. Erst nach dem Umbrechen greifen die oben beschriebenen Funktionen zur Schätzung der Volumenabnahme. Um den Zeitpunkt des Umfallens zu bestimmen, kommt eine baumartengruppenspezifische Weibullfunktion zum Einsatz. Mit dieser Funktion wird für alle stehenden und toten Bäume nach jedem Simulationsintervall berechnet, wie hoch die Wahrscheinlichkeit ist, dass der entsprechende Baum umfällt. Diese Wahrscheinlichkeit wird mit einer Zufallszahl verglichen. Ist die Bruchwahrscheinlichkeit höher, wird der Baum dem Pool des liegenden Totholzes zugefügt und im Verlauf der weiteren Simulation die Volumenabnahme modelliert.

\subsubsection{Habitatmodellierung und Identifikation von Hotspots}

Um besonders wertvolle Flächen für die Lebensgemeinschaften der Alters- und Zerfallsphase von Buchen- und Eichenwäldern (Hotspots) zu identifizieren, wurde eine multivariate Habitatmodellierung für eine Gruppe von Indikatorarten mit der sog. „Ecological-Niche Factor Analysis“ (ENFA) durchgeführt (HIRZEL et al. 2002). Mit der Software „Biomapper“ (HIRZEL et al. 2008) kann eine ENFA komfortabel durchgeführt werden. Die Methode weist den Vorteil auf, dass keine Absenzdaten, d. h. Bestätigungen der Abwesenheit von Arten, vorliegen müssen.

Bei der Habitatmodellierung wird davon ausgegangen, dass die Habitateignung anhand einer Gruppe von Indikatorarten eingeschätzt werden kann. Die Verteilung der Arten im Raum ist abhängig von der Ausprägung bestimmter ökologischer Variablen. Arten, die auf die Alters- und Zerfallsphase angewiesen sind, kommen vorzugsweise in Beständen mit hohem Alter bzw. in Beständen mit alten Baumindividuen vor. Diese Abhängigkeit kann durch einen Vergleich der Häufig- 
keitsverteilung des Bestandesalters an Punkten mit Artfunden mit der Gesamtverteilung im Untersuchungsgebiet quantifiziert werden. Hierbei werden die Mittelwerte und die Standardabweichungen beider Verteilungen herangezogen. Wendet man diese Statistiken auf eine erweiterte Anzahl von Variablen an, so kann die ökologische Nische einer Art bestimmt werden. (HIRZEL et al. 2002, HUTCHINSON 1957). Im Rahmen einer Faktorenanalyse werden die Wechselwirkungen zwischen den Variablen bewertet. Abschließend wird jeder Fläche, für die alle erklärenden Variablen vorliegen, ein Habiateignungsindex auf einer Skala von 0 bis 100 zugewiesen.

Im Zuge der Modellbildung mit Hilfe der Software „Biomapper“ werden verschiedene Kenngrößen zu den Modelleigenschaften und der Modellqualität ausgegeben, die im Folgenden dargestellt werden.

Die „Score Matrix“ gibt Aufschluss über die Einflussstärke der verschiedenen Koeffizienten, die in die Modellierung eingehen (s. Tab. 19). Je höher der absolute Wert eines Koeffizienten für den ersten Faktor ist (Marginalitätsfaktor), desto stärker unterscheidet sich der Lebensraum der Artengruppe vom Mittel der Grundgesamtheit in Bezug auf den entsprechenden Koeffizienten (HIRZEL et al. 2002). Ein positives Vorzeichen zeigt an, dass die Art bezüglich des Koeffizienten höhere Werte als im Gesamtmittel bevorzugt.

Tabelle 19: $\quad$ Score Matrix. Der absolute Wert des Marginalitätsfaktors (Marginality) beschreibt den Grad der Abweichung zwischen dem Mittelwert der Artfunde und der Grundgesamtheit bezüglich der einzelnen Variablen. Die weiteren Faktoren (Spezialisierung: Spec. 1 Spec. 4) beschreiben den Grad der Toleranz der Arten bezüglich Änderungen des Wertes der Variablen. Zeile 2 gibt den Prozentwert der erklärten Spezialisierung eines Faktors an. Die Tabelle bildet aus Darstellungsgründen nur die ersten 5 von 11 Faktoren ab.

\begin{tabular}{lrrrrr}
\hline & $\begin{array}{c}\text { Margi- } \\
\text { nality }\end{array}$ & Spec. 1 & Spec. 2 & Spec. 3 & Spec 4 \\
\hline & $(13 \%)$ & $(19 \%)$ & $(14 \%)$ & $(12 \%)$ & $(11 \%)$ \\
Alter Laubholz Altbestand & 0,598 & 0,018 & 0,122 & 0,136 & 0,260 \\
Distanz zu HB (1/exp(x)) & 0,451 & $-0,058$ & $-0,302$ & 0,048 & 0,161 \\
Distanz zu Referenzflächen (1/exp(x)) & 0,367 & $-0,009$ & $-0,030$ & $-0,047$ & 0,071 \\
Anteil Laubholz & 0,304 & 0,757 & 0,432 & $-0,151$ & $-0,430$ \\
Anteil Eiche & 0,289 & $-0,249$ & 0,105 & $-0,358$ & 0,090 \\
Laub- und Mischwaldkontinuität & 0,284 & $-0,212$ & $-0,612$ & 0,247 & $-0,448$ \\
Natürlicher Bestockungsgrad & 0,153 & $-0,113$ & 0,181 & 0,097 & 0,360 \\
Anteil Buche & $-0,109$ & 0,321 & $-0,516$ & $-0,490$ & 0,494 \\
Flächenanteil Laubholz-Altbestand & $-0,094$ & 0,413 & $-0,013$ & 0,703 & 0,212 \\
Flächengröße & $-0,053$ & $-0,139$ & 0,064 & 0,071 & 0,210 \\
Anteil nicht-standortheimischer Baumarten & 0,037 & 0,107 & 0,136 & $-0,129$ & 0,211 \\
\hline
\end{tabular}


In der vorliegenden Untersuchung nimmt das Alter des Laubholz-Altbestandes die wichtigste Position in Bezug auf den Marginalitätsfaktor ein. Es folgen die Distanzen zu Flächen der Hessischen Biotopkartierung und zu wertvollen Referenzflächen. Weitere wichtige Koeffizienten sind der Laubholzanteil, der Eichenanteil und die Laub- und Mischwaldkontinuität.

Die Faktoren 2 bis 11 stehen für die sogenannte Spezialisierung. Je höher der Wert eines Koeffizienten auf diesen Faktoren ist, desto stärker ist die betrachtete Artengruppe im Werteumfang der jeweiligen Variablen eingeschränkt.

Im Rahmen einer Kreuzvalidierung wird die Qualität des Modells bewertet (s. Abb. 37). Die hierbei dargestellte Kurve setzt die Anzahl der beobachteten Funde $\mathrm{O}_{\mathrm{i}}$ der Habitatklasse ins Verhältnis zu der erwarteten Anzahl an Funden $\mathrm{E}_{\mathrm{i}}$. $\mathrm{O}_{\mathrm{i} /} \mathrm{E}_{\mathrm{i}}=\mathrm{F}_{\mathrm{i}}$. Die erwartete Anzahl entspricht dem flächenproportionalen Anteil der Habitatklasse an der Gesamtzahl der Artfunde.

Der Boyce-Index gibt die Spearman-Correlation zwischen $F_{i}$ und $i$ wieder. Dieser geht gegen 1, wenn die Kurve des Verhältnisses $\mathrm{F}_{\mathrm{i}} / \mathrm{i}$ monoton steigend ist.

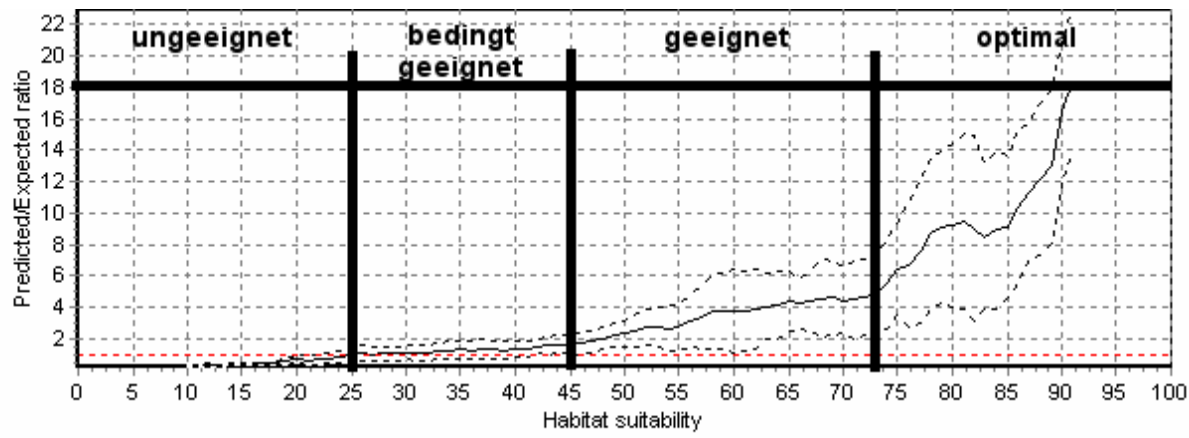
S All replicates
C. Median and $90 \%$ interval
(- Mean and SD
(C Bins Wontinuous $\frac{\text { Window size: }}{20 \neq}$

Model quality

- Bayce index: $0,848+0,208$

Г Stat. on graph

$\Gamma$ Logarithmic scale

$\sqrt{\checkmark}$ Random frequency line

Abbildung 37: Ergebnis der Kreuzvalidierung zur Bestimmung der Qualität des Habitatmodells und zur Ableitung von Klassengrenzen der Habitateignung. Achsen: Predicted/Expected ratio: Abweichung von einer zufälligen Verteilung (Predicted/Expected ratio $=1$ ); Habitat suitability: Habitateignungsindex der ENFA. Klassifizierung: Einteilung der Habitateignung in vier Klassen (ungeeignet, bedingt geeeignet, geeignet, optimal) anhand von Änderungen in der Steigung der Kurve; durchgezogene Linie: Habitateignungsquotient, gestrichelte schwarze Linien: Konfidenz̧änder, rot gestrichelte Linie: Schwellenwert Zufallsverteilung. 
Das im Rahmen dieser Studie erzeugte Modell zeichnet sich durch eine annähernd monoton steigende Kurve, einen hohen Boyce-Index von 0,848 und einem weiten Verhältnis von beobachteten zu erwarteten Funden im Bereich der hohen Habitateignungswerte aus. Die etwas weiteren Konfidenzbänder in diesem Bereich deuten auf eine gewisse Unsicherheit bezüglich der Vorhersagequalität im oberen Bereich der Habitateignung hin. Insgesamt kann die Modellqualität jedoch als gut bezeichnet werden.

Neben der Überprüfung der Modellqualität wird der Kurvenverlauf des Quotienten zwischen vorhergesagten und erwarteten Artfunden auch zur Bildung von Habitateignungsklassen herangezogen (s. Abb. 37). Die Klassengrenzen ergeben sich hierbei durch den Schnittpunkt der Kurve mit der Nulllinie des Predicted/ Expected-Quotienten sowie durch signifikante Änderungen in der Steigung der Kurve.

Eine Besonderheit im Rahmen des vorliegenden Projektes war die Anwendung der Habitatmodellierung auf zukünftige Entwicklungsszenarien. Die Habitateignung wird im Rahmen der ENFA durch einen „environmental envelope algorithm“ (HIRZEL 2011) berechnet, der auf den Ausprägungen der ökologischen Variablen an den Fundorten der betrachteten Arten basiert. Diese Fundorte lagen für zukünftige Szenarien nicht vor. Ebenso produziert der Habitateignungsalgorithmus der ENFA keine einfache Formel im Sinne einer auf erklärenden Variablen basierenden Funktion zur Berechnung der Habitateignung.

Um für die verschiedenen Szenarien und Bezugszeitpunkte die Habitateignung der Waldbestände zu schätzen, war ein weiterer Berechnungsschritt erforderlich. Dabei wurde die auf der Basis der ENFA ermittelte Habitateignung im Stichjahr 2007 mit Hilfe eines allgemeinen additiven Modells (GAM) und unter Verwendung der bereits bei der ENFA verwendeten Variablen geschätzt (Formel 39).

$$
\begin{aligned}
& y_{i}=f\left(\text { alter_l }_{i}\right)+f\left(\text { dist_h }_{-}\right)+f\left(\text { dist_ref }_{i}\right)+f\left(\text { anteil_l }_{i}\right)+ \\
& f\left(\text { anteil_ei }_{i}\right)+f\left(\text { kont }_{i}\right)+f\left(\text { anteil_bu }_{i}\right)+f\left(\text { anteil_alt }_{i}\right)+ \\
& f\left(\text { nat_best }_{i}\right)+f\left(\text { anteil_nsba }_{i}\right) \\
& \mathrm{y}_{\mathrm{i}} \quad=\text { Habitateignung ENFA für Fläche i } \\
& \mathrm{f}=\text { Glättender Term (Spline) } \\
& \text { alter_lh } \quad=\text { Maximales Alter Laubholz } \\
& \text { dist_hb } b_{i} \quad=\text { Negativ-exponentielle Distanz zu Biotopflächen der HB } \\
& \text { dist_ref } \text { f }_{i} \quad=\text { Negativ-exponentielle Distanz zu Referenzflächen } \\
& \text { anteil_lh } \mathrm{h}_{\mathrm{i}} \quad=\text { Anteil Laubholz (Volumen) } \\
& \text { anteil_ei } \dot{i}_{i}=\text { Anteil Eiche (Volumen) } \\
& \text { kont }_{\mathrm{i}} \quad=\text { Laub- und Mischwaldkontinuität (Anteil der Fläche) } \\
& \text { anteil_bu } \text { I }_{i}=\text { Anteil Buche (Volumen) } \\
& \text { anteil_alt }=\text { Anteil Altholz (Kronenschirmfläche) } \\
& \text { nat_best } t_{i}=\text { Natürlicher Bestockungsgrad } \\
& \text { anteil_nsbai }=\text { Anteil nicht-standortheimische Baumarten (Volumen) }
\end{aligned}
$$


Das Modell wurde im weiteren Verlauf der Simulationen zur Vorhersage der Habitateignung verwendet. Der Modelltyp GAM steht in der Software R als Bestandteil der Programmbibliothek mgcv zur Verfügung (R DEVELOPMENT CORE TEAM 2010, WOOD 2006).

Bei der Anwendung des GAMs auf zukünftige Waldzustände wurden die laut „Biomapper“ als „geeignet“ und „optimal“ ausgewiesenen Flächen zusammen betrachtet. Dies war notwendig, da das GAM aus statistischer Sicht bei einer Einschränkung auf die Hotspots der Klasse „optimal“ (nur in etwa 2 Prozent der gesamten Waldfläche) keine stabilen Ergebnisse lieferte.

Alle verwendeten Variablen haben hoch signifikante Effekte auf die Habitateignung. Das Modell erzielt mit einem angepassten $\mathrm{R}^{2}$-Wert von 0,892 und einer erklärten Varianz von 85,4 Prozent sehr zufriedenstellende Werte. Betrachtet man die Residuen über der vorhergesagten Habitateignung, so ist eine leichte Schwäche des Modells im Bereich der hohen Habitateignungen ab 0,9 zu erkennen (s. Abb. 38). Ursache hierfür ist offensichtlich der geringe Umfang an Beobachtungen der wichtigen Variable Laubholzalter.

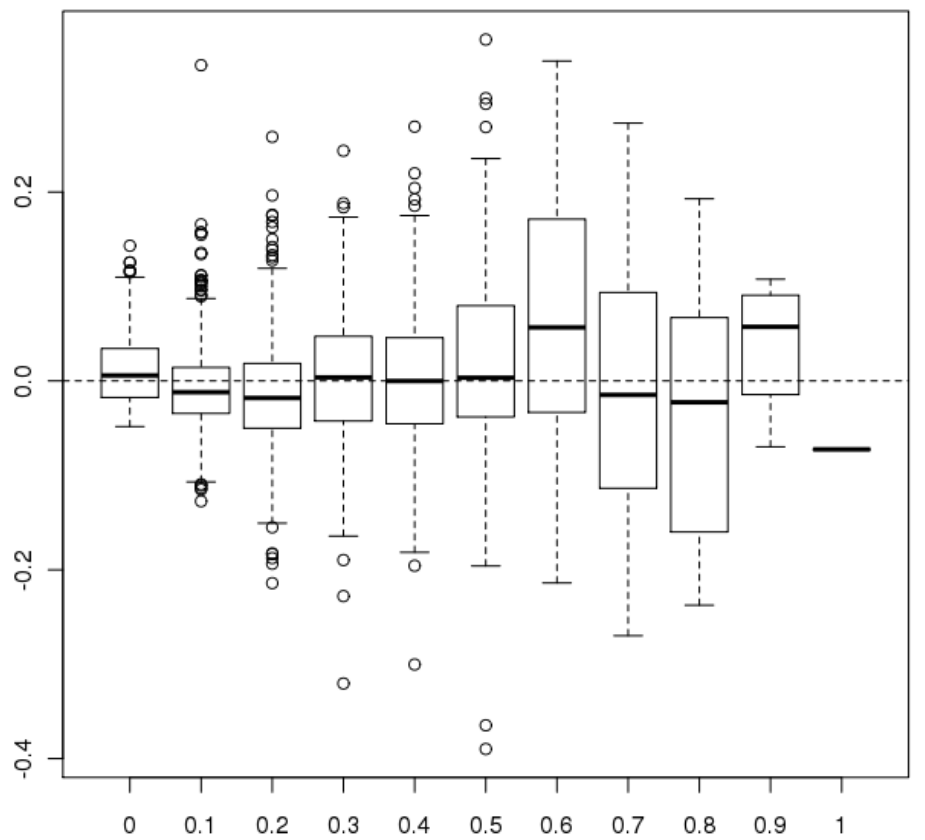

Abbildung 38: Vorbersagequalität des GAM: Residuen (Einheit des Habitateignungsindex) über vorhergesagter Habitateignung

Auf der Basis einer Vorauswahl von Flächen und in Absprache mit den zuständigen Revierleitern erfolgte eine Validierung im Gelände. Hierzu wurde eine Aus- 
wahl von 126 Hektar der identifizierten Hotspots bereist. Hierbei wurden die naturschutzfachliche Qualität der Flächen anhand der Habitatstrukturen (Kleinstrukturen, Baumindividuen, Totholz stehend und liegend) sowie der ökonomische Wert (Anteile von Stammholz der Qualitäten A, B und C) in jeweils drei Stufen angesprochen. Die bereisten Flächen wiesen in 91 Prozent der Fälle gute und sehr gute Habitatstrukturen auf. 78 Prozent der Flächen hatten eine niedrige und 22 Prozent eine mittlere ökonomische Wertigkeit. Bestände mit ökonomisch hohem Wert kamen nicht vor.

\subsubsection{Naturschutifachliche Regeln}

Naturschutzauflagen haben Einfluss auf die Waldbewirtschaftung und modifizieren die üblichen waldbaulichen Regeln in verschiedener Hinsicht. Sie reichen von einem flächenhaften Nutzungsverzicht bis zu Einschränkungen der Baumartenwahl. Aufgrund einer vollflächigen Recherche (s. Tab. 3) für das Hessische Ried wurden die möglichen Auflagen zusammengetragen und flächenscharf in die Simulationsrechnungen des WaldPlaners integriert. Hierbei konnten nur Auflagen berücksichtigt werden, die im Rahmen einer Rechtsgrundlage oder vergleichbaren Regelung konkretisiert und zudem räumlich zuzuordnen waren. Auflagen, die nicht in dieser Form vorlagen, z. B. Naturschutzvorgaben in Vogelschutzgebieten, konnten nicht in die naturschutzfachlichen Regeln integriert werden. Die in die Simulation eingeflossenen Auflagen sind in Tabelle 20 zusammengestellt und werden im Folgenden weiter erläutert.

Tabelle 20: Maßnahmenvorgaben aus Naturschutzsicht für die Simulationsläufe im WaldPlaner $\mathbf{O}=$ immer, $\mathbf{O}=$ bäufig, $\mathbf{O}=$ selten, $-=$ keine Vorgabe)

\begin{tabular}{|c|c|c|c|c|c|c|}
\hline Auflage & $\begin{array}{l}\text { FFH- } \\
\text { Lebens- } \\
\text { raum- } \\
\text { typen } \\
\text { (LRT) }\end{array}$ & $\begin{array}{l}\text { Natur- } \\
\text { schutz- } \\
\text { gebiete } \\
\text { (NSG) }\end{array}$ & $\begin{array}{l}\text { Natur- } \\
\text { wald- } \\
\text { reservat } \\
\text { (NWR) }\end{array}$ & $\begin{array}{l}\text { Gesetzlich } \\
\text { geschützte } \\
\text { Biotope }\end{array}$ & $\begin{array}{l}\text { Kompen- } \\
\text { sationsmaß } \\
\text { nahmen } \\
\text { Flughafen } \\
\text { Frankfurt }\end{array}$ & $\begin{array}{l}\text { Wald } \\
\text { außer } \\
\text { regel- } \\
\text { mäßigem } \\
\text { Betrieb } \\
\text { (WarB) }\end{array}$ \\
\hline $\begin{array}{l}\text { Flächenhafter } \\
\text { Nutzungs- } \\
\text { verzicht }\end{array}$ & 0 & 0 & 0 & - & 0 & - \\
\hline $\begin{array}{l}\text { Erhalt der } \\
\text { Waldgesell- } \\
\text { schaft }\end{array}$ & 0 & 0 & - & 0 & 0 & - \\
\hline Erhalt Altholz & 0 & 0 & - & - & - & - \\
\hline $\begin{array}{l}\text { Mindestanzahl } \\
\text { Habitatbäume }\end{array}$ & 0 & - & - & - & - & - \\
\hline
\end{tabular}




\subsubsection{Flächenhafter Nutzungsverzicht}

Die Maßnahmenvorgabe flächenhafter Nutzungsverzicht unterbindet jegliches forstliches Eingreifen auf den entsprechenden Flächen. Es findet weder eine Nutzung statt, noch werden Pflanzungen durchgeführt.

Im Rahmen der Simulationen wurde der prioritäre FFH-Lebensraumtyp (LRT) „Erlen- und Eschenwälder und Weichholzauenwälder an Fließgewässern“ (*91E0) grundsätzlich mit einem Nutzungsverzicht belegt. Prioritäre Lebensraumtypen sind laut FFH-Richtlinie „vom Verschwinden bedroht“. Im Falle des LRT *91E0 umfasst die Definition der betroffenen Waldgesellschaften sowohl Weichholzauenwälder als auch Schwarzerlenwälder und bachbegleitende Erlen-Eschenwälder.

Der Wald im Naturschutzgebiet „Kühkopf-Knoblochsaue“ ist laut Verordnungstext ganzflächig mit einem Nutzungsverzicht belegt. Des Weiteren gehen die Abteilungen 31A1 und 32A1 im Naturschutzgebiet „Sauergrund“ als Flächen mit Nutzungsverzicht ein. Das Naturwaldreservat „Karlswörth“ zählt ebenfalls zu den Flächen mit Nutzungsverzicht. Es liegt zudem innerhalb des NSG „KühkopfKnoblochsaue“.

Weitere Nullnutzungsflächen befinden sich im Forstamt Groß-Gerau, wo Waldflächen als Kompensationsmaßnahmen für die Flughafenerweiterung ausgewiesen wurden, im Gemeindewald Nauheim im Rahmen eines Ökopunktekontos und in geringem Umfang im Stadtwald Frankfurt.

Die aus der Habitatmodellierung hervorgegangenen Hotspots der Alters- und Zerfallsphase wurden im Laufe der Simulation in Anlehnung an das Kernflächenkonzept von HESSEN-FORST (2011) mit einem Nutzungsverzicht belegt.

Der Wald außer regelmäßigem Betrieb (WarB), der im Rahmen der Eigenbindung von Forsteinrichtungsperiode zu Forsteinrichtungsperiode hinsichtlich der Festlegung des Nutzungsverzichts überprüft wird, wurde in den Simulationsrechnungen nicht mit einem Nutzungsverzicht belegt.

\subsubsection{Erbalt der $W$ aldgesellschaft}

Der Erhalt der Waldgesellschaft wurde dort festgeschrieben, wo bestimmte Waldgesellschaften 1t. NSG-Verordnung oder in FFH-Gebieten geschützt sind. Dabei wurde die räumliche Lage der Lebensraumtypen im Simulationszeitraum nicht verändert. Aus den im Untersuchungsgebiet vorkommenden Naturschutzauflagen im Wald ergeben sich die in Tabelle 21 genannten geschützten Waldgesellschaften. Für jede Waldgesellschaft wurden diejenigen Baumarten festgelegt, die im Laufe der Bestandespflege gefördert werden. Bei einer künstlichen Verjüngung ist die Baumartenwahl auf den entsprechenden Flächen auf die in Tabelle 21 genannten Baumarten beschränkt. Dies bedeutet aber nicht, dass bereits vorhandene oder sich natürlich ansamende Baumarten gezielt beseitigt werden. 
Tabelle 21: Im Untersuchungsgebiet vorkommende geschützte Waldgesellschaften und die zugehörigen Baumarten, die im Rahmen der Simulationsläufe gefördert bzw. im Falle einer künstlichen Verjüngung gepflanzt wurden. Die Baumart Eiche ging als Stiel- oder Traubeneiche ein, nicht als Roteiche. Die Baumartengruppen Weide, Ulme und Wildobst wurden nicht auf der Artenebene differenziert.

\begin{tabular}{|c|c|c|}
\hline Waldgesellschaft & FFH-Lebensraumtyp (LRT) & $\begin{array}{l}\text { Baumartenzusammen- } \\
\text { setzung }\end{array}$ \\
\hline Eichenwald (arm) & $\begin{array}{l}\text { Alte bodensaure Eichenwälder } \\
\text { (LRT 9190) }\end{array}$ & $\begin{array}{l}\text { Eiche: } 70 \% \\
\text { Sandbirke: } 30 \%\end{array}$ \\
\hline $\begin{array}{l}\text { Stieleichen- } \\
\text { Hainbuchenwald }\end{array}$ & $\begin{array}{l}\text { Stieleichen-Hainbuchenwald } \\
\text { (LRT 9160) }\end{array}$ & $\begin{array}{l}\text { Eiche: } 70 \% \text {, } \\
\text { Hainbuche: } 30 \%\end{array}$ \\
\hline Buchenwald & $\begin{array}{l}\text { Hainsimsen-Buchenwald und } \\
\text { Waldmeister-Buchenwald } \\
\text { (LRT } 9110 \text { und LRT 9130) }\end{array}$ & Buche: $100 \%$ \\
\hline Laubmischwald & & $\begin{array}{l}\text { Buche: } 20 \% \text {, Esche: } 35 \% \text {, } \\
\text { Bergahorn: } 35 \% \text {, } \\
\text { Vogelkirsche: } 10 \%\end{array}$ \\
\hline Hartholzauenwald & Hartholzauenwald (LRT 91F0) & $\begin{array}{l}\text { Eiche: } 70 \% \text {, Esche: } 15 \% \text {, } \\
\text { Ulme: } 10 \% \text {, Wildobst: } 5 \%\end{array}$ \\
\hline Weichholzauenwald & Weichholzauenwald (LRT 91E0) & Weide: $100 \%$ \\
\hline Erlenbruchwald & & Roterle: $100 \%$ \\
\hline Eschen-Bach-Wald & Inbegriffen in LRT $91 \mathrm{E} 0$ & Esche: $60 \%$, Roterle: $40 \%$ \\
\hline Erlen-Bach-Wald & Inbegriffen in LRT 91E0 & Esche: $40 \%$, Roterle: $60 \%$ \\
\hline Kiefernwald & & $\begin{array}{l}\text { Waldkiefer: } 60 \% \text {, } \\
\text { Eiche: } 30 \% \text {, Sandbirke: } 10 \%\end{array}$ \\
\hline
\end{tabular}

Mittlerweile sind im WaldPlaner Wachstumsmodelle für zahlreiche Baumarten implementiert (HANSEN u. NAGEL 2011). Für einige naturschutzfachlich relevante Baumarten (Weidenarten, Schwarzpappel, Ulmenarten) liegen aber keine Wachstumsmodelle vor, sodass für diese die Modelle anderer Wirtschaftsbaumarten verwendet werden mussten.

Aus den Naturschutzgebietsverordnungen geht unter $₫ 2$ (Zweck der Unterschutzstellung) hervor, welche Waldgesellschaften in einem Gebiet geschützt sind. Die zu schützenden Waldgesellschaften wurden in Naturschutzgebieten, die gleichzeitig auch FFH-Status haben, auf der Grundlage der Biotoptypenkartierung der FFH-Grunddatenerhebung hergeleitet. In Naturschutzgebieten, die keinen FFHStatus haben, wurden die relevanten Waldgesellschaften aus den Forsteinrichtungsdaten abgeleitet, indem der derzeitig aufstockende Bestand betrachtet wurde.

Laut $\int 30$ des Bundesnaturschutzgesetzes (BNatschG) ist die Zerstörung oder eine sonstige erhebliche oder nachhaltige Beeinträchtigung von gesetzlich 
geschützten Biotopen verboten. Im Untersuchungsgebiet betrifft dies die vorkommenden Waldgesellschaften Bruch-, Sumpf- und Auwälder. Die Verortung konnte aus der Hessischen Biotopkartierung abgeleitet werden. Allerdings ist zu beachten, dass die Flächen der Hessischen Biotopkartierung nicht als rechtsverbindlich gelten, sondern lediglich auf ein Vorkommen der gesetzlich geschützten Biotope hinweisen.

Weiterhin besteht eine Bindung an die Baumarten Buche und Eiche auf einem Teil der Kompensationsflächen der Flughafen AG im Forstamt Groß-Gerau.

\subsubsection{Erhalt Altholz.}

Auf den FFH-Lebensraumtypenflächen mit der Wertstufe A und B wurde ein partieller Erhalt des Altholzes vorgegeben. Es wurden 40 bzw. 20 Prozent aller Bäume mit einem BHD ab $50 \mathrm{~cm}$ aus der Nutzung genommen. Berücksichtigt wurden nur Baumarten der namengebenden Lebensraumtypen.

Im Naturschutzgebiet Mönchbruch ist per Verordnung ein Nutzungsverzicht aller Bäume ab einem Brusthöhendurchmesser von $50 \mathrm{~cm}$ festgeschrieben.

\subsubsection{Mindestanzabl Habitatbäume}

Der WaldPlaner weist aus technischen Gründen unabhängig vom Bestandesalter drei Habitatbäume je Hektar aus. Des Weiteren wurden auf FFH-Lebensraumtypflächen mit dem Erhaltungszustand A sechs Habitatbäume ausgewählt, um den Erhalt der Wertstufe zu gewährleisten (BUNDESAMT FÜR NATURSCHUTZ 2010).

\subsubsection{Waldbauregeln}

\subsubsection{Erfahrungswissen der Forstämter}

Die Aufbereitung und standortsabhängige Analyse des vorhandenen Erfahrungswissens der Forstämter zur Verjüngung, Pflege und Nutzung der Wälder im Hessischen Ried diente einerseits der Ableitung praxisbezogener Verjüngungs- und Nutzungsregeln für die verschiedenen Waldentwicklungsszenarien (Kapitel 2.2.11.2) und andererseits der Entwicklung des in Kapitel 2.2.7 beschriebenen Mortalitätsmodells.

Als Datengrundlage konnten neben der verfügbaren Literatur (u. a. PRIES et al. 1999, ZIMMERMANN 1989) noch verschiedene weitere Quellen genutzt werden. $\mathrm{Zu}$ nennen sind hier zunächst die mündlichen Mitteilungen der Forstamtsleiter im Rahmen von Exkursionen und Besprechungen sowie die schriftlichen Ausführungen ehemaliger Mitarbeiter des Landesbetriebes HESSEN-FORST (ROSENSTOCK, PRADLER, mdl. Mitteilung). Wichtige Informationen über den Betriebsvollzug in den staatlichen Forstämtern konnten aus den von der Landesbetriebsleitung zur Verfügung gestellten HEKAS-Daten (HolzErnte, Kulturen, Astung, Schälschutz) gewonnen werden. Daneben wurde auf alte und aktuelle Forsteinrichtungsdaten, 
Daten der forstökologischen Weiserflächen sowie auf frühere Erhebungen zur Vergrasung von Beständen (PRIES et al. 1999) zurückgegriffen.

Darüber hinaus wurde eine an die örtlichen Revierleiter der vier staatlichen Forstämter gerichtete, standardisierte Umfrage zum Waldzustand durchgeführt. Diese Umfrage erfolgte anhand eines Fragebogens (s. Anhang 3), wo im Anhalt an die Altersstufeneinteilung der WZE für jüngere $(\leq 60 \mathrm{Jahre})$ und ältere Bestände (> 60 Jahre) jeweils zwei bis drei Beispiele für Eiche, Buche und Kiefer betrachtet wurden, die entweder „,besonders vital“ oder aber „stark geschädigt" erschienen. Zusätzlich wurden die jährlichen Waldzustandsberichte zur Einschätzung der Vitalität der Waldbestände im Hessischen Ried herangezogen.

Zudem sollte in der Abfrage eine kurze Dokumentation der Waldverjüngungsmaßnahmen der letzten 15 Jahre anhand prägnanter positiver und negativer Beispiele hinsichtlich der verwendeten Verjüngungsverfahren und -techniken wiedergegeben werden. Der Erfolg von Verjüngungsmaßnahmen wurde stichprobenartig an ausgewählten Flächen im Gelände überprüft.

Die Umfrage zur Vitalität der Bestände wurde differenziert nach Standortseigenschaften analysiert. Die Informationen zu den Bodenarten und dem Geländewasserhaushalt wurden den Forsteinrichtungsdaten entnommen. In Anlehnung an RIEBELING und HOCKE (1988) erfolgte eine Zusammenfassung der Hauptbodenarten zu drei Bodensubstratgruppen. Neben nahezu unverlehmten Sanden wurden besser verlehmte Sande und stark lehmige Standorte (Lehme und Tone) ausgeschieden. Weiterhin wurde nach der Veränderung der Grundwasserstände zwischen den Bezugsjahren 1951 und 2007 stratifiziert.

\subsubsection{Ableitung der Waldbauregeln}

Für die Szenarien wurde ein Regelset für die waldbauliche Behandlung erstellt, welches Vorgaben für die folgenden waldbaulichen Maßnahmen enthält:

- Zuordnung der Waldentwicklungstypen nach den Standortsverhältnissen (Standortstypen)

- Baumartenzusammensetzung der Waldentwicklungstypen

- Zuordnung der Zielstärken nach Standortstyp und Hauptbaumart

- Bewirtschaftung der Bestände nach Hauptbaumart und Grundwasserveränderung

- Verjüngungsgang unter Berücksichtigung der Baumartengruppe des Vorund des Zielbestandes

Alle waldbaulichen Regeln orientierten sich an den Vorgaben der HAFEA (HMULF 2002), der Waldbaufibel von HeSSEN-FORST (2008), dem Erfahrungswissen der örtlichen Forstbediensteten sowie an Versuchsergebnissen der NWFVA. 
Der Standortstyp wurde über die Trophie und die Frischestufe ermittelt. Letztere wurde für die terrestrischen Standorte aus der nutz̧baren Feldkapazität (nFK), bezogen auf eine Tiefe von $140 \mathrm{~cm}$ und der klimatischen Wasserbilanz, (kWB) hergeleitet und stellt somit das pflanzenverfügbare $W$ asser dar. Die grundwasserbeeinflussten Standorte wurden nach dem mittleren berechneten Grundwasserflurabstand und die wechselfeuchten bzw. wechseltrockenen Standorte nach Tiefenlage des Staukörpers eingeschätzt. Dabei wurde die in Tabelle 22 dargestellte Einteilung vorgenommen.

Tabelle 22: $\quad$ Einteilung der Frischestufen

\begin{tabular}{|c|c|c|}
\hline & Frischestufe & $\mathrm{kWB}+\mathrm{nFK}$ \\
\hline \multirow{6}{*}{$\begin{array}{l}\text { terrestrische } \\
\text { Standorte }\end{array}$} & F1 - sehr hoch & $>120 \mathrm{~mm}$ \\
\hline & F2 - hoch & $31-120 \mathrm{~mm}$ \\
\hline & F3 - mäßig & $-9-30 \mathrm{~mm}$ \\
\hline & F4 - gering & -65 bis $-10 \mathrm{~mm}$ \\
\hline & F5 - sehr gering & $<-65 \mathrm{~mm}$ \\
\hline & & Grundwasserstand unter Flur \\
\hline \multirow{4}{*}{$\begin{array}{l}\text { grundwasser- } \\
\text { beeinflusste } \\
\text { Standorte }\end{array}$} & GW1 - nass & $\begin{array}{l}0-60 \mathrm{~cm} \\
\text { (starker GW-Einfluss) }\end{array}$ \\
\hline & GW2 - feucht & $\begin{array}{l}61-150 \mathrm{~cm} \\
\text { (bedeutender GW-Einfluss) }\end{array}$ \\
\hline & GW3 - mäßig feucht & $\begin{array}{l}\text { 151-250 cm } \\
\text { (physiologisch günstiger GW-Einfluss) }\end{array}$ \\
\hline & & Lage des Stauhorizontes \\
\hline \multirow{2}{*}{$\begin{array}{l}\text { Übergangs- } \\
\text { standorte }\end{array}$} & SW1 - wechselfeucht & tiefer anstehend $(61-150 \mathrm{~cm} \mathrm{u.} \mathrm{Flur)}$ \\
\hline & SW2 - wechseltrocken & hoch anstehend (0-60 $\mathrm{cm}$ u. Flur) \\
\hline
\end{tabular}

Auf der Basis dieser Einteilung wurden den einzelnen Standortstypen sogenannte Waldentwicklungstypen (WET) zugeordnet. Unter WET wird die waldbaulich definierte Zielvorstellung für einen Bestand auf einem gegebenen Standort verstanden, die durch das Produktions-, Verjüngungs- und das Bestandesziel charakterisiert ist.

Die für einen Standortstyp möglichen Waldentwicklungstypen (s. Tab. 23) wurden hinsichtlich ihrer Bedeutung in vorrangige (Fettdruck) und nachrangige (Normaldruck) WET aufgeteilt und mit einer prozentualen Gewichtung für ihren Anteil an der angestrebten Waldentwicklung versehen. Dabei erhielten die vorrangigen WET eine gleich verteilte Gewichtung von 90 Prozent, die nachrangigen eine ebenfalls gleich verteilte Gewichtung von 10 Prozent. Die konkrete Zuweisung eines WET erfolgt im WaldPlaner unter Berücksichtigung des Vorbestandes und 
spielt insbesondere bei der Waldverjüngung sowie bei der baumartenspezifischen Steuerung der Eingriffsstärke bei Durchforstungen eine Rolle.

Für jeden WET wurde die prozentuale Baumartenzusammensetzung als Zielvorstellung für den Endbestand (s. Tab. 24) sowie die standortstypen- und baumartenspezifische Zielstärke (s. Tab. 25) festgelegt.

Die waldbauliche Behandlung der Bestände erfolgte entwicklungsphasenorientiert im WaldPlaner über ein Regelset, welches die folgenden ertragskundlichen Kenndaten berücksichtigt:

- Baumart

- Entwicklungsphase

- Oberhöhe (H100)

- Zielstärke

- Eingriffshäufigkeit

- Eingriffsart

- Anzahl Z-Bäume

- maximale Entnahmemenge je Eingriff

- minimale Entnahmemenge je Eingriff

- Grundfläche nach ET

- Bestockungsgrad nach ET

- Kritischer Kronenschlussgrad für Verjüngung 
Tabelle 23: Zuordnung von Waldentwicklungstypen zu den Standortstypen

\begin{tabular}{|c|c|c|c|c|c|c|c|c|}
\hline $\begin{array}{l}\text { Frische- } \\
\text { stufe } \\
\text { Tophie }\end{array}$ & $\begin{array}{c}\text { nass } \\
\text { GW1 }\end{array}$ & $\begin{array}{c}\text { feucht/ } \\
\text { w-feucht } \\
\text { GW2/SW1 }\end{array}$ & $\begin{array}{c}\text { wechsel- } \\
\text { trocken } \\
\text { SW2 }\end{array}$ & $\begin{array}{c}\text { sehr hoch } \\
\text { F1 }\end{array}$ & $\begin{array}{c}\text { hoch } \\
\text { F2 }\end{array}$ & $\begin{array}{c}\text { mäßig } \\
\text { F3 }\end{array}$ & $\begin{array}{l}\text { gering } \\
\text { F4 }\end{array}$ & $\begin{array}{c}\text { sehr } \\
\text { gering } \\
\text { F5 } \\
\end{array}$ \\
\hline \multirow{9}{*}{$\begin{array}{l}\text { eutroph } \\
\text { (1) }\end{array}$} & \multirow{4}{*}{$\begin{array}{l}\text { Ei Es } \\
\text { Ah } \\
\text { Es RErl } \\
\text { RErl }\end{array}$} & \multicolumn{2}{|c|}{ Es Ah Bu Ei HBu } & \multicolumn{3}{|c|}{ Es Ah Bu Es Ah Bu Ei Hbu } & Ei Hbu & $\mathrm{Ki} \mathrm{Li}$ \\
\hline & & \multirow{2}{*}{\multicolumn{2}{|c|}{$\begin{array}{l}\text { Ei Es Ah } \\
\text { HBu }\end{array}$}} & \multicolumn{2}{|c|}{ Bu Es Ah Bu Es Ah } & \multirow{3}{*}{$\begin{array}{l}\mathrm{Es} \mathrm{Li} \\
\mathrm{HBu}\end{array}$} & Ei Bu & \multirow[t]{3}{*}{$\mathrm{Ki} \mathbf{E i}$} \\
\hline & & & & $\mathrm{Ei} \mathrm{HBu}$ & Nuss & & Li Ah Kir & \\
\hline & & \multicolumn{2}{|l|}{ Ei HBu } & & & & $\mathrm{Es}_{\mathbf{s i}}$ & \\
\hline & $\begin{array}{l}\mathrm{Li} \text { Ah Kir } \\
\mathrm{Bu}\end{array}$ & $\begin{array}{l}\text { Li Ah Kir } \\
\mathrm{Bu}\end{array}$ & $\begin{array}{l}\text { Ei Es Ah } \\
\mathrm{HBu}\end{array}$ & $\begin{array}{l}\mathrm{Li} \text { Ah Kir } \\
\mathrm{Bu}\end{array}$ & $\begin{array}{l}\text { Ei Es Ah } \\
\text { Hbu }\end{array}$ & $\begin{array}{l}\mathrm{Li} \text { Ah Kir } \\
\mathrm{Bu}\end{array}$ & $\mathrm{Ki} \mathrm{Li}$ & Rob \\
\hline & $\mathrm{Ei} \mathrm{HBu}$ & Es RErl & & Ei Es Ah & Ei Hbu & $\mathrm{Bu}$ & & \\
\hline & & $\mathrm{SPa}$ & & & $\mathrm{Ei} \mathrm{Bu}$ & & & \\
\hline & & & & $\mathrm{Cl} \mathrm{Du}$ & $\mathrm{Bu}$ & & & \\
\hline & & & & $\mathrm{Bu}$ & & & & \\
\hline \multirow{9}{*}{$\begin{array}{l}\text { mesotroph } \\
\text { (2) }\end{array}$} & \multirow{9}{*}{$\begin{array}{l}\text { Ei HBu } \\
\text { RErl } \\
\text { Ei Bi }\end{array}$} & \multirow{5}{*}{$\begin{array}{l}\text { Ei HBu } \\
\text { REi HBu } \\
\text { Ei Bu }\end{array}$} & \multirow{5}{*}{$\begin{array}{l}\text { Ei HBu } \\
\text { REi HBu }\end{array}$} & Bu Dgl & Dgl Bu & \multirow{5}{*}{$\begin{array}{l}\text { Dgl Bu } \\
\text { REi HBu } \\
\text { Ei Hbu } \\
\text { Ki Bu }\end{array}$} & REi Bu & $\mathbf{K i}$ \\
\hline & & & & $\mathrm{Ei} \mathrm{Bu}$ & Bu Dgl & & Dgl Ki & $\mathbf{K i} \mathbf{B i}$ \\
\hline & & & & REi Bu & Ei HBu & & & \\
\hline & & & & Bu KTa & REi Bu & & Ki Bi Ei & \\
\hline & & & & & K1 Bu & & Ki Dgl & \\
\hline & & $\mathrm{Bu}$ & $\mathrm{Ei} \mathrm{Bi}$ & Ei Hbu & $\mathrm{Ei} \mathrm{Bu}$ & $\mathrm{Bu} \mathrm{Dgl}$ & Ki TKir & Ki TKir \\
\hline & & RErl & $\mathrm{Ei} \mathrm{Bu}$ & $\mathrm{Bu}$ & $\mathrm{Bu}$ & $\mathrm{Bu}$ & $\mathrm{Ki} \mathrm{Bu}$ & Rob \\
\hline & & & Rob & & $\mathrm{KTa} \mathrm{Bu}$ & $\mathrm{KTa} \mathrm{Bu}$ & Str & \\
\hline & & & $\mathrm{Ki} \mathrm{Bi}$ & & & & Rob & \\
\hline \multirow{9}{*}{$\begin{array}{l}\text { oligotroph } \\
\text { (3) }\end{array}$} & \multirow{5}{*}{$\begin{array}{l}\mathbf{B i ~ K i} \\
\mathbf{K i} \mathbf{B i}\end{array}$} & \multirow{5}{*}{$\begin{array}{l}\text { Ki Dgl } \\
\mathrm{Bu} \\
\mathrm{Ei} \mathrm{Bi} \\
\text { Ki Bi Ei } \\
\text { Asp Bi }\end{array}$} & \multirow{5}{*}{$\begin{array}{l}\text { Ei Bi } \\
\text { Ki Bi Ei }\end{array}$} & $\begin{array}{l}\text { Ki Dg1 } \\
\mathrm{Bu}\end{array}$ & $\begin{array}{l}\text { Ki Dg1 } \\
\text { Bu }\end{array}$ & $\begin{array}{l}\text { Ki Dgl } \\
\text { Bu }\end{array}$ & $\begin{array}{l}\text { Ki Dgl } \\
\mathrm{Bu}\end{array}$ & \multirow{5}{*}{$\begin{array}{l}\mathrm{Ki} \\
\mathrm{Ki} \mathrm{Bi}\end{array}$} \\
\hline & & & & KTa Bu & Dgl Bu & Dgl Ki & $\mathbf{K i} \mathbf{B i} \mathbf{E i}$ & \\
\hline & & & & $\mathbf{K i}$ & REi Bu & & $\mathbf{K i}$ & \\
\hline & & & & & & N1 D1 E1 & & \\
\hline & & & & & & $\mathbf{K i}$ & & \\
\hline & Asp Bi & $\mathrm{REi} \mathrm{Bu}$ & $\mathrm{Bi} \mathrm{Ki}$ & REi Bu & $\mathrm{Ki} \mathrm{Bu}$ & $\mathrm{Bi} \mathrm{Ki}$ & Ki TKir & \\
\hline & \multirow[t]{3}{*}{ RErl } & \multirow[t]{3}{*}{$\mathrm{Ki} \mathrm{Bi}$} & \multirow[t]{3}{*}{ Asp Bi } & $\mathrm{Ki} \mathrm{Bi}$ & Ki TKir & $\mathrm{Ki} \mathrm{Ei}$ & $\mathrm{Bi} \mathrm{Ki}$ & \\
\hline & & & & Ei Bi & $\mathrm{KTa} \mathrm{Bu}$ & Ki TKir & & \\
\hline & & & & & & KTa Bu & & \\
\hline
\end{tabular}


Tabelle 24: $\quad$ Baumartenanteile für die verschiedenen $W$ aldentwicklungstypen in Prozent

\begin{tabular}{|c|c|c|c|c|c|c|c|c|c|c|c|c|c|c|c|}
\hline $\begin{array}{l}\dot{\vec{Z}} \\
\dot{5} \\
\dot{y}\end{array}$ & 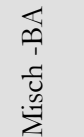 & iت & 绖 & $\vec{\oplus}$ & 胥 & $\underset{2}{2}$ & 我 & $\tilde{z}_{z}^{\infty}$ & $\exists$ 곰 & $\vec{n}$ & के & $\hat{0}$ & $\therefore \overbrace{}^{\vec{b}}$ & 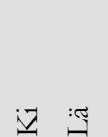 & 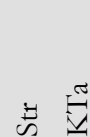 \\
\hline $10 \mathbf{E i}$ & & 80 & & & 5 & & & & 5 & 10 & & & & & \\
\hline $11 \mathbf{E i}$ & $\mathrm{HBu}$ & 80 & & & 15 & & & & & 5 & & & & & \\
\hline $12 \mathbf{E i}$ & $\mathrm{Bu}$ & 75 & & 15 & & & & & & 10 & & & & & \\
\hline $\begin{array}{ll}\mathbf{E i} \\
\end{array}$ & ALh & 40 & & & 10 & 15 & 25 & & 10 & & & & & & \\
\hline $\begin{array}{ll}\mathbf{E i} \\
\end{array}$ & $\mathrm{Bi}$ & 60 & & & & & & & & 40 & & & & & \\
\hline $17 \mathbf{E i}$ & $\mathrm{Ki}$ & 50 & & & & & & & & 10 & & & & 40 & \\
\hline 18 REi & $\mathrm{Bu}$ & & 75 & 20 & & & & & & 5 & & & & & \\
\hline $\begin{array}{ll}19 & \text { REi } \\
\end{array}$ & $\mathrm{HBu}$ & & 75 & & 20 & & & & & 5 & & & & & \\
\hline $\begin{array}{ll}20 \mathbf{B u} \\
\end{array}$ & & & & 90 & & & & & & 10 & & & & & \\
\hline $23 \mathbf{B u}$ & ALh & & & 55 & & 10 & 25 & 5 & & 5 & & & & & \\
\hline $26 \mathrm{Bu}$ & $\mathrm{Dgl}$ & & & 55 & & & & & & 5 & & & 40 & & \\
\hline $29 \mathrm{Bu}$ & $\begin{array}{l}\text { KTa } \\
\text { WTa }\end{array}$ & & & 50 & & & & & & 5 & & & & & 45 \\
\hline $31 \mathbf{A L h}_{\mathbf{f}}$ & & & & 20 & & 34 & 36 & 10 & & & & & & & \\
\hline $33 \mathbf{A L h}_{\mathbf{t}}$ & & 10 & & 10 & & 10 & 50 & 5 & 10 & 5 & & & & & \\
\hline 34 Es & RErl & & & & & & 55 & & 40 & 5 & & & & & \\
\hline $35 \quad$ Ah & ALh & 15 & & 15 & 10 & 30 & & 10 & 20 & & & & & & \\
\hline 40 RErl & & & & & & & & & 90 & 10 & & & & & \\
\hline 42 Asp & $\mathrm{Bi}$ & 5 & & & & & & & 5 & 40 & 50 & & & & \\
\hline 43 Rob & & & & & & & & & & 10 & & 90 & & & \\
\hline $44 \mathbf{M B i}$ & $\begin{array}{l}\text { RErl/ } \\
\mathrm{Ki}\end{array}$ & & & & & & & & 10 & 80 & & & & 10 & \\
\hline $\begin{array}{ll}47 & \mathbf{B i} \\
\end{array}$ & $\mathrm{Ki}$ & 15 & & & & & & & & 70 & & & & 15 & \\
\hline $49 \mathbf{S P a}$ & & & & & & & & & & 10 & 90 & & & & \\
\hline $\begin{array}{ll}50 & \mathbf{F i}\end{array}$ & & & & 20 & & & & & & 20 & & & 60 & & \\
\hline $\begin{array}{ll}62 & \text { Dgl } \\
\end{array}$ & $\mathrm{Bu}$ & & & 20 & & & & & & & & & 80 & & \\
\hline $67 \mathrm{Dgl}$ & $\begin{array}{l}\mathrm{Ki} / \\
\mathrm{Bu}\end{array}$ & & & 10 & & & & & & & & & 60 & 30 & \\
\hline 69 Dgl & $\begin{array}{l}\mathrm{KTa} / \\
\mathrm{Bu}\end{array}$ & & & 10 & & & & & & & & & 50 & & 40 \\
\hline $70 \mathbf{K i}$ & & 10 & & & & & & & & 5 & & & & 85 & \\
\hline $\begin{array}{ll}71 \quad \mathbf{K i} \\
\end{array}$ & $\mathrm{Ei}$ & 20 & & & & & & & & 10 & & & & 70 & \\
\hline $72 \mathbf{K i}$ & $\mathrm{Bu}$ & & & 25 & & & & & & 5 & & & & 70 & \\
\hline $73 \mathbf{~ K i}$ & WLi & & & & & & & & 45 & 5 & & & & 50 & \\
\hline 75 Str & & & & & & & & & & 10 & & & & & 90 \\
\hline $74 \mathbf{~ K i}$ & Bir & & & & & & & & & 20 & & & & 80 & \\
\hline $76 \mathbf{K i}$ & $\begin{array}{l}\mathrm{Dgl} / \\
\mathrm{Bu}\end{array}$ & & & 10 & & & & & & 5 & & & 35 & 50 & \\
\hline $\begin{array}{ll}79 \mathbf{~ K i} \\
\end{array}$ & TKir & & & & & & & & & 10 & & & & 90 & \\
\hline $\begin{array}{ll}80 & \text { Lä } \\
\end{array}$ & & & & 20 & & & & & & 15 & & & & 65 & \\
\hline 92 KTa & $\mathrm{Bu}$ & & & 45 & & & & & & 5 & & & & & 50 \\
\hline 93 Nuss & $\mathrm{HBu}$ & & & & 20 & & & 75 & & 5 & & & & & \\
\hline
\end{tabular}


Tabelle 25: $\quad$ Standortstypen- und baumartensperifische Zielstärkendefinition [cm]

\begin{tabular}{|c|c|c|c|c|c|c|c|c|c|}
\hline T & $\begin{array}{l}\text { sche- } \\
\text { stufe }\end{array}$ & nass & $\begin{array}{c}\text { feucht/ } \\
\text { wechsel- } \\
\text { feucht }\end{array}$ & $\begin{array}{l}\text { wechsel- } \\
\text { trocken }\end{array}$ & $\begin{array}{l}\text { sehr } \\
\text { hoch }\end{array}$ & hoch & mäßig & gering & $\begin{array}{l}\text { sehr } \\
\text { gering }\end{array}$ \\
\hline Trophie & & GW1 & GW2/SW1 & SW2 & F1 & $\mathrm{F} 2$ & F3 & F4 & F4 \\
\hline & $\mathrm{Ei}$ & 75 & 75 & 70 & 70 & 70 & 65 & 65 & 55 \\
\hline & $\mathrm{Bu}$ & 50 & 60 & 50 & 60 & 60 & 55 & 50 & 40 \\
\hline & Edl & 60 & 60 & 50 & 60 & 60 & 50 & 50 & 40 \\
\hline eutroph & Wlb & 45 & 45 & 40 & 45 & 45 & 40 & 40 & 35 \\
\hline (1) & $\mathrm{Fi}$ & 35 & 35 & 35 & 35 & 35 & 35 & 35 & 35 \\
\hline & $\mathrm{Dgl}$ & 60 & 70 & 60 & 70 & 70 & 70 & 65 & 55 \\
\hline & $\mathrm{Ki}$ & 45 & 45 & 40 & 45 & 45 & 45 & 40 & 40 \\
\hline & Lä & 50 & 60 & 50 & 60 & 60 & 60 & 50 & 45 \\
\hline & $\mathrm{Ei}$ & 65 & 65 & 60 & 65 & 60 & 60 & 60 & 50 \\
\hline & $\mathrm{Bu}$ & 45 & 60 & 45 & 60 & 55 & 50 & 45 & 35 \\
\hline & Edl & 55 & 50 & 50 & 55 & 50 & 50 & 45 & 35 \\
\hline meso- & Wlb & 45 & 45 & 40 & 45 & 45 & 45 & 35 & 35 \\
\hline troph & $\mathrm{Fi}$ & 35 & 35 & 35 & 35 & 35 & 35 & 35 & 35 \\
\hline & $\mathrm{Dgl}$ & 60 & 60 & 50 & 65 & 65 & 60 & 55 & 50 \\
\hline & $\mathrm{Ki}$ & 50 & 45 & 40 & 45 & 45 & 45 & 40 & 40 \\
\hline & Lä & 50 & 60 & 50 & 60 & 60 & 60 & 50 & 45 \\
\hline & $\mathrm{Ei}$ & 50 & 50 & 50 & 55 & 55 & 50 & 45 & 45 \\
\hline & $\mathrm{Bu}$ & 40 & 45 & 40 & 50 & 50 & 45 & 40 & 30 \\
\hline & Edl & 40 & 40 & 40 & 40 & 40 & 35 & 35 & 30 \\
\hline oligo- & Wlb & 40 & 40 & 35 & 35 & 35 & 35 & 35 & 30 \\
\hline $\begin{array}{c}\text { (ropn } \\
\text { (3) }\end{array}$ & $\mathrm{Fi}$ & 35 & 35 & 35 & 35 & 35 & 35 & 35 & 35 \\
\hline & $\mathrm{Dgl}$ & 55 & 55 & 50 & 55 & 55 & 50 & 50 & 45 \\
\hline & $\mathrm{Ki}$ & 40 & 40 & 40 & 40 & 40 & 35 & 35 & 35 \\
\hline & Lä & 50 & 50 & 45 & 50 & 50 & 45 & 45 & 40 \\
\hline
\end{tabular}

Bei der Festlegung der jeweiligen Werte für die waldbaulichen Behandlungsregeln wurde unterschieden, ob die Bestände auf Standorten stocken, bei denen keine Veränderungen des Grundwasserpegels stattgefunden hatte (immer grundwassernah bzw. -fern, s. Tab. 26) und solchen, die einer anthropogen bedingten Veränderung des Grundwasserstandes unterlegen waren (s. Tab. 27). In Beständen mit einer Grundwasserabsenkung wurde die Anzahl der Z-Bäume in der Auslesephase erhöht und im Reifestadium reduziert. Weiterhin wurde die minimale Eingriffsstärke je Eingriff reduziert und eine höhere Grundflächenhaltung angestrebt. Dies trägt dem in der Regel stärkeren Schädigungsgrad und höherem Ausfallrisiko in diesen Beständen Rechnung. Für jede Waldentwicklungsphase wurde ein kritischer 
Kronenschlussgrad festgelegt, bei dessen Unterschreitung mit Maßnahmen für eine Waldverjüngung begonnen wird.

Tabelle 26: Waldbauliche Behandlungsregeln für Bestände obne Veränderung des Grundwasserstandes

\begin{tabular}{|c|c|c|c|c|c|c|c|c|c|c|c|}
\hline BA & Phase & $\begin{array}{c}\mathrm{H} 100 \\
\mathrm{~m}\end{array}$ & Eingriff & $\begin{array}{c}\text { Häufig- } \\
\text { keit } \\
\text { n/10Jahre }\end{array}$ & $\begin{array}{c}\text { Z-Bäume } \\
\text { Stk }\end{array}$ & $\underset{\mathrm{Vfm} / \mathrm{ha}}{\min }$ & $\begin{array}{c}\max \\
\mathrm{Vfm} / \mathrm{ha}\end{array}$ & $\begin{array}{l}\text { Durch- } \\
\text { forstung }\end{array}$ & $\begin{array}{c}\text { Grundfl. } \\
\text { (II.EKL) } \\
\mathrm{m}^{2} / \mathrm{ha}\end{array}$ & $\begin{array}{c}\mathbf{B}^{\circ} \\
\left(\mathrm{ET}^{\prime}\right)\end{array}$ & $\begin{array}{c}\mathbf{K}^{\circ} \\
\text { krit. } \\
*)\end{array}$ \\
\hline \multirow{4}{*}{$\begin{array}{c}\mathbf{E i} \\
\text { (Rei) }\end{array}$} & & 12 & R-Gasse & 1 & - & - & - & - & & & 0,4 \\
\hline & Auslese & 14 & DF & 2 & 120 & 30 & 60 & st. Hdf. & 17,3 & 0,9 & 0,4 \\
\hline & Ausreifung & 20 & DF & $1-2$ & 120 & 30 & 60 & st. Hdf. & 22,0 & 1,0 & 0,4 \\
\hline & Reife & 28 & DF & 1 & 120 & 30 & 60 & mäß. Hdf. & 27,4 & 1,1 & \\
\hline \multirow{4}{*}{$\begin{array}{c}\mathbf{B u} \\
(\mathrm{Hbu})\end{array}$} & & 14 & R-Gasse & 1 & - & - & - & - & & & 0,3 \\
\hline & Auslese & 16 & DF & 2 & 80 & 30 & 60 & st. Hdf. & 18,5 & 0,9 & 0,3 \\
\hline & Ausreifung & 24 & DF & $1-2$ & 80 & 30 & 60 & st. Hdf. & 27,8 & 1,0 & 0,3 \\
\hline & Reife & 30 & DF & 1 & 80 & 30 & 60 & mäß. Hdf. & 34,0 & 1,1 & \\
\hline ALh & & 10 & R-Gasse & 1 & - & - & - & - & & & 0,3 \\
\hline$(\mathrm{Ah})$ & Auslese & 12 & DF & 2 & 80 & 30 & 60 & st. Hdf. & 9,7 & 0,9 & 0,3 \\
\hline (Nuss) & Ausreifung & 19 & DF & $1-2$ & 80 & 30 & 60 & st. Hdf. & 19,1 & 1,0 & 0,3 \\
\hline (Kir) & Reife & 28 & DF & 1 & 80 & 30 & 60 & mäß. Hdf. & 34,3 & 1,1 & \\
\hline \multirow{4}{*}{ Es } & & 10 & R-Gasse & 1 & - & - & - & - & & & 0,3 \\
\hline & Auslese & 12 & DF & 2 & 80 & 30 & 60 & st. Hdf. & 14,0 & 0,9 & 0,3 \\
\hline & Ausreifung & 19 & DF & $1-2$ & 80 & 30 & 60 & st. Hdf. & 21,7 & 1,0 & 0,3 \\
\hline & Reife & 28 & DF & 1 & 80 & 30 & 60 & mäß. Hdf. & 29,9 & 1,1 & \\
\hline \multirow{4}{*}{$\begin{array}{l}\text { Erl } \\
(\mathrm{Bi}) \\
(\mathrm{Pa}) \\
\end{array}$} & & 8 & R-Gasse & 1 & - & - & - & - & & & 0,4 \\
\hline & Auslese & 10 & DF & 2 & 80 & 30 & 60 & st. Hdf. & 10,8 & 0,9 & 0,4 \\
\hline & Ausreifung & 18 & DF & $1-2$ & 80 & 30 & 60 & st. Hdf. & 19,9 & 1,0 & 0,4 \\
\hline & Reife & 26 & DF & 1 & 80 & 30 & 60 & mäß. Hdf. & 23,6 & 1,1 & \\
\hline \multirow{4}{*}{$\mathbf{F i}$} & & 10 & R-Gasse & 1 & - & - & 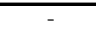 & - & & & 0,5 \\
\hline & Auslese & 12 & DF & 2 & - & 30 & 60 & Ndf. & 24,1 & 0,8 & 0,5 \\
\hline & Ausreifung & 22 & $\mathrm{DF}$ & $1-2$ & - & 30 & 60 & Ndf. & 38,9 & 1,0 & 0,5 \\
\hline & Reife & 28 & $\mathrm{DF}$ & 1 & - & 30 & 60 & mäß.Ndf. & 47,4 & 1,1 & \\
\hline \multirow{4}{*}{ Dg1 } & & 10 & R-Gasse & 1 & - & - & - & - & & & 0,4 \\
\hline & Auslese & 12 & DF & 2 & 120 & 30 & 60 & st. Hdf. & 21,0 & 0,8 & 0,4 \\
\hline & Ausreifung & 26 & $\mathrm{DF}$ & $1-2$ & 120 & 30 & 60 & st. Hdf. & 36,5 & 1,0 & 0,4 \\
\hline & Reife & 32 & DF & 1 & 120 & 30 & 60 & mäß. Hdf. & 46,2 & 1,1 & \\
\hline \multirow{4}{*}{$\mathbf{K i}$} & & 10 & R-Gasse & 1 & - & - & - & - & & & 0,3 \\
\hline & Auslese & 12 & $\mathrm{DF}$ & 2 & 150 & 30 & 60 & st. Hdf. & 20,8 & 0,8 & 0,3 \\
\hline & Ausreifung & 22 & $\mathrm{DF}$ & $1-2$ & 150 & 30 & 60 & st. Hdf. & 28,9 & 0,9 & 0,3 \\
\hline & Reife & 26 & $\mathrm{DF}$ & 1 & 150 & 30 & 60 & mäß. Hdf. & 35,6 & 1,1 & \\
\hline \multirow{4}{*}{ Lä } & & 8 & R-Gasse & 1 & - & - & - & - & & & 0,4 \\
\hline & Auslese & 10 & $\mathrm{DF}$ & 2 & 100 & 30 & 60 & st. Hdf. & 9,7 & 0,9 & 0,4 \\
\hline & Ausreifung & 24 & $\mathrm{DF}$ & $1-2$ & 100 & 30 & 60 & st. Hdf. & 19,1 & 1,0 & 0,4 \\
\hline & Reife & 28 & DF & 1 & 100 & 30 & 60 & mäß. Hdf. & 34,3 & 1,1 & \\
\hline
\end{tabular}

*) = kritischer Kronenschlussgrad für vorzeitige Verjüngungsmaßnahmen

BA: $\quad$ Baumart

H100: $\quad$ Spitzenhöhe (Mittelhöhe der 100 stärksten Bäume/ha)

R-Gasse: Rückegasse

DF: Durchforstung

st. Hdf.: starke Hochdurchforstung

mäß. Hdf.: mäßige Hochdurchforstung

Ndf.: Niederdurchforstung

mäß. Ndf: $\quad$ mäßige Niederdurchforstung

EKL: $\quad$ Ertragsklasse

$\mathrm{B}^{\circ}: \quad$ Bestockungsgrad

$\mathrm{K}^{\circ}$ krit.: $\quad$ kritischer Kronenschlussgrad für vorzeitige Verjüngungsmaßnahmen 
Tabelle 27: Waldbauliche Behandlungsregeln für Bestände mit Absenkung des Grundwasserspiegels unter 2,50 $\mathrm{m}$ Flurabstand

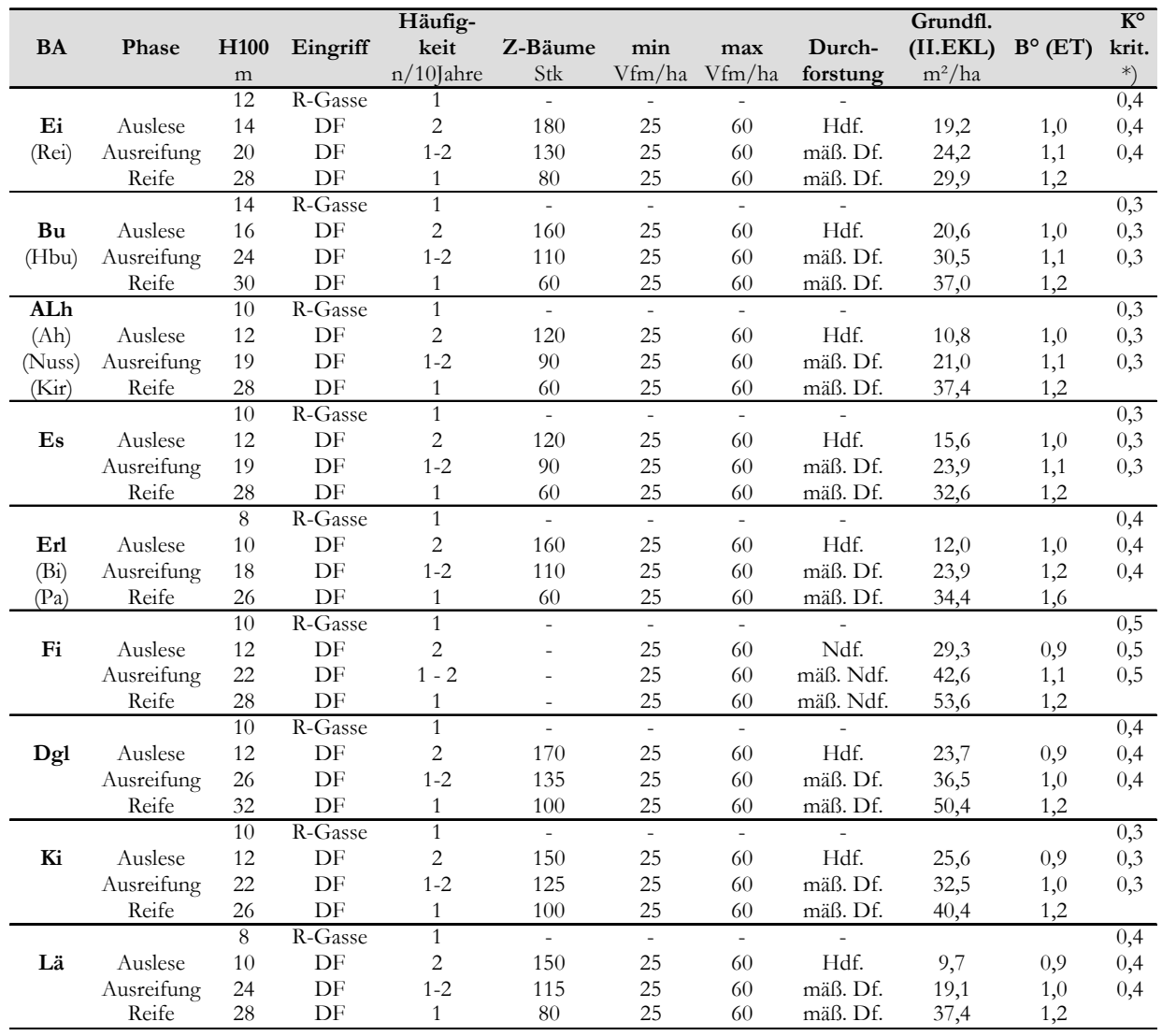

*) = kritischer Kronenschlussgrad für vorzeitige Verjüngungsmaßnahmen

Die Vorgehensweise für den Verjüngungsgang wurde in Abhängigkeit vom Ausgangs- und Zielbestand beschrieben (s. Tab. 28). Dabei wurde nach den unterschiedlichen Lichtansprüchen der Baumarten unterschieden.

Alle genannten waldbaulichen Regeln wurden wie oben beschrieben in den WaldPlaner implementiert. 
Tabelle 28: Verjüngungsgang in Abhängigkeit vom Ausgangs- und Zielbestand

\begin{tabular}{|c|c|c|}
\hline Ausgangsbestand & Zielbestand & $\begin{array}{l}\text { Verjüngungsgang } \\
\left(\mathrm{B}^{\circ}, \text { Jahre }\right)\end{array}$ \\
\hline $\mathrm{Ki}$ & $\mathrm{Ki}$ & $0,4-4-0,2-4-0,0$ \\
\hline \multirow{3}{*}{$\begin{array}{l}\text { sonst. Lichtbaumarten } \\
\text { (Ei, Es, ALn) }\end{array}$} & Lichtbaumart (außer Ki) & $0,6-4-0,2-4-0,0$ \\
\hline & Halbschatt-Baumart & $1,0-4-0,6-4-0,4-8-0,2-4-0,0$ \\
\hline & Schatt-Baumart & $\begin{array}{l}\text { ZSN (max. } 32 \mathrm{~J} ., \text { dann Räumung) } \\
\text { min. } 40 \mathrm{Vfm}-\text { max. } 80 \mathrm{Vfm}\end{array}$ \\
\hline \multirow{3}{*}{$\begin{array}{l}\text { Halbschatt-Baumart } \\
\text { (Ah, Dgl, Fi, Nuss, Kta) }\end{array}$} & Lichtbaumart & $1,0-4-0,0$ \\
\hline & Halbschatt-Baumart & $1,0-4-0,6-8-0,0$ \\
\hline & Schatt-Baumart & $1,0-4-0,6-4-0,2-4-0,0$ \\
\hline \multirow{3}{*}{$\begin{array}{l}\text { Schatt-Baumart } \\
(\mathrm{Bu}, \mathrm{Hbu}, \mathrm{Li})\end{array}$} & Lichtbaumart & $0,4-4-0,0$ \\
\hline & Halbschatt-Baumart & $0,4-8-0,0$ \\
\hline & Schatt-Baumart & $\begin{array}{l}\text { ZSN (max. } 32 \mathrm{~J} ., \text { dann Räumung) } \\
\text { min. } 40 \mathrm{Vfm}-\max .80 \mathrm{Vfm}\end{array}$ \\
\hline
\end{tabular}

(ZSN = Zielstärkennutzung)

\subsubsection{Modellkopplung}

Die Modellkopplung erfolgte in dem Programm WaldPlaner der NW-FVA, das auch für die Simulation großer Waldflächen ausgelegt ist. Es stellt Technologien zur Verfügung, um Prognoserechnungen hochgradig zu parallelisieren und die Ergebnisse effizient in eine angebundene Datenbank zu schreiben. Das System beruht auf dem Einzelbaumwuchsmodell TreeGrOSS und kann standardmäßig die Entwicklung von Beständen unter Berücksichtigung verschiedener waldbaulicher Maßnahmen (Regeln, Behandlungsmodelle, naturschutzfachliche Restriktionen und Risiken) abbilden (s. Abb. 39). Da das Programm mehrere Ergänzungsroutinen bereitstellt, ist es möglich, neben Einzelbaumdaten auch Bestandesdaten (z. B. Forsteinrichtungen) zu importieren. Aus den Rohdaten werden sog. Modellbestände aufgebaut, welche den realen Waldzustand repräsentieren sollen. Neben den flexiblen Import- und Simulationsfunktionen, bietet das System eine Schnittstelle zu gängigen Datenbanken sowie verschiedene Auswertungs- und Darstellungsmöglichkeiten. Von besonderem Vorteil für die Modellkopplung bzw. -integration ist das GIS-Modul des WaldPlaners, da verschiedene Basisinformationen und Teilmodellergebnisse in Form von Geodaten vorliegen. Das GIS-Modul ermöglicht es, die Daten direkt weiterzuverarbeiten. Im Rahmen der Modellkopplung wurde der WaldPlaner so modifiziert, dass er die Steuerung der zusätzlich 
integrierten Teilmodelle übernimmt. Im Zuge der Steuerung werden die Teilmodelle gestartet, initialisiert, und die Ergebnisse gespeichert bzw. an das nachfolgende Teilmodell weitergereicht.

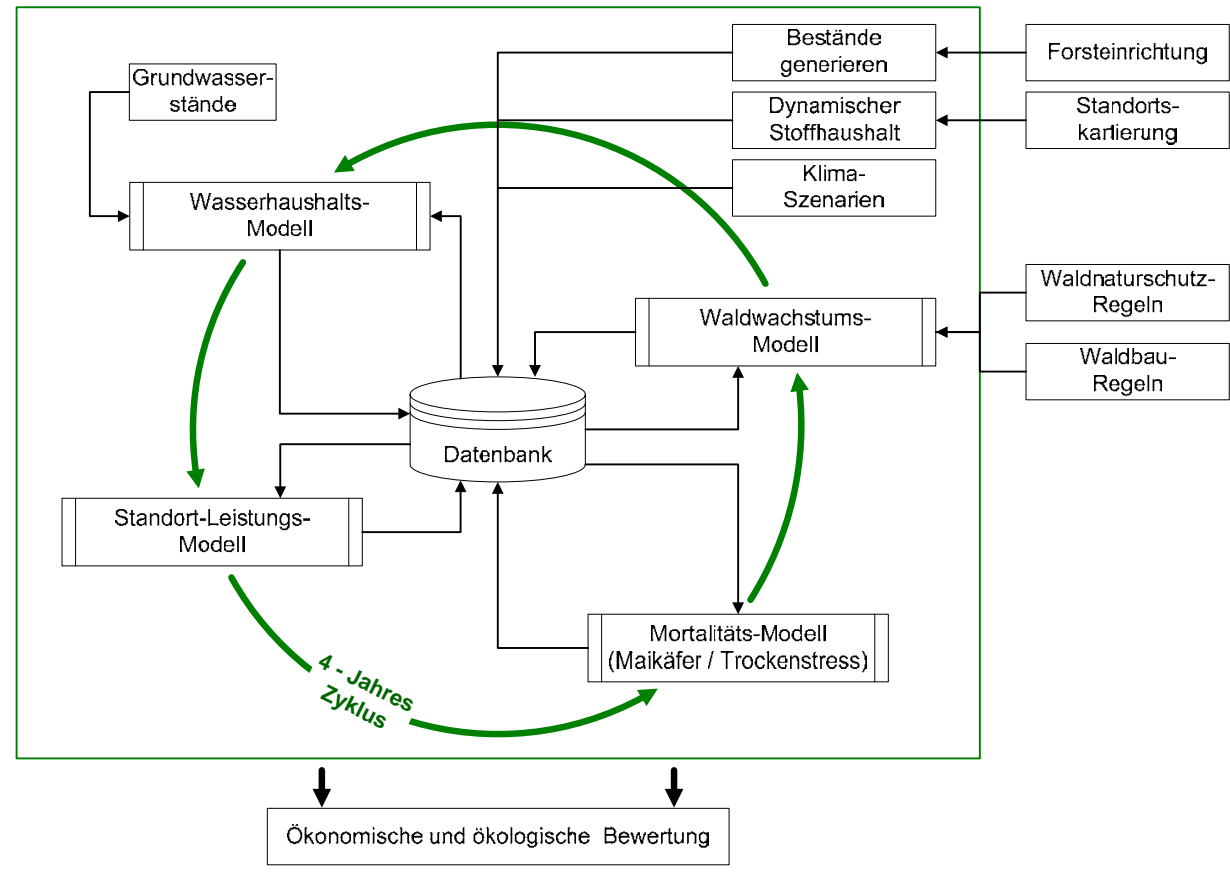

Abbildung 39: Konzept der Modellkopplung zur Integration verschiedener zusätzlicher Modelle in das WaldPlaner-Simulationssystem

Das Standort-Leistungs-Modell sowie das allgemeine Mortalitäts-Modell beruhen auf komplexen statistischen Verfahren, welche nur mit sehr großem Programmieraufwand direkt in das bestehende Java-Softwaresystem WaldPlaner hätten integriert werden können. Beide Modelle wurden in der Statistikumgebung R entwickelt. Daher wurde für die Modellkopplung eine Java/R-Schnittstelle (JRI 2011) implementiert. Diese erlaubt es, R-Funktionen bzw. -Modelle aufzurufen und die Ergebnisse direkt in Java-Programmen zu verwenden. Da das Interface jedoch jeweils nur einmal innerhalb einer JVM (Java Virtual Machine) initialisiert werden kann, wurde eine Server-Client-Architektur erarbeitet (RServer), die es ermöglicht, beliebig viele Instanzen der Schnittstelle zu nutzen. So konnten die parallelen Rechenstrukturen des WaldPlaners beibehalten werden.

Das Maikäfer-Mortalitäts-Modell und die angepassten Waldbaustrategien wurden direkt in Java implementiert und in den WaldPlaner aufgenommen. Das Wasserhaushaltsmodell WaSim/ETH steht als eigenständig ausführbares Programm zur Verfügung. Dieses wird vom WaldPlaner über eine Steuerdatei initiali- 
siert und in einem externen Prozess gestartet. Die Ergebnisse der Wasserhaushaltssimulation (WaSim/ETH) werden in Form von Grids (Rasterdaten) abgespeichert. Nach Beendigung der Wasserhaushaltssimulation liest der WaldPlaner über das integrierte GIS-Modul diese Grids ein, bereitet die Ergebnisse auf und speichert sie in die angebundene Datenbank.

\subsubsection{Simulationsvorbereitung}

Vorbereitend zur Simulation der eigentlichen Szenarien wurden zunächst aus den vorhandenen Datenquellen die Modellbestände generiert und verschiedene Steuertabellen aggregiert. Die Modellbestände im Untersuchungsgebiet wurden auf Basis der Forsteinrichtungsdaten aufgebaut. Verschiedene Standorts- und Klimadaten sowie Behandlungsparameter wurden ebenfalls in diesem vorbereitenden Schritt erstellt und in der angebundenen Datenbank in verschiedene Tabellen abgespeichert. Diese Tabellen halten für das Simulationssystem statische Daten vor, da verschiedene Parameter, wie z. B. der Bodentyp, keiner zeitlichen Dynamik unterliegen oder die dynamische Entwicklung vorab berechnet wurde (z. B. Stickstoffdeposition). Diese Daten wurden für die einzelnen Modellbestände gespeichert und bei Bedarf (während der Simulation) abgerufen.

In einem zweiten Schritt wurden alle Modellbestände auf das der Studie zugrunde liegende Stichjahr (2007) fortgeschrieben. Dabei wurden, wenn vorhanden, bestandesweise dokumentierte Eingriffe modellhaft berücksichtigt. Für Bestände ohne Nutzungsinformationen wurde eine Standardbehandlung unterstellt. Zusätzlich erfolgte in einer Stichprobe eine Plausibilitätsprüfung der Forsteinrichtungsdaten durch Farbinfrarot-Luftbildauswertung und ggf. eine Korrektur. Der so generierte Waldzustand war die Basis für die zu rechnenden Szenarien.

\subsubsection{Szenariosimulation}

Die Simulationsdauer je Szenario betrug 32 Jahre. Die Entwicklung der Bestände wurde dementsprechend vom Jahr 2007 bis zum Jahr 2039 prognostiziert. Der 32jährige Zeitraum ergab sich aus dem Maikäfer-Mortalitäts-Modell, das auf vierjährigen Maikäferzyklen beruht. Es wurden acht Simulationsintervalle á vier Jahre je Szenario gerechnet, in welchen alle Teilmodelle angewendet wurden.

Abbildung 39 verdeutlicht den Ablauf eines Simulationsintervalls und die Modellkopplung: Ein Simulationsintervall beginnt mit der Initialisierung des Wasserbaushaltsmodells (Steuerung WH). Im Rahmen der Initialisierung werden die benötigten Klima- und Grundwasserdaten an das Wasserhaushaltsmodell übergeben und die Steuerdatei parametrisiert. Diese beinhaltet für jeden Modellbestand verschiedene bestandesabhängige Landnutzungsparameter, die von dem übergeordneten Steuerungsprozess aus den Einzelbaumdaten (der Ausgangssituation bzw. des vorherigen Simulationsintervalls) und verschiedenen Standortsparametern abgeleitet und gespeichert werden. Ist die Steuerdatei komplett, wird in einem 
neuen Prozess WaSim/ETH gestartet. Das Programm speichert die relevanten Ergebnisse der Wasserhaushaltssimulation (jährliche Niederschläge etc.) als Rasterdaten im Grid-ASCII-Format. Die Grids werden wiederum von dem übergeordneten Steuerungssystem eingelesen, mit den Bestandespolygonen verschnitten, bestandesweise gemittelt und in die Datenbank gespeichert.

Nach der Wasserhaushaltssimulation wird die Fortschreibung der Modellbestände eingeleitet. Dieser Programmteil ist so parallelisiert, dass die Bestandesentwicklung für vier Jahre unter Berücksichtigung der weiteren Teilmodelle für mehrere Modellbestände gleichzeitig simuliert wird. Hierzu wird zunächst eine definierte Anzahl an Modellbeständen aus der Datenbank eingelesen (MB1 bis MBn). Danach wird für jeden geladenen Modellbestand ein Java/R-Interface geöffnet und für die Modellbestandsbäume der parametrisierten Baumarten die Höhenbonität in Abhängigkeit vom unterstellten Grundwasserstand, vom Klimaszenario und vom bestandesspezifischen Wasserhaushalt korrigiert.

Anschließend wird zunächst das allgemeine Mortalitäts-Modell angewendet. Für dieses Modell wird ebenfalls ein Java/R-Interface verwendet und die Berechnung der Überlebenswahrscheinlichkeit (Hazardrate) in $\mathrm{R}$ durchgeführt. Die Überlebenswahrscheinlichkeiten werden anschließend einzelbaumweise mit einer gleich verteilten Zufallszahl aus dem Intervall [0,1] verglichen. Ist die Zufallszahl größer, stirbt der Modellbaum.

Danach wird das Maikëfer-Mortalitäts-Modell gestartet. Die regionalisierten Engerlingsdichten liegen im GridASCII-Format (100x100 Meter) vor. Der WaldPlaner liest diese Grids ein und verschneidet die Rasterzellenwerte (Engerlingsdichten) mit den Bestandespolygonen und berechnet die mittlere Dichte je Bestand. In Abhängigkeit der Engerlingsdichte und der Einzelbaumalter wird über eine „Schädigungsmatrix“ die Vitalitätsverringerung für jeden Modellbaum berechnet. Unterschreitet die Vitalität eines Modellbaums den Schwellenwert von 0,6, kann der Baum absterben. Ob ein Baum abstirbt, wird ebenfalls über den Vergleich mit einer gleich verteilten Zufallszahl bestimmt.

Im vierten Schritt werden das Wachstum und die dichtebedingte Mortalität (für jeweils vier Jahre) der Bäume des jeweiligen Modellbestands geschätzt. Hierzu greift das System auf das Einzelbaumwuchsmodell TreeGrOSS (NAGEL 2009) zurück. Direkte Auswirkungen auf die Entwicklung der Modellbestände haben die vorgeschalteten Teilmodelle Standort-Leistung, Grundwassermortalität und Maikäfermortalität, da diese die Höhenbonität bzw. das Konkurrenzgefüge der Bestände beeinflussen.

Die mögliche Dynamik der Standortleistungsfähigkeit unter Klimawandel wird in Szenariosimulationen untersucht. Dabei werden die Klimabedingungen für zukünftige Perioden unter Annahme von Klimaszenarien mit dem regionalen Klimamodell WETTREG (SPEKAT et al. 2007) projiziert. Während sich somit die Temperatursummen und klimatischen Wasserbilanzen der Standorte in der Szenariosimulation verändern, werden die übrigen erklärenden Modellvariablen als kon- 
stant angenommen. Der Boden wird zu Beginn der Vegetationszeit als wassergesättigt angesehen, die nutzbare Feldkapazität steht somit in vollem Umfang zur Verfügung. Die Stickstoffdeposition wird analog zum Vorgehen bei der Modellparametrisierung als mittlere jährliche Rate über das Bestandesleben bilanziert. Zur Abschätzung der zukünftigen jährlichen Stickstoffdeposition siehe Kapitel Stickstoffdeposition.

Nach der Wachstumssimulation erfolgt die modellhafte Umsetzung der speziell auf die Situation des Hessischen Rieds angepassten Waldbehandlungsstrategie. Hierzu wird im ersten Intervall einer Szenariosimulation in Abhängigkeit der vorhandenen Bestockung, der Naturschutzsituation, der Trophie und des Wasserhaushalts des Standorts ein Waldentwicklungstyp (WET) festgelegt. Dieser gibt vor allem an, welche Baumartenzusammensetzung bei einer Neubegründung bzw. Verjüngung bestandesweise realisiert werden soll. In Abhängigkeit der Baumartenzusammensetzung und des Standorts werden bestandesweise das Endnutzungsverfahren, das Durchforstungsregime sowie die Verjüngungsprozedur festgelegt. Unterliegt der Bestand naturschutzfachlichen Restriktionen, wird das Behandlungskonzept entsprechend modifiziert. Dies kann beispielsweise zur Folge haben, dass bestimmte Baumarten bei Verjüngungsmaßnahmen nicht verwendet werden dürfen, ein gewisser Altholzanteil erhalten werden muss oder die Nutzung komplett verboten ist. Die Waldbaustrategie wird auf Basis verschiedener Maßnahmenelemente (Zielstärkennutzung, Schirmschlag, Niederdurchforstung, Freistellung der Z-Bäume, Pflanzung, Habitatbaumauswahl etc.) modellhaft umgesetzt.

Mit der waldbaulichen Behandlung ist ein Simulationsintervall abgeschlossen. Die Ergebnisse der Simulation (aller Teilmodelle) werden vom Modul Datenmanagement aufbereitet und in verschiedenen Tabellen abgespeichert. Somit liegen verschiedene Indikatoren und bestandesbeschreibende Größen (z. B. klimatische Wasserbilanz, Habitatbaumanzahl, Bestandestyp, Grundfläche, Bestockungsgrad, Ausfallprozente, Kosten, Erlöse etc.) bis hin zu den Parametern der Modellbäume zu jedem Bestand und Simulationsintervall vor. Dies ermöglicht flexible statische und dynamische Auswertungen sowie Analysen.

\subsubsection{3 Ökologische Bewertung der Ergebnisse der Modellläufe}

\subsubsection{Buchen- und Eichen-Lebensraumtypen der FFH-Richtlinie}

Die Entwicklung der FFH-Eichen- und Buchen-Lebensraumtypen wurde nach dem Verfahren der Arbeitsgruppe der Länderarbeitsgemeinschaft Naturschutz (LANA) und der Forstchefkonferenz (FCK) (BUNDESAMT FÜR NATURSCHUTZ 2010) bewertet.

Im Rahmen des vom BfN in Auftrag gegebenen Forschungs- und Entwicklungsvorhabens „Konzeptionelle Umsetzung der EU-Vorgaben zum FFH-Monitoring und Berichtspflichten in Deutschland" wurden von der LANA-FCK-Kon- 
taktgruppe ein Verfahren für die „Bewertung des Erhaltungszustandes der Lebensraumtypen nach Anhang I der Fauna-Flora-Habitat-Richtlinie Deutschland“ erarbeitet. Die Bewertungsmethodik weicht stellenweise erheblich von den Verfahren der Länder ab. Für die Bewertung der Simulationsläufe im vorliegenden Projekt bot sie sich jedoch an, da viele Eingangsgrößen unmittelbar aus den Simulationsläufen abgeleitet werden konnten (s. Tab. 29). Die Bewertungsschemata des Landes Hessen für die Eichen-Lebensraumtypen hingegen setzen eine detaillierte Aufnahme im Gelände voraus, welche sich stark auf krautige Pflanzen und individuelle Habitatstrukturen stützt. Diese Strukturen standen im WaldPlaner für die Auswertungen nicht zur Verfügung.

Tabelle 29: $\quad$ Kriterien zum länderübergreifenden FFH-Monitoring des Bund-Länder-Arbeitskreises (LANA/FCK) und deren Implementierung im WaldPlaner

\begin{tabular}{|c|c|}
\hline Kriterium LANA/FCK & Bewertung im WaldPlaner \\
\hline \multicolumn{2}{|l|}{$\begin{array}{l}\text { Vollständigkeit der lebensraum- } \\
\text { typischen Habitatstrukturen }\end{array}$} \\
\hline Waldentwicklungsphasen & $\begin{array}{l}\text { Identifizierung von Waldentwicklungsphasen auf der } \\
\text { Basis von } 5 \text { Durchmesserklassen (BHD): Phase 1: } \\
\text { Blöße bis Stangenholz, 0-13 cm; Phase 2: geringes } \\
\text { Baumholz, > 13-35 cm; Phase 3: mittl. Bh., > 35- } \\
49 \mathrm{~cm} \text {; Phase 4: starkes Bh., > 49-70 cm; Phase 5: } \\
\text { sehr starkes Bh./Altholz, > } 70 \mathrm{~cm} \text {. Bewertung in } \\
\text { Abhängigkeit von Flächenanteilen }\end{array}$ \\
\hline Biotop- und Altbäume & $\begin{array}{l}\text { Quantifizierung der Mortalitätsraten der im } \\
\text { WaldPlaner ausgewiesenen Habitatbäume }\end{array}$ \\
\hline Totholz & $\begin{array}{l}\text { Modellierung der Totholzmenge (Erntereste und } \\
\text { Mortalität) unter Berücksichtigung von Zerset- } \\
\text { zungsraten }\end{array}$ \\
\hline
\end{tabular}

Vollständigkeit des lebensraum-

typischen Arteninventars

Deckungsanteil der lebensraumty- Analyse der Baumartenzusammensetzung pischen Gehölzarten (Liste BWI3)

Krautschicht

nicht auswertbar

Beeinträchtigungen

Deckung Störzeiger Krautschicht

nicht auswertbar

Naturverjüngung

Befahrungsschäden

Quantifizierung der Mortalität in der Verjüngung

Schäden an lebensraumtypischen

Standortverhältnissen, Waldvegenicht auswertbar

Quantifizierung der Grundwasserabsenkung tation und Struktur

Deckungsanteil nicht-heimischer Analyse der Baumartenzusammensetzung Gehölzarten 
Da weder die detaillierten Parameter des Hessischen Verfahrens bezüglich der Eichen-Lebensraumtypen noch die kompletten Größen zur Bewertung nach den LANA/FCK-Kriterien zur Verfügung standen, war eine vollständige Bewertung des Erhaltungszustands der Lebensraumtypen nicht möglich. Daher wurden nicht die Wertstufen A, B und $\mathrm{C}$ vergeben, sondern die Entwicklung einzelner wertgebender Kriterien betrachtet.

Die von der LANA/FCK-Kontaktgruppe vorgesehenen Baumartenlisten (BWI3) zur Bestimmung der Anteile lebensraumtypischer Baumarten sind in Tabelle 30 dargestellt.

Tabelle 30: Haupt-, Neben- und Pionierbaumarten der betracbteten Eichen- und Buchen-Lebensraumtypen nach $\mathrm{BWI3}$

\begin{tabular}{|c|c|c|c|}
\hline $\begin{array}{l}\text { Lebens- } \\
\text { raumtyp }\end{array}$ & Hauptbaumarten & Nebenbaumarten & Pionierbaumarten \\
\hline 9110 & Buche & $\begin{array}{l}\text { Hainbuche, Traubeneiche, } \\
\text { Stieleiche, Eibe }\end{array}$ & $\begin{array}{l}\text { Weide, Vogelbeere, } \\
\text { Aspe, Gem. Birke, } \\
\text { Gem. Kiefer }\end{array}$ \\
\hline 9130 & Buche & $\begin{array}{l}\text { Spitzahorn, Bergahorn, Feld- } \\
\text { ahorn, Gem. Esche, Ulme } \\
\text { (Rüster), Linde, Vogel- } \\
\text { kirsche, Elsbeere, Trauben- } \\
\text { eiche, Stieleiche, Eibe, } \\
\text { Hainbuche }\end{array}$ & $\begin{array}{l}\text { Gem. Birke, } \\
\text { Vogelbeere, Aspe, } \\
\text { Weide }\end{array}$ \\
\hline 9160 & $\begin{array}{l}\text { Stieleiche, } \\
\text { Hainbuche }\end{array}$ & $\begin{array}{l}\text { Ulme (Rüster), Traubeneiche, } \\
\text { Gem. Esche, Bergahorn, } \\
\text { Spitzahorn, Feldahorn, } \\
\text { Holzapfel, Vogelkirsche, } \\
\text { Linde, Roterle, Gewöhnliche } \\
\text { Traubenkirsche }\end{array}$ & $\begin{array}{l}\text { Gem. Birke, } \\
\text { Moorbirke, Aspe, } \\
\text { Vogelbeere, Weide }\end{array}$ \\
\hline 9190 & $\begin{array}{l}\text { Stieleiche, } \\
\text { Traubeneiche }\end{array}$ & $\begin{array}{l}\text { Gem. Birke, Moorbirke, } \\
\text { Gem. Kiefer, Roterle }\end{array}$ & Aspe, Vogelbeere \\
\hline $91 \mathrm{~F} 0$ & $\begin{array}{l}\text { Stieleiche, Esche, } \\
\text { Ulme (Rüster) }\end{array}$ & $\begin{array}{l}\text { Hainbuche, Bergahorn, } \\
\text { Spitzahorn, Feldahorn, } \\
\text { Linde, Schwarzpappel, } \\
\text { Gewöhnliche Trauben- } \\
\text { kirsche }\end{array}$ & Roterle, Aspe, Weide \\
\hline
\end{tabular}

\subsubsection{Hotspots}

Parallel zu den Bewertungen nach FFH-Kriterien fand eine Bestimmung der Habitateignung der Waldbestände im Projektgebiet für eine Gruppe an Indikatorarten der Alters- und Zerfallsphase von Buchen- und Eichenwäldern statt (s. Kap. 2.2.9). 
Entsprechend der jeweiligen Änderung der Steigung des Kurvenverlaufs in Abbildung 37 wurden vier Habitateignungsklassen gebildet. Als Hotspots (Habitatklasse „optimal“) wurden alle Waldflächen mit einer Habitateignung über 73 definiert. „Geeignete“ Flächen haben eine Habitateignung zwischen 45 und 73, „,bedingt geeignete" Flächen zwischen 25 und 45 und Flächen mit einer Habitateignung unter 25 werden als ,ungeeignet" bezeichnet.

Auf Grund der bereits beschriebenen Eigenschaften der verwendeten Modelle (ENFA und GAM) wurden zwei verschiedene Ansätze verfolgt: Für die Beschreibung des Ist-Zustandes wurden die Ergebnisse aus der Modellierung der Software „Biomapper“ betrachtet. Die Habitateignung der Waldbestände in den verschiedenen Szenarien und zu verschiedenen Stichjahren wurde mit einem GAM modelliert und dabei die Habitateignungsklassen "geeignet“ und „optimal“ gemeinsam betrachtet.

\subsubsection{4 Ökonomische Bewertung}

Bei der ökonomischen Bewertung wurden zwei unterschiedliche Wege beschritten. Zum einen erfolgte ein rückblickender Aufbau eines „Modellbetriebes“ auf der Basis der Forsteinrichtungsdaten zum Stichjahr 1967. Für diesen stichprobenbasierten Modellbetrieb wurde eine Waldentwicklung unter „Normalbedingungen“ ohne Grundwasserabsenkungen bis zum Jahr 2007 simuliert. Die naturalen Ergebnisse wurden monetär bewertet und mit den tatsächlichen naturalen und monetären Ergebnissen des Zeitraums zwischen 1967 und 2007 verglichen.

Bei dem zweiten Bewertungsansatz handelte es sich um eine Ertragswertberechnung auf der Basis der Holznutzungen und der Verjüngungstätigkeit für die jeweiligen Szenarien und den Simulationszeitraum 2007 bis 2039.

\subsubsection{Modell- und Kalamitätsbetrieb 1967 - 2007}

Gegenstand dieses retrospektiv angelegten Projektteils war die vergleichende Betrachtung und Bewertung der Waldentwicklung im Projektgebiet anhand eines „Modellbetriebes“ sowie des tatsächlichen Betriebsvollzugs zwischen den Stichjahren 1967 und 2007 („Kalamitätsbetrieb“).

Es existieren zahlreiche Gutachten mit betriebswirtschaftlichem Fokus, in denen einzelne Teilbereiche des Hessischen Rieds für zumeist eng begrenzte Zeiträume betrachten wurden. Ziel des gewählten Ansatzes war es hingegen, die Entwicklung des gesamten Gebietes seit Beginn der verstärkten Grundwasserförderung bis in die Gegenwart aus forstbetrieblicher Sicht nachzuvollziehen.

Der Beginn der Betrachtungen für diesen Betriebsvergleich sollte zeitlich vor der Aufnahme der intensiven Grundwasserförderung liegen. Aufgrund der Datenverfügbarkeit wurde als Stichjahr das Jahr 1967 gewählt, auch wenn zu diesem Zeitpunkt lokal bereits eine intensivierte Grundwasserförderung eingesetzt hatte. Datengrundlage für den Ausgangszustand waren historische Forsteinrichtungs- 
daten, die möglichst vor dem Stichjahr datierten. Waren keine entsprechend alten Forsteinrichtungsdatensätze verfügbar, wurde der älteste verfügbare Forsteinrichtungsdatensatz im WaldPlaner auf das Stichjahr zurückgerechnet (s. Kap. 2.1.1.1).

Tabelle 31 enthält eine Übersicht über die Stichjahre der vorliegenden historischen Forsteinrichtungsdaten. Für einige Betriebe sind mehrere Stichjahre aufgeführt, die alle verwendet wurden. Dies war erforderlich, wenn einzelne Betriebe ehemals zu mehreren Forstämtern gehörten.

Tabelle 31: Forstbetriebe und Stichjahre der verfügbaren historischen Forsteinrichtungsdaten

\begin{tabular}{lc|lc}
\hline \multicolumn{1}{c|}{ Betrieb } & Stichjahr & \multicolumn{1}{c}{ Betrieb } & Stichjahr \\
\hline Domänenwald Groß-Gerau & 1985 & Staatswald Langen & 1972 \\
Gemeinde Alsbach-Hähnlein & 1982 & Staatswald Langen & 1981 \\
Gemeinde Biblis & 1966 & Staatswald Mörfelden & 1971 \\
Gemeinde Bickenbach & 1982 & Staatswald Mörfelden & 1992 \\
Gemeinde Biebesheim & 1958 & Stadt Bensheim & 1968 \\
Gemeinde Bischofsheim & 1959 & Stadt Darmstadt & 1966 \\
Gemeinde Büttelborn & 1970 & Stadt Flörsheim & 1977 \\
Gemeinde Büttelborn & 1983 & Stadt Frankfurt & 1962 \\
Gemeinde Egelsbach & 1979 & Stadt Gernsheim & 1982 \\
Gemeinde Erzhausen & 1970 & Stadt Griesheim & 1958 \\
Gemeinde Groß-Rohrheim & 1978 & Stadt Groß-Gerau & 1970 \\
Gemeinde Nauheim & 1983 & Stadt Lampertheim & 1957 \\
Gemeinde Trebur & 1963 & Stadt Langen & 1981 \\
Hospitalwald Hofheim & 1966 & Stadt Mörfelden-Walldorf & 1970 \\
Staatswald Bensheim & 1964 & Stadt Pfungstadt & 1995 \\
Staatswald Bensheim & 1978 & Stadt Riedstadt & 1982 \\
Staatswald Bensheim & 1981 & Stadt Rüsselsheim & 1969 \\
Staatswald Darmstadt & 1964 & Stadt Rüsselsheim & 1987 \\
Staatswald Darmstadt & 1980 & Stadt Rüsselsheim & 1992 \\
Staatswald Darmstadt & 1992 & Stadt Raunheim & 1976 \\
Staatswald Groß Gerau & 1970 & Stadtwerke Mainz & 1986 \\
Staatswald Lampertheim & 1965 & & \\
\hline
\end{tabular}

Grundlage für die Bildung des Modellbetriebes war die Stichprobe des MaikäferProbegrabungsrasters, auf deren Basis eine repräsentative Anzahl von Beständen ausgewählt wurde. Insgesamt handelt es sich um 1.162 Stichprobenpunkte, die mit den Forsteinrichtungsgeometrien und entsprechenden Sachdaten verschnitten wurden. 
Die Flächenauswahl unterschied sich damit von ähnlichen Untersuchungen, bei denen kleinere Gebiete lückenlos betrachtet wurden (HOLECY u. HANEWINKEL 2006) oder fest definierte Bestandestypen mit repräsentativer Baumarten- und Altersklassenverteilung gebildet wurden (DUSCHL 2001, DUSCHL u. SUDA 2002, S. 92). 81 Stichprobenpunkte lagen außerhalb des Waldes (entweder in den 60erJahren, 2007 oder zu beiden Zeitpunkten) und für 95 Stichprobenpunkte waren aufgrund spezieller Besitzverhältnisse in der Vergangenheit (Bundesforsten, Privatwald, Bundeswasserstraßen) und Datenlücken keine Forsteinrichtungsdaten verfügbar. Abbildung 40 zeigt anhand des Stichprobenrasters, dass vor allem für die kommunalen Forstbetriebe im Nordteil des Untersuchungsgebietes auf Forsteinrichtungsdaten mit Stichjahren nach 1967 zurückgegriffen werden musste.

Als Betrachtungseinheit wurde der Bestand gewählt, wobei unter einem Bestand in Anlehnung an KRAMER (1976) die kleinste einheitlich zu bewirtschaftende forstliche Einheit verstanden wird. Sie entspricht in der Regel der kleinsten forstlichen Beschreibungs-, Planungs-, Buchungs- und Kontrolleinheit. Zwischen den heutigen Flächeneinteilungen und den historischen zeigten sich erhebliche Unterschiede. Dies ist vor allem durch Flächenneueinteilungen begründet. Die heutigen Flächenzuschnitte konnten in der Folge nicht direkt als Abgrenzung der Bestände verwendet werden ${ }^{4}$. Deshalb wurde die kleinste zwischen der früheren und der heutigen Forsteinrichtung in Deckung zu bringende Einheit gewählt. Hierfür wurden die alten Forsteinrichtungskarten gescannt, ins GIS importiert, georeferenziert und mit den aktuellen Forsteinrichtungsgeometrien und dem Stichprobenraster verschnitten. Anschließend wurden die derart ermittelten Modellbestände auf die Flächengröße von einem Hektar normiert.

Auf diese Weise wurden für 364 Bestände die Forsteinrichtungsdaten von 1967 bis 1970 übernommen. Ältere Datensätze (Stichtag vor 1967) wurden mithilfe des WaldPlaners bis 1967 fortgeschrieben (182 Bestände) und für 456 Stichprobenpunkte waren nur Forsteinrichtungsdaten jüngeren Stichtages verfügbar. Bei der Rückrechnung (ausgehend von der ältesten verfügbaren Forsteinrichtung) auf das Stichjahr 1967 wurden folgende Grundsätze angewandt:

- die Baumarten wurden übernommen

- das Mischungsverhältnis wurde als konstant unterstellt

- $\quad$ es wurde ein $\mathrm{B}^{\circ}$ von 1,0 angenommen

- die Ertragsklasse wurde übernommen

- vorhandener Unterstand wurde mit einem konstantem $\mathrm{B}^{\circ}$ von 0,3 angenommen

\footnotetext{
${ }^{4}$ Ebenso wenig konnten die früheren Flächeneinteilungen direkt auf das Stichjahr 2007 übertragen werden.
} 


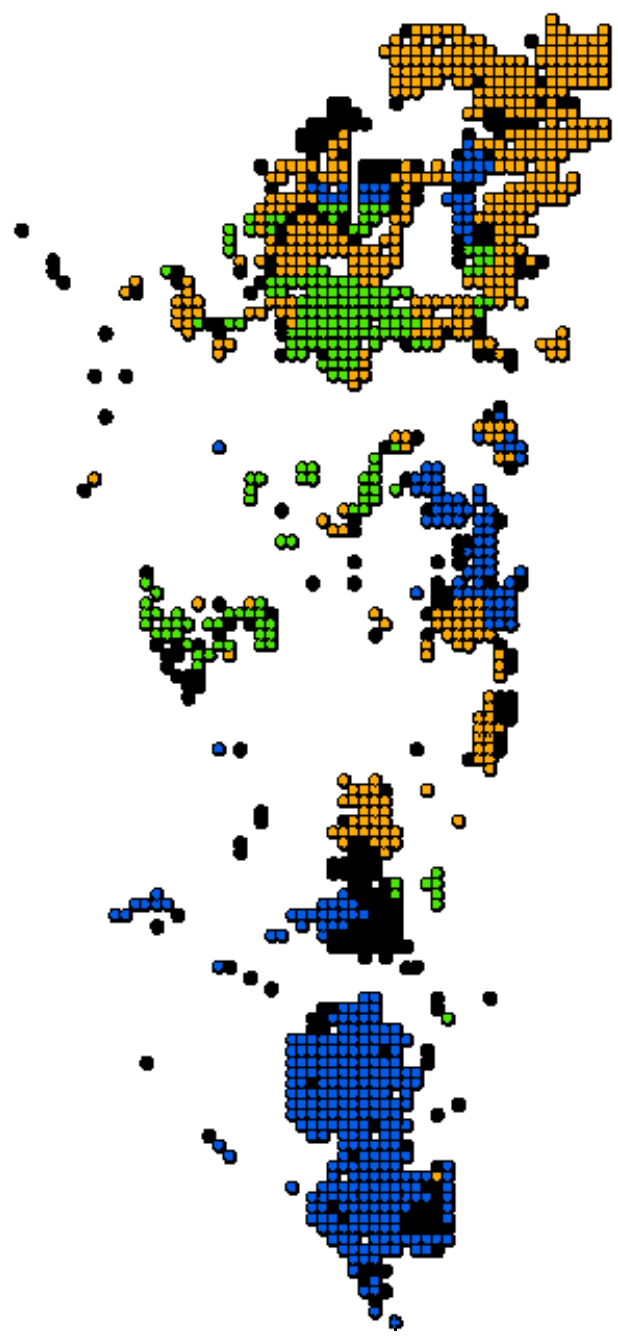

Abbildung 40: Verfügbarkeit von historischen Forsteinrichtungsdaten auf den Stichprobepunkten im Untersuchungsgebiet: grün: historisches Stichjahr 1967, blau: bistorisches Stichjahr vor 1967, gelb: historisches Stichjabr nach 1967, schwarz: keine Daten verfügbar

Bestände, die zum Stichjahr einer Forsteinrichtung nach 1967 jünger waren als die zeitliche Differenz zu diesem Jahr, mussten neu definiert werden, da der damalige Altbestand nicht mehr aus den vorhandenen Daten erkenntlich war. Grundsätzlich wurde angenommen, dass der jeweilige Vorbestand von den gleichen Baumarten gebildet wurde, wie der in den verfügbaren Forsteinrichtungsdaten dargestellte Bestand. Für die Baumarten Roteiche und Douglasie war diese Annahme unplausibel, sodass die Ermittlung der Vorbestände auf der Basis der Zuordnung von Waldentwicklungstypen zu Standortstypen gemäß Tabelle 23 erfolgte. 
Das Alter der Vorbestände wurde in Anlehnung an die in Tabelle 32 aufgelisteten Umtriebszeiten festgelegt mit der Annahme, dass einer Kultur jeweils ein Kahlschlag vorausging und Blößen unverzüglich wieder in Kultur gebracht wurden. Auf der Fläche eines zehnjährigen Eichenbestands im Jahre 1982 wurde also im Jahre 1967 ein 155-jähriger Eichenbestand angenommen.

Tabelle 32: $\quad$ Umtriebszeiten der 60er-bis 80er-Jahre

\begin{tabular}{c|c}
\hline Baumartengruppe & Umtriebszeit (Jahre) \\
\hline Eiche & 160 \\
Buche & 140 \\
Fichte & 80 \\
Kiefer & 120 \\
ELH & 120 \\
WLH (Pa) & $60(40)$ \\
\hline
\end{tabular}

Für den Kalamitätsbetrieb war es wichtig, die Kompatibilität der früheren mit den aktuellen Forsteinrichtungsdaten zu überprüfen. Dabei zeigten sich teilweise Unterschiede hinsichtlich der Baumartenausstattung und des Alters, die nur durch Aufnahmeunterschiede der Forsteinrichtung erklärbar waren. Diese Unplausibilitäten wurden folgendermaßen behandelt:

- Heute vorhandene Baumarten mit einem Alter > 40 Jahre mussten auch vor 40 Jahren vorhanden gewesen sein und wurden im alten Datensatz jeweils ergänzt.

- Baumarten in der herrschenden Schicht ohne Angabe von Flächenanteil und Vorrat - in beiden Stichjahren oder bei Angabe nur in einem Stichjahr wurden nicht berücksichtigt.

- Bei aufgetretenen Altersdifferenzen - bei der Schätzung des Alters nach „wirtschaftlichem Alter“ durch den Forsteinrichter und bei Flächenzusammenlegungen - wurden die alten Daten an die aktuellen Angaben angepasst.

Um das Ausmaß der ökonomischen Beeinträchtigungen für die Forstwirtschaft abschätzen zu können, wurde die tatsächliche Entwicklung der Vollzugsdaten und der Waldbestände mit der im Programm WaldPlaner modellierten Idealentwicklung bei konstanten Grundwasserständen, wie sie im Jahre 1967 vorlagen, und unter Ausblendung der Maikäfergradation (Modellbetrieb) verglichen. Die Vollzugsdaten wurden aus der HEKAS-Datenbank („HolzErnte, Kulturen, Astung, Schälschutz") des Landesbetriebs HESSEN-FORST entnommen. Die Zuordnung der Pflegemaßnahmen und der Einschläge nach Holzartengruppe war in elf verschiedenen Kategorien aufgelistet. Die Einschlagsdaten und Angaben zu Verjüngungs- und sonstigen Maßnahmen waren jeweils flächenbezogen und jahresweise verbucht. Diese Daten lagen jedoch für die einzelnen Betriebe für unterschiedliche 
Zeiträume vor. Teilweise mussten die Vollzugsdaten für die Betriebe, soweit vorliegend, aus den handschriftlichen Aufzeichnungen in den Betriebswerken digitalisiert werden. Für den Stadtwald Frankfurt lagen keine Vollzugsdaten vor.

Die betrachteten Größen waren Holznutzung, Verjüngungsaufwand und Veränderung der Abtriebswerte zwischen 1967 und 2007, jeweils für den Kalamitätsbetrieb und den Modellbetrieb. Diese Ertragsbewertung greift die Mehraufwands-/Minderertrags-Berechnungen auf, wie sie beispielsweise für das Gutachten zum Stadtwald Gernsheim (HOCKE et al. 1997) angewendet wurden. Die Einrichtung eines Modellbetriebes entwickelt den Ansatz von FRIEDEL (2010) weiter, der einen idealisierten Waldzustand auf der Basis von pauschal um eine Bonitätsstufe verbesserten Forsteinrichtungsdaten herleitete 5 .

Zusätzlich wurde der Erfolg der Hauptbaumarten des „Kalamitätsbetriebes“ in Relation zum (potenziell möglichen) Erfolg der Hauptbaumarten im „Modellbetrieb" anhand der oben genannten Größen auf unterschiedlichen Standortsgruppen verglichen.

Die Holznutzungsdaten wurden von den Forstbetrieben mit unterschiedlichem Flächenbezug verbucht. Dabei kamen vor:

- Buchung auf die Abteilung

- Buchung auf die Unterabteilung

- Buchung auf die Beschreibungseinheit

Holzmengen, die auf eine höhere Flächeneinheit gebucht waren, wurden anteilig entsprechend dem Flächenanteil der gebildeten Bestände an der höheren Flächeneinheit zugeschlagen. In der gleichen Weise wurde verfahren, wenn die gebildeten Modellbestände Beschreibungseinheiten nur anteilig enthielten ${ }^{6}$. Im Laufe des betrachteten Zeitraumes waren die Bezeichnungen der Abteilungen, Unterabteilungen und Beschreibungseinheiten nicht konstant beibehalten worden. Während die Abteilungsbezeichnungen im HEKAS-System umgeschrieben wurden, erfolgte keine Umschreibung der Bezeichnungen der Unterabteilungen und Beschreibungseinheiten. Um die Nutzungsdaten trotzdem den Flächen korrekt zuordnen zu können, wurden Transformationstabellen angelegt. Zu diesem Zweck wurden die Karten der Zwischeneinrichtung ebenfalls gescannt, ins GIS importiert, georeferenziert und mit den Modellbeständen verschnitten.

Die Verjüngungsdaten waren von den Forstbetrieben lediglich auf den Ebenen der Abteilungen und Unterabteilungen verbucht - die Maßnahmen konnten also nicht in allen Fällen automatisiert den Beständen zugeordnet werden 7 . Um trotzdem eine Zuordnung auf die Beschreibungseinheiten zu ermöglichen, wurden die

\footnotetext{
${ }^{5}$ FRIEDEL führte allerdings auf der Basis von Abweichungen zum Referenzwert reine Substanzwertberechnungen durch

${ }^{6}$ Diese Flächenabweichungen traten vereinzelt durch die hinsichtlich der Bildung der Modellbestände nicht berücksichtigte Zwischenforsteinrichtung beispielsweise aus den 80er-Jahren auf.

${ }^{7}$ Dieses Problem trat für diejenigen Bestände auf, die als Beschreibungseinheit definiert waren.
} 
Verjüngungsdaten mit den Holznutzungsdaten und Forsteinrichtungsdaten verschnitten. Es wurden also nur diejenigen Verjüngungsmaßnahmen der übergeordneten Flächeneinheit berücksichtigt, bei denen eine Nutzung auf der Modellbetriebsfläche mit der Bezeichnung „Hauptnutzung“, „Mehrnutzung“ oder „Abtrieb“ in einem Zeitraum von 5 Jahren vorausging oder die vorangegangene Forsteinrichtung einen Bestockungsgrad unter 0,6 aufwies.

Erfüllten mehrere Beschreibungseinheiten diese Bedingungen, wurde die Kulturmaßnahme flächengewichtet berücksichtigt. Die Transformationstabellen für die Zwischenforsteinrichtung kamen ebenfalls zur Anwendung.

Für die Zeiträume, für die keine Vollzugsdaten vorlagen, und für den Stadtwald Frankfurt wurde der Vollzug des Kalamitätsbetriebes nach den Regeln des Modellbetriebes fortgeschrieben.

\subsection{Bewirtschaftung Modellbetrieb}

Die waldbauliche Behandlung der Bestände des Modellbetriebs im WaldPlaner erfolgte analog zu den auf die Zukunft gerichteten Waldentwicklungsszenarien über ein an Bestandesentwicklungsphasen orientiertes Regelset.

Zur möglichst realitätsnahen Abbildung der Bestandesbehandlung im Modellbetrieb nach früherer forstbetrieblicher Praxis wurde das waldbauliche Regelset (s. Kap. 2.2.11.2) für den Teilzeitraum von 1962 bis 1992 entsprechend modifiziert. Als wesentliche Abwandlung im Bereich der Bestandespflege wurde durchweg über alle Baumarten eine niederdurchforstungsartige Behandlung unterstellt. Damit entfiel gleichzeitig die Auswahl vorrangig zu begünstigender Z-Bäume. Bei Erreichen bzw. Unterschreiten der als kritisch festgelegten Überschirmungsgrade wurde auf Durchforstungen verzichtet und es erfolgte nur noch eine Kalamitätsnutzung. Für die Endnutzung wurde bei Buche und Edellaubbäumen auch für den früheren Zeitraum bereits eine einzelstammweise Zielstärkennutzung bei gleichzeitiger Naturverjüngung unterstellt. Für die Baumartengruppen Eiche, Weichlaubbäume, Kiefer und Fichte wurde gemäß damals praxisüblichen Vorgehens bei Erreichen eines der Zielstärke entsprechenden durchschnittlichen Bestandesdurchmessers (dg) die Nutzung im Kahlschlag mit anschließender Freiflächenkultur simuliert.

Für den zweiten Zeitabschnitt von 1992 bis 2006 wurde bereits von den heute empfohlenen waldbaulichen Behandlungskonzepten ausgegangen. Deshalb wurde hier für die Modellbetriebssimulation das gleiche waldbauliche Regelset angewandt, wie in den Waldentwicklungsszenarien für Bestände mit durchgehend sicherem Grundwasseranschluss bzw. immer ohne sicheren Grundwasseranschluss.

Bei der Verjüngung von Waldbeständen des Modellbetriebes wurden bezüglich der Baumartenwahl für den gesamten Betrachtungszeitraum folgende Festlegungen getroffen: 
- Buchenbestände werden natürlich wieder in Buche verjüngt.

- Eichenbestände werden in Eiche und zu Teilen, vorrangig auf den schwächeren Standorten, in Roteiche verjüngt.

- Edellaubbaumbestände werden natürlich wieder in Edellaubbäume verjüngt.

- Kiefernbestände werden in Kiefer und zu moderaten Anteilen in die ertragsstärkere Douglasie verjüngt.

- Bei Fichtenbestockungen erfolgt ein Baumartenwechsel mit standortsgemäßer Verjüngung in die Bestandesklassen Eiche, Roteiche oder Douglasie.

\subsection{Vergleichende Betrachtung}

Der Wert der Holznutzungen und Verjüngungsmaßnahmen wurde mit heutigen Erlösen und Kosten bewertet ${ }^{8}$. Die Holznutzung wurde dabei anhand eines Sortimentierungs- und Kostenmodells in Abhängigkeit von der Nutzungsart (planmäßig oder kalamitätsbedingt) bewertet ${ }^{9}$. Die so ermittelten Zahlungsströme wurden auf das Jahr 2007 mit einem Kalkulationszins in Höhe von einem Prozent ${ }^{10}$ prolongiert und bildeten so den Endwert der forstlichen Nutzung nach 40 Jahren. Dieser Endwert wurde für den Vergleich des „Modellbetriebes“ mit dem „Kalamitätsbetrieb“ herangezogen. Die Holznutzungen der Jahre 1985, 1986 und 1990, 1991 wurden wegen des erheblichen Schadholzaufkommens infolge der Stürme vom November 1984 und Februar 1990 nicht normal berücksichtigt. Die großen Sturmholzmengen dieser Jahre führten auch zu verminderten Holzanfällen in den Folgejahren. Deshalb wurden die zusätzlichen Holzmengen dieser Jahre mit dem durchschnittlichen Kalamitätsanteil dieser Flächen (berechnet für den Gesamtzeitraum der Betrachtungsperiode ohne Sturmjahre) zu gleichen Teilen rechnerisch auf alle Folgejahre verteilt. Die Differenzen zwischen den Endwerten der Zahlungsströme des Modellbetriebes und des Kalamitätsbetriebes erlauben einen Vergleich der Erfolgsbeiträge der Hauptbaumarten.

Neben der Betrachtung der maßnahmenbedingten Zahlungsströme wurde auch die Wertentwicklung der Bestände berücksichtigt. Hierzu wurden für die Modellbestände die Abtriebswerte zu den Stichjahren 1967 und 2007 berechnet. In der Waldbewertung werden bei der Bestandesbewertung auch andere Bewertungs-

8 S. Kapitel 2.2.14.2

9 S. Kapitel 2.2.14.2

${ }^{10} \mathrm{Da}$ der Zinssatz die vom Waldbesitzer als Alternative zu realisierende Kapitalverwendungsmöglichkeit abbilden soll, wurde als Maßstab die innerbetriebliche Grenzverzinsung herangezogen. MÖHRING (2001, S.61ff.) errechnete endscheidungsrelevante Grenzrendite von 1,5 bis $2 \%$ für Fichte und Buche im Solling. Unter den gegebenen Bedingungen im Untersuchungsgebiet und der Baumartenausstattung mit ertragsschwächeren Baumarten (v. a. Kiefer) wurde ein leicht geringerer Zinssatz für diese Untersuchung herangezogen. 
konzepte verwendet ${ }^{11}$, für den Vergleich alternativer Entwicklungen des Modellbetriebes und des Kalmitätsbetriebes stellen die Abtriebswerte und ihre Veränderung jedoch besonders aussagefähige Größen dar. In Übereinstimmung mit BRÄUNIG u. DIETER (1999) wurden negative Abtriebswerte nicht berücksichtigt und gleich null gesetzt. Die Ertragswerte der Maßnahmen und die Abtriebswerte ließen sich stichtagsbezogen zur Beurteilung der Wertentwicklung zusammenführen. Die Transformation in Annuitäten war daraufhin finanzmathematisch möglich (vgl. MÖHRING u. RÜPING 2006). Dabei war zu beachten, dass die Annuität nicht für die Umtriebszeit zu berechnen war, sondern nur für die 40-jährige Zeitspanne (vgl. MÖHRING et al. 2006).

Für die Auswertung wurden die Bestände nach Hauptbaumart und Altersklasse zusammengefasst. Zusätzlich erfolgte eine Unterteilung nach Substrat und Grundwasserständen (s. Tab. 33). Als Grenze für den sicheren Grundwasseranschluss von Waldbeständen wurde ein Grundwasserstand von $250 \mathrm{~cm}$ unter Flur festgelegt.

Tabelle 33: Stratifizierung der Auswertungseinheiten für die betriebswirtschaftliche Analyse nach Substratgruppen und Grundwasserverbältnissen

\begin{tabular}{|c|c|}
\hline \multicolumn{2}{|l|}{ Substrat } \\
\hline S & $\begin{array}{l}\text { Standorte mit Rheinsanden und schwach lehmigen Sanden mit geringer } \\
\text { Wasserspeicherfähigkeit (nFK_140 }<140 \mathrm{~mm} \text { ) }\end{array}$ \\
\hline $\mathrm{T}$ & $\begin{array}{l}\text { Tone - Standorte mit Tonschichten, die eine Mächtigkeit von } \geq 60 \mathrm{~cm} \\
\text { aufweisen }\end{array}$ \\
\hline IS_L_SH & übrige Standorte mit mehr oder weniger starken lehmigen Anteil \\
\hline \multicolumn{2}{|c|}{ Grundwasser } \\
\hline GW & $\begin{array}{l}\text { sicherer Grundwasseranschluss } 2007 \text { vorhanden, } \\
\text { Grundwasserstand } 2007 \text { gleich Grundwasserstand } 1967\end{array}$ \\
\hline nGW & kein sicherer Grundwasseranschluss 1967 und 2007 \\
\hline gGW & $\begin{array}{l}\text { sicherer Grundwasseranschluss } 2007 \text { vorhanden, } \\
\text { Grundwasserstand zwischen } 1967 \text { und } 2007 \text { abgesunken }\end{array}$ \\
\hline vGW & $\begin{array}{l}\text { kein sicherer Grundwasseranschluss 2007, } \\
1967 \text { sicherer Grundwasseranschluss vorhanden oder sicherer Grund- } \\
\text { wasseranschluss } 2007 \text { vorhanden, jedoch im Vergleich zu } 1967 \text { über } \\
150 \mathrm{~cm} \text { abgesunken }\end{array}$ \\
\hline
\end{tabular}

11 Richtlinien für die Ermittlung und Prüfung des Verkehrswertes von Waldflächen und Nebenentschädigungen (Waldwertermittlungsrichtlinien - WaldR 2000) vom 12.07.2000, Bundesanzeiger, Jg. 52, Nr. $168 \mathrm{a}$ 


\subsubsection{Bewertung der prognostizierten Waldentwicklung}

Um die forstbetrieblichen Auswirkungen der unterschiedlichen Grundwasser- und Klimaszenarien bewerten und miteinander vergleichen zu können, wurden Mehrkosten und Mindererlöse im Sinne einer Ertragsbewertung erfasst. Die Betrachtung beschränkte sich dabei auf die Holznutzungen und die Verjüngungstätigkeiten, deren laufende Zahlungen zu Endwerten aggregiert wurden. Zusätzlich wurden die Veränderungen der Abtriebswerte zwischen Beginn und Endzeitpunkt der Simulationen erfasst.

In den Simulationsläufen wurde jedem genutzten Baum eine Nutzungsart zugeordnet. Dabei erfolgte eine Unterscheidung zwischen planmäßiger Nutzung und kalamitätsbedingter Nutzung auf der Basis des Mortalitätsmodells (s. Kap. 2.2.7). Zur Bewertung wurde ein Sortimentierungsmodell für diese beiden Nutzungsarten entwickelt. Der erntekostenfreie Holzerlös wurde als Zielgröße in Abhängigkeit von der Nutzungsart und der Baumart durchmesserabhängig gerechnet.

Für die Erstellung des Sortimentierungsmodells wurden die Holzverkaufsdaten der Jahre 1999 bis 2004 des Projektgebiets ausgewertet. Diese Daten umfassten $284.000 \mathrm{fm}$, die sich entsprechend Tabelle 34 auf die Baumartengruppen aufteilten.

Diese verkauften Holzmengen waren nach Verkaufsfällen flächenbezogen aufgelistet und enthielten die Angabe der Sorte (Stammholz, Industrieholz) und Güteklasse (zusammengefasst zu Wertholz, B, BC, C, CGW). Zusätzlich enthielten die Daten die Bezeichnung der Hiebsart. Diese wurde zu den beiden Nutzungsarten „planmäßige Nutzung“" und „kalamitätsbedingte Nutzung“" zusammengefasst.

Tabelle 34: Übersicht über die in der Holzverkaufssammlung erfassten Baumartengruppen

\begin{tabular}{ccccccc}
\hline & $\mathrm{Bu}$ & $\mathrm{Ei}$ & $\mathrm{ELB}$ & $\mathrm{Fi} / \mathrm{Dgl}$ & $\mathrm{Ki}$ & WLB \\
\hline $\mathrm{fm}$ & 45.257 & 38.087 & 5.771 & 15.911 & 159.509 & 19.610 \\
\hline
\end{tabular}

Der Mitteldurchmesser des ausscheidenden Bestandes (Dg), die für Erstellung eines durchmesserabhängigen Sortimentierungsmodells entscheidende Größe, war in den Verkaufsdaten nicht enthalten. Dieser wurde durch die Verknüpfung mit Forsteinrichtungsdaten über das Alter und die Ertragsklasse aus der Ertragstafel ermittelt. Um eine sinnvolle Verknüpfung mit den Forsteinrichtungsdaten zu ermöglichen, blieben Datensätze der Schicht 3 (Verjüngung) unberücksichtigt. Enthielten die Forsteinrichtungsdaten mehrere Alters- und/oder Ertragsklassenangaben zu einer Baumart, erfolgte eine vorratsgewichtete Mittelung des Alters und der Ertragsklasse. Unter der Annahme, dass bei den heute üblichen hochdurchforstungsartigen Eingriffen ${ }^{12}$ der mittlere Durchmesser der entnommenen Bäume ungefähr dem Mitteldurchmesser des Gesamtbestandes entspricht, wurde der nach dem Ansatz von WOLLBORN u. BÖCKMANN (1998) kalibrierte Ertrags-

12 Ausgewerteter Zeitraum: 1999 - 2004 
tafeldurchmesser des Gesamtbestandes als Mitteldurchmesser des ausscheidenden Bestandes verwendet.

\subsection{Ableitung des Sortimentierungsmodells}

Neben der Nutzungsart hat auch die Baumart einen deutlichen Einfluss auf die Güteklassenverteilung. Für viele Baumarten lagen jedoch nur wenige Beobachtungen vor. Die Baumarten wurden also wiederum zu den in Tabelle 34 angegebenen Baumartengruppen zusammengefasst.

Zur Schätzung der Stammholz-Güteklassen wurde ein statistisches Modell entwickelt. Die Bedingungen für eine einfache Regression waren nicht erfüllt (Normalverteilung der Residuen, Varianzhomogenität). Für die benötigte multivariate Analyse (Dg, Baumart, Nutzungsart) nicht-metrischer abhängiger Variablen (Güteklasse) wurde ein multinomiales Logit-Modell mit Hilfe der Funktion „,vglm“ des Paketes „,vgam“ des Statistikprogramms „R“ (R DEVELOPMENT CORE TEAM 2010) entwickelt. Dieses stellt eine Erweiterung des Verfahrens der binären logistischen Regression auf eine kategoriale abhängige Variable mit mehr als zwei Ausprägungen dar. Es wurde hier für die Schätzung der Güteklassenanteile parametrisiert. Dabei werden die Regressionsparameter auf der Grundlage des MaximumLikelihood-Verfahrens geschätzt. Die Zielvariablen wurden in Form von Güteklassenanteilen übergeben, die mit den Einschlagsvolumina je Baumart gewichtet waren. Dadurch erhielten größere Hiebe berechtigterweise ein größeres Gewicht, da bei kleinen Hiebsvolumina unter sonst gleichen Bedingungen mit einer größeren zufälligen Variation der Anteile zu rechnen ist. Datensätze mit Holzmassen unter einem Festmeter konnten verfahrensbedingt nicht berücksichtigt werden. Das resultierende Modell lautet:

mit

$$
G K \sim B A+N A * D g
$$

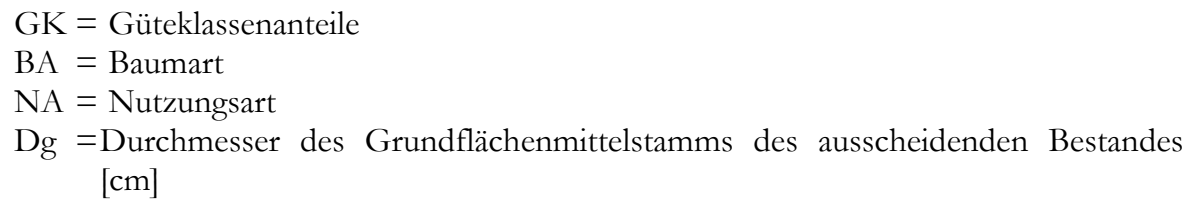

Das Güteklassenmodell wurde in einem zweiten Schritt mit einem Stammholzmodell kombiniert. Für das Stammholzmodell ergab eine binomiale logistische Regression der Holzverkaufsdaten keine statistisch abgesicherten Ergebnisse. Ursächlich könnte hierfür sein, dass bei kalamitätsbedingten Nutzungen der X-Holzanteil höher war als bei planmäßigen Nutzungen und so den Industrieholzanteil verringerte $^{13}$. Dieser Effekt würde dann einer Erhöhung des Industrieholzanteils aufgrund der vermuteten Verschlechterung der Holzqualität entgegenstehen und sich teilweise aufheben. Gutachten auf der Grundlage von doppelten Nummern-

13 X-Holzanteile konnten hier nicht in die Auswertung einbezogen werden. 
büchern (RIEBELING 1989a, 1989b, 1990) oder detaillierten Qualitätsanalysen (STORCH 1995) wiesen deutlich verringerte Stammholzanteile bei kalamitätsbedingter Nutzung nach und rechtfertigten damit, bei kalamitätsbedingten Nutzungen einen verringerten Stammholzanteil zu unterstellen. Um dies zu berücksichtigen, wurden die Sortentafeln von SCHÖPFER u. DAUBER (1989) verwendet. Den planmäßigen Nutzungen wurde der Stammholzanteil der Wertklasse 2 und den kalamitätsbedingten Nutzungen der Stammholzanteil der Wertklasse 3 zugewiesen. Durch den Verzicht auf die Verwendung der ersten Wertklasse für planmäßige Nutzungen wurde der Unterschied zwischen den Nutzungsarten sehr vorsichtig eingeschätzt. Diese Stammholzanteile wurden anschließend mit den Güteklassen aus den Holzverkaufsdaten in einem Modell zusammengeführt.

Abbildung 41 zeigt die Sortimentierungsfächer für die Baumartengruppe Kiefer bei planmäßiger und kalamitätsbedingter Nutzung. Auffällig ist, dass der Bund BC-Holzanteil bei der kalamitätsbedingten Nutzung deutlich geringer ist, der CGW-Anteil hingegen größer. Entsprechende Darstellungen für die weiteren Baumartengruppen finden sich im Anhang (Abbildungen Anhang A4 bis A8).

Die modellierten Sortimentsanteile der beiden Nutzungsarten konnten anschließend mit Marktpreisen bewertet werden. Hierzu wurden sie mit den Stärkeklassenverteilungen ${ }^{14}$ und Holzpreisen der Holzpreisstatistik von HESSENFORST der Jahre 2007 bis $2009^{15}$ über die Baumart, Güteklasse und den Dg mit den Sorten- und Güteklassen des Sortimentsmodells verknüpft. Für Durchmesserwerte von 10 bis $80 \mathrm{~cm}$ (in $2 \mathrm{~cm}$-Stufen) wurde dann der mit den jeweiligen Sortimentsanteilen und für die Stammholzanteile zusätzlich mit den Stärkeklassenanteilen gewichtete mittlere Erlös je Efm berechnet. Dem liegt die vereinfachende Annahme zugrunde, dass die Verteilung der Stärkeklassen durch Kalamitäten unbeeinflusst war. Der Effekt der Kalamitätsnutzung auf die Sortimentsverteilung wurde durch das Modell also leicht unterschätzt.

\footnotetext{
14 Aus SCHÖPFER u. DAuber (1989)

15 Nur Staatswald, die Holzpreise des Jahres 2009 wurden doppelt gewichtet
} 

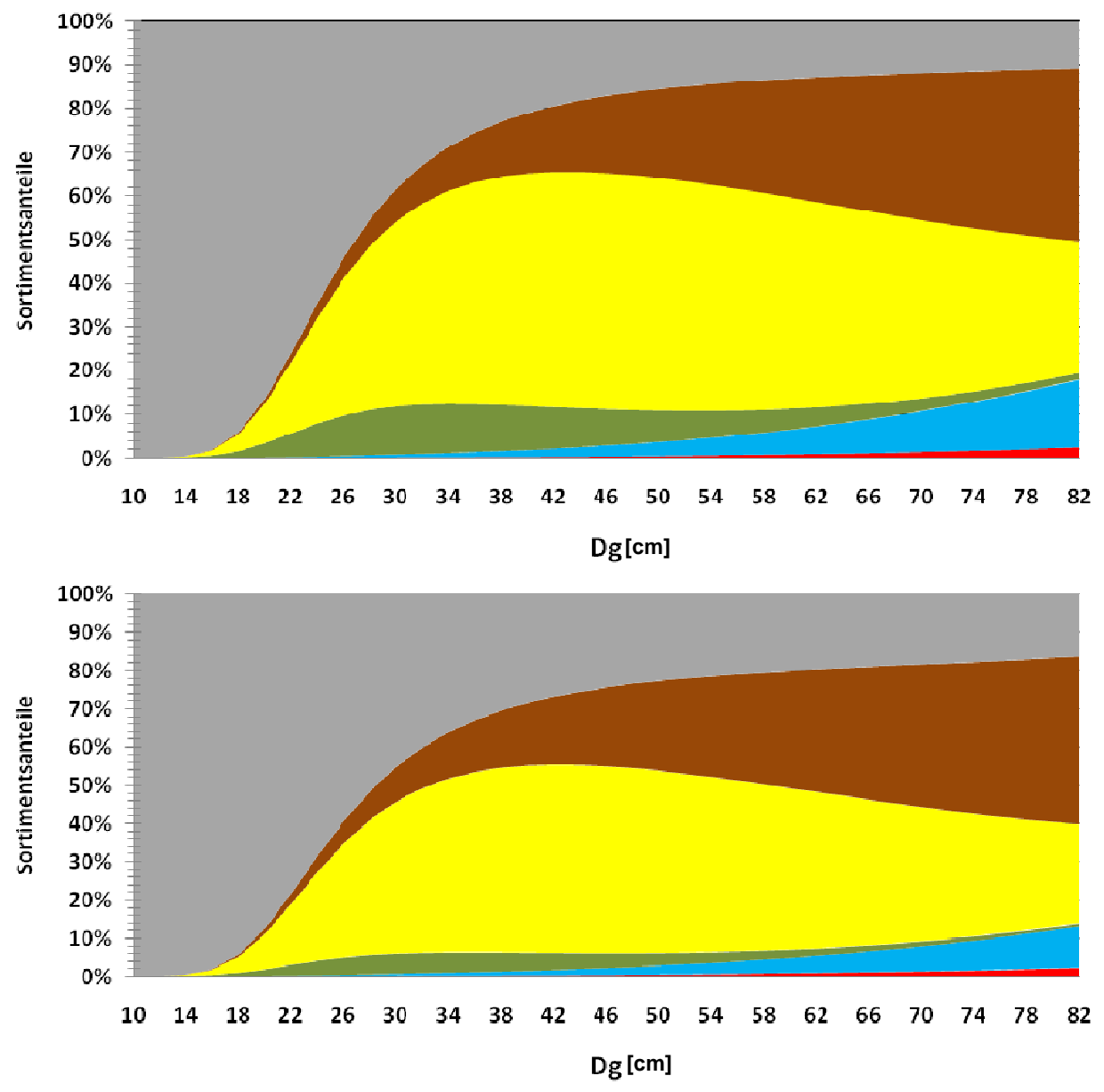

$\square$ W $\square$ B.C C $\square$ CGW NSth

Abbildung 41: Sortimentsanteile [\%] der Baumartengruppe Kiefer (als Beispiel) für planmäßige (oben) und kalamitätsbedingte (unten) Nutzung

\subsection{Holzerntekosten}

Die Daten der Kosten- und Leistungsrechnung ließen keine flächen- oder hiebsbezogene Auswertung der Holzerntekosten zu. Es wurden deshalb die von OFFER u. STAUPENDAHL 2009 mit dem Programm Holzernte ermittelten Holzerntekosten einer motormanuellen Aufarbeitung auf der Basis des EST ${ }^{16}$ (in Kombination mit Seilschlepperrückung) zum einen und auf der Basis von hochmechanisierter Holzernte mit Harvester und Forwarder zum anderen verwendet. In diesem Projekt

${ }^{16}$ EST: Erweiterter Sortentarif

Beiträge aus der NW-FVA, Band 10, 2013 
wurde eine hochmechanisierte Aufarbeitung jeweils bis zu demjenigen (baumartenspezifischen) Dg unterstellt, bei dem das hochmechanisierte Verfahren geringere Kosten pro Festmeter verursacht als die motormanuelle Aufarbeitung. Diese baumartenspezifischen und durchmesserabhängigen Holzerntekosten wurden für die planmäßige Holznutzung unterstellt.

In der Literatur finden sich einige Untersuchungen zu kalamitätsbedingten Mehrkosten bei der Holzernte ${ }^{17}$. Diese ließen sich jedoch nicht auf die kalamitätsbedingten Nutzungen im Hessischen Ried übertragen, da es sich hier überwiegend nicht um die ansonsten dominierenden Sturmschäden handelt ${ }^{18}$, sondern um Trocknis- und Insektenschäden. Erhöhte Holzerntekosten waren hier vor allem durch geringe Hiebsmengen (Sammelhieb) verursacht. Deshalb wurde aus den in den Gutachten von RIEBELING 1989b und RIEBELING 1990 aufgeführten erhöhten Holzwerbungskosten ein durchschnittlicher Aufschlag von 1,30€/Efm für kalamitätsbedingte Nutzungen auf die dynamischen durchmesserabhängigen Holzerntekosten abgeleitet.

Für die beiden genannten Gutachten wurden detaillierte Aufschriebe von Einzelmaßnahmen ähnlich zu den oben genannten doppelten Nummernbüchern geführt. Diese Aufschriebe wurden auch für das Projekt ausgewertet. In den simulierten Szenarien erfolgte keine Unterscheidung zwischen flächiger Kalamitätsnutzung und Sammelhieb mit verstreutem Hiebsanfall. Deshalb wurde bei der Herleitung des Zuschlages der bisherige Anteil des Sammelhiebes an der Kalamitätsnutzung unterstellt.

In Abbildung 42 werden die erntekostenfreien Holzerlöse für Laub- und Nadelholz bei planmäßiger bzw. kalamitätsbedingter Nutzung dargestellt.

17 Vgl. Bundesamt FÜr Umwelt (BAFU) 2008

18 mit Ausnahme der Stürme in den Jahren 1984 und 1990 


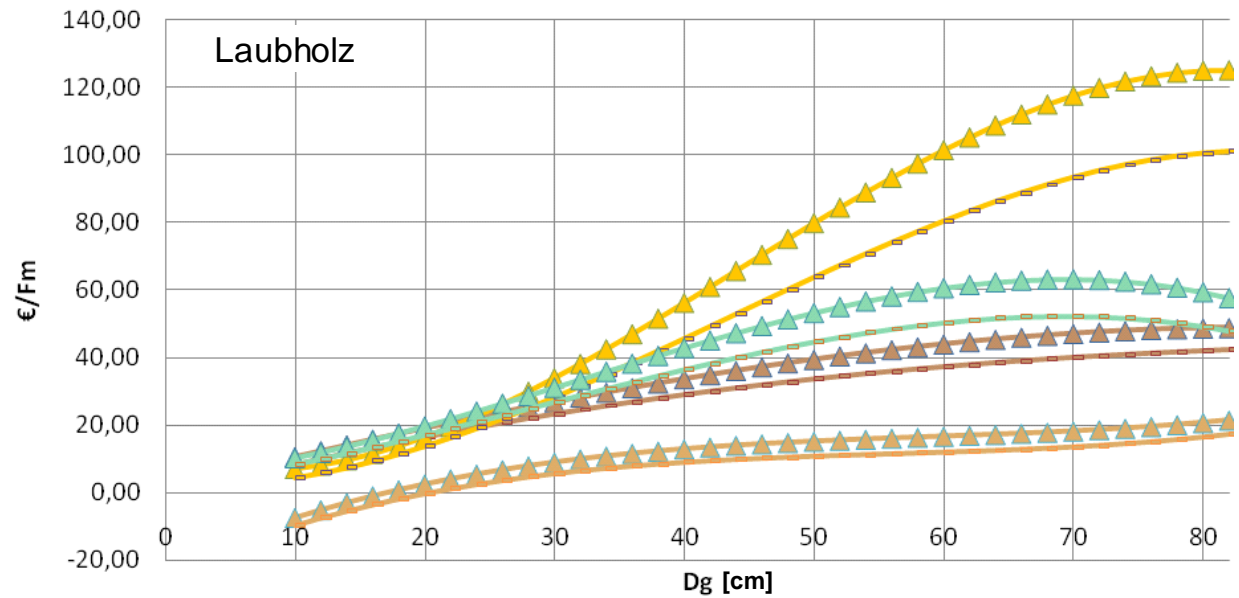

$$
\begin{aligned}
& \triangle \text { Bu_planmäßig } \longrightarrow \text { Bu_kalamität } \longrightarrow \text { Ei_planmäßig }- \text { Ei_kalamität } \\
& \triangle-\text { ELB_planmäßig } \longrightarrow \text { ELB_kalamität } \longrightarrow \text { WLB_planmäßig } \longrightarrow \text { WLB_kalamität }
\end{aligned}
$$

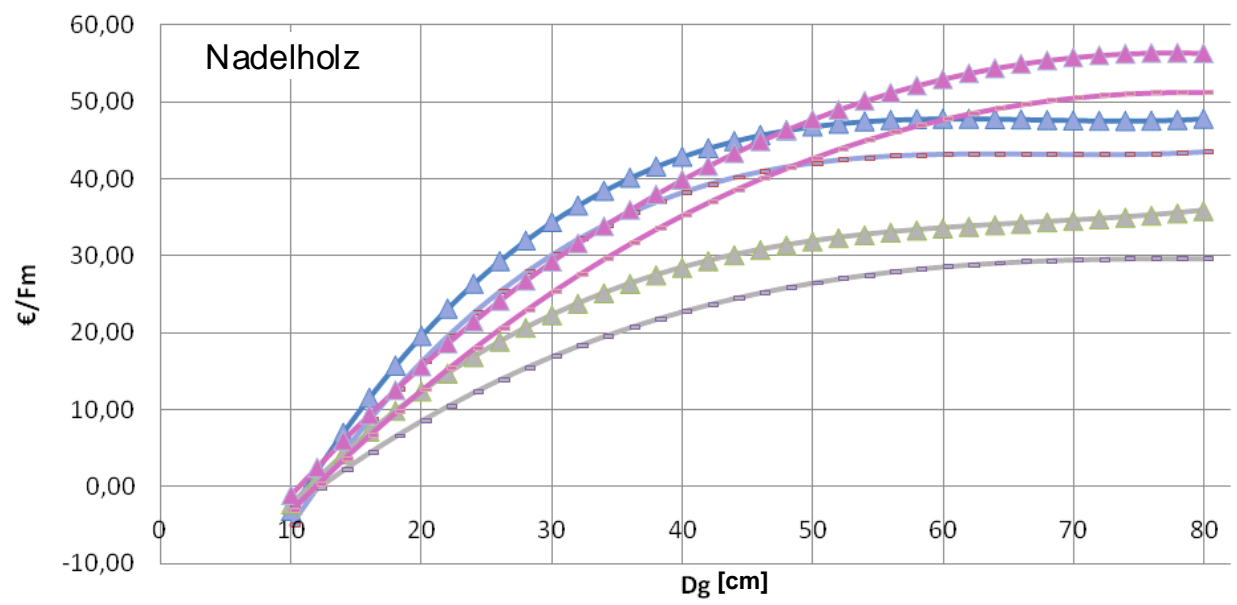

$$
\begin{aligned}
& - \text { Fi_planmäßig }- \text { Fi_kalamität }- \text { Ki_planmäßig } \\
& - \text { Ki_kalamität } \longrightarrow \text { Dgl_planmäßig }- \text { Dgl_kalamität }
\end{aligned}
$$

Abbildung 42: Erntekostenfreie Holzerlöse [€/fm] der Baumartengruppen bei planmäßiger und kalamitätsbedingter Nutzung. Douglasie wurde, obwohl der Baumartengruppe Fichte zugehörig, separat betrachtet. 


\subsection{Verjüngung}

Auch im Bereich Waldverjüngung sind Mehraufwendungen zu erwarten (vgl. HAUB 1997, FrIEDEL 2010). Für dieses Projekt wurden die unterschiedlichen Gesamtflächen mit aktiven Verjüngungsmaßnahmen betrachtet. Die Wachstumssimulationen berechneten in Abhängigkeit vom Mortalitätsmodell und den Maikäferdichten das Überleben und den Ausfall mit dann erforderlicher Wiederholung der Kulturen. Zur Ermittlung des Kulturaufwandes wurde die szenariospezifische Kulturfläche mit den Kulturkostensätzen der Waldbewertung multipliziert.

\subsection{Vergleichende Betrachtung}

Die für die verschiedenen Szenarien simulierten Zahlungsströme wurden im Sinne einer Ertragsbewertung mit einem Zinssatz von einem Prozent auf das Jahr 2007 abdiskontiert und bildeten so den Vorwert der forstlichen Nutzung der 32-jährigen Periode. Dieser Vorwert wird als Zielgröße des Vergleichs zwischen den Szenarien herangezogen. Mit dieser Methode lässt sich auch der relative Erfolg der Hauptbaumarten herleiten. Die Berücksichtigung der Wertveränderung der Bestände erfolgte analog der in Kapitel 2.2.14.1.2 beschriebenen Methode.

\subsection{Naturschutzrechtliche Nutzungseinschränkungen}

Grundsätzlich wurden die vorhandenen naturschutzrechtlichen Bewirtschaftungseinschränkungen in die Szenarien integriert. Bei Flächenüberschneidungen definierte die „strengere“ Schutzkategorie die gültigen Einschränkungen. So enthielten etwa Prozessschutzflächen auch Lebensraumtypen gemäß der FFH-Richtlinie, für sie wurde jedoch ausschließlich der Nutzenentgang durch den Prozessschutz kalkuliert. Zusätzlich erfolgte ein flächenscharfer Simulationslauf, bei dem alle Bewirtschaftungseinschränkungen „ausgeschaltet“ waren und die Bewirtschaftung nur nach den allgemeinen Waldbauregeln vorgegeben wurde. Die Bewertung erfolgte im Weiteren analog zu dem Vergleich der Szenarien. 


\section{Ergebnisse}

\subsection{Klimatische Verhältnisse}

Analog zur Vorgehensweise bei der Regionalisierung der klimatischen Messwerte (s. Kap. 2.1.2.1) wurden die Stationsdaten der Klimaszenarien auf das Modellraster interpoliert. Allerdings umfasst der WETTREG-Datensatz (SPEKAT et al. 2007) teilweise andere Stationen als das Stationsmessnetz des DWD. Für die Interpolation der Klimadaten der trockenen und feuchten Variante des A1B-Szenarios wurden 34 Stationen (davon 6 Klimastationen) verwendet (s. Anhang, Tab. A1).

Nach dem Klimaszenario A1B wird im Hessischen Ried für die Periode 2030 bis 2039 mit einem Anstieg der Jahresmitteltemperatur um $1,2{ }^{\circ} \mathrm{C}$ bis $1,3{ }^{\circ} \mathrm{C}$ gerechnet. Dieser Anstieg fällt für die Vegetationsperiode bzw. für die Vegetationsruhe in Abhängigkeit von der Klimavariante sehr unterschiedlich aus. Die deutlichste Temperaturzunahme ist mit $1,8^{\circ} \mathrm{C}$ auf $18,4^{\circ} \mathrm{C}$ bei der trockenen Variante in der Vegetationsperiode zu verzeichnen, während sie bei der feuchten Variante mit $0,9{ }^{\circ} \mathrm{C}$ in der Vegetationsperiode moderater ausfällt. Dagegen ist in der Vegetationsruhe bei der feuchten Variante der Temperaturanstieg mit $1,7^{\circ} \mathrm{C}$ deutlich höher als bei der trockenen Variante mit $0,7^{\circ} \mathrm{C}$ (s. Tab. 35 und 36).

Tabelle 35: $\quad$ Mittlere Klimakennwerte (Ø) der Dekade 2030 bis 2039 für das Klimaszenario A1B trockene V ariante und für die Klimanormalperiode 1961 - 1990 (Ønorm)

\begin{tabular}{lcccccc}
\hline Klimakennwert & \multicolumn{2}{c}{ Jahr } & \multicolumn{2}{c}{ Vegetationsperiode } & \multicolumn{2}{c}{ Vegetationsruhe } \\
& $\begin{array}{c}2030-39 \\
\varnothing\end{array}$ & $\begin{array}{c}1961-90 \\
\varnothing_{\text {norm }}\end{array}$ & $\begin{array}{c}2030-39 \\
\varnothing\end{array}$ & $\begin{array}{c}1961-90 \\
\varnothing_{\text {norm }}\end{array}$ & $\begin{array}{c}2030-39 \\
\varnothing\end{array}$ & $\begin{array}{c}1961-90 \\
\varnothing_{\text {norm }}\end{array}$ \\
& 655 & 745 & 309 & 371 & 346 & 374 \\
$\begin{array}{l}\text { Niederschlag, } \\
\text { korrigiert } \\
{[\mathrm{mm}]}\end{array}$ & & & & & & \\
$\begin{array}{l}\text { potenzielle } \\
\text { Verdunstung }\end{array}$ & 659 & 606 & 510 & 470 & 149 & 136 \\
$\begin{array}{l}{[\mathrm{mm}]} \\
\text { klimatische }\end{array}$ & -4 & 139 & -201 & -99 & 197 & 238 \\
$\begin{array}{l}\text { Wasserbilanz } \\
{[\mathrm{mm}]}\end{array}$ & & & & & & \\
$\begin{array}{l}\text { Temperatur } \\
{\left[{ }^{\circ} \mathrm{C}\right]}\end{array}$ & 11,3 & 10,1 & 18,4 & 16,6 & 5,1 & 4,4 \\
\hline
\end{tabular}



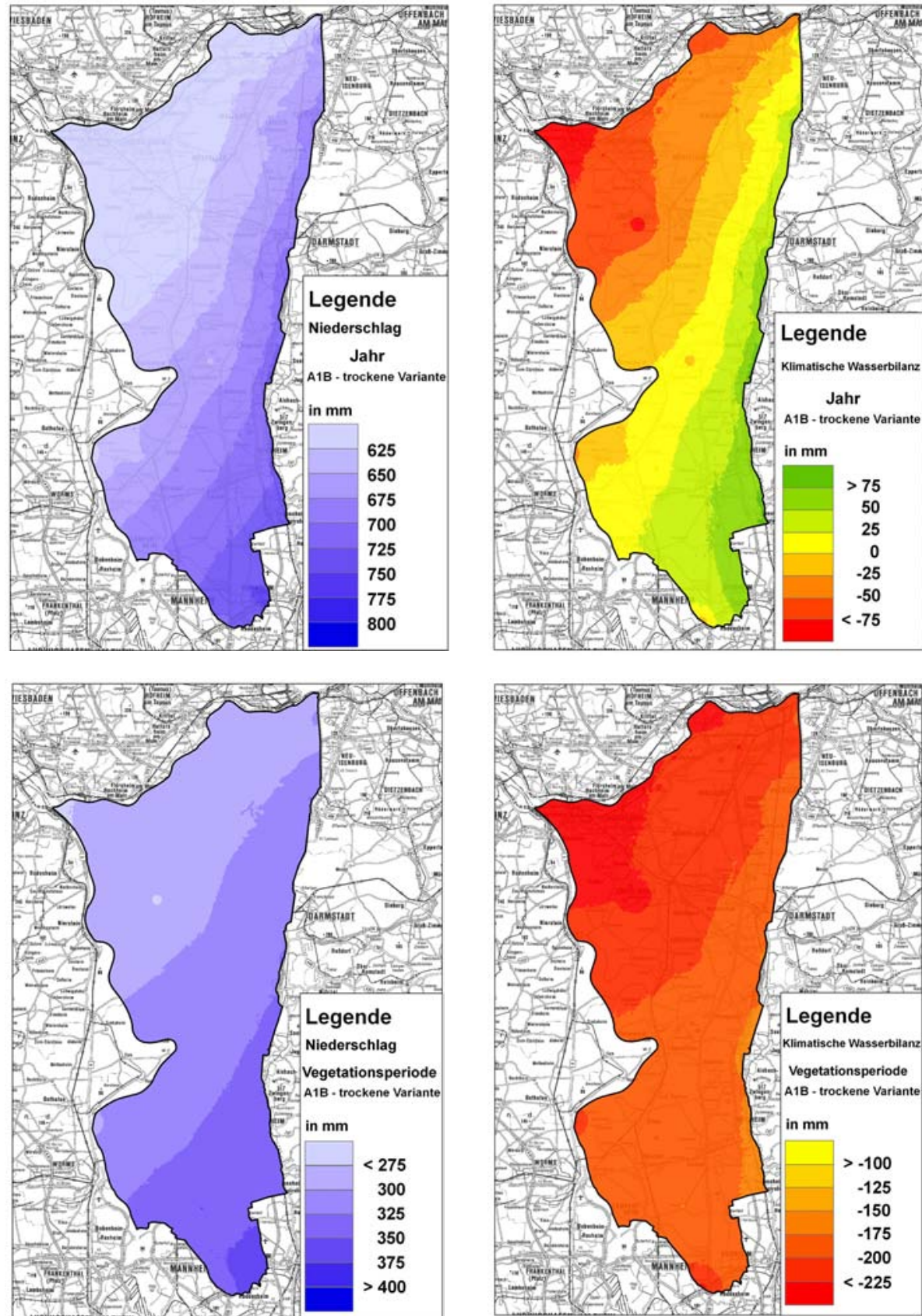

Abbildung 43: Mittlere Niederschlagssumme [mm] (links) und Klimatische Wasserbilan₹ [mm] (rechts) im Untersuchungsgebiet für das Klimaszenario A1B - trockene V ariante, 2030 - 2039, Jahr (oben) und Vegetationsperiode (unten) 

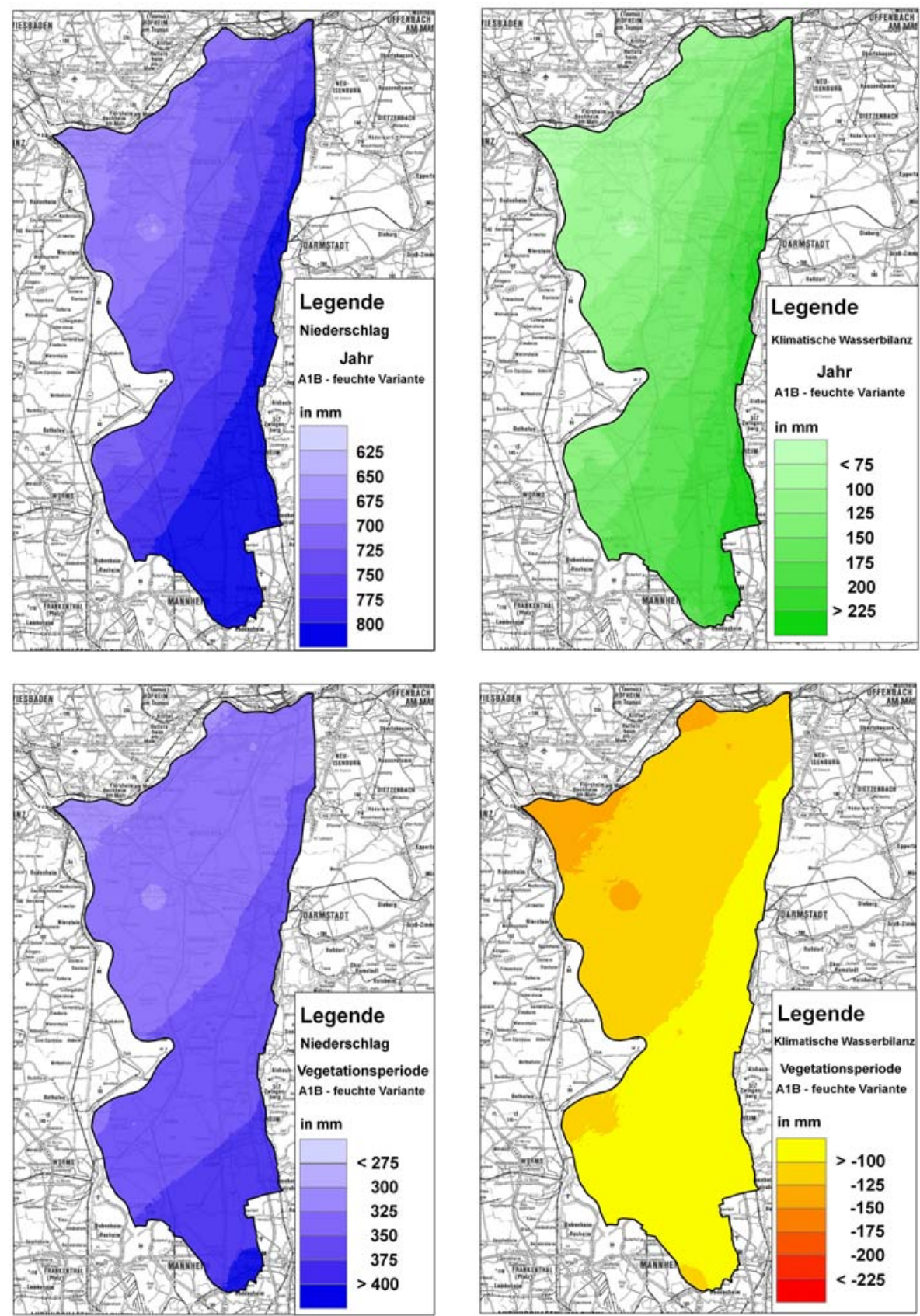

Abbildung 44: Mittlere Niederschlagssumme [mm] (links) und Klimatische Wasserbilanz. [mm] (rechts) im Untersuchungsgebiet für das Klimaszenario A1B - feuchte Variante, 2030 - 2039, Jahr (oben) und Vegetationsperiode (unten)

Beiträge aus der NW-FVA, Band 10, 2013 
Erwartungsgemäß werden bei der trockenen Variante die mittleren jährlichen Niederschlagssummen für die Periode 2030 bis 2039 um rund 12 Prozent $(655 \mathrm{~mm})$ niedriger projiziert als für die Klimanormalperiode 1961 - 1990 (s. Tab. 35). Die Abnahme in der Niederschlagssumme fällt mit -17 Prozent in der Vegetationsperiode noch deutlicher aus als für die Vegetationsruhe mit -8 Prozent. Da gleichzeitig die potenzielle Verdunstung (Grasreferenz) auf knapp $660 \mathrm{~mm}$ ansteigt, ist unter den Bedingungen der trockenen Variante in Zukunft mit einer signifikanten Verschlechterung der klimatischen Wasserbilanz zu rechnen. Im Flächenmittel liegt diese bei $-201 \mathrm{~mm}$ in der Vegetationsperiode und $-197 \mathrm{~mm}$ in der Vegetationsruhe. Dies bedeutet eine Abnahme der KWB im Vergleich zur Klimanormalperiode um knapp $150 \mathrm{~mm}$. Mit einem mittleren Defizit von $4 \mathrm{~mm}$ im Jahresmittel liegt die KWB bei der trockenen Variante deutlich unter dem hessischen Durchschnitt von $238 \mathrm{~mm}$ Überschuss und ebenfalls deutlich unter dem gesamtdeutschen Mittelwert von 191 mm Überschuss (ANDERS et al. 2004). Damit zählt das Hessische Ried zu den trockensten Gebieten Hessens.

An der räumlichen Niederschlagsverteilung wird sich auch in Zukunft unter Annahme der trockenen Variante des A1B-Szenarios keine wesentliche Veränderung ergeben. Die geringsten Niederschlagssummen mit rund $600 \mathrm{~mm}$ werden am westlichen Rand des Untersuchungsgebietes erwartet, zum Odenwaldrand steigt der Mittelwert der Dekade 2030 bis 2039 auf 700 bis $750 \mathrm{~mm}$ (s. Abb. 43). In der Vegetationsperiode variieren die Niederschläge zwischen rund 250 und $350 \mathrm{~mm}$. $\mathrm{Da}$ die potenziellen Verdunstungssummen von West nach Ost abnehmen, weist die KWB die höchsten mittleren Defizite in der Vegetationsperiode mit $<-200 \mathrm{~mm}$ am westlichen Rand des Untersuchungsgebietes auf.

Tabelle 36: $\quad$ Mittlere Klimakennwerte (Ø) der Dekade 2030 bis 2039 für das Klimaszenario A1B feuchte Variante und für die Klimanormalperiode 1961 - 1990 (Ønorm)

\begin{tabular}{lcccccc}
\hline Klimakennwert & \multicolumn{2}{c}{ Jahr } & \multicolumn{2}{c}{ Vegetationsperiode } & \multicolumn{2}{c}{ Vegetationsruhe } \\
& $\begin{array}{c}2030-39 \\
\varnothing\end{array}$ & $\begin{array}{c}1961-90 \\
\varnothing_{\text {norm }}\end{array}$ & $\begin{array}{c}2030-39 \\
\varnothing\end{array}$ & $\begin{array}{c}1961-90 \\
\varnothing_{\text {norm }}\end{array}$ & $\begin{array}{c}2030-39 \\
\varnothing\end{array}$ & $\begin{array}{c}1961-90 \\
\varnothing_{\text {norm }}\end{array}$ \\
\hline $\begin{array}{l}\text { Niederschlag, } \\
\text { korrigiert } \\
{[\mathrm{mm}]}\end{array}$ & 765 & 745 & 352 & 371 & 413 & 374 \\
$\begin{array}{l}\text { potenzielle } \\
\text { Verdunstung }\end{array}$ & 600 & 606 & 455 & 470 & 145 & 136 \\
$\begin{array}{l}\text { [mm }] \\
\text { klimatische }\end{array}$ & 165 & 139 & -103 & -99 & 268 & 238 \\
$\begin{array}{l}\text { Wasserbilanz } \\
{[\mathrm{mm}]}\end{array}$ & & & & & & \\
$\begin{array}{l}\text { Temperatur } \\
{\left[{ }^{\circ} \mathrm{C}\right]}\end{array}$ & 11,4 & 10,1 & 17,5 & 16,6 & 6,1 & 4,4 \\
\hline
\end{tabular}


Die klimatischen Verhältnisse der feuchten Variante des A1B-Szenarios unterscheiden sich von den Verhältnissen der Klimanormalperiode 1961 - 1990 deutlich weniger, als dies bei der trockenen Variante der Fall ist (s. Tab. 36). Während im Mittel der Periode 2030 bis 2039 sogar etwas mehr Niederschlag fällt, ist bei der potenziellen Verdunstung mit keiner Veränderung zu rechnen. Allerdings werden in der Vegetationsruhe die Niederschläge im Mittel zunehmen (+10 Prozent), während in der Vegetationsperiode mit einer leichten Abnahme der Niederschlagshöhe gerechnet werden muss (-5 Prozent). Die klimatische Wasserbilanz beträgt in der Vegetationsperiode -103 mm. Die höheren Niederschlagssummen in der Vegetationsruhe führen zu einer im Vergleich zur trockenen Variante deutlich positiven klimatischen Wasserbilanz von $268 \mathrm{~mm}$, sodass auch im Jahresmittel die KWB mit $165 \mathrm{~mm}$ kein Defizit aufweist. Das räumliche Muster der Niederschlagsverteilung und der KWB weist ein ähnliches Bild auf wie bei der trockenen Variante, wobei das Defizit in der Vegetationsperiode deutlich moderater ausfällt als unter trockenen Klimabedingungen (s. Abb. 44)

Unter Annahme der trockenen Variante des A1B-Szenarios wird die Wasserversorgung der Bestände im Hessischen Ried zukünftig einer weiteren Verschlechterung unterliegen. Die KWB weist in der Vegetationsperiode ein hohes Defizit auf, das nur auf Böden mit einer guten Wasserspeicherkapazität annähernd ausgeglichen werden kann. Dies setzt voraus, dass der Bodenwasserspeicher zu Beginn der Vegetationsperiode vollständig gefüllt ist. Der erwartete Rückgang der Niederschlagsmengen wird jedoch dazu führen, dass die Böden zu Beginn der Vegetationsperiode häufiger als bisher nicht wassergesättigt sind. Insbesondere Bestände, die auf Böden mit einer geringen nutzbaren Feldkapazität stocken, werden unter den Bedingungen der trockenen Variante vermehrt unter Trockenstress leiden. In diesem Zusammenhang ist daran zu erinnern, dass die nutzbare Feldkapazität der Sande tendenziell überschätzt wird (s. Kap. 2.1.2.2.1). Bei der feuchten Variante sind die Veränderungen der klimatischen Verhältnisse gegenüber der Klimanormalperiode moderat, sodass nur in ausgeprägten Trockenperioden die Verdunstungsleistung der Bestände stark eingeschränkt wäre.

\subsection{Auswirkungen der Klima- und Grundwasserstandszenarien auf den Wasserhaushalt der Bestände}

Das wesentliche Ziel der Untersuchungen zum Wasserhaushalt besteht darin, den Einfluss des Grundwassers auf die Wasserversorgung der Waldgebiete im Hessischen Ried zu quantifizieren und mögliche Trockenstresssituationen unter vorgegebenen Grundwasserstands- und Klimaszenarien zu identifizieren. Die in Kapitel 2.2.1 beschriebenen drei Grundwasserstandsszenarien wurden mit drei Klimasze-

narien kombiniert. Die neun Kombinationen wurden nach folgenden Kriterien ausgewertet: 
- Bestimmung wesentlicher Wasserhaushaltskomponenten als Gebietsmittel der Waldflächen

- Bilanzierung der Wasserhaushaltskomponenten getrennt nach Waldflächen mit und ohne sicherem Grundwasseranschluss

- Untersuchung der Auswirkungen eines extremen Trockenjahres auf den Wasserhaushalt der Wälder

- Simulation des Wasserhaushaltes ausgesuchter Einzelbestände

Die Bilanzierung des Wasserhaushaltes der Waldflächen erfolgte für die Dekade 2030 bis 3039. Dabei wurden jeweils die Kennwerte für das Jahr, die Vegetationsperiode und die Vegetationsruhe berechnet und ausgewertet.

\subsubsection{Gebietswasserhaushalt}

Auf Grundlage der Modellkalibrierung wurde der Wasserhaushalt der Waldbestände im Hessischen Ried für den Zeitraum 2007 bis 2039 mit dem Modell WaSiM/ETH (SCHUlla u. JASPER 2007) simuliert. Ausgehend vom Status quo wurde die Waldentwicklung mit dem WaldPlaner (HANSEN 2006, NAGEL 2009) fortgeschrieben (s. Kap. 2.2.1.2.2). Nach Abschluss eines 4-Jahres-Zyklus wurden die aktuellen Bestandesparameter wie Blattflächenindex und Bedeckungsgrad an das hydrologische Modell übergeben. Den meteorologischen Antrieb bilden die Tageswerte des Klimaszenarios A1B (trockene und feuchte Variante) und die Messwerte der Stationen des DWD. Beim Referenz-Klimaszenario wird das hydrologische Modell mit den Messdaten der Jahre 1960 bis 1993 angetrieben. Der Auswertungsdekade 2030 bis 2039 liegen somit die Daten der Jahre 1984 bis 1993 zugrunde.

Zur Beurteilung der Wirkung der Grundwasserstands- und Klimaszenarien auf den Wasserhaushalt der Bestandesflächen bietet sich der Vergleich der potenziellen und realen Verdunstung sowie der Grundwasserneubildung an. Die Klimatische Wasserbilanz und das Verhältnis zwischen realer und potenzieller Verdunstung (relative Verdunstung) dienen als Indikatoren zur Identifizierung von Wasserstresssituationen für die Waldbestände. Aufgrund kaum vorhandener Reliefunterschiede und der hohen Infiltrationskapazitäten der Böden (überwiegend Sandböden) im Untersuchungsgebiet findet keine nennenswerte Bildung von Oberflächen- oder Zwischenabfluss statt. Die Gewässer werden fast ausschließlich über das Grundwasser gespeist.

Die mittlere Jahresniederschlagssumme (P) der Periode 2030 bis 2039 beträgt bei Referenz-Klimaszenario-Bedingungen $726 \mathrm{~mm}$. Unter den Annahmen der feuchten Variante des A1B-Szenarios muss mit einer Zunahme der Niederschläge auf $773 \mathrm{~mm}$ gerechnet werden, während die trockene Variante eine mittlere Jahressumme von $662 \mathrm{~mm}$ erwarten lässt. Allen Szenarien liegen korrigierte Niederschläge zugrunde (RICHTER 1995). Dies impliziert eine Erhöhung der Niederschlagssumme um etwa $100 \mathrm{~mm}$ gegenüber den nicht korrigierten Werten. Dabei fallen in 
der Vegetationsruhephase etwas mehr Niederschläge als während der Vegetationsperiode. Sollten in Zukunft die Bedingungen der trockenen Klimavariante eintreten, würden sowohl im Winter wie auch im Sommer die Niederschläge deutlich abnehmen. Bei der feuchten Variante würden insbesondere außerhalb der Vegetationszeit die Niederschlagssummen deutlich ansteigen (s. Tab. 37).

Die potenzielle Verdunstung (ETP) der Bestände liegt bei den Klimaszenarien Referenz und A1Bf bei ungefähr $750 \mathrm{~mm}$ und damit um rund $60 \mathrm{~mm}$ unter den Werten der trockenen A1B-Variante. Die Unterschiede werden maßgeblich durch den erhöhten Verdunstungsanspruch in der Vegetationsperiode hervorgerufen. Während der Vegetationsruhe ist die potenzielle Evapotranspiration unter den Klimabedingungen des A1B-Szenarios (beide Varianten) nur leicht höher als unter den heutigen Klimaverhältnissen. Die Berechnung des mittleren Blattflächenindex und Bedeckungsgrads über alle Bestandesflächen im Hessischen Ried zeigt, dass zum Ende der Simulationsperiode die Parameterwerte fast identisch sind. Dies ist unter anderem darin begründet, dass die im WaldPlaner implementierten Waldbauregeln bereits an die veränderten Standortsbedingungen (Grundwasser, Klima) angepasst wurden. Infolgedessen weichen die Ergebnisse der ETP innerhalb eines Klimaszenarios unabhängig vom zugrunde liegenden Grundwasserstandsszenario kaum voneinander $\mathrm{ab}$.

Die berechnete reale Verdunstung (ETR) fasst die Ergebnisse der Evaporation, Interzeption und Transpiration zusammen. Im Mittel der Dekade 2030 bis 2039 variiert die Verdunstungssumme zwischen knapp $600 \mathrm{~mm}$ (Ref.) und $630 \mathrm{~mm}$ (A1Bt), wobei rund 75 Prozent der Verdunstungsleistung in der Vegetationsperiode erfolgt (s. Tab. 37). Die Gebietsmittelwerte zeigen, dass mit zunehmendem Flächenanteil der Bestände mit sicherem Grundwasseranschluss die reale Evapotranspiration zunimmt, von $597 \mathrm{~mm}$ auf $607 \mathrm{~mm}$ beim Referenz-Szenario, von $619 \mathrm{~mm}$ auf $624 \mathrm{~mm}$ beim A1Bf-Szenario und von $610 \mathrm{~mm}$ auf $629 \mathrm{~mm}$ beim A1Bt-Szenario (s. Tab. 37).

Die Bedeutung der Grundwasserverfügbarkeit für die Bestände wird insbesondere in der Vegetationsperiode sichtbar, wenn infolge negativer Wasserbilanzen das Boden- und Grundwasser als zusätzlicher Speicher zum Niederschlag benötigt wird, um den Verdunstungsanspruch der Pflanzen zu decken.

Die Wasserbilanz berechnet sich aus der Differenz zwischen Niederschlag, realer Verdunstung und Abfluss und entspricht damit der Grundwasserneubildung (GWN). Unter heutigen Klimabedingungen werden im Mittel rund $120 \mathrm{~mm}$ Niederschlag jährlich der GWN zugeführt. Umgerechnet auf die Waldfläche von 27.660 Hektar entspricht dies einer Menge von rund 33 Millionen Kubikmetern. Sollten in Zukunft die Niederschläge zunehmen (A1B, feuchte Variante), kann mit einer Erhöhung der GWN auf rund $150 \mathrm{~mm}$ (41,5 Millionen $\mathrm{m}^{3}$ ) gerechnet werden. 
Tabelle 37: Gebietsmittel-Kennwerte der Dekade 2030 bis 2039 für die untersuchten Grundwasserund Klimaszenarien $(P=$ Niederschlag, ETP = potenzielle Verdunstung, $K W B=$ Klimatische $W$ asserbilan₹, ETR $=$ reale Verdunstung, $G W N=$ Grundwasserneubildung; ETR $/ E T P=$ relative Verdunstung)

\begin{tabular}{|c|c|c|c|c|c|c|}
\hline $\begin{array}{l}\text { GW-Szenario/ } \\
\text { Klimaszenario }\end{array}$ & $\begin{array}{c}\mathrm{P} \\
(\mathrm{mm})\end{array}$ & $\begin{array}{l}\text { ETP } \\
(\mathrm{mm})\end{array}$ & $\begin{array}{l}\mathrm{KWB} \\
(\mathrm{mm})\end{array}$ & $\begin{array}{l}\text { ETR } \\
(\mathrm{mm})\end{array}$ & $\begin{array}{l}\text { GWN } \\
(\mathrm{mm})\end{array}$ & $\begin{array}{c}\text { ETR/ } \\
\operatorname{ETP}(-)\end{array}$ \\
\hline \multicolumn{7}{|c|}{ Jahr } \\
\hline GW_/Ref. & 726 & 764 & -38 & 597 & 129 & 0,78 \\
\hline $\mathrm{GW}_{0} /$ Ref. & 726 & 764 & -38 & 602 & 124 & 0,79 \\
\hline $\mathrm{GW}_{+} /$Ref. & 726 & 763 & -37 & 607 & 120 & 0,80 \\
\hline GW_/A1Bf & 773 & 758 & 15 & 619 & 154 & 0,81 \\
\hline $\mathrm{GW}_{0} / \mathrm{A} 1 \mathrm{Bf}$ & 773 & 758 & 15 & 622 & 151 & 0,82 \\
\hline $\mathrm{GW}_{+} / \mathrm{A} 1 \mathrm{Bf}$ & 773 & 757 & 16 & 624 & 149 & 0,82 \\
\hline GW_/A1Bt & 662 & 811 & -149 & 610 & 52 & 0,76 \\
\hline $\mathrm{GW}_{0} / \mathrm{A} 1 \mathrm{Bt}$ & 662 & 813 & -151 & 620 & 43 & 0,77 \\
\hline $\mathrm{GW}_{+} / \mathrm{A} 1 \mathrm{Bt}$ & 662 & 816 & -154 & 629 & 34 & 0,77 \\
\hline \multicolumn{7}{|c|}{ Vegetationsperiode } \\
\hline GW_/Ref. & 335 & 606 & -271 & 455 & -121 & 0,75 \\
\hline $\mathrm{GW}_{0} /$ Ref. & 335 & 606 & -271 & 460 & -125 & 0,76 \\
\hline $\mathrm{GW}_{+} /$Ref. & 335 & 606 & -271 & 464 & -129 & 0,77 \\
\hline $\mathrm{GW}_{-} / \mathrm{A} 1 \mathrm{Bf}$ & 344 & 585 & -241 & 463 & -119 & 0,79 \\
\hline $\mathrm{GW}_{0} / \mathrm{A} 1 \mathrm{Bf}$ & 344 & 585 & -241 & 466 & -122 & 0,80 \\
\hline $\mathrm{GW}_{+} / \mathrm{A} 1 \mathrm{Bf}$ & 344 & 585 & -241 & 468 & -124 & 0,80 \\
\hline GW_/A1Bt & 307 & 638 & -331 & 458 & -151 & 0,72 \\
\hline $\mathrm{GW}_{0} / \mathrm{A} 1 \mathrm{Bt}$ & 307 & 640 & -333 & 466 & -160 & 0,73 \\
\hline $\mathrm{GW}_{+} / \mathrm{A} 1 \mathrm{Bt}$ & 307 & 643 & -336 & 474 & -167 & 0,74 \\
\hline \multicolumn{7}{|c|}{ Vegetationsruhe } \\
\hline GW_/Ref. & 392 & 158 & 234 & 142 & 249 & 0,90 \\
\hline $\mathrm{GW}_{0} /$ Ref. & 392 & 158 & 234 & 143 & 249 & 0,90 \\
\hline $\mathrm{GW}_{+} /$Ref. & 392 & 158 & 234 & 143 & 249 & 0,90 \\
\hline $\mathrm{GW}_{-} / \mathrm{A} 1 \mathrm{Bf}$ & 429 & 172 & 257 & 153 & 273 & 0,91 \\
\hline $\mathrm{GW}_{0} / \mathrm{A} 1 \mathrm{Bf}$ & 429 & 172 & 257 & 156 & 273 & 0,91 \\
\hline $\mathrm{GW}_{+} / \mathrm{A} 1 \mathrm{Bf}$ & 429 & 172 & 257 & 156 & 273 & 0,91 \\
\hline GW_/A1Bt & 356 & 173 & 183 & 153 & 203 & 0,88 \\
\hline $\mathrm{GW}_{0} / \mathrm{A} 1 \mathrm{Bt}$ & 356 & 173 & 183 & 154 & 202 & 0,89 \\
\hline $\mathrm{GW}_{+} / \mathrm{A} 1 \mathrm{Bt}$ & 356 & 174 & 182 & 155 & 201 & 0,89 \\
\hline
\end{tabular}


Unter den Annahmen der trockenen Variante des A1B-Szenarios muss dagegen mit einer deutlichen Abnahme der Grundwasserneubildung auf im Mittel unter $50 \mathrm{~mm}$ (12 Millionen $\mathrm{m}^{3}$ ) gerechnet werden (s. Tab. 37, Jahreswerte). Während in der Vegetationsperiode ein Aufbrauch von Boden- und Grundwasser stattfindet (negative GWN), werden die Speicher in der Vegetationsruhe wieder aufgefüllt. Entsprechend hohe Überschüsse werden in der GWN berechnet. Die klimatische Wasserbilanz (KWB) ist ein einfach zu berechnender Indikator, um potenzielle Trockenstressverhältnisse zu ermitteln. In Kapitel 3.1 wurde die KWB flächendeckend für das Untersuchungsgebiet Hessisches Ried auf Basis einer Grasreferenzverdunstung berechnet. Im Vergleich hierzu ist die KWB auf Grundlage der realen (Forsteinrichtung) und simulierten Bestandesparameter deutlich ungünstiger, da ein Baumbestand in der Regel einen höheren Verdunstungsanspruch aufweist als eine reine Grasfläche. Dabei ist eine negative KWB jedoch nicht automatisch mit dem Eintreten von Wassermangelsituationen gleichzusetzen, da auf Standorten mit sicherem Grundwasseranschluss genauso hohe negative Bilanzen berechnet werden wie auf Standorten ohne Grundwasseranschluss. Die Berücksichtigung des pflanzenverfügbaren Wassers (Boden- und Grundwasser) ist folglich notwendig, um beurteilen zu können, ob ein Defizit in der KWB auf Trockenstress hindeutet. Je höher jedoch das Defizit in der KWB ausfällt, desto größer ist die Wahrscheinlichkeit, dass ein Bestand zeitweise unter Wassermangel leidet.

Im langjährigen Mittel der Dekade 2030 bis 2039 schwankt die KWB in der Jahressumme zwischen $25 \mathrm{~mm}$ (A1Bf), knapp -40 mm (Ref.) und rund $-150 \mathrm{~mm}$ (A1Bt). In der Vegetationsperiode liegt das Defizit je nach Klimavariante zwischen $-240 \mathrm{~mm}$ und knapp $-340 \mathrm{~mm}$ (s. Tab. 37). In einzelnen Trockenjahren und auf voll bestockten Waldflächen kann das Defizit deutlich höher ausfallen. In der Vegetationsruhe weist die KWB dagegen auf allen Waldflächen deutlich positive Werte auf, da die Niederschlagssumme den Verdunstungsanspruch übersteigt.

Die relative Verdunstung beschreibt das Verhältnis von realer zu potenzieller Evapotranspiration (ETR/ETP). Die relative Verdunstung kann Werte zwischen 0 und 1 einnehmen. Bei Werten nahe 1,0 besteht in den Beständen eine fast uneingeschränkte Wasserversorgung. Je kleiner der Wert für die relative Verdunstung wird, desto stärker limitieren die Waldbestände ihren Wasserverbrauch. Im Jahresmittel schwankt die relative Verdunstung in Abhängigkeit des zugrunde liegenden Szenarios zwischen 0,76 und 0,84. In der Vegetationsperiode werden im Mittel aller Bestandesflächen Werte zwischen 0,72 und 0,81 erreicht, wobei auf einzelnen Bestandesflächen die relative Verdunstung unter 0,50 liegt. Da dies Mittelwerte für die Vegetationsperiode sind, können während längerer Trockenphasen auch noch deutlich niedrigere Werte auftreten. In der Vegetationsruhe ist die Spannweite für die relative Verdunstung gering und auch zwischen den Szenarien gibt es mit Werten um 0,90 kaum Unterschiede.

Der Gebietswasserhaushalt zeigt zwischen den einzelnen Grundwasserstandsszenarien kaum Unterschiede. Nur in der Vegetationsperiode nehmen die realen 
Verdunstungssummen in der Gesamtbilanz aller Bestandesflächen in Abhängigkeit von der Flächengröße mit Grundwasseranschluss leicht zu. Eine Bilanzierung der realen Verdunstung getrennt nach Beständen mit und ohne sicheren Grundwasseranschluss erscheint deshalb sinnvoll.

\subsubsection{Einfluss des Grundwassers auf die Bestandesverdunstung}

Unter den aktuellen Verhältnissen im Hessischen Ried verfügen die Waldbestände auf rund 5.200 Hektar der Waldfläche über einen sicheren Anschluss (Flurabstand bis 2,50 m) an das Grundwasser (s. Abb. 45). Dies entspricht einem Flächenanteil von knapp 19 Prozent der gesamten Waldfläche von 27.660 Hektar. Beim Grundwasserstandsszenario GW+ wären dies 10.870 Hektar (39,3 Prozent der Bestandesfläche) und beim Szenario GW- 2.541 Hektar (9,2 Prozent der Bestandesfläche).
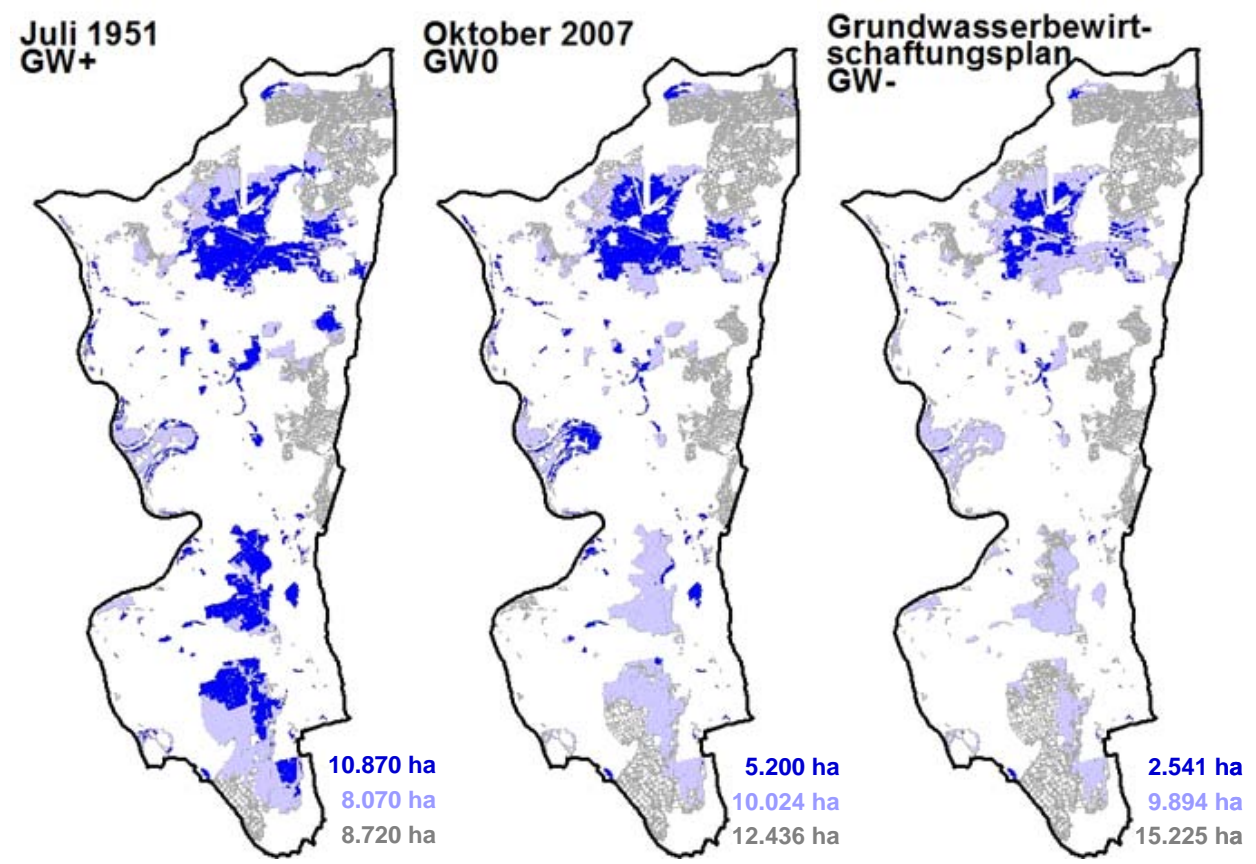

GW-Flurabstand $<2,50 \mathrm{~m}$

GW-Flurabstand 2,50-5,00 m

GW-Flurabstand $>5,00 \mathrm{~m}$

Abbildung 45: Grundwasserflurabstände der Waldbestände nach Klassen für die untersuchten Grundwasserstandsszenarien im Hessischen Ried 
Rund 650 ha Bestandesfläche im Mönchsbruch und in der Knoblauchsaue, die beim Szenario GW0 über sicheren Grundwasseranschluss verfügen, werden auch beim Szenario GW+ dieser Klasse zugeschlagen, obwohl sich bei der Regionalisierung der Messwerte des Jahres 1951 ein größerer Flurabstand ergab. Dies liegt darin begründet, dass beim Szenario GW+ (Juli 1951) die Anzahl der Stützstellen im Vergleich zum Status quo deutlich geringer ist und die Wechselwirkung zwischen Grundwasser und Vorfluter im Grundwassermodell noch nicht berücksichtigt wurde. Erfahrungsgemäß hat es in diesem Bereich keine nennenswerten Grundwasserveränderungen gegeben.

Die reale Verdunstung in der Vegetationsperiode unterscheidet sich auf Standorten mit und ohne sicheren Grundwasseranschluss in Abhängigkeit vom Klimaszenario mehr oder weniger deutlich voneinander. Die mittlere Verdunstungssumme der Dekade 2030 bis 2039 beträgt für das Referenz-Klima $452 \mathrm{~mm}$ auf Flächen ohne sicheren Grundwasseranschluss (s. Tab. 38).

Tabelle 38: Reale Verdunstung (ETR) [mm] in der Dekade 2030 bis 2039 für die untersucbten Grundwasser $(G W)$ - und Klimaszenarien (ges. $=$ Gebietsmittelwert, GWmit $=$ Mittelwert der Wälder mit sicherem Grundwasseranschluss, GWohne $=$ Mittelwert der Wälder obne gesicherten Grundwasseranschluss)

\begin{tabular}{lccc|ccc}
\hline $\begin{array}{l}\text { GW-Szenario/ } \\
\text { Klimaszenario }\end{array}$ & $\begin{array}{c}\text { ETR } \\
\text { ges. }\end{array}$ & $\begin{array}{c}\text { ETR } \\
\mathrm{GW}_{\text {mit }}\end{array}$ & $\begin{array}{c}\text { ETR } \\
\mathrm{GW}_{\text {ohne }}\end{array}$ & $\begin{array}{c}\text { ETR } \\
\text { ges. }\end{array}$ & $\begin{array}{c}\text { ETR } \\
\mathrm{GW}_{\text {mit }} \\
\text { Vegetationsperiode }\end{array}$ & $\begin{array}{c}\text { ETR } \\
\mathrm{W}_{\text {ohne }}\end{array}$ \\
\hline $\mathrm{GW}_{-} /$Ref. & 455 & 484 & 452 & 143 & 146 & 142 \\
$\mathrm{GW}_{0} /$ Ref. & 458 & 484 & 452 & 142 & 142 & 142 \\
$\mathrm{GW}_{+} /$Ref. & 464 & 485 & 452 & 143 & 145 & 142 \\
$\mathrm{GW}_{-} / \mathrm{A} 1 \mathrm{Bf}$ & 463 & 482 & 461 & 156 & 156 & 156 \\
$\mathrm{GW}_{0} / \mathrm{A} 1 \mathrm{Bf}$ & 466 & 487 & 461 & 156 & 156 & 156 \\
$\mathrm{GW}_{+} / \mathrm{A} 1 \mathrm{Bf}$ & 468 & 480 & 461 & 156 & 156 & 156 \\
$\mathrm{GW}_{-} / \mathrm{A} 1 \mathrm{Bt}$ & 460 & 509 & 455 & 153 & 153 & 153 \\
$\mathrm{GW}_{0} / \mathrm{A} 1 \mathrm{Bt}$ & 465 & 508 & 455 & 153 & 158 & 154 \\
$\mathrm{GW}_{+} / \mathrm{A} 1 \mathrm{Bt}$ & 474 & 507 & 455 & 153 & 158 & 155 \\
\hline
\end{tabular}

Die Bestände mit gesichertem Grundwasseranschluss verdunsten im Mittel rund $30 \mathrm{~mm}$ mehr. Vergleichbar ist die reale Evapotranspiration beim Klimaszenario A1Bf, wobei die Differenz zwischen Standorten mit und ohne sicheren GW-Anschluss mit rund $20 \mathrm{~mm}$ etwas niedriger ist. Die größten Unterschiede ergeben sich beim Klimaszenario A1Bt. Die mittlere Verdunstungssumme in der Vegetationsperiode beträgt unter trockenen Klimabedingungen knapp $610 \mathrm{~mm}$ auf Waldflächen mit sicherem $\mathrm{GW}$-Anschluss und liegt damit um rund $60 \mathrm{~mm}$ über den Werten auf den grundwasserferneren Standorten (s. Tab. 38). In der Vegetations- 
ruhephase gibt es keine nennenswerten Unterschiede in der Verdunstungsleistung der Wälder in Abhängigkeit vom Grundwasseranschluss.

Die Bedeutung des Grundwassers für die Wasserversorgung der Wälder im Hessischen Ried steigt mit zunehmender Trockenheit. Vor diesem Hintergrund kann die Analyse eines einzelnen Trockenjahres Rückschlüsse auf das Wasserstressrisiko der Waldflächen liefern.

\subsubsection{Auswirkung eines extremen Trockenjabres auf den $W$ asserbaushalt}

Das Jahr 1976 ist als extrem trockenes Jahr in Deutschland in die Geschichte eingegangen. Selbst in den verwendeten Varianten des Klimaszenarios A1B tritt bis 2039 kein niederschlagsärmeres Jahr auf.

Die Jahresniederschlagssumme betrug 1976 im Hessischen Ried im Gebietsmittel 499 mm (korrigiert!). Die Niederschlagshöhe in der Vegetationsperiode war mit $213 \mathrm{~mm}$ deutlich niedriger als in der Vegetationsruhe mit $286 \mathrm{~mm}$ (s. Tab. 39). Die potenzielle Evapotranspiration der Wälder war infolge der trocken-warmen Witterung mit rund $1.000 \mathrm{~mm}$ überdurchschnittlich hoch, wobei knapp $850 \mathrm{~mm}$ der ETP in die Vegetationsperiode fallen. Die klimatische Wasserbilanz war aufgrund der geringen Niederschlagshöhe und der hohen ETP mit Werten von rund $-630 \mathrm{~mm}$ in der Vegetationsperiode extrem negativ. Auch die positive KWB von $114 \mathrm{~mm}$ in der Vegetationsruhe führte bei der Jahressumme nur zu einer leichten Verringerung des Defizits in der KWB (s. Tab. 39).

Die reale Verdunstung schwankt je nach Grundwasserstandsszenario zwischen $509 \mathrm{~mm}(\mathrm{GW}-)$ und $543 \mathrm{~mm}(\mathrm{GW}+)$. Die unterschiedlichen Verdunstungshöhen, die sich aus dem Flächenanteil der Bestände mit sicherem Grundwasseranschluss ergeben, werden ausschließlich in der Vegetationsperiode berechnet. Während der Vegetationsruhe ist die Verdunstungsleistung bei allen Szenarien gleich (s. Tab. 39).

Der Vergleich der Verdunstungsleistung auf Bestandesflächen mit und ohne sicheren Grundwasseranschluss zeigt, dass in extremen Trockenjahren das zusätzliche Wasserangebot zu einer deutlichen Erhöhung der realen Verdunstung führt. Während die Bestände ohne Grundwasseranschluss im Mittel der Vegetationsperiode 1976 nur $351 \mathrm{~mm}$ Wasser verdunsten, liegt die reale Evapotranspiration auf den Flächen mit Grundwasseranschluss um über $100 \mathrm{~mm}$ höher (s. Tab. 40). Dies hat zur Folge, dass auf diesen Bestandesflächen die relative Verdunstung einen Wert von 0,55 aufweist, bei grundwasserfernen Standorten dagegen von 0,42. Auf voll bestockten Beständen erreicht die relative Verdunstung teilweise nur Werte von rund 0,20 im Mittel der Vegetationsperiode. 
Tabelle 39: $\quad$ Mittlere Kennwerte für das Jabr 1976 und für die untersuchten Grundwasserstandsszenarien $(P=$ Niederschlag, ETP $=$ potenzielle Verdunstung, $K W B=$ Klimatische $W$ asserbilan₹, ETR $=$ reale Verdunstung, GWN = Grundwasserneubildung, ETR $/ E T P=$ relative Verdunstung)

\begin{tabular}{lcccccc}
\hline $\begin{array}{l}\text { GW-Szenario/ } \\
\text { Klima 1976 }\end{array}$ & $\begin{array}{c}\text { P } \\
(\mathrm{mm})\end{array}$ & $\begin{array}{c}\text { ETP } \\
(\mathrm{mm})\end{array}$ & $\begin{array}{c}\text { KWB } \\
(\mathrm{mm})\end{array}$ & $\begin{array}{c}\text { ETR } \\
(\mathrm{mm})\end{array}$ & $\begin{array}{c}\text { GWN } \\
(\mathrm{mm})\end{array}$ & $\begin{array}{c}\text { ETR/ } \\
\text { ETP }(-)\end{array}$ \\
\hline & & Jahr & & & \\
$\mathrm{GW}_{-} / 1976$ & 499 & 1013 & -514 & 509 & -10 & 0,51 \\
$\mathrm{GW}_{0} / 1976$ & 499 & 1013 & -514 & 524 & -25 & 0,52 \\
$\mathrm{GW}_{+} / 1976$ & 499 & 1012 & -513 & 543 & -44 & 0,54 \\
\hline & \multicolumn{7}{c}{ Vegetationsperiode } \\
$\mathrm{GW}_{-} / 1976$ & 213 & 841 & -628 & 361 & -148 & 0,43 \\
$\mathrm{GW}_{0} / 1976$ & 213 & 841 & -628 & 373 & -160 & 0,44 \\
$\mathrm{GW}_{+} / 1976$ & 213 & 840 & -627 & 392 & -179 & 0,47 \\
\hline & & & & & \\
$\mathrm{GW}_{-} / 1976$ & 286 & 172 & 114 & 150 & 135 & 0,87 \\
$\mathrm{GW}_{0} / 1976$ & 286 & 172 & 114 & 151 & 135 & 0,88 \\
$\mathrm{GW}_{+} / 1976$ & 286 & 172 & 114 & 151 & 135 & 0,88 \\
\hline
\end{tabular}

Nach MÜLLER (2006, 2007) reagierten Kiefernbestände im nordostdeutschen Tiefland bei Unterschreitung des Angebots an pflanzenverfügbarem Bodenwasser auf unter 60 Prozent der nFK im Oberboden mit einer Abnahme im Durchmesserzuwachs. Unter 40 Prozent findet kein Durchmesserzuwachs mehr statt. Eine Wasserverfügbarkeit von < 60 Prozent stellt nach BECK (2001) auf Sandböden einen Grenzwert dar, der zu Wachstumseinbußen führt. Unter der Annahme, dass gleiche Grenzwerte für die relative Verdunstung gültig sind, hätte dies zur Folge, dass viele grundwasserferne Standorte im Hessischen Ried während längerer Trockenphasen Vitalitäts- und Wachstumseinbußen erfahren.

Tabelle 40: Reale Verdunstung (ETR) [mm] im Jahr 1976 für die untersuchten Grundwasser$(G W)$ und Klimaszenarien (ges. = Gebietsmittelwert, GWmit $=$ Mittelwert der Wälder mit sicherem Grundwasseranschluss, GWobne $=$ Mittelwert der Wälder obne sicheren Grundwasseranschluss)

\begin{tabular}{lccc|ccc}
\hline $\begin{array}{l}\text { GW-Szenario/ } \\
\text { Klima } 1976\end{array}$ & $\begin{array}{c}\text { ETR } \\
\text { ges. }\end{array}$ & $\begin{array}{c}\text { ETR } \\
\text { GW }_{\text {mit }}\end{array}$ & $\begin{array}{c}\text { ETR } \\
G_{\text {ohne }}\end{array}$ & $\begin{array}{c}\text { ETR } \\
\text { ges. }\end{array}$ & $\begin{array}{c}\text { ETR } \\
G_{\text {mit }}\end{array}$ & $\begin{array}{c}\text { ETR } \\
G_{\text {ohne }}\end{array}$ \\
\hline \multicolumn{3}{c}{ Vegetationsperiode } & \multicolumn{3}{c}{ Vegetationsruhe } \\
$\mathrm{GW}_{-} / 1976$ & 361 & 458 & 351 & 150 & 150 & 150 \\
$\mathrm{GW}_{0} / 1976$ & 373 & 467 & 351 & 150 & 155 & 151 \\
$\mathrm{GW}_{+} / 1976$ & 392 & 463 & 351 & 150 & 153 & 151 \\
\hline
\end{tabular}




\subsubsection{W Wasserbaushalt ausgesuchter Einzelbestände}

Für ausgewählte Waldbestände im Hessischen Ried wurden die Einflüsse verschiedener Standortsfaktoren auf den Wasserhaushalt untersucht. Dazu wurden entweder Standorte mit ähnlicher Bestandesstruktur oder der gleiche Standort für verschiedene Szenarien vergleichend betrachtet. Die Auswertung der Einzelbestandsverhältnisse wurde für den gesamten Simulationszeitraum durchgeführt. Im Einzelnen wurde der Einfluss der Bodenfeuchte, des Grundwassers und der Maikäfermortalität explizit untersucht.

Die Bodenfeuchte eines Standortes hängt maßgeblich von den Bodeneigenschaften (Substrat, Lagerungsdichte etc.) ab. Böden mit einem hohen Sandanteil verfügen über eine geringere Wasserhaltefähigkeit als schluffige Böden, wie z. B. Lehme (s. Kap. 2.1.2.2, Abb. 5). Auf Standorten ohne sicheren Grundwasseranschluss stellt der Bodenwasservorrat den einzigen zusätzlichen Speicher zum Niederschlagsangebot dar. Da in der Vegetationsperiode die Verdunstungsleistung der Waldbestände in der Regel nicht durch den Niederschlag gedeckt wird, kommt dem Bodenwasser eine wichtige Bedeutung bei der Wasserversorgung zu. Je höher der Bodenwasservorrat ist, desto länger kann ein Waldbestand seinen Verdunstungsanspruch während niederschlagsarmer Witterungsperioden befriedigen. Dabei wird davon ausgegangen, dass zu Beginn der Vegetationsperiode der Boden infolge der Auffüllung während der Vegetationsruhephase nahezu wassergesättigt ist.

Am Beispiel zweier Waldbestände im Hessischen Ried wurden die Auswirkungen der Bodenfeuchte auf die Verdunstung untersucht. Als Indikator zur Beurteilung der Verdunstungsleistung wurde die relative Evapotranspiration (ETR/ETP) in der Vegetationsperiode ausgewertet. Angetrieben wurde die Modellsimulation mit den Daten der Klimanormalperiode 1961 - 1990. Bei den untersuchten Beständen handelt es sich jeweils um Eichenkulturen, die in ihren Eigenschaften (Alter, Bestockungsgrad etc.) sehr ähnlich sind. Während der Eichenbestand des Forstamtes Langen in Abteilung 14 auf einem frischen Standort (Lehmboden) stockt, ist der Standort der Eichenkultur in Abteilung 226 des Stadtwaldes Frankfurt als mäßig trocken (Reinsand) zu charakterisieren. Dies verdeutlicht auch der unterschiedlich hohe Wert der nutzbaren Feldkapaziät (nFK) bezogen auf $140 \mathrm{~cm}$ Bodentiefe. Der Lehmstandort verfügt über eine $\mathrm{nFK}$ von $152 \mathrm{~mm}$, der reine Sandstandort im Frankfurter Stadtwald dagegen nur über eine nFK von $108 \mathrm{~mm}$. Beide Waldbestände besitzen keinen Grundwasseranschluss.

Die mittlere relative Verdunstung in der Vegetationsperiode unterliegt während der Simulationsperiode starken Schwankungen (s. Abb. 46). In Jahren mit überdurchschnittlich hohen Niederschlägen erreicht die relative Verdunstung Werte, die um 0,90 variieren. Hierbei gibt es keine nennenswerten Unterschiede zwischen den beiden Eichenbeständen. Da die Niederschlagssummen in der Vegetationsperiode überdurchschnittlich hoch sind $(>350 \mathrm{~mm})$, kann der Verdunstungsanspruch der Bestände weitgehend gedeckt werden. In trockenen Jahren stellt 
sich die Situation allerdings anders dar. Hier fällt die relative Verdunstung in der Vegetationsperiode auf dem mäßig trockenen Standort auf mittlere Werte von 0,5 oder niedriger. In extremen Trockenjahren liegt die relative Verdunstung sogar unter 0,3. Der Eichenbestand auf dem frischen Standort erfährt zwar auch eine starke Einschränkung in der Verdunstungsleistung, jedoch liegen die Werte für die relative Evapotranspiration deutlich über denen des mäßig trockenen Standortes (s. Abb. 46).

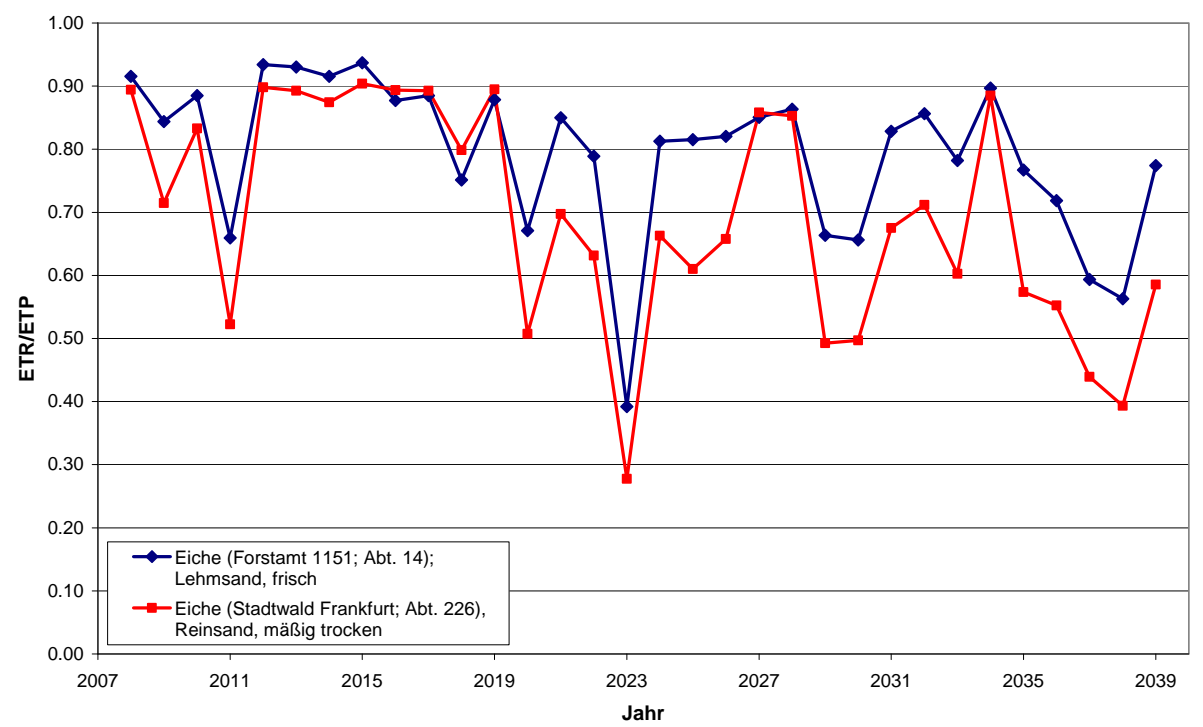

Abbildung 46: Relative Verdunstung (ETR/ETP) in der Vegetationsperiode in Abhängigkeit von der Bodenfeuchte

Mit der Bestandesentwicklung nimmt auch der Verdunstungsanspruch zu. Dies zeigt sich im Laufe der Simulation dahingehend, dass nach rund 20 Jahren die reale Verdunstung der jungen Eichenbestände kontinuierlich ansteigt, sodass auch in normalen bis feuchten Vegetationsperioden die relative Verdunstung zurückgeht. Die Werte schwanken auf dem frischen Standort um 0,8 und liegen auf dem mäßig trockenen Standort unter 0,7. Nur in überdurchschnittlich feuchten Jahren mit einer Niederschlagshöhe von rund $470 \mathrm{~mm}$ in der Vegetationsperiode liegt die relative Verdunstung auf beiden Standorten bei 0,9.

Die Auswertungen zur Bodenfeuchte zeigen, dass das pflanzenverfügbare Bodenwasser wichtig ist, um den Verdunstungsanspruch der Wälder im Hessischen Ried zu decken. Insbesondere während längerer Trockenphasen in der Vegetationsperiode und bei gut bestockten Beständen kann die Höhe des Bodenwasservorrats das Trockenstressrisiko entscheidend mindern.

Ebenso wie die Höhe des Bodenwasservorrats ist für viele Bestände im Hessischen Ried die Verfügbarkeit von Grundwasser von elementarer Bedeutung. Um den Einfluss des Grundwassers auf die Verdunstung der Bestände zu untersuchen, 
wurde exemplarisch für einen Eichenbestand im Forstamt Langen (Abteilung 12) der Wasserhaushalt mit und ohne sicherem Grundwasseranschluss im hydrologischen Modell gerechnet. Auch hier zeigt sich, dass insbesondere in einer niederschlagsarmen Vegetationsperiode die reale Verdunstung stark eingeschränkt wird, wie der minimale Wert für die relative Verdunstung verdeutlicht. Dieser liegt für die Vegetationsperiode bei der Simulation ohne Grundwasseranschluss bei 0,46 (s. Abb. 47). Mit Grundwasseranschluss würde die relative Verdunstung auf 0,64 signifikant erhöht werden.

Die Simulation mit Grundwasseranschluss zeigt auch, dass der Verdunstungsanspruch der Waldbestände während einer Trockenperiode nicht komplett aus dem Grundwasser gedeckt werden kann, da nur die tiefsten Wurzeln den Grundwasserkörper und Kapillarsaum erschließen (Notversorgung). Das Trockenstressrisiko ist auf Standorten mit sicherem Grundwasseranschluss jedoch erheblich geringer als auf Standorten, die über keinen gesicherten Anschluss verfügen oder diesen infolge Grundwasserabsenkungen verloren haben.

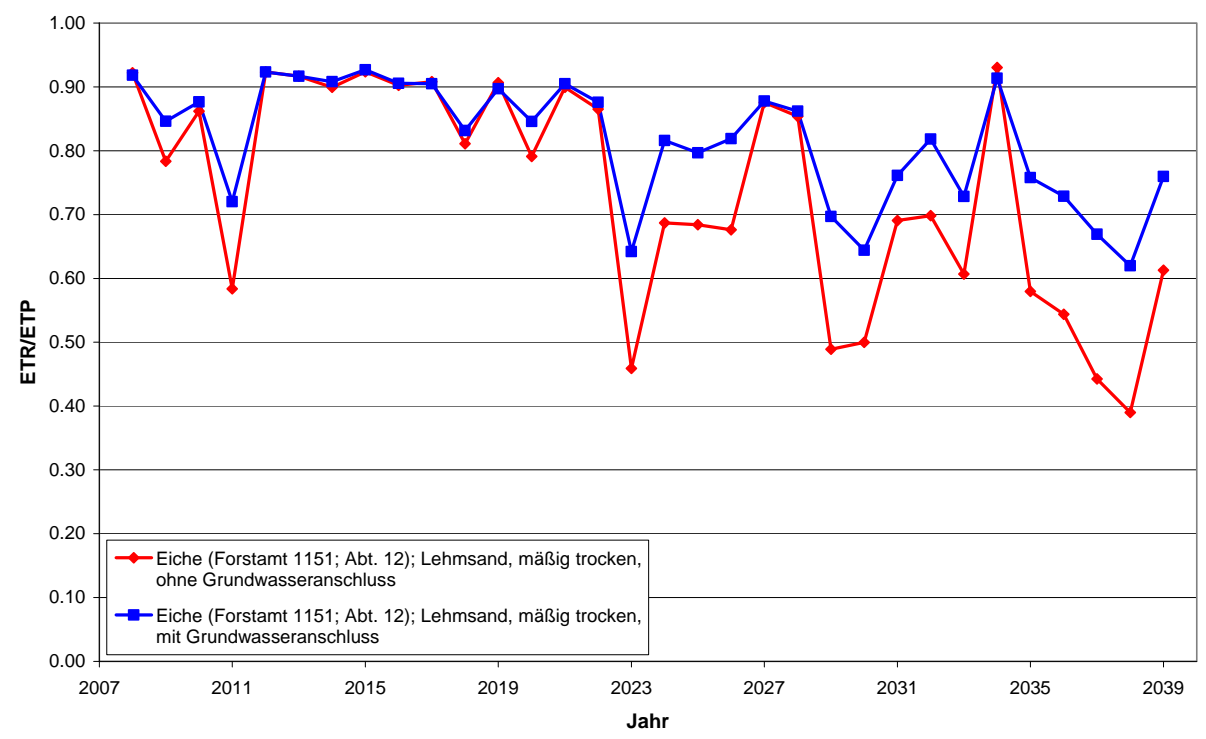

Abbildung 47: Relative Verdunstung (ETR/ETP) in der Vegetationsperiode in Abbängigkeit vom Grundwasser

Neben den flächenhaften Grundwasserabsenkungen treten im Hessischen Ried lokal massive Schädigungen durch den Maikäfer auf, die häufig mit dem Verlust der Grundwasserverfügbarkeit der Bestände einhergehen. Am Beispiel eines Waldbestandes im Forstamt Langen (Abt. 18) wird aufgezeigt, wie die Schädigungen des Maikäferfraßes den Wasserhaushalt nachhaltig verändern.

Die Bestandesentwicklung wird anhand des Blattflächenindexes (LAI) für die neun simulierten Klima- und Grundwasserszenarien auf dem untersuchten Stand- 
ort dargestellt (s. Abb. 48). Während in den ersten Jahren der Simulation der Waldbestand bei allen Szenarien eine ähnliche Entwicklung aufweist, nimmt beim Grundwasserstandsszenario GW- der LAI nach vier Jahren kontinuierlich ab. Nach etwa 15 Jahren liegt der LAI annähernd bei Null, da der Bestand sich fast vollständig infolge der Maikäfergradation aufgelöst hat. Bei den Grundwasserstandsszenarien GW0 und GW+ verfügt der Bestand über Grundwasseranschluss, sodass bis zum Ende der Simulation keine nennenswerten Schädigungen auftreten und der Bestand in die Endnutzung überführt wird.

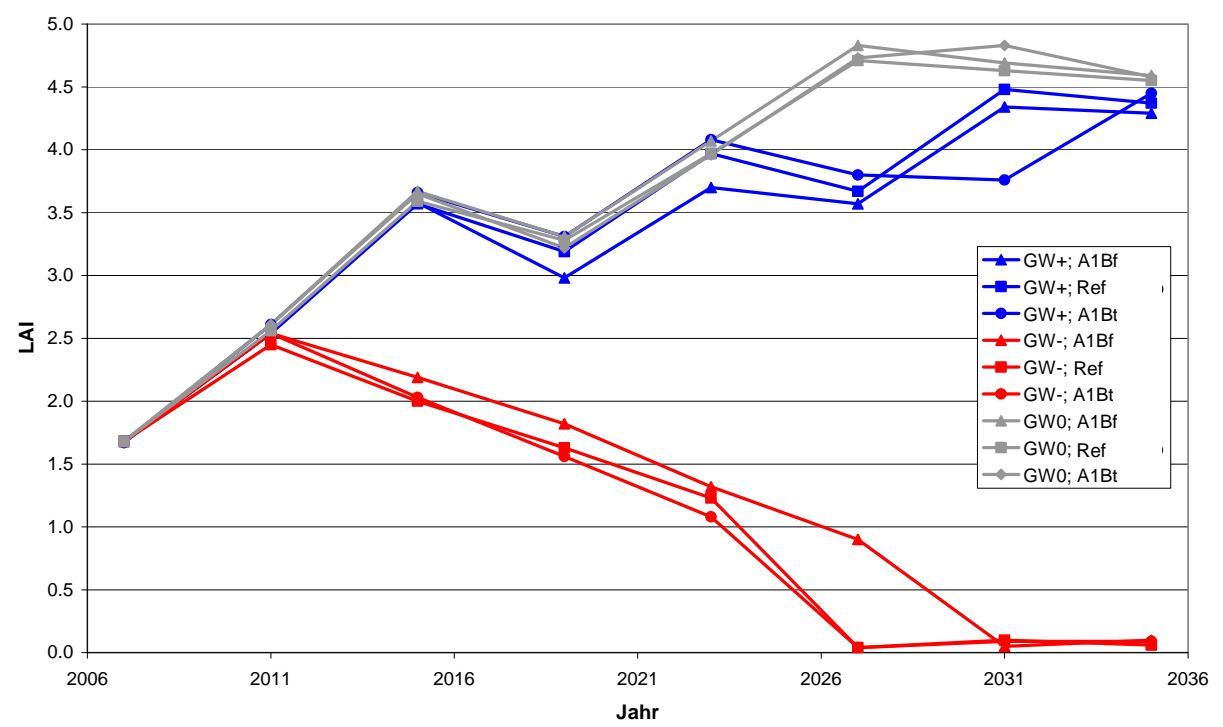

Abbildung 48: Entwicklung des Blattlächenindex (LAI) der Baumschicht am Beispiel eines Waldbestandes im Forstamt Langen für die untersuchten Grundwasser- und Klimaszenarien

In Abbildung 49 sind exemplarisch für zwei Szenarien die berechneten Verdunstungssummen und die relative Verdunstung in der Vegetationsperiode dargestellt. Auffällig ist, dass trotz abnehmendem LAI beim GW--Szenario die reale Verdunstung nur geringfügig unter den Werten des GW0-Szenarios liegt. Die Ursache hierfür ist, dass der Bestandes-LAI (s. Abb. 48), der nur aus der Baumvegetation abgeleitet wurde, um den LAI der Bodenvegetation erhöht wird. Da der Altbestand genutzt wird und die nachwachsende Verjüngung durch den Maikäfer stark geschädigt wird, entstehen beim Szenario GW- im Laufe der Simulation große Lücken im Bestand, die durch die Bodenvegetation aufgefüllt wird. Dadurch entspricht der gesamte LAI annähernd dem des nicht geschädigten Bestandes beim Szenario GW0. Erst nach rund 20 Jahren Simulation ist der Bestand soweit aufgelöst, dass kaum noch eine Baumvegetation vorhanden ist. Der kumulierte LAI aus Bestandes- und Bodenvegetation erreicht dann nur noch Werte von rund 2,0 und liegt damit deutlich unter dem LAI des nicht durch Maikäfer geschädigten Waldbestandes. Folglich verdunstet in den letzten 10 Jahren der Simulationsperiode beim 
Szenario GW- erheblich weniger Wasser als beim GW0-Szenario. Die Differenz beträgt in einzelnen Jahren über $200 \mathrm{~mm}$ (s. Abb. 49). Auch bei der relativen Verdunstung treten zum Ende der Simulationsperiode deutliche Unterschiede auf. So liegt die relative Verdunstung des nicht geschädigten Bestandes meist rund 0,1 unter den Werten des geschädigten Bestandes.

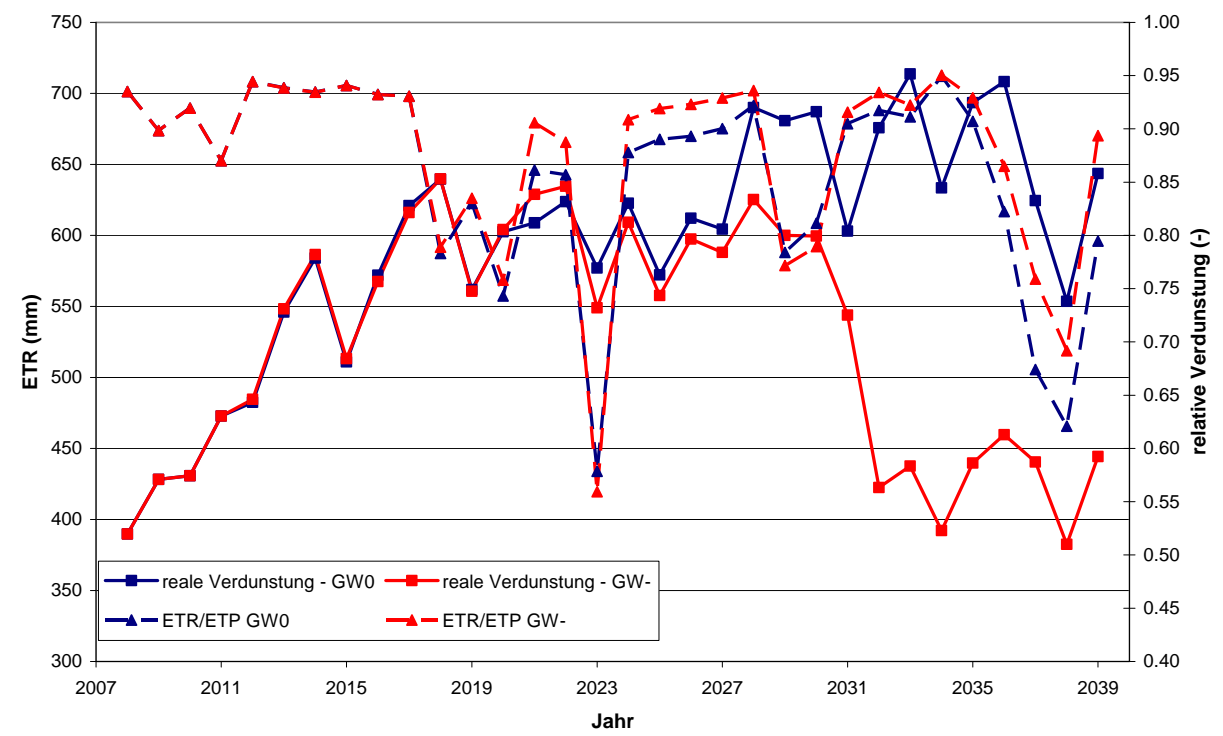

Abbildung 49: Simulierte reale Verdunstung (ETR) und berechnete relative Verdunstung (ETR/ETP) für die Vegetationsperiode mit dem Referenz-Klima (Forstamt Langen, Abt. 18)

Die Untersuchung einzelner ausgesuchter Bestände zeigt, dass neben den klimatischen Verhältnissen die Standorteigenschaften maßgeblich den Wasserhaushalt eines Waldes charakterisieren. Dabei können unterschiedliche Standortsverhältnisse (Boden, Grundwasser etc.) bei vergleichbaren Waldbeständen (Baumart, Alter etc.) stark voneinander abweichende Ausprägungen der einzelnen Wasserhaushaltskomponenten verursachen. Die Änderungen der Standortseigenschaften (Grundwasser, Mortalität, Bewirtschaftungsstrategien) können dabei die Veränderungen, die aus dem Klimasignal resultieren, kompensieren oder verstärken.

\subsubsection{Bewertung des Trockenstressrisikos}

Seit mehreren Jahrzehnten ist der Wald im Hessischen Ried stark geschädigt, ohne dass sich eine Tendenz zur Erholung abzeichnet. Die Ökosysteme sind aufgrund der natürlichen klimatischen Voraussetzungen und vielseitiger, intensiver Nutzungsansprüche besonders empfindlich gegenüber Störungen. In den 1970erJahren traten gehäuft Trockenjahre auf, die auf die durch großräumige Grundwasserabsenkungen bereits stark angespannte Wasserversorgung der Wälder 
gravierende Auswirkungen zeigten und in den Folgejahren die Stabilität der Wälder massiv beeinträchtigten.

Die modellbasierten Untersuchungen zum Wasserhaushalt der Bestände im Hessischen Ried haben gezeigt, dass maßgeblich die Verfügbarkeit von Grundwasser und die Wasserspeicherkapazität der Böden die Trockenstressanfälligkeit bestimmen. Anhand der flächenhaften Information zum Grundwasser und zum pflanzenverfügbaren Bodenwasser werden die Standorte im Hessischen Ried in Bezug auf die Zunahme des Trockenstressrisikos bewertet (s. Abb. 50).
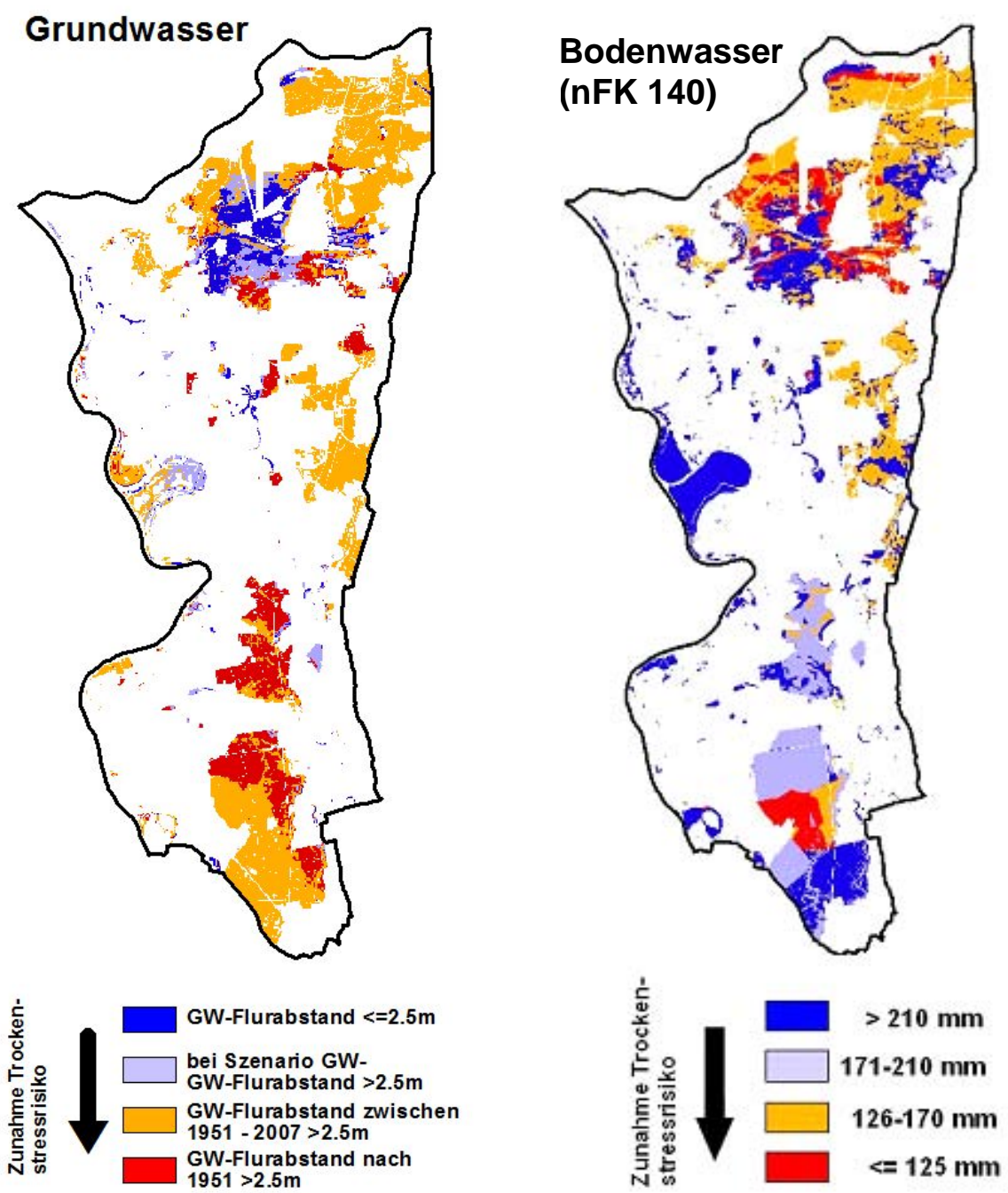

Abbildung 50: Trockenstresszunahme in Abhängigkeit vom verfügbaren Grund- (links) und Bodenwasser (rechts) 
Infolge der flächenhaften Grundwasserabsenkungen in den 1960er- und 1970erJahren haben viele Waldbestände den gesicherten Grundwasseranschluss (Flurabstand $<2,50 \mathrm{~m}$ ) verloren und sind damit während längerer Trockenphasen auf den Bodenwasserspeicher angewiesen. Da diese Bestände sich zuvor unter optimalen Bedingungen entwickeln konnten, ist das Trockenstressrisiko hier besonders hoch (s. Abb. 50, links, rot). Davon betroffen sind weite Flächen des Gernsheimer, des Jägersburger Waldes sowie des Lorscher Waldes im Süden des Untersuchungsgebietes. Weiterhin sind viele Bestände im Darmstädter Westwald, im Stadt- und Staatswald Langen sowie im Stadtwald Groß-Gerau ohne sicheren Grundwasseranschluss. Die Grundwasserabsenkung hat dazu geführt, dass auf rund 5.750 Hektar Waldfläche der gesicherte Grundwasseranschluss verloren gegangen ist.

Die Waldbestände, die auch in der Vergangenheit auf Standorten mit einem Flurabstand > 2,50 m stockten, nehmen mit knapp 16.800 Hektar den größten Flächenanteil im Hessischen Ried ein (s. Abb. 50, links, orange). Da die Wälder auf diesen Standorten seit ihrer Begründung über keine optimale Wasserversorgung verfügen, kann unterstellt werden, dass diese Bestände an die schlechteren Standortsbedingungen angepasst sind. Das Trockenstressrisiko wird deshalb als nicht so hoch eingestuft, wie für die Waldflächen, die den Grundwasseranschluss verloren haben.

Rund 5.200 Hektar der Waldfläche im Hessischen Ried stocken zurzeit noch auf grundwassernahen Standorten (s. Abb. 50, links, blau). Sie befinden sich überwiegend in der Knoblochsaue und im Mönchbruch. Etwa die Hälfte hiervon würde bei einer weiteren Absenkung, wie es im Szenario GW- unterstellt wird, den gesicherten Anschluss an das Grundwasser verlieren (s. Abb. 50, links, hellblau). Eine Absenkung auf das Niveau der Grenzgrundwasserstände des Grundwasserbewirtschaftungsplanes ist jedoch nur in Zeiträumen mit einem erhöhten Wasser bedarf denkbar, sodass Wassermangelsituationen nur periodisch und räumlich begrenzt auftreten würden. Das Trockenstressrisiko ist deshalb als nicht sehr hoch einzustufen.

Neben dem Grundwasser stellt der Bodenwasserspeicher eine wichtige zusätzliche Quelle pflanzenverfügbaren Wassers dar. Hierbei nimmt das Trockenstressrisiko von den Standorten mit hohen nFK-Werten $(>210 \mathrm{~mm})$ zu den Standorten mit geringem Bodenwassergehalt ( $\leq 125 \mathrm{~mm} n \mathrm{nFK} 140)$ kontinuierlich zu (s. Abb. 50, rechts). Trockenere Standorte treten im Hessischen Ried kaum auf (Lampertheimer Wald, Stadtwald Frankfurt, FA Langen, FA Groß-Gerau), obwohl viele Böden als Hauptsubstrat Sand aufweisen. Häufig sind diese Böden jedoch von mehr oder weniger mächtigen schluffhaltigen Bändern durchzogen, die über eine deutlich höhere Wasserspeicherkapazität verfügen als reine Sandböden. Die nutzbare Feldkapazität dieser Böden liegt dann über $125 \mathrm{~mm}$ (Lorscher Wald, Gernsheimer und Jägersburger Wald, Darmstädter Westwald, FA Langen, FA Groß Gerau). Die grundwassernahen Standorte sowie Böden mit nFK-Werten über 
$210 \mathrm{~mm}$ (Knoblochsaue, Mönchbruch, Viernheimer Wald) weisen das geringste Trockenstressrisiko auf.

\subsection{Auswirkungen der Klima- und Grundwasserszenarien auf den Stoffhaushalt der Bestände}

\subsubsection{Atmosphärische Stoffeinträge}

Detaillierte Langzeitreihen für die atmosphärischen Stoffeinträge liegen für das Rhein-Main-Gebiet nicht vor (PRIES et al. 1999). Daher wurde für die Konstruktion von Depositionszeitreihen auf EMEP Daten (Cooperative Programme for Monitoring and Evaluation of the Long-range Transmission of Air pollutions in Europe) zurückgegriffen und diese mit historischen Zeitreihen (SCHÖPP et al. 2003) kombiniert. Die Abbildung 51 zeigt beispielhaft eine solche Zeitreihe der atmosphärischen Säure- und Stickstoffeinträge für Mitteleuropa. Hiernach sind die atmosphärischen Stoffeinträge gerade in dem Zeitraum stark angestiegen, in dem durch den Bau von Großwasserwerken zur überregionalen Versorgung die Grundwasserstände im Hessischen Ried stark abgesunken sind (PRIES et al. 1999). Während der ausgeprägten Trockenperioden (1971 - 1976 und 1989 - 1993; IVEN 1996) erreichten die Eintragsraten und Luftbelastungen ihre maximalen Werte. Da die Kombination von Stressfaktoren eine größere Wirkung hat als ein einzelner Stressfaktor, sind schadstoffbelastete Wälder nicht mehr so widerstandsfähig gegenüber Trockenstress oder Insektenbefall (MCNULTY et al. 2010). Entsprechend ergibt sich das Gefährdungspotenzial von Waldökosystemen aus der Kombination der Risikofaktoren Bodenzustand, atmosphärische Eintragssituation, klimatische Bedingungen und biotische Stressoren.

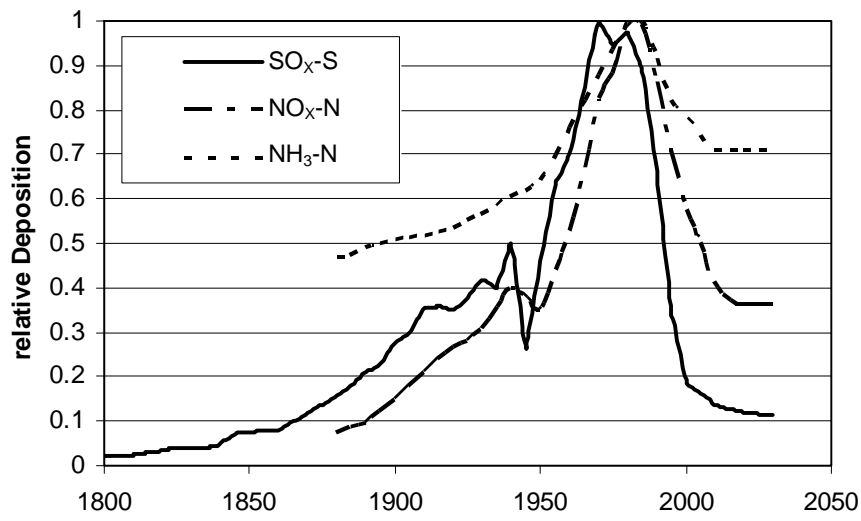

Abbildung 51: Zeitliche Entwicklung der relativen Deposition von Sulfat (SO $\mathrm{X}_{X^{-}}$) und Stickstoff $\left(\mathrm{NO}_{X}-\mathrm{N}\right.$ und $\left.\mathrm{NH}_{3}-\mathrm{N}\right)$ in Mitteleuropa nach ALVETEG (1998) 
Seit Anfang der 90er-Jahre bis heute hat sich die Depositionssituation erheblich verändert, so sind z. B. die Schwefeleinträge um bis zu 90 Prozent zurückgegangen (s. Abb. 14). Ähnlich wie bei den Schwelfeldioxiden wurden auch bei den Stickoxiden Fortschritte bei der Luftreinhaltung erzielt. Nicht so erfreulich verhält es sich demgegenüber bei den reduzierten Stickstoffverbindungen Ammoniak und Ammonium. Die Abbildung 51 zeigt, dass das Depositionsniveau nahezu gleich geblieben ist. Die atmosphärischen Stickstoffdepositionen sind mittlerweile vielerorts zur Hauptgefährdung für die Waldstruktur und die Qualität des neu gebildeten Grundwassers von ursprünglich $\mathrm{N}$-limitierten Waldökosystemen geworden (MATSON et al. 2002). Entsprechend sind erhöhte N-Einträge auch mit höheren Austrägen in die Atmosphäre (GUNDERSEN 1991) und in die Hydrosphäre (BORKEN u. MATZNER 2004) verbunden.

Zur Interpretation der regionalen Versauerungs- und N-Austragsunterschiede liefert die Abbildung 52 einen Überblick über die Verteilung der Stoffeinträge im Rhein-Main-Gebiet. Die Maxima der SOx-S Depositionen sind im Norden und im Süden des Untersuchungsgebietes anzutreffen. Demgegenüber befinden sich die am geringsten belasteten Waldgebiete im Zentrum und im Westen des Gebietes.

Anhand der regionalen Verteilung der NOy-N und NHx-N Einträge (s. Abb. 52) ist zu erkennen, dass diese Stickstoffverbindungen verschiedene Quellen haben. So erreichen die NOy-N Einträge im Umfeld des Flughafens FrankfurtMain ihre maximalen Werte. Die überwiegend landwirtschaftlich geprägten $\mathrm{NHx}$ N Einträge weisen hingegen ein weiteres Maximum im Süden des Untersuchungsgebietes auf. Für beide Stickstoffverdingungen gilt, dass die geringsten Eintragsraten im Westen des Untersuchungsgebietes erreicht werden. Der Einfluss der Baumarten auf die NOy-N-Einträge lässt sich sehr gut im Norden des Untersuchungsgebietes an den blaugrauen Flächen erkennen. Bei ihnen handelt es sich um die besseren Standorte, die mit Laubbäumen bestockt sind. 

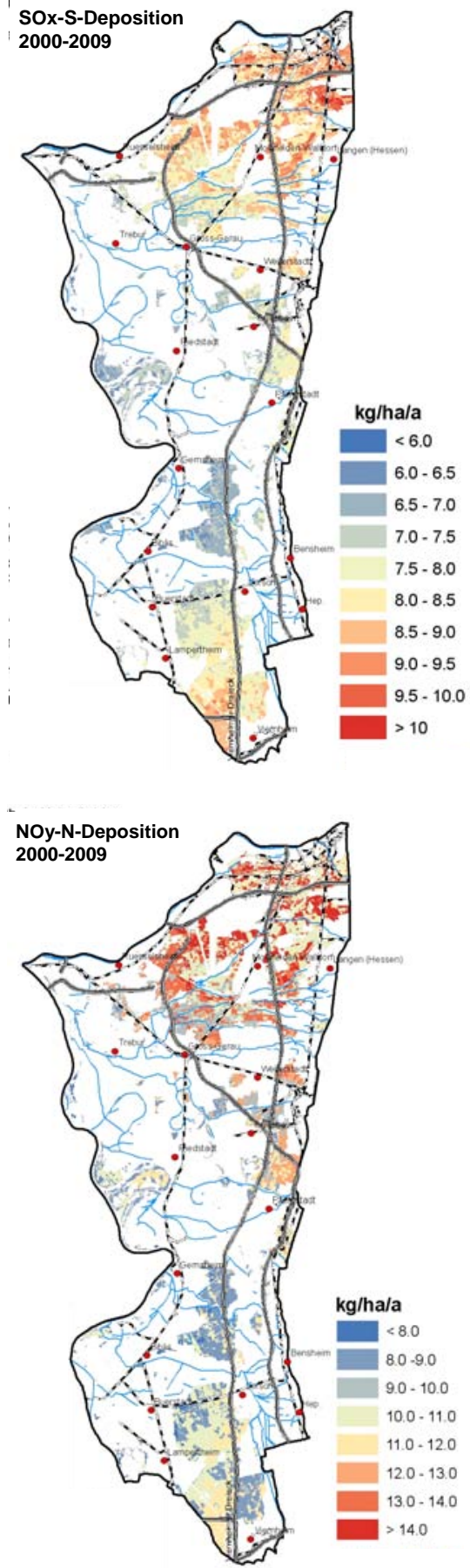

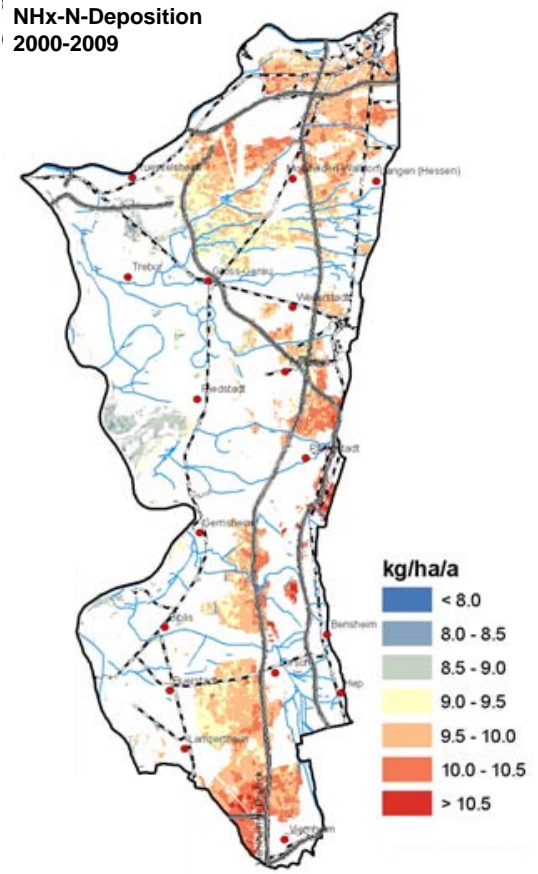

Abbildung 52:

Regionalisierung der mittleren SOx-S- (oben links), $N H x-N$ - (oben rechts) und $N O y-N-$ (unten) Gesamtdepositionen $[\mathrm{kg} / \mathrm{ha} / \mathrm{a}]$ für das Rhein-Main-Gebiet (Periode: 2000 2009)

Beiträge aus der NW-FVA, Band 10, 2013 


\subsubsection{Versauerungs- und Nährstoffsituation}

\subsubsection{Zustand und Dynamik}

Neben den atmosphärischen Säureeinträgen ist im Hinblick auf die langfristige Nachhaltigkeit der Nährstoffversorgung insbesondere die Verwitterungsrate von entscheidender Bedeutung. Die Abbildung 53 zeigt die mit dem Modell PROFILE regionalisierte Silikatverwitterungsrate. Zur besseren Vergleichbarkeit wurden die Verwitterungsraten bis $1 \mathrm{~m}$ Profiltiefe aufsummiert.

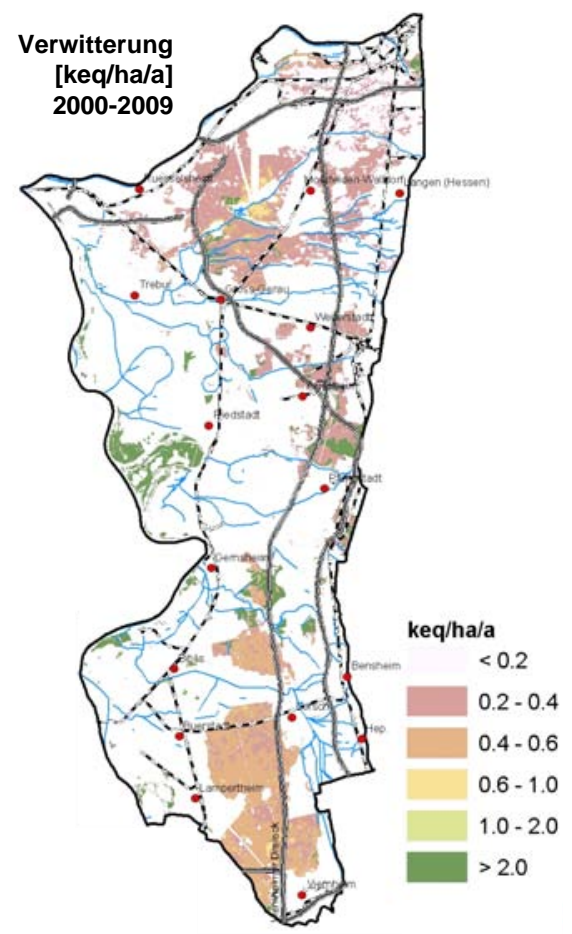

Abbildung 53: Regionalisierung der Verwitterungsraten [keq/ha/ a] für $1 \mathrm{~m}$ Profiltiefe im Rhein-MainGebiet für die Periode 2000 bis 2009

Es zeigen sich im Wesentlichen drei Gruppen für das Untersuchungsgebiet:

1. Die sehr armen carbonatfreien Flugsandstandorte mit geringen Verwitterungsoberflächen und Verwitterungsraten von unter 0,2 Kiloäquivalente pro Hektar und Jahr (keq ha- $\cdot \mathrm{a}^{-1}$ ) Diese Standorte sind vorwiegend im Norden des Gebietes anzutreffen.

2. Die etwas besseren Sandstandorte mit Verwitterungsraten zwischen 0,2$0,6 \mathrm{keq} \mathrm{ha}^{-1} \mathrm{a}^{-1}$. Die modellierten Raten befinden sich in einem plausiblen Wertespektrum, wie der Vergleich mit anderen Untersuchungen und Modellrechnungen zeigt. So ermittelte DuLTz (1993) für saure Sandböden 
aus Geschiebedecksanden Verwitterungsraten von 0,056 keq ha-1 $\mathrm{a}^{-1}$. BECKER et al. (2000) berechneten für die armen Sandstandorte des Level II-Programms Verwitterungsraten zwischen 0,24 und 0,27 keq ha-1 $\mathrm{a}^{-1}$. BOLTE u. WOLFF (2001) verwendeten eine Silikatverwitterungsrate von $0,25 \mathrm{keq} \mathrm{ha}^{-1} \mathrm{a}^{-1}$ für arme pleistozäne Sande im Bundesgebiet. Die Angaben für Verwitterungsraten auf niederländischen Sandböden variieren zwischen 0,1 bis $0,7 \mathrm{keq} \mathrm{ha}^{-1} \mathrm{a}^{-1}$ (VAN DER SALM et al. 1998) bzw. 0,16 bis 0,58 keq ha-1 $\mathrm{a}^{-1}$ (VAN DER SALM 2001). BECKER et al. (2000) ermittelte für Sandlöss-Böden eine Verwitterungsrate von $0,5 \mathrm{keq} \mathrm{ha-1} \mathrm{a}^{-1}$.

3. Die dritte Gruppe sind die Böden mit sehr hohen Verwitterungsraten. Hierzu zählen die Ton- und Schluffböden sowie die Böden, die unter direktem Einfluss von Carbonaten stehen. VAN DER SALM et al. (1998) schätzen in den Niederlanden Verwitterungsraten von 0,135-6,0 keq ha-1 $\mathrm{a}^{-1}$ für Schluffböden und zwischen $0,1-1,750 \mathrm{keq} \mathrm{ha}^{-1} \mathrm{a}^{-1}$ für Tonböden aus Flussablagerungen. Naturgemäß sind die Rhein-Weiß-Standorte durch sehr hohe Lösungsraten gekennzeichnet und setzen entsprechende Mengen an basischen Kationen frei. Die Verwitterungsraten im südlichen JägersburgerWald erscheinen zunächst etwas zu gering. Hierbei ist jedoch zu beachten, dass die hier dargestellten Verwitterungsraten nur bis $1 \mathrm{~m}$ aufsummiert wurden. In den Profilen der BÜK $1: 50.000$ sind die Horizonte ab $1 \mathrm{~m}$ Tiefe durch Carbonatvorkommen gekennzeichnet. Dieses ist aus den Karten zwar nicht ablesbar, wird aber in den Modellierungen über die veränderte Wurzelverteilung und somit geringeren Basenentzügen aus dem Oberboden berücksichtigt (s. Abb. 52.). Es muss jedoch an dieser Stelle auch klar gesagt werden, dass die Abschätzung der Verwitterungsrate immer mit erheblichen Unsicherheiten behaftet ist (KLAMINDER et al. 2011).

Insbesondere auf Standorten mit einer geringen Silikatverwitterungsrate und mäßiger Säurebelastung durch die atmosphärischen Einträge kann der Beitrag des Waldwachstums und der Waldbewirtschaftung auf die Bodenversauerung beträchtlich sein (HolmberG et al. 2000, NiLSSON et al. 1982). Die Abbildung 54 zeigt beispielhaft die mittleren jährlichen Nettoaufnahmeraten für basische Kationen und Stickstoff. Neben dem Einfluss der Baumart (Elementgehalte in den Baumkompartimenten, vgl. JACOBSEN et al. 2003) zeigt sich ein enger Zusammenhang mit der Zuwachsleistung der Bestände. Entsprechend sind auf den ertragsreicheren Standorten im Westen und im Bereich des Jägersburger Waldes die höchsten Nettoentzüge zu verzeichnen. Die Angaben bewegen sich in einer Größenordung wie sie auch bei anderen Untersuchungen abgeschätzt wurden (vgl. NAGEL u. GREGOR 1999). Es zeigt sich, dass unter den gegenwärtigen Standortbedingungen (erhöhte Stickstoffeinträge) die Nettoaufnahmeraten die Silikatverwitterungsraten (s. Abb. 53) z. T. übertreffen. Werden auf diesen Standorten die Sickerwasserverluste der basischen Kationen nicht durch die atmosphärischen Einträge kompen- 
siert, dann ist die stoffliche Nachhaltigkeit gefährdet. Daher ist es von Bedeutung, dass die sehr armen Standorte aufgrund der geringen Aufnahmeraten auch weiterhin mit Kiefern bestockt bleiben (vgl. Süden des Untersuchungsgebietes, Abb. 54). Des Weiteren sollten Nährstoffentzüge auf den schwach mesotrophen Standorten nicht über eine konventionelle Nutzung hinausgehen. Hier würden die Bestände bei einer intensivierten Biomassenutzung wahrscheinlich mit Zuwachseinbußen reagieren (EGNELL u. VALINGER 2003, HELMISAARI et al. 2011, NORD-LARSEN 2002), welche die erzielten Gewinne aufzehren würden.
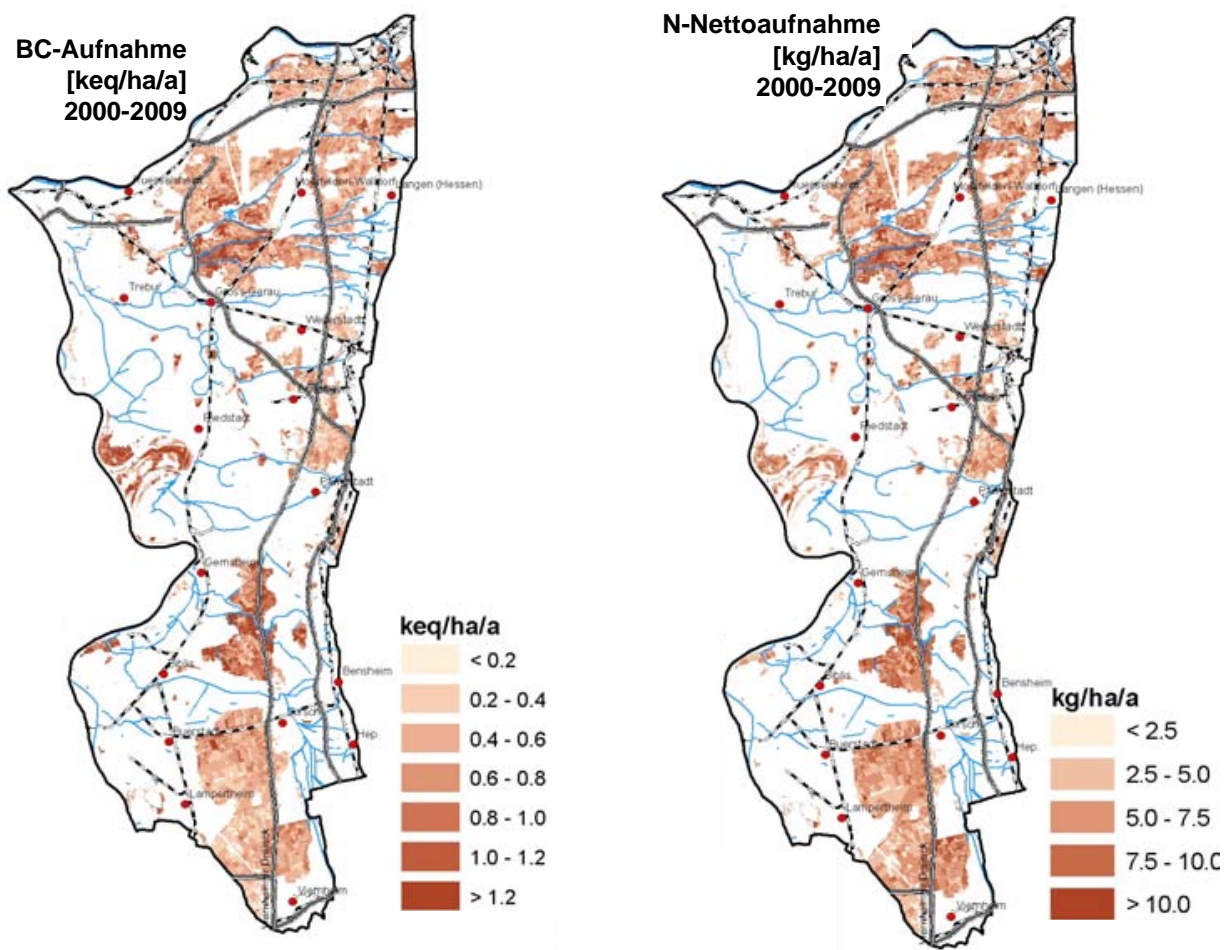

Abbildung 54: Regionalisierung der mittleren jährlichen Nettoaufnahme basischer Kationen (BC, links) und Stickstoff (N, rechts) im Rhein-Main-Gebiet für die Periode 2000 bis 2009

Die Basensättigung ist ein relativ guter Indikator, der die beschriebenen Ein- und Austräge und Bodenverhältnisse integriert und zusammen mit der Austauschkapazität (Ake) entscheidend für die Ausstattung eines Standortes mit wichtigen Makronährelementen wie Calcium, Magnesium oder Kalium ist (SCHULTE-BISPING et al. 2001, STOCK 2004, MeIWES u. MeEsenburg 2007). Standorte mit äußerst geringem Sättigungsgrad sind vor allem im Süden und in einigen kleineren Arealen im Norden anzutreffen (s. Abb. 55). 


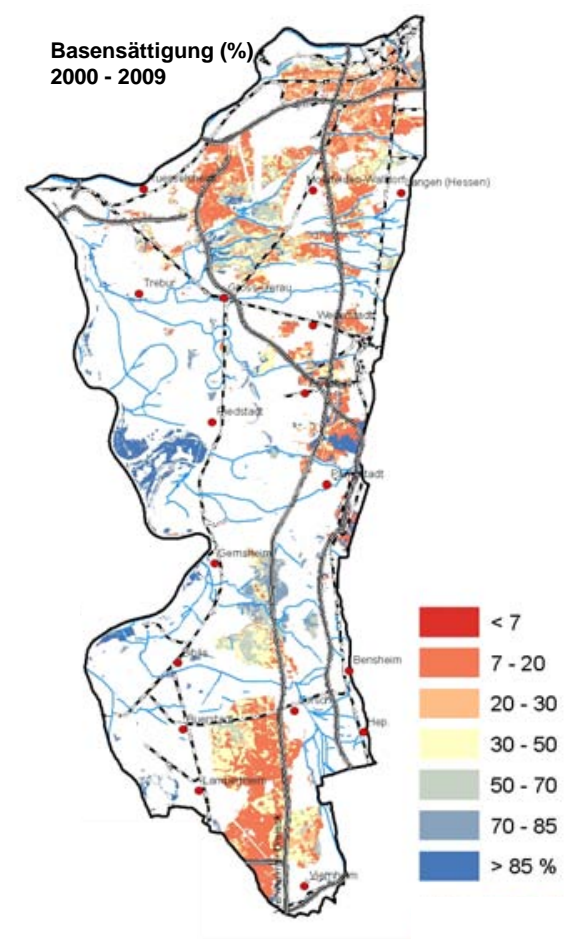

Abbildung 55: Regionalisierung der Basensättigung [\%] im Wurzelraum (1 m) im Rhein-Main-Gebiet für die Periode 2000 bis 2009

Insbesondere der Bereich des Jägersburger Waldes ist durch einen sehr kleinräumlichen Wechsel von Standorten mit hoher und niedriger Basensättigung gekennzeichnet. Diese Unterschiede sind das Resultat von kleinräumlich sehr variablen Rheinweiß-Vorkommen, die auf den sandigen Standorten entscheidend für den Sättigungsgrad mit basischen Kationen sind. Von besonderem Interesse sind bei den dargestellten Ergebnissen die Standorte mit sehr geringen Basenvorräten. In der Literatur (MEIWES et al. 1986, REUSS 1983, ULRICH 1995) wird häufig eine Basensättigung von 15-20 Prozent als kritischer Wert genannt, bei dessen Unterschreitung ein signifikanter Anstieg toxischer $\mathrm{Al}^{3+}$-Ionen in der Bodenlösung zu erwarten ist. Sinkt die Basensättigung unter diesen Schwellenwert, so führt dies bei den relativ säuretoleranten einheimischen Baumarten wie Buche, Eiche, Tanne, Fichte und Kiefer zu Säurestress und zu einer Einschränkung der Nährstoffaufnahme (SVERDRUP et al. 1994, WEBER-BLASCHKE et al. 2002, CHOI et al. 2005). Nicht säuretolerante Baumarten wie die Edellaubhölzer stellen jedoch noch höhere Anforderungen an die Basensättigung (FORTMANN et al. 2007). So sollte die Basensättigung z. B. bei Ahorn und Esche die Grenze von 30 Prozent nicht unterschreiten (WEBER u. BAHR 2000). 
Abbildung 55 zeigt die simulierte Dynamik der Basensättigung in den letzten Jahrzehnten. Etwa seit Beginn der 60er-Jahre zeigt sich eine erhebliche Reduktion der Basenvorräte in den Böden. Die maximale Reduktionsrate (70er-Jahre) wird zeitgleich mit den maximalen Säurebelastungen erreicht. Somit fällt der Basenverlust zwar mit dem Zeitpunkt der Grundwasserabsenkungen zusammen, er ist jedoch zum überwiegenden Teil nicht mit den Absenkungen in Verbindung zu bringen. Allgemein können zwar alkalische Grundwässer die atmosphärischen Säureeinträge neutralisieren (KNUTSSON 1994). Ein statistisch abgesicherter Effekt diesbezüglich lässt sich auf Grundlage der verfügbaren Daten jedoch im Rhein-Main-Gebiet nicht quantifizieren. Dieses lässt sich auch dadurch erklären, dass nach der Absenkung des Grundwassers das ausgeschiedene Rheinweiß in den oberen Bodenschichten verbleibt und so auch weiterhin zur Pufferung der eingetragenen Säure zur Verfügung steht. Weiterhin ist zu berücksichtigen, dass die sehr nährstoffschwachen Standorte (geringe Basensättigung), die am stärksten von der Versauerung durch atmosphärische Stoffeinträge betroffen sind (s. Abb. 56, rechts), im gesamten Untersuchungszeitraum keinen sicheren Grundwasseranschluss besessen haben (s. Abb. 50). Insofern ist ein Effekt der Grundwasserabsenkung auf die Standortsqualität dieser Standorte nur ein theoretisches Problem.
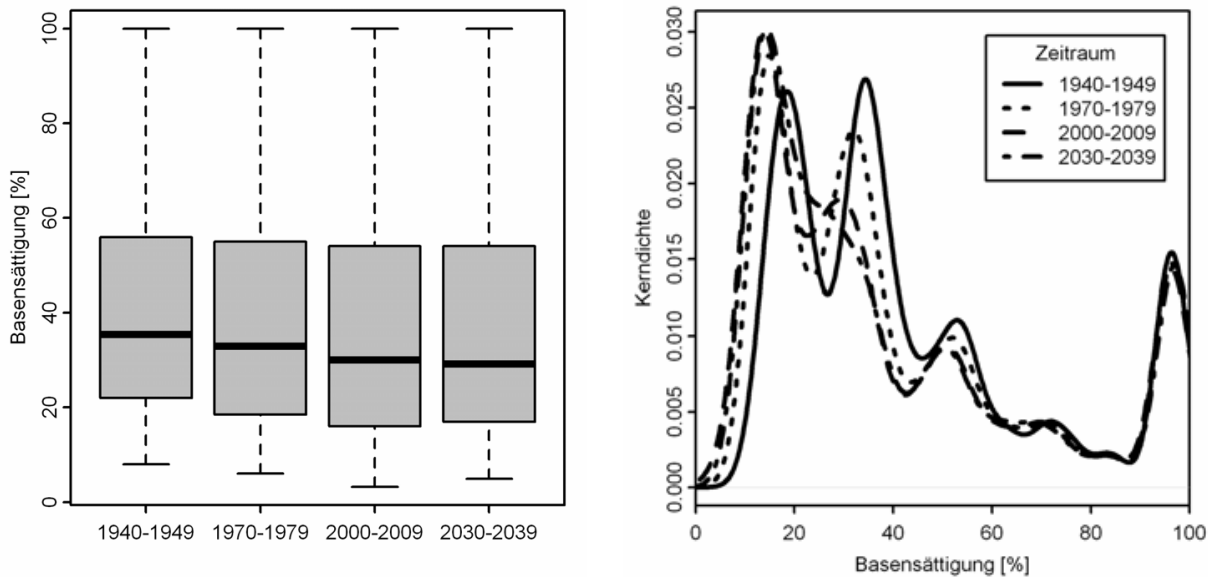

Abbildung 56: Szenario der zeitlichen Dynamik der Basensättigung im Wurzelraum $(1 \mathrm{~m})$ im RheinMain-Gebiet (links: Box-Whisker-Plot; rechts: Kerndichteschätzung)

Eine entsprechende Dynamik der bodenchemischen Veränderungen für den Zeitraum von 1954 bis 1986 zeigen auch die Untersuchungen von ULRICH (1995) beispielhaft für Hainsimsen-Buchenwälder in Südniedersachsen. Die Ergebnisse der Kerndichteschätzung (s. Abb. 56, rechts) verdeutlichen, dass insbesondere die nährstoff- und pufferschwachen Standorte von den Basenverlusten betroffen sind und insgesamt die Anzahl der Standorte unter einer Basensättigung von 20 Prozent angestiegen ist. 


\subsubsection{Auswirkungen der Szenarioannabmen}

Die unterschiedlichen Grundwasser- und Klimaszenarien zeigen nur sehr geringe Unterschiede hinsichtlich der Basensättigung (s. Abb. 57). Dieses kann zum Teil dadurch erklärt werden, dass einige Effekte in Wechselwirkung zueinander stehen. So sind durch die Ausfälle der Bestände bei den trockenen Szenarien zwar die Nährstoffentzüge durch die Baumaufnahme reduziert, auf der anderen Seite kommt es immer wieder zu erhöhten Nitratausträgen und den damit verbundenen Verlusten von basischen Kationen mit dem Sickerwasser.

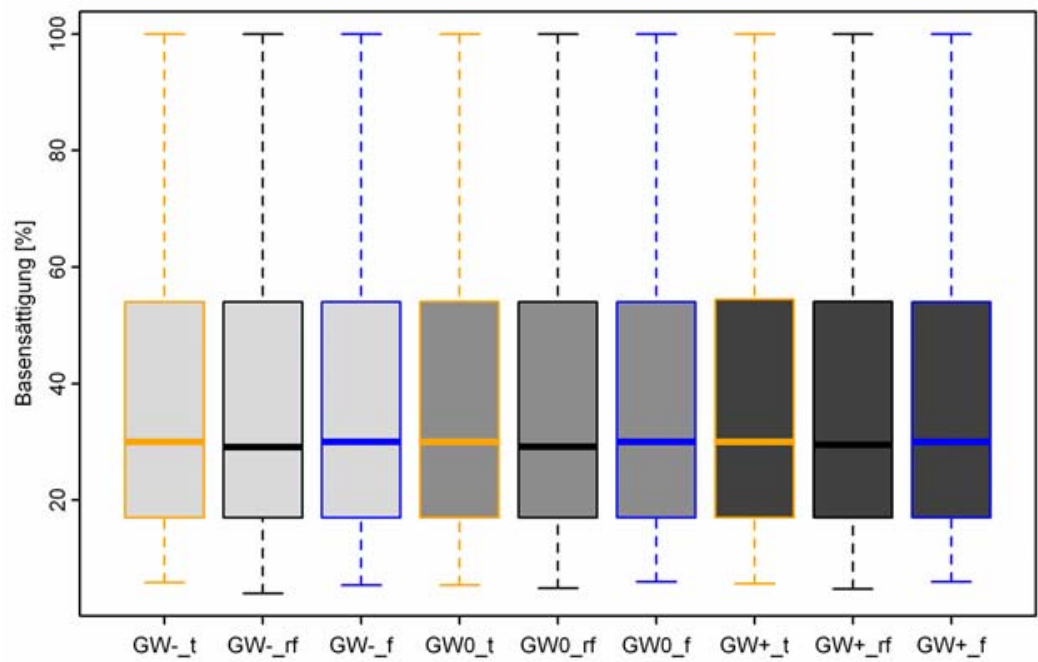

Abbildung 57: Einfluss unterschiedlicher Grundwasser- und Klimaszenarien auf die Basensättigung [\%] im Wurzelraum $(1 \mathrm{~m}$ ) im Rhein-Main-Gebiet für die Periode 2030 - 2039

Werden nur die grundwassernahen Standorte betrachtet, zeigt sich, dass diese durch hohe Basensättigungen gekennzeichnet sind (s. Abb. 58). Diese Standorte haben sich auch sehr robust hinsichtlich der atmosphärischen Säureeinträge gezeigt, insofern sind auch durch die Veränderung des Grundwasserspiegels keine gravierenden Effekte zu erwarten. Dieses liegt zum einen an gestiegenen Verwitterungsraten durch die veränderten Wassergehalte im Boden und zum anderen an einer verringerten Grundwasserneubildungsrate durch die höheren Grundwasserstände. Auch die Untersuchungen von KROS et al. (1995) zeigen nur geringe Auswirkungen einer gesteigerten Grundwasserneubildungsrate durch Grundwasserabsenkungen auf die Basensättigung im Boden. 


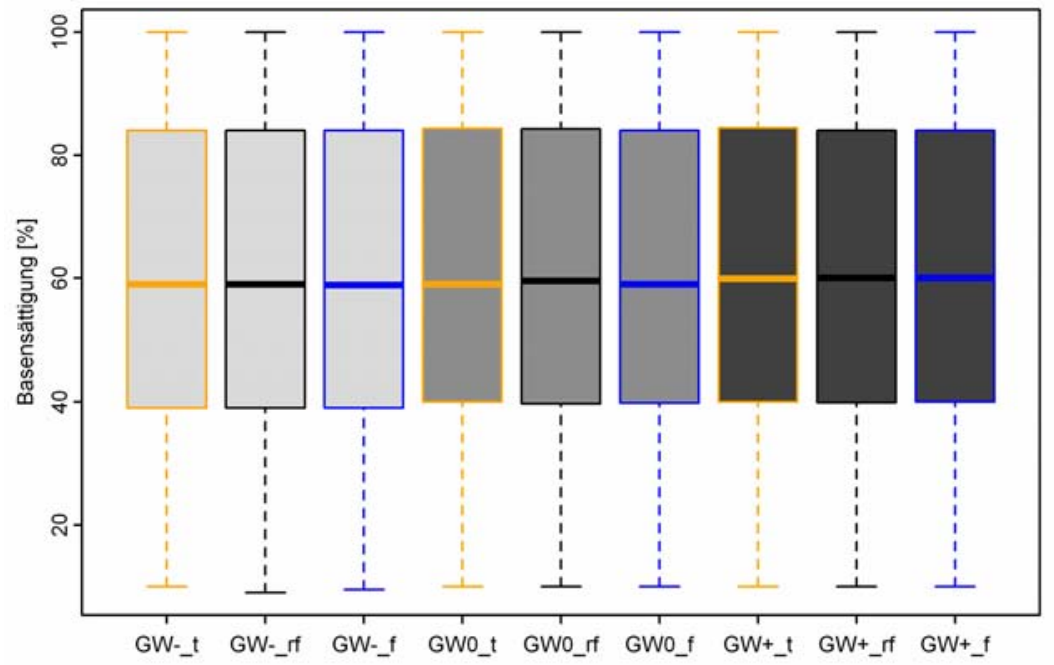

Abbildung 58: Einfluss unterschiedlicher Grundwasser- und Klimaszenarien auf die Basensättigung [\%] im Wurzelraum $(1 \mathrm{~m})$ der grundwassernahen Standorte $(<150 \mathrm{~cm}$ unter GOK) im Rhein-Main-Gebiet für die Periode 2030 - 2039

Generell führen bei Standorten mit Grundwasseranschluss tiefere Grundwasserstände zu höheren Grundwasserneubildungsmengen und höhere Grundwasserneubildungsmengen sind mit höheren Auswaschungsverlusten von basischen Kationen im Boden verbunden. Da sich die Veränderungen der Grundwasserneubildungsmengen jedoch nur in einem geringen Wertespektrum abspielen, sind kaum Unterschiede erkennbar.

Dass der Modellierungsansatz durchaus in der Lage ist, die Effekte von veränderten Rahmenbedingungen auf den bodenchemischen Zustand zu beschreiben, zeigt ein Szenario mit veränderter Nutzungsintensität (s. Abb. 59). Bei diesen Varianten wurde das Derbholz mit bzw. ohne Rinde genutzt. Die Rindenfunktionen berücksichtigen das Bestandesalter und die baumartenspezifischen Elementgehalte in der Derbrinde (vgl. JACOBSEN et al. 2003). Die Kerndichteschätzung zeigt, dass sich die Auswirkungen insbesondere auf den nährstoffschwachen Standorten konzentrieren und entsprechend diese Standorte von einer intensivierten Nutzung ausgeschlossen werden sollten, da unter den aktuellen Wachstumsbedingungen die Standorte schon bei einer konventionellen Nutzung an ihren Grenzbereich angelangt sind. 

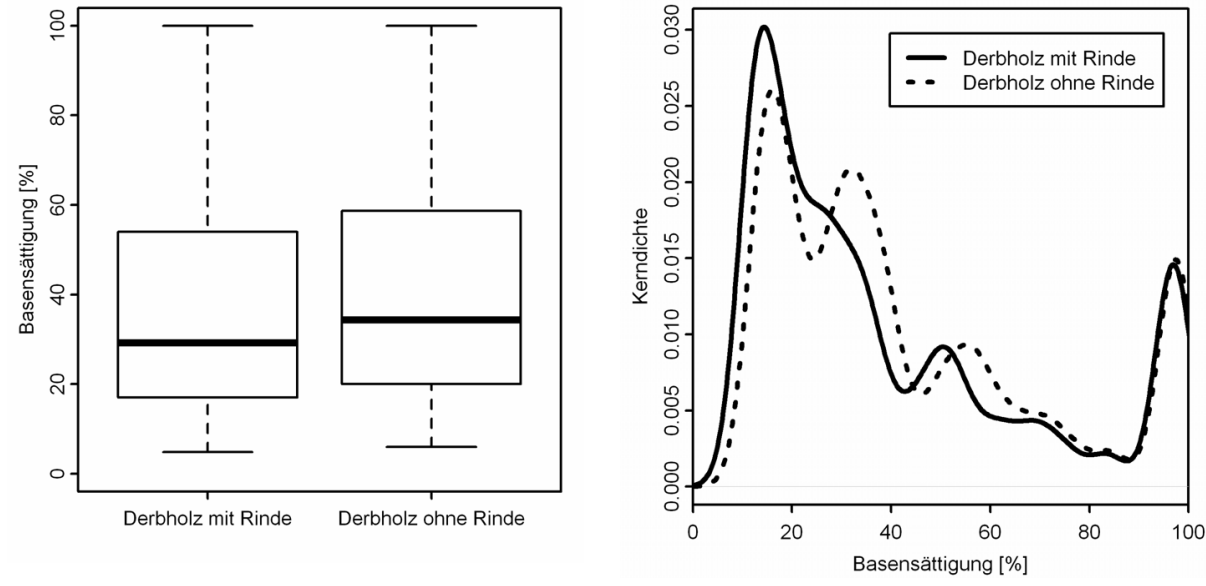

Abbildung 59: Einfluss unterschiedlicher Nutzungsszenarien auf die Basensättigung [\%] im Wurzelraum $(1 \mathrm{~m})$ im Rhein-Main-Gebiet (links: Box-Whisker-Plot, rechts: Kerndichteschätzung)

\subsubsection{Stickstoffhaushalt}

\subsubsection{Denitrifikation}

Stickstoffemissionen aus dem Boden werden i. d. R. durch den mikrobiellen Prozess der Denitrifikation verursacht. Hierbei wird das Nitrat der Bodenlösung $\mathrm{zu}$ Nitrit $\left(\mathrm{NO}_{2}\right)$, weiter zu Stickstoffmonoxid (NO), zu Distickstoffoxid (Lachgas $=\mathrm{N}_{2} \mathrm{O}$ ) und letztendlich zu elementarem Stickstoff $\left(\mathrm{N}_{2}\right)$ reduziert. Optimale Bedingungen für die Mikroorganismen liegen bei hohen Wassergehalten, pH-Werten, Temperaturen und Gehalten an leicht verfügbarer organischer Substanz vor (NORMAN et al. 2008, SIMEK u. COOPER 2002).

Die modellierten Denitrifikationsraten liegen für den weitaus größten Teil der Waldfläche im Untersuchungsgebiet bei etwa $1 \mathrm{~kg}$ pro Hektar und Jahr (s. Abb. 60). Einen entsprechenden Wert ermittelten auch NAGEL u. GREGOR (1999) für 90 Prozent der Waldflächen in Deutschland. DUTCH u. INESON (1990) fanden bei ihrer Literaturauswertung typische Raten zwischen 0,1-3,0 kg je Hektar und Jahr, wobei die höheren Werte den feuchteren Böden zugeordnet werden konnten. Entsprechend zeigen sich auf den feuchteren und nährstoffreicheren Böden im Westen auch die höchsten N-Emissionen. Hohe Raten sind entlang der Fließgewässer zu erkennen, da hier oberflächennahes Grundwasser und somit höhere Bodenwassergehalte vorliegen. Von den schlechteren Standorten weisen die stärker mit N-Depositionen belasteten Bereiche im Norden (s. Abb. 52) die höchsten Raten auf. Der Einfluss des $\mathrm{pH}$-Wertes auf die Denitrifikationsrate lässt sich auf den besseren Standorten im Westen des Untersuchungsgebietes erkennen. Es zeigt sich, dass unter leicht verringerten N-Depositionen in der Periode von 2030 bis 
2039 auf diesen Standorten auch die Denitrifikationraten weiter zurückgehen. Diese geringen Raten gelten jedoch nur für ungestörte Waldökosysteme mit mäßigen Stickstoffbelastungen. So schätzten z. B. TIETEMA et al. (1991) für einen hoch N-belasteten Eichen-Buchen-Mischwald mit Grundwassereinfluss die N-Verluste durch Denitrifikation auf bis zu $20 \mathrm{~kg}$ pro Hektar und Jahr. Nach Kahlschlägen wurden Raten zwischen 3-40 kg je Hektar und Jahr ermittelt (DUTCH U. INESON 1990, GUNDERSEN 1991).
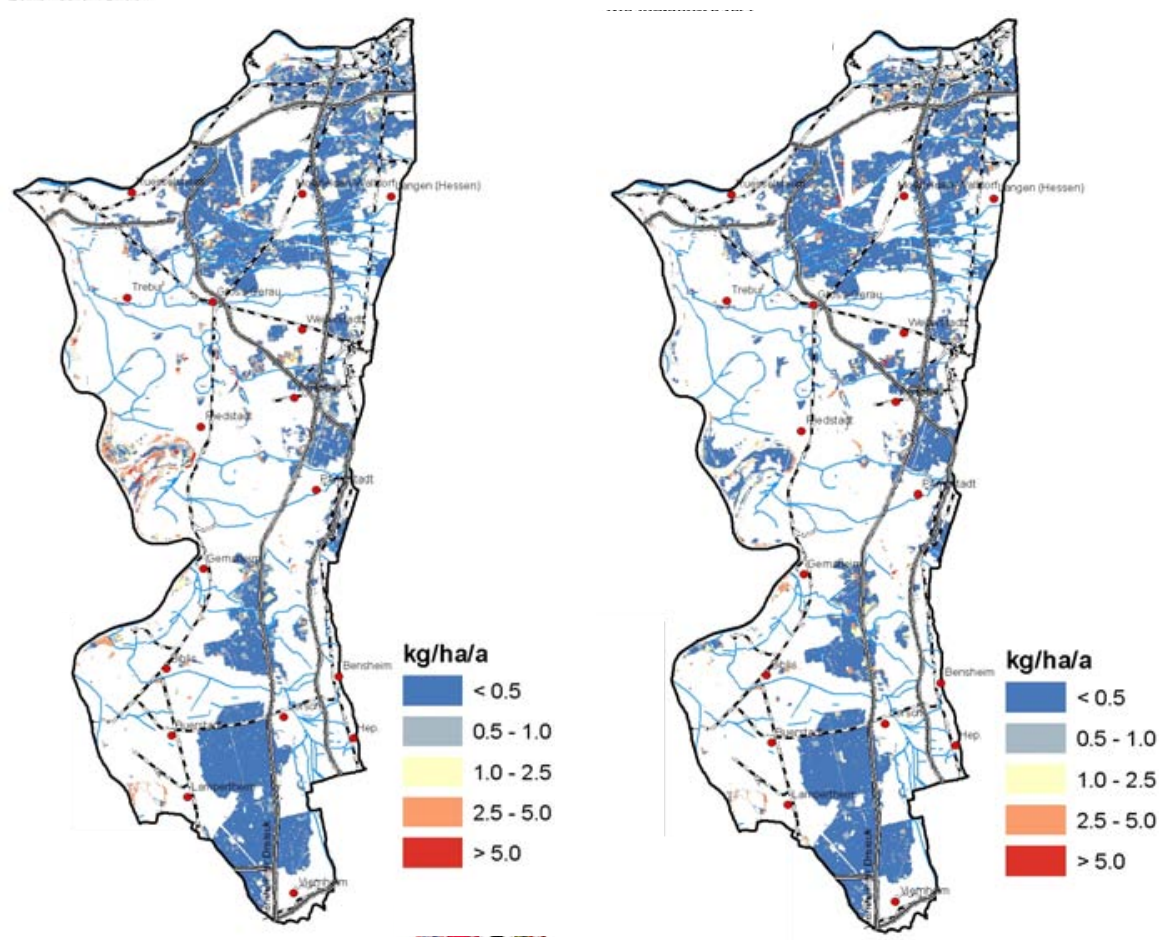

Abbildung 60: Regionalisierung der Denitrifikationsraten $[\mathrm{kg} / \mathrm{hal}$ a] im Rhein-Main-Gebiet für die Perioden 2000 bis 2009 und 2030 bis 2039

In Abbildung 61 ist der Effekt der Grundwasser- und Klimaszenarien auf die Denitrifikationsraten eines Beispielbestandes im Forstamt Langen dargestellt. Die Simulationen zeigen einen Anstieg der Denitrifikationsraten bei allen drei Szenarien mit einer weiteren Absenkung des Grundwasserspiegels (GW-). Durch die hohen Mortalitätsraten in diesem Bestand kommt es zu einem Abbau des Vorrats an organischer Substanz im Oberboden und entsprechend erhöhter N-Freisetzung. Bei gleichzeitig reduzierten Aufnahmeraten steht somit dem System ein Überschuss an Stickstoff zur Verfügung, der zum Teil an die Atmosphäre abgeben wird. 

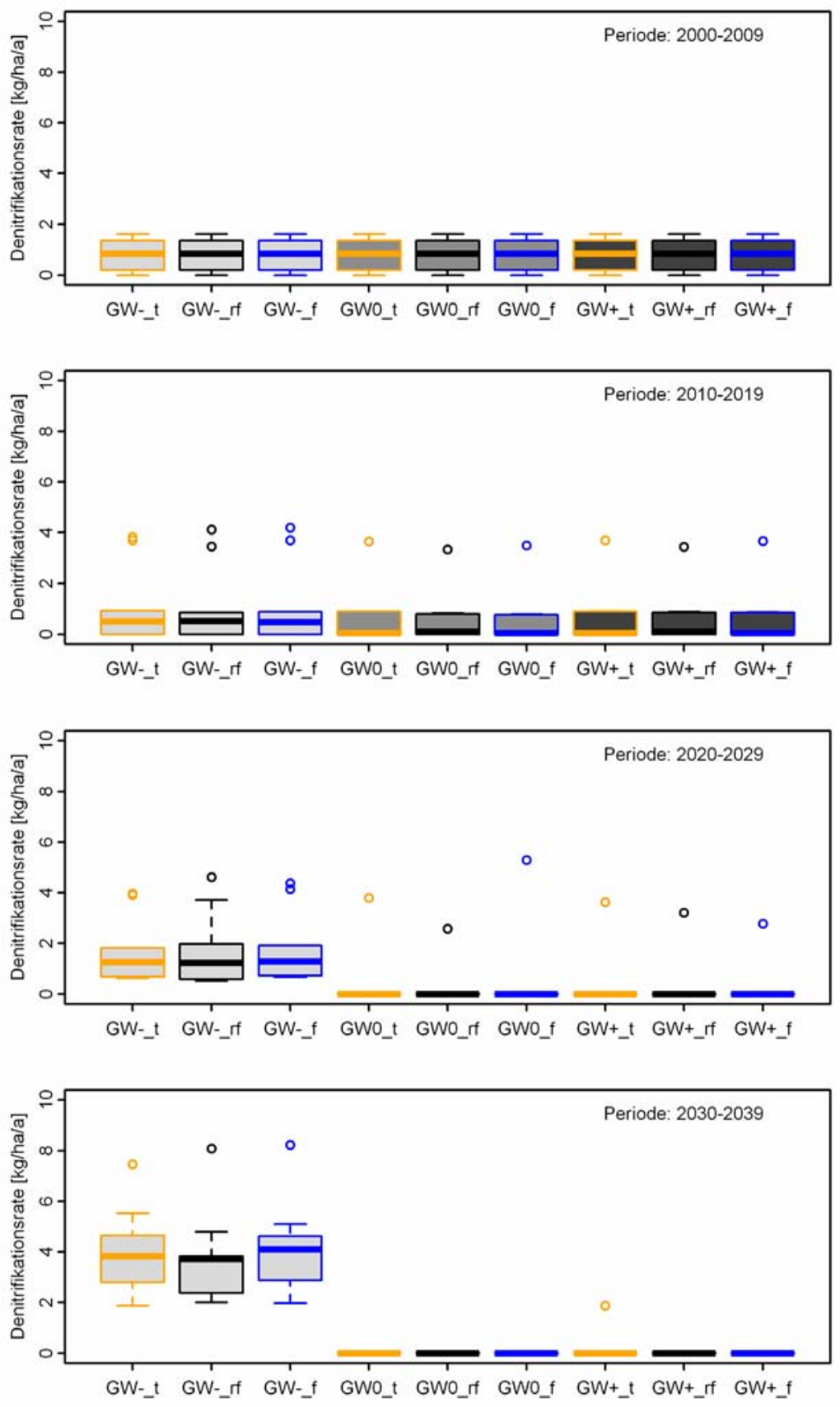

Abbildung 61: Einfluss unterschiedlicher Grundwasser- und Klimaszenarien auf die Denitrifikationsrate [kg/ha/a] (Beispiel: Buchenfläche, Fo A Langen, Abt. 18) 
Bei der Interpretation der Ergebnisse sollte beachtet werden, dass die Zwischenspeicherung des Stickstoffs durch die Bodenvegetation nicht im Modell berücksichtigt wird. Entsprechend kann eine dichte Bodenvegetation helfen, Nitratausträge auf Kahlflächen zu verhindern (HUBER et al. 2004). Diese muss sich jedoch erst nach der Auflichtung der Bestände etablieren. Des Weiteren wird der Anstieg der Bodentemperatur infolge des erhöhten Strahlungseinfalls (GÖTTLEIN et al. 2003) ebenfalls nicht im Modell abgebildet, sodass davon ausgegangen werden kann, dass sich diese beiden Fehler zumindest z. T. ausgleichen.

Die Szenarien mit Grundwasseranstieg (GW+) machen sich bei den Denitrifikationsraten aus zweierlei Gründen nur wenig bemerkbar. Zum einen wird durch den intakten Bestand ausreichend Stickstoff in das Wachstum umgesetzt. Zum anderen erfolgt die Anhebung des Grundwasserspiegels an diesem Standort auf etwa 2,5 m unter Flur. Für eine Erhöhung der Denitrifikation sind aber insbesondere höhere Bodenfeuchten in den oberen Bodenschichten mit höheren $\mathrm{C}_{\mathrm{org}^{-}}$ Gehalten entscheidend. An grundwassernahen Standorten würden sich mit dem Wiederanstieg der Grundwasserstände höhere Wassergehalte im Boden und entsprechende optimale Bedingungen für die Nitrifikation und anschließend für die Denitrifikation ergeben. Eine sofortige Abnahme der $\mathrm{N}_{2} \mathrm{O}$-Konzentrationen in der Bodenatmosphäre nach sinkendem Grundwasserspiegel wird auch durch die Untersuchungen von TIETEMA et al. (1991) bestätigt. Die beiden Klimaszenarien „feucht“ (f) und „trocken“ (t) unterschieden sich gegenüber dem Referenzszenario (rf) auch durch eine wesentliche Temperaturerhöhung. Dieses führt zum einen zu einer Erhöhung der Mineralisierungsleistung und zum anderen laufen die Prozesse der Nitrifikation und Denitrifikation beschleunigt ab. So lassen sich die leicht erhöhten Denitrifikationsraten bei den trockenen Klimaszenarien erklären (vgl. Periode 2030 - 2039, GW-).

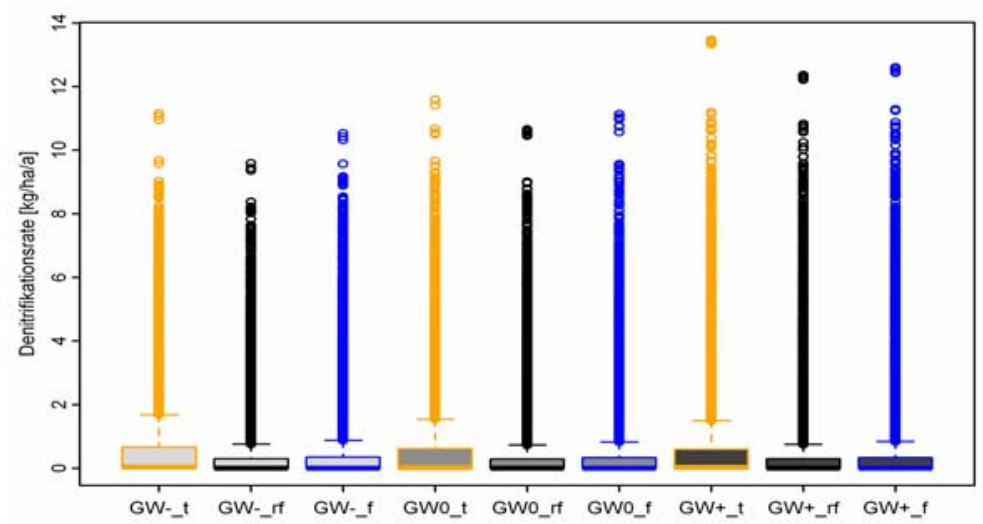

Abbildung 62: Einfluss unterschiedlicher Grundwasser- und Klimaszenarien auf die Denitrifikationsraten $[\mathrm{kg} / \mathrm{ha} / \mathrm{a}]$ im Rhein-Main-Gebiet für die Periode 2030 - 2039 
Abbildung 62 zeigt die vorab beschriebenen Effekte für das ganze Untersuchungsgebiet. Hierbei zeigen sich höhere Austräge bei allen trockenen Szenarien ( $\mathrm{t}$ ) und bei den Szenarien mit Grundwasserabsenkungen (GW-).

\subsubsection{Koblenstoff- und Stickstoffdynamik}

Die Kohlenstoff- und Stickstoffdynamik im Oberboden ist besonders hinsichtlich der Nitratausträge von Bedeutung. Die C- und N-Dynamik soll an dieser Stelle zusammen betrachtet werden, da das C/N-Verhältnis ein wichtiger Indikator für das Waldwachstum (LAUBHANN et al. 2010) sein kann, aber auch für das Risiko der Nitrat-Auswaschung entscheidend ist (GUNDERSEN et al. 1998). Die regionale Verteilung der C/N-Verhältnisse im Untersuchungsgebiet weist zunächst wieder auf die besseren Standorte im Westen hin (s. Abb. 63). Durch die höheren N-Einträge im Norden des Gebietes (s. Abb. 52) sind die C/N-Verhältnisse in diesem Bereich stärker verengt als im Süden. Mit steigenden Stickstoff-Einträgen kann dieser nicht mehr sinnvoll in Wachstum umgesetzt werden und reichert sich im Boden an. Das C/N-Verhältnis des Auflagehumus ist im industrialisierten Mitteleuropa in den letzten Jahrzehnten merklich gesunken (u. a. ZEZSCHWITZ 1985, BUBERL et al. 1994, VANMECHELEN et al. 1997). Die C-Akkumulationsraten betrugen über den Simulationszeitraum in etwa $100 \mathrm{~kg} \cdot$ pro Hektar und Jahr und die NAkkumulationsraten etwa $10 \mathrm{~kg}$ je Hektar und Jahr. Nach MELLERT et al. (2008) werden infolge der hohen N-Einträge in der Vergangenheit N-Akkumulationen von ca. 100 bis $400 \mathrm{~kg} \mathrm{~N} /$ ha in den letzten 20 Jahren erwartet. Auf solche hohe Akkumulationsraten weisen auch die Untersuchungen von BRINKMANN u. NIEDER (2002), MEIWES et al. (2002, 2009), PRIETZEL et al. (2006) und TIETEMA (2004) hin. MOL-DiJKSTRA et al. (2009) ermittelten mit verschiedenen Modellansätzen C-Akkumulationsraten von 160 bis $978 \mathrm{~kg}$ (Limit-Values), 0 bis $535 \mathrm{~kg}$ (NBalance Methode) und -30 bis $254 \mathrm{~kg}$ (SMART2 Model) je Hektar und Jahr für die europäischen Wälder des EU-Level II-Monitorings. Auch LISKI et al. (2002) ermittelten für Westeuropa Werte in dieser Größenordnung. Diese Daten zeigen, dass sich bei gleich gebliebenen oder sich verengenden $\mathrm{C} / \mathrm{N}$-Verhältnissen gleichzeitig erhebliche N-Mengen im Boden angereichert haben dürften. Vergleichbare NAkkumulationsraten mit entsprechender Dynamik der C/N-Verhältnisse wurden auch an einem Fallbeispiel von PRIETZEL et al. (2006) gefunden.

Gespeicherte Stickstoffmengen in dieser Größenordnung bergen natürlich auch ein erhebliches Gefährdungspotenzial. Dieses geht nach den Simulationen nur zu einem geringen Teil von einer Temperaturerhöhung im Zuge des Klimawandels aus. Gefahren bestehen vielmehr aufgrund von erhöhten Mortalitätsraten oder Bestandeszusammenbrüchen aufgrund von Maikäferbefall. Durch die fehlende Stickstofffestlegung im Bestand und die erhöhte Nettofreisetzung von Stickstoff durch den Humusvorratsabbau kann es zu erheblichen Nitratausträgen mit dem Sickerwasser kommen, wenn es durch rechtzeitige Verjüngung oder eine dichte Bodenvegetation nicht gelingt, den Stickstoffkreislauf geschlossen zu halten 
(WEIS et al. 2008). Detaillierter werden die Austragsraten im folgenden Kapitel diskutiert und beschrieben.

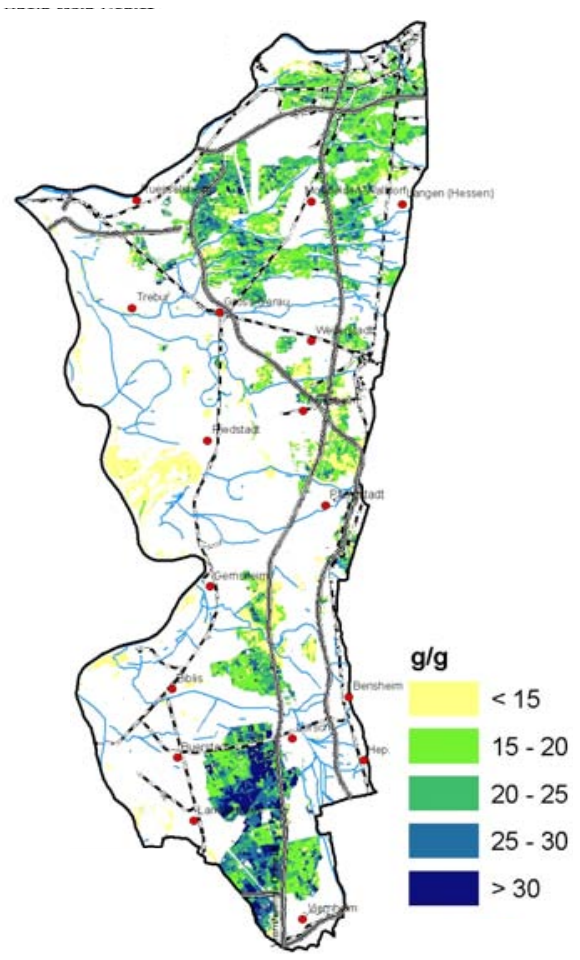

Abbildung 63: Regionalisierung der durchschnittlichen C/N-Verbältnisse im Oberboden des RheinMain-Gebietes für die Periode 2000 bis 2009

\subsubsection{N-Austräge mit dem Sickerwasser}

Die Nitratkonzentrationen im Grund- und Oberflächenwasser in bewaldeten Wassereinzugsgebieten sind in der Regel wesentlich geringer als die in landwirtschaftlich geprägten Einzugsgebieten (LANGUSCH u. MATZNER 2002, HeIDE et al. 2008). Somit kann nitratarmes Wasser aus Waldeinzugsgebieten z. B. mit nitratbelastetem Wasser aus landwirtschaftlich genutzten Gebieten verschnitten werden, um die Grenzwerte der Trinkwasserverordnung für Nitrat einzuhalten. Aufgrund dieser hohen Bedeutung der Wälder für die Grund- und Sickerwasserqualität können schon geringe Anstiege der Nitratkonzentrationen zu erheblichen Auswirkungen hinsichtlich des Wassermanagements führen. In Böden mit guter Basensättigung führt die Auswaschung von Nitrat zu Nährstoffverlusten, in saureren Böden, in denen Säuren über die Auflösung von Oxiden (Mn-, Al-Oxide) gepuffert werden, werden vornehmlich Mangan und Aluminium zusammen mit dem Nitrat 
tiefer im Boden verlagert und erhöhen das Risiko einer Gewässerversauerung mit Aluminiumausträgen (DISE et al. 2001). Daher sollen im Folgenden die verschiedenen Szenarien hinsichtlich ihrer Auswirkungen auf die N-Austräge mit dem Sickerwasser untersucht werden.

Die für das Untersuchungsgebiet modellierten durchschnittlichen N-Austräge (s. Abb. 64) zeigen für die meisten Flächen Werte zwischen 0-2,5 kg je Hektar und Jahr. Dieser Wertebereich entspricht in etwa dem tolerierbaren Austrag unter Critical Loads-Bedingungen für Nadelwälder (0,5-3 kg) und Laubwälder (2-4 kg) (SPRANGER et al. 2004). Aufgrund der geringen Grundwasserneubildungsmengen im Rhein-Main-Gebiet muss jedoch beachtet werden, dass auch schon geringe Austräge zu kritischen Stickstoffkonzentrationen führen können. Die modellierten Austragsmengen werden auch durch Messungen der Nitratkonzentrationen im Sickerwasser unter den drei Intensivmessflächen im Jägersburger Wald bestätigt (2$3 \mathrm{~kg}$ jährlich pro Hektar).

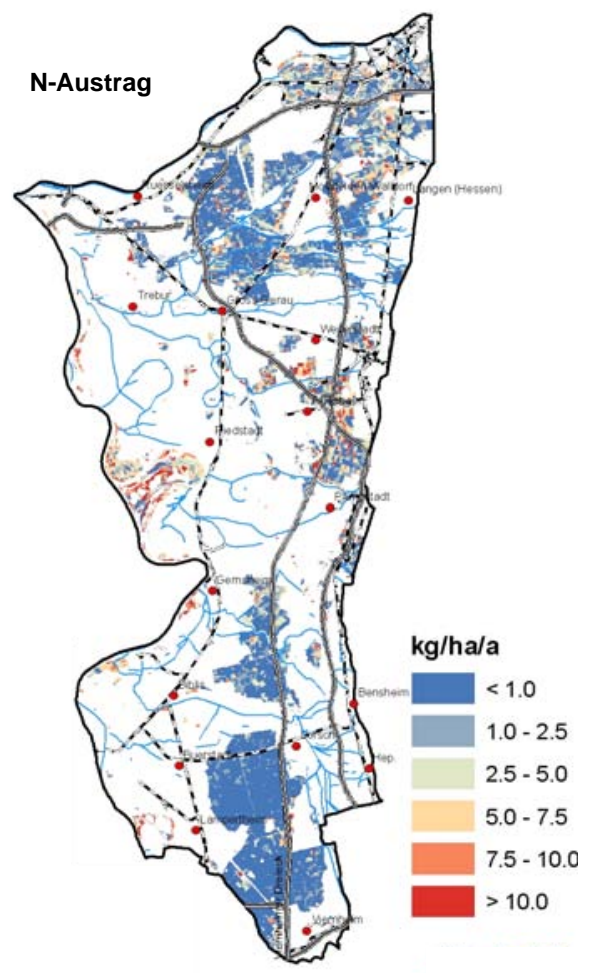

Abbildung 64: Regionalisierung der durchschnittlichen Stickstoff-Austräge [kg/ha/ a] mit dem Sickerwasser im Rhein-Main-Gebiet für die Periode 2000 bis 2009 
Die geringsten N-Austräge zeigen sich auf den sauren Standorten im Süden des Untersuchungsgebietes. Entsprechend den hier vorgestellten Ergebnissen zeigte z. B. eine Nitratinventur in bayerischen Waldgebieten, dass die Gefahr von erhöhten Nitratkonzentrationen auf den mageren und übernutzten Standorten mit einer hohen Stickstoffspeicherungsreserve am geringsten ist (MELLERT et al. 2005). In einer weiteren Studie über 57 Waldflächen in Deutschland (BORKEN u. MATZNER 2004) wiesen ebenfalls die Kiefernbestände, die i. d. R auf diesen Standorten anzutreffen sind, die geringsten Nitratausträge auf. Neben den standörtlichen Unterschieden sind vor allem Störungen der Bestände oder der Böden für erhöhte Austräge verantwortlich (AHRENDS et al. 2005, BLOCK 2006, ROTHE u. MELLERT 2004). So kommt es nach Kahlschlägen oder einem Bestandeszusammenbruch durch Sturmwurf oder Maikäferbefall zu einer Verringerung der Kohlenstoff- und Stickstoffvorräte im Oberboden. Der Rest des freigesetzten Stickstoffs, der nicht von Pflanzen aufgenommen, in der Bodenvegetation zwischengespeichert (BERGMANN 1998, BOLTE 1999) oder durch die Denitrifikation gasförmig an die Atmosphäre abgegeben wird, wird mit dem Sickerwasser aus dem Wurzelraum ausgetragen.

Entsprechend zeigen die Simulationen insbesondere bei den trockenen Szenarien den Effekt einer Bestandesstörung (s. Abb. 65). Dies führt zum Teil zu kurzfristig erheblichen Austragsschüben. Diese bewegen sich mit jährlichen Austrägen zwischen 10 und $20 \mathrm{~kg}$ je Hektar in einer Größenordnung, wie sie auch nach Kahlschlägen oder Sturmwürfen beobachtet wurden (BORMANN u. LIKENS 1979, KohlPAinter u. GÖTTLEIN 2009, MELlERT et al. 1998, PARdO et al. 1995). Auch der Zeitraum (4-6 Jahre) der erhöhten Austräge deckt sich mit experimentellen Befunden aus der Literatur (HORNBECK et al. 1987, MELLERT et al. 1998). Nach den hohen Austrägen in den Anfangsjahren sinke diese häufig unter das Niveau der Referenzbestände ab (KLINK et al. 2010, WEIS et al. 2008).

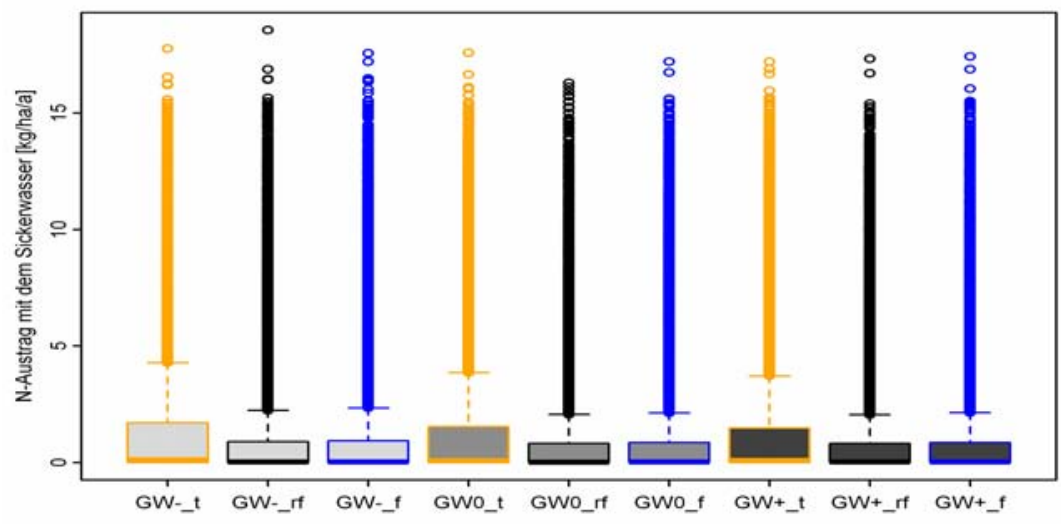

Abbildung 65: Einfluss unterschiedlicher Grundwasser- und Klimaszenarien auf die N-Austräge $[\mathrm{kg} / \mathrm{ha} / \mathrm{a}]$ im Rhein-Main-Gebiet für die Periode 2030 - 2039 

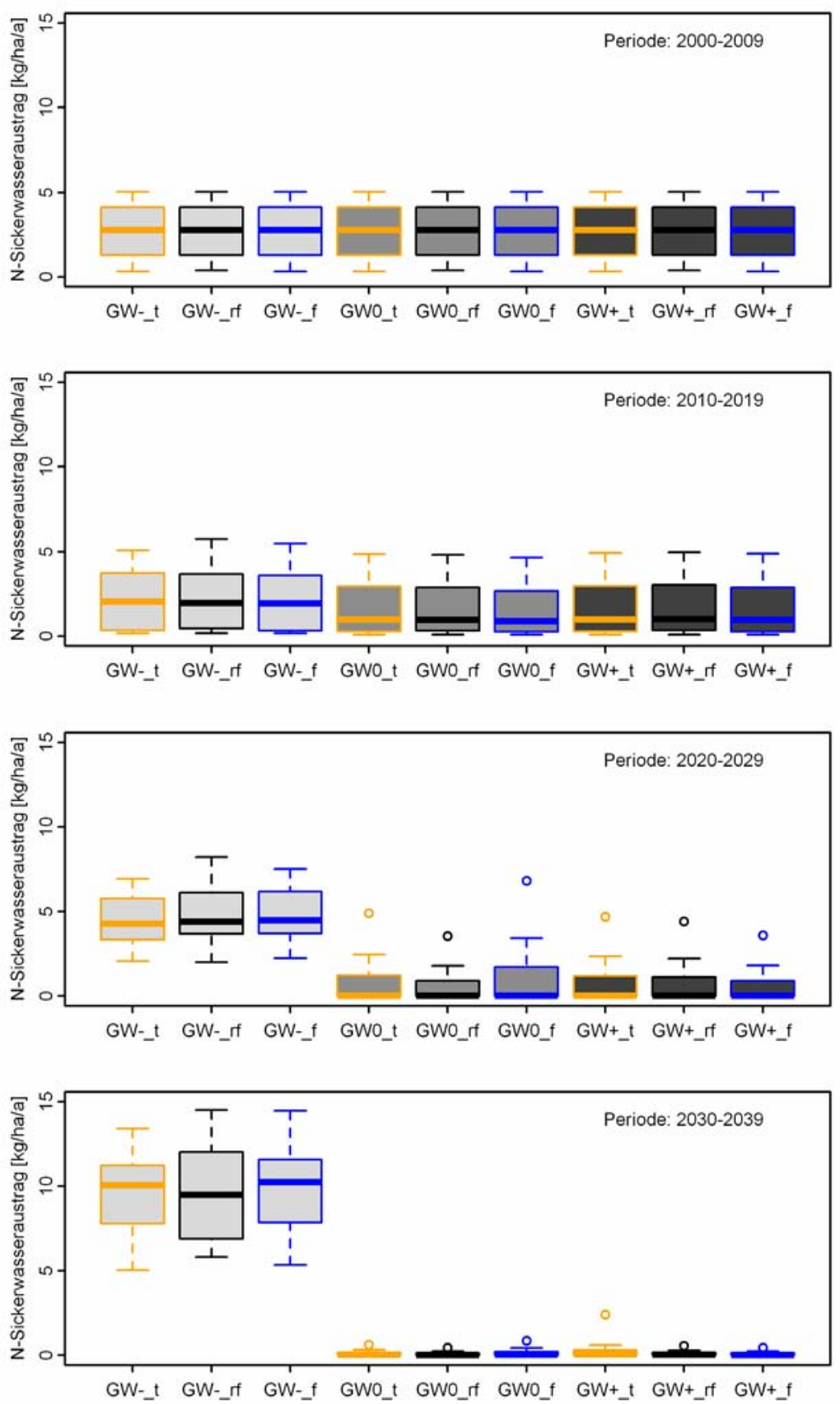

Abbildung 66: Einfluss der Grundwasser- und Klimaszenarien auf die N-Austräge [kg/ ha/ a] mit dem Sickerwasser am Beispiel einer ausgewäblten Buchenfläche (Fo A Langen, Abt. 18)

Beiträge aus der NW-FVA, Band 10, 2013 
In Abbildung 66 wird die ausgewählte Buchenfläche (FoA Langen, Abt. 18) hinsichtlich der Stickstoff-Austragsentwicklung untersucht. Die Simulationen zeigen einen erheblichen Anstieg der N-Austräge mit dem Sickerwasser bei allen drei Klimaszenarien im Zuge einer weiteren Absenkung des Grundwasserspiegels (GW-). In der Folge kommt es zu einem Abbau des Vorrats an organischer Substanz im Oberboden und entsprechend erhöhter N-Freisetzung. Bei gleichzeitig reduzierten Aufnahmeraten steht somit dem System ein Überschuss an Stickstoff zur Verfügung, der mit dem Sickerwasser aus dem Boden gewaschen wird.

Der Effekt einer veränderten Nutzungsintensität und Veränderungen der atmosphärischen Stoffeinträge auf die Stickstoffaufnahme werden in Abbildung 67 dargestellt.

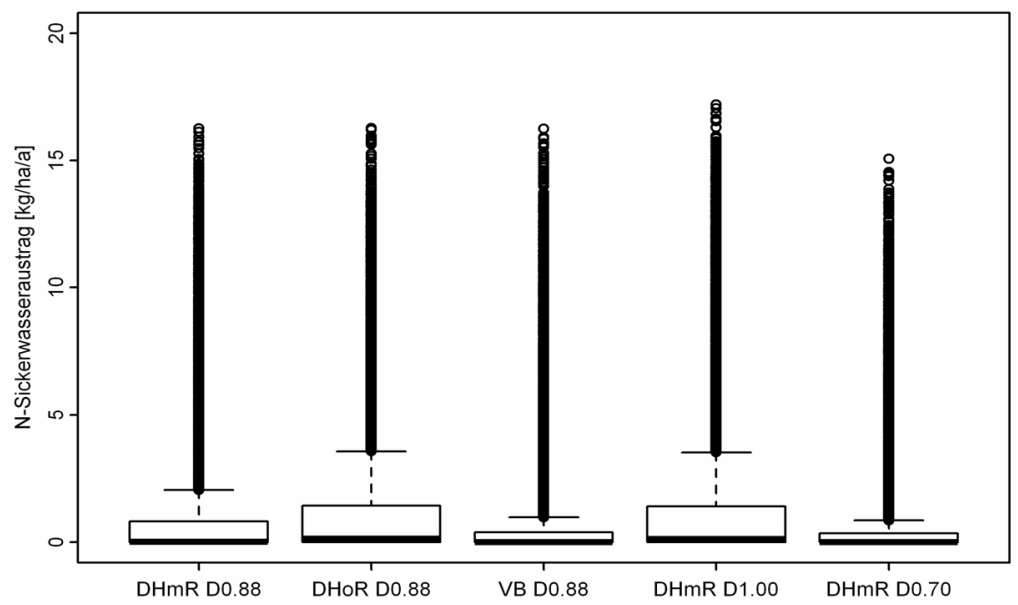

Abbildung 67: Einfluss unterschiedlicher Nutzungsintensitäten und $N_{X}-N$-Depositionen auf die $N$ Austräge [kg/hala] im Rhein-Main-Gebiet für die Periode 2030 - 2039 (DHmR: Derbholz mit Rinde, DHoR: Derbholz ohne Rinde, VB: Vollbaumnutzung, D: $\mathrm{NH}_{X^{-}}$ $\mathrm{N}$-Deposition. Die Zahl beschreibt den Anteil der aktuellen $\mathrm{NH}_{X^{-}} \mathrm{N}$-Deposition an der $\mathrm{NH}_{X}-\mathrm{N}$-Deposition des Berugsjabres 1990.)

Das Szenario DHoR D0.88 zeigt den Effekt einer verringerten Intensität (keine Rindennutzung) im Vergleich zur konventionellen Waldbewirtschaftung (Derbholz m. R.) für das Standardszenario der Waldentwicklung. Durch die veränderte Nutzungsintensität erhöht sich der N-Austrag mit dem Sickerwasser. Entsprechend beschreibt das Szenario der Vollbaumnutzung eine Verringerung der N-Austräge mit dem Sickerwasser. Eine entsprechende Reduktion der N-Austräge könnte auch durch eine weitere Reduktion der Deposition (Szenario: DHmR D0.70) erreicht werden. Das Szenario DHmR D1.00 beschreibt die Austragssituation unter der Annahme, dass die NHx-N-Deposition auf dem Niveau von 1990 geblieben wären. Insgesamt zeigen die Szenarien, dass neben einer Veränderung der atmo- 
sphärischen Belastungssituation auch durch die Nutzungsintensitäten (vgl. AHRENDS et al. 2010a) gezielt in den N-Kreislauf eingegriffen und Austragsspitzen minimiert werden können. Eine Erhöhung der Nutzungsintensität sollte jedoch nur auf Standorten durchgeführt werden, die aufgrund ihrer Ausstattung mit anderen Nährstoffen eine nachhaltige Waldbewirtschaftung zulassen. Aufgrund der aktuellen Belastungssituation im Untersuchungsgebiet erscheint jedoch ein sogenanntes „Stickstoffharvesting“ nicht notwendig.

\subsubsection{Evaluierung und Diskussion der Modellansätz̧e}

Um die Gültigkeit und Plausibilität der durchgeführten Simulationen zu prüfen, wurden im Folgenden die bodenchemischen Simulationsergebnisse realen Messungen an Bodenprofilen gegenübergestellt. Hierbei ist jedoch $\mathrm{zu}$ beachten, dass schon die kleinräumliche Variabilität der untersuchten Zielgrößen beachtlich sein kann (GRIGAL et al. 1991, BRUELHEIDE u. UDELHOVEN 2005, PENNE et al. 2010, SCHÖNING et al. 2006). So können durch Heterogenitäten des Ausgangsmaterials auf kleinstem Raum Austauscher- und Pufferbereich nebeneinander existieren. Entsprechend kann auf kleiner Fläche bei gleicher Bodentiefe die Basensättigung zwischen $>80 \%$ und $<15 \%$ schwanken (MALESSA et al. 2001). Eine entsprechende Variabilität wird im Untersuchungsgebiet natürlich durch das Vorkommen der Kalkanreicherungen in den Profilen verursacht. Die Abbildung 68 zeigt die kleinräumliche Variabilität anhand von 24 Bohrungen je Bestand auf den Monitoring-Flächen im Jägersburger Wald. Jede dargestellte Linie ist schon ein Mittelwert aus 4 Bohrungen. Entsprechend ist die tatsächliche Variabilität noch wesentlich höher.
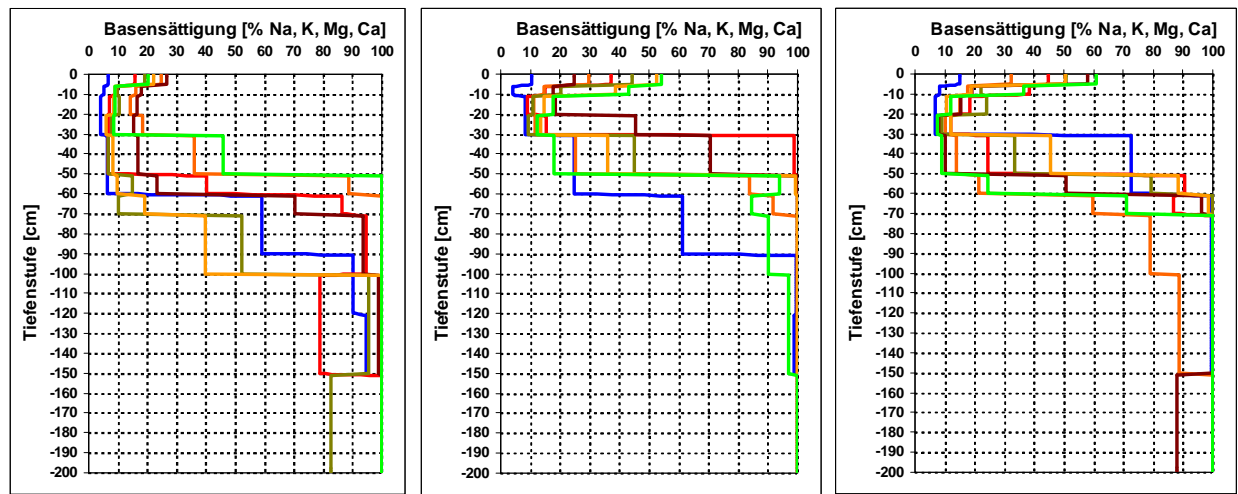

Abbildung 68: Kleinräumliche Variabilität der Basensättigung [\%] an den Intensivmonitoringflächen im Jägersburger W ald (links: Kiefer, Mitte: Eiche, rechts: Buche). Jede Linie beschreibt den Mittelwert aus 4 Bobrungen. 
Die Abbildung 69 vermittelt einen Eindruck von der Güte der durchgeführten Modellierungen. Aufgrund der hohen kleinräumlichen Variabilität sprechen besonders die unsystematischen Abweichungen um die 1:1-Linie für die Qualität und die Übertragbarkeit des verwendeten Modellansatzes auf das Untersuchungsgebiet. Der Einfluss der verfügbaren Bodeninformationen auf das Modellergebnis kann anhand der rechten Spalte in der Abbildung 69 bewertet werden.

Bei dieser Simulation wurden die Informationen für Bodenart, Lagerungsdichte, $\mathrm{C}_{\text {org }}$-Gehalt, Kalkgehalt und Horizontierung der BÜK 50 entnommen. Das Ergebnis dieser Auswertung zeigt die erwartete Reduzierung des Bestimmtheitsmaßes durch die Verwendung von kleinmaßstäblicheren Bodendaten. Dennoch ist die Übereinstimmung der geschätzten und der am Standort gemessenen Werte immer noch relativ gut.

Auch wenn gezeigt werden konnte, dass das Modellsystem die Basensättigung und das $\mathrm{C} / \mathrm{N}$-Verhältnis im Oberboden relativ gut abbilden kann, ist wegen beträchtlicher Kenntnislücken eine vollständige flächenhafte Bilanzierung des $\mathrm{N}$ Haushaltes der Waldökosysteme noch immer mit erheblichen Unsicherheiten behaftet. So kann beispielsweise die N-Gesamtdeposition in Wälder mit einem Fehler $\pm 30 \%$ (BuiLTJES et al. 2011) bestimmt werden. Insbesondere der Anteil der Trockendeposition an der Gesamtdeposition von Ammoniak ist unklar. Eine weitere unsichere Größe bei der N-Bilanzierung sind die gasförmigen N-Verluste. Auf gut durchlüfteten trockenen Sandböden sind die gasförmigen N-Emissionen vermutlich zu vernachlässigen. Demgegenüber sind sie auf tonhaltigen vernässten Standorten nur sehr schwer abschätzbar. Die größte Unsicherheit besteht jedoch in der langfristigen Dynamik des N-Speichers im Boden. Hierbei geht es vorwiegend um die Betrachtung der stabilen Fraktionen der organischen Substanz (JANDL et al. 2007), in der ein großer N-Anteil gespeichert wird. Dieses gilt insbesondere, wenn sich die Mineralisierungsbedingungen der organischen Substanz im Boden und besonders im Auflagehumus im Zuge des Klimawandels verändern. Die C- u. NAkkumulationsraten hängen entscheidend vom Abbaukoeffizienten der stabilen Kohlenstoffverbindungen ab. Der in dieser Untersuchung verwendete Standardwert von BONTEN et al. (2011a) wird in der Literatur auch durch die Untersuchungen von LISKI et al. (2005) und COUTEAUX et al. (1998) bestätigt. Neben der Abbaurate unter „Standardbedingungen“ ist insbesondere hinsichtlich der klimatischen Auswirkungen auch die Sensitivität der Abbaukoeffizienten infolge der Temperaturänderungen entscheidend (LISKI et al. 2005). Generell wird der Abbau von organischer Substanz in der Literatur immer noch sehr kontrovers diskutiert (Agren u. Bosatta 2002, Davidson et al. 2000, Giardina u. RYAN 2000, LISKI et al. 1999, THORNLEY u. CANNEL 2001). 

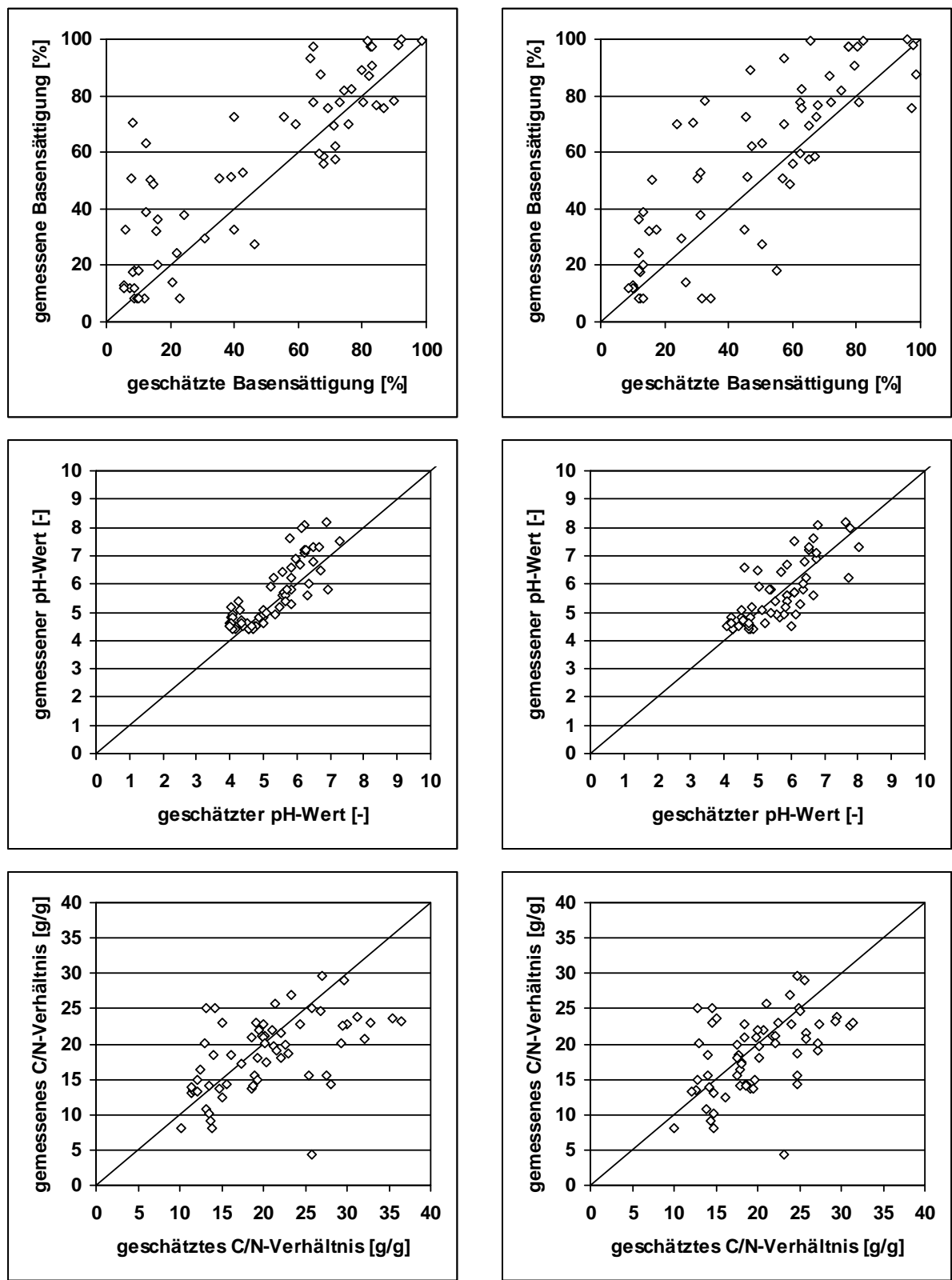

Abbildung 69: Beziehung zwischen geschätzter und gemessener Basensättigung (oben), pH-Wert der Bodenlösung (Mitte) und zwischen dem C/N-Verbältnis im Oberboden (unten). Die linke Spalte zeigt "reale" Bodenprofile und die rechte Spalte die Profile der BÜK $1: 50.000$. 
Weitere Problembereiche bestehen in der Kenntnis von Bestandesparametern, die bei diesem dynamischen Modellierungsansatz erforderlich sind. Die grundlegenden Informationen können zwar flächendeckend anhand von Forsteinrichtungsdaten abgeleitet werden, ihre Rekonstruktion und die Extrapolation in die Zukunft mit Hilfe von Waldwachstumsmodellen sind jedoch mit Unsicherheiten verbunden. So sind z. B. die Stickstoffeinträge durch die atmosphärische Deposition bei der Modellierung des Waldwachstums von zentraler Bedeutung. LAUBHANN et al. (2009) haben gezeigt, dass aus einer Erhöhung der N-Deposition um $1 \mathrm{~kg}$ pro Jahr und Hektar in Abhängigkeit von der Baumart eine Zunahme des Grundflächenzuwachses zwischen 1,2\% und 1,49\% resultiert. Diese veränderten Zuwachsraten wirken sich wiederum auf die Aufnahmeraten aus. Eine größere Rolle dürften jedoch die zahlreichen Bestandesausfälle aus der Vergangenheit spielen, die kaum oder gar nicht zu rekonstruieren sind.

\subsubsection{Bewertung der Standortsbedingungen}

Entsprechend der Dynamik und Komplexität der Wechselbeziehungen in Waldökosystemen wird im Folgenden eine dynamische Standortsbewertung vorgestellt, die Veränderungen der $\mathrm{C} / \mathrm{N}$-Verhältnisse, der Basensättigung und der aktuellen Kationenaustauschkapazität in Abhängigkeit vom pH-Wert berücksichtigt.

Für die Darstellung werden die bodenchemischen Kennwerte bis in eine Profiltiefe von einem Meter herangezogen. Dieses Vorgehen ist als eine konservative Abschätzung anzusehen. Eine bessere Einstufung der Standorte, die z. B. in zwei Metern Tiefe über Rheinweiss-Vorkommen verfügen, macht sicherlich für Altbestände Sinn. Es muss jedoch auch beachtet werden, dass Jungbestände bis zu 45 Jahre brauchen, um mit ihrem Wurzelwerk in diese Tiefen vorzudringen (CZAJKOWSKI et al. 2009). Der Vergleich mit der herkömmlichen Standortskartierung zeigt zunächst, dass generell ähnliche Regionen und Bereiche von beiden Verfahren ausgewiesen werden (s. Abb. 70 und 72). Die dynamische Standortsbewertung weist jedoch einen wesentlich höheren Detaillierungsgrad auf. Inwieweit dieser auch inhaltlich gerechtfertig ist, wurde anhand der Standortsbewertungen von über 400 Profilen aus der „Zimmermannkartierung“ (ZIMMERMANN 1956) und der Baumartenverteilung im Untersuchungsgebiet überprüft.

Hinsichtlich der Nährstoffsituation können neben der ,klassischen“ Standortsbewertung mit dem vorgestellten Modellsystem auch die Auswirkungen von veränderten Bewirtschaftungsstrategien und die Schutzfunktion der Wälder für das Grundwasser untersucht werden. 


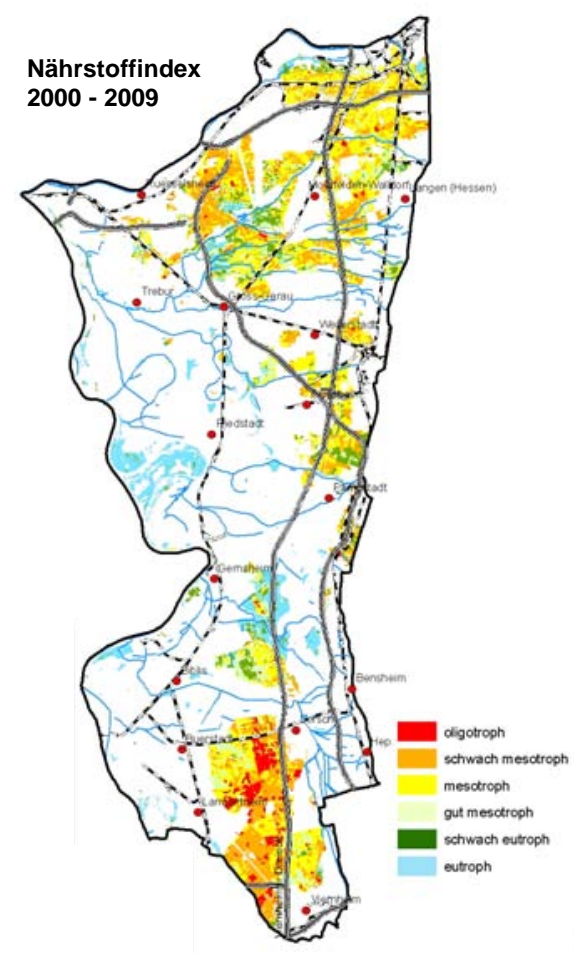

Abbildung 70: Regionalisierung des Nährstoffstatus im Rhein-Main-Gebiet für die Periode 2000 bis 2009

\subsection{Erfahrungswissen der Forstämter}

\subsubsection{Waldbestandsverbältnisse}

Von den Revierleitern wurden insgesamt 173 Bestände der drei Hauptbaumarten Eiche, Buche und Kiefer gemeldet (s. Kap. 2.2.11.1). Die Altersspanne reichte von 15 bis 234 Jahre. Auch wenn eine statistische Absicherung der Umfrageergebnisse nicht möglich war, lassen sich dennoch einige charakteristische Trends hinsichtlich der Einschätzung des Waldzustandes aufzeigen. Einen ersten Eindruck vermittelt die Tabelle 41. Die Systematik der Umfrage hätte eine vergleichbare Anzahl vitaler und geschädigter gemeldeter Bestände erwarten lassen. Tatsächlich wurden aber nicht selten beide Kategorien in unterschiedlicher Häufigkeit gemeldet. So überwog in der jüngeren Altersstufe mit 61 Prozent die Anzahl vitaler Bestände, während von den älteren Beständen nur noch 34 Prozent als „,besonders vital“ eingeschätzt wurden. 
Tabelle 41: Anzabl der in der Umfrage gemeldeten „besonders vitalen" bžw. „stark geschädigten“ Bestände

\begin{tabular}{ccc}
\hline Bis 60 Jahre & besonders vital & stark geschädigt \\
\hline Eiche & 14 & 7 \\
Buche & 3 & 3 \\
Kiefer & 18 & 12 \\
\hline Summe & 35 & 22 \\
\hline Über 60 Jahre & besonders vital & stark geschädigt \\
\hline Eiche & 10 & 29 \\
Buche & 12 & 32 \\
Kiefer & 17 & 77 \\
\hline Summe & 39 &
\end{tabular}

Im Jahr 2007 wiesen sechs der gemeldeten Bestände einen gesicherten Grundwasseranschluss auf (Grundwasserstand bis 2,50 Meter unter Flur) und wurden unabhängig vom Bodensubstrat als „besonders vital“ angesprochen.

Die Unterteilung der grundwasserferneren Bestände in Altersstufen, Bodensubstratgruppen und Geländewasserhaushalt ergab folgende Trends:

Jüngere Bestände (bis 60 Jahre):

Alle gemeldeten Bestände auf verlehmten, frischen Standorten wurden unabhängig von der Baumart als vital eingeschätzt.

Auf den Sanden und lehmigen Sanden entfielen bei Eiche und Kiefer etwa 60 Prozent der Meldungen auf vitale Bestände. Bei der Buche war auf den besseren Sanden mit frischem Geländewasserhaushalt das Verhältnis ausgeglichen. Auf mäßig frischen, reinen Sanden waren alle aufgeführten Bestände stark geschädigt.

Ältere Bestände (> 60 Jahre):

Auf verlehmten Standorten wurden nur Eichen und Buchen gemeldet. Bei sehr guter Wasserversorgung (feucht) waren diese Bestände vital. Dagegen war auf frischen und wechselfeuchten/-trockenen Standorten das Verhältnis ausgeglichen.

Auf den Sanden und lehmigen Sanden war bei allen drei Baumarten der Anteil geschädigter Bestände größer als der Anteil vitaler Bestände. Mit sich verbessernder Wasserversorgung nahm die Vitalität der Bestände zu. Bei der Buche fanden sich auf den reinen Sanden kaum noch vitale Bestände.

Ergänzend wurde im Waldzustandsbericht 2007 der ungünstige Zustand der Baumkronen im Vergleich zum Landesdurchschnitt mit anhaltend erhöhter Kronenverlichtung belegt. So wurde u. a. für ältere Eichen eine mittlere Kronenverlichtung von 46 Prozent angegeben. Der Anteil an stark geschädigten Bäumen 
mit einer Kronenverlichtung von mehr als 60 Prozent und damit einem erhöhten Absterberisiko ist für Eiche seit 1984 von 0,4 auf 20 Prozent im Jahr 2007 angestiegen.

\subsubsection{Waldverjüngung}

Die wesentlichen Hemmnisse für die Waldverjüngung im Hessischen Ried waren und sind die Faktoren Vergrasung, Maikäferfraß sowie verdämmende Begleitvegetation (z. B. Brombeere oder Calamagrostis) und die sich immer stärker ausbreitende Spätblühende Traubenkirsche, die in mehreren natürlichen Altersstufen flächig vertreten ist. Darüber hinaus spielte der Verbiss durch Schalenwild eine nicht unerhebliche Rolle und ist zumindest lokal immer noch von größerer Bedeutung.

Die Auswertung früherer Aufnahmen (PRIES et al. 1999) ergab, dass Waldbestände mit einem Bestockungsgrad von $<0,3$ i. d. R. unabhängig von der Baumart nahezu vollständig vergrast waren. Mit zunehmendem Deckungsgrad nahm die Tendenz zur Vergrasung kontinuierlich ab und war ab einem Bestockungsgrad über 0,85 normalerweise vernachlässigbar gering. Eine Ausnahme bildete die Kiefer, die auch in älteren, voll bestockten Beständen häufig eine Grasdecke aufwies. Die zunehmende Auflichtung der Bestände hat die Vergrasungssituation bis heute noch deutlich verschärft und wurde deshalb differenziert bei der Modellierung des Wasserhaushaltes berücksichtigt.

Aufgrund der Verjüngungshemmnisse sowie der Vielfalt der waldbaulichen Ausgangssituationen wurde bei den Waldverjüngungsmaßnahmen ein sehr differenziertes Vorgehen favorisiert. Die verschiedenen Verjüngungsarten Naturverjüngung, Saat und Pflanzung wurden daher häufig nach- oder miteinander kombiniert. Des Weiteren wurden zur Risikostreuung Baumartenmischungen bevorzugt. Neben Kiefer, Eiche, Buche, Winterlinde, Hainbuche und den Edellaubhölzern wurden zunehmend die trockenheitstoleranten Baumarten Douglasie und Roteiche integriert. Die Stieleiche wurde aufgrund ihrer weiteren ökologischen Amplitude und ihrer geringeren Spätfrostgefährdung gegenüber der Traubeneiche bevorzugt. Charakteristisch für alle Verjüngungsmaßnahmen war, dass eine intensive Bodenbearbeitung zur Sicherung des Verjüngungserfolges nahezu durchweg erforderlich erscheint.

Betrachtet man die Verjüngungsaktivitäten der Jahre 1997 bis 2007 in den staatlichen Forstämtern, so wurden auf einer Fläche von 1.535 Hektar Naturverjüngungen, Saaten und Pflanzungen durchgeführt (s. Abb. 71). Dabei entfielen jeweils rund 20 Prozent der verjüngten Fläche auf Eiche, Buche, Edellaubhölzer, Kiefer und sonstige Baumarten (Roteiche, Douglasie, Weichlaubhölzer und sonstige Nadelhölzer). In größerem Ausmaß natürlich verjüngt wurden Buche und Kiefer mit Flächenanteilen von knapp 50 bzw. rund 30 Prozent. Auffallend war 
der hohe Anteil an Nachbesserungen. Mit über 500 Hektar an Ergänzungspflanzungen wird deutlich, dass gut ein Drittel der Verjüngungsflächen von Ausfällen betroffen war. Häufig wurden misslungene Buchen- und Eichenkulturen durch Roteiche, Douglasie oder Kiefer ersetzt.

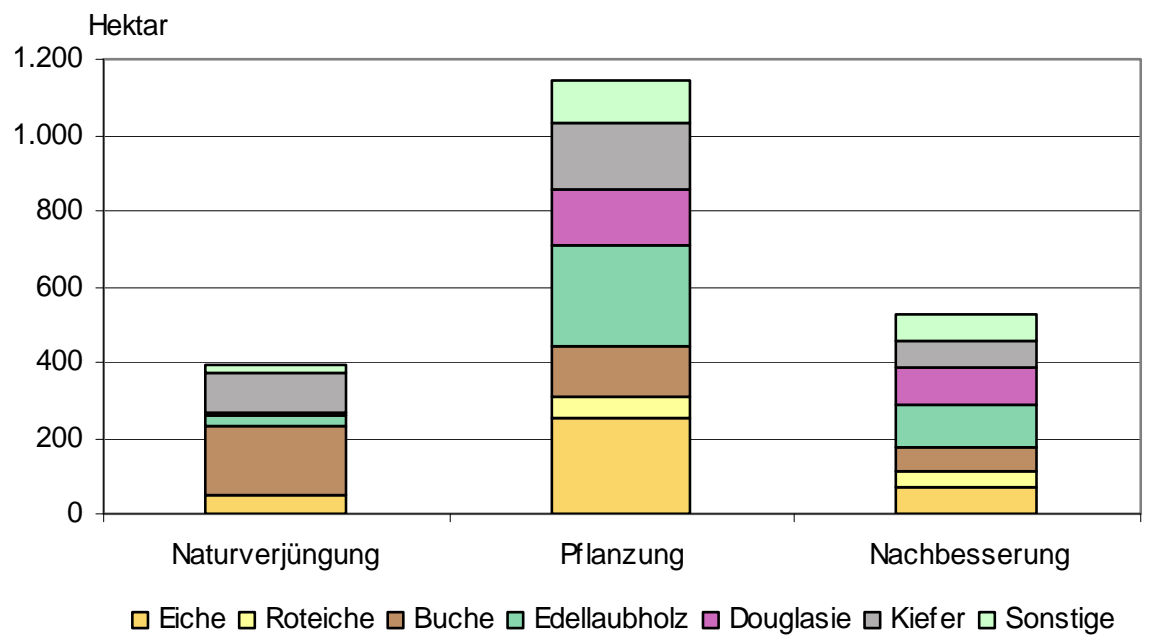

Abbildung 71: Verjüngungsaktivitäten [ha] der staatlichen Forstämter in den Jahren von 1997 - 2007

Über 75 Prozent der Waldverjüngungsmaßnahmen wurden auf Teilflächen mit geringer ( $<1 \mathrm{ha}$ ) oder sehr geringer Flächengröße $(<0,5 \mathrm{ha})$ durchgeführt. Großpflanzen, wie sie nach den Stürmen 1990/1991 auch auf größeren Flächen zum Einsatz kamen, wurden nur noch ausnahmsweise verwendet. Der Anteil der Saaten war mit rund 2 Prozent bislang noch gering, dabei waren die bisherigen Erfahrungen mit Stieleiche und Roteiche aber Erfolg versprechend.

\subsection{Auswirkungen auf die waldbaulichen Potenziale}

\subsubsection{Veränderung der Standortstypen}

\subsubsection{Ausgangssituation 2007}

Die Angaben zu den Frischestufen (s. Tab. 42) der Waldstandorte des Hessischen Rieds sind das Ergebnis der Auswertung der regionalisierten Bodenkarte und der klimatischen Wasserbilanz. Danach liegt der Schwerpunkt der Wasserversorgung der Waldstandorte im Hessischen Ried derzeit mit relativ gleichen Anteilen von jeweils rund 30 Prozent in den Frischestufen sehr hoch und hoch, gefolgt von der Frischestufe mäßig, die knapp ein Viertel ausmacht. Die Frischestufe F4 (gering) nimmt nur einen kleinen Flächenanteil ein, die Stufe F5 (sehr gering) kommt nicht vor. 
Auf den knapp fünf Prozent wechseltrockenen Standorten verursacht eine hoch anstehende Stauschicht einen scharfen Wechsel zwischen kürzeren Nassphasen und länger anhaltender Austrocknung dieser Böden. Sie werden dadurch zu sogenannten Eichenzwangsstandorten, da diese Baumart an solche extremen Schwankungen in der Wasserversorgung am besten angepasst ist und auch stärker verdichtete Schichten zu durchwurzeln vermag.

Tabelle 42: $\quad$ Flächenanteile [\%] der Waldstandorte im Jahre 2007 nach Trophie und Frischestufe (in Klammern absolute Flächenanteile [ha])

\begin{tabular}{|c|c|c|c|c|c|c|c|c|}
\hline $\begin{array}{r}\begin{array}{r}\text { Frische- } \\
\text { stufe }\end{array} \\
\text { Trophie }\end{array}$ & $\begin{array}{l}\text { nass } \\
\text { GW1 }\end{array}$ & $\begin{array}{c}\text { feucht/ } \\
\text { wechsel- } \\
\text { feucht } \\
\text { GW2/SW1 }\end{array}$ & $\begin{array}{c}\text { wechsel- } \\
\text { trocken } \\
\text { SW2 }\end{array}$ & $\begin{array}{l}\text { sehr } \\
\text { hoch } \\
\text { F1 } \\
\end{array}$ & $\begin{array}{c}\text { hoch } \\
\text { F2 }\end{array}$ & $\begin{array}{c}\text { mäßig } \\
\text { F3 }\end{array}$ & $\begin{array}{c}\text { gering } \\
\text { F4 }\end{array}$ & Summe \\
\hline eutroph & $\begin{array}{c}0,2 \\
(50)\end{array}$ & $\begin{array}{c}4,4 \\
(1.227)\end{array}$ & $\begin{array}{c}2,4 \\
(668)\end{array}$ & $\begin{array}{c}13,3 \\
(3.693)\end{array}$ & $\begin{array}{c}7,8 \\
(2.156)\end{array}$ & $\begin{array}{c}1,2 \\
(321)\end{array}$ & $\begin{array}{l}0,1 \\
(16)\end{array}$ & $\begin{array}{c}29,4 \\
(8.130)\end{array}$ \\
\hline $\begin{array}{l}\text { meso- } \\
\text { troph }\end{array}$ & $\begin{array}{c}0,1 \\
(18)\end{array}$ & $\begin{array}{c}3,4 \\
(935)\end{array}$ & $\begin{array}{c}2,2 \\
(605)\end{array}$ & $\begin{array}{c}16,1 \\
(4.441)\end{array}$ & $\begin{array}{c}19 \\
(5.267)\end{array}$ & $\begin{array}{c}20,9 \\
(5.779)\end{array}$ & $\begin{array}{c}3,1 \\
(852)\end{array}$ & $\begin{array}{c}64,7 \\
(17.897)\end{array}$ \\
\hline $\begin{array}{l}\text { oligo- } \\
\text { troph }\end{array}$ & 0 & 0 & 0 & $\begin{array}{c}0,5 \\
(147)\end{array}$ & $\begin{array}{c}3,9 \\
(1.090)\end{array}$ & $\begin{array}{c}1,4 \\
(380)\end{array}$ & $\begin{array}{l}0,1 \\
(15)\end{array}$ & $\begin{array}{c}5,9 \\
(1.632)\end{array}$ \\
\hline Summe & $\begin{array}{l}0,3 \\
(68)\end{array}$ & $\begin{array}{c}7,8 \\
(2.162)\end{array}$ & $\begin{array}{c}4,6 \\
(1.273)\end{array}$ & $\begin{array}{c}29,9 \\
(8.281)\end{array}$ & $\begin{array}{c}30,6 \\
(8.513)\end{array}$ & $\begin{array}{c}23,5 \\
(6.480)\end{array}$ & $\begin{array}{c}3,3 \\
(883)\end{array}$ & $\begin{array}{c}100 \\
(27.659)\end{array}$ \\
\hline
\end{tabular}

Die feuchten und die nur gering vertretenen nassen Standorten stellen rund ein Drittel der rund 18 Prozent Waldflächen dar, die gegenwärtig noch sicheren Grundwasseranschluss besitzen. Die übrigen Standorte mit tiefer anstehendem, aber noch gut wurzelerreichbarem Grundwasser (Flurabstand zwischen 1,50 m und 2,50 m) sind in der Frischestufe F1 (sehr hoch) enthalten.

Damit ergibt sich im Vergleich zu den Angaben der Geländewasserhaushaltsstufen in den Forsteinrichtungsdaten, die einen deutlichen Schwerpunkt im mäßig frischen Bereich ausweisen, eine systematische Verschiebung zum Besseren. Sie ist vor allem auf eine bessere Einschätzung der Sandstandorte gemäß der aktuellen Kartieranleitung zurückzuführen, wobei hierdurch ggf. eine Überschätzung der nFK der Sandstandorte erfolgte.

Nach der Trophie überwiegen mit einem Flächenanteil von fast zwei Dritteln die Standorte mittlerer Nährstoffversorgung. Knapp 30 Prozent der Standorte sind eutroph und nur sechs Prozent der Waldstandorte sind oligotroph. Damit weichen die Flächenbilanzen der Trophiestufen nach der Auswertung der regionalisierten Bodenkarte kaum von den in den Forsteinrichtungsdaten enthaltenen Angaben ab. 
Die flächenmäßig bedeutendste, auf ca. 21 Prozent der Fläche vorkommende Standortseinheit in der Kombination von Trophie und Wasserversorgung stellen die mesotrophen Standorte mit der Frischestufe F3 (mäßig) dar. Fast ebenso groß ist der Anteil der Frischestufe F2 (hoch) in derselben Trophiestufe. Zusammen mit den nächst bedeutenden Kombinationen der Frischestufe F1 (sehr hoch) mit sehr guter bzw. mittlerer Nährstoffversorgung und den eutrophen Standorten in der Frischestufe F2 sind bereits rund 80 Prozent der Waldstandorte des Hessischen Rieds charakterisiert.

Standorte der Frischestufe F1 (sehr hoch) gibt es verbreitet im Bereich des Mönchbruchs sowie nördlich daran anschließend zwischen der A 67 und der Startbahn West des Frankfurter Flughafens. Größere Teile des Mönchbruchs haben noch einen ausgeprägten Grundwasseranschluss und sind deshalb sogar als feuchte bzw. wechselfeuchte Standorte charakterisiert. Weitere Flächenschwerpunkte grundwasserbeeinflusster bzw. Standorte der Frischestufe F1 befinden sich in der Kühkopf-Knoblochsaue und in Teilen des Jägersburger Waldes. Aufgrund ihrer Tiefgründigkeit und gewisser Lehm- und Schluffanteile sind auch die südlichen und östlichen Teile der Viernheimer Heide derzeit in die Frischestufe F1 eingestuft. Die Standorte der Frischestufen F3 und F4 konzentrieren sich im Norden und Nordosten des Untersuchungsgebietes (Stadtwald Frankfurt, Bereich Kelsterbach und Forstamt Langen). Hier handelt es sich im Wesentlichen um sandige Substrate geringer Wasserhaltefähigkeit über Schotter bzw. Kies. Eine Besonderheit auf größeren Flächenanteilen des Jägersburger Waldes sind die wechseltrockenen Standorte. Der Großteil der restlichen Waldstandorte fällt in die Frischestufe F2 (s. Abb. 75).

Neben den Gebieten der dominierenden mesotrophen Standorte kommen Bereiche mit davon abweichender Nährstoffausstattung auffallend räumlich konzentriert vor (s. Abb. 72). Eutrophe Standorte bestimmen die Kühkopf-Knoblochsaue, wesentliche Teile des Mönchbruchs, Bereiche des Gernsheimer, Jägersburger und Bürstädter Waldes sowie Flächen östlich der A5 bei Seeheim. Die geringer verbreiteten oligotrophen Standorte sind vor allem Teilen des Lorscher Waldes und der Viernheimer Heide zwischen Lampertheim und Viernheim zuzuordnen.

Die aktuell besten Waldstandorte des Hessischen Rieds mit der Kombination sehr guter Nährstoffausstattung und feuchter bzw. sehr hoher Frischestufe sind demnach Teile des Mönchbruchs, der Kühkopf-Knoblochsaue sowie Teile des Gernsheimer und Jägersburger Waldes, letztere allerdings mit Abstrichen, da Grundwasserabsenkungen der Vergangenheit Einschränkungen in der Wasserverfügbarkeit z. B. durch Wechseltrockenheit bedingen 


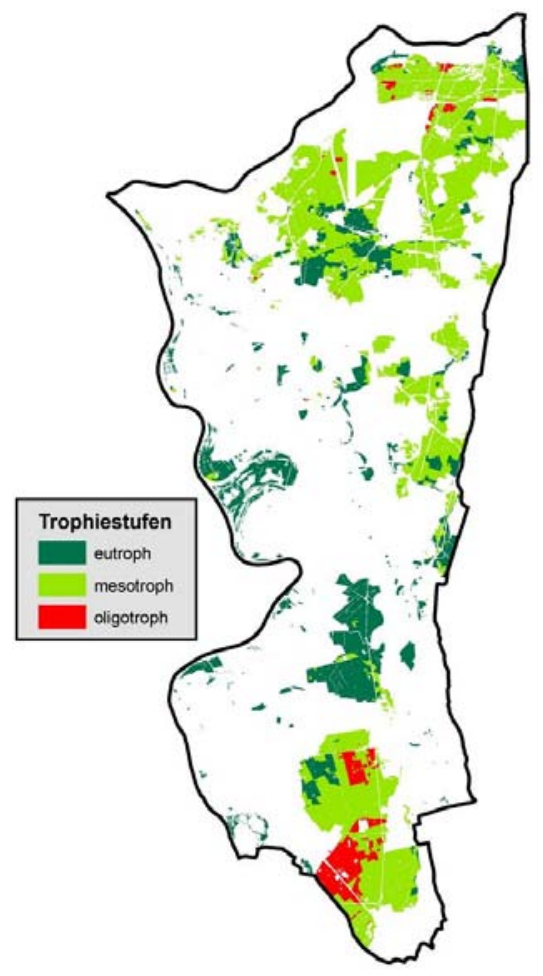

Abbildung 72: Nährstoffversorgung der Waldstandorte im Hessischen Ried im Jahr 2007

\subsubsection{Veränderung der Frischestufen}

In Abhängigkeit von den unterstellten kombinierten Grundwasser- und Klimaszenarien führen Simulationen bis zur Dekade 2040 - $2050 \mathrm{zu}$ teilweise erheblichen Veränderungen des pflanzenverfügbaren Wassers (s. Abb. 73 u. 74). Der im Anschluss an den Berechnungszeitraum der Waldentwicklungsszenarien gelegene Zeitbezug wurde gewählt, da ab hier im verwendeten Klimaszenario A1B eine deutlich stärkere Dynamik hinsichtlich der Temperatur- und Niederschlagsänderung einsetzt. Diese Entwicklung war bei der langfristigen Entscheidung über Waldentwicklungsziele, die an zu erwartende Veränderungen am besten angepasst sind, unbedingt einzubeziehen.

Unabhängig von den unterstellten Klimaszenarien nimmt der Anteil grundwasserbeeinflusster Standorte bei einer Anhebung des Grundwasserspiegels auf den Stand von 1951 deutlich zu. Statt bislang 18 Prozent hätten hiernach 37 Prozent der Waldfläche einen gesicherten Grundwasseranschluss, was einer Zunahme um etwa 5.000 Hektar entspricht. Dagegen führt die maximale Ausnutzung des Grundwasserbewirtschaftungsplanes, wie sie im Szenario GW- unterstellt wird, klimaunabhängig zu einer Reduzierung der Flächen mit sicherem Grundwasser- 
anschluss um 2.660 Hektar auf einen Anteil von 9,2 Prozent der Waldflächen (s. Tab. 43).

Tabelle 43: Relative Flächenanteile [\%] mit und ohne sicherem Grundwasseranschluss (Grundwasserstand $<2,5$ m unter Flur) bei den drei verschiedenen Grundwasserszenarien

\begin{tabular}{ccc}
\hline Szenario & $\begin{array}{c}\text { mit sicherem } \\
\text { Grundwasseranschluss [\%] }\end{array}$ & $\begin{array}{c}\text { ohne sicheren } \\
\text { Grundwasseranschluss [\%] }\end{array}$ \\
\hline GW+ & 37,0 & 63,0 \\
GW0 & 18,8 & 81,2 \\
GW- & 9,2 & 90,8 \\
\hline
\end{tabular}

Die terrestrischen Standorte machen unabhängig vom Grundwasserszenario immer den weit überwiegenden Teil der Waldstandorte im Hessischen Ried aus. Standorte, die entweder bereits seit 1950 keinen sicheren Grundwasseranschluss hatten oder diesen im Rahmen der Simulationen verlieren, weisen eine auffällige klimasensitive Veränderung des Wasserhaushaltes auf. Das Ausmaß der Verschiebungen der Flächenanteile innerhalb der verschiedenen Frischestufen differiert zwischen den Klimaszenarien erheblich (s. Abb. 73).

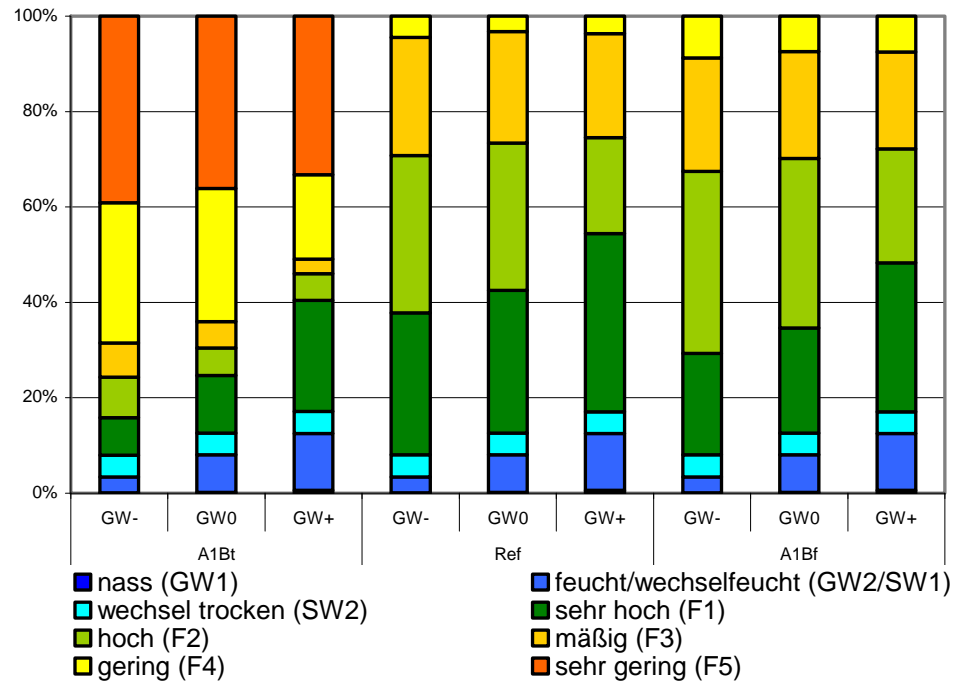

Abbildung 73: Relativer Flächenanteil [\%] der Frischestufen in Abhängigkeit von den Grundwasserund Klimaszenarien für die Dekade 2040 - 2050 (Szenario GW0/Ref entspricht den Verbältnissen 2007)

Bezogen auf den Ausgangszustand im Jahr 2007 (entspricht dem Szenario GW0/ Ref) sind die Veränderungen in den Szenarien mit trockener Klimaausprägung besonders augenfällig. Bei einer klimatischen Wasserbilanz von rund $-200 \mathrm{~mm}$ in der Vegetationszeit verschlechtern sich dann bis zum Ende des Simulationszeit- 
raumes die meisten Standorte der bislang sehr hohen, hohen und mäßigen Frischestufen. Es überwiegen die Standorte der geringen und sehr geringen Frischestufen, die im Szenario GW-/A1Bt rund 70 Prozent der Gesamtfläche ausmachen (s. Abb. 74).

Dagegen weisen die übrigen Szenarien gegenüber dem Basis-Jahr 2007 unabhängig vom Klima vergleichsweise moderate Differenzierungen auf. Die Veränderungen der Flächen der Frischestufen variieren lediglich in einer Spanne von rund 10 Prozent. Unter diesen Rahmenbedingungen treten Standorte der Frischestufe F5 nicht und solche der Stufe F4 in nur sehr begrenztem Umfang auf (s. Abb. 74).

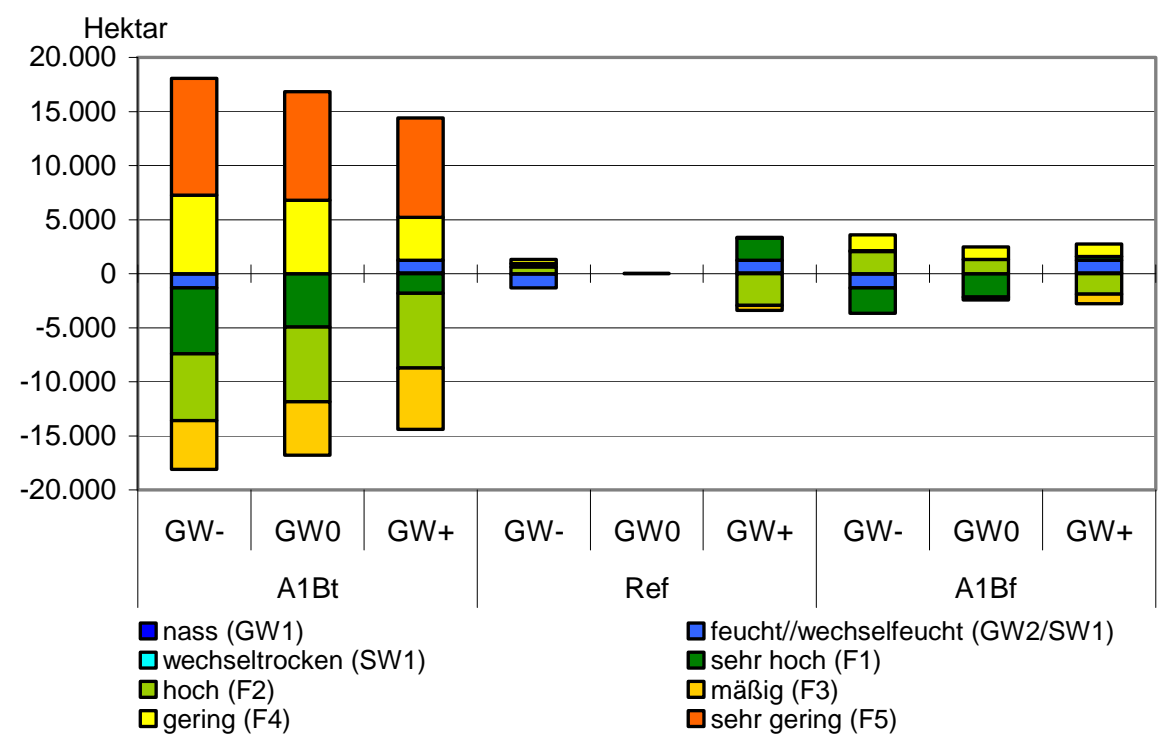

Abbildung 74: Flächenveränderungen [ha] der Frischestufen in Abhängigkeit von den Grundwasser-und Klimaszenarien

Sehr anschaulich wird die szenariobedingte Variation der Veränderungen der Frischestufen in der Betrachtung ihres räumlichen Ausmaßes und ihrer Verteilung am Beispiel des feuchten Szenarios GW+/A1Bf und des trockensten Szenarios GW-/A1Bt (s. Abb. 75). Im feuchten Szenario verbleibt ein großer Teil der Waldstandorte in den Frischestufen F2 und F3. Für größere Bereiche des Gernsheimer, Jägersburger und Bürstädter Waldes würde sich durch die Wiederherstellung des sicheren Grundwasseranschlusses unabhängig vom Klima eine Verbesserung hin zur Stufe F1 ergeben. Größere Verschlechterungen der Wasserversorgung würden sich nur für Bereiche der Viernheimer Heide ergeben. Dagegen gibt es im trockensten Szenario kaum noch Standorte in der hohen Frischestufe (F2). Feuchte Standorte und die Frischestufe F1 finden sich nur noch im Bereich des Mönchbruchs aufgrund des noch bestehenden Grundwasseranschlusses. Trockene Standorte würden im Norden, im Westen um Darmstadt und um Lampertheim dominieren, 
der größte Teil der Standorte im Süden wäre in der Frischestufe mäßig (F3). Dramatische Verschlechterungen um bis zu drei Frischestufen sind nicht selten.

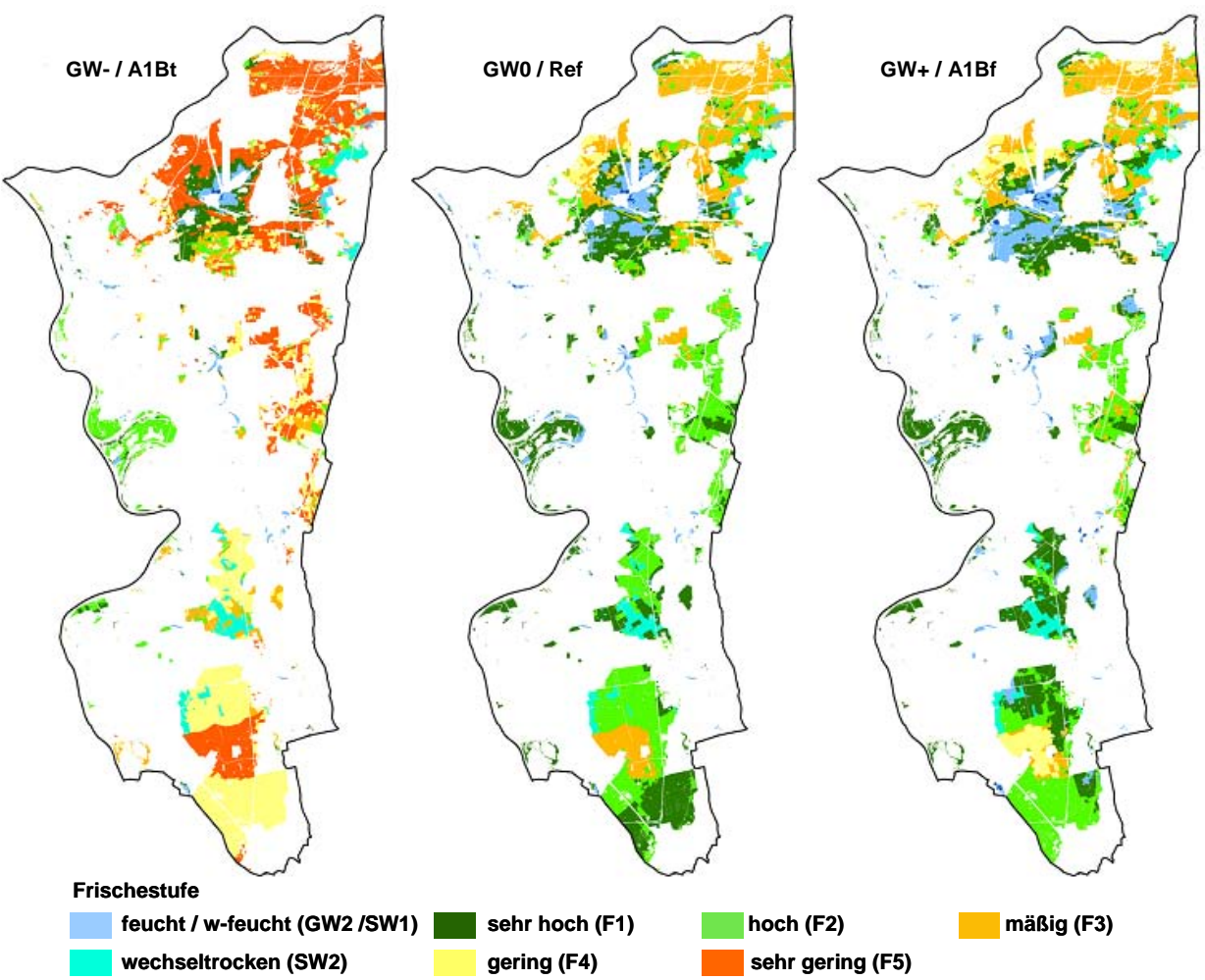

Abbildung 75: Frischestufen 2007 (Mitte, entspricht Szenario GW0/Ref) verglichen mit den Szenarien $G W-/ A 1 B t$ (links) und GW+/A1Bf (rechts) für die Dekade 2040 bis 2050

Ein standortgerechter Waldbau erfordert bei einer Veränderung des Standortes zwangsläufig auch eine Anpassung der waldbaulichen Zielsetzung. Durch die Anwendung der Waldbau-Regelsets (s. Kap. 2.2.11.2) führen die standörtlichen Veränderungen je nach Szenario zu waldbaulichen Anpassungsmaßnahmen u. a. hinsichtlich des angestrebten Waldentwicklungstyps, der Zielstärke und der Grundflächenhaltung. Da die Nährstoffausstattung der Standorte für den betrachteten Zeitraum einer vergleichsweise geringeren Beeinflussung unterliegt, wird die Entwicklung des Faktors „pflanzenverfügbares Wasser" so zu einer zentralen Frage. 


\subsubsection{Veränderungen der Waldstruktur}

\subsubsection{Baumartenverteilung}

\subsection{Ausgangssituation 2007}

Ein wesentliches Merkmal zur Beschreibung von Wäldern ist ihre Baumartenausstattung. Das wirtschaftliche Augenmerk liegt dabei i. d. R. auf der Baumart, die im Bestandesgefüge mit dem größten Mischungsanteil vertreten ist. Eine Auswertung der Bestandesklassen weist für die Kiefernbestandesklasse einen Flächenanteil von 40 Prozent an der Waldfläche des Hessischen Rieds auf (s. Tab. 44). Der hohe Kiefernanteil ist sowohl standörtlich bedingt durch den hohen Anteil grundwasserferner Sandstandorte als auch durch vorrangige Verwendung der Kiefer bei den großflächigen Wiederaufforstungen nach dem zweiten Weltkrieg. Der Anteil von 22,5 Prozent Buchenbestände ist Ausdruck der hohen Konkurrenzkraft dieser Baumart auf den besser wasserversorgten Standorten, wo sie in viele Kiefern- und Eichenbestände zunächst als Unterbau eingebracht wurde, sich durchgesetzt hat und vielfach schon vorverjüngt ist. Dadurch sind nach dieser Auswertung auch Bestände, deren wirtschaftliches Schwergewicht ursprünglich auf Kiefer oder Eiche lag, mittlerweile als der Bestandesklasse Buche zugehörig zu klassifizieren.

Tabelle 44: $\quad$ Anteil [\%] und Fläche [ba] der Bestandesklassen im Jahr 2007

\begin{tabular}{lcccccccc}
\hline Bestandesklasse & Ei & Bu & ELB & WLB & Fi & Dgl & Ki & Lä \\
\hline $\begin{array}{l}\text { Anteil der } \\
\text { Bestandesklasse [\%] }\end{array}$ & 21,9 & 22,5 & 6,3 & 6,8 & 0,8 & 1,3 & 40 & 0,3 \\
\hline $\begin{array}{l}\text { Fläche der } \\
\text { Bestandesklasse [ha] }\end{array}$ & 6.065 & 6.235 & 1.752 & 1.878 & 217 & 370 & 11.054 & 89 \\
\hline
\end{tabular}

Auch bei einer Betrachtung der Baumartenzusammensetzung nach Baumartengruppen in der Hauptschicht dominiert hier mit einem Flächenanteil von fast 40 Prozent ebenfalls die Kiefer, die Eiche kommt auf 23 Prozent und die Buche erreicht danach nur 20 Prozent (s. Abb. 76). Edel- und Weichlaubbäume nehmen zusammen immerhin 15 Prozent ein, während andere Nadelbaumarten wie Fichte, Lärche und Douglasie kaum ins Gewicht fallen. 


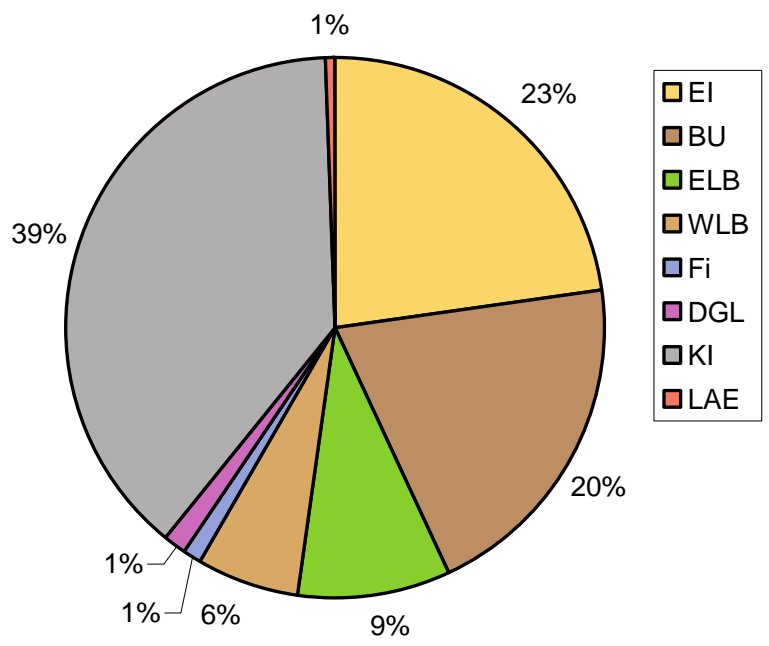

\section{Abbildung 76: Flächenanteile [\%] der Baumartengruppen in der Hauptschicht}

Während ein Unterstand mit geringeren Deckungsgraden großflächig vorhanden ist, kommt ein stammzahlreicher und für die weitere Bestandesentwicklung bedeutsamer Unterstand, der mindestens ein Drittel der Bestandesfläche überschirmt, nur auf rund 16 Prozent der Waldfläche vor. Die mit Abstand bedeutendste Baumartengruppe dieses Unter- und Zwischenstandes ist, vor allem aufgrund ihrer häufigen Verwendung im Unterbau, die Buche. Dabei sind in dieser Baumartengruppe Rotbuche und Hainbuche mit nahezu gleichen Anteilen vertreten. Nennenswert sind weiterhin dichtere Unterstandspartien aus Edellaubbäumen wie Ahorn und Esche, die überwiegend aus Naturverjüngung hervorgegangen sind. Das trifft auch für den Unterstand aus Weichlaubbäumen zu. Bei dem Großteil der in der zweiten Bestandesschicht erfassten Eichen handelt es sich um Roteichen, die häufiger auf nicht oder nur gering überschirmten Störungslöchern vorangebaut worden waren (s. Tab. 45). Die auf fast einem Viertel der Bestandesfläche vorhandene Verjüngungsschicht wird ebenso wie der Unterstand durch die Baumartengruppe Buche dominiert. Hier handelt es sich zu 85 Prozent um Rotbuche, während die Hainbuche deutlich geringer vertreten ist. Der hohe Anteil an Edellaubbaumverjüngung ist in erster Linie Ausdruck des großen Naturverjüngungspotenzials dieser Baumartengruppe. Die Lichtbaumarten Kiefer und Eiche können erst in nur noch gering überschirmten bzw. stark aufgelichteten Beständen vorverjüngt werden. Voranbauten der Douglasie haben bislang flächenmäßig keine größere Bedeutung erlangt. 
Tabelle 45: Anteile [\%] der Baumartengruppen im Unter- und Zwischenstand sowie der Verjüngungsschicht mit jeweils mindestens einem Drittel überschirmter Bestandesfläche (in Klammern: Fläche [ha])

\begin{tabular}{cccccccc}
\hline $\begin{array}{c}\text { Baumarten- } \\
\text { gruppe }\end{array}$ & $\mathrm{Ei}$ & $\mathrm{Bu}$ & $\mathrm{ELB}$ & WLB & Fi & Dgl & $\mathrm{Ki}$ \\
\hline $\begin{array}{c}\text { Unter- } \\
\begin{array}{c}\text { Zwischenstand } \\
(4.350)\end{array}\end{array}$ & 5 & 74 & 13 & 7 & $<1$ & 1 & $<1$ \\
$\begin{array}{c}\text { Nachwuchs } \\
(6.760)\end{array}$ & 4 & 56 & 32 & 1 & 0 & 1 & 7 \\
\hline
\end{tabular}

Für die hier beschriebene Verjüngung, die mindestens ein Drittel der Bestandesfläche überschirmt, wird von deren Übernahmewürdigkeit ausgegangen. In großen Bestandeseinheiten vorhandene kleinere Partien mit dichter Verjüngung werden durch die Systematik dieser Auswertung vernachlässigt, während Bestände mit größeren Anteilflächen sehr dichten Nachwuchses mit der gesamten Bestandesfläche in die ausgewiesenen Verjüngungsflächen eingegangen sind.

\subsection{Veränderungen der Baumartenzusammensetzung}

Die bis zur Mitte des Jahrhunderts projizierten Szenarien der Grundwasserstandsund Klimaänderungen können, wie in Kapitel 3.2 dargestellt, teils zu erheblichen Auswirkungen auf die Waldstandorte des Hessischen Rieds vor allem im Hinblick auf das pflanzenverfügbare Wasser führen. Auf die Zukunft gerichtete waldbauliche Entscheidungen müssen diese Veränderungen berücksichtigen und auf eine Anpassung der Wälder hinwirken. Zentrale Bedeutung kommt dabei der Wahl angepasster Baumarten bei Verjüngungsentscheidungen bzw. deren Förderung im Rahmen der Bestandespflege zu. Ein planerisches Instrument zur bestandesweisen Festlegung angestrebter Baumartenmischungen und Produktionsziele auf standörtlicher Grundlage ist der Waldentwicklungstyp (WET). Die Zuordnung zukünftig standortgemäßer WET zu den Kombinationen aus Nährstoffversorgung und pflanzenverfügbarem Wasser erfolgte unter Berücksichtigung der Erkenntnisse zu Anbauwürdigkeit und Risiko der Baumarten bei Einbeziehung praktischer Erfahrungen im Untersuchungsgebiet (s. Kap. 2.2.11.2). Im Sinne der Risikoverteilung und zur Berücksichtigung unterschiedlicher waldbaulicher Ausgangssituationen wurden jedem Standortstyp i. d. R. mehrere mögliche WET zugeordnet.

Die Zuweisung vorrangiger Waldentwicklungstypen, die ausschließlich die nach den verschiedenen Grundwasser- und Klimaszenarien in 40 Jahren erwartete Standortausstattung des Hessischen Rieds berücksichtigt (potenzielle WET), zeigt Abbildung 77. Dabei stellt das Szenario GW0/Ref eine ausschließlich nach dem Standort ausgerichtete „Zielbestockung" für das Hessische Ried unter heutigen Bedingungen dar. Danach würden WET mit führender Eiche den größten 
Flächenanteil einnehmen und zusammen mit der an Bedeutung gewinnenden Roteiche fast 40 Prozent Flächenanteil erreichen, gefolgt von Waldentwicklungstypen mit führender Buche unter Beimischung von Nadelholz (Douglasie, Küstentanne) oder Edellaubholz. Führendes Edellaubholz wäre auf über 10 Prozent der Fläche vorzusehen, ebenso wie Douglasie. Letzteres geht zusammen mit dem Waldentwicklungstyp Küstentanne-Buche vor allem zu Lasten des Kiefernanteils, der danach nur noch bei einem Flächenanteil von etwa 10 Prozent liegen würde.

Vor allem die in der trockenen Ausprägung des Klimaszenarios A1B zu erwartenden Veränderungen der Standorte führen zu davon deutlich abweichenden Verteilungen der potenziellen Waldentwicklungstypen (s. Abb. 77).

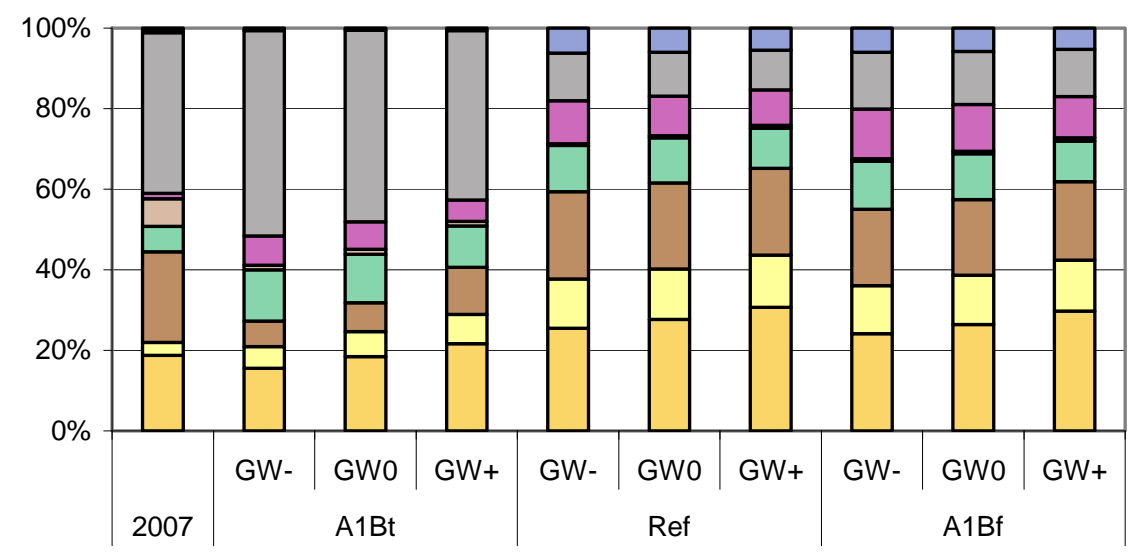

\section{पEi $\square$ Rei $\square$ Bu $\square E L b$ WLb $\square$ Dgl $\square$ Ki $\square$ KTa $\square$ Fi $\square$ Lä}

Abbildung 77: Flächenanteile [\%] der auf rein standörtlicher Grundlage geplanten Waldentwicklungstypen (potenzielle WET) nach fübrender Baumart in Abhängigkeit von den szenariobedingten Standortsveränderungen (linke Säule: Ausgangszustand im Jabr 2007)

Während sich der Anteil von WET mit führendem Laubholz in den Klimaszenarien Ref und A1Bf bei etwa 70 Prozent bewegt, fällt er bei trockener Klimaausprägung je nach Grundwasserszenario auf 40 bis 50 Prozent ab. Waldentwicklungstypen mit führender Kiefer kämen danach auf Flächenanteile, die zumindest dem aktuellen Bestockungsanteil dieser Baumart entsprächen (GW+/A1Bt) bzw. ihn bei ungünstigeren Grundwasserverhältnissen sogar deutlich überträfen. Stark zurückgehen würde der Anteil der für führende Buche geeigneten Standorte, vor allem bei unverändertem bzw. weiter zurückgehendem Grundwasseranschluss. Dagegen würde der Flächenanteil der Eichen-WET unter Einbeziehung der Roteiche den aktuellen Eichenanteil knapp behaupten oder ihn bei Vergrößerung der Fläche mit sicherem Grundwasseranschluss noch etwas übertreffen. 


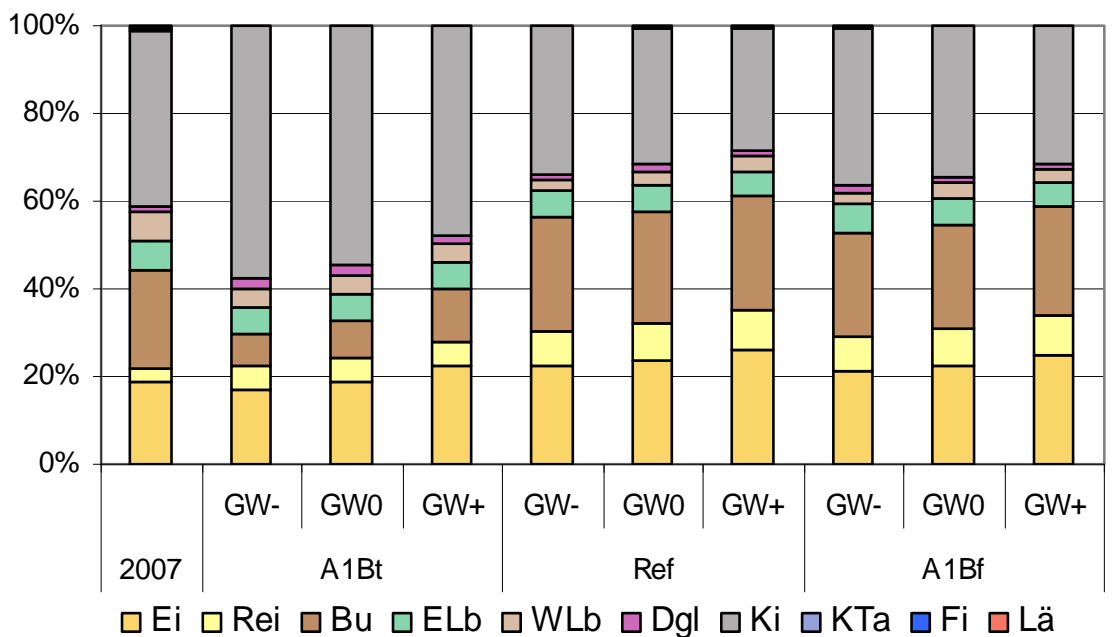

Abbildung 78: Flächenanteile [\%] der Bestandesklassen 2007 (linke Säule) und der unter Berücksichtigung der waldbaulichen Ausgangssituation geplanten $W$ aldentwicklungstypen nach führender Baumart in Abhängigkeit von den szenariobedingten Standortsveränderungen

Die Betrachtungen zur Baumartenwahl als reine Funktion künftig erwarteter Standorts- und Klimabedingungen können strategische Entscheidungen unterstützen. Für die kurz- und mittelfristige Umsetzung spielt jedoch die waldbauliche Ausgangsituation eine ausschlaggebende Rolle. Aus mehreren standortsgemäßen WET-Alternativen wird deshalb für die Simulation der Waldentwicklungsszenarien jene ausgewählt, für die durch übernahmefähigen Unterstand oder eine etablierte Verjüngungsschicht bereits eine oder mehrere Baumarten vorhanden sind bzw. das Verjüngungspotenzial des Hauptbestandes genutzt werden kann.

Bei der Gesamtbetrachtung fällt auf, dass der Anteil von Buchen-WET in den Szenarien Ref und A1Bf danach um insgesamt rund 5 Prozent höher ausfällt als bei rein standörtlicher WET-Planung (s. Abb. 77 und 78). Der hohe Rotbuchenanteil im Unterstand (ca. $1.700 \mathrm{ha}$ ) und im Nachwuchs (> $3.200 \mathrm{ha}$ ) der derzeitigen Bestockung führt in den Szenarien ohne Klimaänderung und in der feuchten Variante des Klimaszenarios A1B zu Waldentwicklungstypen mit führender Buche in einem Umfang, der zumindest dem heutigen Buchenanteil in der Hauptschicht entspricht bzw. diesen sogar übertrifft. Bei trockener Klimaausprägung gingen dagegen Buchen-WET drastisch zurück, da sie aufgrund der Trockenheit vor allem ohne Anhebung des Grundwassers (GW0 und GW-) auf großer Fläche nicht mehr standortgemäß wären. Nach dieser Planung würden die Eichen-WET - Roteiche eingeschlossen - in den trockenen Szenarien (GW-/A1Bt und GW0/A1Bt) den heutigen Eichenanteil etwa behaupten. Unter der Voraussetzung einer Erhöhung der Standortanteile mit sicherem Grundwasseranschluss bzw. in den feuchteren Klimaszenarien A1Bf und Ref würde die WET-Zuordnung zu einer größeren 
Flächenbedeutung von Eichen-WET einschließlich nennenswerter Roteichenanteile von bis zu 34 Prozent (GW+/Ref) führen. Bei den Nadelbaumarten bliebe aufgrund ihres Naturverjüngungspotenzials die aktuelle Dominanz der Kiefer bestehen bzw. würde in den Szenarien mit trockenem Klima noch ausgebaut. Waldentwicklungstypen mit führender Douglasie oder Küstentanne als standortgemäße Alternativen (s. Abb. 77) kämen nur in geringem Umfang bzw. im Fall der Küstentanne so gut wie gar nicht vor, da sie in den aktuellen Beständen nur gering vertreten sind.

Zur Differenzierung des Einflusses der Faktoren Grundwasser und Klimaänderung auf die Zuweisung der Waldentwicklungstypen wurde eine Stratifizierung der Waldstandorte nach ihrem „Grundwasserstatus“ vorgenommen. Danach lassen sich vier Straten unterscheiden:

1. Standorte, die in allen Szenarien einen sicheren Grundwasseranschluss mit einem Grundwasserflurabstand von weniger als 2,50 $\mathrm{m}$ aufweisen (Flächenumfang ca. 2.650 ha),

2. Standorte, die derzeit einen Grundwasserflurabstand von weniger als 2,50 m aufweisen, deren Flurabstand sich aber im Szenario GW- auf mehr als 2,50 m vergrößert (ca. 2.600 ha),

3. Standorte, deren Grundwasserflurabstand sich zwischen 1951 und 2007 auf mehr als 2,50 m vergrößert hat (ca. 5.700 ha) und schließlich

4. durchgängig grundwasserferne Standorte, deren Grundwasserflurabstand bereits vor 1951 größer als 2,50 m war, mit einer Fläche von nahezu 17.000 ha.

Die Waldstandorte des ersten Stratums (s. Abb. 79) bleiben durch ihren durchgängig bestehenden sicheren Grundwasseranschluss von den Auswirkungen etwaiger Klimaveränderungen weitgehend unbeeinflusst und sind zukünftig wie schon heute bevorzugte Laubholzstandorte mit einem Schwerpunkt bei allen Waldentwicklungstypen mit führender Eiche aber auch mit führender Buche. Lediglich graduelle Unterschiede zwischen den unterschiedlichen Grundwasserszenarien resultieren aus szenariobedingten Veränderungen der Grundwasserflurabstände innerhalb wurzelerreichbarer Tiefen (z. B. Anstieg eines mittleren Flurabstandes von $1 \mathrm{~m}$ auf $1,5 \mathrm{~m}$ bei GW-).

Die Standorte des zweiten Stratums (s. Abb. 80), die heute ebenfalls noch einen sicheren Grundwasseranschluss aufweisen, würden diesen im Szenario GWverlieren. Soweit der Grundwasseranschluss mit einem Flurabstand von weniger als 2,50 m erhalten bleibt (Szenarien GW0 und GW+), handelt es sich auch in Zukunft um bevorzugte Eichen- und Buchenstandorte, allerdings gäbe es auf den schwächer nährstoffversorgten Standorten auch zunehmende Kiefernanteile. Bei Verlust des sicheren Grundwasseranschlusses (GW-) würden diese Standorte „klimasensitiv“, was bei ungünstiger Klimaentwicklung (A1Bt) deutlich höhere 
Flächenanteile mit führender Kiefer und abnehmende Flächenanteile mit führender Eiche und Buche zur Folge hätte.

Das dritte Stratum (Abb. 81) weist aktuell keinen sicheren Grundwasseranschluss auf, umfasst aber beträchtliche Flächen des Untersuchungsgebietes, auf denen bis zu Beginn der 1950er-Jahre das Grundwasser für die aufstockenden Bestände noch wurzelerreichbar war, der Grundwasserflurabstand aber zwischen 1951 und 2007 auf über 2,50 m gestiegen ist. Die Baumartenwahl wird hier hauptsächlich durch das Angebot an pflanzenverfügbarem Wasser bestimmt. Bei einer Klimaveränderung zu deutlich trocken-wärmeren Verhältnissen (A1Bt) wäre die Buche hier kaum noch als führende Baumart zu berücksichtigen und vor allem würde der Anteil an Beständen mit führender Kiefer deutlich zunehmen. Demgegenüber würde die modellhafte Annahme einer Wiederherstellung historischer Grundwasserstände der fünfziger Jahre des letzten Jahrhunderts (Szenario GW+) diese Flächen trotz ungünstiger Klimaveränderungen wieder weit überwiegend zu geeigneten Standorten für führendes Laubholz, vorrangig Eiche und Buche, machen.

Mit einem Anteil von über 58 Prozent an der heutigen Waldfläche des Untersuchungsgebietes überwiegen die Standorte, die in der Vergangenheit und in Zukunft durchgängig über alle Szenarien hinweg einen tiefer als 2,50 m unter Flur liegenden Grundwasserspiegel aufweisen (s. Abb. 82). Bei ihnen bestimmt neben der waldbaulichen Ausgangssituation und der Nährstoffversorgung vor allem das pflanzenverfügbare Wasser die standortsgerechte Zuordnung der Waldentwicklungstypen. Mit abnehmenden Niederschlägen und steigenden Temperaturen, was am stärksten durch das Klimaszenario A1Bt abgebildet wird, verschlechtert sich die Wasserversorgung der Bestände gerade auf den dieses Stratum dominierenden Böden mit geringer Wasserspeicherkapazität dramatisch. Bei diesem Klimaszenario käme die Buche als führende Baumart kaum noch infrage und die Eichenanteile schrumpften deutlich. Der Anteil führender Kiefer würde noch über ihren heutigen Flächenanteil hinaus steigen, da es selbst für Roteiche und Douglasie teilweise schon zu trocken würde.

Entgegen den langfristigen Auswirkungen der Standortsveränderung auf die WET-Planung in den einzelnen Szenariokombinationen zeichnen sich hinsichtlich der zum Ende des Simulationszeitraumes im Jahre 2039 mittelfristig erreichten Verteilung der Bestandesklassen nur geringfügige Differenzen zwischen den neun simulierten Szenarien ab (s. Abb. 83). 


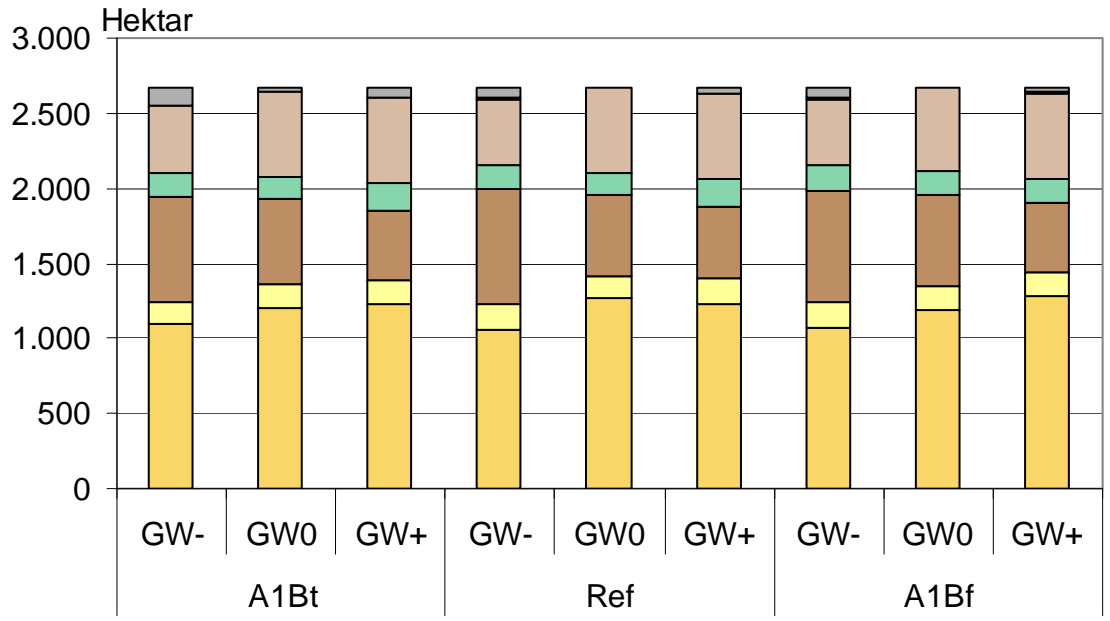

$\square \mathrm{Ei} \quad \square \mathrm{REi} \quad \square \mathrm{Bu} \quad \square \mathrm{ELb} \quad \square \mathrm{WLb} \quad \square \mathrm{Dgl} \quad \square \mathrm{Ki} \quad \square \mathrm{KTa}$

Abbildung 79: Fläche [ha] der Waldentwicklungstypen (führende Baumart) unter Berücksichtigung der waldbaulichen Ausgangssituation für Standorte, deren Grundwasserflurabstand in allen Szenarien nicht größer als 2,50 $\mathrm{m}$ ist

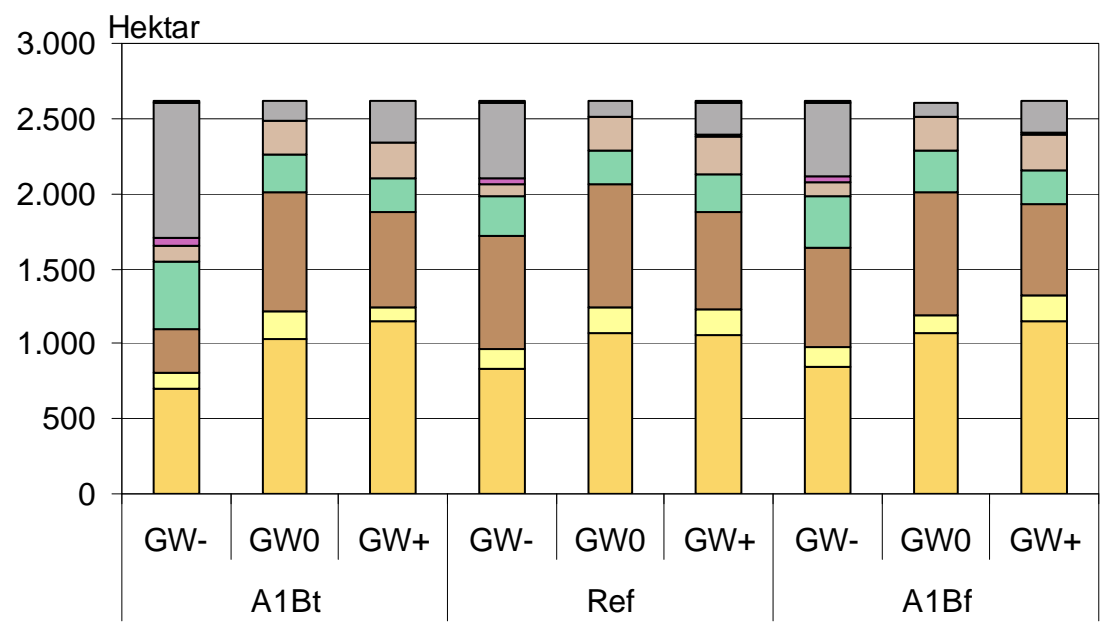

$\square \mathrm{Ei} \quad \square \mathrm{REi} \quad \square \mathrm{Bu} \quad \square \mathrm{ELb} \quad \square \mathrm{WLb} \quad \square \mathrm{Dgl} \quad \square \mathrm{Ki} \quad \square \mathrm{KTa}$

Abbildung 80: Fläche [ha] der Waldentwicklungstypen (fübrende Baumart) unter Berücksichtigung der waldbaulichen Ausgangssituation für Standorte, deren Grundwasserflurabstand im Szenario $G W$ - auf mehr als 2,50 m ansteigt 


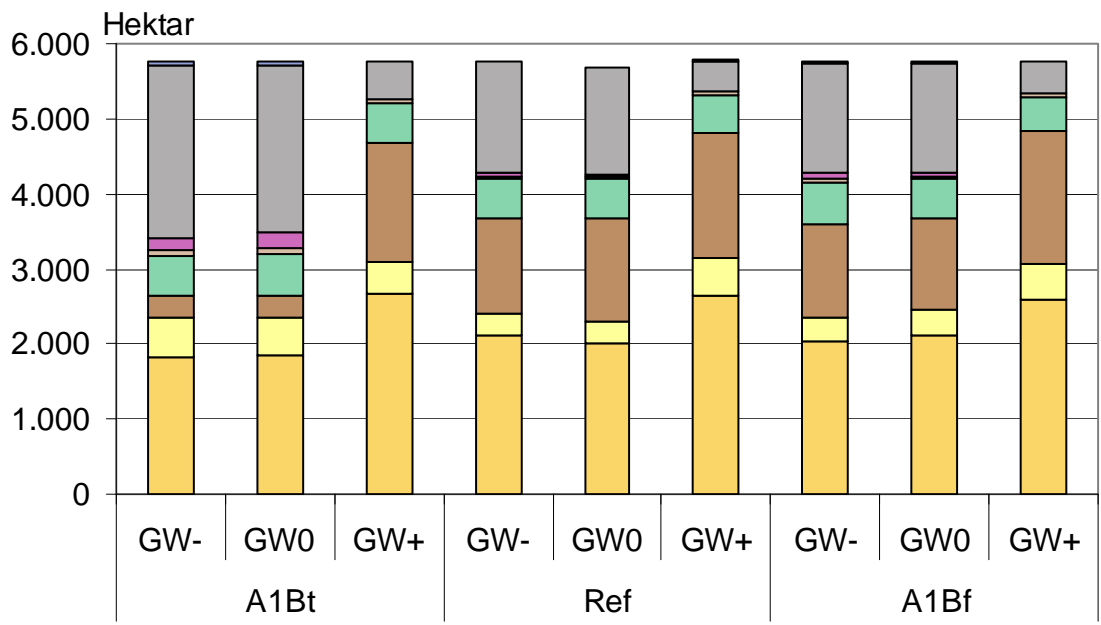

$\square \mathrm{Ei} \quad \square \mathrm{REi} \quad \square \mathrm{Bu} \quad \square \mathrm{ELb} \quad \square \mathrm{WLb} \quad \square \mathrm{Dgl} \quad \square \mathrm{Ki} \quad \square \mathrm{KTa}$

Abbildung 81: Fläche [ha] der Waldentwicklungstypen (führende Baumart) unter Berücksichtigung der waldbaulichen Ausgangssituation für Standorte, deren Grundwasserflurabstand zwischen 1951 und 2007 auf über 2,50 m gestiegen ist

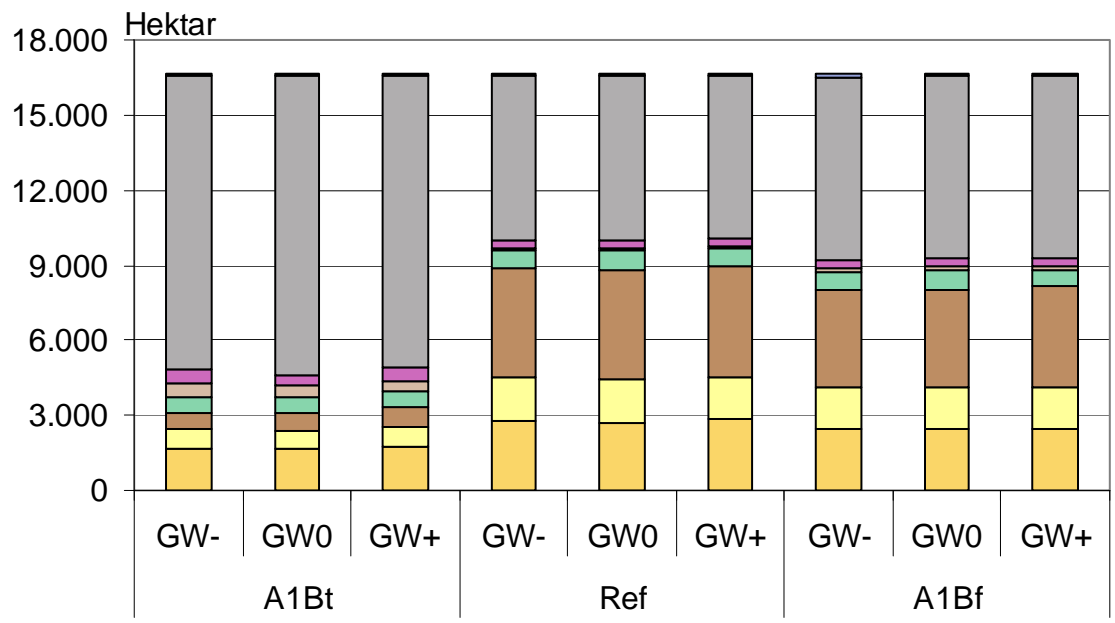

$\square \mathrm{Ei} \quad \square \mathrm{REi} \quad \square \mathrm{Bu} \quad \square \mathrm{ELb} \quad \square$ WLb $\quad \square \mathrm{Dgl} \quad \square \mathrm{Ki} \quad \square \mathrm{KTa}$

Abbildung 82: Fläche [ha] der Waldentwicklungstypen (führende Baumart) unter Berücksichtigung der waldbaulichen Ausgangssituation für Standorte, deren Grundwasserflurabstand bereits vor 1951 größer als 2,50 m war 


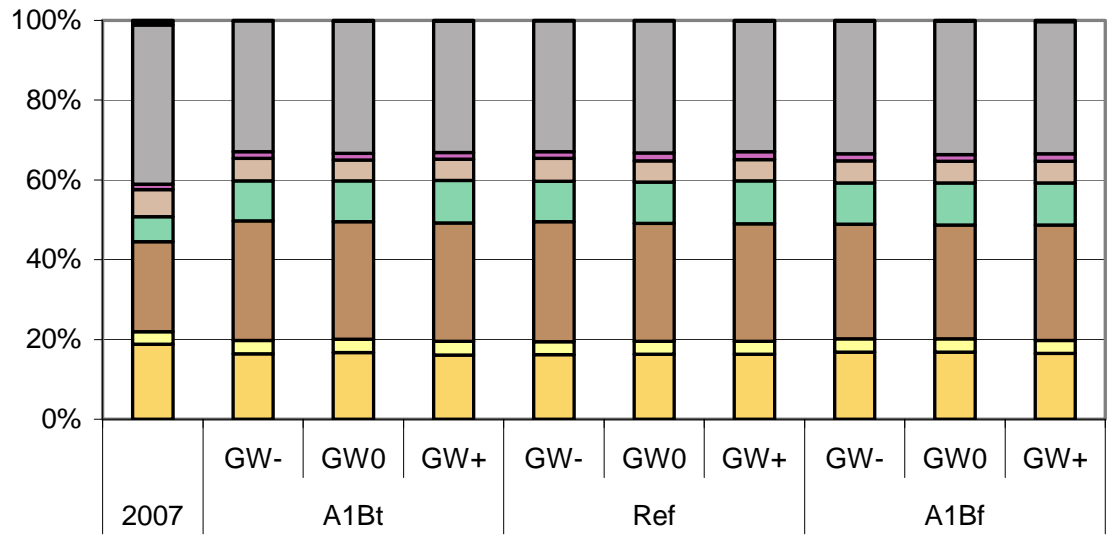

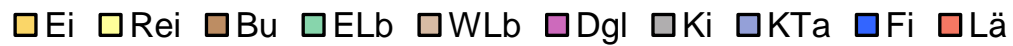

Abbildung 83: Flächenanteile [\%] der Bestandesklassen im Jahre 2039 als Ergebnis der Simulation in Abhängigkeit von den Szenarien (linke Säule: Ausgangszustand im Jahr 2007)

Die größte Abweichung ist zwischen den Szenarien GW+/Ref und GW0/A1Bt mit einer Differenz von lediglich 1,6 Prozent (!) im Flächenanteil der Buchenbestandesklasse zu verzeichnen. Das ist zunächst ein überraschender Befund. Im Vergleich zur Ausgangssituation von 2007 kommt es im Ergebnis der Simulation relativ übereinstimmend über alle Szenarien zu einer Zunahme der Buche und des Edellaubholzes von ursprünglich zusammen 29 Prozent auf 40 Prozent. Verbunden ist das mit einem Rückgang der Lichtbaumarten. Dieser fällt für die Bestandesklasse Kiefer, die einen Rückgang von fast 10 Prozent verzeichnet, am drastischsten aus. Leichte Flächenverluste verzeichnen Eichen- (einschl. Roteichen-) und Weichlaubholzbestände. Ursächlich dafür ist in erster Linie die Abnutzung von Kiefern- und in geringerem Umfang auch Eichenbeständen bei gleichzeitiger Überführung eines Unterstandes, der hauptsächlich aus Buche und Edellaubholz besteht, in den Hauptbestand. Eine aktive Verjüngungsentscheidung zugunsten der Lichtbaumarten wird dabei nicht ausgelöst, wobei die damit simulierte Entwicklung durchaus bisher geübter Praxis entspricht.

In Tabelle 46 ist der Erreichungsgrad der für die Zukunft geplanten Zielbestockung für den Ausgangszeitpunkt 2007 und das Ende der Simulation 2039 dargestellt. Die ausgewählten Szenarien GW-/A1Bt und GW+/A1Bf markieren den Korridor, innerhalb dessen sich die anderen Grundwasser- und Klimakombinationen bewegen. 
Tabelle 46: Zielerreichung (Flächenanteile [\%]) binsichtlich der Umsetzung der geplanten Waldentwicklungstypen (WET) im Vergleich mit dem tatsächlichen Bestandestyp 2007 und am Ende des Simulationszeitraumes 2039 (Szenarien $G W-/ A 1 B t$ und $G W+/ A 1 B f$ )

\begin{tabular}{ccc|cc}
\hline & \multicolumn{2}{c|}{ Szenario GW-/A1Bt } & \multicolumn{2}{c}{ Szenario GW+/A1Bf } \\
& Stand 2007 & Stand 2039 & Stand 2007 & Stand 2039 \\
\hline $\begin{array}{c}\text { akt. Bestandestyp } \\
\text { = WET }\end{array}$ & $48 \%$ & $20 \%$ & $53 \%$ & $33 \%$ \\
$\begin{array}{c}\text { akt. Hauptbaumart } \\
=\begin{array}{c}\text { Hauptbaumart WET } \\
\text { keine }\end{array}\end{array}$ & $22 \%$ & $33 \%$ & $22 \%$ & $32 \%$ \\
\begin{tabular}{c} 
Übereinstimmung \\
\hline
\end{tabular} & $30 \%$ & $47 \%$ & $25 \%$ & $35 \%$ \\
\hline
\end{tabular}

Die Basis der Auswertung ist der Vergleich des unter Berücksichtigung der szenariobedingten Standortsveränderung und der waldbaulichen Ausgangslage zugewiesenen Waldentwicklungstyps und der tatsächlichen Baumartenzusammensetzung der Bestände zu den beiden Zeitpunkten. Die prognostizierten Entwicklungen verdeutlichen, dass durch ein Vorgehen, das in der Vergangenheit angelegte Entwicklungen ohne weitere Überprüfung in die Zukunft trägt, entscheidende Weichenstellungen in Richtung einer risikoärmeren Baumartenzusammensetzung angesichts der eingetretenen und erwarteten Standortsveränderungen versäumt werden. Die Einwuchsdynamik bzw. die Überführung von Buchenunterstand würde in beiden Szenarien mittelfristig sogar zu einer weiteren Entfernung von einer zielgerechten Bestockung führen. Die entstehende Abweichung wäre bei der sehr ungünstigen, aber keinesfalls auszuschließenden Entwicklung der Standortsverhältnisse des Szenarios GW-/A1Bt gravierend. Hier würde die auf großer Fläche anzustrebende Erhaltung bzw. Erhöhung des Flächenanteils an Trockenheit anpassungsfähiger Waldentwicklungstypen mit führender Kiefer oder auch Douglasie ganz deutlich verfehlt, während in den weniger ungünstigen Klimaszenarien vor allem die geplanten höheren Eichen- und Roteichenanteile nicht erreicht würden.

Einen räumlichen Eindruck von der Zielerreichung bzw. Zielabweichung für das trockenste und das feuchteste Grundwasser- und Klimaszenario hinsichtlich einer standortsangepassten Bestockung im Jahre 2039 vermittelt Abbildung 84. 


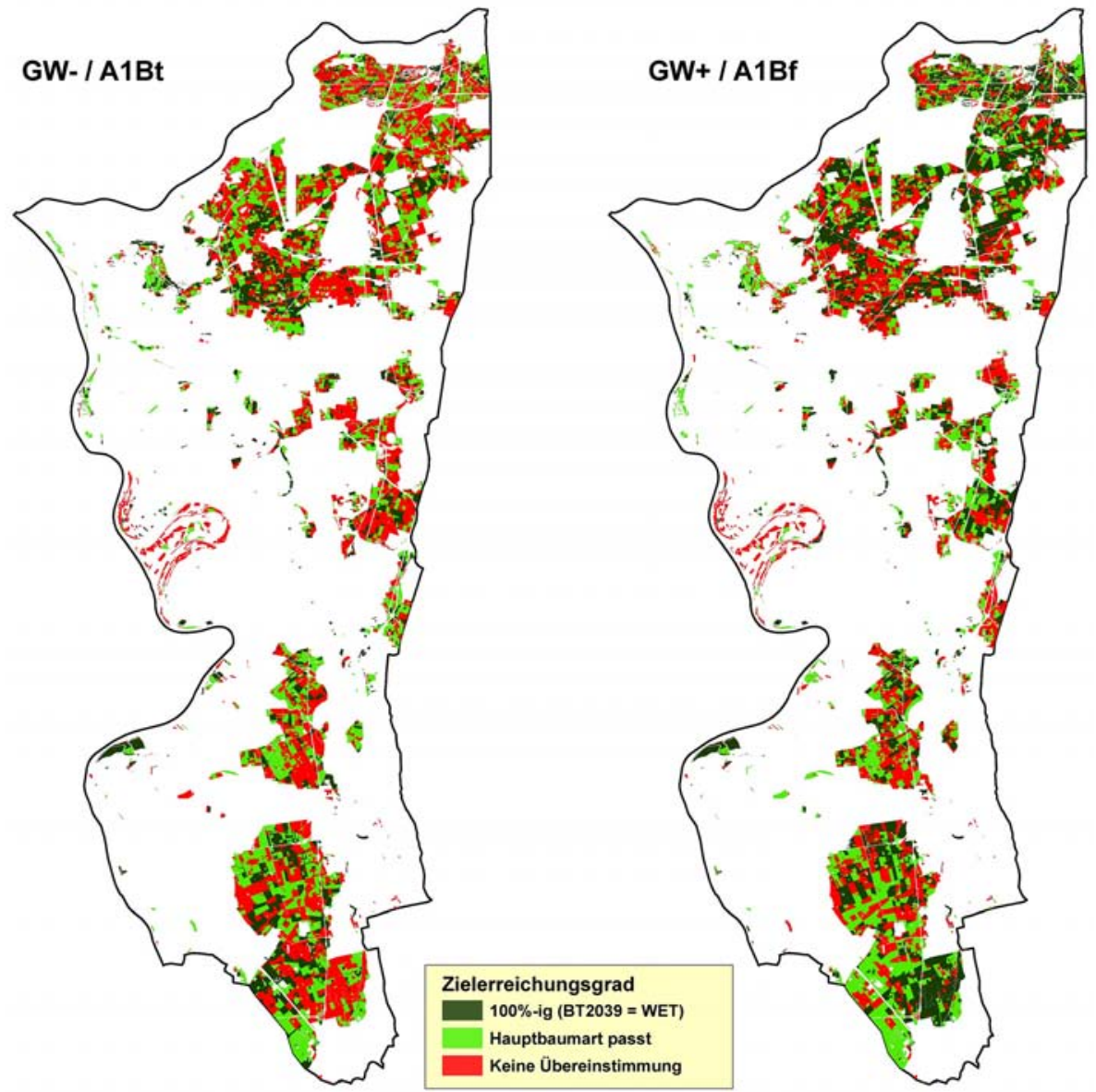

Abbildung 84: Vergleich zwischen dem geplantem Waldentwicklungstyp (WET) und dem im Jahr 2039 in den Simulationen ermitteltem Zustand für die Szenarien GW-/A1Bt (links) und $G W+/ A 1 B f($ rechts) (,Zielerreichungsgrad")

\subsubsection{Horizontale und vertikale Waldstruk.tur}

\subsection{Ausgangssituation 2007}

Der Aufbau der Wälder im Hessischen Ried lässt sich über die Altersstruktur, die Durchmesserverteilung sowie die vertikale Schichtung der Bestände beschreiben.

Bis auf den überhöhten Flächenanteil in der dritten Altersklasse liegt bei summarischer Betrachtung aller Baumarten ein sehr ausgeglichener Altersklassenaufbau vor (s. Abb. 85). Der Überhang in der dritten Altersklasse ergibt sich im Wesentlichen aus den Nachkriegsaufforstungen mit Kiefer. Die geringen Flächenanteile der Buche in der Hauptschicht in der I. und II. Altersklasse sind auf die längeren Überschirmungszeiträume von Buchennachwuchs zurückzuführen. In der 
vergleichsweise hohen Ausstattung an Eichen- und Roteichenjungbeständen lassen sich die verstärkten Anstrengungen zur künstlichen Bestandesbegründung dieser Baumarten in den letzten 40 Jahren ablesen. Das durchschnittliche flächengewogene Alter der drei Hauptbaumarten beträgt bei Eiche rund 90, bei Buche ca. 100 und bei Kiefer 80 Jahre.

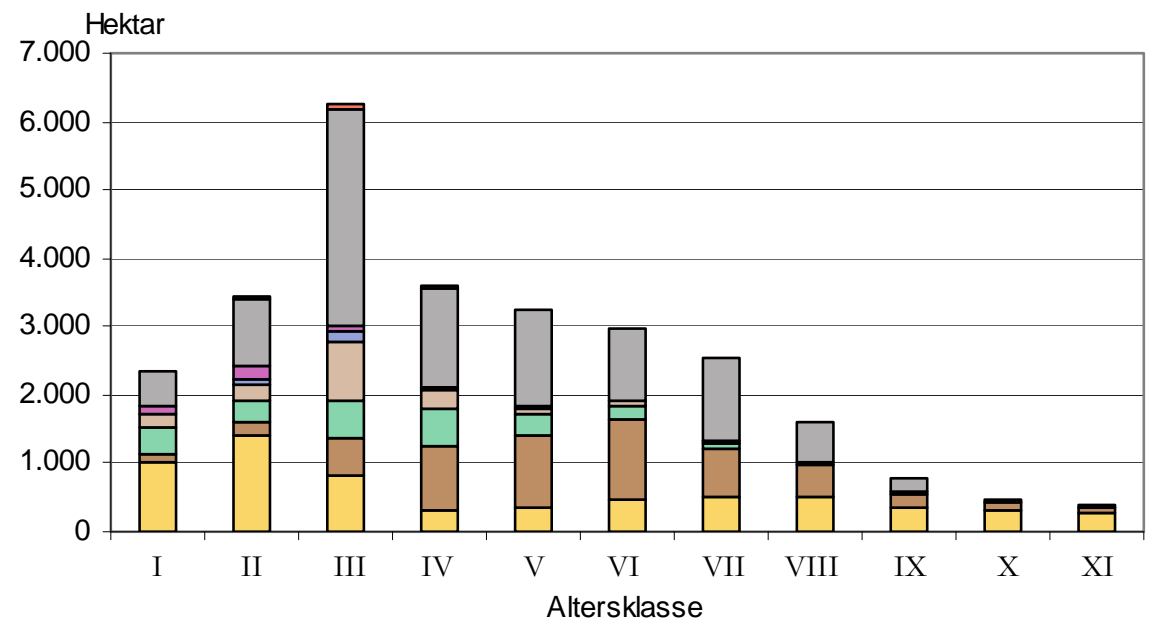

$\square \mathrm{Ei} \quad \square \mathrm{Bu} \quad \square \mathrm{ELb} \quad \square \mathrm{WLb} \quad \square \mathrm{Fi} \quad \square \mathrm{Dgl} \quad \square \mathrm{Ki} \quad \square \mathrm{Lä}$

Abbildung 85: Altersklassenaufbau der Baumartengruppen in der Hauptschicht im Jahr 2007 (Bezugsgröße: Kronenschirmfläche [ha])

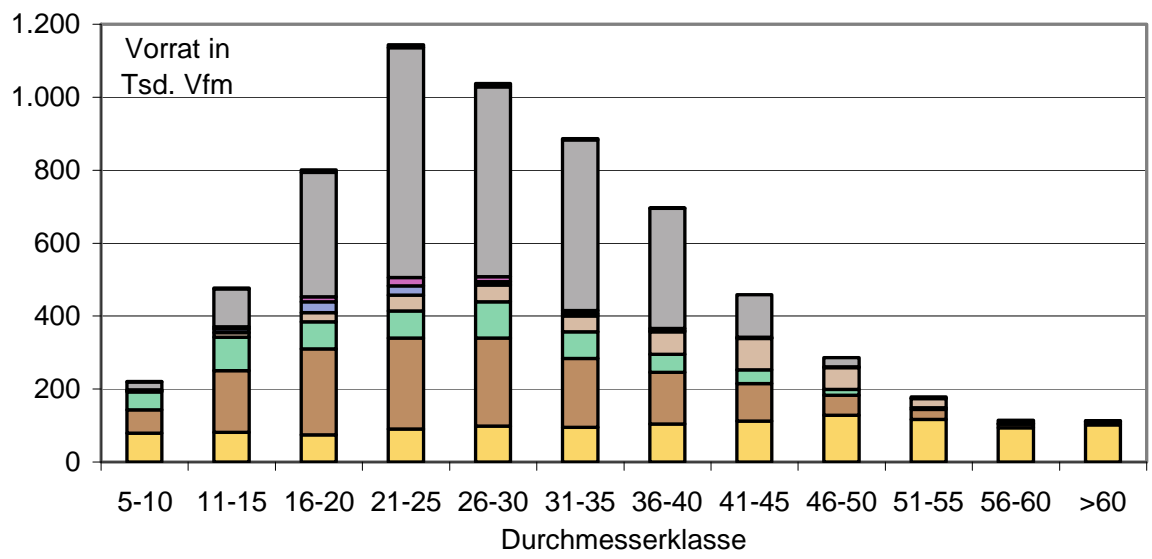

$\square \mathrm{Ei} \quad \square \mathrm{Bu} \quad \square \mathrm{ELb} \quad \square \mathrm{WLb} \quad \square \mathrm{Fi} \quad \square \mathrm{Dgl} \quad \square \mathrm{Ki} \quad \square \mathrm{Lä}$

Abbildung 86: Durchmesserverteilung (gem. Wachstumssimulator) der Baumartengruppen in 5-cmKlassen im Jabr 2007 (Bezugsgröße: Vorrat [1000 V fm]) 
Bei einem Gesamtvorrat (alle Bestandesschichten) von ca. 6,4 Millionen Vfm ergibt sich ein hektarbezogener Durchschnittsvorrat von $232 \mathrm{Vfm}$. Bei der Eiche spiegelt sich der Altersklassenaufbau in einer ausgeglichenen Vorratsverteilung über alle Durchmesserklassen wieder (s. Abb. 86), während die Buche trotz höherem Flächendurchschnittsalter kaum zielstarke Dimensionen erreicht. Größere Anteile der Kiefernvorräte befinden sich je nach unterstelltem Szenario bereits in der Zielstärke oder erreichen diese während des Simulationszeitraumes.

Für die Beschreibung der vertikalen Schichtigkeit der Bestände wurden neben dem Hauptbestand Unterstand und Nachwuchs nur berücksichtigt, wenn sie eine Überschirmung von mindestens einem Drittel der Fläche aufweisen.

Unter diesen Voraussetzungen werden 71 Prozent aller Bestände (ca. 17.200 ha) als einschichtig und 27 Prozent (ca. 9.700 ha) als zweischichtig eingestuft. Lediglich zwei Prozent (ca. 700 ha) der Bestände weisen eine mehrschichtige Bestandesstruktur auf.

Die Bestandesdichte wird von der Forsteinrichtung über den Bestockungsgrad beschrieben, der sich auf eine ertragstafelorientierte Grundflächenhaltung bei mäßig starker Durchforstung bezieht. In Abhängigkeit von Baumart und Waldentwicklungsstadium variieren die angestrebten Zielbestockungsgrade in einer recht weiten Spanne. Während im Differenzierungsstadium weitgehender Dichtstand angestrebt wird, wird im Auslesestadium meist ein gestaffeltes Vorgehen favorisiert. Dabei werden erst stärkere Absenkungen des Bestockungsgrades vorgesehen, um später sukzessive die Grundfläche wieder ansteigen zu lassen. Bestockungsgrade unter 0,6 stellen jedoch auch in jüngeren Beständen des Auslesestadiums Waldgefügestörungen dar, die oft negative Folgen wie z. B. Qualitätsminderung durch Wasserreiserbildung, Sonnenbrand oder frühzeitige Vergrasung ganzer Bestände nach sich ziehen können. Steht dagegen die Verjüngung älterer Bestände an, die häufig mit einem Baumartenwechsel verbunden ist, werden nicht selten bewusst niedrigere Bestockungsgrade angestrebt.

Da im WaldPlaner die Ertragstafeln nicht hinterlegt sind, wird hier als Dichtemaß die Kronenschirmfläche verwendet, wobei den im Simulationsprogramm generierten Bäumen eine „normale“ Kronendimension unterstellt wird. Hiernach sind über 50 Prozent der Bestände annähernd voll überschirmt (Überschirmung $>0,8)$. Etwa ein Viertel der Bestände sind dagegen stark aufgelichtet (s. Tab. 47).

Tabelle 47: $\quad$ Kronenschlussgrad 2007

\begin{tabular}{lcccc}
\hline Kronenschlussgrad & $\leq 0,6$ & $0,61-0,8$ & $0,81-1,0$ & $>1,0$ \\
\hline Hektar & 6.560 & 6.496 & 5.920 & 8.679 \\
Prozent & 23,7 & 23,5 & 21,4 & 31,4 \\
\hline
\end{tabular}




\subsection{Veränderungen der Waldstruktur}

Der hohe Flächenanteil der dritten Altersklasse im Jahre 2007 verschiebt sich innerhalb des Simulationszeitraumes erwartungsgemäß in die Altersklassen IV und V. Im Jahr 2039 weist der Altersklassenaufbau der Hauptschicht zwischen den sechs Szenarien der Klimavarianten Ref und A1Bf keine größeren Unterschiede auf. Dagegen ist im trockenen Klimaszenario mit nur geringen Differenzen zwischen den Grundwasservarianten ein deutlich veränderter Altersklassenaufbau zu beobachten. Die größten Unterschiede ergeben sich zwischen den Kombinationen GW-/A1Bt und GW+/A1Bf, beispielhaft dargestellt in der Abbildung 87. Kennzeichnend beim trockenen Szenario sind die deutlich geringeren Flächenanteile in den höheren Altersklassen (ab 120 Jahre) sowie der um knapp 3.000 Hektar höhere Flächenanteil in den Altersklassen I und II.
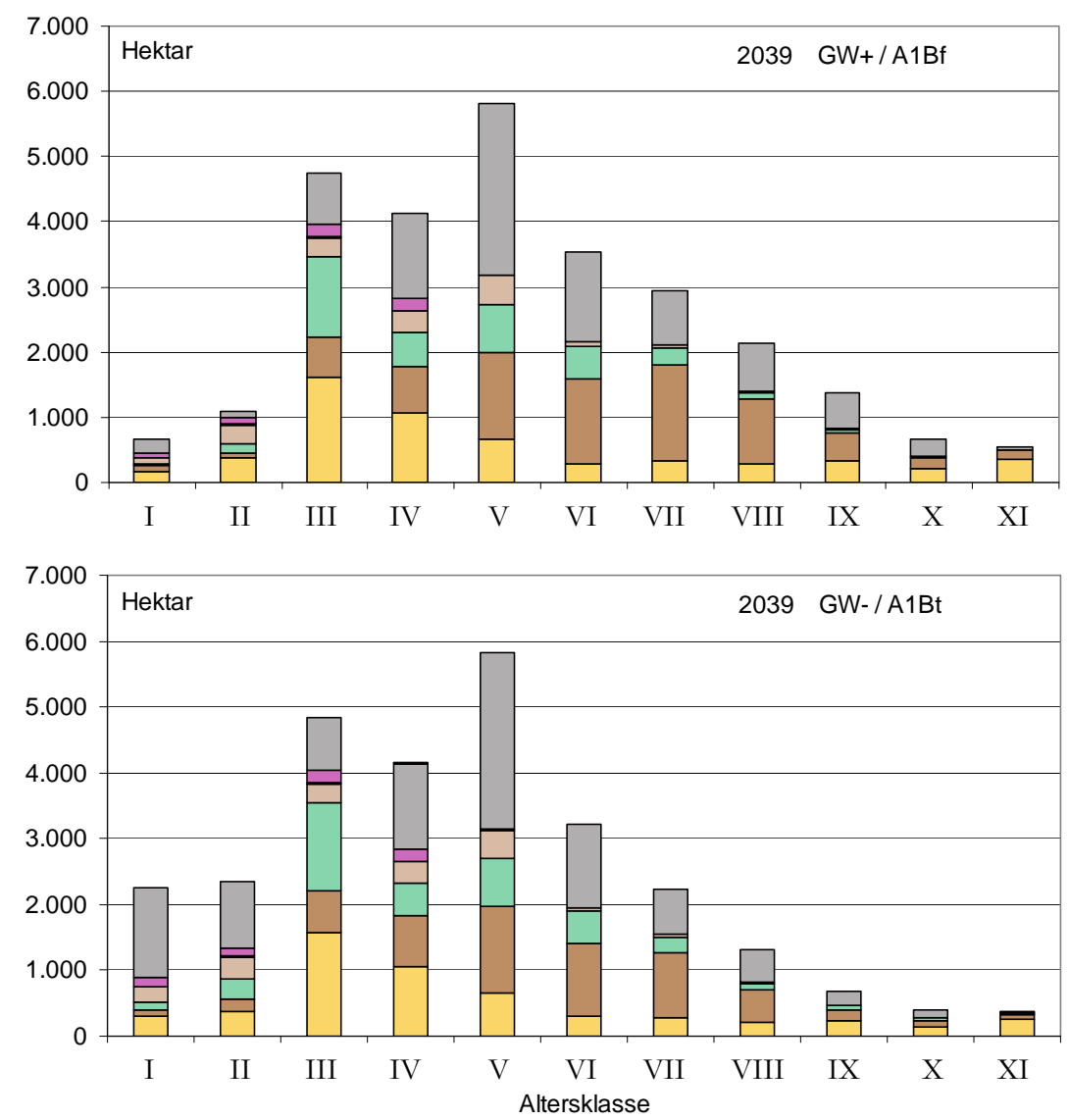

$\square$ Ei $\square$ Bu $\square$ ELb $\square$ WLb $\square$ Fi $\square$ Dgl $\square$ Ki $\square$ Lä

Abbildung 87: Altersklassenverteilung im Jahr 2039 bei den Szenarien GW+/A1Bf (oben) und GW-/ A1Bt (unten) (Bequgsgröße: Kronenschirmfläche [ha]) 
Die im Abschnitt 3.4.1.2 bereits beschriebene Verschlechterung der Standortsverhältnisse in den trockenen Szenarien (GW-/A1Bt) führt über die Herabsetzung der Zielstärke zu einer schnelleren Abnutzung der Bestände. In der Folge tragen vermehrte Endnutzungen zu einer Reduzierung der Flächenanteile in den Altersklassen über 120 Jahre bei.

Damit verbunden ist eine Erhöhung der Flächen in der I. und II. Altersklasse. Dadurch bleibt das flächengewogene Durchschnittsalter der drei Hauptbaumarten hier nahezu unverändert, während es sich in den anderen Szenarien mit höher angesetzten Zielstärken und kleinerer Verjüngungsfläche etwas erhöht (s. Tab. 48).

Tabelle 48: $\quad$ Flächengewogenes Durchschnittsalter [Jahre] der Baumarten in der Hauptschicht

\begin{tabular}{lc|ccc|ccc|ccc}
\hline & 2007 & \multicolumn{3}{|c|}{ A1Bt } & \multicolumn{3}{c}{2039} \\
& & GW- & GW0 & GW + & GW- & GW0 & GW + & GW- & GW0 & GW + \\
\hline Eiche & 89 & 89 & 90 & 92 & 96 & 96 & 97 & 96 & 96 & 97 \\
Buche & 102 & 101 & 103 & 105 & 111 & 112 & 112 & 110 & 111 & 112 \\
Kiefer & 80 & 78 & 80 & 82 & 101 & 102 & 102 & 100 & 101 & 102 \\
\hline
\end{tabular}

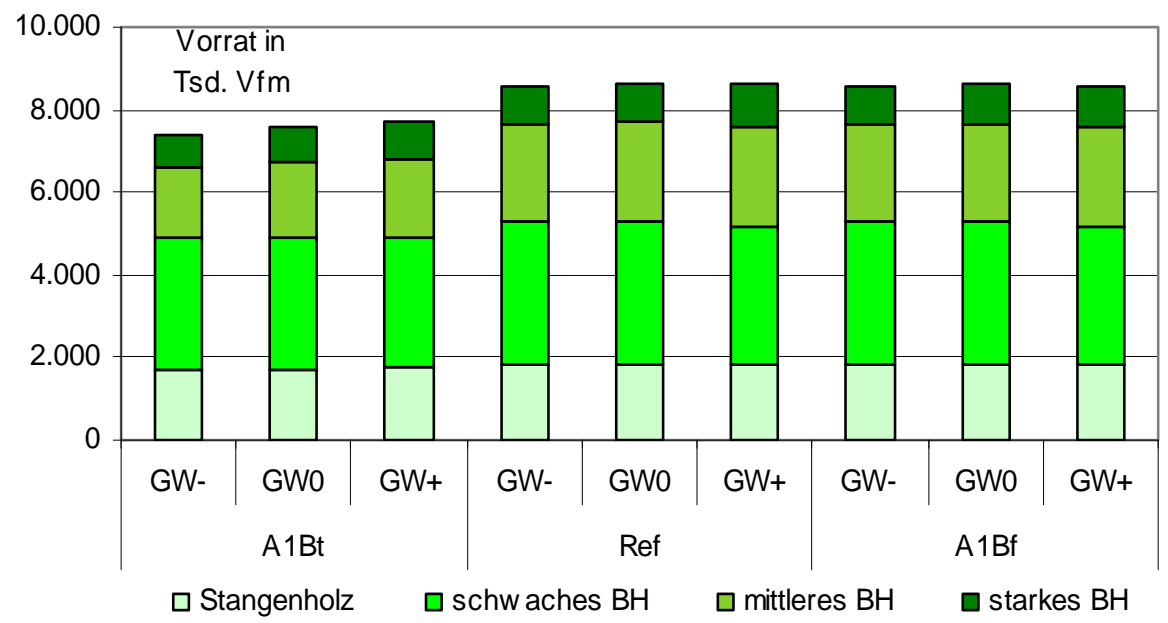

Abbildung 88: Szenarioabhängige Verteilung der Holzvorräte [1000 Vfm] im Jabr 2039 untergliedert nach natürlichen Altersstufen

Darüber hinaus führen die unterschiedlichen Nutzungsansätze auch zu Veränderungen in der Vorratshaltung und in der Durchmesserstruktur der Vorräte. So variieren die Holzvorräte in Abhängigkeit der unterstellten Szenarien in einer Spanne von 7,3 (GW-/A1Bt) bis 8,7 (GW0/Ref) Millionen Vfm (s. Abb. 88), wobei die größten Differenzen mit rund 600.000 Vfm im Bereich des mittleren Baumholzes 
liegen. Die geringere Vorratshaltung wird vor allem durch einen Vorratsabbau bei der Buche (etwa 310.000 Vfm) und der Kiefer (etwa 220.000 Vfm) verursacht.

Der Vorrat an besonders starkem Holz mit einem BHD $>70 \mathrm{~cm}$ beläuft sich in der Summe aller Baumarten auf 79.000 Vfm. Eine Überprüfung dieser Vorräte ergab, dass 71 Prozent in Beständen mit Naturschutzauflagen stocken und 21 Prozent auf Habitatbäume entfallen. Die restlichen 8 Prozent des Volumens verteilen sich auf Überhälter oder auf Bäume in Beständen, deren dg noch unter der festgelegten Zielstärke liegt.

In allen Szenarien nimmt die Schichtigkeit der Bestände gegenüber dem Ausgangszustand $2007 \mathrm{ab}$. Im Gegensatz zu den auffälligen Veränderungen der horizontalen Strukturen zwischen den Szenarien sind die Unterschiede für das vertikale Strukturelement Schichtigkeit nur marginal (s. Abb. 89). Mehrschichtige Bestände, die 2007 noch auf 2,5 Prozent der Fläche vorkamen, sind 2039 unabhängig vom Szenario kaum noch vertreten. Der Anteil der einschichtigen Bestände steigt von 62,3 Prozent auf rund 71 Prozent bei den Szenarien mit Referenz- oder A1BfKlima und auf rund 76 Prozent in den trockenen Szenarien.

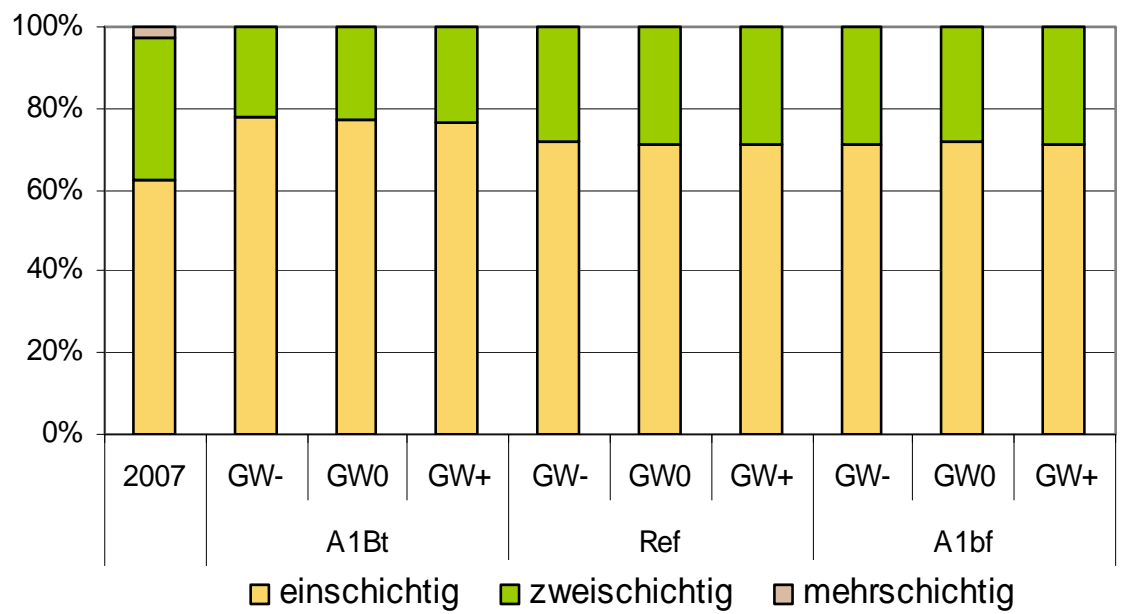

Abbildung 89: Anteile [\%] ein-, zwei- und mehrschichtiger Bestände in den Jahren 2007 sowie 2039 in Abhängigkeit von den Szenarien

Für die Abnahme der Vertikalstruktur der Bestände gibt es mehrere Ursachen. Eine Homogenisierung der Bestände ergibt sich einerseits durch das Einwachsen des Unterstandes in die Hauptschicht und andererseits durch eine modellbedingte, unter zunehmendem Wasserstress durchaus plausible, höhere Mortalität unterständiger Bäume. Darüber hinaus führen die schnelleren Abnutzungen älterer, häufig mehrschichtiger Bestände in den trockenen Klimaszenarien zu höheren Flächenanteilen einschichtiger Jungbestände. Des Weiteren wird nahezu kein Unterbau geplant, da Mischbaumarten bereits bei der Kulturbegründung eingebracht werden. 
Die Bestandesdichte beeinflusst ganz entscheidend das Zuwachsverhalten und damit die Vorratsentwicklung der Bestände. In Abhängigkeit von Baumart, Bestandesoberhöhe und Grundwassereinfluss werden im Rahmen der angewandten Waldbauregeln unterschiedliche Zielgrundflächen angestrebt. Da nach den Forsteinrichtungsdaten für 2007 die durchschnittliche Bonität der meisten Baumarten um die II. Ertragsklasse schwankt, erfolgte die Festlegung der Zielgrundflächen baumartenspezifisch auf Basis der Ertragstafelwerte für die II. Ertragsklasse, mäßige Durchforstung (SCHOBER 1987).

Die nachfolgenden Auswertungen zur Bestandesdichte erfolgten anhand des Kronenschlussgrades der Hauptschicht. Im Vergleich zum Ausgangszustand 2007 nehmen die Flächenanteile mit voller Überschirmung in allen Szenarien zu. Die Zunahme liegt in den trockenen Szenarien bei rund 5 Prozent und in den anderen Szenarien mit rund 7 Prozent etwas höher. Der Anteil der aufgelichteten Bestände mit einer Kronenschirmfläche von $<0,6$ bleibt in den trockenen Szenarien bei rund einem Viertel und nimmt in den restlichen Szenarien nur leicht um 1,5 bis 3 Prozent ab.

Eine differenzierte Betrachtung der wichtigsten Bestandesklassen zeigt, dass die Eichen- und Buchenbestände eine deutlich höhere Überschirmung aufweisen als die Kiefernbestände (s. Tab. 49).

Tabelle 49: $\quad$ Durchschnittlicher Überschirmungsgrad im Jahr 2039 für das gesamte Hessische Ried und für die wichtigsten Betriebstypen nach der führenden Baumart

\begin{tabular}{cccc|ccc|ccc}
\hline $\begin{array}{l}\text { Klimaszenario } \\
\begin{array}{l}\text { Grundwasser- } \\
\text { szenario }\end{array}\end{array}$ & GW- & GW0 & GW + & GW- & GW0 & GW + & GW- & GW0 & GW+ \\
\hline Eiche & 1,19 & 1,20 & 1,17 & 1,21 & 1,20 & 1,17 & 1,21 & 1,20 & 1,17 \\
Buche & 1,07 & 1,08 & 1,08 & 1,12 & 1,12 & 1,12 & 1,11 & 1,12 & 1,11 \\
Kiefer & 0,75 & 0,73 & 0,73 & 0,78 & 0,78 & 0,76 & 0,78 & 0,78 & 0,76 \\
\hline
\end{tabular}

Dabei ist zu beachten, dass die hohe Schattentoleranz der Buche zu Überschirmungsgraden größer 1,0 führen kann. Das trifft auch auf Eichenbestände mit Buchenbeimischung in der Hauptschicht zu. Verstärkt wird dieser Effekt dadurch, dass deutlich mehr Eichen- und Buchenbestände auf grundwasserabgesenkten Standorten stocken, für die im Sinne einer vorsichtigeren Bestandesbehandlung höhere Grundflächen angestrebt werden. Dagegen stocken die Kiefernbestände überwiegend auf schon immer grundwasserfernen Standorten, auf denen eine normale Bewirtschaftung mit stärkeren Eingriffen und geringerer Grundflächenhaltung vorgegeben ist. (s. Kap. 2.2.11.2, Tab. 25). Des Weiteren setzt auf einem größeren Anteil der Kiefernfläche während des Simulationszeitraumes bereits die Zielstärkennutzung ein, während sich Eichen- und Buchenbestände noch im Ausreifungsstadium befinden. Dieser Effekt wirkt durch herabgesetzte Zieldurch- 
messer in den trockenen Szenarien tendenziell stärker. Dabei ist die Endnutzung der Kiefer nicht zwangsläufig mit kurzfristigem Schirmschlag und Kiefernnaturverjüngung verbunden, sondern kann bei zeitlich gestreckter Zielstärkennutzung unter Übernahme vorhandenen Buchenunterstandes zu längeren lockeren bis lichten Schirmstellungen der Kiefer führen.

\subsubsection{Potenziale der nachbaltigen Holzproduktion}

\subsection{Ausgangszustand 2007}

Im Jahr 2007 belief sich der Gesamtderbholzvorrat aller Bestände im Hessischen Ried auf ca. 6,4 Millionen Vfm, was einem durchschnittlichen Hektarvorrat von $232 \mathrm{Vfm} /$ ha entspricht. Damit liegt der Holzvorrat je Hektar deutlich unter dem von der BWI 2 ermittelten Durchschnittsvorrat für Hessen. Dieser betrug im Jahre 2002 rund $320 \mathrm{Vfm} / \mathrm{ha}$, was gleichzeitig dem Bundesdurchschnitt entsprach. Vergleichbar niedrige Hektarvorräte wie das Hessische Ried wiesen die Bundesländer Brandenburg und Sachsen-Anhalt auf, die ebenfalls viele Sandstandorte mit Kiefer als Hauptbaumart aufweisen. Die Höhe des Holzvorrates wird neben der Baumartenverteilung von der Altersklassen- und Durchmesserverteilung sowie der vertikalen Ausnutzung des Raumes durch die Besetzung der verschiedenen Schichten mitbestimmt. Das Potenzial der nachhaltigen Holzproduktion wird, ausgehend von der gegenwärtigen Zusammensetzung und Struktur der Waldbestände, vor allem von der Leistungsfähigkeit der Standorte bestimmt. Das im Rahmen der Szenariosimulationen verwendete Standort-Leistungs-Modell schätzt die potenzielle Leistungsfähigkeit der Baumarten in Abhängigkeit von Standorts- und Klimavariablen als Mittelhöhe der Bestände im Alter 100 Jahre. Die Bonitätsschätzung für eine Baumart beruht auf den Flächen aller Bestände, in denen die jeweilige Baumart mit mindestens einem Baum vorkommt. Das so ermittelte potenzielle Höhenwachstum im Hessischen Ried liegt gegenwärtig für Eiche bei 27,3 m, für Buche bei 31,8 $\mathrm{m}$ und für Kiefer bei 28,7 $\mathrm{m}$ und damit höher als die jeweilige I. Ertragsklasse der Baumarten nach den Ertragstafeln (SCHOBER 1987). Dagegen ergibt das auf der Basis der Forsteinrichtungsdaten berechnete flächengewogene Mittel der Bonitäten für Eiche, Buche und Kiefer jeweils ungefähr eine II. Ertragsklasse und fällt damit geringer aus als die Schätzung des Standort-LeistungsModells.

Beide Größen lassen sich nur bedingt miteinander vergleichen. Die Unterschiede erklären sich u. a. durch den Bonitätsabfall der über 100-jährigen Bestände, ein verzögertes Jugendwachstum aufgrund gebietstypisch erhöhter Kulturgefahren und längerer Überschirmung. Außerdem kann im Hessischen Ried möglicherweise schon heute nicht mehr - wie im Modell unterstellt - von einer vollständigen Auffüllung des Bodenwasserspeichers zu Vegetationszeitbeginn ausgegangen werden (PRIES et al. 1999). Weitere, das Ried kennzeichnende Einflussgrößen wie überdurchschnittliche Nadel- bzw. Blattverluste, Maikäferfraß, Mistelbefall und Eichen- 
fraßgesellschaft können die tatsächliche Unterschreitung der potenziellen Standortleistungsfähigkeit mit verursachen.

\subsection{Entwicklung der Gesamtwuchsleistung}

Der Gesamtzuwachs der Bestände des Hessischen Rieds bis zum Ende des Simulationszeitraumes ergibt sich aus der Vorratszunahme zwischen den Stichjahren 2007 und 2039 zuzüglich der zwischenzeitlichen Holznutzungen einschließlich abgestorbener Bäume. Der durchschnittliche laufende Zuwachs liegt in Abhängigkeit von den Szenarien im Mittel des 32-jährigen Beobachtungszeitraumes zwischen 9,7 und 10,3 Vfm pro Hektar und Jahr. Das im Rahmen der Szenariosimulationen geschätzte Zuwachsniveau erscheint in Anbetracht der Vorschädigung der Bestände, des hohen Durchschnittsalters der Hauptbaumarten Kiefer und Buche und des allgemein niedrigen Volumenzuwachses von Eichenbeständen recht hoch. Der Unterschied zwischen dem zuwachsschwächsten und gleichzeitig trockensten Szenario GW-/A1Bt und den zuwachsstärksten Szenarien bei Grundwasseranhebung und unverändertem Klima bzw. feuchter Ausprägung von A1B beträgt 6 Prozent und fällt damit vergleichsweise gering aus (s. Tab. 50). Dabei ist zu beachten, dass das im Modell hinterlegte Zuwachsmodell selbst nicht klimasensitiv ist, sondern die Unterschiede nur indirekt aus den periodisch ermittelten Bonitätsunterschieden resultieren.

Neben dem Klimaeinfluss zeigt sich mit dem jeweils höchsten Zuwachs in den Grundwasseraufspiegelungs-Szenarien auch ein Trend zwischen den Grundwasserszenarien. Die Differenz zwischen den Szenarien GW- und GW+ beläuft sich bei Referenz- oder A1Bf-Klima auf $50.000 \mathrm{Vfm}$ und bei A1Bt-Klima auf 160.000 Vfm.

Tabelle 50: Gesamtzuwachs [Mio. Vfm] und durchschnittlicher laufender Volumenzunachs [V fm/ba/a] für den Zeitraum von 2007 bis 2039 in Abbängigkeit von den Szenarien

\begin{tabular}{lccc|ccc|ccc}
\hline $\begin{array}{l}\text { Klimaszenario / } \\
\begin{array}{l}\text { Grundwasser- } \\
\text { szenario }\end{array}\end{array}$ & GW- & GW0 & GW + & GW- & GW0 & GW+ & GW- & GW0 & GW+ \\
\hline $\begin{array}{l}\text { Gesamtzuwachs } \\
{[\text { Mio. Vfm }]}\end{array}$ & 8,59 & 8,66 & 8,75 & 8,99 & 9,02 & 9,04 & 8,99 & 9,02 & 9,04 \\
$\begin{array}{l}\text { lfd. Zuwachs } \\
\text { [Vfm/ha/a }\end{array}$ & 9,7 & 9,8 & 9,9 & 10,2 & 10,2 & 10,3 & 10,2 & 10,2 & 10,3 \\
\hline
\end{tabular}

Deutlich größere Unterschiede als in der Zuwachsleistung bestehen zwischen den Szenarien hinsichtlich des Verhältnisses zwischen Holznutzung und Vorratsentwicklung (s. Abb. 90). Die Holznutzung in den Szenarien mit Referenz- und A1BfKlima erreicht eine Größenordnung von etwa 6 Millionen Vfm, wohingegen vor allem forcierte Endnutzungen aufgrund herabgesetzter Zieldurchmesser in den Szenarien mit trockenem Klima zu einer höheren Gesamtnutzung von rund 
6,7 Millionen Vfm führen. Dazu kommt das Volumen von Bäumen, die aufgrund von Schadeinflüssen wie Grundwasserabsenkung, Engerlingsfraß oder anderen Faktoren abgestorben sind („Kalamitätsholz"). Es bewegt sich für die unterschiedlichen Szenarien zwischen 790.000 und $920.000 \mathrm{Vfm}$ bzw. 0,89 und 1,04 Vfm pro Hektar und Jahr, wobei hier die geringeren Mengen in den trockenen Szenarien anfallen. Insgesamt liegt der Nutzungssatz auf der tatsächlich genutzten Fläche - auf ca. 2.200 Hektar der Waldfläche finden aufgrund naturschutzfachlicher Restriktionen keine Nutzungen statt - zwischen 8,4 und 9,2 Vfm pro Hektar und Jahr.

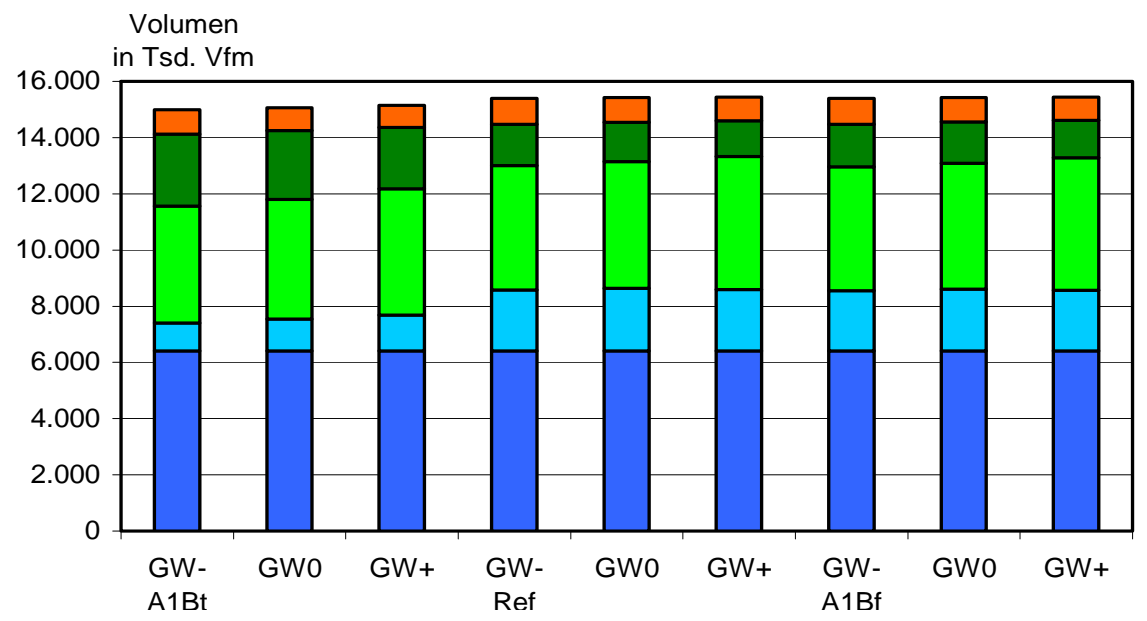

口Vorrat 2007 QVorratsaufbau $\square$ Vornutzungen $\square$ Endnutzungen $\square$ Kalamitätsholz

Abbildung 90: Szenarioabhängige Vorratsentwicklung [1000 Vfm] und Nutzungsmassen im Hessischen Ried für den Zeitraum 2007 bis 2039

In allen Szenarien wird der Zuwachs im Betrachtungszeitraum nicht vollständig genutzt. So kommt es innerhalb der 32 Jahre zu einem Vorratsaufbau, der je nach Szenario zwischen knapp einer und 2,2 Millionen Vfm liegt. Die Vorratssteigerung fällt im Szenario GW-/A1Bt am geringsten aus, immerhin steigt der durchschnittliche Hektarvorrat aber auch noch von 232 auf durchschnittlich $268 \mathrm{Vfm}$. Dieser geringere Vorratsaufbau konzentriert sich hier stark auf die Flächen, auf denen aus Naturschutzgründen jegliche Nutzung unterbleibt. Für die bewirtschaftete Fläche ist demzufolge in den A1Bt-Szenarien nur von einem geringen Vorratsaufbau auszugehen. Der größte Vorratsaufbau, der zu einem durchschnittlichen Hektarvorrat von 312 Vfm im Jahre 2039 führt, vollzieht sich im Szenario GW0/Ref.

Bei der Bewertung der Zuwachsentwicklung in den Waldentwicklungsszenarien ist die komplexe Wirkung mehrerer Einflussgrößen zu berücksichtigen. So unterliegen zuwachsbestimmende Größen wie die Baumartenzusammensetzung, der Altersklassenaufbau und die standörtliche Zuordnung der Baumarten über den Simulationszeitraum gewissen Veränderungen. Die szenarioabhängigen standört- 
lichen Veränderungen wirken sich auf die Baumartenzusammensetzung aus (s. Kap. 3.5.2.1). So werden in den trockenen Szenarien die ertragsschwächeren Baumarten Kiefer und Eiche aufgrund ihrer höheren Trockenheitstoleranz gefördert. Außerdem verschiebt sich durch die früher einsetzenden Endnutzungen in den A1Bt-Szenarien der Altersklassenaufbau zugunsten der bei den Licht- und Halbschattbaumarten zuwachsstärkeren I. und II. Altersklasse. Gleichzeitig führen die Standortsveränderungen in den Waldentwicklungsszenarien unmittelbar zu Veränderungen in der Leistungsfähigkeit der Baumarten, was seinen Ausdruck in den mit dem Standort-Leistungsmodell geschätzten Bonitätsänderungen findet. Diese Bonitätsänderungen sind auf die Dynamik der Einflussgrößen „Temperatursumme in der Vegetationszeit" und „Wasserversorgung des Standortes“ zurückzuführen. Dabei kommt im Hessischen Ried, wie Abbildung 91 unterstreicht, auch der Grundwassersituation eines Standortes große Bedeutung zu.

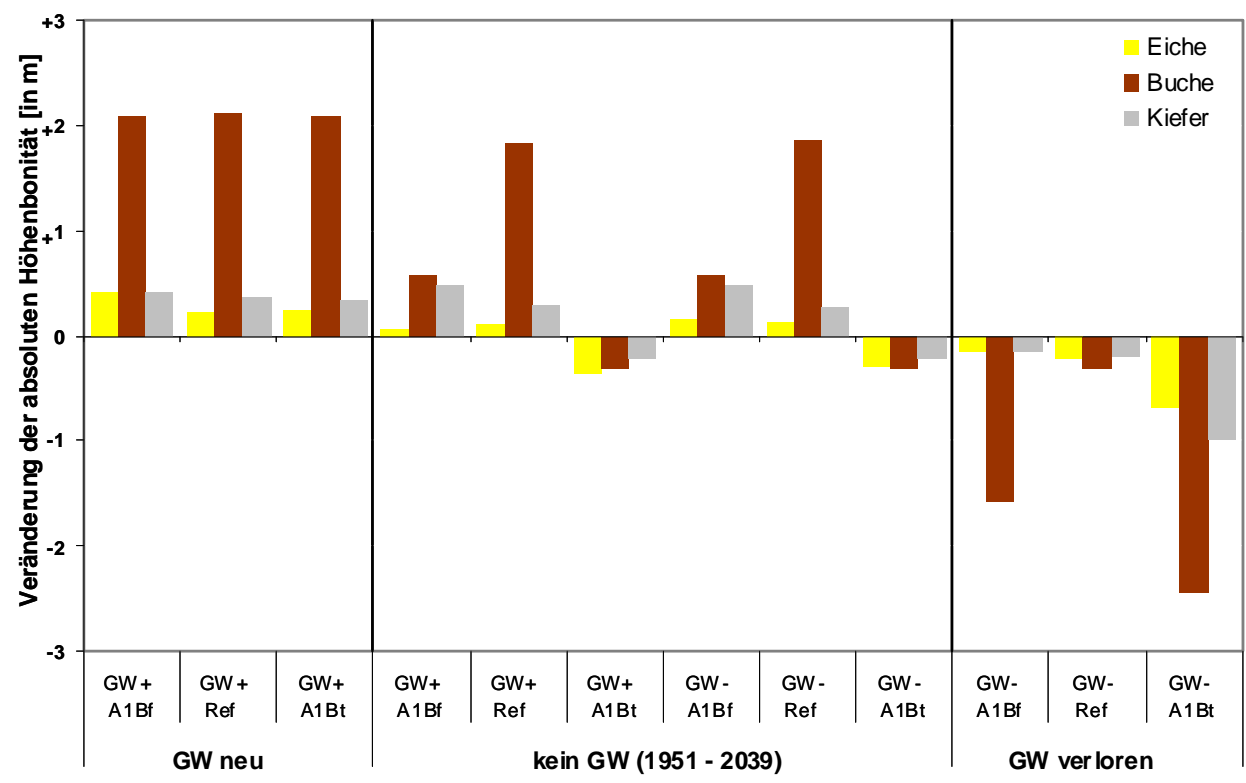

Abbildung 91: Geschätz̨te Veränderung der absoluten Höhenbonitäten [m] (b100 im Alter 100) für die Hauptbaumarten im Hessischen Ried bis 2039 in Abbängigkeit von den Szenarien und der Grundwassersituation des Standorts (Schätzung mit dem Standort-Leistungsmodell, ALBERT u. SCHMIDT 2008)

Generell sind die absoluten Bonitätsänderungen der Baumarten als Maß für deren jeweilige Leistungsfähigkeit in der summarischen Betrachtung für das gesamte Hessische Ried über alle Szenarien vergleichsweise gering. Eine Erklärung dafür liegt in den Temperatur- und Niederschlagsverläufen der Klimaprojektionen. Demnach ist erst nach 2040 mit einem steilen Temperaturanstieg und deutlich 
abnehmenden Vegetationszeitniederschlägen zu rechnen, während die Veränderungen im Simulationszeitraum zunächst moderat bleiben (s. Kap. 3.1). Tendenziell am geringsten fällt die Abnahme der Bonitäten als Reaktion auf sich verschlechternde Standortsbedingungen für die feuchte Variante des Klimaszenarios A1B aus. Aufschlussreicher als die absolute Höhe der Veränderungen ist ein Vergleich der Reaktionsmuster der Baumarten. Es gibt Hinweise auf Unterschiede in ihrer Sensitivität gegenüber den erwarteten Änderungen. Von den drei Hauptbaumarten reagiert die Buche am deutlichsten auf Veränderungen in der Wasserversorgung, sowohl auf grundwasserfernen Standorten bei Verschlechterung der klimatischen Wasserbilanz als auch auf die Veränderung der Grundwassersituation ihrer Standorte. Dies führt zu einer Verringerung der Gesamtwuchsleistung um bis zu 20 Prozent. Das potenzielle Höhenwachstum von Eiche und Kiefer wird dagegen über alle Szenarien hinweg nur wenig beeinflusst.

Die gesonderte Auswertung nach der Grundwassersituation der Standorte über die verschiedenen Szenarien verdeutlicht, dass grundwassernahe Standorte ungünstige Klimaänderungen kompensieren können (s. Abb. 91). Standorte, für die z. B. durch Aufspiegelung ein sicherer Grundwasseranschluss neu oder wieder hergestellt wird, ermöglichen unabhängig von Klimaveränderungen eine höhere Leistung der Baumarten. Hingegen ist auf Standorten, die diesen Grundwasseranschluss verlieren, mit einem deutlichen Rückgang der Leistungsfähigkeit der Baumarten zu rechnen. Das gilt zuerst für die Buche, die sowohl positiv als auch negativ am stärksten reagiert. Standorte, die Grundwasseranschluss behalten oder für die er sogar wieder hergestellt wird, puffern also je nach ihrem Anteil an der Gesamtfläche die negativen Auswirkungen des Klimawandels für das gesamte Hessische Ried mehr oder weniger stark ab. Für die Waldentwicklungsszenarien variiert der Anteil dieser Standorte, wie bereits dargestellt, zwischen nur ca. 9 Prozent (GW-), ca. 19 Prozent (GW0, entspricht dem aktuellen Stand) und ca. 37 Prozent im Szenario GW+ in Anlehnung an die Grundwasserstände von 1951.

\subsubsection{Entwicklung des Schadholzaufkommens}

Die Forstwirtschaft im Hessischen Ried wurde in den letzten Jahrzehnten u. a. durch den hohen Anfall an Kalamitätsholz bestimmt. Die Buchungen zum Betriebsvollzug weisen für den Zeitraum der Jahre 2000 - 2010 einen Schadholzanteil von rund 40 Prozent der genutzten Holzmasse aus (HEKAS-Auswertung 2010). Auch die Waldzustandsberichte (NW-FVA 2007, 2011) belegen eine gegenüber den Mittelwerten des Landes Hessen deutlich erhöhte Mortalität im Hessischen Ried. Der im Rahmen der simulierten Waldentwicklungsszenarien ermittelte Schadholzanteil erscheint dagegen zunächst gering. Demnach würden je nach Szenario in 32 Jahren nur 11 bis 14 Prozent des insgesamt genutzten Holzes als Schadholz anfallen. Allerdings handelt es sich bei den durch die Mortalitätsmodelle in den Simulationen abgebildeten Schadholzmengen nicht um die betriebsüblich als ,Kalamitätsnutzung’ oder ,Sammelhieb’ verbuchten Entnahmen stark vorge- 
schädigter Bäume sowie von Bäumen aus Sturmwurf oder aufgrund von Käferbefall, sondern ausschließlich um durch Trocknis, natürliche Konkurrenz oder Engerlingsfraß abgestorbene Bäume. Aus methodischen Gründen konnte die Entnahme geschädigter lebender Bäume vor Einsetzen einer weiteren Holzentwertung nicht berücksichtigt werden bzw. ist für ältere Bestände nur durch die Herabsetzung der Zielstärken auf den trockenen Standorten und daraus resultierende höhere Nutzungsmassen indirekt und teilweise mit erfasst. Außerdem konnte ein Sturmschadensrisiko, das in der Vergangenheit durchaus zu größeren Kalamitätsholzmengen und nachfolgender Destabilisierung von Waldbeständen im Hessischen Ried führte (z. B. Mitte der achtziger Jahre und 1990) aufgrund fehlender Parametrisierungsgrundlagen nicht in das Waldentwicklungsmodell implementiert werden. Berücksichtigt sind dagegen die Risikokomplexe Grundwasserabsenkungen und Maikäfer. Zu ihrer Abbildung wurden Module integriert, die erhöhte Absterberaten im Zusammenhang mit Grundwasserabsenkungen und hohen Engerlingsdichten abbilden.

In den Waldentwicklungsszenarien wurde für jeden Simulationsschritt zuerst das allgemeine Mortalitätsmodell angewandt, das u. a. den Einfluss des Grundwasserstandes und dessen Veränderung berücksichtigt. Mit jeweils knapp 50 Prozent des Gesamtanfalls wird damit für alle Szenarien bereits der größte Teil des Schadholzes beschrieben (s. Tab. 51). Da junge Bestände im Parametrisierungsdatensatz nicht enthalten waren, setzt die Wirkung des allgemeinen Mortalitätsmodells erst in Beständen ab der dritten Altersklasse ein.

Aufgrund hoher Engerlingsdichten abgestorbene Bäume machen weitere rund 14 Prozent des Kalamitätsholzaufkommens aus. Das restliche Drittel erklärt sich durch Absterbeprozesse bei Überschreitung maximaler Bestandesdichten, wie sie in dichten Waldbeständen allgemein und unabhängig von den Besonderheiten des Hessischen Rieds zu beobachten sind.

Der Massenanfall abgestorbener Bäume fällt in den A1Bt-Szenarien deutlich geringer aus als in den Ref- und A1Bf-Szenarien. Da das allgemeine Mortalitätsmodell nicht klimasensitiv wirkt, sind unterschiedliche Mortalitätsraten zwischen den Klimaszenarien auf die angepasste Bewirtschaftung der Bestände und damit in Zusammenhang stehende Veränderungen der Waldstrukturen zurückzuführen. So führen herabgesetzte Zielstärken auf den trockeneren Standorten und ggf. bei Verlust des Grundwasseranschlusses zu früheren Endnutzungen, die Wertverluste verhindern sollen und erhöhten Absterberaten zuvorkommen. 
Tabelle 51: $\quad$ Übersicht über die Nutzungsmassen und den Massenanfall abgestorbener Bäume über den 32-jährigen Simulationszeitraum in Abhängigkeit von den Szenarien

\begin{tabular}{|c|c|c|c|c|c|c|c|c|c|}
\hline \multirow{2}{*}{$\begin{array}{c}\text { Klimaszenario } \\
\text { Grundwasserszenario }\end{array}$} & \multicolumn{3}{|c|}{$\mathrm{A} 1 \mathrm{Bt}$} & \multicolumn{3}{|c|}{ Ref } & \multicolumn{3}{|c|}{$\mathrm{A} 1 \mathrm{Bf}$} \\
\hline & GW- & GW0 & GW+ & GW- & GW0 & GW+ & GW- & GW0 & GW+ \\
\hline $\begin{array}{l}\text { Gesamtnutzung } \\
{\left[\text { Tsd. } \mathrm{m}^{3}\right]}\end{array}$ & 7.587 & 7.510 & 7.461 & 6.818 & 6.781 & 6.846 & 6.846 & 6.819 & 6.876 \\
\hline Anteil Vornutzung [\%] & 55 & 56 & 60 & 65 & 66 & 69 & 64 & 66 & 69 \\
\hline Anteil Endnutzung [\%] & 34 & 33 & 29 & 21 & 21 & 19 & 22 & 21 & 19 \\
\hline Anteil abgestorben [\%] & 11 & 11 & 11 & 14 & 13 & 12 & 14 & 13 & 12 \\
\hline $\begin{array}{l}\text { Masse abgestorben } \\
{\left[\text { Tsd. } \mathrm{m}^{3}\right]}\end{array}$ & 865 & 811 & 790 & 919 & 873 & 836 & 921 & 871 & 833 \\
\hline davon: & & & & & & & & & \\
\hline $\begin{array}{l}\text { Anteil allg. Mortalität } \\
\text { (u. a. GW) }[\%]\end{array}$ & 48 & 49 & 49 & 47 & 49 & 49 & 47 & 49 & 49 \\
\hline $\begin{array}{l}\text { Anteil Mortalität } \\
\text { durch Maikäfer [\%] }\end{array}$ & 14 & 14 & 14 & 13 & 14 & 14 & 13 & 14 & 14 \\
\hline $\begin{array}{l}\text { Anteil dichtebedingte } \\
\text { Mortalität }[\%]\end{array}$ & 38 & 37 & 37 & 40 & 37 & 37 & 40 & 37 & 37 \\
\hline
\end{tabular}

Beim Vergleich der Grundwasserszenarien innerhalb der Klimaszenarien fällt erwartungsgemäß in den GW+ Varianten die geringste und in den GW- Varianten die höchste Menge an Schadholz an (s. Tab. 51). Dabei reagieren vor allem Eiche und Buche auf die unterschiedlichen Grundwasserszenarien. So liegt der Schadholzanteil von Eiche in den GW- Szenarien um etwa $10.000 \mathrm{~m}^{3}$ höher als in den $\mathrm{GW}+$ Szenarien. Bei Buche beträgt die Differenz 12 bis $14.000 \mathrm{~m}^{3}$. Dagegen sind für die überwiegend auf grundwasserfernen Standorten stockende Kiefer keine nennenswerten Unterschiede feststellbar. Die Unterschiede zwischen den Grundwasserszenarien beruhen ohnehin nur auf maximal 30 Prozent der Fläche, da für alle Szenarien ca. 61 Prozent der Standorte als immer grundwasserferne und mind. 9 Prozent (im Szenario GW-) als permanent grundwassernahe Standorte eingestuft wurden (s. Kap. 2.2.1).

Auch die Vertikalstruktur der Bestände wirkt sich auf die Mortalität aus. Zu Simulationsbeginn sind Eiche und Kiefer häufiger in der Hauptschicht vertreten, während Mischbaumarten wie Buche, Hainbuche oder Linde oftmals unterständig sind. In der Folge wird in Abhängigkeit von der sozialen Stellung im Bestandesgefüge für Eichen und Kiefern zunächst eine hohe Überlebenswahrscheinlichkeit geschätzt. Im Laufe der Simulation verändern sich die Bestandesstrukturen durch 
das Einwachsen der Buche in die Hauptschicht, wodurch sich deren Überlebenswahrscheinlichkeit im Modell verbessert.

Die für Absterbeprozesse relevanten Standortsparameter Bodensubstrat und nutzbare Feldkapazität sind als konstante Größen szenariounabhängig. Günstig auf die modellierte Überlebenswahrscheinlichkeit der Eichen wirkt der Umstand, dass die nutzbare Feldkapazität nFK_140 im Parametrisierungsdatensatz für die reinen Sande nur $100 \mathrm{~mm}$ und für die tonigen und lehmigen Standorte nur durchschnittlich $190 \mathrm{~mm}$ betrug, wohingegen die Mittelwerte für das gesamte Untersuchungsgebiet mit $148 \mathrm{~mm}$ für Sande und mit über $250 \mathrm{~mm}$ für lehmhaltige Substrate und Tone deutlich höher liegen.

Für Bestände, die nach 1940 begründet wurden, ist die Einflussgröße ,Referenz-Grundwasserstand', die eine Anpassung der Baumwurzeln an bestehende Standortsverhältnisse und ggf. wurzelerreichbares Grundwasser ausdrückt, ein Grundwasserstand nach 1970. Im Zusammenhang mit der Entwicklung der Grundwasserstände, wie sie beispielhaft am Verlauf des Grundwasserstands am Pegel Groß-Rohrheim (Nr. 544002) im Jägersburger Wald dargestellt ist (s. Abb. 6), unterliegen diese jüngeren Bestände demnach keiner Grundwasserabsenkung mehr. Vielmehr konnten sie sich an die herrschenden Verhältnisse anpassen bzw. partiell sogar von leichten zwischenzeitlichen Erholungen der Grundwasserstände profitieren. Absterbeerscheinungen sind in diesem Fall geringer als in älteren Beständen, die voll an frühere hohe Grundwasserstände angepasst waren und auf Grundwasserabsenkungen nicht mehr entsprechend reagieren konnten.

Über alle Waldentwicklungsszenarien gleichgerichtet geht die Fläche mit Ausfallraten von über 20 Prozent des Vorrates von durchschnittlich 480 Hektar (2011) auf rund 115 Hektar (2039) mit der Zeit (s. Abb. 92) deutlich zurück. Gleichzeitig nehmen die anfallenden Schadholzmengen von etwa $77.000 \mathrm{~m}^{3}$ im ersten simulierten 4-Jahres-Schritt auf ca. $46.000 \mathrm{~m}^{3}$ im letzten Simulationsschritt ab. Der größte Teil der abgestorbenen Bäume fällt zu allen Zeitpunkten und über alle Baumarten aufgrund der in diesem Stadium hohen dichtebedingten Mortalität in der natürlichen Altersstufe schwaches Baumholz mit Stückmassen zwischen 0,3 und $0,4 \mathrm{Vfm}$ an.

Die massive Auflichtung von Beständen mit hoher Mortalitätsrate führt zur Unterschreitung kritischer Kronenschlussgrade mit der Folge einer vorzeitigen Nutzung und Verjüngung dieser Bestände. Damit greift waldbauliches Handeln auf den besonders betroffenen Standorten weiteren sukzessiven Absterbeprozessen vor.

Durch Engerlinge bedingte Mortalität fallen je nach Szenario 110.000$126.000 \mathrm{~m}^{3}$ Kalamitätsholz an. Damit werden die durch Engerlingsfraß verursachten Schäden im Derbholzbereich wahrscheinlich deutlich unterschätzt 


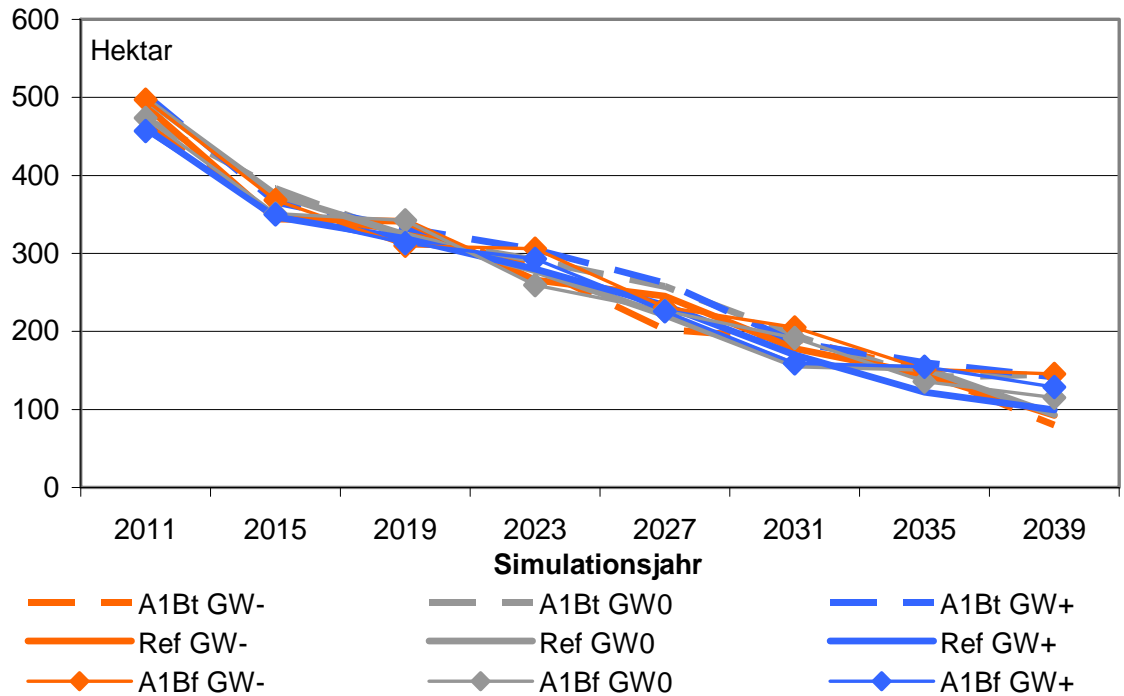

Abbildung 92: Entwicklung der Fläche [ha] mit Ausfallraten von über 20 Prozent des Holqvorrates über den Simulationszeitraum in Abhängigkeit von den Grundwasser- und Klimaszenarien

Absterbeerscheinungen bei Überschreitung maximaler Bestandesdichten, die der WaldPlaner unabhängig von gebietsspezifischen Bedingungen abbildet, konzentrieren sich szenariounabhängig zu einem hohen Anteil auf Flächen mit naturschutzfachlich begründetem Nutzungsverzicht.

\subsubsection{Walderneuerung}

Die Verjüngung von Waldbeständen leistet einen wesentlichen Beitrag zur nachhaltigen Sicherung aller Waldfunktionen. Dabei bietet insbesondere diese Waldentwicklungsphase die Möglichkeit, steuernd auf die Baumartenzusammensetzung einzuwirken, um auf bereits eingetretene oder künftig zu erwartende Veränderungen der Wachstumsbedingungen reagieren zu können.

Verjüngungsziel und Verjüngungszeitpunkt werden ganz wesentlich von der jeweiligen standörtlichen und waldbaulichen Ausgangssituation und deren zu erwartender Veränderung bestimmt. Wichtige Beurteilungskriterien sind u. a. die aktuelle Baumartenzusammensetzung, die Bestandes- und Altersstruktur sowie das Naturverjüngungspotenzial der Waldbestände. Darüber hinaus können Verjüngungshemmnisse, wie starke Vergrasung oder erhöhte Maikäferengerlingsdichten, Verjüngungsziel und -zeitpunkt beeinflussen.

Daneben sind auf größerer Fläche spezielle naturschutzfachliche Zielsetzungen zu beachten, wo einerseits durch den Schutz der natürlichen Alters- und Zerfallsphase die zur Verjüngung anstehende Fläche reduziert und zum anderen ein klar definiertes Verjüngungsziel vorgegeben wird. Hierbei darf nicht unberücksichtigt 
bleiben, dass es sich bei einem Großteil der Verjüngungsmaßnahmen um investive (künstliche) Waldverjüngungen handelt, die mit enormen Kosten verbunden sind.

Vor dem Hintergrund der verschiedenen zugrunde gelegten Entwicklungsszenarien kann sich das Verjüngungsgeschehen im Hessischen Ried sehr differenziert gestalten. Beispielsweise können günstige Wuchsbedingungen zu einem schnelleren Erreichen der Zielstärke des Ausgangsbestandes und damit zu einem früheren Verjüngungszeitpunkt führen. Sich verschlechternde Standortsbedingungen, wie sie in den Szenarien mit trockenem (A1Bt) Klima für weite Bereiche angenommen werden können, führen aufgrund herabgesetzter Zielstärken und einer höheren Einzelbaummortalität zum frühzeitigen Auflösen älterer Bestände. Neben einem beschleunigten Verjüngungsgang ist damit häufig ein vollständiger Bestockungswechsel, zumindest aber die künstliche Einbringung angepasster Mischbaumarten verbunden.

Für das Untersuchungsgebiet mit einer Gesamtgröße von insgesamt 27.660 Hektar stehen auf Basis der aktuellen standörtlichen und waldbaulichen Ausgangssituation rein rechnerisch bis zum Jahr 2039 rund 5.000 Hektar zur Waldverjüngung an. Diese überschlägige Kalkulation der Verjüngungsfläche erfolgte auf Grundlage der Baumartenzusammensetzung und der Altersstruktur der Hauptbestandesschicht sowie durchschnittlicher Produktionszeiten von 200 Jahren für Eiche, 80 Jahre für die Weichlaubhölzer und 140 Jahre für die anderen Baumartengruppen. Die dabei nicht einbezogene Übernahme von Unterstand und der Nutzungsverzicht auf naturschutzrelevanten Flächen führen jedoch zu einer Überschätzung der Fläche investiver Verjüngung. Darüber hinaus orientieren sich die Abnutzungen älterer Bestände nicht am Alter, sondern an den vorgegebenen Zielstärken.

Die Berücksichtigung unterschiedlicher Grundwasser- und Klimaszenarien führt im Modell zunächst zu Veränderungen des pflanzenverfügbaren Wassers und infolgedessen häufig zu veränderten Waldentwicklungszielen.

Bei der Interpretation der im Folgenden vorgestellten Ergebnisse ist zu beachten, dass der tatsächlich notwendige Flächenumfang investiver Waldverjüngung schwer einzuschätzen ist. Unter die investiven Waldverjüngungsmaßnahmen fallen neben Saat und Pflanzung auch gezielt eingeleitete Naturverjüngungen (z. B. Kiefernnaturverjüngung mit maschineller Bodenverwundung). Nachwuchs aus spontaner Naturverjüngung erfüllt gerade unter den Rahmenbedingungen des Hessischen Rieds häufig nicht die Anforderungen einer nach Qualität und Baumartenzusammensetzung zielgerechten Walderneuerung. Deshalb kann der Anteil investiver Verjüngungsmaßnahmen höher ausfallen. Beschrieben ist die ,einfach' verjüngte Fläche, d. h. Ausfälle, die eine Nachbesserung oder komplette Wiederholung der Kultur erfordern, was im Hessischen Ried erfahrungsgemäß häufiger vorkommt, werden in der Flächenbilanz (s. Tab. 52) nicht erfasst. 
Tabelle 52: $\quad$ Szenarioabhängige Verjüngungsfläche [ha] im Hessischen Ried unterteilt in investive Verjüngung und Naturverjüngung

\begin{tabular}{lccc|ccc|ccc}
\hline & \multicolumn{3}{c|}{ A1Bt } & \multicolumn{3}{c|}{ Ref } & \multicolumn{3}{c}{ A1Bf } \\
& GW- & GW0 & GW + & GW- & GW0 & GW + & GW- & GW0 & GW + \\
\hline invest. Verj. & 4.601 & 4.299 & 3.869 & 1.656 & 1.585 & 1.698 & 1.768 & 1.742 & 1.757 \\
Naturverj. & 131 & 174 & 162 & 126 & 170 & 114 & 171 & 124 & 101 \\
\hline Gesamt & 4.732 & 4.473 & 4.031 & 1.782 & 1.755 & 1.812 & 1.939 & 1.866 & 1.858 \\
\hline
\end{tabular}

Die Angaben zur investiven Verjüngung beruhen auf der Summe der Flächen in den Altersklassen I und II. Die Naturverjüngung basiert auf den Bestandesflächen mit einer übernahmewürdigen Verjüngungsschicht, die mindestens ein Drittel der Fläche überschirmt. Von den potenziellen Ausfallursachen wird nur der Engerlingsfraß des Maikäfers berücksichtigt, während Wildverbiss, Dürre, Frost oder Pilzerkrankungen durch das Modell nicht abgebildet werden können.

Die bis zum Jahr 2039 zu verjüngende Waldfläche unterscheidet sich besonders deutlich in Abhängigkeit von den unterstellten Klimaszenarien. Bei konstantem Grundwasserregime (GW0) ist die zu verjüngende Fläche im trockenen Klimaszenario mit rund 4.500 Hektar gegenüber der Referenz bzw. dem feuchten Szenario um ca. 60 Prozent erhöht. Darüber hinaus variiert die zu verjüngende Fläche innerhalb des trockenen Klimaszenarios auch zwischen den Grundwasserszenarien in einer vergleichsweise deutlichen Spanne von etwa 700 Hektar. Bei sinkendem Grundwasserspiegel (GW-) ist mit einer Verjüngungsfläche von ca. 4.730 Hektar zu rechnen, wobei der Anteil investiver Verjüngung mit 97 Prozent deutlich überwiegt.

Auch in den anderen Szenarien entfallen durchweg über 90 Prozent der Fläche auf investive Verjüngungsmaßnahmen. Die zwar nicht selten spontan aufkommende natürliche Verjüngung, i. d. R. aus Buche, Hainbuche, Weich- oder Edellaubbäumen, erreicht häufig keine ausreichende Dichte, sodass der Anteil gesicherter Naturverjüngung nur 3-10 Prozent der Verjüngungsfläche einnimmt.

Bei sich verschlechternden Klimabedingungen kommt es unabhängig von den unterstellten Grundwasserszenarien über alle Baumartengruppen hinweg zu einer Zunahme ihrer tatsächlichen Verjüngungsfläche (s. Abb. 93). Die größte flächenmäßige Zunahme mit rund 1.900 Hektar ist im trockenen Klimaszenario bei der Kiefer zu beobachten, wodurch ihr Anteil an der Gesamtverjüngung von derzeit etwa 18 Prozent auf bis zu 52 Prozent anwächst. Die Zunahme für die Eichen und Douglasien fällt hingegen vergleichsweise moderat aus, da sich besonders unter dem trockenen Klimaszenario viele der heute noch in der Frischestufe F3 befindlichen Standorte in Richtung der Frischestufen F4 (gering) und F5 (sehr gering) entwickeln, die der Kiefer vorbehalten sind. 


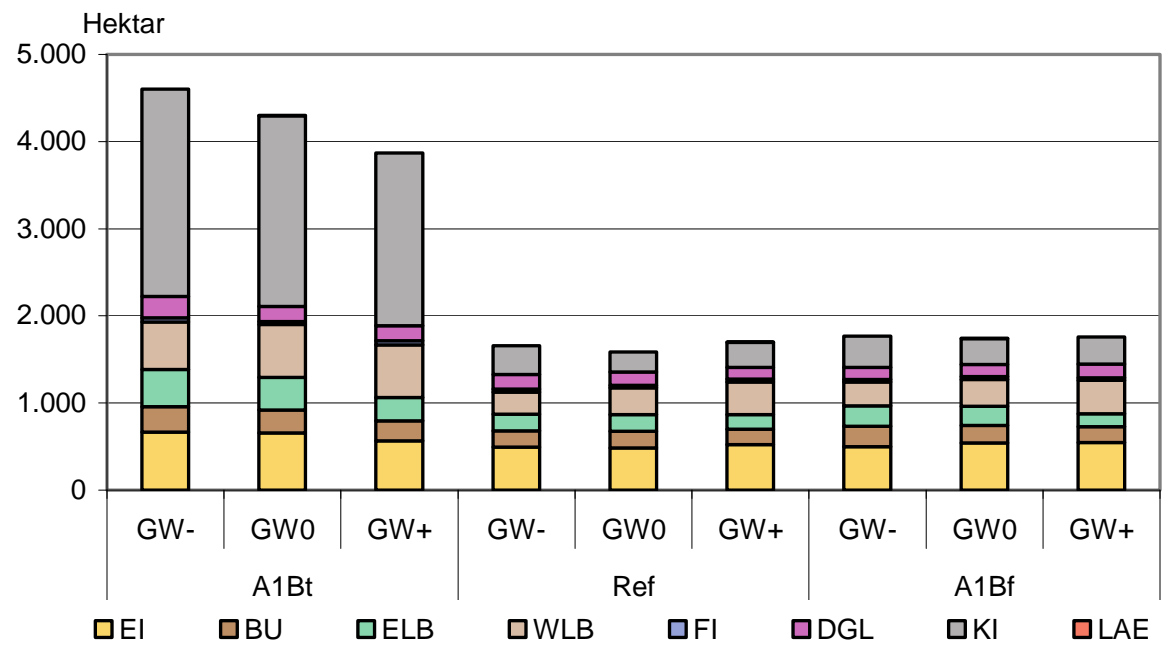

Abbildung 93: Simulierte Verjüngungsfläche [ba] im Hessischen Ried bis zum Jahr 2039 nach Szenarien und Baumartengruppen

Die Buche und die Weichlaubbäume profitieren als Mischbaumarten von der deutlichen Erweiterung der Verjüngungsfläche. Die Weichlaubbäume sind in nahezu allen geplanten Waldentwicklungstypen mit einem durchschnittlichen Mischungsanteil von 10 Prozent vertreten. Die Ausdehnung der Buchenanteilsfläche beruht überwiegend auf der Einbringung in Kiefern- und Douglasien-Mischbestandstypen (Kiefer-Buche, Kiefer-Douglasie-Buche, Douglasie-Buche). Die in geringerem Umfang beteiligte Hainbuche rekrutiert sich sowohl aus Naturverjüngung wie auch aus der künstlichen Begründung von Eichen-Hainbuchen-Beständen.

Aus betriebswirtschaftlicher Sicht sind vor allem die Kosten für künstliche Verjüngungsmaßnahmen von Interesse. Neben dem hohen Anteil von rund 90 Prozent investiver Verjüngung ist auch von umfangreichen Nachbesserungen auszugehen. Auf Grundlage der Betriebsvollzugsdaten der letzten 10 Jahre beträgt der Anteil der Nachbesserungen 50 Prozent der Verjüngungsfläche. In der Regel ist eine Zäunung der Flächen unerlässlich.

Die bisherigen Erfahrungen der Forstämter sowie die Ergebnisse aus Verjüngungsversuchen der NW-FVA lassen den Schluss zu, dass Verjüngungsmaßnahmen unter den gegebenen Rahmenbedingungen im Hessischen Ried in der Regel ohne gezielte Bodenvorbereitungen nicht Erfolg versprechend sind. Insbesondere auf Freiflächen oder unter aufgelichtetem Schirm entwickelt sich meist sehr schnell eine konkurrenzstarke Bodenvegetation (z. B. dichte Reitgras-Decken), die einerseits ein massives Verjüngungshemmnis darstellen und andererseits die Lebensbedingungen der Maikäferengerlinge verbessern können. 


\subsection{Waldschutz}

Eingangsgröße für die Prognose des Einflusses der Waldmaikäfer auf die Bestände ist die Populationsdichte der Engerlinge im dritten Larvenstadium (E3-Dichte). Für jeden der 7.201 Bestände und für jedes Waldentwicklungsszenario (GW-, GW0, GW+) wurde auf der Basis der Grabungsdaten 2009/2010 die Engerlingsdichte modelliert (s. Kap. 2.2.7.2.1). Eine Dynamisierung dieser Dichten, also die zeitliche Entwicklung der Population der Waldmaikäfer in Ausbreitung und Dichte konnte aufgrund fehlender konsistenter Zeitreihen der Grabungsdaten nicht erfolgen. Somit blieben die Populationsdichten während des gesamten Simulationszeitraumes für das jeweilige Szenario unverändert.

Da die standörtlichen und grundwasserbedingten Verhältnisse für das Untersuchungsgebiet relativ heterogen sind, besitzen maikäferbezogene Auswertungen über das Gesamtgebiet hinweg häufig nur geringe Aussagekraft. Daher wurden die Auswertung nach sieben naturräumlich getrennten oder hinsichtlich ihrer standörtlichen Ausstattung unterschiedlichen Regionen vorgenommen (s. Abb. 94).

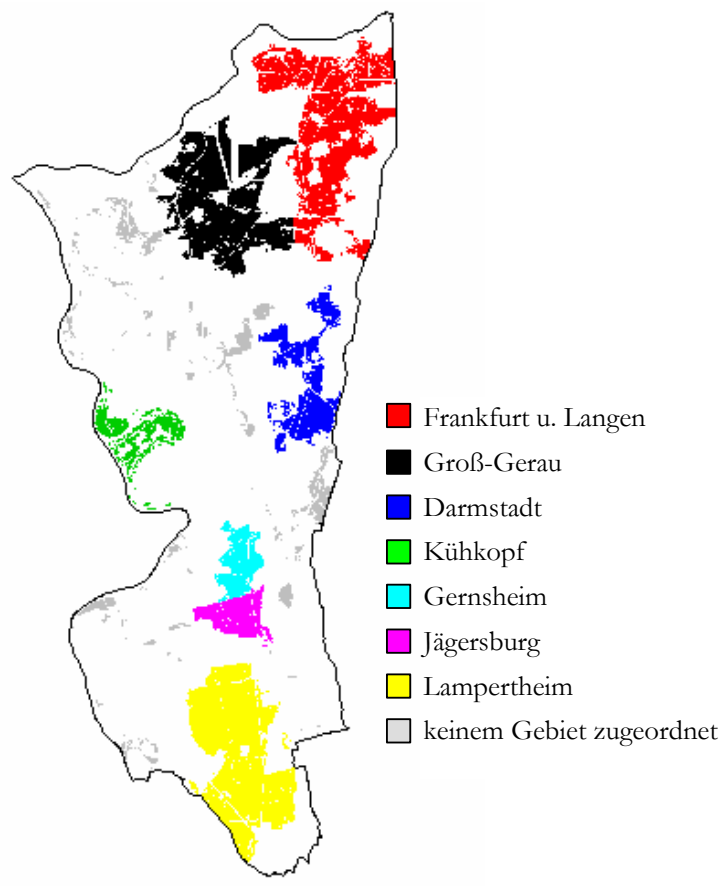

Abbildung 94: Einteilung des Hessischen Rieds in Regionen zur Analyse der Auswirkungen des Maikäferbefalls

Durch diese gebietsweise Betrachtung traten maikäferbedingte Effekte wesentlich deutlicher hervor. Benannt wurden die Regionen in Anlehnung an die aktuellen 
Forstamts- und Revierbezeichnungen. Nicht jede Waldfläche des Hessischen Rieds wurde einem dieser Gebiete zugeteilt. Die nicht zugewiesenen Flächen nehmen nahezu 10 Prozent der gesamten Waldfläche ein. Knapp 70 Prozent der Waldfläche des Hessischen Rieds ist den drei Gebieten Groß-Gerau, Frankfurt u. Langen sowie Lampertheim mit nahezu ähnlichen Anteilen zugeordnet (s. Tab. 53).

Tabelle 53: $\quad$ Flächenangaben zu den Auswertungsgebieten für die Engerlingsdichten

\begin{tabular}{lcc}
\hline Gebiet & $\begin{array}{c}\text { Waldfläche } \\
{[\text { ha] }}\end{array}$ & $\begin{array}{c}\text { Anteil an der Gesamtwaldfläche } \\
\text { des Hess. Rieds [\%] }\end{array}$ \\
\hline Groß-Gerau & $5.886,5$ & 21,3 \\
Frankfurt u. Langen & $6.472,8$ & 23,4 \\
Kühkopf & $1.234,8$ & 4,5 \\
Darmstadt & $2.431,8$ & 8,8 \\
Gernsheim & $1.197,6$ & 4,3 \\
Jägersburg & $1.232,1$ & 4,5 \\
Lampertheim & $6.512,5$ & 23,5 \\
keinem Gebiet zugeordnet & $2.691,5$ & 9,7 \\
\hline Waldfläche gesamt & $27.659,6$ & 100,0 \\
\hline
\end{tabular}

Bei der Regionalisierung (Interpolation) der Populationsdichte der Engerlinge in die Fläche traten in einigen wenigen Fällen modellbedingte „Ausreißer“ auf. So gab es einzeln gelegene, meist randständige Bestände, die wesentlich höhere Dichten aufwiesen als der Rest der Modellregion. Dies betraf insgesamt 11 Bestände in den Gebieten Darmstadt und Lampertheim. Diese 11 Bestände wiesen die „Ausreißer“ in unterschiedlichen Szenarien auf. Da die „Ausreißer“ nur im Modell vorkamen und nicht durch reale Messwerte gestützt werden, wurden die 11 Bestände in den Auswertungen nicht weiter berücksichtigt. Abbildung 95 zeigt exemplarisch anhand des Szenarios GW0/Ref für das Jahr 2039 drei der 11 „Ausreißer“. In der Abbildung sind die Engerlingsdichten der gesamten Bestände des Untersuchungsgebietes und die durch Engerlinge verursachte Mortalität angegeben. Es ist zu erkennen, dass sich die drei rechts abgebildeten Bestände mit einer Dichte von über 20 Engerlingen pro Quadratmeter von den anderen Beständen merklich unterscheiden. Darüber hinaus zeigt sich, dass bereits bei geringen Engerlingsdichten eine hohe Mortalität in den Beständen unabhängig von der Altersklasse auftreten kann. Bei Dichten ab fünf Engerlingen pro Quadratmeter werden Waldbäume im Modell in ihrer Vitalität stärker beeinträchtigt und sterben mit höherer Wahrscheinlichkeit ab. Auf junge Waldbäume (Kultur/natürliche Verjüngung) wirkt diese Dichte bereits letal. 
Darüber hinaus traten durch die Modellierung (Interpolation) der Populationsdichte in die Fläche kaum ,reine“ Nullwerte auf. Aus diesem Grund wurden für die Auswertungen für die Dichteklasse Null die Werte kleiner oder gleich 0,49 zur Dichteklasse Null zusammengefasst.

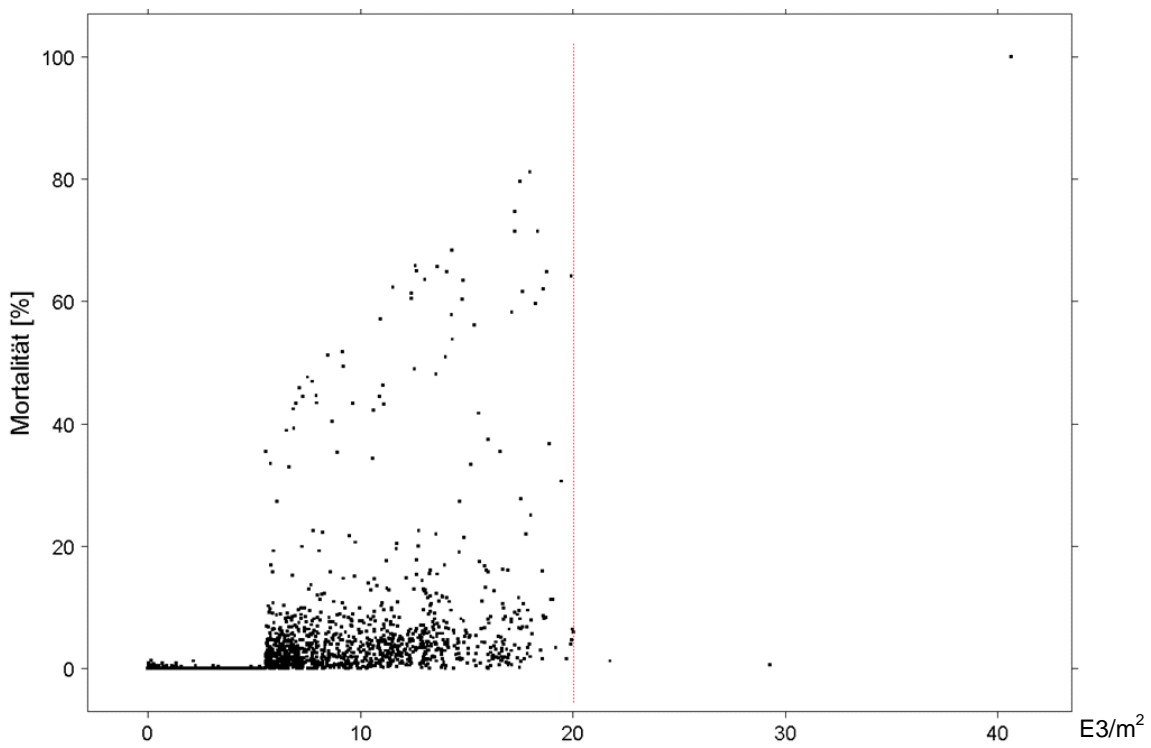

Abbildung 95: Modellierte Ausgangsdichte $\left[\mathrm{E} 3 / \mathrm{m}^{2}\right]$ der Waldmaikäfer-Engerlinge (E3-Stadium) und Mortalität der Bestände [\%] für das Szenario GW0/Ref im Jahr 2039

\subsubsection{Populationsdichte der Waldmaikëfer im Hessischen Ried}

\subsubsection{Vergleich der realen und der geschätəten Populationsdichte}

Auf Basis der Grabungen des Jahres 2009 (500 x 500 m-Raster im Hessischen Ried) und 2010 (250 x 250 m-Raster in Pfungstadt/Darmstadt) wurden die Ausgangsdichten der Engerlinge im dritten Larvenstadium (E3-Dichte) für die verschiedenen Grundwasserszenarien abgeleitet. Es ist auffällig, dass die modellierten Dichten in allen Szenarien niedrigere Werte aufweisen, als die in den Grabungen ermittelten Dichten. Die höchsten aus den Mittelwerten der Grabungen regionalisierten Dichten lagen (nach Ausschluss der „Ausreißer") für alle Szenarien bei rund 20 Engerlingen pro Quadratmeter. Der Maximalwert der Grabungswerte dagegen betrug 100 Engerlinge pro Quadratmeter. Der Unterschied ist dadurch zu erklären, dass das Modell Mittelwerte für Bestände schätzt, aber die realen Grabungswerte mehr oder weniger stark variieren, sodass in ein und demselben Bestand Dichten zwischen null und 100 Engerlingen pro Quadratmeter auftreten können. Es kann daher unterstellt werden, dass die Auswirkungen der Engerlinge auf die Waldbäume im Modell tendenziell eher zu gering geschätzt werden. 
Das Gebiet Darmstadt weist im Szenario GW0 (s. Tab. 54) die höchste Differenz zwischen der Grabungsdichte und der modellierten Ausgangsdichte auf. Die modellierte mittlere Dichte liegt hier rund zwei $\mathrm{E} 3 / \mathrm{m}^{2}$ unter der mittleren Grabungsdichte. Dieser Unterschied ist als erheblich einzuschätzen, da zwei $\mathrm{E} 3 / \mathrm{m}^{2}$ sich bereits stark schädigend auf die Waldbäume auswirken können. Eine ebenfalls hohe Differenz ist für das Gebiet Jägersburg festzustellen. Die geschätzte Dichte für das Szenario GW0 liegt mit rund einem Engerling pro Quadratmeter unter der realen Dichte. Die anderen Gebiete weisen geringe Differenzen von - 0,2 bis $0,3 \mathrm{E} 3 / \mathrm{m}^{2}$ auf, wobei die geschätzte Dichte für GW0 mit Ausnahme der Gebiete Kühkopf und Gernsheim immer niedriger ist, als die bei den Grabungen ermittelte Dichte.

Tabelle 54: Vergleich der Engerlingsdichten (E3-Stadium) $\left[\mathrm{E} 3 / \mathrm{m}^{2}\right]$ der Grabung 2009 und der modellierten Ausgangsdichten für das Szenario GWO

\begin{tabular}{lccc}
\hline Gebiet & Grabung 2009 & $\begin{array}{c}\text { Szenario GW0 } \\
\text { Mittlere Anzahl E3/m } \mathbf{m}^{2}\end{array}$ & Differenz \\
\hline Groß-Gerau & 1,6 & 1,3 & 0,3 \\
Frankfurt u. Langen & 0,1 & 0,1 & 0,0 \\
Kühkopf & 0,0 & 0,1 & $-0,1$ \\
Darmstadt & 12,0 & 10,3 & 1,7 \\
Gernsheim & 0,8 & 1,0 & $-0,2$ \\
Jägersburg & 6,7 & 5,9 & 0,8 \\
Lampertheim & 5,0 & 4,9 & 0,1 \\
\hline
\end{tabular}

\subsubsection{Vergleich der modellierten Populationsdichten}

Im Vergleich der modellierten Dichten ist festzustellen, dass über die gesamte Waldfläche des Hessischen Rieds betrachtet das Szenario Grundwasserabsenkung (GW-) mit im Mittel rund drei $\mathrm{E} 3 / \mathrm{m}^{2}$ zu der höchsten Populationsdichte führt. Die Engerlingsdichte der Szenarien Grundwasseranhebung $(\mathrm{GW}+)$ und Status quo (GW0) betragen beide im Mittel ca. zwei E3/ $\mathrm{m}^{2}$. Die höchsten mittleren Dichten liegen bei allen Szenarien bei rund 20 Engerlingen pro Quadratmeter.

Werden die modellierten Dichten der Gebiete insgesamt verglichen, ist augenscheinlich, dass die höchsten Dichten in allen Szenarien im Gebiet Darmstadt auftreten (s. Abb. 96). Ebenfalls hohe Dichten weisen die Gebiete Jägersburg und Lampertheim auf. In den anderen Gebieten sind bei allen Szenarien niedrigere Ausgangsdichten zu verzeichnen, wobei die geringsten Dichten in den Gebieten Kühkopf, Frankfurt/Langen und Gernsheim auftreten. Diese Verteilung der Dichten ist außer auf den Grundwasserstand und die Tonmächtigkeit des Bodens vor allem auch auf den Einfluss der räumlichen Lage zurückzuführen (s. Kap. 2.2.7.2.1). 


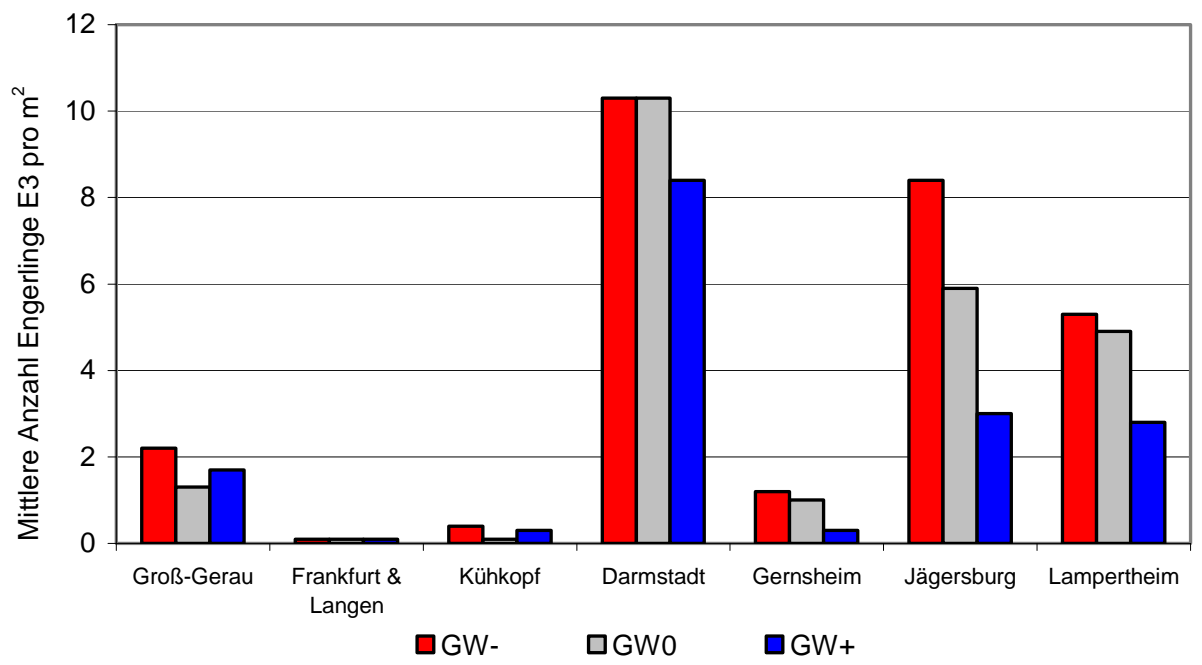

Abbildung 96: Mittlere modellierte E3-Engerlingsausgangsdichte $\left[\mathrm{E} 3 / \mathrm{m}^{2}\right]$ der $W$ aldmaikäfer für die Szenarien $G W$-, GW0 und $G W+$

Zwischen den Szenarien ergeben sich die Unterschiede vor allem durch den Einfluss des Grundwasserstandes auf die Engerlingsdichte, denn der Einfluss der räumlichen Lage und der Tonmächtigkeit im Boden auf die Dichte bleibt in den Szenarien unverändert.

In Darmstadt sind die modellierten Engerlingsdichten für die Szenarien GWund GW0 ohne Unterschied am höchsten, während das Szenario GW+ die geringste Ausgangsdichte aufweist (s. Abb. 96). Die größten Differenzen zwischen den Ausgangsdichten der Szenarien treten im Gebiet Jägersburg auf. Wie erwartet kommen die höchsten Ausgangsdichten im Szenario GW- und die niedrigsten im Szenario GW+ vor. Im Gebiet Frankfurt u. Langen sind die modellierten Ausgangsdichten bei allen Szenarien nahezu gleich gering. Im Gebiet Groß-Gerau stellt sich die Situation anders dar. Das Szenario GW0 weist in diesem Gebiet eine geringere Ausgangsdichte als das Szenario GW+ auf. Dies ist darauf zurückzuführen, dass im Rahmen der Regionalisierung der wenigen für 1951 vorliegenden Pegelmessungen bei diesem Szenario hier geringere Grundwasserstände ermittelt wurden, als sie für das Szenario GW0 angenommen werden.

Die Maximalwerte der modellierten mittleren Ausgangsdichten der Szenarien belaufen sich auf höchstens ca. $20 \mathrm{E} 3 / \mathrm{m}^{2}$. Sie treten in den Gebieten Darmstadt, Lampertheim, Jägersburg und Groß-Gerau auf (s. Abb. 97). Besonders auffällig ist das Gebiet Groß-Gerau, welches trotz geringer mittlerer Ausgangsdichte hohe Maximalwerte aufweist, was auf die für 1951 unterstellten Grundwasserstände zurückzuführen ist, die wie die Ausgangssubstrate und räumlichen Effekte in die Dichteschätzungen eingegangen sind. 


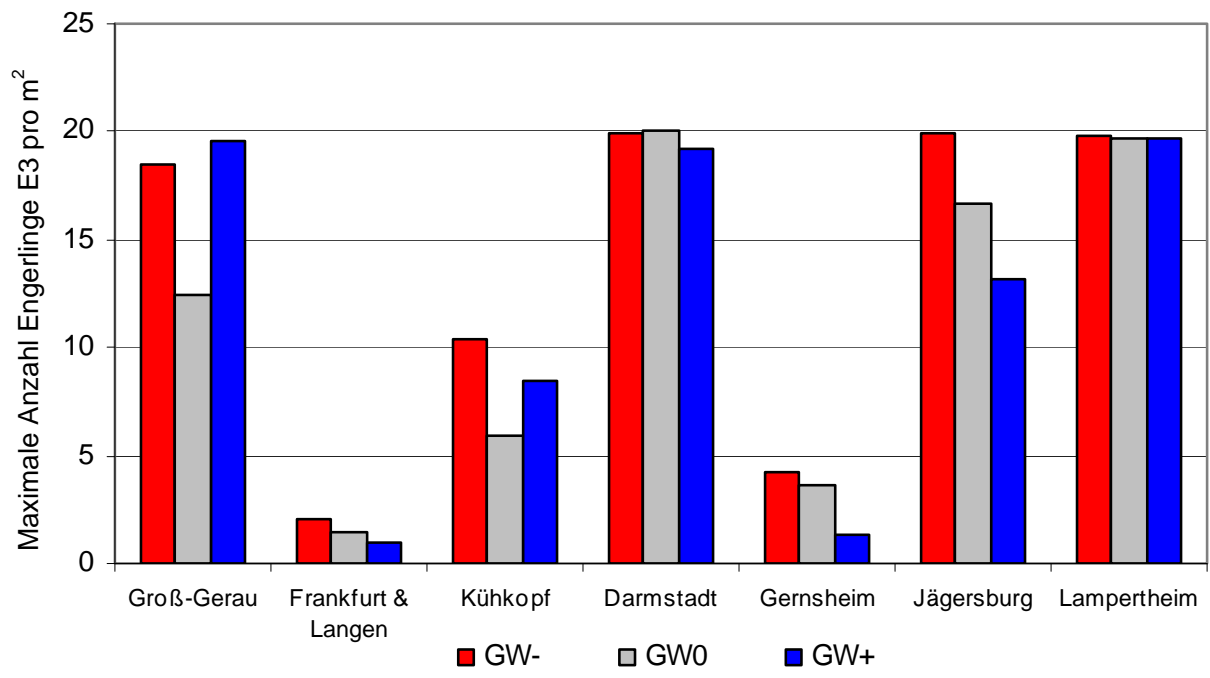

Abbildung 97: Maximalwerte der modellierten mittleren E3-Engerlingsdichten [E3/ $\left.\mathrm{m}^{2}\right]$ für die Szenarien $G W$-, $G W 0$ und $G W+$

In den Abbildungen 98 und 99 werden die Unterschiede der Verteilung der modellierten mittleren Ausgangsdichte der Waldmaikäfer-Engerlinge für die Szenarien bestandesscharf kartografisch verdeutlicht. Abgebildet sind die Ausgangsdichten für das gesamte Hessische Ried (s. Abb. 98) sowie für die Gebiete Groß-Gerau, Darmstadt, Jägersburg und Lampertheim (s. Abb. 99).

Es ist erkennbar, dass das Gebiet Darmstadt, das Gebiet mit den höchsten Engerlingsdichten, im nördlichen Bereich im Szenario GW+ deutlich geringere modellierte Dichten aufweist als in den anderen Szenarien. In anderen Bereichen von Darmstadt sind auf hohem Niveau die Unterschiede zwischen den modellierten Dichten eher gering. In ähnlicher Weise trifft das auch für das Gebiet Lampertheim zu. Zwischen den Szenarien GW- und GW0 bestehen in Lampertheim kaum Unterschiede. Die geringsten Dichten treten im Szenario GW+ in einem Streifen vom Nordwesten nach Südosten auf (s. Abb. 99).

Große Unterschiede zwischen den Ausgangsdichten der Szenarien weist das Gebiet Jägersburg auf. Die höchsten modellierten Dichten kommen im Szenario GW- vor allem im südlichen Bereich vor. In diesen Bereich sind die Dichten im Szenario GW+ am geringsten.

Im Norden des Gebietes Groß-Gerau stellt sich die Situation umgekehrt dar. Das Szenario GW+ weist gegenüber den anderen Szenarien in diesem Bereich erhöhte Dichten auf (s. Abb. 99). Ausschlaggebend hierfür ist - wie bereits erwähnt - der gegenüber dem für das Status quo-Szenario zugrunde gelegten Grundwasserstand bei der Regionalisierung ermittelte niedrigere Grundwasserstand für das Jahr 1951. 


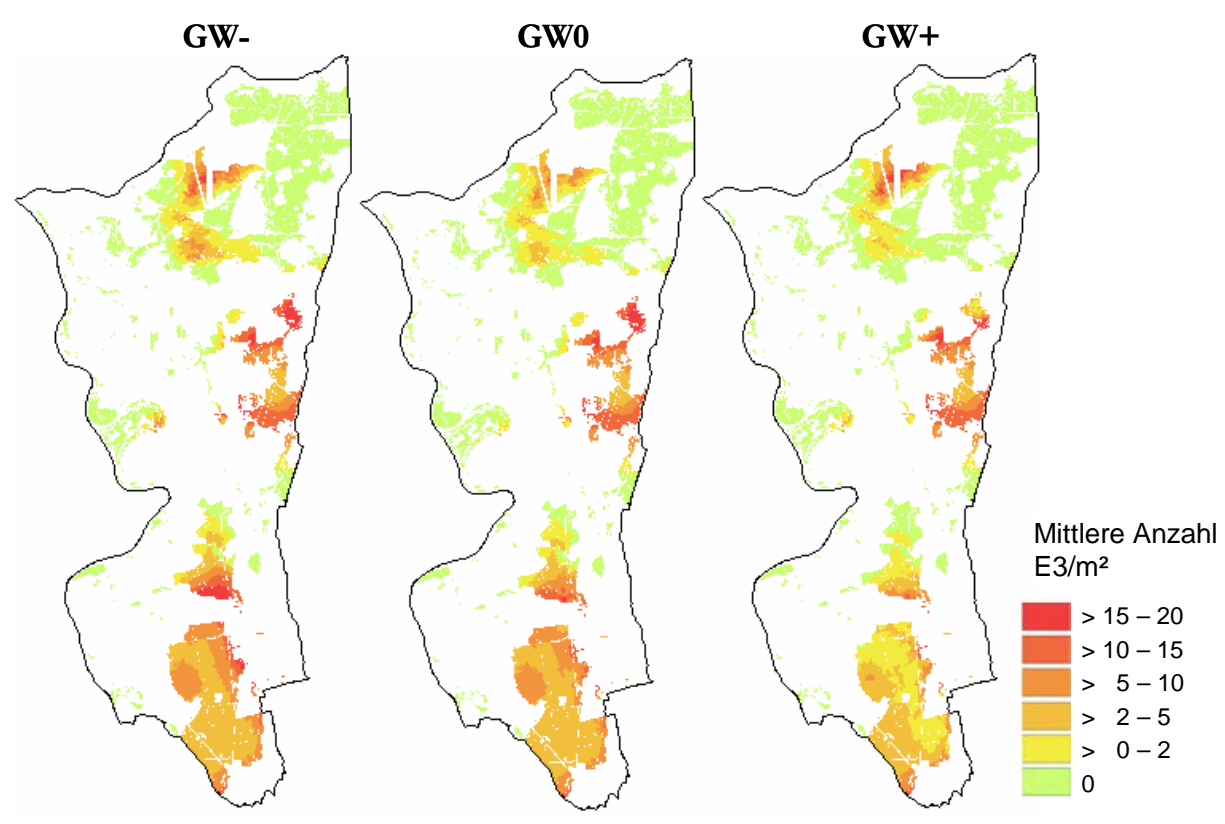

Abbildung 98: Modellierte E3-Engerlingsdichte [E3/ $\left.\mathrm{m}^{2}\right]$ der Szenarien $G W-, G W 0$ und $G W+$ für das Hessische Ried 

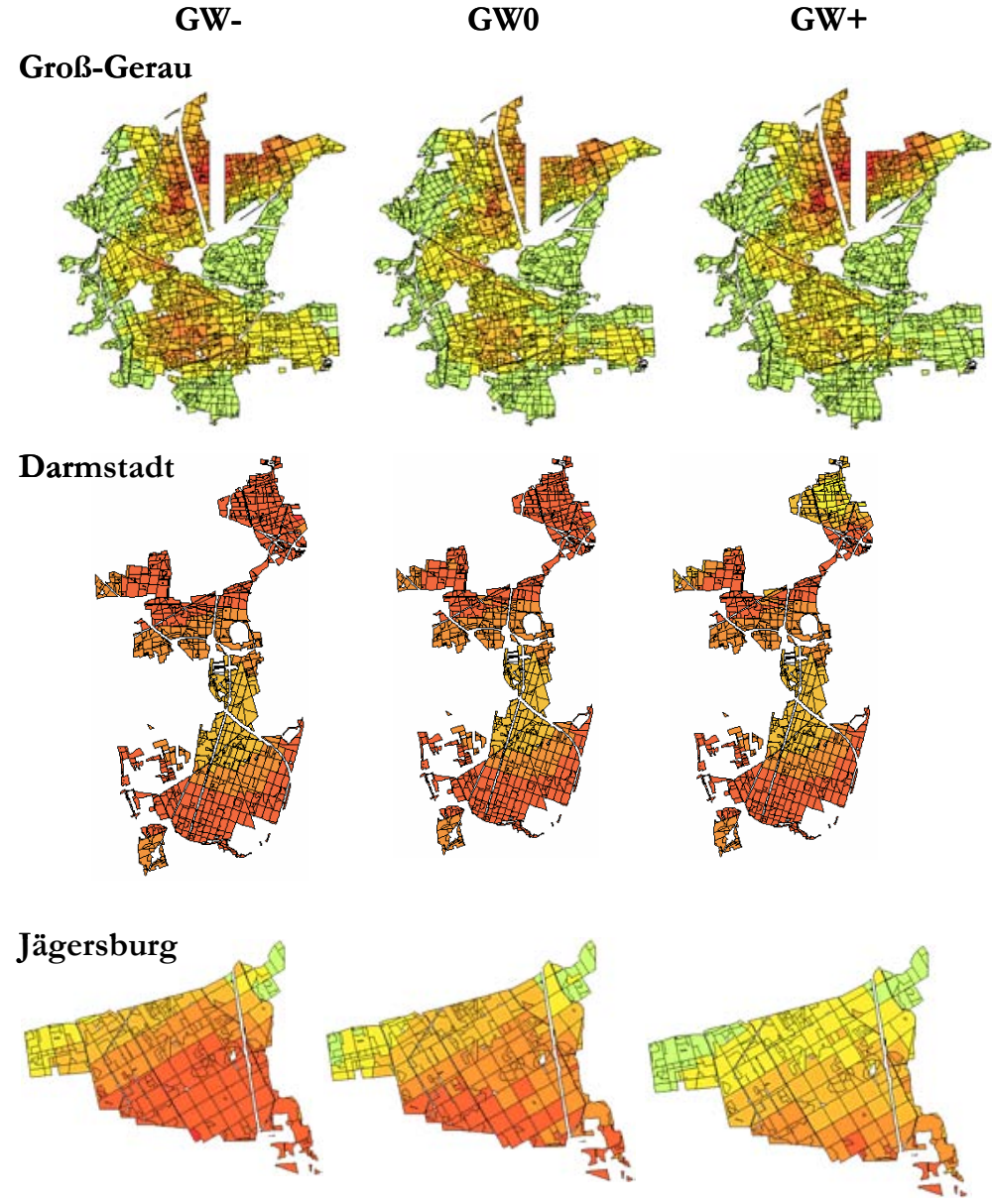

\section{Lampertheim}
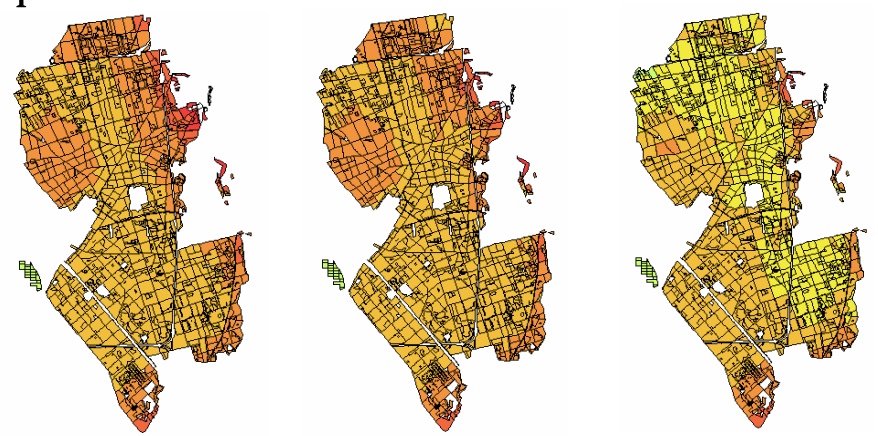

Mittlere Anzahl

$\mathrm{E} 3 / \mathrm{m}^{2}$

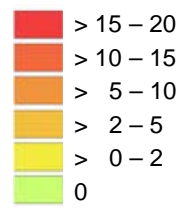

Abbildung 99: Modellierte E3-Engerlingsdichten $\left[\mathrm{E} 3 / \mathrm{m}^{2}\right]$ der Szenarien $G W-, G W 0$ und $G W+$ für die Gebiete Groß-Gerau, Darmstadt, Jägersburg und Lampertheim 


\subsubsection{Einfluss der Bodenartengruppe auf die modellierte Engerlingsdichte}

Neben der räumlichen Lage der Grabungsinformation und den Grundwasser-Flurabständen hat die Tonmächtigkeit des Standortes Einfluss auf die Modellierung der Dichten (s. Kap. 2.2.7.2.1). Der Zusammenhang zwischen Bodenartengruppen (s. Tab. 33) und der modellierten Dichte der Waldmaikäfer wird in Abbildung 100 für die um die Maikäfer-Ausreißerdichten bereinigten Flächen dargestellt.

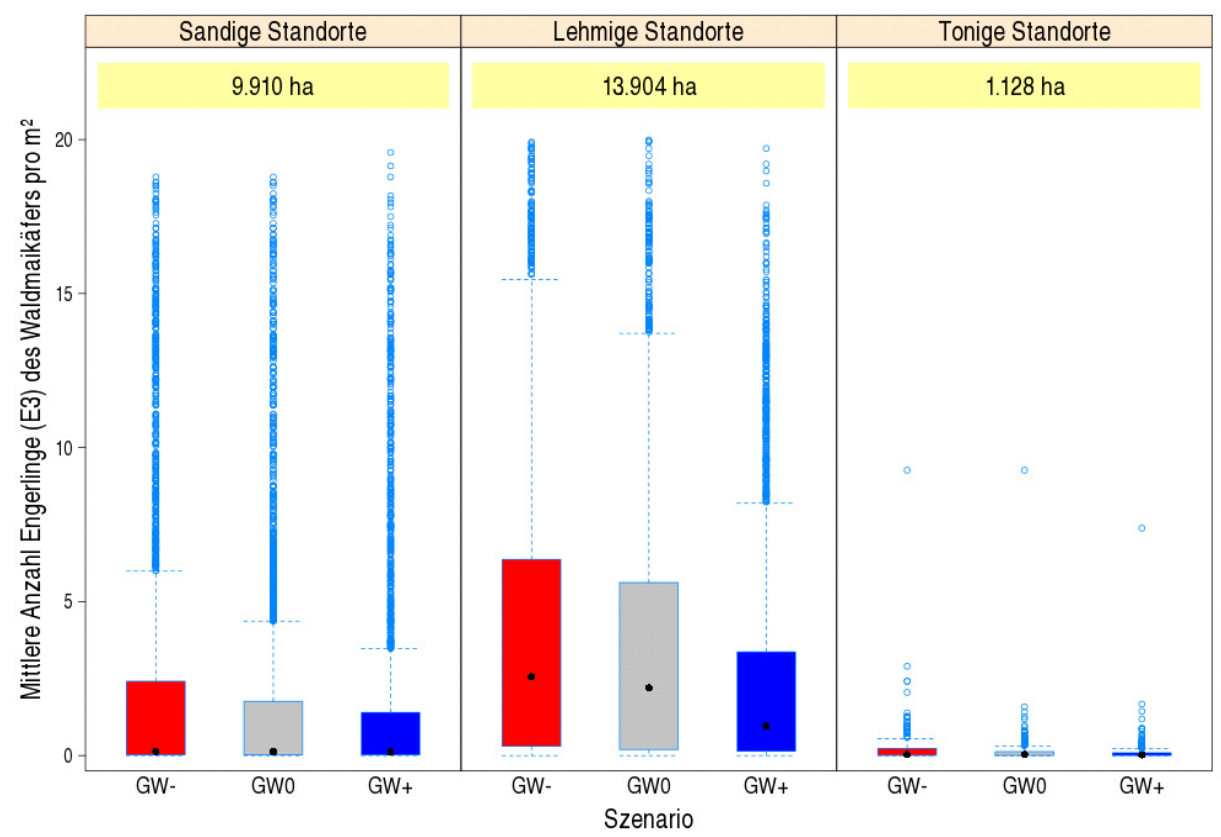

Abbildung 100: Modellierte E3-Engerlingsdichten $\left[\mathrm{E} 3 / \mathrm{m}^{2}\right]$ stratifiziert nach Bodenartengruppen für die Szenarien $G W$-, GW0 und $G W+$

In allen Szenarien kommen die meisten Waldmaikäfer auf lehmigen Standorten $(56 \%)$ und relativ hohe Dichten auf den sandigen Standorten vor (40\%). Tonige Standorte sind mit einem Anteil von $5 \%$ sehr gering vertreten und nur regional (Jägersburg) von Bedeutung. Die unterschiedlichen Grundwasserszenarien haben im Modell ebenfalls einen gewissen Einfluss auf die Engerlingsdichten. Im Vergleich zum Szenario GW0 werden bei sinkendem Grundwasserstand (GW-) auch leicht erhöhte Maikäferdichten beobachtet, bei steigendem Grundwasserspiegel $(\mathrm{GW}+)$ dagegen geringere Maikäferdichten, insbesondere auf den lehmigen Standorten.

Bei der gebietsspezifischen Betrachtung (s. Abb. 101) weist Darmstadt, das Gebiet mit den höchsten Ausgangsdichten, kaum einen Unterschied zwischen den Dichten auf sandigen und lehmigen Standorten auf. Auf lehmigen Standorten kommen in diesem Gebiet lediglich etwas höhere Maximal- und geringere Mini- 
malwerte vor. Selbst die wenigen Bestände auf den tonigen Standorten weisen eine hohe Ausgangsdichte auf. Im Gebiet Lampertheim sind die Unterschiede zwischen den Ausgangsdichten auf sandigen und lehmigen Standorten ebenfalls gering. Tonige Standorte sind in Lampertheim nicht vorhanden.

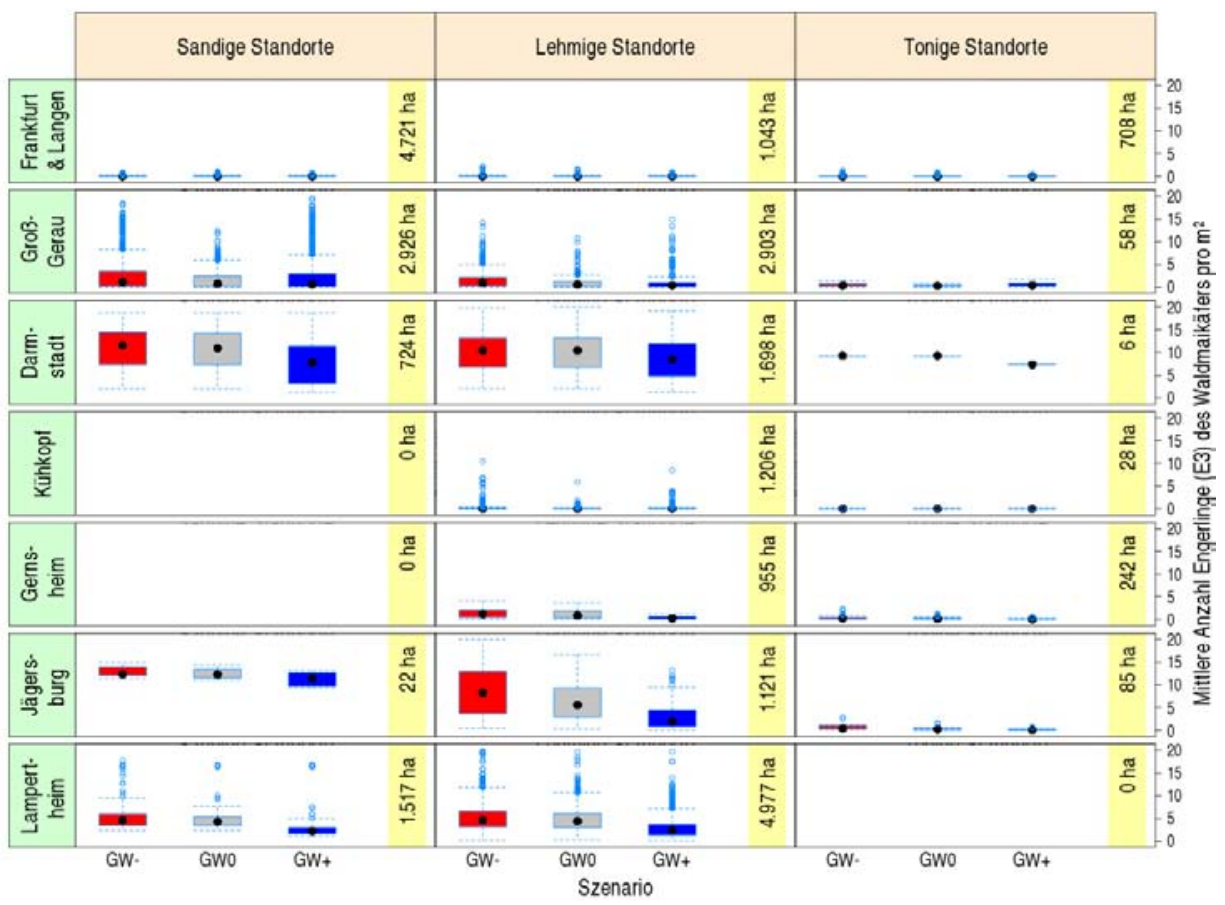

Abbildung 101: Modellierte E3-Engerlingsdichte $\left[\mathrm{E} 3 / \mathrm{m}^{2}\right]$ für die Szenarien $G W$-, GW0 und $G W+$ nach Bodenartengruppen und Regionen stratifiziert

Im Gebiet Jägersburg ist, unter Beachtung der geringen Anzahl an sandigen und tonigen Standorten, die Ausgangsdichte auf sandigen Standorten sehr hoch, auf lehmigen Standorten hoch sowie auf tonigen Standorten am geringsten. Auf den lehmigen Standorten weist Jägersburg den deutlichsten Unterschied zwischen den Szenarien auf. Die Grundwasseranhebung bzw. -absenkung wirkt hier am eindeutigsten. Die Ausgangsdichte in Jägersburg ist auf lehmigen Standort im Szenario GW- am höchsten und bei GW+ am geringsten.

Das Gebiet Frankfurt u. Langen weist auf allen Standorten und Szenarien sehr geringe Ausgangsdichten auf. Es treten keine erkennbaren Unterschiede auf. Dementsprechend kann auf keine Präferenz des Vorkommens des Waldmaikäfers in einer Bodenartengruppe geschlossen werden. Für dieses Gebiet wurde, auch außerhalb der Simulation, postuliert, dass es von den Maikäfern in der aktuellen Massenvermehrung noch nicht besiedelt wurde. 
In den Gebieten Groß-Gerau, Kühkopf und Gernsheim sind die Unterschiede zwischen den Ausgangsdichten ebenfalls gering, nur die Maximalwerte liegen bei den sandigen und lehmigen Standorten in Groß-Gerau höher. In den Gebieten Kühkopf und Gernsheim kommen keine sandigen Standorte vor.

\subsubsection{Einfluss des Grundwasseranschlusses auf die modellierte Populationsdichte der Waldmaikëfer}

Zur Bewertung des Grundwassereinflusses auf die Engerlingsdichte wurde eine Stratifizierung in die Klassen „GW-Anschluss 1951 bis 2007 nie vorhanden“, „GW-Anschluss 1951 bis 2007 verloren“ und „GW-Anschluss 1951 bis 2007 (noch) vorhanden" vorgenommen. Diese Art der Klassifizierung betrachtet den sicheren Grundwasseranschluss bis 2,50 m Flurabstand von 1951 bis zum Beginn des Simulationslaufes. Die Szenarien GW-, GW0 und GW+ können durch unterschiedliche Grundwasserbewirtschaftung diese Standorte zukünftig beeinflussen und damit auch Einfluss auf den zukünftigen Grundwasseranschluss nehmen. Abbildung 102 stellt die Ausgangsdichten der Waldmaikäfer je Grundwasseranschlussklasse für die drei Szenarien dar. Dadurch wird der Zusammenhang zwischen bisheriger und zukünftiger Grundwasserbewirtschaftung und deren Einfluss auf die Maikäferdichten verdeutlicht.

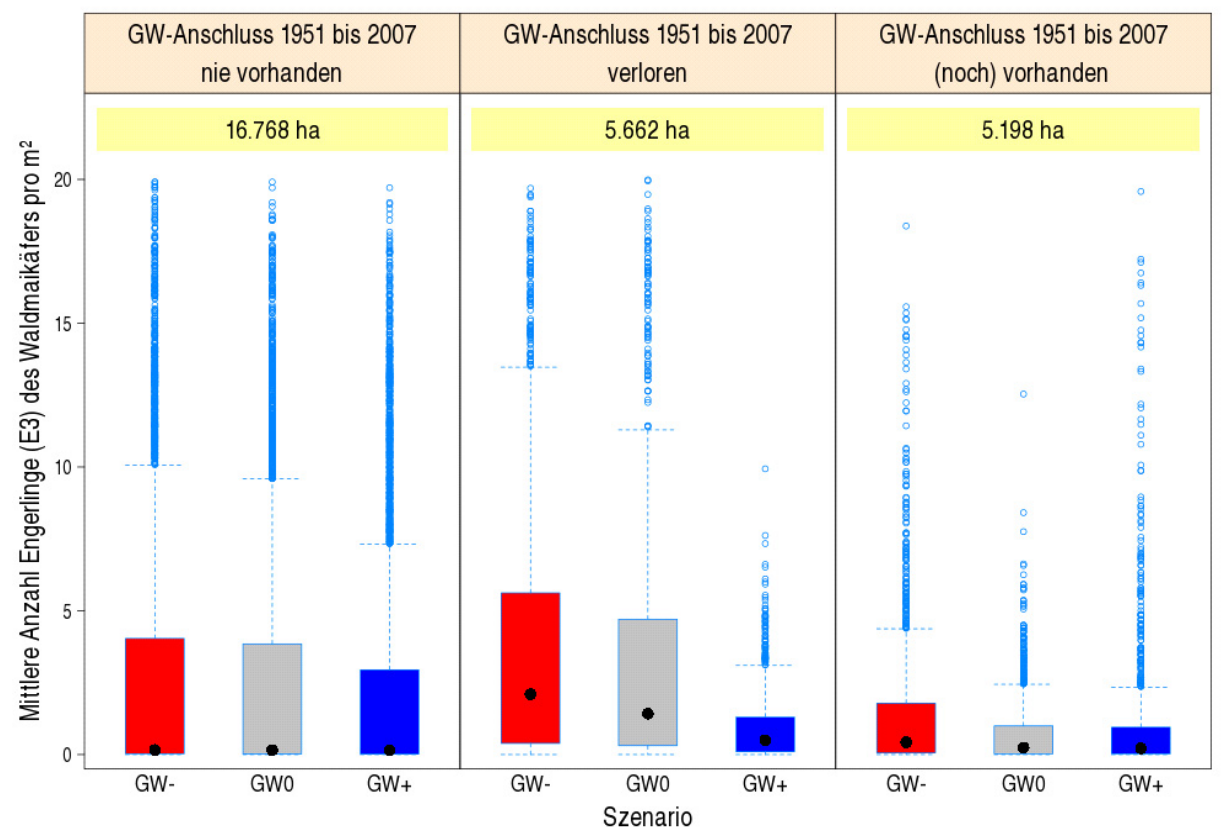

Abbildung 102: Modellierte E3-Engerlingsdichten $\left[\mathrm{E} 3 / \mathrm{m}^{2}\right]$ bei unterschiedlicher Entwicklung des Grundwasserstandes für die Szenarien $G W-, G W 0$ und $G W+$ 
Mit rund 61 Prozent haben die meisten Bestände im Hessischen Ried seit 1951 niemals einen gesicherten Grundwasseranschluss gehabt. Etwa 20 Prozent haben ihn in diesem Zeitraum verloren. Knapp 19 Prozent konnten dagegen ihren sicheren Grundwasseranschluss bisher erhalten. Die mittleren Engerlingsdichten aller Szenarien sind in Beständen mit verlorenem GW-Anschluss am höchsten. Ebenso ist bei diesen Beständen der Unterschied der modellierten Ausgangsdichten zwischen den Szenarion am größten. Die geringste Ausgangsdichte kommt wiederum im Szenario GW+ vor. Innerhalb der Gruppe der Bestände, die bis heute immer sicheren Grundwasseranschluss hatten, sowie der Gruppe, die dies nie hatte, unterscheiden sich die mittleren Engerlingsdichten zwischen den Szenarien deutlich geringer. Bestände, die nie GW-Anschluss besaßen oder ihn verloren haben, weisen hohe Streuungen der Maikäferdichten auf. Bei Beständen mit durchgehend sicherem GW-Anschluss ist diese Streuung der Engerlingsdichten dagegen in allen Szenarien geringer.

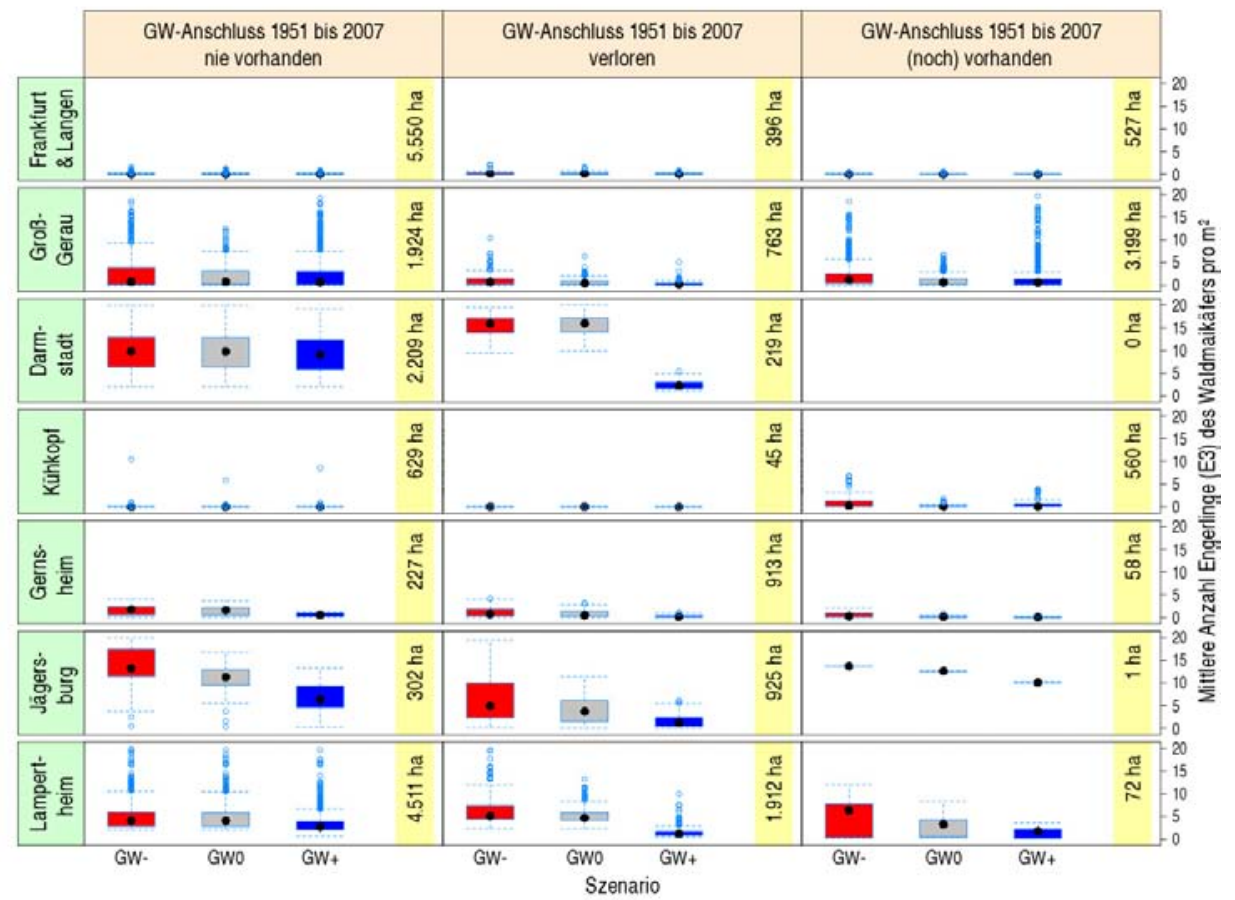

Abbildung 103: Modellierte E3-Engerlingsdichten [E3/ $\left.\mathrm{m}^{2}\right]$ bei unterschiedlicher Entwicklung des Grundwasserstandes für die Szenarien $G W-, G W 0$ und $G W+$ in den Untersuchungsgebieten

In Abbildung 103 werden die modellierten Ausgangsdichten der WaldmaikäferEngerlinge, stratifiziert nach Grundwasseranschlussklassen der Bestände, getrennt nach Gebieten dargestellt. Gebiete mit hohen Maikäferdichten, wie Darmstadt, Lampertheim und Jägersburg, weisen für die Bestände, die nie sicheren GW-An- 
schluss hatten oder ihn verloren haben, die höchsten Dichten auf. Bestände, die immer sicheren GW-Anschluss hatten, kommen in Darmstadt nicht und in Lampertheim und Jägersburg kaum vor. Unabhängig vom Grundwasserstatus sind in den Gebieten Frankfurt u. Langen, Kühkopf und Gernsheim die Ausgangsdichten in allen Beständen gering.

Bei einem Vergleich der Ausgangsdichten der Szenarien besteht der größte Unterschied für die Bestände mit verlorenem GW-Anschluss in Darmstadt. Für diese Bestände ist die modellierte Dichte des Szenarios GW+ am geringsten. Für die anderen Gebiete sind die Unterschiede der Ausgangdichten zwischen den Szenarien, mit Ausnahme von Jägersburg, deutlich geringer. In Jägersburg ist für Bestände ohne sicheren GW-Anschluss die Ausgangsdichte für das Szenario GW+ am geringsten und für das Szenario GW- am höchsten. In Beständen ohne GWAnschluss treten sowohl hohe als auch sehr niedrige Engerlingsdichten auf. Bestände mit hohen Populationsdichten, die immer sicheren GW-Anschluss hatten, kommen in den Gebieten kaum vor. Auffällig ist hier vor allem GroßGerau mit stark streuenden Maikäferdichten sowie Lampertheim auf 72 Hektar Fläche mit ähnlich hohen Dichten wie in den anderen Grundwasseranschlussklassen. Für das Gebiet Darmstadt kann festgestellt werden, dass die meisten Bestände nie Grundwasseranschluss hatten und in allen drei Szenarien hohen Maikäferdichten aufweisen. Eine Änderung der Grundwasserbewirtschaftung dürfte hier den geringsten Einfluss auf Maikäferdichten zeigen.

\subsubsection{Einfluss der Populationsdichte der Waldmaikäfer auf die Mortalität der Waldbäume}

Über das gesamte Hessische Ried betrachtet, ergab die Simulation im WaldPlaner für die einzelnen Szenarien im Mittel sehr geringe Mortalitäten in Derbholzbeständen mit unerheblichen Unterschieden. Im Mittel sterben pro Bestand altersklassenunabhängig bis zum Jahr 2039 im Szenario GW- ca. 0,7 Prozent, im Szenario GW0 ca. 0,8 Prozent und im Szenario GW+ ca. 1,1 Prozent der Bäume.

Abbildung 104 stellt die Mortalität für die einzelnen Gebiete dar. Es wird der mittlere Anteil der abgestorbenen Bäume pro Bestand und Szenario bis zum Jahr 2039 betrachtet. Enthalten sind alle abgestorbenen Bäume über die gesamten Altersklassen. Da die Mortalität der Bäume von der Populationsdichte der Waldmaikäfer abhängt, weisen die Gebiete im Hessischen Ried entsprechend der modellierten Ausgangsdichte unterschiedliche Mortalitäten auf. In Darmstadt beispielsweise, dem Gebiet mit den höchsten Waldmaikäferdichten, kommen entsprechend die höchsten Mortalitäten vor. Im Szenario GW- fallen in Darmstadt ca. 5,4 Prozent der Bäume eines Bestandes aus. Der Anteil an abgestorbenen Bäumen ist im Szenario GW0 mit ca. 5,2 Prozent nahezu gleich hoch. Eine deutlich geringere Mortalität tritt in Darmstadt im Szenario GW+ mit im Mittel ca. 3,7 Prozent auf.

Beiträge aus der NW-FVA, Band 10, 2013 


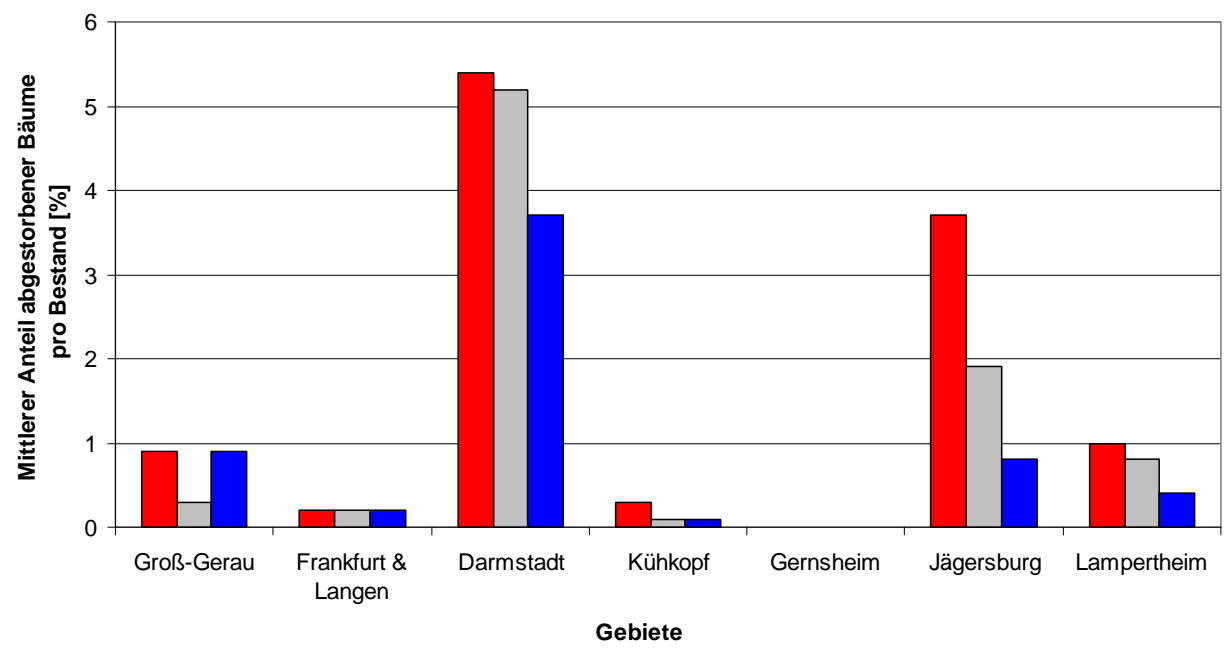

$\square \mathrm{GW}-\square \mathrm{GWO} \square \mathrm{GW}+$

Abbildung 104: Mittlerer altersklassenunabbängiger Anteil [\%] abgestorbener Bäume pro Bestand und Szenario bis zum Jahr 2039

Die Differenzen zwischen den Mortalitäten der Szenarien entstehen ebenfalls durch die modellierten Ausgangsdichten. Die größten Unterschiede weist das Gebiet Jägersburg auf. Entsprechend der Ausgangsdichte ist die Mortalität im Szenario GW- mit ca. 3,7 Prozent am höchsten. Die Mortalität für das Szenario GW0 beträgt ca. 1,9 Prozent. Im Szenario GW+ fallen hingegen im Mittel nur ca. 0,8 Prozent der Bäume pro Bestand aus. Jägersburg ist mit den Gebieten Darmstadt und Lampertheim das einzige Gebiet, in dem GW- die höchste und GW+ die niedrigste Mortalität aufweist. Groß-Gerau besitzt gleich hohe Mortalitäten für die Szenarien GW- und GW+. Mit 0,9 Prozent liegt die Mortalität beider Szenarien höher als die Mortalität des Szenarios GW0 mit 0,3 Prozent. Die geringste Mortalität weist Gernsheim auf, gefolgt von den Gebieten Kühkopf und Frankfurt u. Langen.

\subsubsection{Gefährdung von Kulturen und natürlicher Verjüngung}

Je jünger ein Baum ist, desto höher ist die Gefahr, dass er durch den Wurzelfraß der Engerlinge abstirbt. Dabei ist die Anzahl der Engerlinge pro Quadratmeter entscheidend für das Ausmaß der Schädigung. Im Modell wurde angenommen, dass sich Dichten von 5 und mehr E3/ $\mathrm{m}^{2}$ letal auf Kulturen und natürlich verjüngte Flächen auswirken. 1 bis $3 \mathrm{E} 3 / \mathrm{m}^{2}$ wirken bereits stark schädigend.

Im Szenario GW- weist ein großer Teil der Waldflächen eine modellierte Engerlingsdichte von mehr als 5 Waldmaikäfern pro Quadratmeter auf. Insgesamt sind in diesem Szenario ca. 24,7 Prozent (6.200 ha) der Waldfläche betroffen. Im Szenario GW0 kommt diese Dichte auf ca. 21 Prozent (5.251 ha) der Waldfläche 
vor. Die geringste Waldfläche mit auf jungen Bäumen letal wirkenden Dichten ist im Szenario GW+ mit 17,7 Prozent (3.170 ha) zu verzeichnen. Abbildung 105 stellt die betroffenen Waldflächen für die einzelnen Gebiete und Szenarien dar.

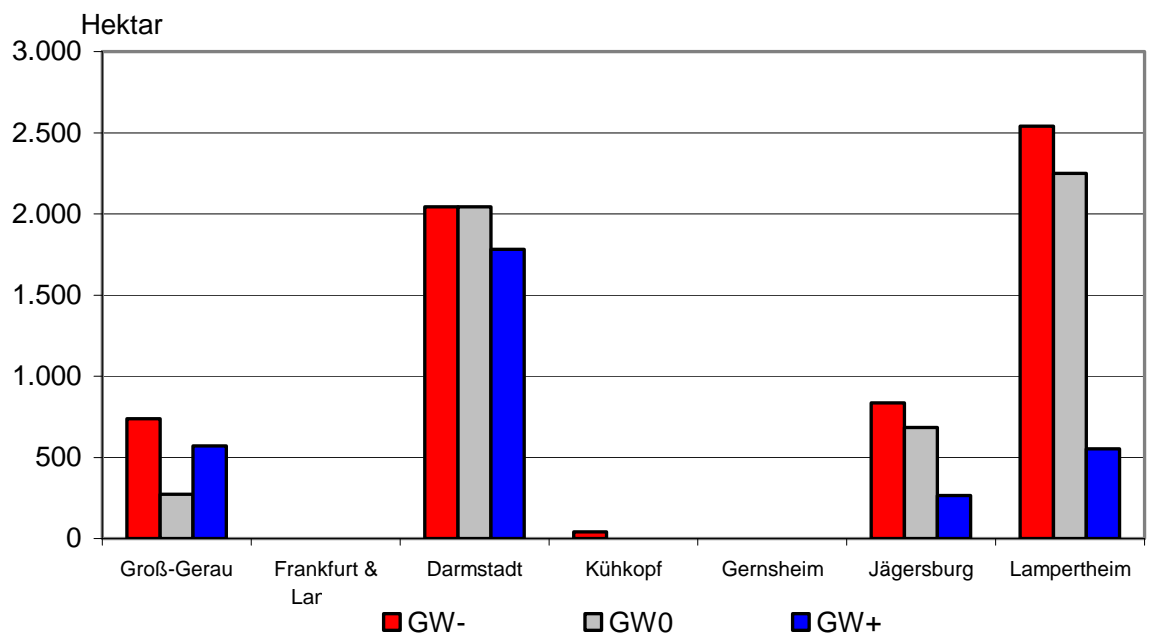

Abbildung 105: Waldfläche [ha] mit einer modellierten Engerlingsdichte über $5 \mathrm{E3} / \mathrm{m}^{2}$

Besonders stark betroffen ist das Gebiet Darmstadt. Hier ist bei den Szenarien GW- und GW0 eine Waldfläche von jeweils ca. 2.044 Hektar betroffen. Das sind etwa 84,2 Prozent der Waldfläche. Im Szenario GW+ ist mit ca. 73,4 Prozent (1.781 ha) die betroffene Waldfläche zwar etwas geringer, aber immer noch sehr hoch, sodass auf großer Fläche eine gezielte Bewirtschaftung, insbesondere bei Verjüngungsmaßnahmen, stark eingeschränkt ist.

Neben Darmstadt sind auch in den Gebieten Lampertheim und Jägersburg große Waldflächen aufgrund der Ausgangsdichte von über $5 \mathrm{E} 3 / \mathrm{m}^{2}$ von einem flächigen Ausfall der Kulturen und natürlichen Verjüngung bedroht. In beiden Gebieten ist die größte Waldfläche im Szenario GW- und die geringste im Szenario GW+ betroffen. In Lampertheim ist im Szenario GW- der relative Anteil mit ca. 39,1 Prozent (2.540 ha) aber nur knapp halb so hoch wie in Darmstadt. Ähnlich stellt sich die Situation für das Szenario GW0 mit einer Anteilfläche von ca. 34,6 Prozent (2.249 ha) dar. Aber auch beim Szenario GW+ sind immer noch ca. 8,5 Prozent (553 ha) der Waldfläche von einer letal wirkenden Dichte betroffen. In Jägersburg können im Szenario GW- auf ca. 68 Prozent (ca. 836 ha) der Waldfläche weder Kulturen noch eine natürliche Verjüngung etabliert werden. Im Gegensatz dazu betrifft es im Szenario GW0 ca. 55,7 Prozent (685 ha) und im Szenario GW+ ca. 21,3 Prozent (266 ha) der Waldfläche. Die Wirkung der Grundwasseranhebung ist in diesem Gebiet am höchsten. 
Im Gebiet Groß-Gerau weisen im Szenario GW- ca. 12,5 Prozent (738 ha), im Szenario GW0 ca. 4,6 Prozent (272 ha) und im Szenario GW+ ca. 9,7 Prozent (570 ha) Engerlingsdichten über fünf E3 pro Quadratmeter auf. Der höhere Anteil im Szenario GW+ ist auf die Parameter der Modellierung der Ausgangsdichte zurückzuführen. Im Gebiet Kühkopf werden nur beim Szenario GW- auf ca. 3,4 Prozent (42 ha) der Waldfläche diese hohen Engerlingsdichten erreicht. Frankfurt u. Langen sowie Gernsheim besitzen keine Waldflächen mit modellierten Dichten über $5 \mathrm{E} 3 / \mathrm{m}^{2}$.

\subsubsection{Gefährdung älterer Bäume}

Nachfolgend wird die Mortalität der älteren Bäume mit einem BHD von über sieben Zentimetern betrachtet. Über das gesamte Hessische Ried und dem gesamten Simulationszeitraum von 2007 bis 2039 hinweg ist die Mortalität im Szenario GW+ für die älteren Bäume am geringsten. Es fallen durch den Waldmaikäfer im Mittel über die Klimavarianten in diesem Szenario ca. 47.000 Vfm aus. Der Ausfall im Szenario GW- ist im Mittel mit über $100.000 \mathrm{Vfm}$ mehr als doppelt so hoch als im Szenario GW+. Das Szenario GW- weist die höchste Mortalität auf. Im Szenario GW0 beträgt die Mortalität im Mittel rund $65.000 \mathrm{Vfm}$. Bezogen auf ein Jahr und einen Hektar ergeben sich sehr geringe Ausfälle. Die Unterschiede zwischen den Szenarien sind ebenfalls sehr gering. Die Ausfälle können für einzelne Bestände in einzelnen Jahren aber auch sehr hoch sein.

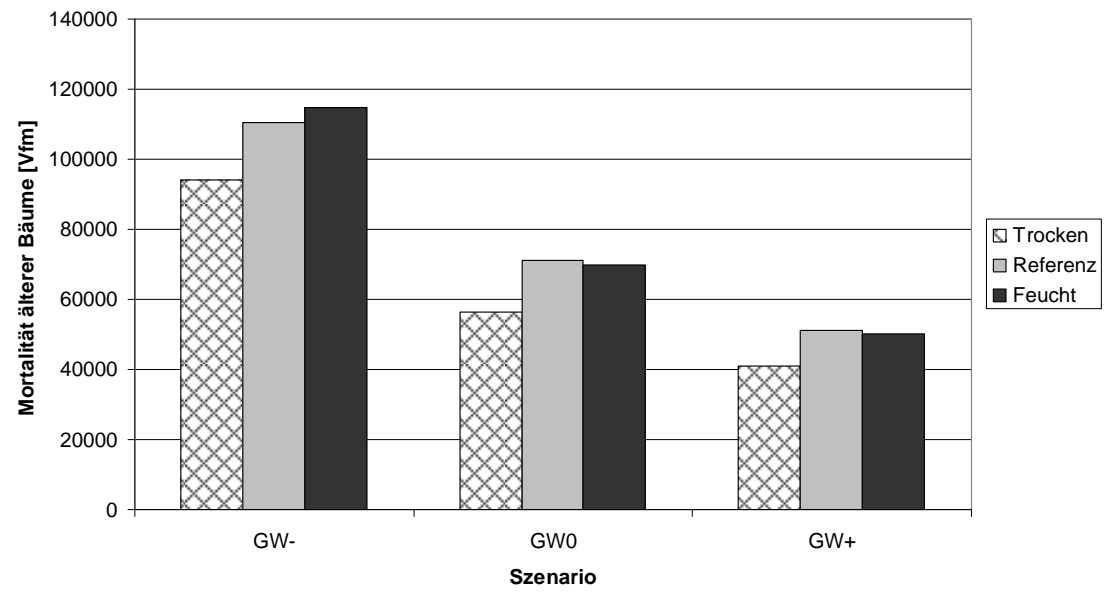

Abbildung 106: Kumulierter Ausfall [V fm] älterer Bäume im Zeitraum 2007 bis 2039

Bei einem Vergleich der Klimavarianten der Szenarien ist die Mortalität im Szenario GW+ mit der Klimavariante trocken (A1Bt) am geringsten. Der Ausfall beträgt von 2007 bis 2039 ca. $41.000 \mathrm{Vfm}$. Die höchsten Ausfälle sind mit fast 115.000 Vfm im Szenario GW-/A1Bf festzustellen (s. Abb. 106) Die Ausfälle pro Jahr und Hektar sind sehr gering und betragen bei allen Varianten nur rund 
0,1 Vfm. Nicht quantifizieren lässt sich der Einfluss der verminderten Vitalität älterer Bäume durch den Wurzelfraß der Engerlinge auf den Zuwachs. Er konnte dementsprechend im Wachstumsmodell nicht berücksichtigt werden.

\subsection{Naturschutz}

\subsubsection{Entwicklung der Waldlandschaft „Hessisches Ried“ von 1800 bis beute}

Für die Artenvielfalt im Wald hat die Habitatkontinuität häufig eine entscheidende Bedeutung. Daher wurde die Bewaldungskontinuität im Untersuchungsraum durch den Vergleich von historischen (Haas'sche Karte 1788 - 1813, Preußische Landesaufnahme 1900) und aktuellen Kartenwerken ermittelt und in Form eines GISDatensatzes aufbereitet.

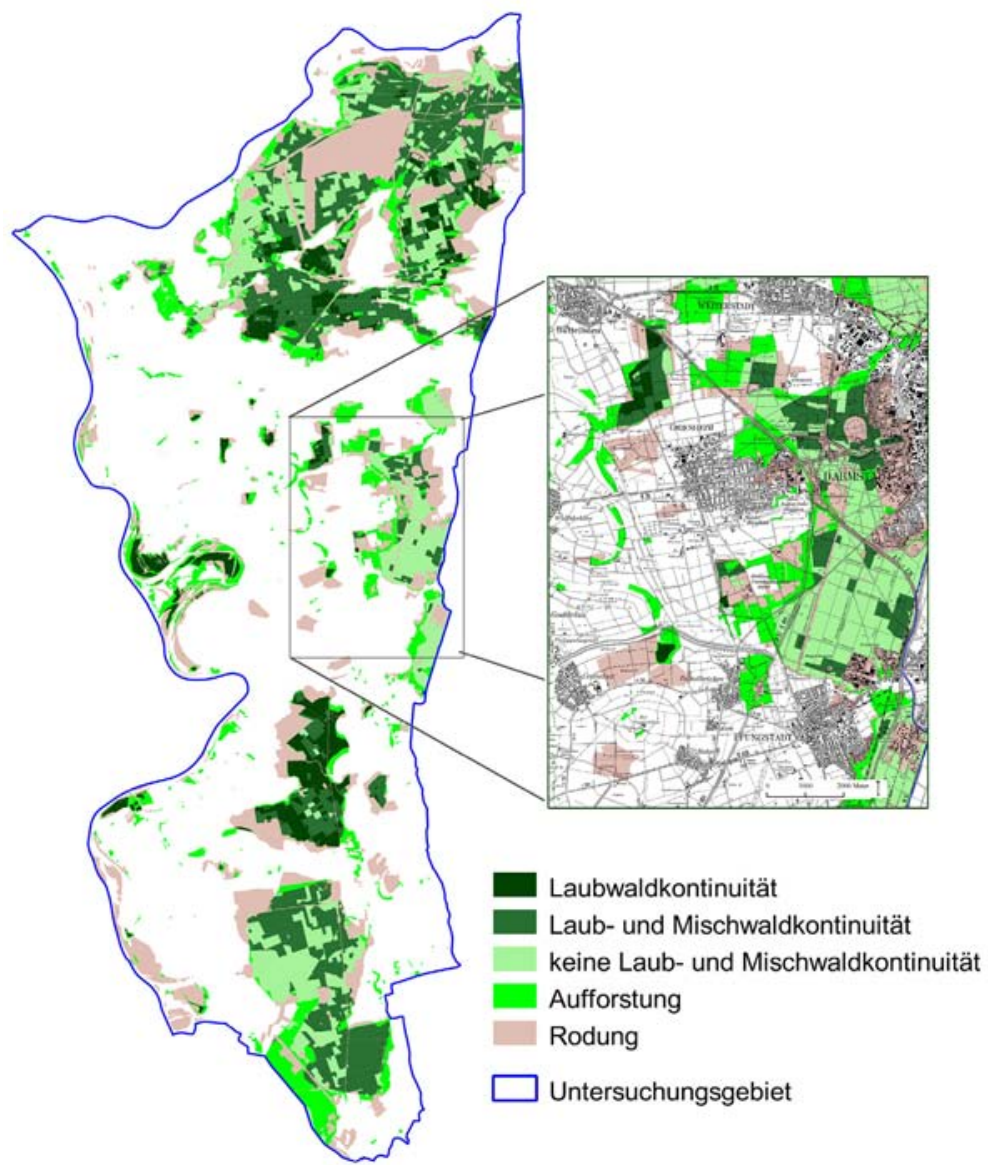

Abbildung 107: Waldflächenentwicklung im Hessischen Ried von 1800 bis beute 
Die Waldfläche hat zwischen 1800 und 2008 deutlich von 34.284 Hektar auf 30.109 Hektar abgenommen. Der Anteil der Waldfläche an der Landschaft ist von 32 auf 28 Prozent gesunken.

Der Laubwaldbestand ist um 47 Prozent von 14.634 Hektar auf 7.769 Hektar zurückgegangen, während der Nadelwaldanteil eine Zunahme um 250 Prozent von 2.720 Hektar auf 9.506 Hektar erfahren hat (s. Abb. 107 und 108). Bei den LaubNadel-Mischwäldern ist ein Rückgang um 24 Prozent von 16.930 Hektar auf 12.834 Hektar zu verzeichnen.

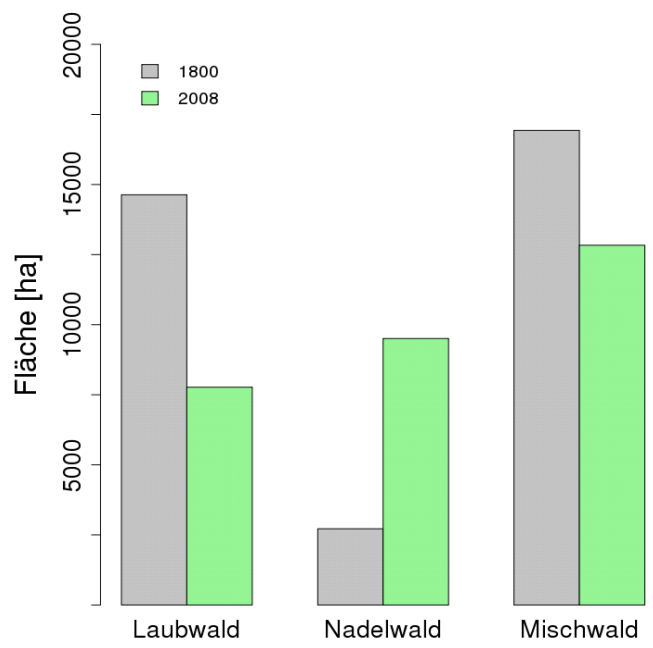

Abbildung 108: Flächen mit Laub-, Misch- und Nadelwald um 1800 und 2008

Die kontinuierlich mit Laubwald bestockte Fläche beträgt 3.756 Hektar (s. Abb. 109). 1.039 Hektar Nadelwald und 6.120 Hektar Mischwald sind unverändert vorhanden. Insgesamt sind 47 Prozent der Laubwaldfläche und 55 Prozent der Mischwaldfläche in den vergangenen 200 Jahren durch Rodung verloren gegangen oder in Nadelwald umgewandelt worden. Zusätzlich haben aber jeweils Aufforstungen im Umfang von rund 2.000 Hektar in allen drei Waldtypen stattgefunden.

Betrachtet man die heutige Waldfläche, so lassen sich die verschiedenen Ausprägungen von Waldkontinuität wie folgt quantifizieren: Der Anteil des seit mindestens 200 Jahren bestehenden „historisch alten“ Waldes an der heutigen Waldfläche beträgt 77 Prozent (s. Abb. 110, alles außer Aufforstungen). Demgegenüber steht ein Anteil von 23 Prozent jungen Waldes, der nach 1800 aufgeforstet wurde. Flächen, an denen kontinuierlich Laubholz beteiligt war (Mischwald), und reiner Laubwald, haben insgesamt einen Anteil von 51 Prozent an der heutigen Waldfläche (s. Abb. 110, Grüntöne). 

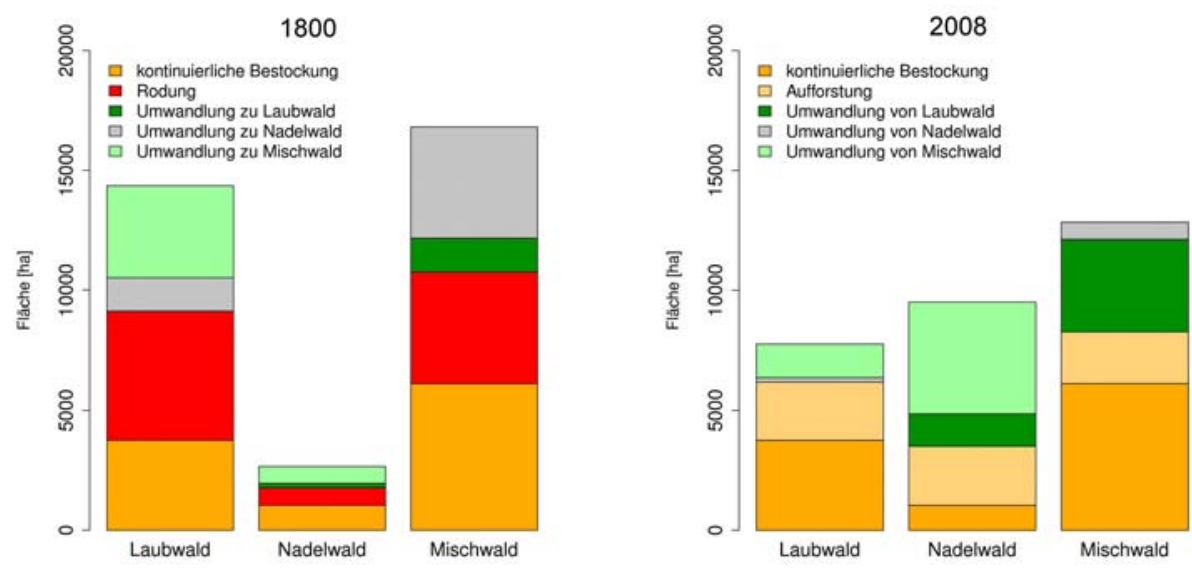

Abbildung 109: Flächenbilanz [ha] der Waldtypen Laub-, Nadel- und Mischwald von 1800 bis 2008. Die Gesamthöbe der Säulen entspricht der Waldfläche von 1800 (linke Abbildung) brw. 2008 (rechte Abbildung) in den Kategorien Laub-, Misch- und Nadelwald. Die einzelnen Segmente geben Aufschluss über Bewaldungskontinuität, Umwandlung, Rodung und Aufforstungen.

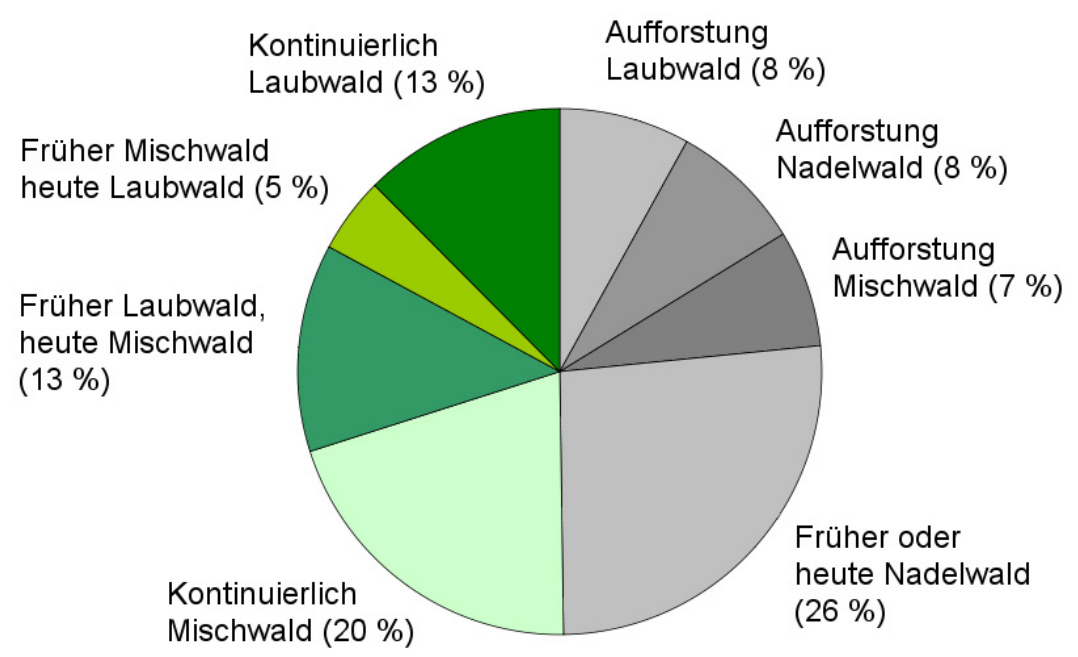

Abbildung 110: Anteile [\%] der verschiedenen Formen von Waldkontinuität an der heutigen $W$ aldfläche (2008); Grüntöne: Laub- bzw. Laub- und Mischwaldkontinuität, Grautöne: Aufforstungen oder Nadelwaldbeteiligung

Beiträge aus der NW-FVA, Band 10, 2013 


\subsubsection{Schutzgüter im Wald}

\subsubsection{Lebensräume}

Als Schutzgüter im Rahmen dieser Untersuchung werden FFH-Wald-Lebensraumtypen innerhalb von FFH-Gebieten und Waldbiotope der Hessischen Biotopkartierung $(\mathrm{HB})$ angesehen. Die räumliche Verteilung der FFH-Lebensraumtypen und HB-Flächen ist in Abbildung 111 dargestellt.

Während sich die naturschutzfachlichen Auswertungen im engeren Sinne auf Eichen- und Buchenwälder beschränken, werden in die Simulationsläufe des WaldPlaners die naturschutzfachlichen Einschränkungen für alle Wald-Lebensraumtypen und Biotoptypen einbezogen.
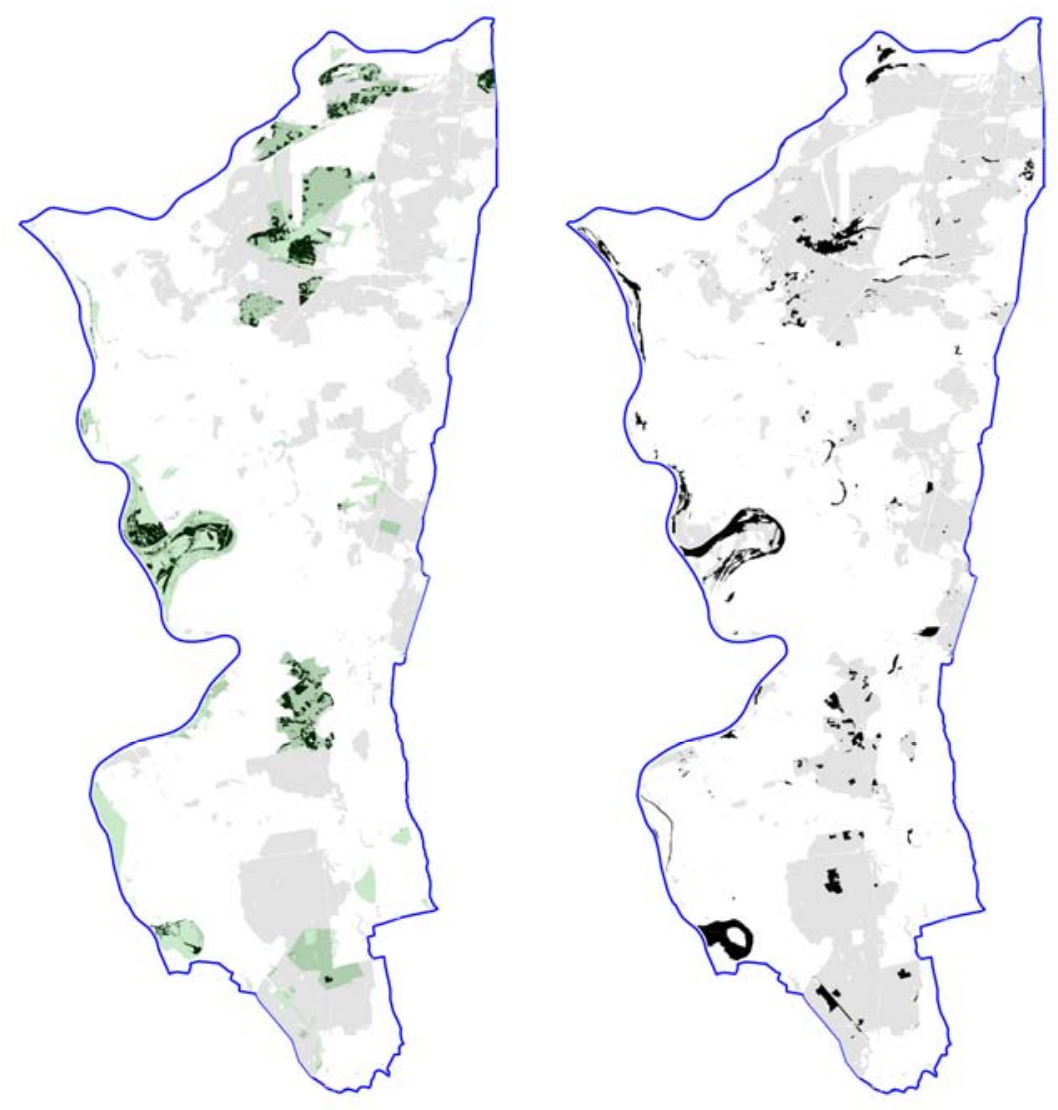

Abbildung 111: Links: Räumliche Verteilung der Waldlebensraumtypen (dunkelgrün) innerbalb der FFH-Gebiete (hellgrïn), rechts: Waldbiotopflächen (dunkelgrün) gemäß der Hessischen Biotopkartierung 
Insgesamt ergibt sich eine Summe von 2.022 Hektar Wald-Lebensraumtypen (s. Tab. 55). Dies entspricht einem Anteil von 28 Prozent an der in FFH-Gebieten liegenden Waldfläche. Bezogen auf die gesamte Waldfläche im Untersuchungsgebiet haben die im Rahmen der Grunddatenerhebung erfassten Wald-Lebensraumtypen einen Anteil von ca. 7 Prozent. Der Lebensraumtyp „SternmierenEichen-Hainbuchenwald“ (9160) nimmt mit 647 Hektar den größten Anteil vor dem Lebensraumtyp „Eichen-/Ulmen-Eschen-Mischwälder am Ufer großer Flüsse“ (91F0, Hartholzaue) mit 572 Hektar ein.

Tabelle 55: Wald-Lebensraumtypen innerhalb von FFH-Gebieten im Hessischen Ried

\begin{tabular}{|c|c|c|c|c|}
\hline LRT & $\begin{array}{c}\text { Fläche } \\
\text { [ha] }\end{array}$ & Anzahl & $\begin{array}{c}\text { mittlere } \\
\text { Größe [ha] }\end{array}$ & $\begin{array}{c}\max . \text { Größc } \\
\text { [ha] }\end{array}$ \\
\hline Hainsimsen-Buchenwald (9110) & 177 & 92 & 1,9 & 30,3 \\
\hline Waldmeister-Buchenwald (9130) & 213 & 108 & 2,0 & 44,4 \\
\hline $\begin{array}{l}\text { Sternmieren-Eichen-Hainbuchenwald } \\
(9160)\end{array}$ & 647 & 254 & 2,5 & 16,0 \\
\hline $\begin{array}{l}\text { Alte bodensaure Eichenwälder mit } \\
\text { Quercus robur auf Sandebenen ( } 9190)\end{array}$ & 233 & 136 & 1,7 & 8,6 \\
\hline $\begin{array}{l}\text { Erlen- und Eschenwälder an } \\
\text { Fließgewässern (91E0) }\end{array}$ & 180 & 232 & 0,8 & 22,7 \\
\hline $\begin{array}{l}\text { Eichen-/Ulmen-Eschen-Mischwälder } \\
\text { am Ufer großer Flüsse (91F0) }\end{array}$ & 572 & 77 & 7,4 & 64,6 \\
\hline Summe & 2.022 & 899 & & \\
\hline
\end{tabular}

Die Waldflächen der Hessischen Biotopkartierung (HB) nehmen im Hessischen Ried insgesamt 2.944 Hektar ein (s. Tab. 56). Hierbei haben die Biotopkomplexe mit 2.065 Hektar den größten Anteil. Diese Komplexe des Typs „C“ (HMULF 1995) stellen eng verzahnte, kartierwürdige, aber nicht räumlich im Einzelnen abgegrenzte Flächen mit Biotopen dar, welche außer Waldbiotoptypen auch Biotope des Offenlandes beinhalten können. Neben den Biotopkomplexen sind 879 Hektar der Hessischen Biotopkartierung als Waldbiotope räumlich konkret abgegrenzt. Abzüglich der Nicht-Waldbereiche der Biotopkomplexe ergeben sich 1.466 Hektar Waldbiotope im Hessischen Ried.

Wie schon im Falle der FFH-Lebensraumtypen nimmt der Biotoptyp „Sonstige Eichen-Hainbuchenwälder“ (01.142), welcher laut Kartieranleitung zur Hessischen Biotopkartierung mit dem LRT „Sternmieren-Eichen-Hainbuchenwald“ gleichgesetzt ist (HMULF 1995), mit 349 Hektar den größten Anteil unter den flächenscharf kartierten Biotoptypen ein. 
Tabelle 56: Waldflächen der Hessischen Biotopkartierung und Biotopkomplexe mit Waldanteil im Hessischen Ried

\begin{tabular}{lrrrr}
\hline \multicolumn{1}{c}{ Biotoptyp } & $\begin{array}{c}\text { Fläche } \\
{[\mathrm{ha}]}\end{array}$ & $\begin{array}{c}\text { Anzahl } \\
{[\mathrm{N}]}\end{array}$ & $\begin{array}{c}\text { mittlere } \\
\text { Größe [ha] }\end{array}$ & $\begin{array}{c}\text { max. } \\
\text { Größe [ha] }\end{array}$ \\
\hline $\begin{array}{l}\text { Buchenwälder mittlerer und } \\
\text { basenreicher Standorte }\end{array}$ & 20 & 8 & 2,4 & 7,2 \\
Bodensaure Buchenwälder & 37 & 6 & 6,2 & 27,2 \\
Sonstige Eichen-Hainbuchenwälder & 349 & 66 & 5,3 & 57,8 \\
Eichenwälder & 1 & 1 & 0,6 & 0,6 \\
Weichholzauenwälder u. -gebüsche & 69 & 24 & 2,9 & 25,8 \\
Hartholzauenwälder & 85 & 19 & 4,5 & 44,4 \\
Bachauenwälder & 15 & 4 & 3,6 & 10,6 \\
Bruch- und Sumpfwälder & 148 & 80 & 1,8 & 23,8 \\
Übrige stark forstwirtschaftliche & 125 & 12 & 10,4 & 33,9 \\
geprägte Laubwälder & 10 & 25 & 0,4 & 1,6 \\
Sandkiefernwälder & 16 & 22 & 0,7 & 5,4 \\
Schlagfluren und Vorwald & 4 & 18 & 0,2 & 1,5 \\
Waldränder & 2.065 & 59 & 35,0 & 493,9 \\
Biotopkomplexe & 2.944 & 344 & & \\
\hline Summe & 1.466 & & & \\
\hline abzüglich Offenland in & & & & \\
Biotopkomplexen & & & & \\
\hline
\end{tabular}

\subsubsection{Arten}

Die betrachteten Indikatorarten der Alters- und Zerfallphase von Buchen- und Eichenwäldern umfassen alle Fledermausarten mit hoher Waldbindung (Bechsteinfledermaus, Großer und Kleiner Abendsegler, Bartfledermaus, Braunes Langohr, Fransenfledermaus und Rauhautfledermaus (es wurden nur die Quartiernachweise einbezogen)) sowie die Käferarten Eremit, Heldbock, Hirschkäfer und Veilchenblauer Wurzelhalsschnellkäfer.

Die räumliche Verbreitung dieser Arten weist erhebliche Klumpungen auf, da ein Großteil der Artkartierungen im Rahmen der Grunddatenerhebung (GDE) innerhalb von FFH-Gebieten stattgefunden hat (s. Abb. 112). Weiterhin ist zu beachten, dass die vorliegenden Kartierungen keinen Anspruch auf eine vollständige Darstellung aller Vorkommen im Hessischen Ried erheben. 


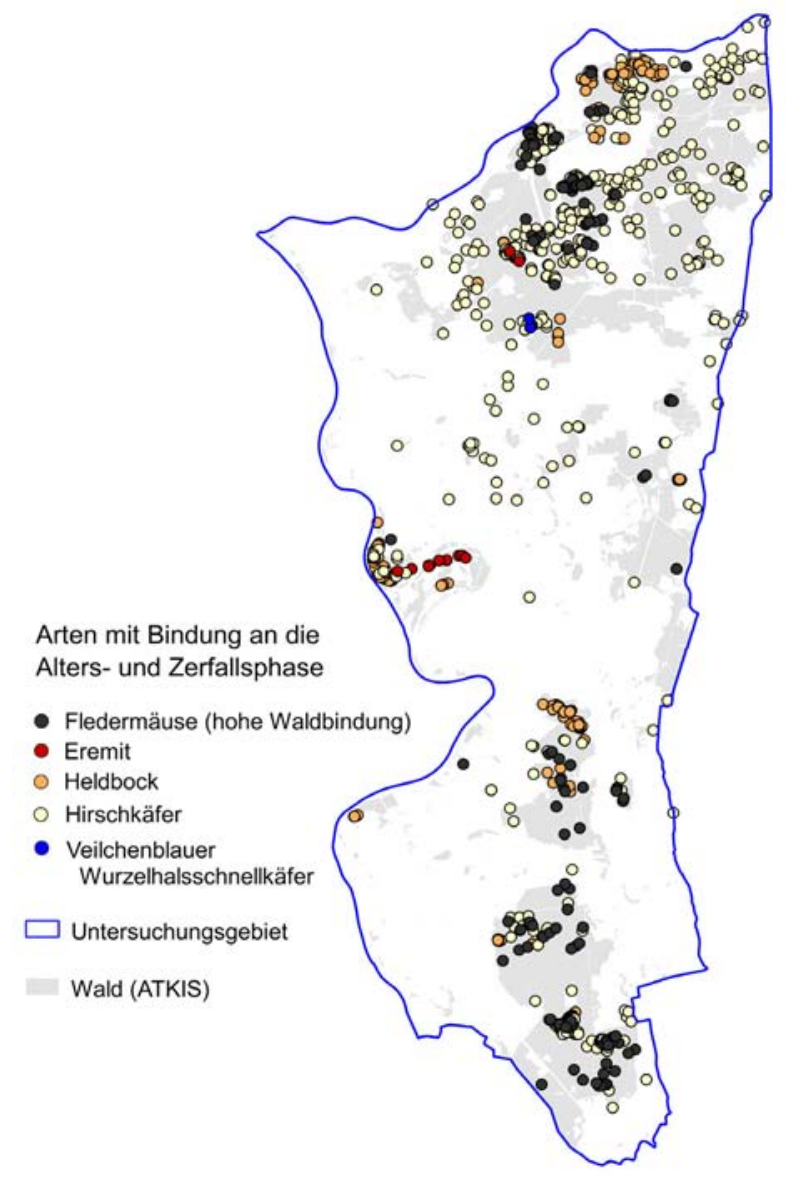

Abbildung 112: Räumliche Verteilung von Arten mit Bindung an die Alters- und Zerfallsphase in Eichen- und Buchenwäldern (Quelle: natis-Datenbank) 


\subsubsection{Schutagebiete}

\subsubsection{Räumliche Überlagerungen}

Naturschutzfachliche Bewirtschaftungsauflagen für die Forstwirtschaft leiten sich aus verschiedenen rechtlichen Grundlagen (Naturschutzrecht, Forstrecht) ab. Hierbei muss zwischen der Schutzgebietskulisse an sich und den tatsächlichen, flächenkonkreten Auflagen für die Forstwirtschaft (s. Kap. 3.8.4) unterschieden werden. Die Schutzgebietskulissen auf Waldflächen überlagern sich zum Teil deutlich (s. Tab. 57).

Tabelle 57: $\quad$ Schutzgebietsüberlagerungen im Wald in Hektar. Die Schutzgüter Lebensraumtypen in FFH-Gebieten (LRT) und Waldbiotope der Hessischen Biotopkartierung (HB) sowie Waldflächen außer regelmäßigem Betrieb (WarB) werden zu Übersichtszwecken mit aufgefübrt (kursiv).

\begin{tabular}{lrrrrrrrr}
\hline & VSG & FFH & NSG & NWR & WarB & LRT & HB & $\begin{array}{c}\text { überlage- } \\
\text { rungsfrei }\end{array}$ \\
\hline VSG & 13.290 & 5.639 & 2.711 & 49 & 1.828 & 1.511 & 1.254 & 6.701 \\
FFH & 5.639 & 7.221 & 2.343 & 49 & 1.438 & 1.961 & 993 & 1.076 \\
NSG & 2.711 & 2.343 & 2.827 & 49 & 1.486 & 971 & 688 & 84 \\
NWR & 49 & 49 & 49 & 49 & 46 & 39 & 47 & 0 \\
W arB & 1.828 & 1.438 & 1.486 & 46 & 2.321 & 623 & 477 & 450 \\
LRT & 1.511 & 1.961 & 971 & 39 & 623 & 1.961 & 433 & 0 \\
HB & 1.254 & 993 & 688 & 47 & 477 & 433 & 1.466 & 114 \\
\hline
\end{tabular}

VSG $=$ Vogelschutzgebiet, FFH = Gebiet nach Fauna-Flora-Habitat-Richtlinie, NSG = Naturschutzgebiet, NWR $=$ Naturwaldreservat

Um die Komplexität der Schutzgebietsüberlagerungen im Wald zu bewerten, wird die Nettoabdeckung mit der Bruttoabdeckung der Schutzgebiete ins Verhältnis gesetzt. Hierbei geht die Fläche bei einer Mehrfachüberlagerung im Falle der Nettoabdeckung nur einfach, bei der Bruttoabdeckung jedoch mehrfach in die jeweilige Summe ein. Insgesamt beträgt die Nettoabdeckung mit Schutzgebieten der Kategorien Vogelschutzgebiet (VSG), FFH-Gebiet und Naturschutzgebiet (NSG) in den Wäldern des Hessischen Rieds 14.972 Hektar oder 48 Prozent. Das Verhältnis von Brutto- zu Nettofläche ergibt einen Überlagerungsfaktor von 1,6. Abbildung 113 veranschaulicht die räumliche Verteilung der Mehrfachüberlagerungen. 


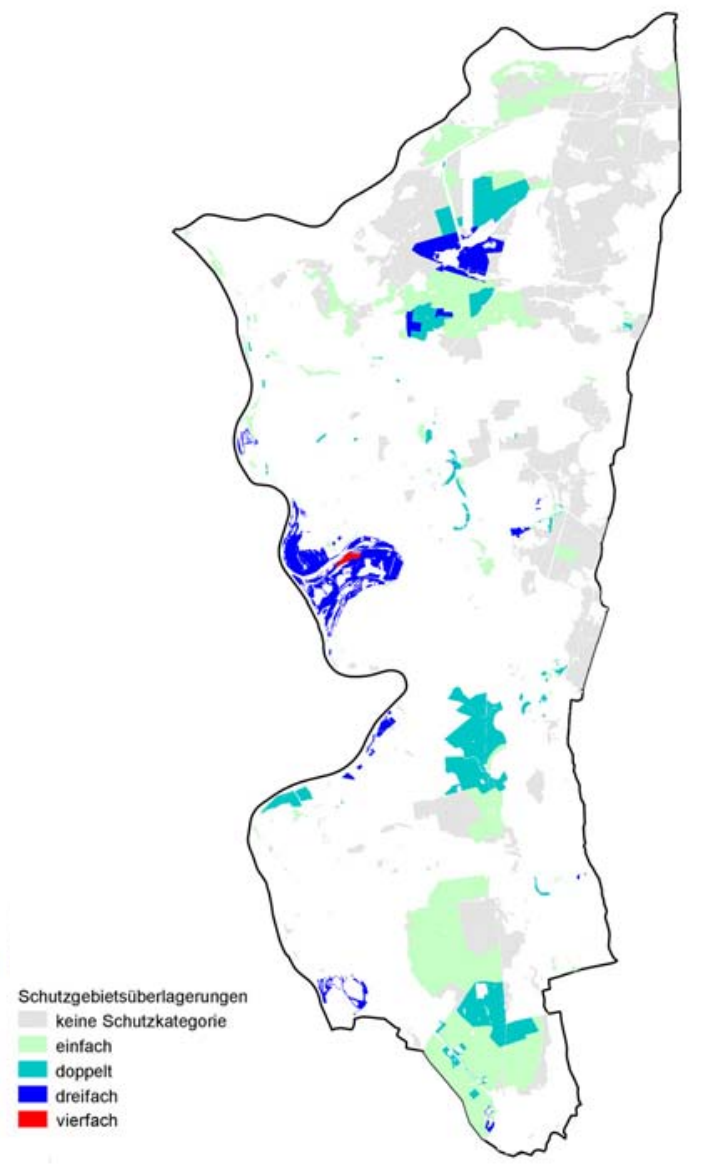

Abbildung 113: Mehrfachüberlagerungen der Schutzgebietskategorien Vogelschutagebiet, FFH-Gebiet, Naturschutzgebiet und Naturwaldreservat, dargestellt für die Waldfläche des Hessischen Rieds

\subsubsection{Vergleich geschüt_ter und nicht geschützter Wälder}

Die Betrachtung der Altersklassen- und Baumartenverteilungen innerhalb und außerhalb von FFH- und Naturschutzgebieten zeigt einige Unterschiede (s. Abb. 114).

Innerhalb der Schutzgebietskulisse ist der Anteil von Edellaub- und Weichlaubbäumen höher, während der Anteil der Buche, vor allem in den mittleren Altersklassen, deutlich geringer ist. Die beiden höchsten Altersklassen sind in den Schutzgebieten stärker besetzt. 

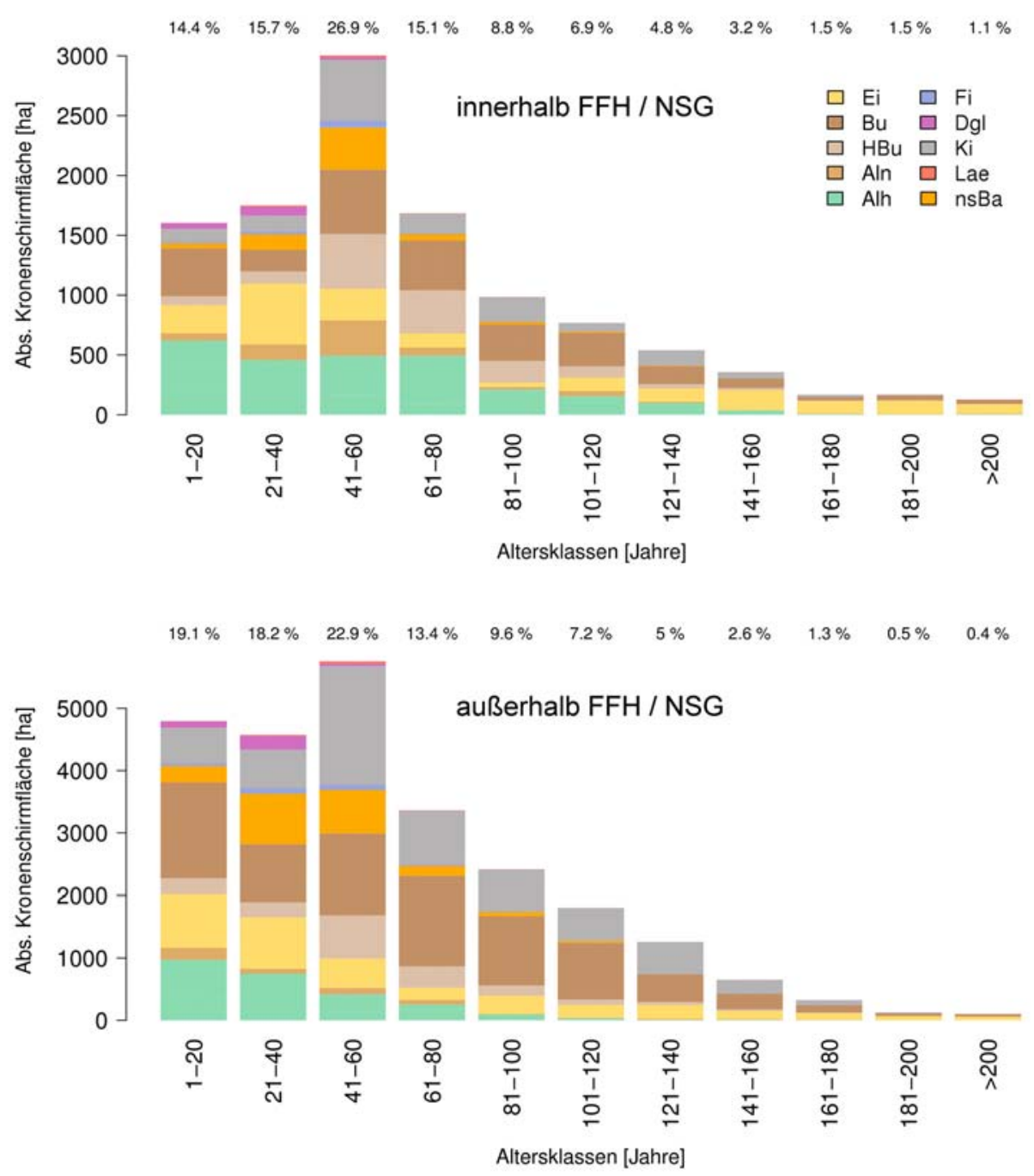

Abbildung 114: Baumartenverteilung nach Altersklassen innerhalb (oben) und außerbalb (unten) der Schutagebietskulisse (FFH, NSG) (Bezugsgröße: absolute Kronenschirmfläche [ha]; nsBa: nicht-standortheimische Baumarten, ₹. B. Roteiche und Robinie; Aln = Andere Laubbäume mit niedriger Umtriebszeit, Alh $=$ Andere Laubbäume mit hoher Umtriebszeit); oberbalb der Säulen: prozentualer Anteil der jeweiligen Altersklasse

Bei Betrachtung der Anteile der verschiedenen Altersklassen im Vergleich zwischen Schutzgebietskulisse und Gesamtwaldfläche ist zu erkennen, dass im Fall der Buche die Altersklassen X und XI (181-200 Jahre und älter 200 Jahre) sowie im Falle der Eiche die höchsten vier Altersklassen innerhalb der Schutzgebietskulisse deutlich überrepräsentiert sind (s. Abb. 115). Unterrepräsentiert sind bei der Buche 
die Altersklasse II (21-40 Jahre) und bei der Eiche die Altersklassen I (0-20 Jahre) und V (81-100 Jahre).
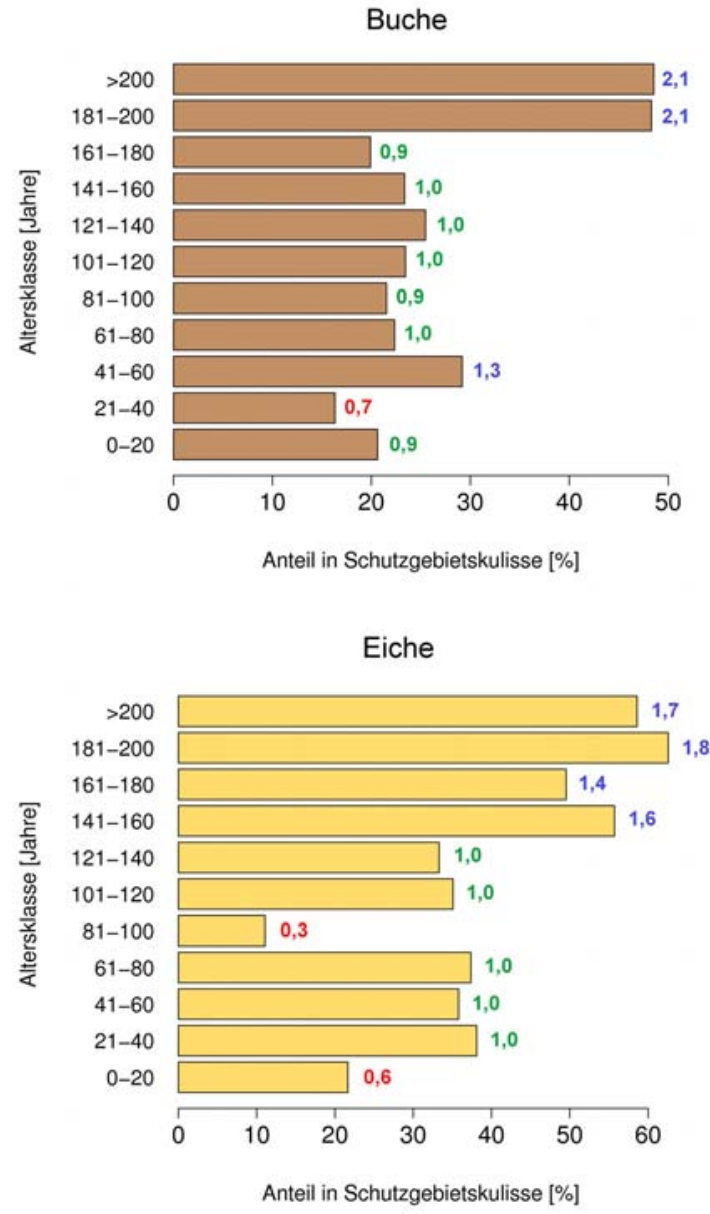

Abbildung 115: Anteile [\%] der einzelnen Altersklassen (Buche und Eiche) innerbalb von FFH- und Naturschutzgebieten (Bezugsgröße: Kronenschirmfläche [ha]). Farbige Werte: Repräsentanzfaktor, errechnet aus dem Verbältnis des Anteils der Altersklasse in Schutzgebieten zu dem Anteil auf der Gesamtwaldfläche (rot: unterrepräsentiert, grün: proportional, blau: überrepräsentiert).

Innerhalb der Schutzgebiete befindet sich ein deutlich höherer Anteil an eutrophen Flächen als außerhalb von Schutzgebieten (s. Abb. 116, oben rechts). Dies ist vor allem auf die großen Gebiete „Kühkopf-Knoblochsaue“ und „Mönchbruch“ zurückzuführen. Zudem haben die frischen und feuchten Standorte einen erhöhten Anteil innerhalb von Schutzgebieten. 


$\begin{array}{ll}\text { Frischestufe } & \text { Trophie } \\ \square \text { trocken } & \square \text { eutroph } \\ \square \text { frisch } & \square \text { mesotroph } \\ \square \text { feucht/nass } & \square \text { oligotroph }\end{array}$

$\begin{array}{ll}\text { Linke Säule } & \text { Schutzgebiete (FFH und NSG), } 8050 \text { ha } \\ \text { Rechte Säule } & \text { : außerhalb Schutzgebiete. } 19609 \text { ha }\end{array}$

GW-
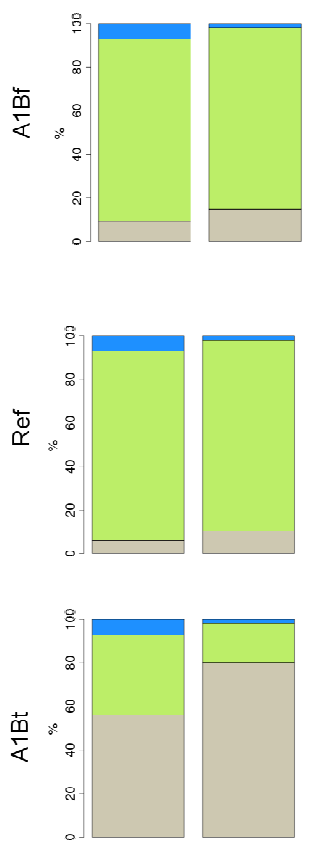

GWO
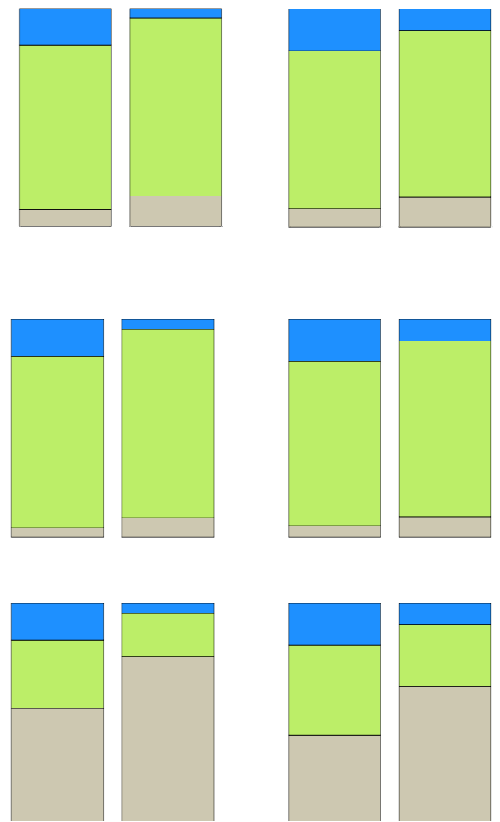

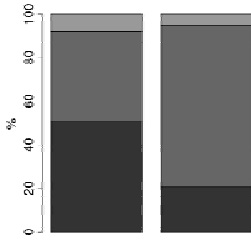

GW+

Abbildung 116: Flächenanteile [\%] von Standorten verschiedener Frische- und Trophiestufen innerhalb von Schutzgebieten (FFH und NSG, jew. linke Säulen) und außerbalb von Schutzgebieten (jew. rechte Säulen). Trophie: oben rechts, Stichjahr 2007; Frischestufen: unten, nach Szenarien zum Stichjabr 2039; Frischestufen wie folgt zusammengefasst: trocken = Frischestufen F4 und F5; frisch = Frischestufen F1, F2 und F3; feucht $/$ nass $=$ Frischestufen $G W 1, G W 2$ und $S W 1$.

Interessant ist auch ein Vergleich der Frischestufen nach den Szenariorechnungen zum Endzeitpunkt der Simulation. Hier unterscheidet sich insbesondere das trockene Klimaszenario von den übrigen Varianten. Der Anteil trockener Standorte steigt im Simulationszeitraum sowohl innerhalb als auch außerhalb der Schutzgebietskulisse stark an (Veränderung von 2007 bis 2039 hier nicht dargestellt). Jedoch verbleiben innerhalb der Schutzgebiete auch bei dem trockenen Klimaszenario noch etwa 40 Prozent frische und feuchte Standorte, im Falle des Grundwasserszenarios GW+ sogar rund 60 Prozent. Der Unterschied zu den 
Flächen außerhalb der Schutzgebiete vergrößert sich deutlich. Hier können lediglich 20 bzw. 30 Prozent frischer und feuchter Standorte erhalten werden.

\subsubsection{Schutzgüter innerhalb und außerhalb von Schutzgebieten}

Für die Schutzgüter der Hessischen Biotopkartierung und die in dem Projekt betrachteten Arten wurde eine Überlagerungsanalyse mit der Schutzgebietskulisse durchgeführt. Große Bereiche der im Rahmen der Hessischen Biotopkartierung kartierten Waldbestände liegen innerhalb von Schutzgebieten (s. Tab. 58). Dies trifft insbesondere auf die Biotoptypen mit einer hohen absoluten Fläche zu. Von den flächenscharf kartierten Biotopen haben insgesamt 560 Hektar (64 Prozent) einen Schutzstatus. 253 Hektar (29\%) liegen in Naturschutzgebieten und 518 Hektar (59\%) in FFH-Gebieten. Eine gleichzeitige Belegung mit beiden Schutzkategorien ist häufig der Fall.

Tabelle 58: Verteilung der Biotope und Biotopkomplexe der Hessischen Biotopkartierung innerhalb der bestehenden Schutzgebietskulisse (FFH und NSG $=S G$ ). Mehrfachüberlagerungen zwischen Biotopen und Komplexen sind möglich. Netto-SG: Auch Flächen mit gleichzeitigem FFH- und NSG-Status gehen nur einfach in die Summe ein.

\begin{tabular}{|c|c|c|c|c|c|}
\hline & \multirow{2}{*}{$\begin{array}{c}\text { Gesamt- } \\
\text { fläche } \\
\text { [ha] }\end{array}$} & \multicolumn{3}{|c|}{$\begin{array}{c}\text { Innerhalb } \\
\text { Schutzgebietskulisse }\end{array}$} & \multirow{2}{*}{$\begin{array}{c}\text { Anteil in } \\
\text { SG } \\
{[\%]}\end{array}$} \\
\hline & & $\begin{array}{l}\text { FFH } \\
\text { [ha] }\end{array}$ & $\begin{array}{l}\text { NSG } \\
\text { [ha] }\end{array}$ & $\begin{array}{l}\text { Netto SG } \\
\quad[\text { ha] }\end{array}$ & \\
\hline $\begin{array}{l}\text { Buchenwälder mittlerer und } \\
\text { basenreicher Standorte }\end{array}$ & 20 & 1 & 0 & 1 & 4,7 \\
\hline Bodensaure Buchenwälder & 37 & 2 & 0 & 2 & 5,0 \\
\hline Sonstige Eichen-Hainbuchenwälder & 349 & 264 & 13 & 269 & 77,0 \\
\hline Eichenwälder & 1 & 0 & 0 & 0 & 0,0 \\
\hline $\begin{array}{l}\text { Weichholzauenwälder und } \\
\text {-gebüsche }\end{array}$ & 69 & 45 & 43 & 45 & 65,0 \\
\hline Hartholzauenwälder & 85 & 79 & 82 & 82 & 97,1 \\
\hline Bachauenwälder & 15 & 0,04 & 0 & 0,04 & 0,3 \\
\hline Bruch- und Sumpfwälder & 148 & 78 & 101 & 107 & 72,1 \\
\hline $\begin{array}{l}\text { Übrige stark forstwirtschaftlich } \\
\text { geprägte Laubwälder }\end{array}$ & 125 & 42 & 9 & 42 & 33,4 \\
\hline Sandkiefernwälder & 10 & 3 & 0 & 3 & 31,2 \\
\hline Schlagfluren und Vorwald & 16 & 2 & 4 & 4 & 27,2 \\
\hline Waldränder & 4 & 2 & 1 & 2 & 64,9 \\
\hline Biotopkomplexe & 2.065 & 1.578 & 1.394 & 1.687 & 81,7 \\
\hline
\end{tabular}


Einzelne Biotoptypen mit einer geringen absoluten Fläche liegen nur zu einem sehr geringen Flächenanteil in der Schutzgebietskulisse. Auffällig sind hier die Biotoptypen „Buchenwälder mittlerer und basenreicher Standorte“ (01.110), „Bodensaure Buchenwälder“ (01.120) und „Bachauenwälder“ (01.173).

Hingegen befinden sich die vorliegenden Artfunde zu einem erheblichen Anteil innerhalb der Schutzgebietskulisse. Dies kann vor allem durch die explizite Artkartierung innerhalb von Schutzgebieten (Grunddatenerhebung FFH und Einzelgutachten) erklärt werden.

\subsubsection{Forstliche Nutzungsbeschränkungen durch Naturschutzauflagen}

Konkrete naturschutzfachlich begründete Auflagen für die Forstwirtschaft wurden aus den jeweiligen Rechtsgrundlagen der Schutzgebiete abgeleitet.

Von der Gesamtfläche des Waldes im Hessischen Ried (27.659 ha, s. Kap. 2.1) sind 1.774 Hektar oder 6,4 Prozent aus der forstlichen Nutzung genommen (s. Abb. 117). Das Naturschutzgebiet „Kühkopf-Knoblochsaue“ (einschließlich dem Naturwaldreservat „Karlswörth“) geht hier mit 1.179 Hektar ein. Den zweitgrößten Anteil am nutzungsfreien Wald haben die Kompensationsflächen im Bereich des Flughafens Frankfurt mit 509 Hektar. Die restlichen 86 Hektar teilen sich auf Ökokontoflächen im Gemeindewald Nauheim (58 ha) und Einzelflächen im Naturschutzgebiet Sauergrund (16 ha) und im Stadtwald Frankfurt (12 ha) auf. Zusätzlich sind 1.969 Hektar mit weiteren naturschutzfachlichen Auflagen belegt. Weitaus überwiegend (1.942 ha) betreffen diese den Erhalt bestimmter Waldgesellschaften und damit die Festlegung auf eine bestimmte Baumartenzusammensetzung (s. Tab. 59).

Tabelle 59: Waldflächen in Schutrgebieten (NSG, FFH-Gebiet) mit der Auflage des Erbalts bestimmter Waldgesellschaften (ohne Flächen mit Nutzungsverzicht; Bezeichnungen der Waldgesellschaften, wie in den jeweiligen recbtlichen Grundlagen vorgefunden)

\begin{tabular}{lc}
\hline Waldgesellschaft & Fläche [ha] \\
\hline Stieleichen-Hainbuchenwald & 857,5 \\
Buchenwald & 328,8 \\
Erlenbruchwald & 227,6 \\
Eichenwald & 213,4 \\
Laubmischwald & 177,2 \\
Hartholzaue & 50,0 \\
Weichholzaue & 41,6 \\
Kiefernwald & 34,9 \\
Eschen-Bachwald & 10,5 \\
\hline
\end{tabular}




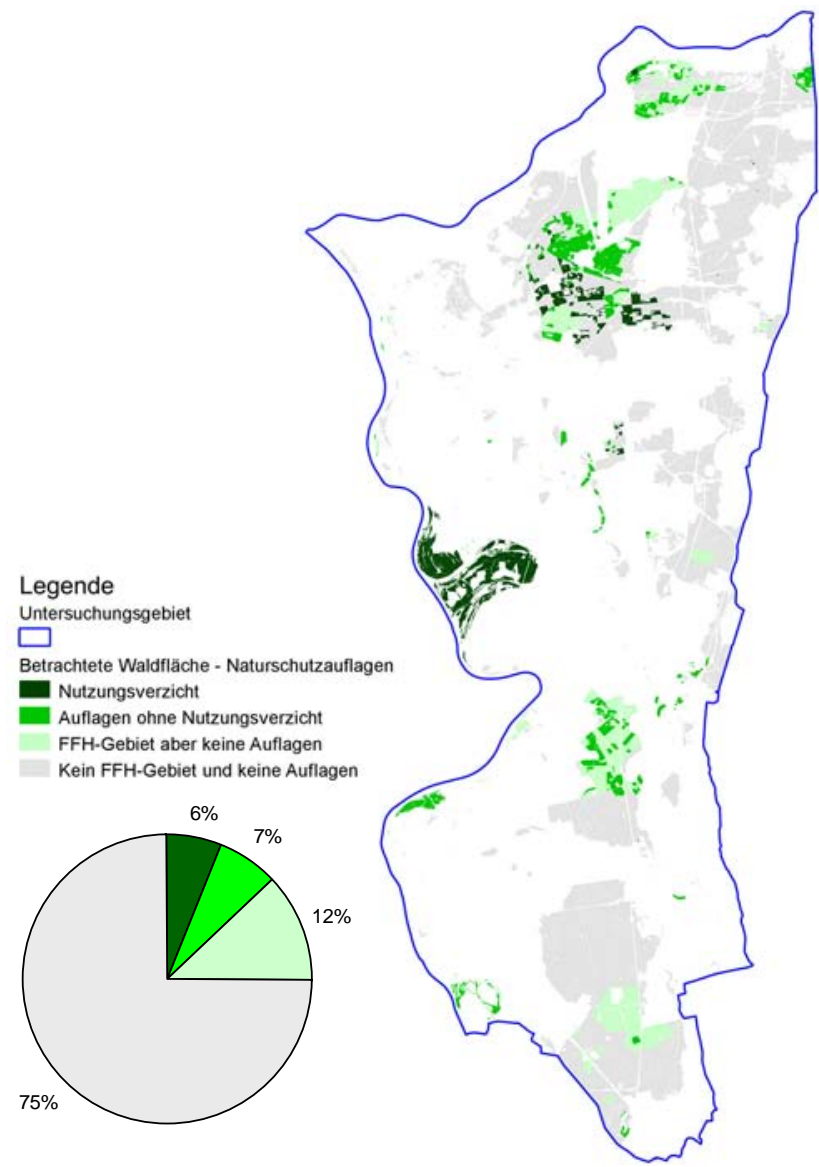

Abbildung 117: Waldflächen mit konkreten Naturschutzauflagen aus geltendem Recht im Hessischen Ried (rechts: Karte, links: prozentuale Verteilung)

Die Festlegung auf eine bestimmte Waldgesellschaft beruht auf verschiedenen rechtlichen Grundlagen (s. Tab. 60). Den größten Flächenumfang haben mit 1.317 Hektar die Lebensraumtypen innerhalb von FFH-Gebieten. ${ }^{19}$. Innerhalb von Naturschutzgebieten sind laut den jeweiligen Verordnungen auf 521 Hektar Waldgesellschaften festgeschrieben. Weitere 130 Hektar resultieren jeweils aus Flächen mit möglichem Vorkommen gesetzlich geschützter Biotope ( $\int 30$ BNatschG) und Kompensationsmaßnahmen der Flughafen AG im Forstamt Groß-Gerau.

$19 \mathrm{Im}$ Rahmen dieses Projektes wird davon ausgegangen, dass auf den kartierten LRT-Flächen die jeweiligen Waldgesellschaften erhalten werden. In der Praxis ist eine räumliche Verlagerung innerhalb eines FFH-Gebietes nicht ausgeschlossen.

Beiträge aus der NW-FVA, Band 10, 2013 
Tabelle 60: Naturschut_fachliche Vorgabe der Waldgesellschaft auf Flächen ohne Nutzungsverzicht nach (Rechts-)Grundlage (Mehrfachbelegungen sind möglich)

\begin{tabular}{lc}
\hline (Rechts-)Grundlage & Fläche [ha] \\
\hline Lebensraumtypen (FFH) & $1.317,0$ \\
NSG-VO & 521,3 \\
Kompensationsmaßnahmen FFM & 130,4 \\
\30-Hinweis aus HB & 130,2
\end{tabular}

Zusätzlich zur Festlegung auf eine Waldgesellschaft muss laut Naturschutzgebietsverordnung auf 520 Hektar im Naturschutzgebiet „Mönchbruch“ auf die Nutzung von Bäumen mit einem BHD über $50 \mathrm{~cm}$ verzichtet werden.

Weitere Nutzungsrestriktionen wurden bei den Simulationsrechnungen angenommen, um einer Verschlechterung des Erhaltungszustandes in den abgegrenzten FFH-Lebensraumtypen entgegenzuwirken. Im Falle der Erhaltungszustände A bzw. B wurden 40 bzw. 20 Prozent der Bäume mit einem BHD über $50 \mathrm{~cm}$ von einer Nutzung im Simulationszeitraum ausgenommen. Von dieser Einschränkung waren insgesamt 859 Hektar Waldfläche betroffen. Die Auflagen überlagern sich teilweise mit den Festlegungen auf eine Waldgesellschaft.

\subsubsection{Hotspots der xylobionten Artenvielfalt}

\subsubsection{Ausgangszustand}

Zur Bestimmung der Habitateignung der Waldbestände im Hessischen Ried für Arten der Alters- und Zerfallsphase von Buchen- und Eichenwäldern wurde eine Habitatmodellierung (Ecological-Niche Factor Analysis, ENFA, s. HIRZEL et al. 2002) mit der Software „Biomapper“ durchgeführt. Die Waldbestände mit einer optimalen Habitateignung werden im Folgenden als Hotspots bezeichnet. Im Rahmen der Schätzung der Habitateignung für die Zukunftsszenarien mit einem verallgemeinerten additiven Modell (GAM) war es erforderlich, auch die Waldbestände mit der Habitateignungsklasse „geeignet" als Hotspots einzubeziehen (s. Abschnitt 2.2.9). Diese werden im Folgenden als „,erweiterte Hotspots“ bezeichnet, um sie von den mit der ENFA-Methode identifizierten Hotspots abzugrenzen.

Die auf der Grundlage der ENFA-Methode identifizierten Hotspots liegen vorrangig in den naturschutzfachlich besonders wertvollen Gebieten wie den „Schwanheimer Eichen“, dem „Mönchbruch“, der „Kühkopf-Koblochsaue“ oder dem nördlichen Teil des Jägersburger Waldes (s. Abb. 118). Damit bestätigt sich die Treffsicherheit des Verfahrens. Auch eine stichprobenweise Überprüfung vor Ort ergab eine hohe naturschutzfachliche Eignung der Hotspots. 


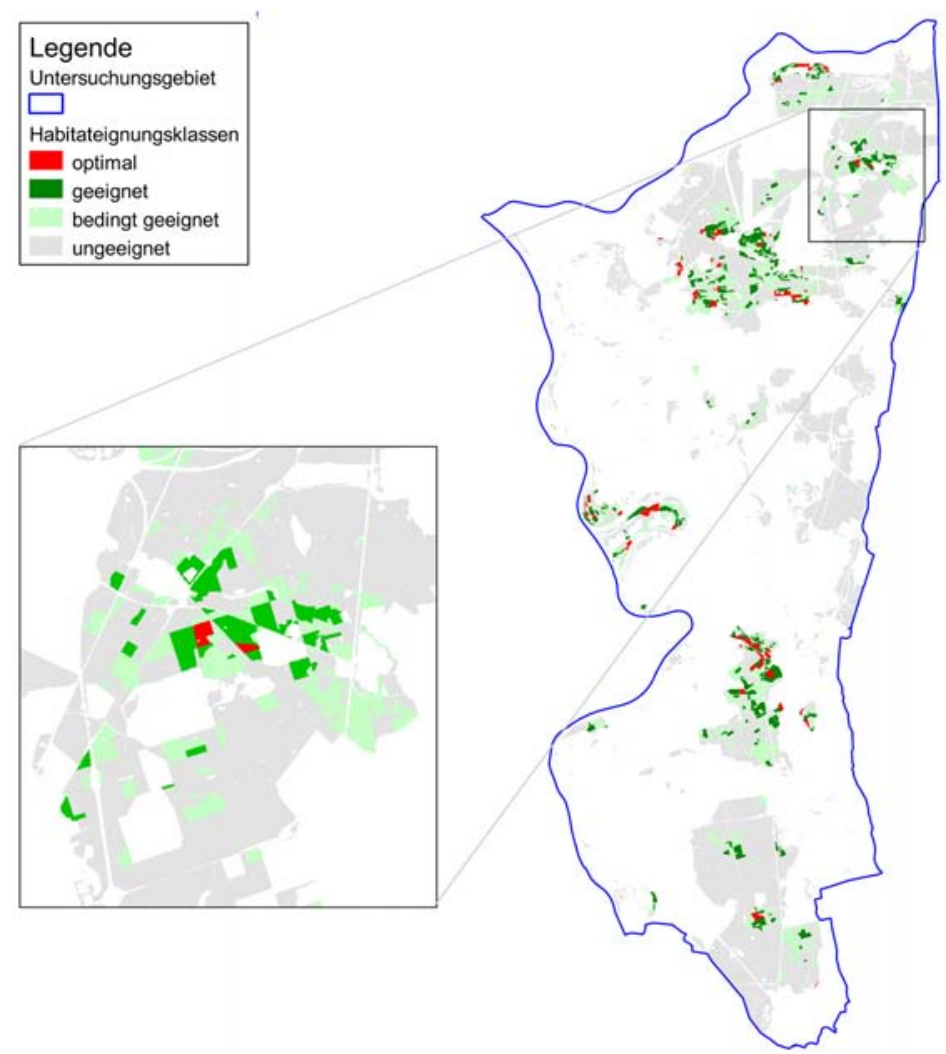

Abbildung 118: Verteilung der Habitateignungsklassen für Arten der Alters- und Zerfallsphase in den Wäldern des Untersuchungsgebietes als Ergebnis der Habitatmodellierung mit der Software „Biomapper"

Die sechs wichtigsten Variablen, die im Rahmen der Modellierung zu einer hohen Habitateignung führen, sind das Alter des Laubholzes, die Distanz zu Eichen- und Buchenbiotoptypen der Hessischen Biotopkartierung und zu bekannten Referenzflächen mit vorteilhaften Strukturen von Altbeständen, der Anteil des Laubholzes, speziell der Eiche, sowie die Bewaldungskontinuität von Laub- und Mischwald (s. Kap. 2.2.9).

Die Waldbestände aus den verschiedenen Habitateignungsklassen zeigen plausible Unterschiede hinsichtlich wichtiger Kriterien. So liegt das Alter des Laubholzes auf den Flächen der Habitateignungsklassen „optimal“ und „geeignet“ im Mittel bei knapp 200 Jahren (s. Abb. 119). Ungeeignete Flächen hingegen weisen ein mittleres Alter von unter 100 Jahren auf. Geeignete und optimale Waldbestände sind weitgehend reine Laubwälder (sehr hoher Anteil Laubholz), haben einen Eichenanteil von mindestens 20 Prozent und sind zudem historisch alte Laub- bzw. Mischwälder. 
Neg. Exp. Distanz Hessische Biotopkartierung

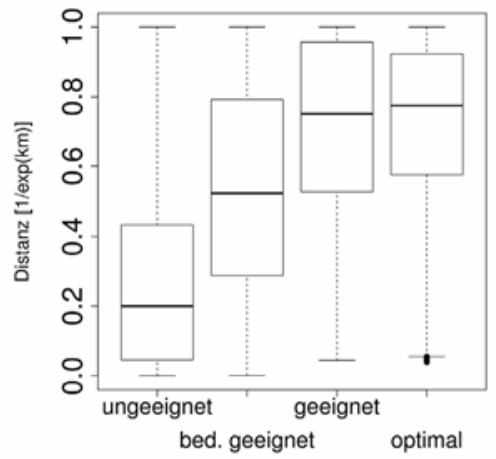

Anteil Laubholz

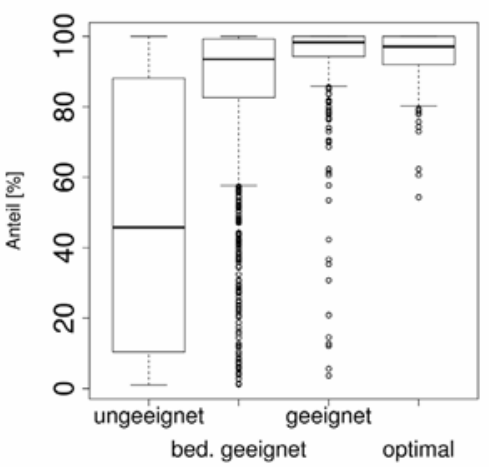

Maximales Alter Laubholz

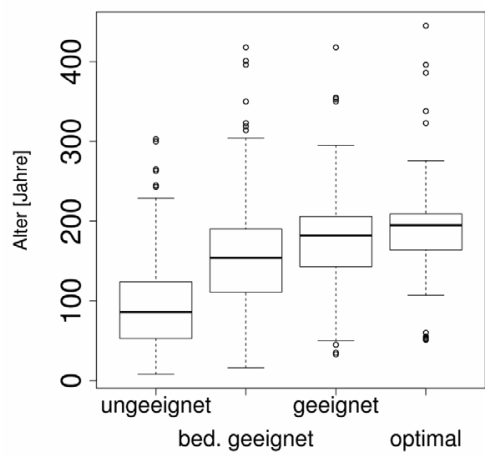

Neg. Exp. Distanz Referenzflächen
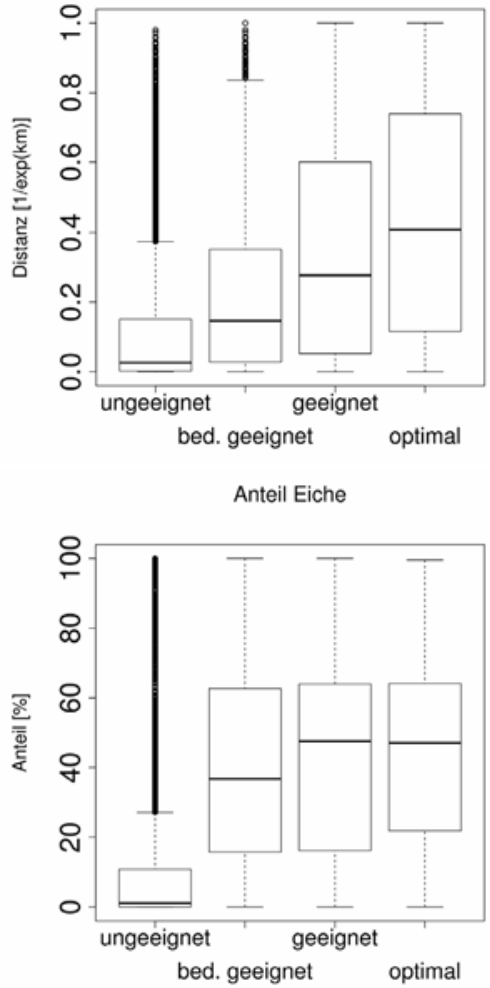

Anteil Laub- und Mischwaldkontinuităt

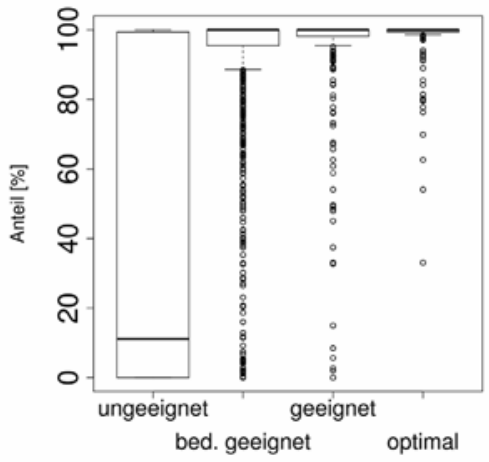

Abbildung 119: Ausprägung der sechs V ariablen mit den größten Einflïssen auf die Habitateignung, dargestellt über den Habitateignungsklassen „,ptimal", ,geeignet", „, bedingt geeignet" und "ungeeignet" 
Ausschlaggebend für die abschließende Berechnung der Habitateignung im Rahmen der ENFA ist jedoch nicht die Ausprägung einer einzelnen Variable, sondern immer eine lineare Kombination aller verwendeten Variablen. Dies bedeutet, dass ein hohes Alter des Laubholzes alleine nicht ausreicht, um einer Fläche eine hohe Habitateignung zuzuweisen. Auch die übrigen Variablen müssen vorteilhafte Ausprägungen annehmen, um eine entsprechende Habitateignung zu erreichen.

Insgesamt ergeben sich durch die Habitatmodellierung 499 Hektar Fläche der Habitateignungsklasse „optimal“ (s. Tab. 61). Diese Fläche ist aufgeteilt in 69 Einzelflächen mit einer mittleren Flächengröße von 7,2 Hektar. Betrachtet man die landschaftsökologischen Kenngrößen, fällt vor allem auf, dass sich die Core Area (Innenbereiche) bei einem angenommenen Pufferbereich von 60 Metern (zwei Baumlängen) auf nur noch 122 Hektar reduziert. Eine Validierung der Hotspots im Gelände fand wie in Kapitel 2.2.9 beschrieben statt. 75 Prozent der Hotspots befinden sich innerhalb von FFH-Gebieten. Jedoch liegen nur 30 Prozent in Naturschutzgebieten.

Tabelle 61: Kenngrößen zu den Hotspots (optimale Flächen) und den erweiterten Hotspots (optimale und geeignete Flächen) der Habitatmodellierung (ENFA). Landschaftsökologische Kenngrößen: Core Area = Innenbereiche der Flächen bei einem Pufferwert von 60 Metern.

\begin{tabular}{|c|c|c|}
\hline \multirow[t]{2}{*}{ Kenngrößen } & \multicolumn{2}{|c|}{ Habitateignungsklasse } \\
\hline & $\begin{array}{c}\text { optimal } \\
\text { (Hotspots) }\end{array}$ & $\begin{array}{c}\text { optimal + geeignet } \\
\text { (erweiterte Hotspots) }\end{array}$ \\
\hline \multicolumn{3}{|l|}{ Deskriptive Kenngrößen } \\
\hline Gesamtfläche [ha] & 499 & 2.320 \\
\hline Anzahl $[\mathrm{N}]$ & 69 & 217 \\
\hline mittlere Flächengröße [ha] & 7,2 & 10,7 \\
\hline Standardabweichung [ha] & 7,9 & 18,4 \\
\hline \multicolumn{3}{|c|}{ Landschaftsökologische Kenngrößen } \\
\hline Core Area [ha] & 122 & 750 \\
\hline Anzahl Core Areas $[\mathrm{N}]$ & 59 & 217 \\
\hline
\end{tabular}

Erwartungsgemäß unterscheiden sich die Hotspots hinsichtlich der Baumartenund Altersstruktur deutlich von den restlichen Waldflächen (s. Abb. 120). Besonders auffällig ist der hohe Anteil der oberen Altersklassen. Zukünftig problematisch könnte der sehr geringe Eichenanteil in den jüngeren Altersklassen werden. Soll der Eichenanteil nachhaltig gesichert werden, so müssten Anstrengungen zur Etablierung von Eichen-Jungbeständen unternommen werden. 

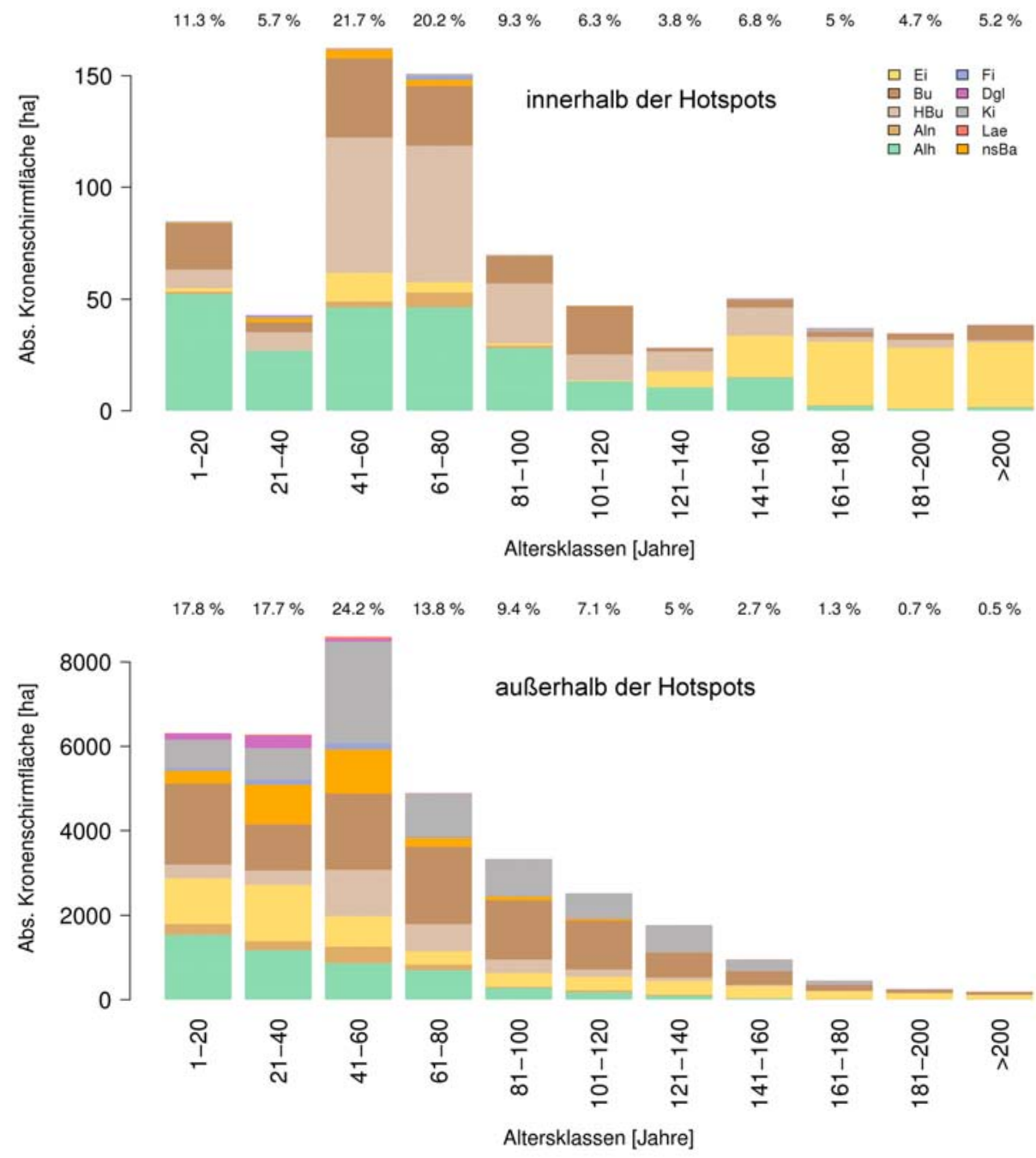

Abbildung 120: Baumartenverteilung nach Altersklassen innerhalb (oben) und außerbalb (unten) der Hotspots (Habitateignung „optimal") zum Stichjahr 2007 (Bezugsgröße: absolute Kronenschirmfläche [ba]; nsBa: nicht-standortheimische Baumarten, ₹. B. Roteiche und Robinie; Aln = Andere Laubbäume mit niedriger Umtriebszeit, Alb = Andere Laubbäume mit hoher Umtriebszeit); oberbalb der Säulen: prozentualer Anteil der jeweiligen Altersklasse

Circa 80 Prozent der Hotspots befinden sich auf nährstoffreichen Böden (s. Abb. 121). Im Unterschied dazu beträgt der Anteil eutropher Standorte auf den restlichen Waldflächen nur etwa 30 Prozent. Hingegen ist im Hinblick auf den Wasserhaushalt kein vergleichbar deutlicher Unterschied zwischen den Hotspots und der 
übrigen Waldfläche zu erkennen. Auch zwischen den Klimaszenarien Referenz und A1Bf unterscheiden sich die Frischestufen nur geringfügig. Auffällig ist jedoch, dass die Hotspots bei dem trockenen Klimaszenario A1Bt einen höheren Anteil frischer und nasser Standorte umfassen.
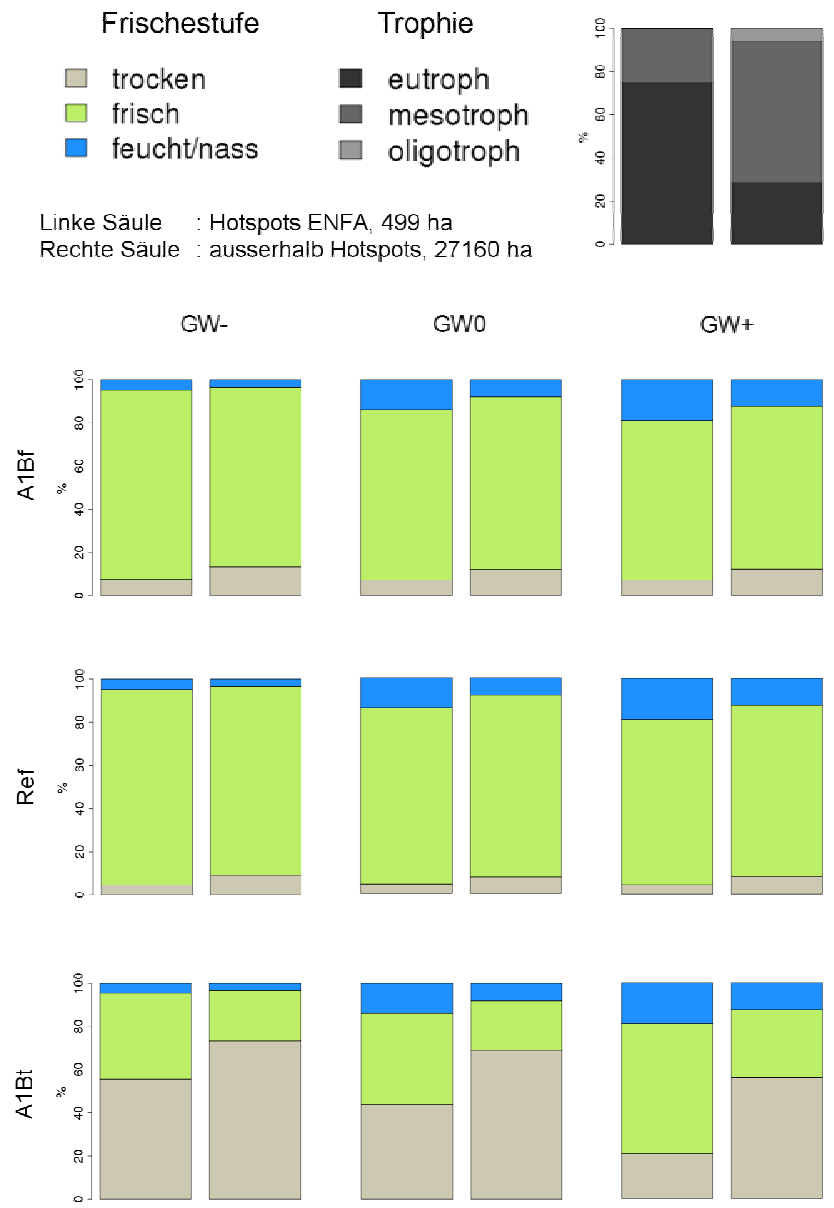

Abbildung 121: Flächenanteile [\%] von Standorten verschiedener Frische- und Trophiestufen innerhalb von Hotspots (jew. linke Säulen) und außerbalb von Hotspots (jew. rechte Säulen). Trophie: oben rechts, Stichjahr 2007; Frischestufen: unten, nach Szenarien zum Stichjabr 2039; Frischestufen wie folgt zusammengefasst: trocken = Frischestufen F4 und F5; frisch = Frischestufen F1, F2 und F3; feucht/nass = Frischestufen GW1, GW2 und SW1.

\subsubsection{Entwicklung der Habitateignung}

Die Entwicklung der Habitateignung für die verschiedenen Zukunftsszenarien wurde mit einem verallgemeinerten additiven Modell (GAM) berechnet (s. Kap. 
2.2.9). Die Auswertungen beziehen sich auf die „erweiterten Hotspots“ (Habitateignungsklassen ,geeignet“ und „optimal“). Diese umfassen 2.304 Hektar, verteilt auf 220 Einzelflächen (s. Tab. 62). Bei einer Annahme von $60 \mathrm{~m}$ Pufferzone (zwei Baumlängen) ergeben sich 764 Hektar Core Area.

Tabelle 62: $\quad$ Kenngrößen ₹u den über ein GAM ermittelten erweiterten Hotspots. Core Area = Innenbereiche der Hotspots bei einem Pufferwert von 60 Metern.

\begin{tabular}{lr|lc}
\hline Deskriptive Kenngrößen & & \multicolumn{2}{|l}{ Landschaftsökologische Kenngrößen } \\
\hline Gesamtfläche [ha] & 2.304 & Core Area [ha] & 764 \\
Anzahl Einzelflächen [N] & 220 & Anzahl Core Areas [N] & 202 \\
mittlere Flächengröße [ha] & 10,5 & & \\
Standardabweichung [ha] & 17,9 & & \\
\hline
\end{tabular}

Der Ergebnisvergleich mit dem „Biomapper“ zeigt, dass die Vorhersagequalität des GAM sehr gut ist. So stimmen die modellierten Flächen der Habitatklassen „geeignet“ und „optimal“ im Jahr 2007 zu 82 Prozent mit den Flächen aus dem ursprünglichen Modell des Software „Biomapper“ überein.

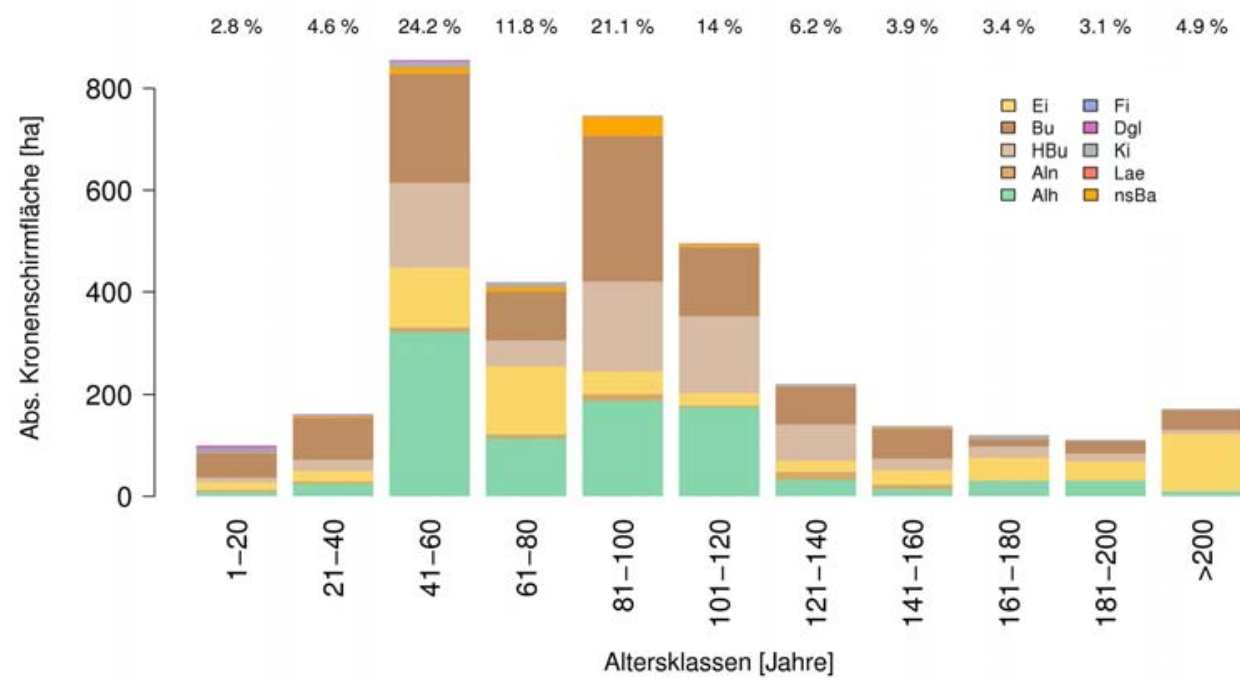

Abbildung 122: Baumartenverteilung nach Altersklassen innerhalb der über das GAM ermittelten erweiterten Hotspots (Habitateignung ,optimal" und „geeignet) im Jabr 2039 im Szenario GW0/Ref (Bezugsgröße: absolute Kronenschirmfläche [ha]; nsBa: nicht-standortheimische Baumarten, ₹. B. Roteiche und Robinie; Aln = Andere Laubbäume mit niedriger Umtriebszeit, Alh = Andere Laubbäume mit hoher Umtriebszeit); oberbalb der Säulen: prozentualer Anteil der jeweiligen Altersklasse

Die Altersklassen- und Baumartenzusammensetzung der erweiterten Hotspots im Jahre 2039 (Szenario GW0/Ref) zeigt einen sehr geringen Anteil junger Bestände 
unter 40 Jahren (s. Abb. 122). Dieser Mangel an jungen Beständen kann sich langfristig negativ auf das Lebensraumangebot für die Arten der Alters- und Zerfallsphase auswirken. Die hohen Altersklassen sind wie schon im Ausgangszustand 2007 (s. Abb. 123 oben) relativ gut besetzt. Lediglich der Anteil der Eiche nimmt in diesen Altersklassen etwas ab.

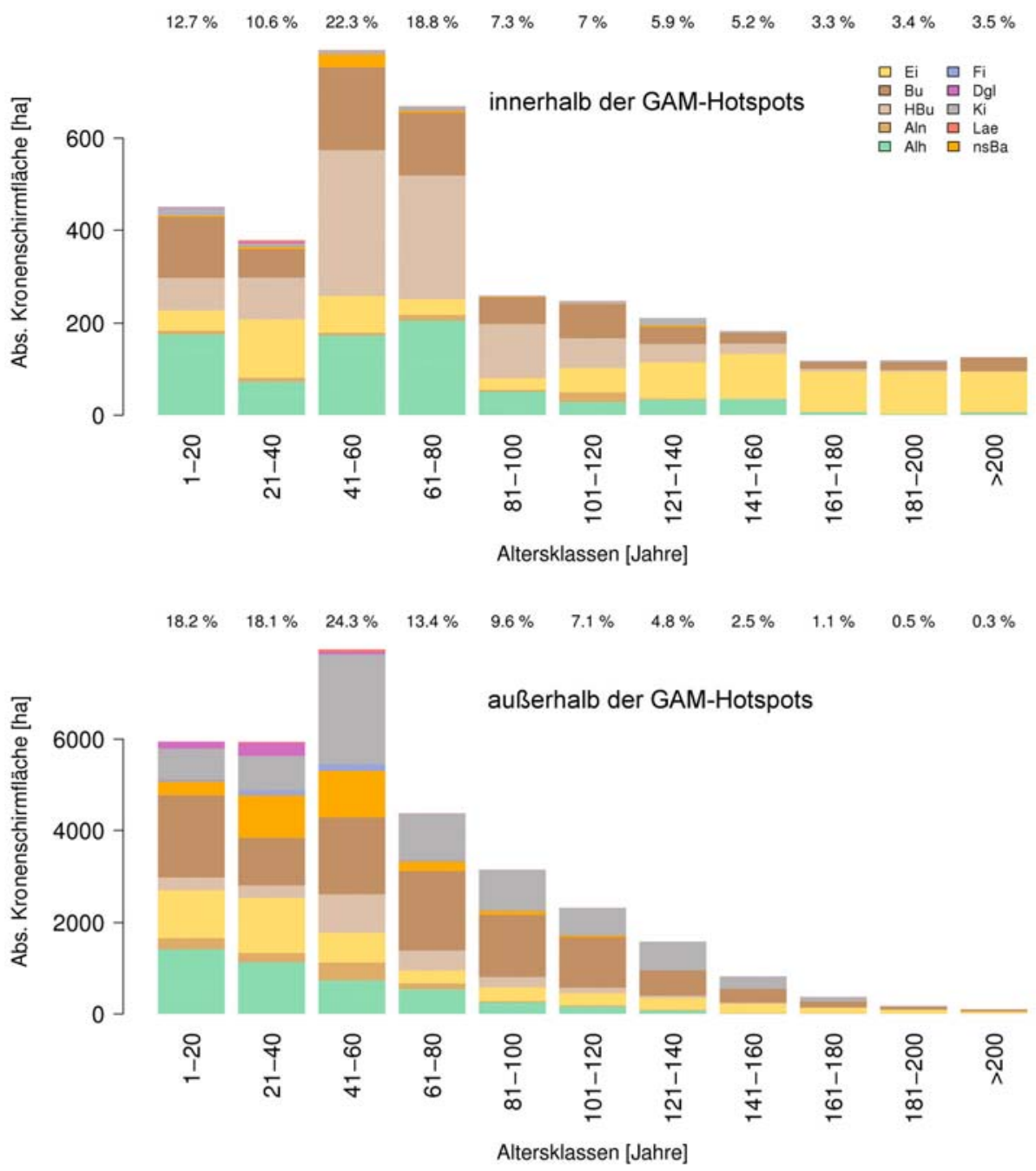

Abbildung 123: Baumartenverteilung nach Altersklassen innerbalb (oben) und außerbalb (unten) der über ein GAM ermittelten erweiterten Hotspots im Jahr 2007 (Bezugsgröße: absolute Kronenschirmfläche [ha]; nsBa: nicht-standortheimische Baumarten, ₹. B. Roteiche und Robinie; Aln $=$ Andere Laubbäume mit niedriger Umtriebszeit, Alh $=$ Andere Laubbäume mit hoher Umtriebszeit); oberhalb der Säulen: prozentualer Anteil der jeweiligen Altersklasse 
Die über das GAM ermittelten erweiterten Hotspots weisen in Bezug auf die Altersklassen- und Baumartenzusammensetzung ein sehr ähnliches Bild wie die mit dem „Biomapper" modellierten Bestände auf (s. Abb. 120 und 121).

Auch in Bezug auf die Nährstoff- und Wasserversorgung stimmen die Ergebnisse des GAM mit denen der ENFA weitgehend überein (s. Abb. 124).

$\begin{array}{lll} & \text { Frischestufe } & \text { Trophie } \\ \square \text { trocken } & \\ \square \text { frisch } & & \text { eutroph } \\ & \text { mesotrop } \\ \text { feucht/nass } & \square \text { oligotroph }\end{array}$

Linke Säule : GAM geeignet und optimal Rechte Säule : außerhalb GAM

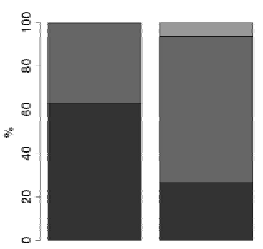

GW-

GWO

GW+
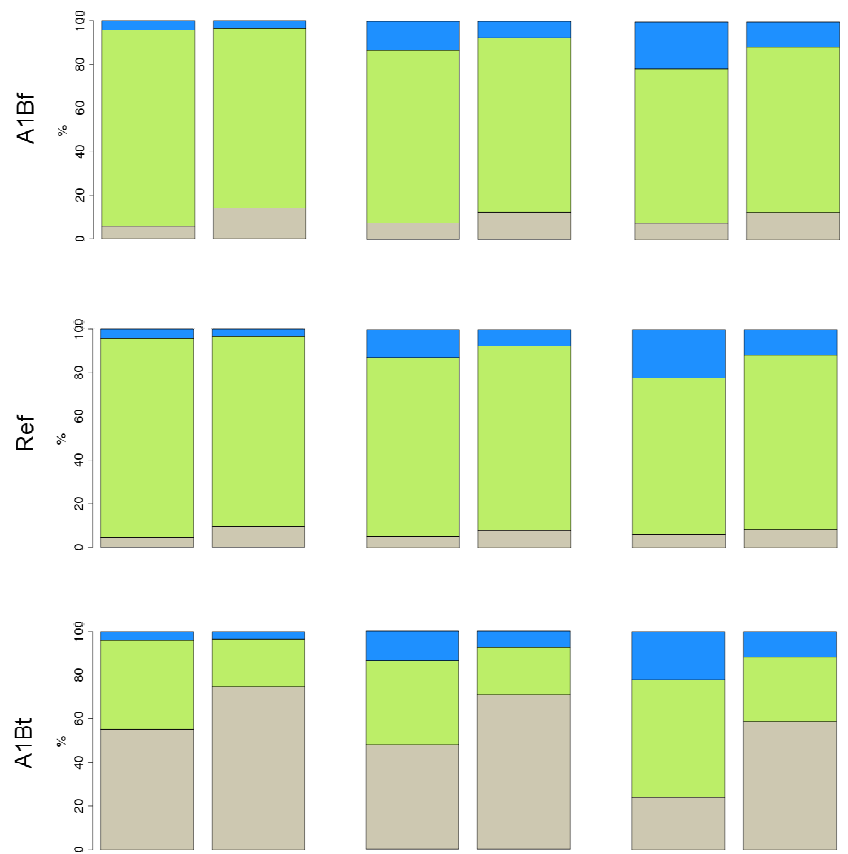

Abbildung 124: Flächenanteile [\%] von Standorten verschiedener Frische- und Trophiestufen innerhalb von erweiterten Hotspots (jew. linke Säulen) und außerhalb von erweiterten Hotspots (jew. rechte Säulen). Trophie: oben rechts, Stichjabr 2007; Frischestufen: unten, nach Szenarien zum Stichjabr 2039; Frischestufen wie folgt zusammengefasst: trocken = Frischestufen F4 und F5; frisch = Frischestufen F1, F2 und F3; feucht/nass = Frischestufen GW1, GW2 und SW1. 


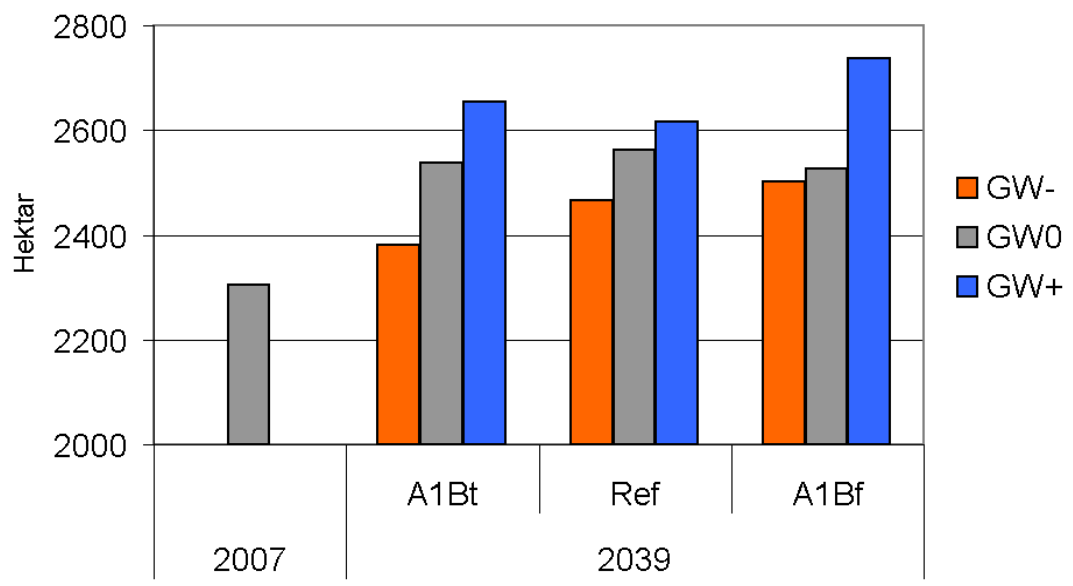

Abbildung 125: Fläche [ha] der erweiterten GAM-Hotspots 2007 und 2039 nach Klima- und Grundwasserszenarien

Im Simulationszeitraum vergrößert sich die Fläche der erweiterten Hotspots um ca. 10 Prozent (s. Abb. 125). Ein Anstieg des Grundwassers führt zu einer weiteren Flächenausdehnung. Dies gilt insbesondere für das feuchte Szenario.

Im Klimaszenario A1Bt ergibt sich zwischen den Grundwasserszenarien GWund GW+ ein Unterschied von 270 Hektar. Hierfür verantwortlich ist die unterschiedliche waldbauliche Planung und Behandlung der Waldbestände. In den Szenarien mit ungünstigeren Wasserhaushaltsbedingungen erlangt die Kiefer eine deutlich größere Bedeutung. Erntereife Eichen- und Buchenbestände werden konsequent zugunsten dieser Baumart umgebaut, da viele Standorte nicht mehr laubholzfähig wären und in der waldbaulichen Planung Kiefer vorgesehen ist. Hinzu kommt, dass die Erntereife in trockenen Szenarien frühzeitiger eintritt, da die Zielstärken wegen niedrigerer Wuchsleistungen herabgesetzt sind. Von diesem Umbau sind in einigen Fällen auch Bestände betroffen, die aufgrund ihres hohen Anteils an Eichen der oberen Altersklassen eine relativ hohe Habitateignung haben.

Nach der Simulation können diese naturschutzfachlich wertvollen Flächen insbesondere bei dem trockenen Klimaszenario und einer erhöhten Grundwassernutzung nicht erhalten werden. 


\subsubsection{Naturschutafachliche Entwicklung der Buchen- und Eichenwälder im Simulationszeitraum}

\subsubsection{Simulierte Bestandesentwicklung in den Szenarien}

Um die unterschiedliche Wirkungsweise des WaldPlaners bei der Simulation der Waldentwicklung in den verschiedenen Szenarien zu verdeutlichen, wurden die einzelnen Prozesse Entnahme, Mortalität (allgemeine-, Maikäfer- und dichtebedingte Mortalität), Zuwachs, Einwuchs und Pflanzung näher betrachtet. Als Maßeinheit wird die Summe der betreffenden Kronenschirmflächen bezogen auf einen Hektar Waldfläche verwendet (s. Abb. 126).

Die Bestandesentwicklung wird vorrangig durch Entnahme und Zuwachs bestimmt. Nachgelagert spielen in den trockenen Klimaszenarien die Pflanzung sowie in allen Szenarien Einwuchs und Mortalität eine gewisse Rolle. Zwischen den einzelnen Szenarien bestehen nur geringe Unterschiede. Lediglich das trockene Klimaszenario (die drei linken Säulen in Abbildung 126) fällt durch leicht erhöhte Nutzungsmengen und Pflanzungen auf. Grund hierfür sind in erster Linie der herabgesetzte Zieldurchmesser und ein aktiver Bestandesumbau zu trockenheitstoleranten Baumarten. Im Hinblick auf die Mortalität ist zu berücksichtigen, dass erhöhte Ausfälle im Hessischen Ried räumlich konzentriert auftreten und lokal ein dramatisches Ausmaß annehmen können. Auf die Gesamtfläche bezogen haben geschädigte Bestände allerdings nur einen vergleichsweise geringen Anteil.

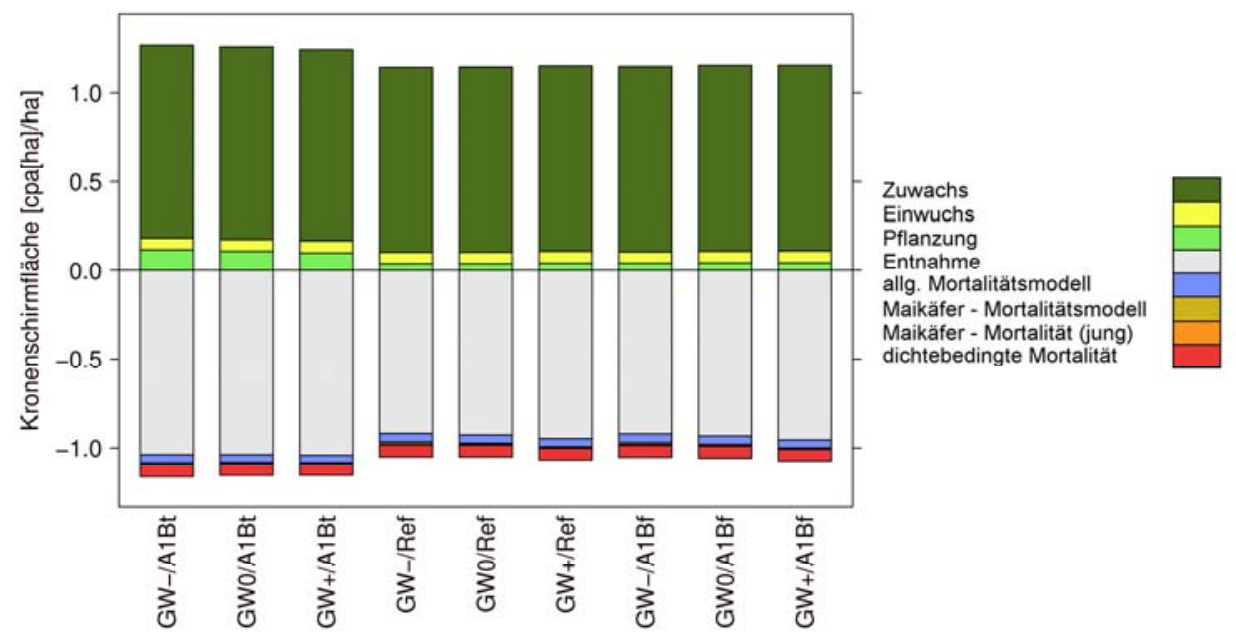

Abbildung 126: Darstellung der im Rahmen der Simulationsläufe wirksamen Prozesse anhand der aufsummierten Kronenschirmfläche (cpa [ha]) je Hektar aufgegliedert nach Szenarien 
Da die Entwicklung des Eichenanteils im Hessischen Ried von besonderer naturschutzfachlicher Bedeutung ist, wurde eine gesonderte Prozessanalyse für alle Waldbestände durchgeführt, die entweder 2007 oder 2039 die Baumart Eiche enthalten. Die Ergebnisse wurden getrennt nach den Baumarten Eiche und Buche betrachtet (hier nicht graphisch dargestellt). Der Eichenanteil wird in erster Linie durch den Zuwachs und die Entnahme der Eiche gesteuert. Weitere Prozesse mit starkem Einfluss auf den Eichenanteil sind Eichen-Pflanzungen, Einwuchs der Buche (negativ), Einwuchs der Eiche (positiv) sowie die Maikäfermortalität der Eiche (negativ). Diese Prozesse besitzen jedoch im Vergleich zu Entnahme und Zuwachs eine untergeordnete Bedeutung.

\subsubsection{Flächenentwicklung der Eichen- und Buchenbestände}

Die Fläche mit führender Eiche und Buche insgesamt nimmt im Klimaszenario A1Bt geringfügig ab und steigt in den Klimaszenarien Ref und A1Bf an (s. Abb. 127). Die Schwankungen bewegen sich im Bereich von -3,3 Prozent bzw. +2,5 Prozent bezogen auf die Fläche der Baumarten in 2007. Im trockenen Klimaszenario kann die Abnahme der zusammengenommenen Eichen- und Buchenwälder teilweise durch den Waldumbau in Richtung trockenheitstoleranterer Bestandestypen wie Kiefernwälder erklärt werden.

Der Anteil der Eiche geht in allen Szenarien bis zum Jahr 2039 deutlich zurück, während die Buche an Fläche hinzugewinnt. Der Hauptgrund für diese Entwicklung ist der hohe Anteil der Buche und Hainbuche im bereits 2007 vorhandenen Nachwuchs und in der Verjüngung. Während die Eiche genutzt wird, übernimmt die Buche auf vielen Flächen die Rolle der Hauptbaumart. Auch das Laubholz mit hoher Umtriebszeit ist 2007 in den jüngeren Bestandesschichten stark vertreten.

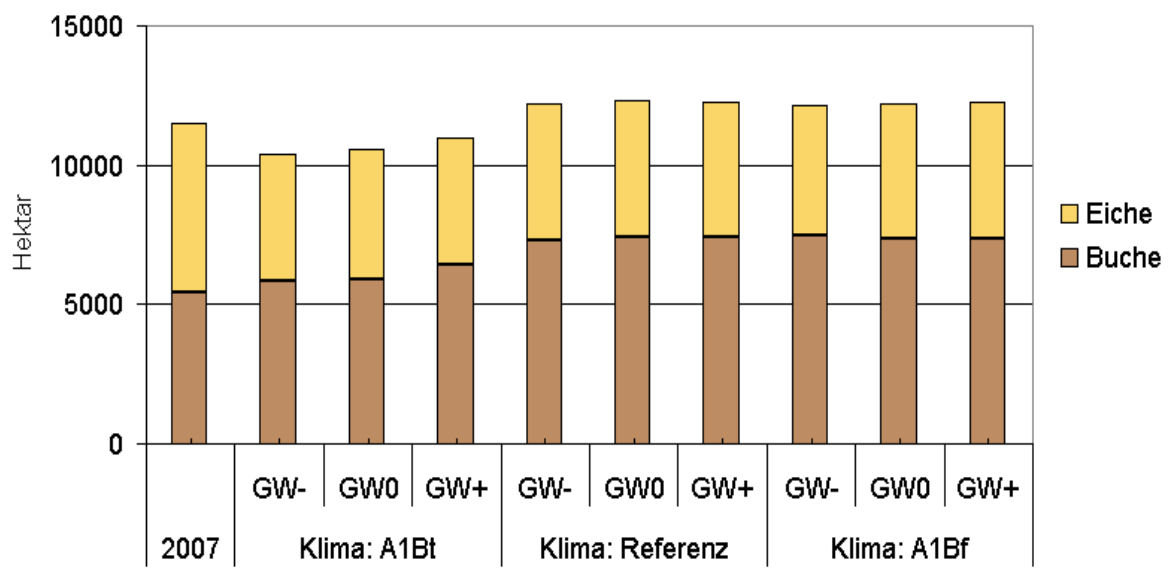

Abbildung 127: Flächen [ha] der Bestände mit fübrender Baumart Eiche brw. Buche im Jahr 2007 und 2039 nach Klima- und Grundwasserszenarien

Beiträge aus der NW-FVA, Band 10, 2013 


\subsubsection{Entwicklung der Eichen- und Buchenwald-Lebensraumtypen in den FFH-Gebieten}

\subsection{Lebensraumtypische Baumarten}

Die Anteile der lebensraumtypischen Baumarten unterscheiden sich nach 32 Jahren Simulation in den verschiedenen Szenarien nicht wesentlich voneinander (s. Abb. 128, nur Extremszenarien).
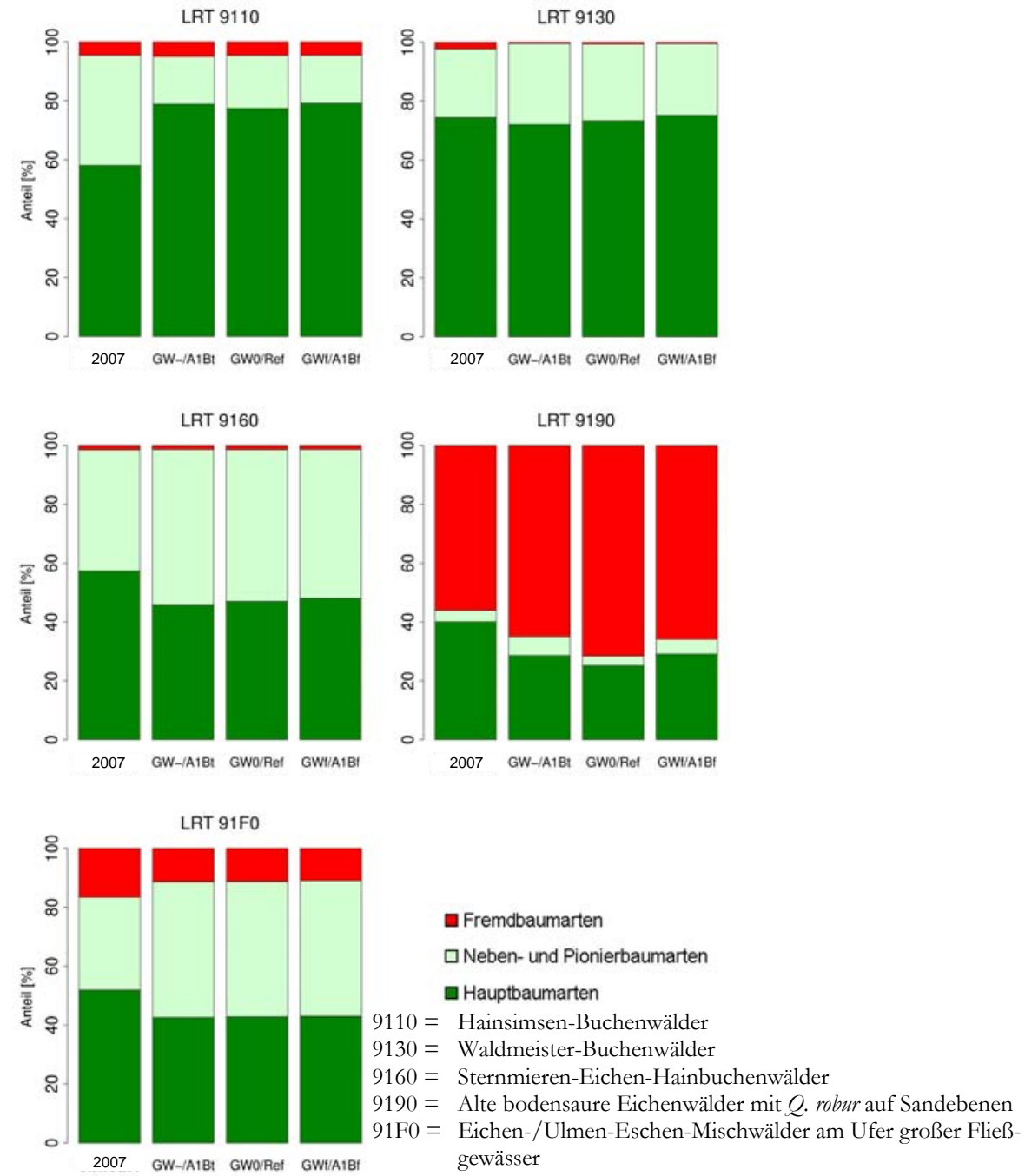

Abbildung 128: Anteile [\%] von Haupt-, Neben- und Pionierbaumarten sowie nicht lebensraumtypischen Baumarten (,Fremdbaumarten", Liste nach BWI3) auf Eichen- und BuchenwaldLebensraumtypenflächen innerbalb der FFH-Gebieten im Jahr 2007 und am Ende der Simulation im Jahr 2039 nach den Extremszenarien $G W-/ A 1 B t$ und $G W+/ A 1 B f$ sowie dem Referenzszenario GW0/Ref (Bezugsgröße: Kronenschirmfläche [ha]) 
Allerdings verläuft die Entwicklung in den Buchen-Lebensraumtypen tendenziell anders als in den Eichen-Lebensraumtypen: Auf den Flächen der Buchen-Lebensraumtypen erhöht sich der Anteil lebensraumtypischer Hauptbaumarten (LRT 9110 „Hainsimsen-Buchenwälder“) oder bleibt zumindest stabil (LRT 9130 „Waldmeister-Buchenwälder"). In den Eichen-Lebensraumtypen ist hingegen eine Abnahme des Anteils lebensraumtypischer Hauptbaumarten zu beobachten.

Die Flächen des LRT 9110 umfassen im Untersuchungsgebiet nur 177 Hektar. Da die hohen Zuwächse der Buche die Nutzungen ausgleichen bzw. übersteigen, erhöht sich hier der Buchenanteil. Auffällig ist jedoch die sehr unausgewogene Altersklassenverteilung (s. Abb. 129, oben).

Die Entwicklung der Flächen des LRT 9130 („Waldmeister-Buchenwälder“) verläuft ähnlich. Auch hier entwickelt sich der Anteil der lebensraumtypischen Baumarten durch gesicherten Zuwachs und Einwuchs der Buche positiv. Die Altersklassenverteilung weist auch hier stärkere Unregelmäßigkeiten auf (s. Abb. 129, unten).

LRT 9110

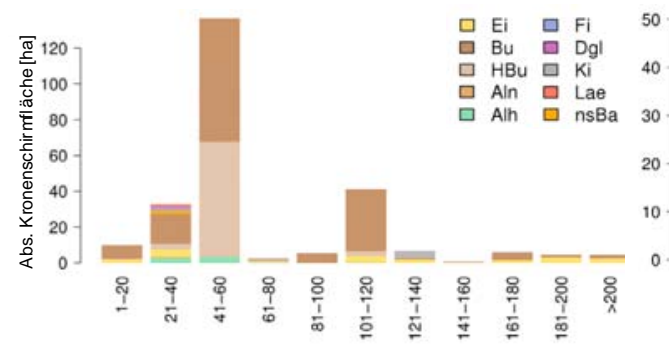

LRT 9130
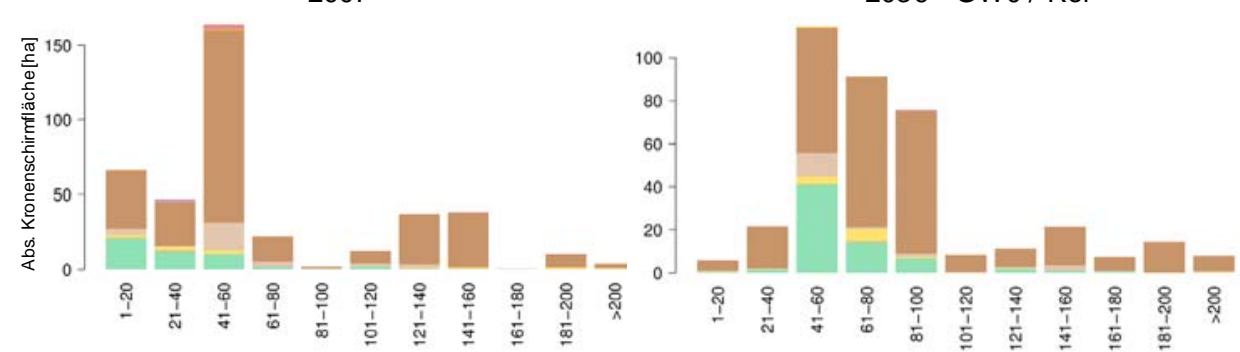

Abbildung 129: Baumartenverteilung nach Altersklassen 2007 (links) und 2039 für das GWO/RefSzenario (rechts) auf den Flächen der Buchen-Lebensraumtypen (oben: LRT 9110, „Hainsimsen-Buchenwälder"; unten: LRT 9130, „Waldmeister-Buchenwälder") (Bezugsgröße: absolute Kronenschirmfläche [ha]; nsBa: nicht-standortheimische Baumarten, ₹. B. Roteiche und Robinie; Aln = Andere Laubbäume mit niedriger Umtriebszeit, $A l b=$ Andere Laubbäume mit hoher Umtriebszeit)

Auf den Flächen des LRT 9160 („Sternmieren-Eichen-Hainbuchenwälder ${ }^{\circ}$ ) ist die Eiche zum Stichjahr 2007 in den hohen Altersklassen VI bis XI (> 100 Jahre) stark 
vertreten. Da es nur bedingte Nutzungseinschränkungen für die Lebensraumtypflächen gibt, wird im Laufe der Simulationen ein großer Teil der zielstarken Eichen genutzt. In den niedrigen Altersklassen I bis V $(\leq 100$ Jahre) hingegen ist die Eiche zum Teil sehr deutlich unterrepräsentiert (besonders in der Altersklasse III $=41$ 60 Jahre). Hier dominieren die Baumarten der Gruppe Laubhölzer mit hoher Umtriebszeit, die Buche, vor allem aber die Hainbuche (s. Abb. 130, oben). Durch die Zuwächse der Laubhölzer mit hoher Umtriebszeit und der Buche sowie durch die Nutzung der Eiche sinkt der Anteil lebensraumtypischer Hauptbaumarten des LRT 9160 bis zum Jahre 2039 ab.
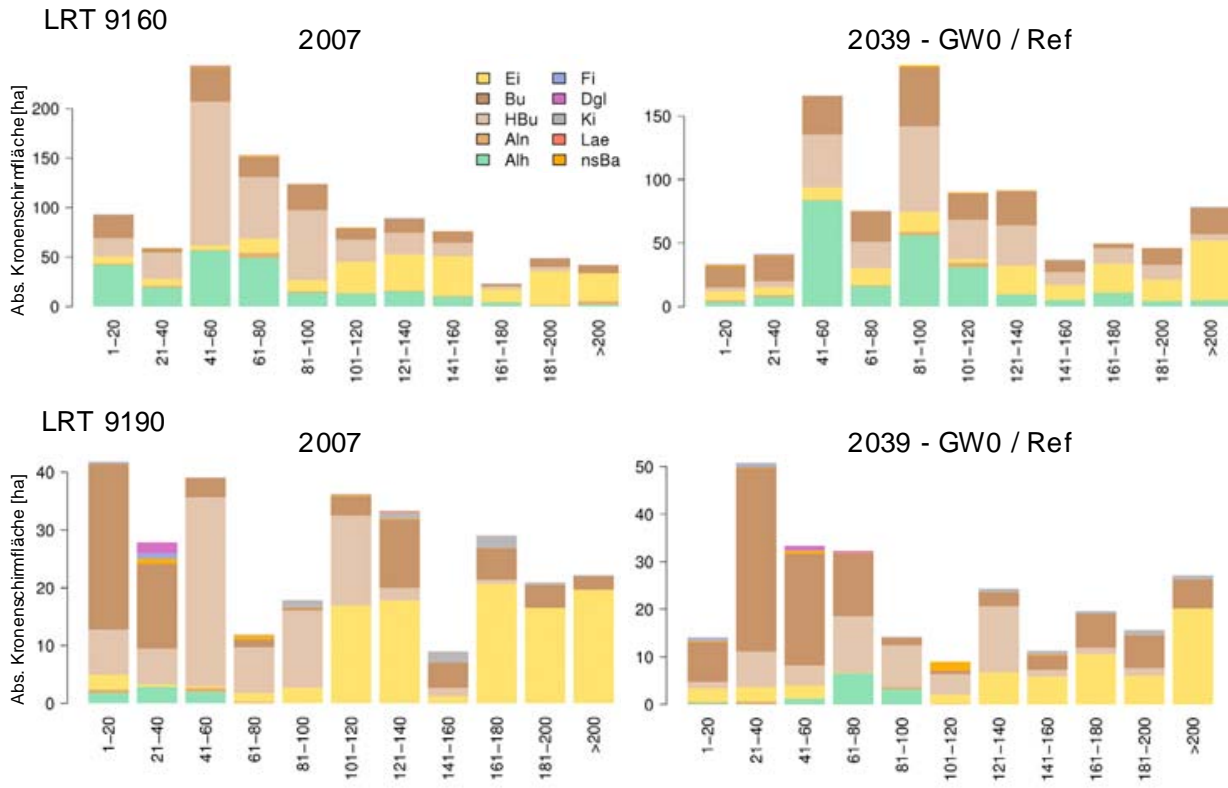

Abbildung 130: Baumartenverteilung nach Altersklassen 2007 (links) und 2039 für das GW0/RefSzenario (rechts) auf den Flächen der Eichen-Lebensraumtypen (oben: LRT 9160, „Sternmieren-Eichen-Hainbuchenwälder"; unten: LRT 9190, „Alte bodensaure Eichenwälder mit Quercus robur auf Sandebenen ") (Bezugsgröße: absolute Kronenschirmfläche [ha]; nsBa: nicht-standortheimische Baumarten, ₹: B. Roteiche und Robinie; Aln $=A n$ dere Laubbäume mit niedriger Umtriebszeit, Alh = Andere Laubbäume mit boher Umtriebszeit)

Die Entwicklung der Baumartenanteile stellt sich auf den Flächen des LRT 9190 („Alte bodensaure Eichenwälder mit Quercus robur auf Sandebenen“) ähnlich wie beim LRT 9160 dar (s. Abb. 130, unten). Auch hier führen die Nutzung der Eichen in den hohen Altersklassen und das starke Aufkommen der Buche in den unteren Altersklassen zu einer negativen Entwicklung des Anteils lebensraumtypischer Hauptbaumarten. Der hohe Anteil nicht lebensraumtypischer Baumarten ist darauf zurückzuführen, dass weder die Buche noch die Hainbuche laut der Baumartenliste der BWI3 für den LRT 9190 als typisch gewertet werden. 
Auch auf den Flächen des LRT 91F0 („Eichen-/Ulmen-Eschen-Mischwälder am Ufer großer Fließgewässer") nimmt der Anteil lebensraumtypischer Hauptbaumarten ab. Dies ist bedingt durch die Konkurrenzschwäche der Eiche gegenüber den anderen vorhandenen Baumarten. Eingriffe in die Eiche spielen hier keine Rolle, da die Flächen des LRT 91F0 nahezu komplett in nutzungsfreien Wäldern liegen. Der Rückgang der Eiche ist durch die starken Zuwächse der übrigen Baumarten bedingt.

\subsection{Anteile der Waldentwicklungsphasen}

Der Anteil der Waldentwicklungsphasen „starkes Baumholz“ und „sehr starkes Baumholz" (Phasen 4 und 5, 49-70 cm bzw. $>70 \mathrm{~cm}$ BHD, BUNDESAMT FÜR NATURSCHUTZ 2010) der heimischen Laubbaumarten nimmt in allen betrachteten Lebensraumtypen im Laufe der simulierten 32 Jahre unabhängig von den verschiedenen Grundwasser- und Klimaszenarien geringfügig zu (s. Abb. 131).

LRT 9110

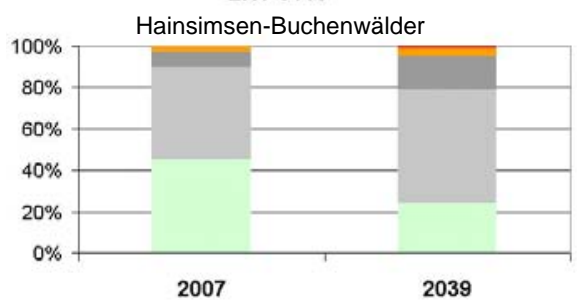

LRT 9160

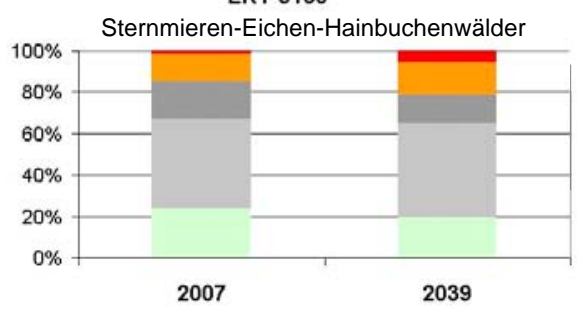

LRT 91F0

Eichen-/Ulmen-Eschen-Mischwälder am Ufer gr.

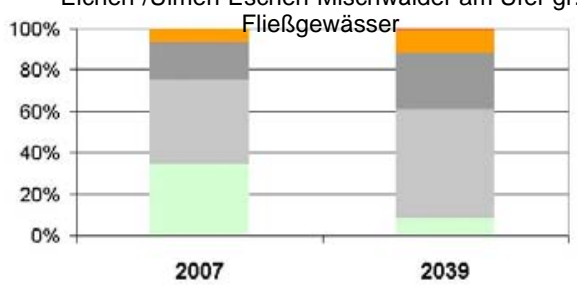

LRT 9130

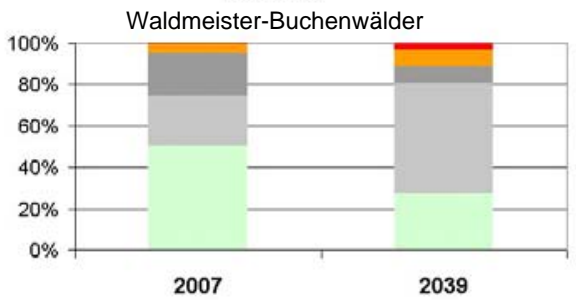

LRT 9190

Alte bodensaure Eichenwälder mit $Q$. robur auf

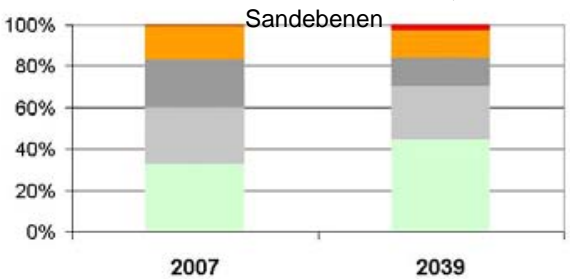

Waldentwicklungsphasen nach Brusthöhendurchmesser

Phase 5: $>70 \mathrm{~cm}$, sehr starkes Baumholz

Phase 4: $>$ in-70 cm, starkes Baumholz

Phase 3: = 35-49 cm, mittleres Baumholz

Phase 2: $>13-35 \mathrm{~cm}$, geringes Baumholz

Phase 1: $\quad \leq 13 \mathrm{~cm}$, Blöße bis Stangenholz

Abbildung 131: Anteile [\%] der Waldentwicklungsphasen heimischer Laubbäume 2007 und 2039 (flächengewichteter Mittelwert aller Szenarien) für die 5 Buchen- und Eichen-Lebensraumtypen in den untersuchten FFH-Gebieten (Bezugsgröß3e: Kronenschirmfläche [ha]) 
Die Szenarien unterscheiden sich hierbei nicht wesentlich voneinander. Daher wird in Abbildung 131 für das Jahr 2039 ein flächengewichteter Mittelwert aller Szenarien dargestellt. In Anlehnung an das Verschlechterungsverbot wurden im Rahmen der Simulationen 40 Prozent des Altholzes auf LRT-Flächen der Wertstufe A und 20 Prozent auf den Flächen der Wertstufe B erhalten. Erhöhte Mortalitäten durch Grundwasser- oder Maikäfereinfluss spielen auf den Flächen der Lebensraumtypen in den verschiedenen Szenarien keine entscheidende Rolle.

\subsection{Entwicklung des Totholzvorrats}

Für die Auswertung der Totholzentwicklung auf den Flächen der 5 Buchen- und Eichen-Lebensraumtypen der untersuchten FFH-Gebiete konnten lediglich die im Simulationszeitraum anfallenden Holzmengen berücksichtigt werden, da für das Stichjahr 2007 keine flächendeckenden und detaillierten Informationen über die vorhandenen Totholzmengen vorlagen.

Die zum Ende der Simulationen akkumulierten Totholzvorräte liegen bei den Lebensraumtypen auf schwächer nährstoffversorgten Standorten „HainsimsenBuchenwald“ (LRT 9110) und „Alte Bodensaure Eichenwälder mit Quercus robur auf Sandebenen“ (LRT 9190) in allen Szenarien deutlich unter $30 \mathrm{Vfm} / \mathrm{ha}$ (s. Abb. 132).

Auf den Flächen des Lebensraumtyps „Waldmeister-Buchenwald“ (LRT 9130) liegen die Totholzmengen in allen Szenarien zwischen 30 und 40 Vfm pro Hektar. Es fallen besonders die hohen Anteile der Erntereste an der gesamten Totholzmenge auf. Die Buche unterliegt hierbei einer sehr geringen dichtebedingten Mortalität.

Im Lebensraumtyp „Sternmieren-Eichen-Hainbuchenwälder“ (LRT 9160) werden Totholzmengen von knapp unter $30 \mathrm{Vfm} /$ ha erreicht. Das Verhältnis zwischen Ernteresten und mortalitätsbedingtem Totholz ist hier ausgeglichen.

Auf den Flächen des Lebensraumtyps „Eichen/Ulmen-Eschen-Mischwälder am Ufer großer Flüsse“ (LRT 91F0) erreichen die Totholzvorräte Werte von knapp über $30 \mathrm{Vfm} / \mathrm{ha}$. Die hohen Anteile des mortalitätsbedingten Totholzes erklären sich durch den Nutzungsverzicht, der auf großen Teilen der Hartholzauenflächen liegt, sodass eine vergleichsweise hohe dichtebedingte Mortalität auftritt.

Für eine Gesamtabschätzung wären zu den hier dargestellten Totholzvorräten die Ist-Vorräte des Jahres 2007 abzüglich der Zersetzung im Simulationszeitraum zu addieren. 

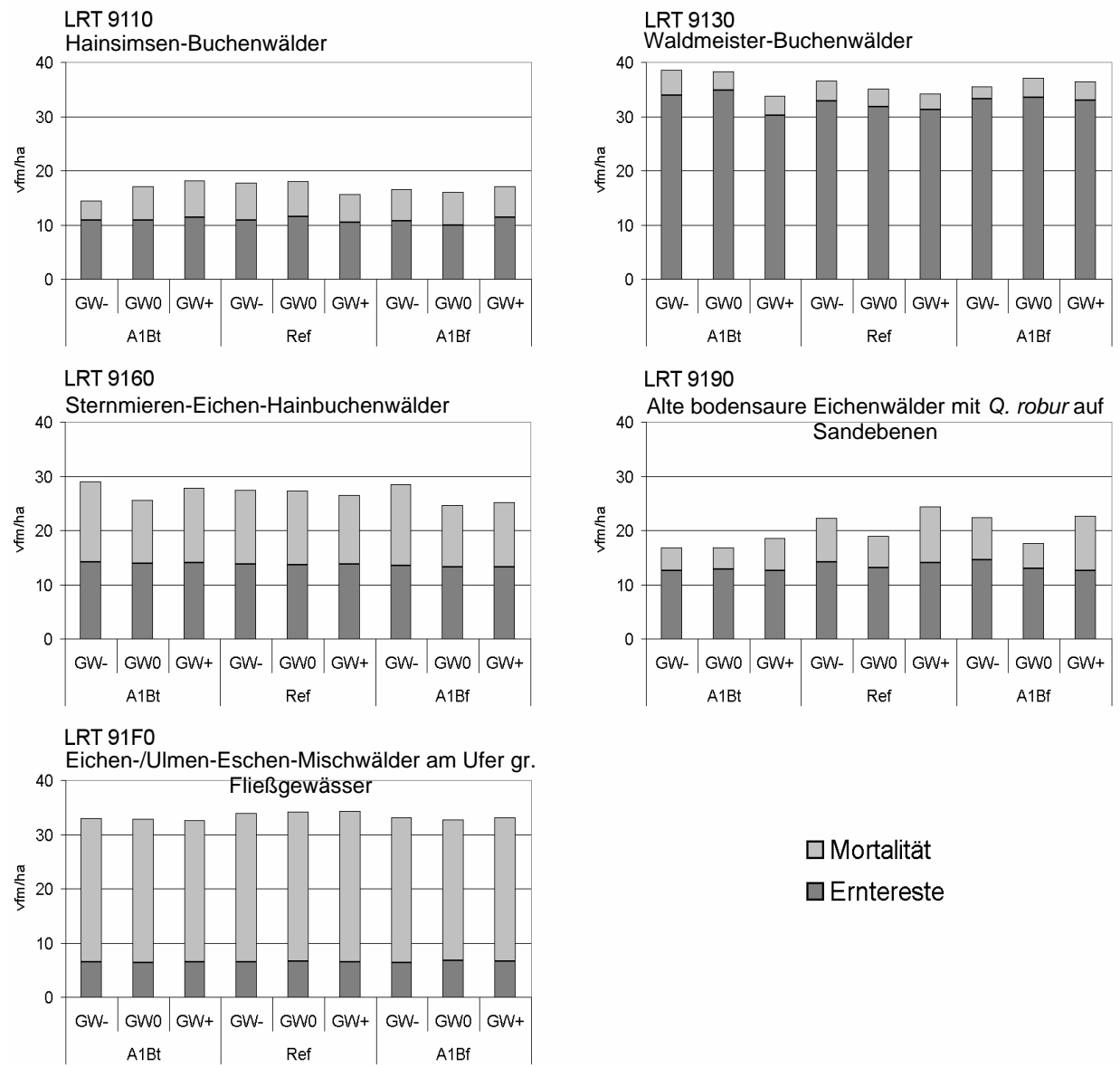

\section{$\square$ Mortalität \\ 口Erntereste}

Abbildung 132: Flächengewichtete Totholzvorräte [Vfm/ha] der 5 untersuchten Buchen- und EichenLebensraumtypen im Jahr 2039 nach Szenarien und Herkunft (natürliche „Mortalität" oder „Ernterest")

\subsection{Beeinträchtigungen}

Der Lebensraumtyp „Sternmieren-Eichen-Hainbuchenwald“ (LRT 9160) ist außer durch die Baumartenzusammensetzung auch durch einen hohen Grundwasserstand definiert (SSYMANK et. al 1998). Nach ELLENBERG (1996) kann die Buche nicht gedeihen, wenn der Grundwasserspiegel auf lehmreichen Standorten 12 Wochen oder länger weniger als $50 \mathrm{~cm}$ unter Flur liegt. Diese Größe kann hier nur als grober Anhaltspunkt verwendet werden. Die vorliegenden Informationen im Projekt „Waldentwicklungsszenarien für das Hessische Ried“ lassen keine Aussagen über die Dauer bestimmter Grundwasserflurabstände im Jahresverlauf zu. Die für die verschiedenen Szenarien festgesetzten Grundwasserflurabstände beziehen 
sich jeweils auf einen bestimmten Zeitpunkt (Juli- bzw. Oktoberstand 1951 und 2007). Als jährliche Schwankung des Flurabstandes werden $50 \mathrm{~cm}$ angenommen.

Es wird daher unterstellt, dass die standörtlichen Grundvoraussetzungen für den Lebensraumtyp „Sternmieren-Eichen-Hainbuchenwald“ bei einem Flurabstand des Grundwassers von mehr als $100 \mathrm{~cm}$ mit hoher Wahrscheinlichkeit nicht erfüllt sind. Im gegenwärtigen Zustand (Grundwasserszenario GW0) nehmen die Flächen mit einem Grundwasser-Flurabstand von weniger als einem Meter selbst auf den bereits als LRT 9160 ausgewiesenen Flächen nur einen Anteil von 15 Prozent ein. Durch eine Erhöhung des Grundwasserstandes (GW+) kann der Anteil auf 23 Prozent erhöht werden. Bei dem Szenario GW- reduziert sich dieser auf sieben Prozent (s. Abb. 133).

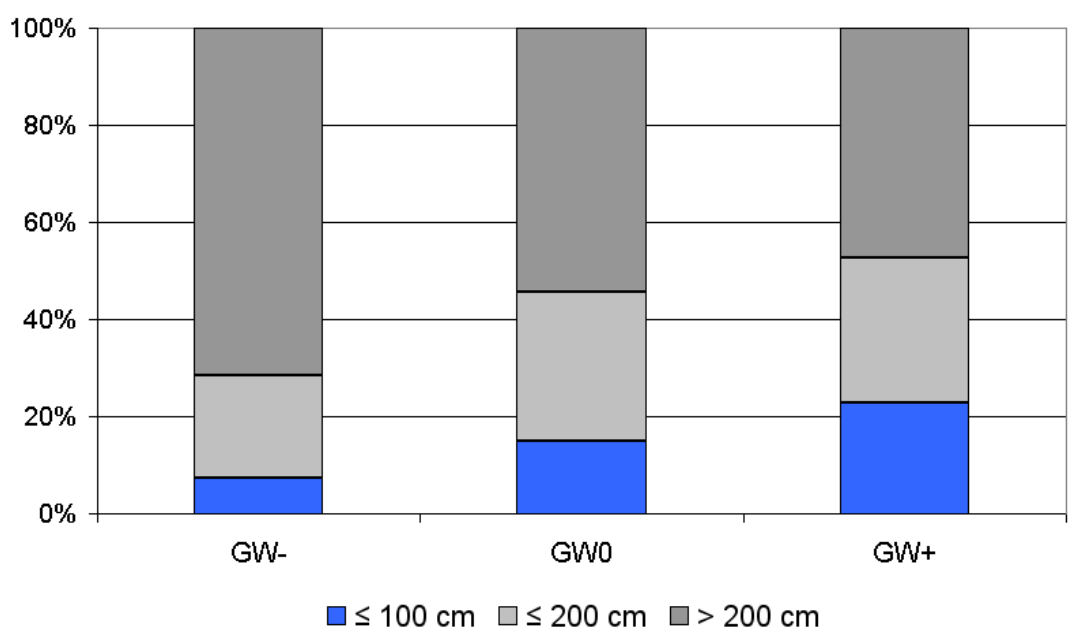

Abbildung 133: Anteile der Flächen des Lebensraumtyps 9160 („Sternmieren-Eichen-Hainbuchenwald“) innerbalb von FFH-Gebieten mit einem Grundwasserflurabstand von $\leq 100 \mathrm{~cm}$, $\leq 200 \mathrm{~cm}$ und $>200 \mathrm{~cm}$ nach Grundwasserszenarien im Jahr 2039

\section{8 Ökonomische Bewertung}

\subsubsection{Modell- und Kalamitätsbetrieb}

\subsubsection{Bestandesklassenentwicklung}

Die Bestandesklassenverteilung für die über das 250 × $250 \mathrm{~m}$-Stichprobenraster ausgewählten Bestände im Jahre 1967 (Ausgangszustand) und deren Veränderung bis zum Jahr 2007 zum einen im sogenannten Modellbetrieb und zum anderen im Kalamitätsbetrieb verdeutlichen die Auswirkungen der verstärkten Grundwasserabsenkungen ab Mitte der Sechzigerjahre (s. Abb. 134). 
1967 dominierten auf 80 Prozent der Fläche Kiefern- und Eichenbestandesklassen. Mit rund 20 Prozent bleibt der Anteil der Eichenbestandesklassen im Jahr 2007 gegenüber dem Basisjahr in beiden „Betriebsvarianten“ konstant. Die Fläche der kieferndominierten Bestandesklassen nimmt im Kalamitätsbetrieb mit $17 \%$ deutlich stärker ab als im Modellbetrieb mit einem Flächenverlust von 12 Prozent. Flächengewinne verzeichnen vor allem die Buchenbestandesklassen, wobei diese besonders im Kalamitätsbetrieb mit 15 Prozent vergleichsweise hoch ausfallen.

Ausgangszustand 1967

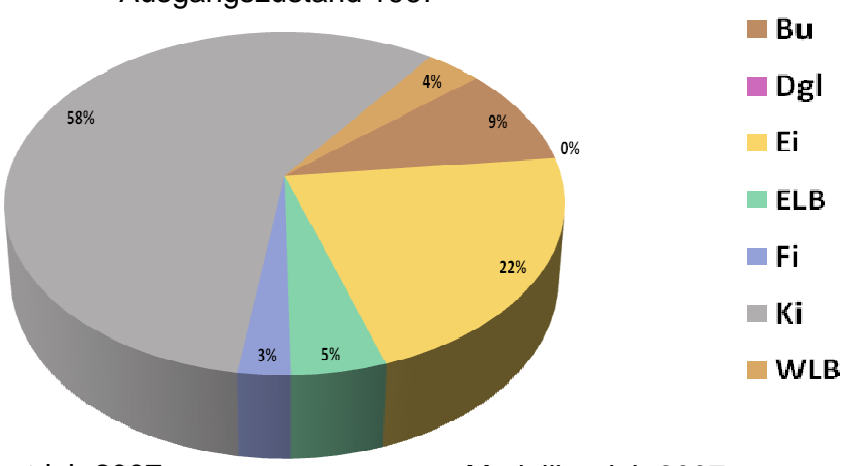

Kalamitätsbetrieb 2007

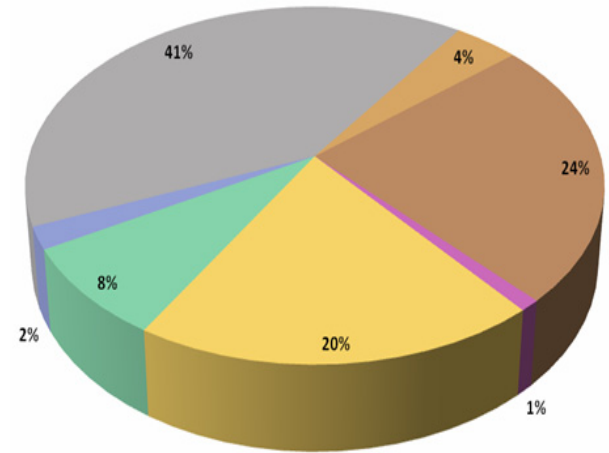

Modellbetrieb 2007

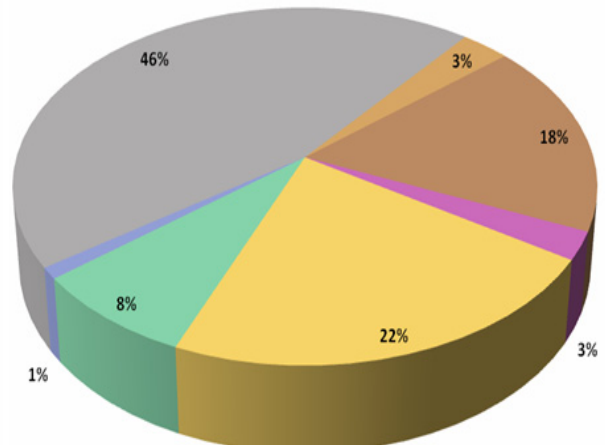

Abbildung 134: Bestandesklassenverteilung [\%] in den Jabren 1967 und 2007 im Kalamitäts- bzw. Modellbetrieb

Wesentliche Ursache für die Zunahme des Buchenanteils ist das verbreitete Auftreten von Buchennaturverjüngung. Bereits 1967 war die Buche die dominierende Baumart im Nachwuchs und im Unterstand, wie Abbildung 135 verdeutlicht. Auch die Fichte war trotz des geringen Vorkommens in der Hauptschicht im Nachwuchs mit rd. 10 Prozent vergleichsweise häufig vertreten, konnte sich jedoch in diesen Beständen bis 2007 meist nicht als führende Baumart durchsetzen. Die Edellaubholzbestände nehmen in beiden „Betriebsvarianten“ gleichermaßen um 3 Prozent zu. Die Anteile der Douglasie wurden im Kalamitätsbetrieb erstaunlicherweise nicht in dem Maße gesteigert wie im Modellbetrieb, wobei ihr Flächenanteil insgesamt als vergleichsweise gering einzustufen ist. 


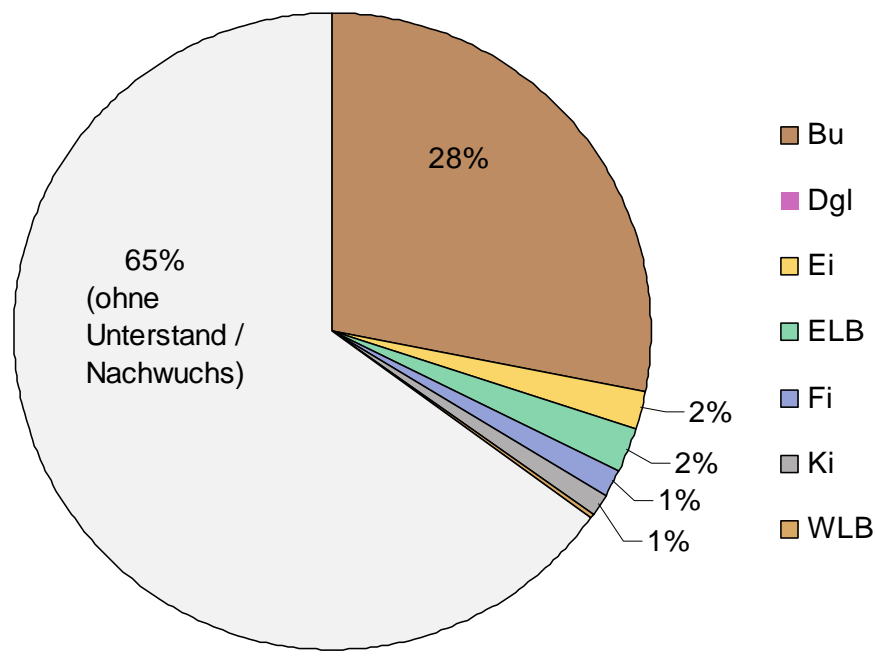

Abbildung 135: Anteile [\%] der Baumartengruppen im Jahr 1967 im Unterstand und Nachwuchs an der Gesamtstichprobenfläche

Hinsichtlich der Grundwassersituation lassen sich Standorte mit permanent sicherem Grundwasseranschluss (GW), solche, die im Untersuchungszeitraum nie über einen gesicherten Grundwasseranschluss verfügten (nGW), Standorte, bei denen der Grundwasserstand stark abgesunken ist, aber noch sicherer Grundwasseranschluss besteht (gGW) und Standorte, bei denen der gesicherte Grundwasseranschluss in der betrachteten Zeit von 1967 bis 2007 verloren gegangen ist (vGW) unterscheiden. Zusätzlich wurde nach sandigen (S), tonigen (T) und lehmigen Bodensubstraten (L) differenziert.

Während sich im Modellbetrieb die Grundwasserstände von 1967 nicht verändern, können im Kalamitätsbetrieb Bestände den sicheren Grundwasseranschluss zwischen 1967 und 2007 verlieren. Die Verteilung der Bestandesklassen im Jahr 1967 auf die im Methodenteil beschriebenen Standortsgruppen ist in der Abbildung 136 dargestellt. Die Mehrheit der Kiefernbestände stockte bereits 1967 auf grundwasserfernen Sand- und Lehmstandorten. In nennenswertem Umfang waren Kiefernbestände jedoch auch auf Sand- und Lehmstandorten anzutreffen, die zwischen 1967 und 2007 den Grundwasseranschluss verlieren oder bei denen der Grundwasserstand in diesem Zeitraum zumindest deutlich absinkt. Die Eichenund Buchenbestände ohne sicheren Grundwasseranschluss verteilten sich im Gegensatz zur Kiefer etwas gleichmäßiger auf Sand- und Lehmstandorte. Den sicheren Grundwasseranschluss verlieren Buchen- und Eichenbestände überwiegend auf lehmigen Substraten. Erwähnenswert ist das Vorkommen von Eichenbeständen auf Tonstandorten, die ebenfalls im Betrachtungszeitraum den Grundwasseranschluss verlieren. Der Schwerpunkt der Edellaubholzbestände lag bereits 1967 auf grundwasserferneren Lehmen. 


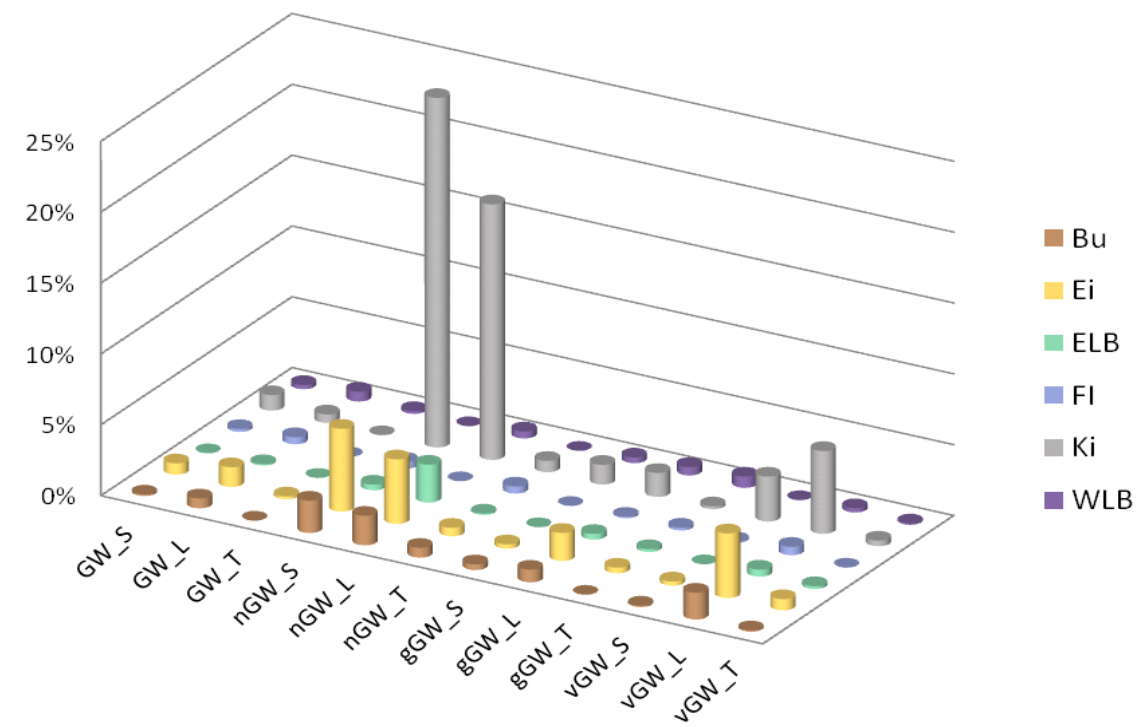

Abbildung 136: Bestandesklassenverteilung [\%] der 981 Stichprobenbestände auf die Standortstraten ( $G W=$ permanent sicherer Grundwasseranschluss, $n G W=$ niemals sicherer Grundwasseranschluss, $g G W=$ gesunkener sicherer Grundwasseranschluss, $\nu G W=$ verloren gegangener gesicherter Grundwasseranschluss, $S=$ Sande, L=Lehme, $T=$ Tone), Bezugsjabr 1967

\subsubsection{2 Ökonomische Kenngrößen}

Gegenstand der vergleichenden ökonomischen Betrachtung des Zeitraumes von 1967 bis 2007 sind die erntekostenfreie Holzerlöse, die Kulturkosten und die Wertveränderungen der Waldbestände. Diese Größen wurden jeweils auf das Jahr 2007 prolongiert und zu Ertragswerten aggregiert. Abbildung 137 zeigt die Gegenüberstellung der Gesamtertragswerte für die Summe der jeweils einen Hektar großen Stichprobenflächen.

Die Gesamtdifferenz zwischen den aggregierten Ertragswerten beträgt knapp zweieinhalb Millionen Euro bzw. durchschnittlich ca. 2.500 Euro pro Hektar für die 40-jährige Periode. Die „finanzmathematisch korrekt berechnete“ durchschnittliche jährliche Belastung entspricht der Annuität dieser Differenz und beläuft sich auf $51 € / \mathrm{ha} / \mathrm{Jahr}$. Bezogen auf das Untersuchungsgebiet, das durch die Stichprobe repräsentiert wird, ergibt sich eine Gesamtertragsdifferenz von ca. 70 Millionen Euro für die 40-jährige Periode. Im Kalamitätsbetrieb werden damit nur ca. $70 \%$ der Ertragswerthöhe des Modellbetriebes realisiert. Die Zusammensetzung dieser Gesamtsumme ist in den folgenden Abbildungen dargestellt. Eine einzelbestandesweise Betrachtung der Ertragswertdifferenzen findet sich im Anhang (s. Anhang 5, Abb. A9 und A10). 


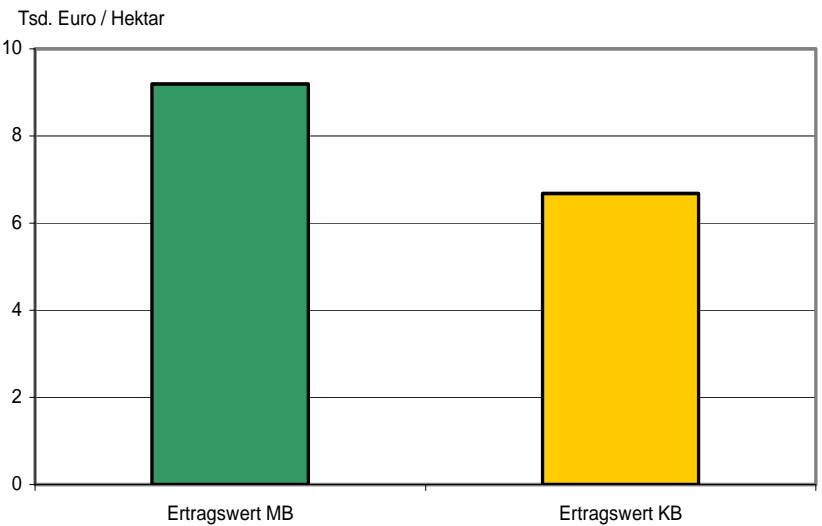

Abbildung 137: Ertragswertvergleich [1000€/ha] für die Summe der 981 Stichprobenflächen des Modell- (MB) brw. Kalamitätsbetriebes (KB)

Abbildung 138 zeigt die Wertentwicklung der Bestände. Die Abtriebswerte nehmen gegenüber 1967 in beiden Varianten zu, jedoch nicht in gleichem Maße. Der Wertzuwachs im Kalamitätsbetrieb erreicht in den betrachteten 40 Jahren nur rund 40 Prozent des Wertzuwachses des Modellbetriebes. Die Differenz zwischen beiden Varianten beläuft sich auf ca. 1,5 Millionen Euro. Übertragen auf das Gesamtgebiet beträgt die Differenz ca. 42 Millionen Euro. Die Annuität dieser Differenz ergibt für den 40-jährigen Betrachtungszeitraum einen Wert von 31 Euro je Hektar und Jahr.

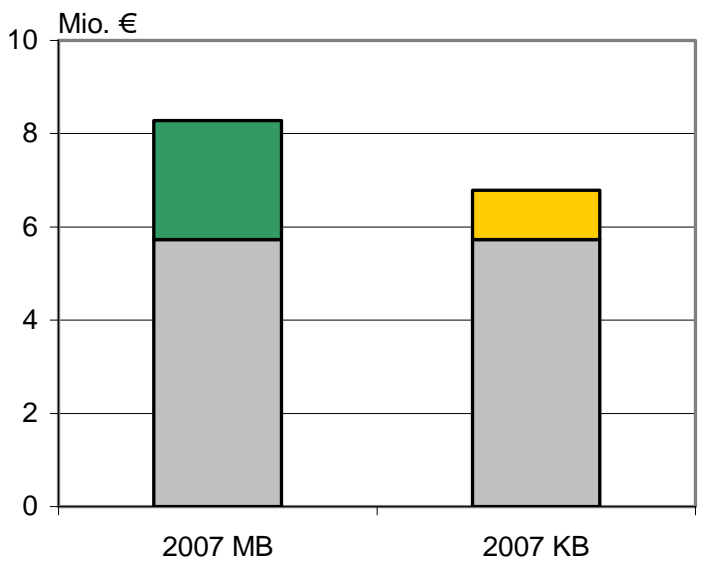

Abtriebswert $1967 \quad \square$ Zuwachs AW im MB $\square$ Zuwachs AW im KB

Abbildung 138: Abtriebswerte (AW) [Mio. €] der Bestände im Modell- (MB) und Kalamitätsbetrieb (KB) 2007; grau binterlegt: Abtriebswert 1967 
Die erntekostenfreien Holzerlöse sämtlicher Holznutzungen der betrachteten Periode wurden auf das Jahr 2007 prolongiert und so Holzertragswerte berechnet. Dabei unterschieden sich die Holzeinschläge des Modellbetriebs von den tatsächlich realisierten des Kalamitätsbetriebes nur leicht. Der Holzeinschlag des Modellbetriebes betrug 6,7 Vfm/ha, der realisierte Holzeinschlag des Kalamitätsbetriebes 6,4 Vfm/ha. Der Holzeinschlag des Kalamitätsbetriebes enthält auch die Sturmholzmengen der Jahre 1985, 1986 und 1990, 1991, jedoch zeitlich verteilt und mit sturmbereinigten Kalamitätsanteilen (s. Methodenteil). Die verbuchten Kalamitätsnutzungen der HEKAS-Daten des Kalamitätsbetriebes während der 40-jährigen Periode nehmen einen Anteil von 29 Prozent an der Gesamtnutzung aller Baumarten der Stichprobenflächen ein. Mit etwa 14 Prozent ist der Kalamitätsholzanteil im Modellbetrieb nur halb so hoch. Eine differenziertere Analyse der Kalamitätsanteile erfolgt im Zuge der baumartenspezifischen Betrachtung. Wie aus Abbildung 139 ersichtlich ist, beträgt die Differenz der Ertragswerte der Holznutzung annähernd 850.000 Euro. Für das gesamte Projektgebiet „Hessisches Ried“ ergibt sich demzufolge eine Differenz von knapp 25 Millionen Euro, entsprechend einer Annuität von 18 Euro/ha/Jahr.

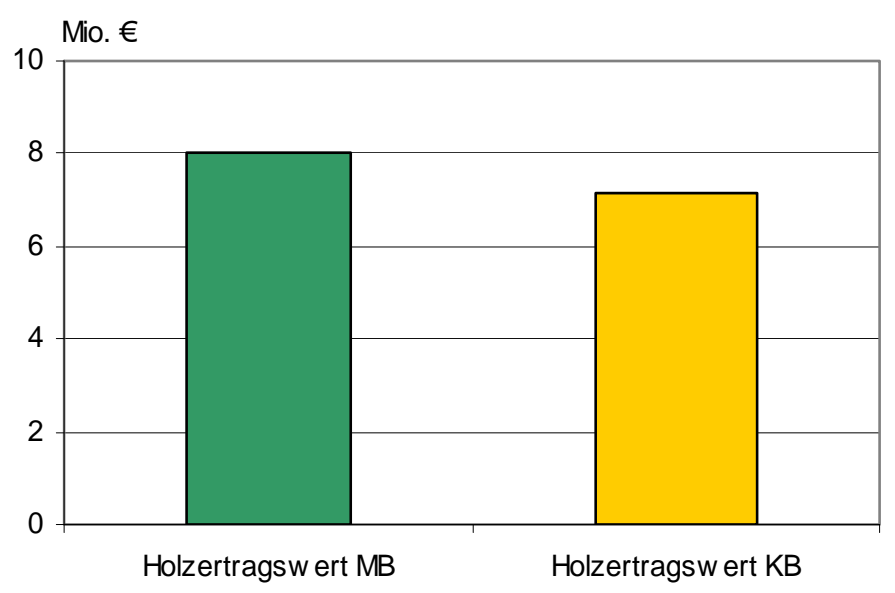

Abbildung 139: Auf das Jahr 2007 prolongierte erntekostenfreie Holzerlöse (Holzertragswerte) [Mio. €] im Modell- (MB) und Kalamitätsbetrieb (KB)

Demgegenüber fiel die Differenz zwischen den prolongierten Kulturkosten beider Varianten geringer aus (s. Abb. 140). Aufgrund eines insgesamt höheren Bedarfs investiver Kulturmaßnahmen im Kalamitätsbetrieb beträgt die Differenz knapp 120.000 Euro für die Stichprobenfläche und ca. 2,8 Millionen Euro für die Gesamtfläche des Projektgebietes. Dieser Wert entspricht einer Annuität von rund 2 Euro/ha/Jahr. 


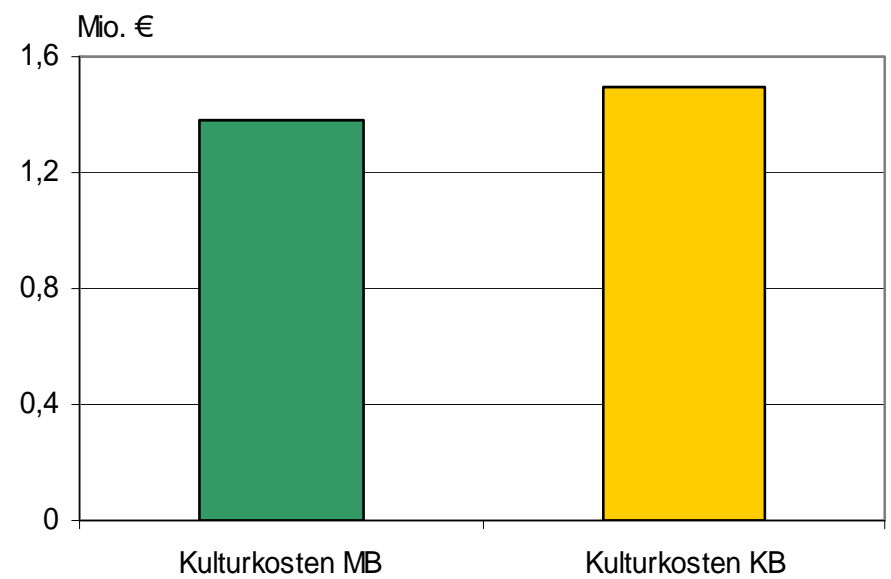

Abbildung 140: Prolongierte Kulturkosten [Mio. €] im Modell- (MB) und Kalamitätsbetrieb (KB)

\subsubsection{Baumartenspezifische Betrachtung}

In Abbildung 141 sind die Ertragswerte je Hektar in Abhängigkeit von Bestandesklasse und Betriebsvariante aufgetragen.

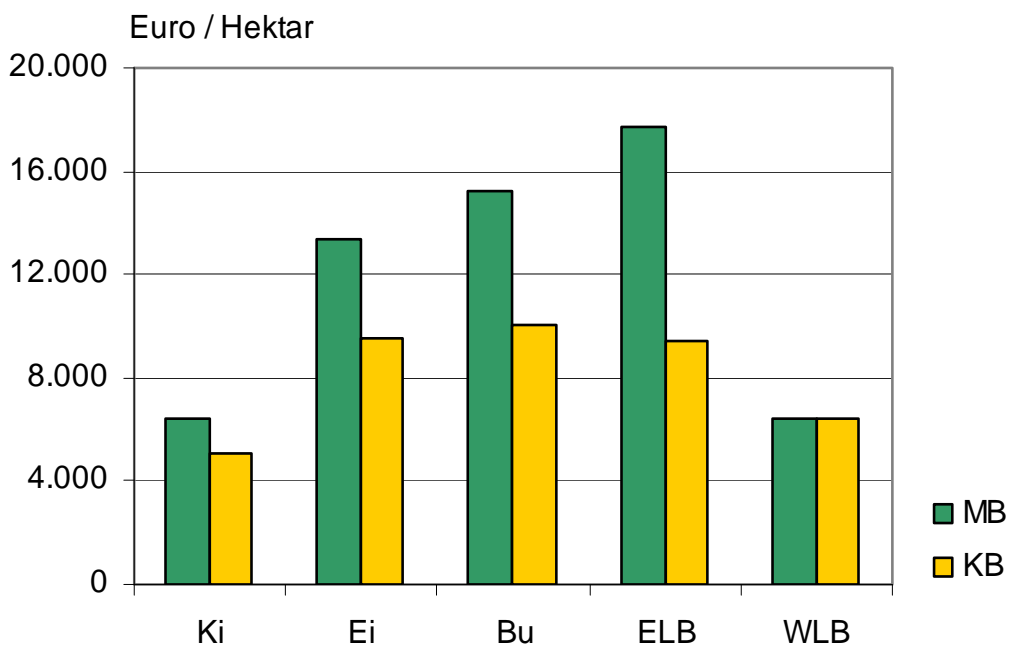

Abbildung 141: Ertragswerte [€/ha] nach Bestandesklassen im Modell- (MB) und Kalamitätsbetrieb (KB)

Die Kiefernbestände weisen im Durchschnitt die geringsten Ertragswerte auf. Gleichzeitig ist hier die Differenz zwischen den beiden Varianten (auch relativ) gering ausgeprägt. Auch die Weichlaubholzbestände zeigten sich kaum beeinträch- 
tigt. Die größten Einbrüche der Ertragswerte sind bei den Buchen- und Edellaubholzbeständen zu beobachten, was neben der verringerten Vitalität - insbesondere bei den Edellaubholzbeständen - auch auf eine Verringerung der Wertholzanteile infolge von Holzentwertungen zurückzuführen ist. Die Edellaubholzbestände verlieren im Kalamitätsbetrieb fast die Hälfte ihres im Modellbetrieb erreichten Ertragswertes. Auch bei der Eiche führt ein deutlich geringerer Wertholzanteil zu starken Ertragswertverlusten im Kalamitätsbetrieb.

Abbildung 142 zeigt die Entwicklung der Kalamitätsnutzungen im zeitlichen Verlauf. Erkennbar ist ein allmählicher Anstieg des Kalamitätsanteils für die drei Hauptbaumarten mit erheblichen Ausreißern infolge von Sturmereignissen. Die Holzmengen dieser Jahre wurden mit durchschnittlichen Kalamitätsanteilen besonders verrechnet (s. Kap. 2.2.14.1.2). Trotz der Schwankungen ist erkennbar, dass der Kalamitätsanteil von anfangs wenigen Prozentpunkten in den 60er-Jahren dauerhaft auf über 20 bis 30 Prozent ansteigt. Insbesondere die Eiche zeigt sich stark beeinträchtigt.

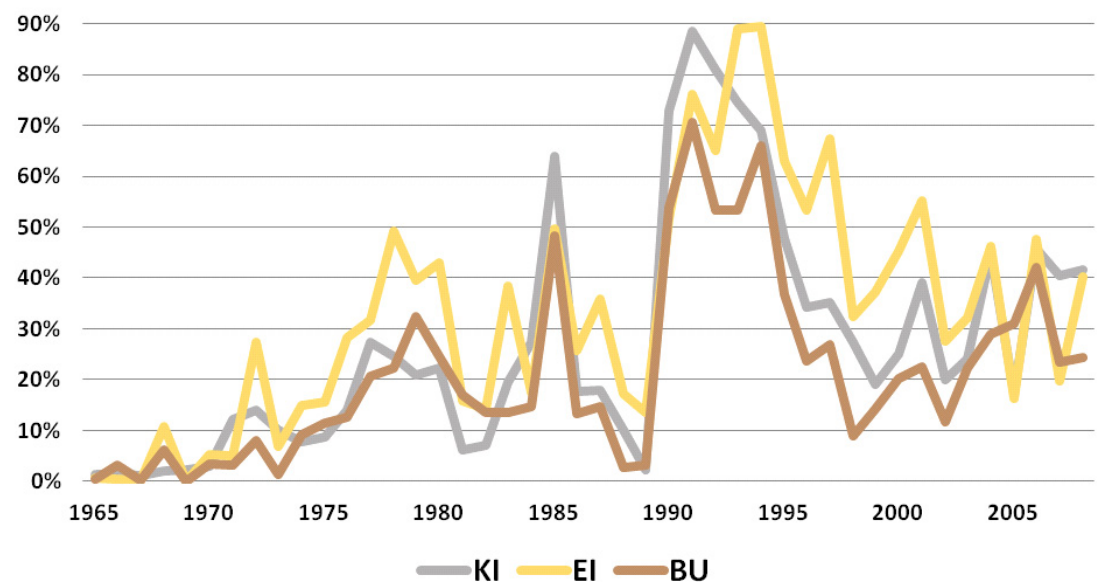

Abbildung 142: Kalamitätsnutzungsanteile in Prozent der Gesamtnutzung für die Hauptbaumarten im gesamten Hessischen Ried zwischen 1967 und 2007 (Quelle: Betriebsvollzug)

\subsection{Buche}

Buchenbestände waren 1967 lediglich auf 9 Prozent der Stichprobenflächen zu finden. Sie konnten ihren Flächenanteil bis zum Jahre 2007 jedoch deutlich erweitern. Zur detaillierten Betrachtung werden die Bestände nach Grundwassersituationen stratifiziert. Abbildung 143 zeigt die mittleren Ertragswerte pro Hektar für diejenigen Standortsgruppen, auf denen mindestens 10 Buchenbestände stocken. 


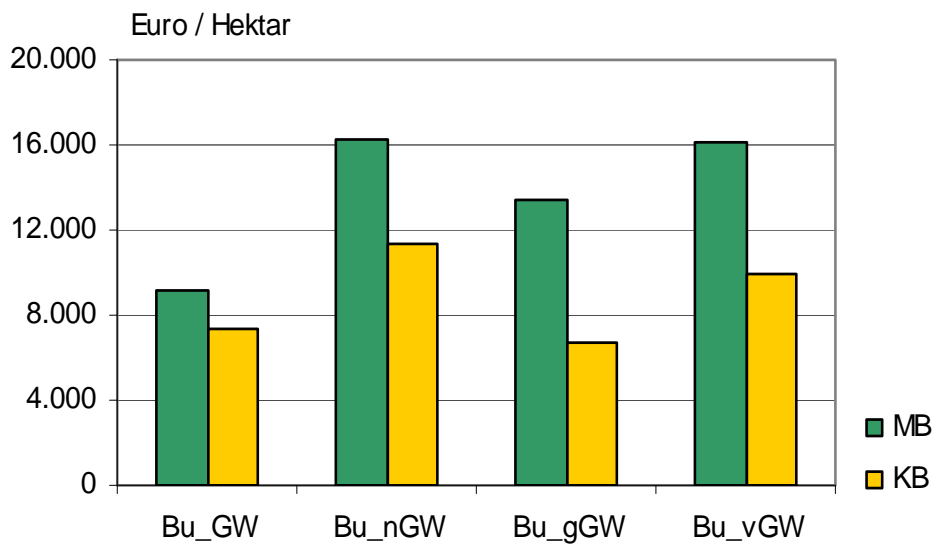

Abbildung 143: Ertragswerte [€/ha] von Buchenbeständen im Kalamitäts- (KB) und Modellbetrieb (MB) nach Grundwassersituation ( $G W=$ permanent sicherer Grundwasseranschluss, $n G W=$ niemals sicherer Grundwasseranschluss, $g G W=$ gesunkener sicherer Grundwasseranschluss, $v G W=$ verloren gegangener gesicherter Grundwasseranschluss)

Die Differenz (absolut und relativ) zwischen Modell- und Kalamitätsbetrieb ist bei Buchenbeständen auf Standorten mit Grundwasserabsenkungen (gGW, vGW) größer als bei Buchenbeständen auf Standorten ohne Grundwasserabsenkungen (GW, nGW). Die Ertragswerte erscheinen zunächst gering, jedoch stocken die Buchenbestände überwiegend auf Standorten, die nie über einen sicheren Grundwasseranschluss verfügten (s. Abb. 136) und auf denen die höchsten Ertragswerte bei den Buchenbeständen verzeichnet wurden.

Für die Betrachtung der Kalamitätsanteile (s. Abb. 144) wurden nur diejenigen Bestände herangezogen, die zu beiden Stichjahren Buchenbestände waren, bei denen also kein Wechsel der führenden Baumart stattgefunden hat. Der mittlere Kalamitätsholzanteil am realisierten Gesamteinschlag der Jahre 1967 - 2007 liegt bei rund 25 Prozent und variiert in Abhängigkeit von der Grundwassersituation des Standorts in einer Spanne von 15 Prozent $(\mathrm{GW})$ bis 34 Prozent (vGW). Buchenbestände auf grundwassernahen oder immer grundwasserfernen Standorten weisen deutlich geringere Kalamitätsanteile auf als Bestände, die ihren Grundwasseranschluss verloren haben (vGW) oder wo der Grundwasserspiegel zumindest stärker abgesenkt worden ist $(\mathrm{gGW})$. Bei Verlust des gesicherten Grundwasseranschlusses erreichen die Kalamitätsnutzungen gegenüber grundwassernahen Standorten mehr als doppelt so hohe Werte. Immer grundwasserferne Standorte $(\mathrm{nGW})$ weisen hingegen einen nur fünf Prozent höheren Kalamitätsanteil als grundwassernahe Standorte auf. 


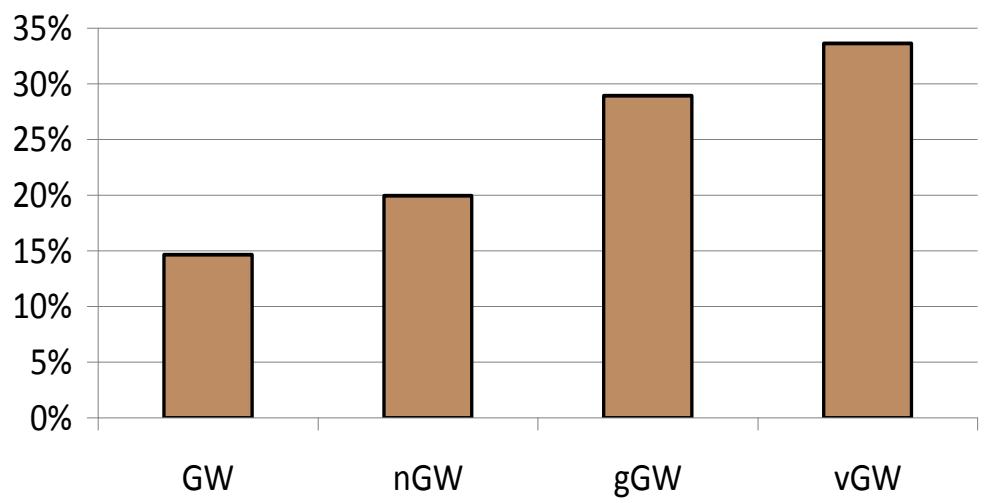

Abbildung 144: Reale Kalamitätsnutzunganteile [\%] an der Gesamtnutzung [Efm o. R.] der Buchenbestände von 1967 bis 2007 nach Grundwassersituation (GW = permanent sicherer Grundwasseranschluss, $n G W=$ niemals sicherer Grundwasseranschluss, $g G W=$ gesunkener sicherer Grundwasseranschluss, $v G W=$ verloren gegangener gesicherter Grundwasseranschluss)

\subsection{Eiche}

Auch die Ertragswerte der Eichenbestände erreichen im Kalamitätsbetrieb nicht die Höhe, die im Modellbetrieb realisiert werden kann (s. Abb. 145). Die Differenz zwischen den beiden Betriebsvarianten ist wiederum dort am größten, wo der sichere Grundwasseranschluss verloren gegangen ist (vGW) oder das Grundwasser stärker abgesenkt wurde ( $g G W)$, wobei die Höhe der Differenzen wesentlich geringer als bei der Buche ist

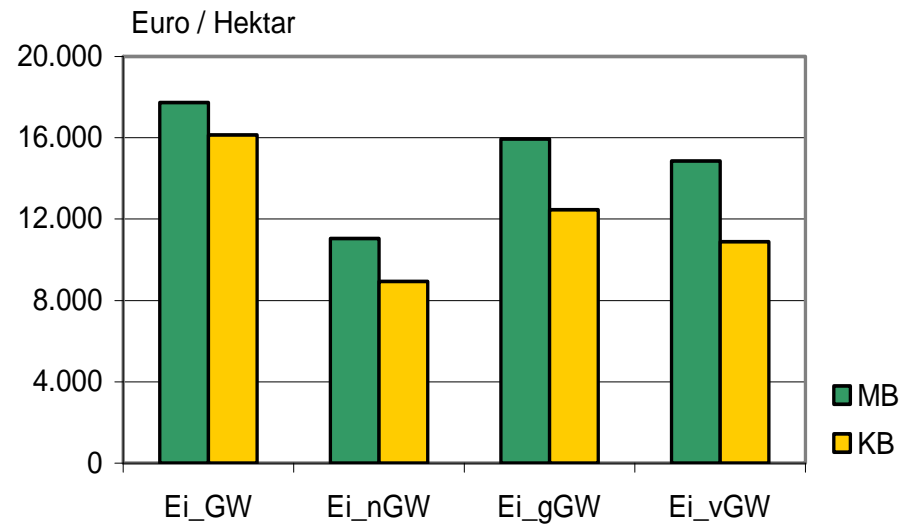

Abbildung 145: Ertragswerte [€/ha] von Eichenbeständen im Kalamitäts- (KB) und Modellbetrieb (MB) nach Grundwassersituation ( $G W=$ permanent sicherer Grundwasseranschluss, $n G W=$ niemals sicherer Grundwasseranschluss, $g G W=$ gesunkener sicherer Grundwasseranschluss, $v G W=$ verloren gegangener gesicherter Grundwasseranschluss) 
Eichenbestände stockten 1967 auf 22 Prozent der Waldfläche und verteilten sich im Gegensatz zur Buche auf deutlich mehr Standortsstraten (Grundwassersituation u. Bodensubstrat). Deshalb werden die Kalamitätsanteile differenziert nach Grundwassersituation und Bodensubstrat betrachtet. Die höchsten Kalamitätsanteile (> 40 Prozent) sind auf sandigen, grundwassernahen Standorten mit stärkeren Grundwasserabsenkungen zu verzeichnen (s. Abb. 146). Auf durchweg grundwasserfernen oder grundwassernahen Standorten ohne Grundwasserabsenkungen sind dagegen keine nennenswerten Unterschiede zwischen den Substratgruppen zu erkennen.

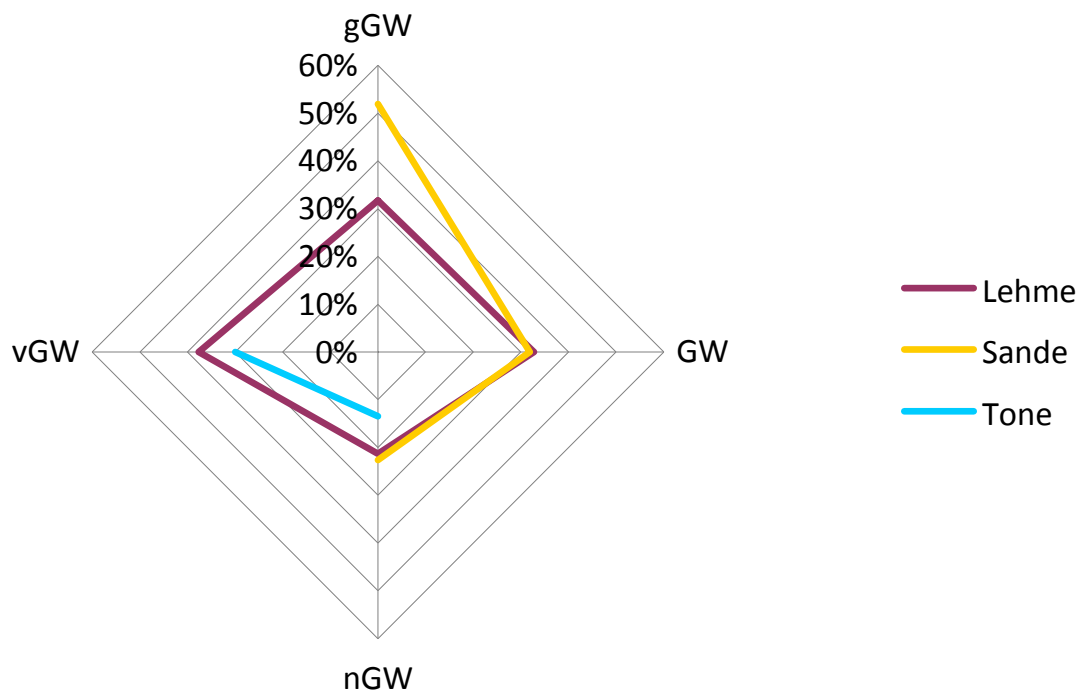

Abbildung 146: Reale Kalamitätsnutzungsanteile [\%] an der Gesamtnutzung [Efm o. R.] von Eichenbeständen von 1967 bis 2007 nach Grundwassersituation (GW = permanent sicherer Grundwasseranschluss, $n G W=$ niemals sicherer Grundwasseranschluss, $g G W=$ gesunkener sicherer Grundwasseranschluss, $v G W=$ verloren gegangener gesicherter Grundwasseranschluss) und Substrat

Bei den Eichenbeständen zeichnet sich auch ein altersabhängiger Trend hinsichtlich des Kalamitätsanteils ab. Der Anteil kalamitätsbedingter Holznutzungen steigt mit zunehmendem Bestandesalter an (s. Abb. 147) bevor in der vierten erweiterten Alterstufe (121- bis 160-jährige Bestände) ein leichter Rückgang zu verzeichnen ist. 


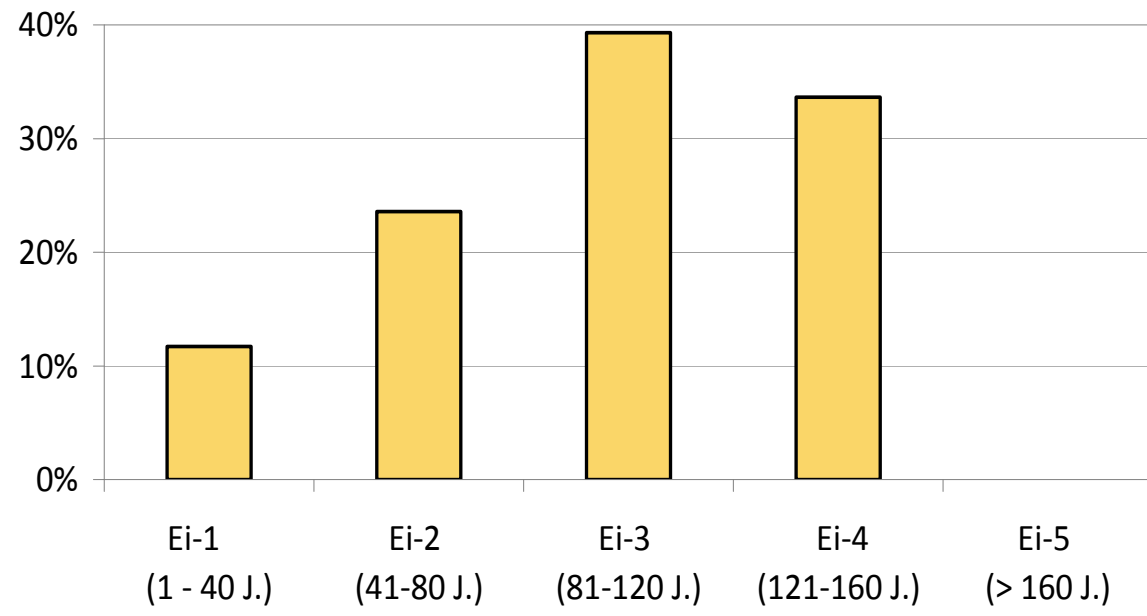

Abbildung 147: Reale Kalamitätsnutzungsanteile [\%] an der Gesamtnutzung [Efm o. R.] der Eichenbestände von 1967 bis 2007 nach erweiterten Altersstufen (Stufe 5 war 1967 nicht besetat)

\subsection{Kiefer}

Die Kiefernbestände weisen insgesamt geringere Unterschiede der Ertragswerte zwischen Modell- und Kalamitätsbetrieb auf als die Eichen- und Buchenbestände.

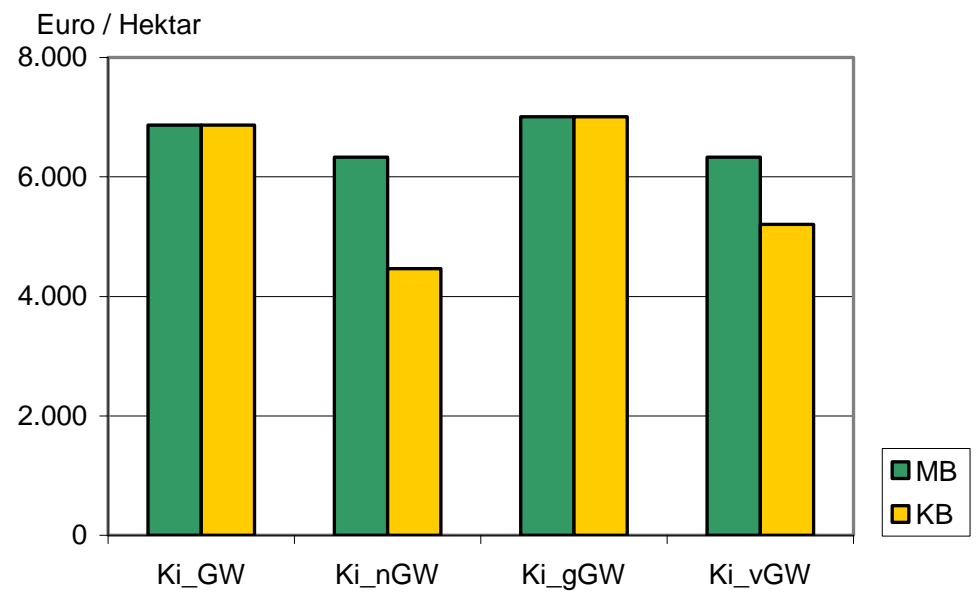

Abbildung 148: Ertragswerte [€/ha] von Kiefermbeständen im Kalamitäts- (KB) und im Modellbetrieb (MB) nach Grundwassersituation (GW = permanent sicherer Grundwasseranschluss, $n G W=$ niemals sicherer Grundwasseranschluss, $g G W=$ gesunkener sicherer Grundwasseranschluss, $v G W=$ verloren gegangener gesicherter Grundwasseranschluss) 
Auf grundwassernahen Standorten (GW, gGW) unterscheiden sich die Ertragswerte zwischen den beiden Varianten trotz teilweiser Grundwasserabsenkungen (gGW) nicht (s. Abb. 148). Die geringsten Ertragswerte werden auf den bereits im Jahre 1967 grundwasserfernen Standorten erzielt, wo im Kalamitätsbetrieb nur 71 Prozent des Modellbetriebsertrages erreicht wird. Bei den immer grundwasserfernen Standorten handelt es sich vorwiegend um Sande, während die Standorte mit Verlust des sicheren Grundwasseranschlusses vor allem durch (an)lehmige Bodensubstrate gekennzeichnet sind. (s. Abb. 136).

Der durchschnittliche kalamitätsbedingte Anteil Holznutzungen beträgt in der Kiefer 34 Prozent und ist damit im Vergleich zu Eiche und Buche vergleichsweise hoch. Allerdings stockt der Großteil der Kiefernbestände ohnehin auf den hinsichtlich Wasser- und Nährstoffversorgung ungünstigsten Standorten. Die stärksten Zunahmen kalamitätsbedingter Holznutzungen waren auf (an)lehmigen und tonigen Standorten mit Grundwasserabsenkungen bzw. vollständigem Verlust des Grundwasseranschlusses zu verzeichnen (s. Abb. 149).

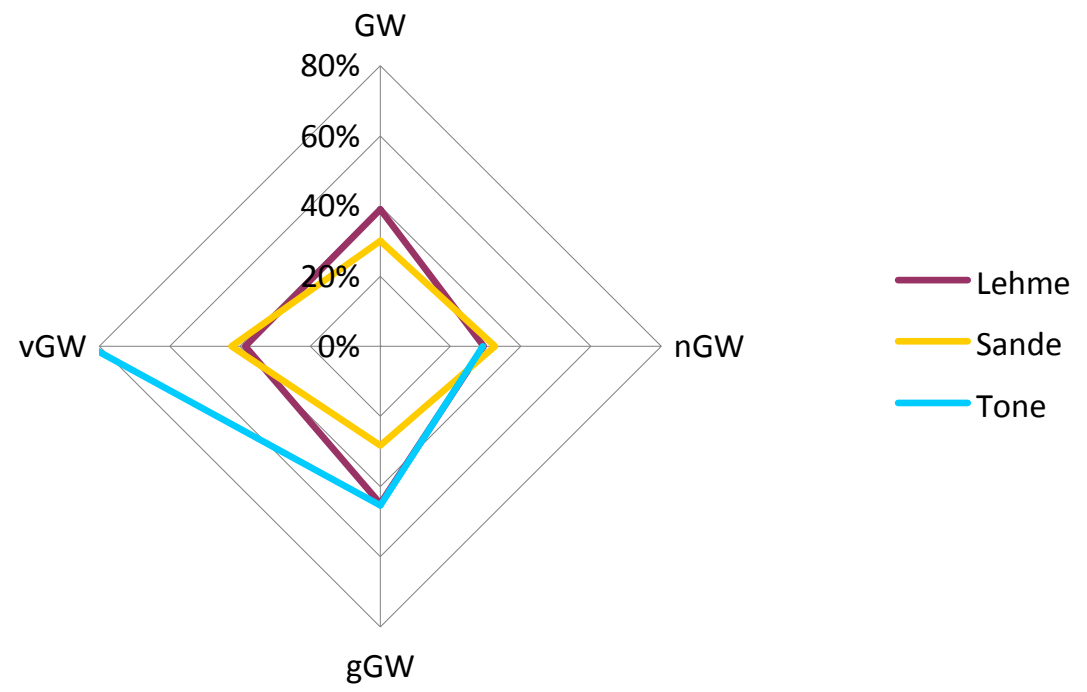

Abbildung 149: Reale Kalamitätsnutzungsanteile [\%] an der Gesamtnutzung von Kiefernbeständen [Efm o. R.] von 1967 bis 2007 nach Grundwassersituation (GW = permanent sicherer Grundwasseranschluss, $n G W=$ niemals sicherer Grundwasseranschluss, $g G W=$ gesunkener sicherer Grundwasseranschluss, $\nu G W=$ verloren gegangener gesicherter Grundwasseranschluss) und Substrat

Vergleichbar mit den Eichenbeständen zeigt sich auch bei den Kiefernbeständen ein zunehmender Kalamitätsanteil mit zunehmendem Alter (s. Abb. 150), wobei auch in Kiefernbeständen ein leichter Rückgang der Kalamitätsnutzungen in der vierten Altersstufe zu beobachten ist. 


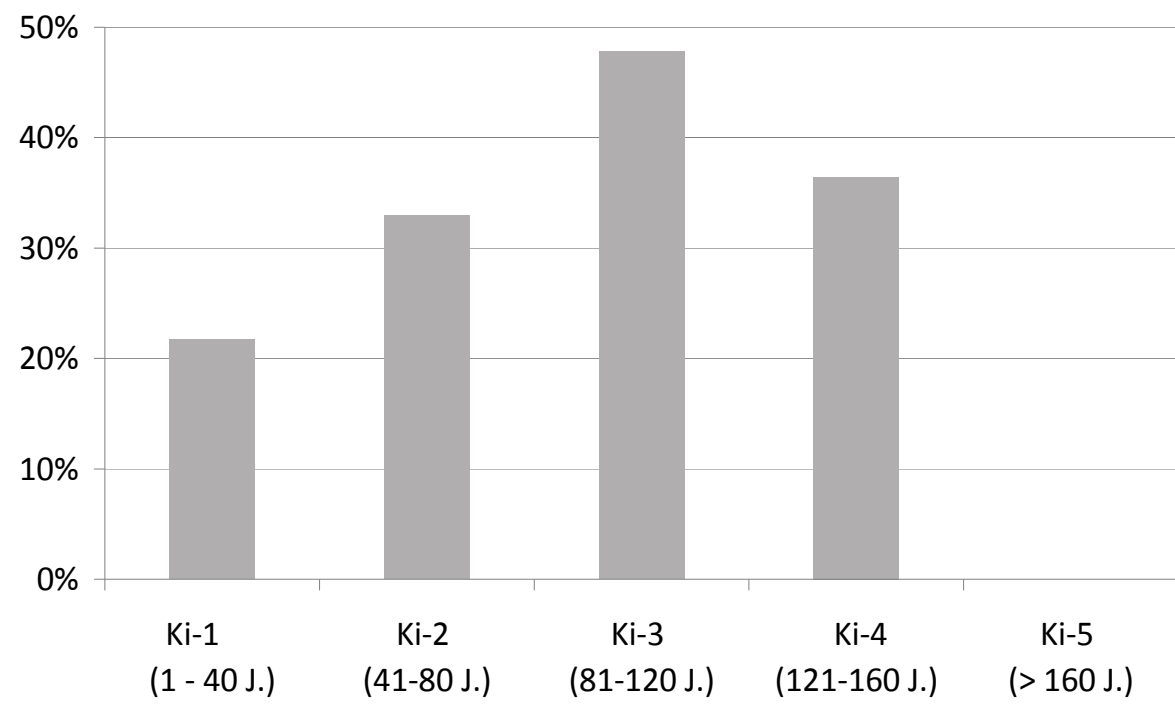

Abbildung 150: Reale Kalamitätsnutzungsanteile [\%] an der Gesamtnutzung [Efm o. R.] der Kiefernbestände von 1967 bis 2007 nach erweiterten Altersstufen (Stufe 5 war 1967 nicht beset?t)

\subsubsection{Bewertung der Szenarien der prognostizierten Waldentwicklung}

Nach dem Rückblick und der Bewertung der Entwicklungen der Vergangenheit (Periode 1967 bis 2007) soll nun auf der Basis von Szenarien der Blick in die wirtschaftliche Zukunft des Untersuchungsgebietes gewagt werden. Für den wirtschaftlichen Vergleich der Szenarien wurden die mit Hilfe des Produktionsmodells simulierten erntekostenfreien Holzerlöse und Kulturkosten und die in der Periode bis 2039 erwarteten Wertveränderungen der Waldbestände auf das Anfangsjahr 2007 diskontiert und zu Ertragswerten aggregiert.

\subsubsection{Holzerlöse}

Abbildung 151 zeigt die diskontierten erntekostenfreien Holzerlöse in den unterschiedlichen Szenariokombinationen. Dabei weist das Szenario GW- in den trockenen und feuchten Klimaszenarien etwas höhere diskontierte erntekostenfreie Holzerlöse auf als das Szenario GW+. Die Differenz zwischen den Extremwerten $\mathrm{GW}+$ bei feuchtem Klimaszenario und GW- bei trockenem Klimaszenario betrug knapp 14 Millionen Euro. Bezieht man Abbildung 152 in die Betrachtung mit ein, wird sichtbar, dass die höheren Holzerlöse durch die vergleichsweise höheren Gesamtnutzungsmassen bedingt werden. 


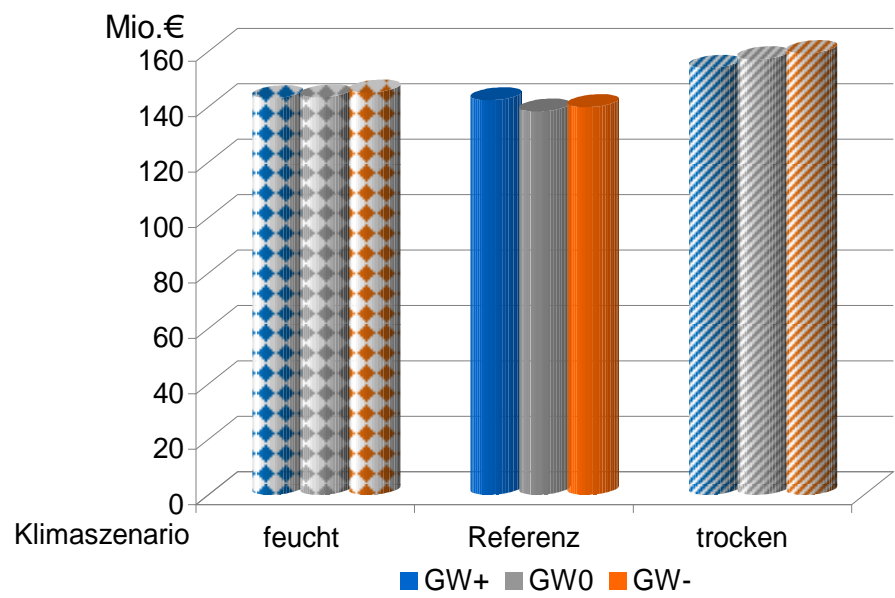

Abbildung 151: Summen der diskontierten erntekostenfreien Holzerlöse [Mio. €] von 2007 bis 2039 für die verschiedenen Klima- und Grundwasserszenarien

In der Kombination aus GW- und trockenem Klimaszenario wird ein waldbauliches Behandlungsregime wirksam, das unter anderem ein Herabsetzen der Zielstärken zur Reduzierung des Entwertungsrisikos und eine Verkürzung der Produktionszeiträume vorsieht. Die Nutzungsmassen liegen im zeitlichen Verlauf kontinuierlich über denen der anderen Szenarien. Der Unterschied ist jedoch zu Beginn der Simulationsperiode größer, bis sich die Nutzungsmassen nach einem stärkeren Absinken den anderen Szenariokombinationen annähern.

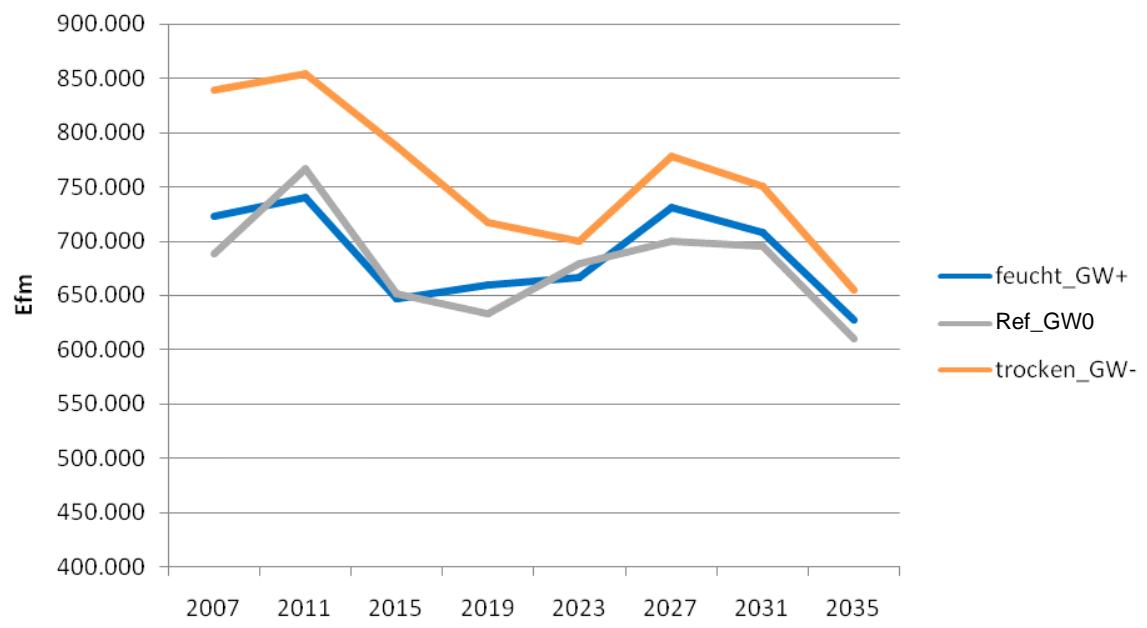

Abbildung 152: Gesamtnutzungsmassen [Efm 0. R.] in jeweils vierjährigen Simulationsschritten zwischen 2007 und 2039 für das Referenzszenario Ref_GW0 und die beiden Extremszenarien feucht_GW+ und trocken_GW- 
Tabelle 63 zeigt die Anteile des Kalamitätsholzes an der Gesamtnutzung. Diese Kalamitätsnutzungsanteile waren innerhalb eines Klimaszenarios bei dem Szenario GW-immer am höchsten. Auffällig sind die vergleichsweise niedrigen Kalamitätsholzanteile im trockenen Klimaszenario. Dieser Sachverhalt erklärt sich wiederum durch die herabgesetzten Zielstärken.

Tabelle 63: $\quad$ Kalamitätsnutzungsanteile [\%] an der Gesamtnutzung nach Szenarien

\begin{tabular}{lccc}
\hline Klimaszenario & \multicolumn{3}{c}{ Grundwasserszenario } \\
& GW + & GW0 & GW- \\
\hline feucht & $12,3 \%$ & $13,0 \%$ & $14,0 \%$ \\
Referenz & $12,4 \%$ & $15,3 \%$ & $15,7 \%$ \\
trocken & $10,8 \%$ & $11,0 \%$ & $11,6 \%$ \\
\hline
\end{tabular}

\subsubsection{Wertentwicklung der Bestände}

Als Folge der unterschiedlichen Stärke der Eingriffe in die Waldbestände verändern sich die Abtriebswerte in der Simulationsperiode bis 2039 in sehr unterschiedlichem Maße. Die Veränderungen der Abtriebswerte bis zum Jahr 2039 im Vergleich zum Ausgangsjahr 2007 sind in Abbildung 153 dargestellt.

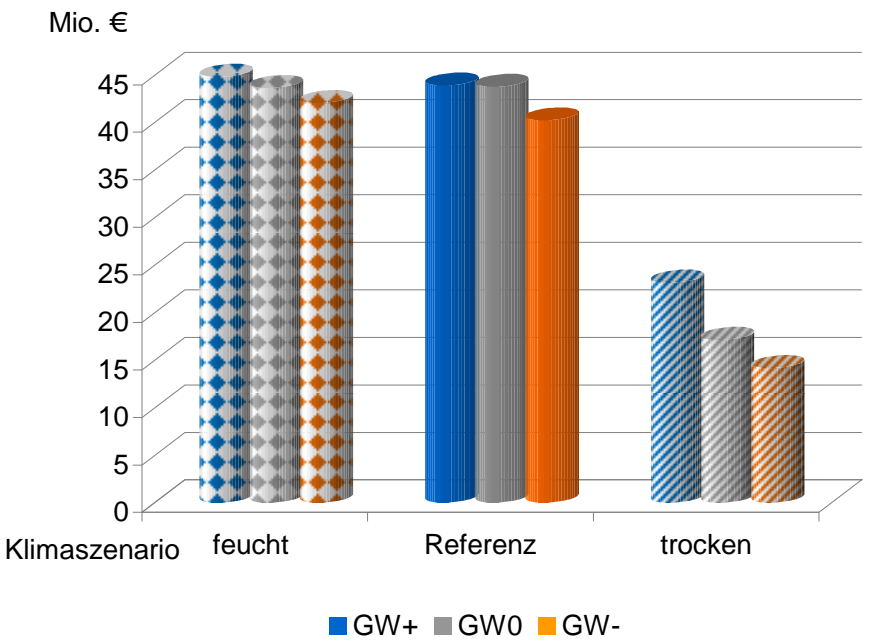

Abbildung 153: Erböbung der diskontierten Abtriebswerte [Mio. €] der Wälder im Projektgebiet von 2007 bis 2039 in den verschiedenen Szenarien

Innerhalb der einzelnen Klimaszenarien verzeichnen die Bestände bei dem Grundwasserszenario GW+ jeweils die höchsten Werterhöhungen und bei GW- die geringsten. Im trockenen Klimaszenario erreicht die Wertveränderung nur knapp 
die Hälfte $(G W+)$ beziehungsweise knapp ein Drittel (GW- u. GW0) der Werterhöhung der anderen beiden Klimaszenarien, deren Wertentwicklung keine nennenswerten Unterschiede aufweist. Somit hat insbesondere die Nutzungsstrategie innerhalb des trockenen Klimaszenarios eine erhebliche Bedeutung für die Wertentwicklung der Bestände.

\subsubsection{Kulturkosten}

Auch hinsichtlich des Kulturaufwandes lassen sich szenarioabhängige Differenzierungen erkennen. Tabelle 64 zeigt, dass im trockenen Klimaszenario im Vergleich aktive Verjüngungsmaßnahmen in erheblich höherem Umfang erforderlich sind. $\mathrm{Zu}$ beachten ist dabei, dass die herabgesetzten Zielstärken (und Umtriebszeiten) im trockenen Klimaszenario zu einer Erhöhung der Kulturfläche führen. Innerhalb des trockenen Klimaszenarios nimmt die erforderliche aktive Verjüngungsfläche vom Szenario GW+ zum Szenario GW- zu. Diese Tendenz ist auch innerhalb der anderen beiden Klimaszenarien zu beobachten. Die Kulturkosten spiegeln die naturalen Daten wider und sind im trockenen Klimaszenario ungefähr doppelt so hoch wie bei den anderen beiden Szenarien, deren Werte eine untereinander vergleichbare Höhe erreichen. Innerhalb der einzelnen Klimaszenarien zeigt sich jeweils eine Zunahme der Kulturkosten vom Grundwasserszenario GW+ über GW0 zu GW-, wobei deutliche Unterschiede zwischen den Grundwassserszenarien vor allem im trockenen Klimaszenario auftreten (s. Abb. 154).

Tabelle 64: Flächengröße und Maßnahmenanz̧abl aktiver Verjüngung nach Szenarien

\begin{tabular}{|c|c|c|c|}
\hline Klimaszenario & Grundwasserszenario & $\begin{array}{c}\text { Kulturfläche } \\
\text { [ha] }\end{array}$ & $\begin{array}{c}\text { Anzahl Kultur- } \\
\text { maßnahmen }\end{array}$ \\
\hline \multirow{3}{*}{ feucht } & GW+ & 1.480 & 433 \\
\hline & GW0 & 1.551 & 437 \\
\hline & GW- & 1.669 & 436 \\
\hline \multirow{3}{*}{ Referenz } & GW+ & 1.401 & 429 \\
\hline & GW0 & 1.404 & 415 \\
\hline & GW- & 1.576 & 415 \\
\hline \multirow{3}{*}{ trocken } & GW+ & 3.588 & 804 \\
\hline & GW0 & 4.053 & 861 \\
\hline & GW- & 4.603 & 930 \\
\hline
\end{tabular}




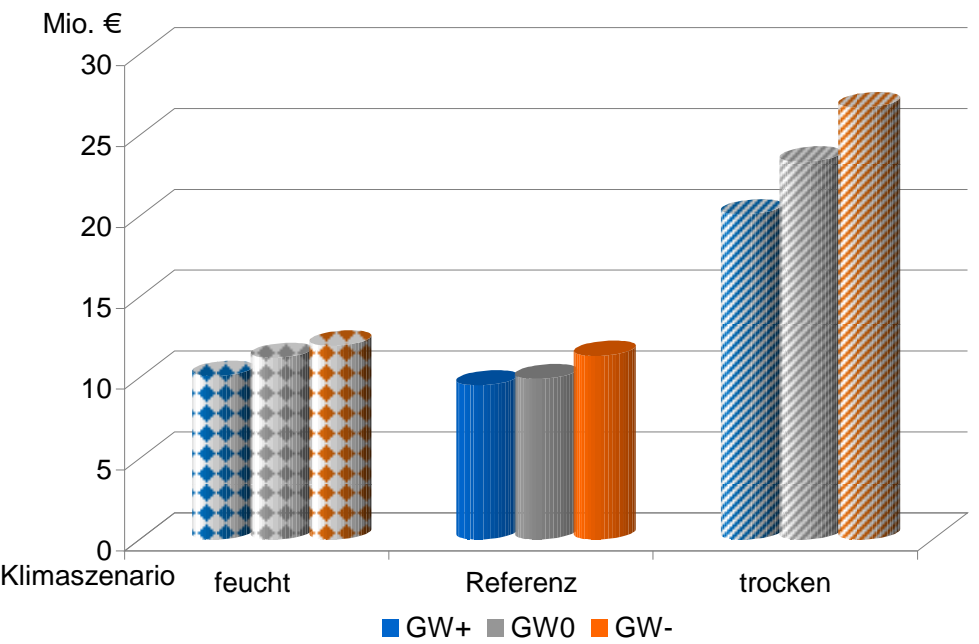

Abbildung 154: Summe der diskontierten Kulturkosten [Mio. €] von 2007 bis 2039 nach Szenarien

\subsubsection{Ertragswerte}

Da eine erhöhte Holznutzung, Kulturkosten und die Wertentwicklung der Bestände nicht unabhängig voneinander sind, wurden sie zum Vergleich der neun Szenarienkombinationen zu Ertragswerten aggregiert. Abbildung 155 zeigt diese Ertragswerte.

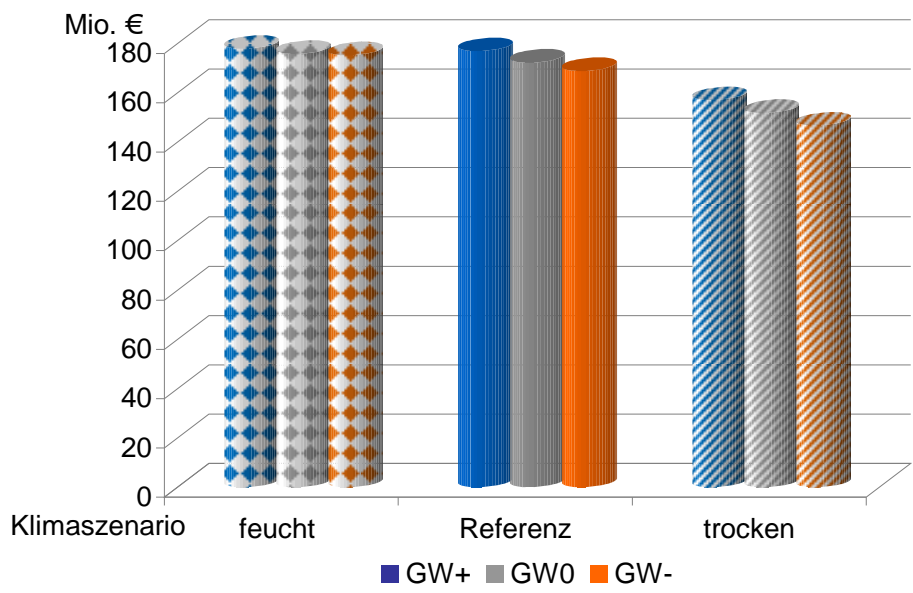

Abbildung 155: Ertragswerte [Mio. €] der Bewirtschaftung von 2007 bis 2039 nach Szenarien 
Wenngleich die Unterschiede zwischen den Ertragswerten geringer ausfallen als bei den einzeln betrachteten Größen, weisen auch die Ertragswerte innerhalb der drei Klimaszenarien eine Abnahme vom Grundwasserszenario GW+ über GW0 zu GW- auf. Insgesamt variieren die Ertragswerte in einer Spanne von rd. 170 Millionen Euro (feucht/GW+) und ca. 140 Millionen Euro (trocken/GW-).

\subsubsection{Baumartensperifische Betrachtung}

\subsubsection{Buche}

Die Buchenbestände im Projektgebiet stocken vornehmlich auf Flächen, die in allen drei Grundwasserszenarien zu keinem Zeitpunkt über einen sicheren Grundwasseranschluss verfügen. Nur auf einem Teil der lehmigen Standorte führt daher das Szenario GW+ zu einer Wiederherstellung des gesicherten Grundwasseranschlusses. Im Szenario GW- verlieren etwa sieben Prozent der Buchenbestände den Grundwasseranschluss, sodass dann nur noch neun Prozent einen sicheren Anschluss zum Grundwasser aufweisen.

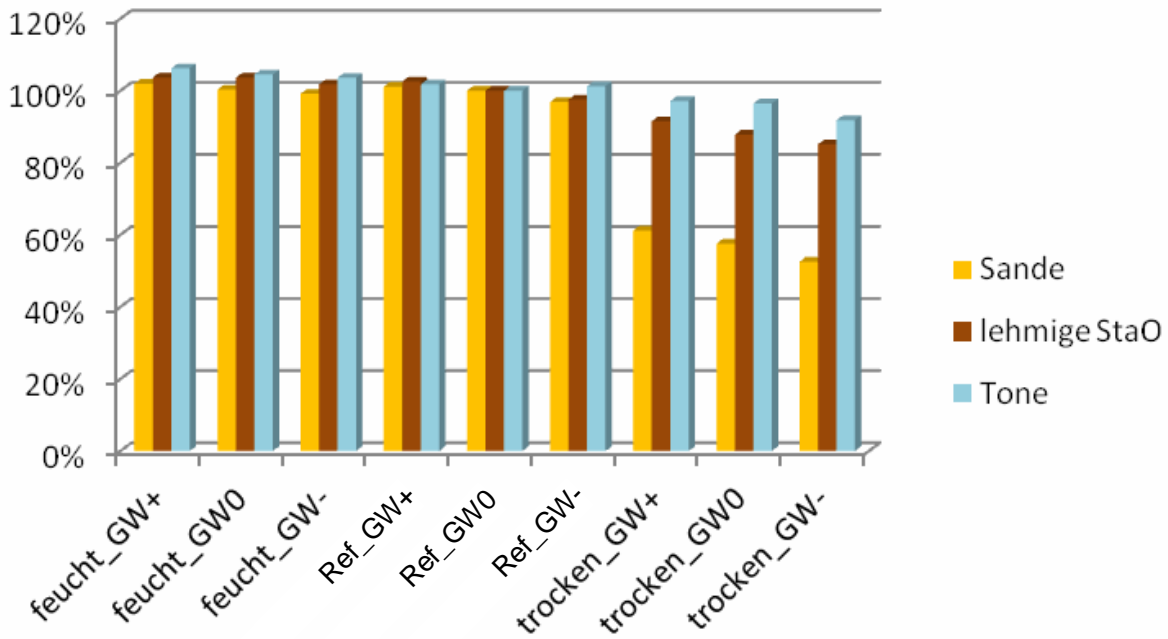

Abbildung 156: Durchschnittliche Ertragswerte der Buchenbestände in Prozent der Referenzszenariokombination Ref_GWO für verschiedene Szenarien und Substrate in der Simulationsperiode

Abbildung 156 zeigt die relativen Ertragswerte der Buchenbestände in Abhängigkeit von den unterstellten Szenariokombinationen als prozentualer Anteil der Ertragswerte der Referenzszenariokombination „Ref_GW0“ differenziert nach Substraten. Diese Referenzertragswerte betragen für den simulierten Zeitraum $8.000 € /$ ha auf den lehmigen Standorten, 7.100€/ha auf den Sanden und $7.500 € /$ ha auf den tonigen Standorten. Hierbei muss beachtet werden, dass den 
Standortseinheiten unterschiedliche Altersklassenverteilungen zugrunde liegen und somit die absoluten Werte nicht unmittelbar zu vergleichen sind.

Die Buchenbestände zeigen generell eine Verschlechterung der Ertragswerte vom Grundwasserszenario GW+ über GW0 zu GW- und vom feuchten zum trockenen Klima. Die gegenüber dem Referenzertragswert deutlichsten Rückgänge sind im trockenen Klimaszenario auf sandigen Böden zu verzeichnen, wo die Buche nur noch 50-60 Prozent des Referenzwertes erreicht. Die Ertragsverbesserungen durch das Szenario GW+ bewegen sich im feuchten Klimaszenario im Bereich weniger Prozentpunkte, führen im trockenen Klimaszenario jedoch zu Ertragssteigerungen von bis zu 10 Prozent.

Eine Analyse der Ertragswertveränderungen der Buchenbestände, die im Jahre 2007 einen sicheren Grundwasseranschluss haben und diesen im Rahmen des Szenarios GW- verlieren, führt zu noch weitaus deutlicheren Veränderungen der Ertragswerte (s. Abb. 157).

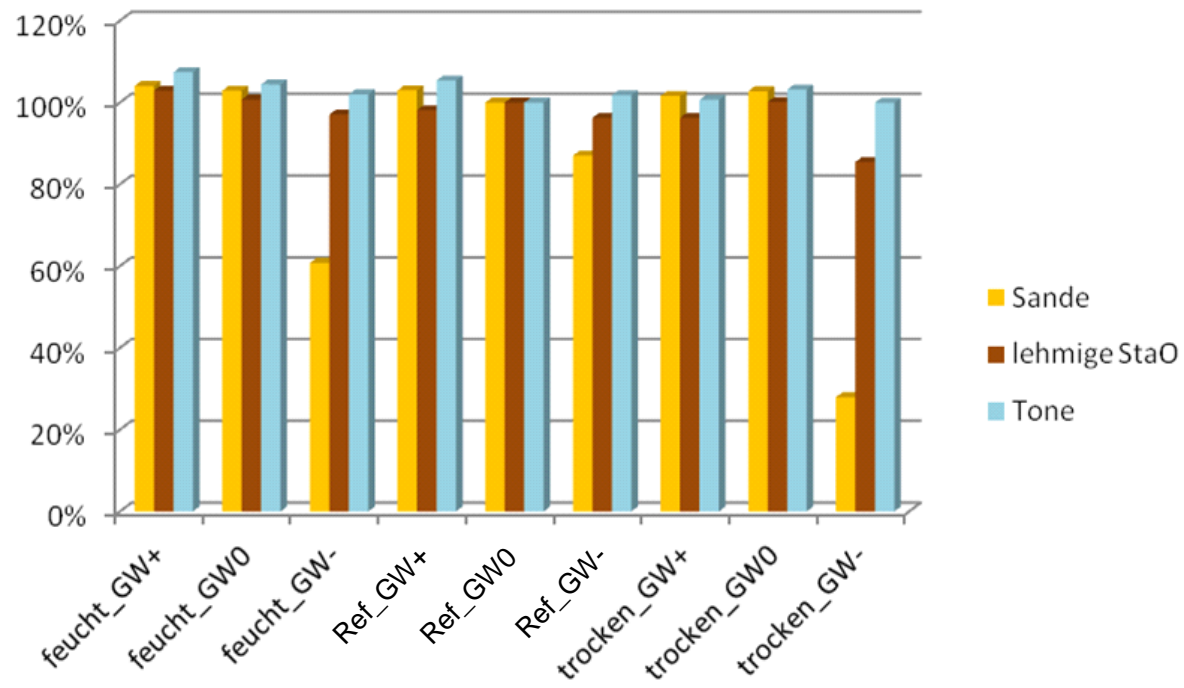

Abbildung 157: Durchschnittliche Ertragswerte der Buchenbestände, die auf Flächen stocken, die 2007 einen sicheren Grundwasseranschluss aufweisen, diesen aber im Rahmen des Szenarios $G W$-verlieren, in Prozent der Referenzszenariokombination Ref_GWO für verschiedene Szenarien und Substrate in der Simulationsperiode

Von den betroffenen 340 Hektar Buchenbeständen stocken 121 Hektar auf Sanden, 191 Hektar auf lehmigen Standorte sowie 27 Hektar auf Tonen. Die entsprechenden Referenzertragswerte betragen $9.000 € /$ ha auf den Sanden, $10.000 € /$ ha auf den lehmigen Standorten und $11.700 € /$ ha auf den Tonen. Zu beachten ist, dass jeweils nur die Werte einer Standortsgruppe miteinander verglichen werden dürfen, da die Standortsgruppen unterschiedliche Altersklassenausstattungen aufweisen. Die Unterschiede der Ertragswerte sind zwischen dem 
Zustand „mit" und „ohne“ sicheren Grundwasseranschluss erheblich größer als bei der Gesamtbetrachtung. Der Ertragsverlust durch Grundwasserabsenkung macht gegenüber dem Referenzwert (Ref_GW0, Sand) in der „trockensten“ Kombination (trockenes Klima_GW-, Sand) über 70 Prozent aus, was neben einer höheren Mortalität und abnehmenden Leistungsfähigkeit der Bestände nicht zuletzt auch auf die erforderliche Veränderung der waldbaulichen Behandlung zurückzuführen ist.

\subsubsection{Eiche}

Auch die Eichenbestände im Projektgebiet stocken mehrheitlich auf Flächen, die in allen drei Grundwasserszenarien zu keinem Zeitpunkt über einen sicheren Grundwasseranschluss verfügen. Gegenüber der Buche ist der Anteil der Bestände, bei denen das Grundwasserszenario den Grundwasseranschluss positiv oder negativ beeinflusst, jedoch höher. Dies betrifft insbesondere die lehmigen und tonigen Standorte. Bei einer weiteren Absenkung des Grundwassers gemäß dem Szenario GW- verlieren weitere 8 Prozent der Eichenbestände den Grundwasseranschluss, sodass dann noch 11 Prozent einen sicheren Kontakt zum Grundwasser aufweisen. Im Szenario GW+ werden 22 Prozent der Eichenbestände wieder in Kontakt mit dem Grundwasser gebracht.

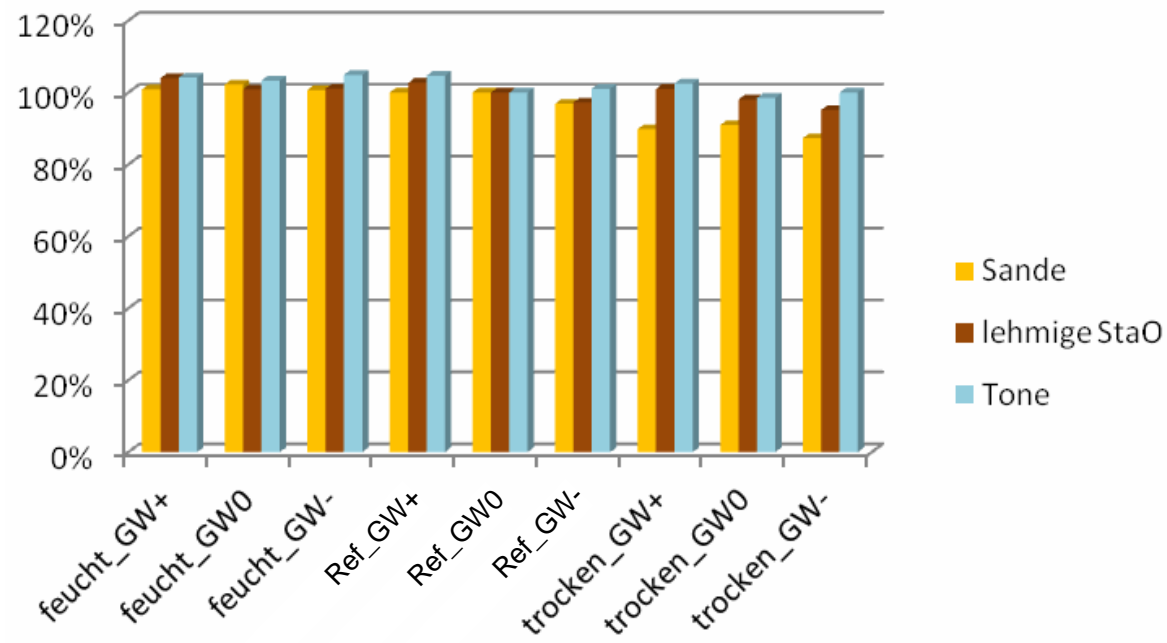

Abbildung 158: Durchschnittliche Ertragswerte der Eichenbestände in Prozent der Referenzszenariokombination Ref_GWO für verschiedene Szenarien und Substrate in der Simulationsperiode

Abbildung 158 zeigt die relativen Ertragswerte der Eichenbestände in Abhängigkeit von den unterstellten Szenariokombinationen als prozentualer Anteil der Ertragswerte der Referenzszenariokombination „Ref_GW0“ differenziert nach Substraten. Die Referenzertragswerte betragen für den simulierten Zeitraum gerun- 
det $5.700 € /$ ha auf den lehmigen Standorten, ca. $6.000 € /$ ha auf den Sanden und $6.700 € /$ ha auf den tonigen Standorten

Auch die Eichenbestände zeigen generell eine Verschlechterung der Ertragswerte vom feuchten zum trockenen Klima, jedoch sind die Unterschiede im Vergleich zu den Buchenbeständen geringer ausgeprägt und auf den Sandstandorten noch am auffälligsten. Der Einfluss der Grundwasserszenarien auf die Ertragswerte der Eichenbestände ist dagegen uneinheitlich und schwach ausgeprägt.

Entsprechend der Vorgehensweise bei der Buche werden auch bei der Eiche die Bestände separat betrachtet, die im Szenario GW- den sicheren Grundwasseranschluss verlieren. Die Fläche der betroffenen Bestände umfasst 636 Hektar, wovon 155 Hektar auf Sanden, 435 Hektar auf lehmigen Standorten und 46 Hektar auf Tonen stocken. Die Referenzertragswerte betragen $6.500 € /$ ha auf den Sanden, $7.800 € /$ ha auf den lehmigen Standorten und $8.700 € /$ ha auf den Tonen. Die szenarioabhängigen Unterschiede der Ertragswerte sind auch hier erheblich größer als bei der Gesamtbetrachtung. Die Ertragsminderung macht bei Verlust des Grundwasseranschlusses bis zu 15 Prozent innerhalb eines Klimaszenarios aus, wobei die Einbußen auf den sandigen Standorten am größten sind (s. Abb. 159).

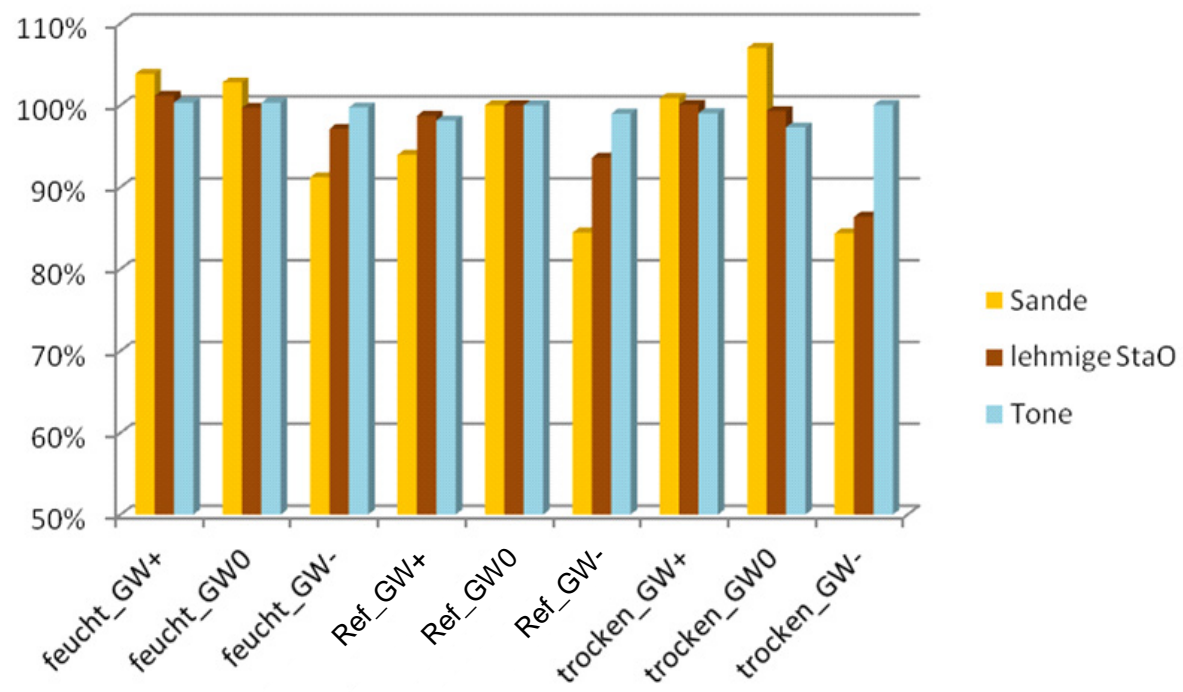

Abbildung 159: Durchschnittliche Ertragswerte der Eichenbestände, die auf Flächen stocken, die 2007 einen sicheren Grundwasseranschluss aufweisen, diesen aber im Rabmen des Szenarios $G W$-verlieren, in Prozent der Referenzszenariokombination Ref_GW0 für verschiedene Szenarien und Substrate in der Simulationsperiode

\subsubsection{Kiefer}

Gegenüber der Buche und der Eiche ist der Anteil der Flächen, die in allen drei Grundwasserszenarien zu keinem Zeitpunkt über sicheren Grundwasseranschluss 
verfügen, bei der Kiefer noch höher. Deshalb verlieren bei einer weiteren Absenkung des Grundwasserstandes nur weitere vier Prozent der Kiefernbestände Grundwasseranschluss, sodass dann noch fünf Prozent sicheren Kontakt zum Grundwasser aufweisen. Umgekehrt erlangen durch eine Grundwasseranhebung im Szenario GW+ etwa 15 Prozent der Kiefernbestände wieder sicheren Grundwasseranschluss.

Abbildung 160 zeigt die relativen Ertragswerte der Kiefernbestände in Abhängigkeit von den unterstellten Szenariokombinationen als prozentualer Anteil der Ertragswerte der Referenzszenariokombination „Ref_GW0“ differenziert nach Substraten. Die Referenzertragswerte betragen für den simulierten Zeitraum gerundet $5.100 € /$ ha auf den lehmigen Standorten, ca. 5.200 €/ha auf den Sanden und $5.300 € /$ ha auf den tonigen Standorten. Auch hier ist wieder zu beachten, dass den Standortseinheiten unterschiedliche Altersklassenverteilungen zugrunde liegen und somit die absoluten Werte nicht unmittelbar zu vergleichen sind.

Die Ertragswerte der Kiefernbestände reagieren im feuchten Klimaszenario kaum und uneinheitlich auf die Grundwasserszenarien. In den beiden anderen Klimaszenarien nehmen die Ertragswerte mit sich verschlechterndem Grundwasserregime ab, wobei diese Reaktion auf Sandstandorten wiederum stärker ausgeprägt ist.

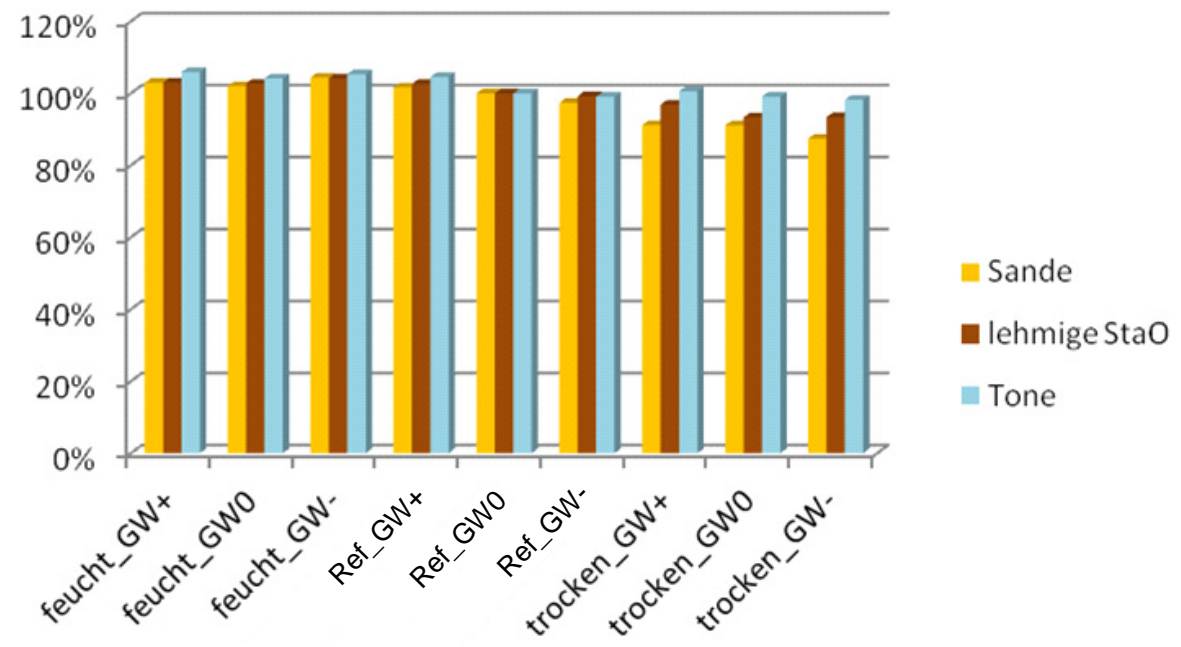

Abbildung 160: Durchschnittliche Ertragswerte der Kiefernbestände in Prozent der Referen₹szenariokombination Ref_GW0 für verschiedene Szenarien und Substrate in der Simulationsperiode

Die ausschließliche Betrachtung derjenigen Kiefernbestände, die im Szenario GWden sicheren Grundwasseranschluss verlieren, führt wiederum zu weitaus differenzierteren Ertragsverlusten als bei einer Gesamtbetrachtung. Die in Betracht kommende Fläche umfasst 426 Hektar, wovon 191 Hektar als sandige, 229 Hektar als lehmige und 7 Hektar als Tonstandorte eingestuft sind. Die Referenzertragswerte 
betragen $6.000 € /$ ha auf den Sanden, $7.000 € /$ ha auf den lehmigen Standorten und $7.000 € /$ ha auf den Tonen. Der Ertragsverlust ohne Grundwasseranschluss erreicht maximal bis zu 25 Prozent innerhalb eines Klimaszenarios, wobei auch bei der Kiefer die Einbußen auf den sandigen Standorten am größten sind (s. Abb. 161).

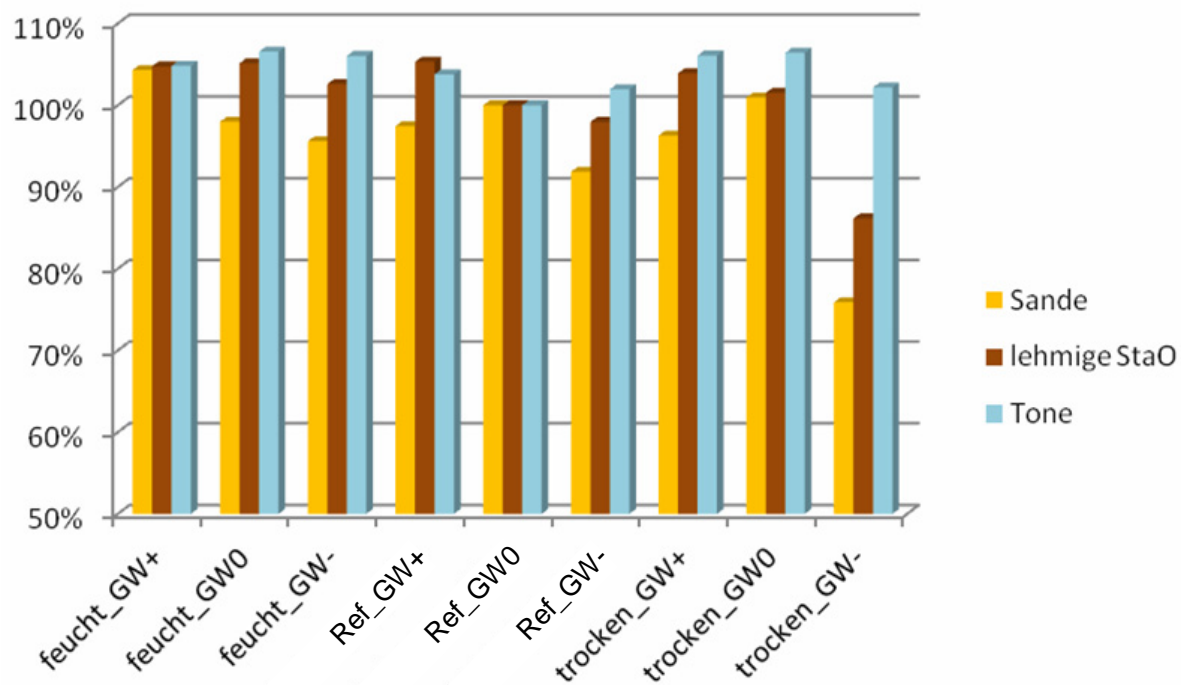

Abbildung 161: Durchschnittliche Ertragswerte der Kiefernbestände, die auf Flächen stocken, die 2007 einen sicheren Grundwasseranschluss aufweisen, diesen aber im Rabmen des Szenarios $G W$-verlieren, in Prozent der Referenzszenariokombination Ref_GWO für verschiedene Szenarien und Substrate in der Simulationsperiode

\subsubsection{Vergleich der Baumarten}

Die Unterschiede der Ertragswerte liegen zwischen den Szenarien für die Hauptbaumarten bei einer Gesamtbetrachtung im Bereich unter 10 Prozent. Werden hingegen nur diejenigen Bestände berücksichtigt, die im Grundwasserszenario GWden sicheren Grundwasseranschluss verlieren, erreichen die Differenzen der Ertragswerte gegenüber den Szenarien, bei denen der Grundwasseranschluss erhalten bleibt, deutlich höhere Werte.

Tabelle 65 zeigt die minimalen Ertragswerte in Prozent der bereits beschriebenen Referenzertragswerte. Grundwasserabsenkungen führen demzufolge besonders auf Sandstandorten zu teilweise erheblichen Ertragseinbußen. Darüber hinaus sind die Ertragseinbußen unter diesen Standortsbedingungen bei der Buche am höchsten. Die Douglasienbestände weisen dagegen durchweg stabile Ertragswerte auf, wobei aber einschränkend zu berücksichtigen ist, dass die Douglasienfläche im Untersuchungsraum sehr begrenzt ist und die Bestände vergleichsweise jung sind. 
Tabelle 65: $\quad$ Minimale Ertragswerte in Prozent der Ertragswerte bei dem Klimaszenario Referenz. und dem Grundwasserszenario GWO

\begin{tabular}{lccc}
\hline & Sande & lehmige StO & Tone \\
\hline $\mathrm{Bu}$ & $28 \%$ & $85 \%$ & $100 \%$ \\
$\mathrm{Ei}$ & $84 \%$ & $86 \%$ & $100 \%$ \\
$\mathrm{Ki}$ & $76 \%$ & $86 \%$ & $102 \%$ \\
$\mathrm{ELB}$ & $91 \%$ & $94 \%$ & $100 \%$ \\
$\mathrm{Dgl}$ & $99 \%$ & $99 \%$ & $100 \%$ \\
\hline
\end{tabular}

\subsubsection{Naturschutæbedingte Bewirtschaftungsbeschränkungen}

Große Teile des Projektgebietes unterliegen besonderen naturschutzfachlichen Vorschriften, die in Bewirtschaftungseinschränkungen resultieren. Folgende Beschränkungen liegen u. a. in folgenden Kategorien vor:

- Prozessschutz: keine regulären Eingriffe

- NSG Mönchbruch: keine Ernte von Bäumen mit BHD > $50 \mathrm{~cm}$

- LRT (FFH-Lebensraumtypen): Erhalt des guten Erhaltungszustandes des Waldtyps mit Altholzanteil von 20 Prozent bzw. 40 Prozent

- WET-Vorgabe: Vorgabe der Baumartenwahl

Tabelle 66: $\quad$ Übersicht über die Ertragsdifferenzen infolge von diversen Naturschutzanforderungen

\begin{tabular}{lcccc}
\hline Schutzanforderung & $\begin{array}{c}\text { Fläche ohne } \\
\text { Überlappung } \\
\text { [ha] }\end{array}$ & BA & $\begin{array}{c}\text { durchschnittliche } \\
\text { Ertragsdifferenz } \\
\text { pro ha [€] }\end{array}$ & $\begin{array}{c}\text { Ertragsdifferenz } \\
\text { gesamt } \\
{[€]}\end{array}$ \\
\hline $\begin{array}{l}\text { Prozessschutz / } \\
\text { Nutzungsverzicht }\end{array}$ & 1.774 & alle & -2.536 & -4.498 .864 \\
$\begin{array}{l}\text { Altholznutzungsverzicht } \\
\text { im NSG Mönchbruch }\end{array}$ & 520 & alle & -320 & -60.450 \\
$\begin{array}{l}\text { Zustandserhaltung } \\
\text { in Lebensraumtypen }\end{array}$ & 756 & Ei, Bu & -324 & -45.437 \\
$\begin{array}{l}\text { Vorgabe des } \\
\text { Waldentwicklungstyps }\end{array}$ & 693 & alle & -224 & -55.232 \\
\hline Gesamt & 3.743 & & -1.352 & -5.059 .983 \\
\hline
\end{tabular}

Die aus diesen Auflagen resultierenden Ertragsminderungen sind in Tabelle 66 dargestellt. Die gesamte Minderung beträgt etwas mehr als fünf Millionen Euro für den Simulationszeitraum bzw. rund 160.000 Euro pro Jahr. Die Ertragsminderungen sind im Prozessschutzgebiet am höchsten und belaufen sich dort auf ca. $2.500 € / \mathrm{ha}$ bzw. $80 € / \mathrm{ha} / \mathrm{Jahr}$. Hierbei ist zu beachten, dass der in die Bewertung eingegangene Wertzuwachs der Bestände durch den Nutzungsverzicht nicht realisiert werden kann. 


\section{Diskussion und Schlussfolgerungen}

In der vorliegenden Studie werden die Datengrundlagen, Methoden und Ergebnisse mehrerer modellgestützter Simulationen der Waldentwicklung im Hessischen Ried unter Annahme unterschiedlicher Grundwasserverhältnisse und klimatischer Bedingungen sowie unter Beachtung naturschutzfachlicher Anforderungen vorgestellt. Die Analysen und Prognosen bilden eine raumbezogene Wissens- und Entscheidungsbasis für Politik, Fachverwaltungen und Waldbesitzer, um die Waldfunktionen bzw. die gesellschaftlichen Ansprüche an den Wald in der Fläche neu zu gewichten, Vermeidungs- bzw. Anpassungsstrategien zu entwickeln und gezielte Maßnahmen zur Sicherung der Waldfunktionen einzuleiten.

Anders als bei früheren Beweissicherungsverfahren im Hessischen Ried steht nicht die Analyse der gegenwärtigen Waldzustände im Vordergrund der Betrachtungen, sondern die Analyse der Waldentwicklung in einem repräsentativen Modellbetrieb mit und ohne Grundwasserabsenkung seit Mitte der sechziger Jahre des letzten Jahrhunderts bis zum Stichjahr 2007 sowie die modellgestützte Entwicklungsprognose für die Wälder von 2007 bis zum Jahr 2039 unter sich ändernden Umweltbedingungen.

Wegen fehlender Vergleichsmöglichkeiten werden im Folgenden die Ergebnisse dieses Projektes für sich diskutiert.

\subsection{Material und Methoden}

Zur Durchführung des Projektes mussten zahlreiche analog vorliegende Informationen erstmalig aufbereitet und digitalisiert werden. Hierdurch wurden unerwartet Ressourcen gebunden, der Start der Modellierungsarbeiten verzögert, aber auch die Datenbasis wesentlich verbessert.

Für die Standortskartierung wurden die alten Substratkartierungen von ZIMMERMANN (1953/54, unveröff.) und LEHMANN (1981, unveröff.) erschlossen. Auf dieser Grundlage war es möglich, die Substratverhältnisse im Ried erstmals vollflächig in einer digitalen Karte darzustellen. Gleichzeitig wurden die nutzbaren Feldkapazitäten bis auf eine Tiefe von $140 \mathrm{~cm}$ auf Basis der bodenkundlichen Kartierungsanleitung (KA5) (AG BODEN 2005) neu berechnet (vgl. OvERBECK et al. 2011) und die Frischestufen in Abhängigkeit vom pflanzenverfügbaren Wasser in der Vegetationszeit, also der Summe aus nutzbarer Feldkapazität und klimatischer Wasserbilanz, neu definiert. Die größere Bezugstiefe gegenüber dem Hessischen Standortskartierungsverfahren wurde gewählt, um die Heterogenität der Böden aus quartären Substraten besser zu berücksichtigen. Die hieraus resultierenden Werte überschätzen aber wahrscheinlich die nFK bei den schwach lehmigen Sanden. Zudem ist zu bedenken, dass durch die generell nach unten abnehmende Durchwurzelungsintensität nicht das gesamte potenziell pflanzenverfügbare Wasser 
genutzt werden kann (RIEK 1998). Dennoch wurde mit der Aufbereitung der Standortsdaten eine bisher nicht gegebene Entscheidungsgrundlage geschaffen. Diese wurde ergänzt und aufgewertet durch die Angaben zu den Grundwasserständen für bestimmte Bezugsjahre, die dankenswerterweise vom Büro BGS Umwelt Darmstadt zur Verfügung gestellt und auch zur Festlegung der Grundwasserszenarien genutzt wurden.

Zur Parametrisierung der Mortalitätsmodelle wurde auf die in den vergangenen Jahrzehnten vom Servicezentrum Forsteinrichtung und Naturschutz (FENA) des Landesbetriebes HESSEN-FORST angelegten und betreuten Weiserflächen zurückgegriffen. Bei der Aufbereitung und Eingabe der Daten stellte sich heraus, dass nur ein Teil der Flächen geeignet war, weil zwischenzeitliche Kalamitätsnutzungen nicht verbucht waren, unvollständige Datensätze vorlagen oder die Schlussaufnahmen bei Aufgabe der Flächen wegen zu hoher Ausfälle fehlten. Dementsprechend liefern die Mortalitätsmodelle eher zu vorsichtige Schätzungen für die Mortalitätsraten. Dies gilt besonders für die Buche, für die nur eine relativ geringe Zahl der ursprünglich angelegten Weiserflächen genutzt werden konnte.

Die Basis für die Szenariorechnungen bildeten die Forsteinrichtungsdaten der im Hessischen Ried gelegenen Forstbetriebe. Sie wurden einheitlich auf den Stichtag 01.01.2007 fortgeschrieben. Dabei mussten vielfach periodisch unverändert gebliebene Bonitäten übernommen werden, die die Vorschädigungen der Bestände ebenso wenig berücksichtigten, wie jene Bestockungsgrade, die in stark geschädigten Flächen auch die Grundflächen der zopftrockenen Bäume enthielten oder bei denen zwischen dem realen Forsteinrichtungsstichjahr und dem einheitlichen Stichtag der Simulationsrechnungen ein starker Schadensfortschritt auftrat. Diese Datenmängel ließen sich im Rahmen des Projektes trotz Überprüfungen im Luftbild nicht befriedigend beheben. Sie schmälern in Gebieten mit früher verloren gegangenem sicherem Grundwasseranschluss die Effekte der Grundwasser- und Klimaszenarien. Zur Simulation der Entwicklung des Modellbetriebes zwischen den Stichjahren 1967 und 2007 war es zudem nur teilweise möglich, auf die Forsteinrichtungswerke aus den sechziger Jahren zurückzugreifen, weil sich diese nach mehreren Organisationsänderungen nicht mehr auffinden oder Flächen nicht mehr eindeutig zuordnen ließen. Daher mussten in einigen Betrieben die Bestände teilweise von jüngeren Forsteinrichtungsstichtagen über längere Zeiträume zurückgerechnet werden.

Sowohl zur Dokumentation der Vitalitätsentwicklung als auch zur Bereitstellung zuverlässiger Planungsdaten erscheint es notwendig, eine eigene Betriebsklasse „Hessisches Ried“ für die von HESSEN-FORST bewirtschafteten bzw. betreuten Wälder zu schaffen und deren Naturalausstattung durch eine permanente, systematische Stichprobe zu erfassen. Die methodischen Voraussetzungen wurden hierfür mit Einführung der Betriebsinventur in die hessische Forsteinrichtungspraxis durch die FENA in Zusammenarbeit mit der NW-FVA in den letzten Jahren geschaffen. Die vorliegende Studie liefert eine sehr gute Datengrundlage zur 
Optimierung der Stichprobenumfänge für diese auf mehrere Merkmale auszurichtende Inventur. Als Bindglied zur Nutzung der repräsentativ erhobenen Informationen für die einzelbestandesweise Planung bietet sich eine vereinfachte Bestandesinventur an. Ein ähnliches Vorgehen ist auch dem Kommunalforstamt der Stadt Frankfurt zu empfehlen.

Einen besonders hervorzuhebenden Erfolg des Projektes stellt die Kopplung verschiedener Teilmodelle im WaldPlaner dar. Mit diesem flächendifferenziert, raumbezogen und auf verschiedenen Skalen arbeitenden Prognosewerkzeug war es möglich, die Auswirkungen der verschiedenen Grundwasserstands- und Klimaszenarien für das große Untersuchungsgebiet einzelbestandsweise und unter Beachtung bestimmter waldbaulicher und naturschutzfachlicher Regeln zu quantifizieren. Ein vergleichbares integrierendes Simulationssystem steht derzeit anderen Forschungseinrichtungen in Deutschland nicht zur Verfügung.

Bei der Festlegung der waldbaulichen Regeln für die Standorte mit einer Absenkung der Grundwasserstände auf eine für die Baumwurzeln nicht mehr erreichbare Tiefe wurde das Erfahrungswissen der forstlichen Praxis im Umgang mit verschärften Trockenstresssituationen berücksichtigt. Diese Anpassung der waldbaulichen Behandlung milderte von vornherein die Auswirkungen der sich mit den verschiedenen Szenarien ändernden Grundwasserstände und Klimabedingungen ab und muss bei der Interpretation der Ergebnisse berücksichtigt werden.

Mit den erstmalig im gesamten Hessischen Ried systematisch durchgeführten Engerlingsgrabungen in einem $500 \times 500 \mathrm{~m}$-Raster wurde eine verlässliche Basis zur Beurteilung der Befallsdichten im Jahre 2009 und zur Entwicklung eines vorläufigen Maikäfer-Mortalitätsmodells geschaffen. Folgeinventuren und eine systematische Erfassung der Maikäferschäden wären sehr wünschenswert, um den Kenntnisstand über die Populationsdynamik dieses wichtigen Schädlings im Hessischen Ried besser zu verstehen, die ökologischen und ökonomischen Folgen seines Fraßes zu erfassen und das Maikäfer-Mortalitätsmodell zu verbessern.

Die Bestandesdaten an den Rasterpunkten der Engerlingsgrabungen wurden auch genutzt, um einen repräsentativen Betrieb für das Hessische Ried zu generieren. Durch den Vergleich der simulierten und der tatsächlichen Entwicklung dieses Modell- bzw. Kalamitätsbetriebes zwischen 1967 und 2007 konnten die Auswirkungen der Grundwasserabsenkungen ab Mitte der sechziger Jahre des vergangenen Jahrhunderts gut nachvollziehbar aufgezeigt und monetär bewertet werden. 


\subsection{Wasserhaushalt im Klimawandel}

Der Wasserhaushalt der Waldbestände im Hessischen Ried wurde unter der Vorgabe verschiedener Grundwasser- und Klimaszenarien mit Hilfe des hydrologischen Modells WASIM-ETH geschätzt. Ziel der Wasserhaushaltsuntersuchungen war es, die Bedeutung des Grundwassers für die Wasserversorgung der Bestände zu bestimmen. Weiterhin wurde das Trockenstressrisiko der Bestände in Abhängigkeit von den Standortbedingungen und möglicher Klimaänderungen abgeschätzt.

Unter Annahme einer Klimaentwicklung gemäß der ECHAM5-Klimaszenarien A1B (WETTREG, jeweils trockene und feuchte Variante (SPEKAT et al. 2007)) treten bis zum Jahr 2039 bezüglich des Niederschlages mehr oder weniger große Unterschiede in den simulierten Wasserbilanzen auf. Durch die Verwendung der beiden Varianten und nicht der mittleren Entwicklung des Klimaszenarios A1B wurde für das Projekt ein ökologischer Rahmen aufgespannt und den Unsicherheiten der Klimaprojektionen in einem gewissen Maße Rechnung getragen. Eine Klimaänderung im Sinne des trockenen A1B-Szenarios würde zu einer deutlichen Verringerung des Niederschlagsangebots in der Vegetationsperiode bei gleichzeitig zunehmenden Verdunstungsanspruch der Waldbestände führen, mit der Folge, dass die Gefahr von Wassermangelsituationen zunimmt. Auf Standorten mit sicherem Grundwasseranschluss kann von einem verminderten Trockenstressrisiko ausgegangen werden. Hier ist die Verdunstungsleistung der Wälder signifikant höher als auf Standorten ohne sicheren Grundwasseranschluss. Bei Eintreten der feuchten Variante des A1B-Klimaszenarios würde sich dagegen nur wenig gegenüber den derzeitigen hydrologischen Verhältnissen verändern.

Für die Wälder im Hessischen Ried hat dies folgende Konsequenzen:

- In Jahren mit normaler bis feuchter Witterung ist eine ausreichende Wasserversorgung der Waldbestände auf den meisten Standorten durch den Niederschlag und den Bodenwasservorrat gewährleistet, es sei denn, die Verdunstungsverluste durch übermäßig dichte Begleitvegetation verhindern dies.

- In ausgeprägten Trockenjahren sind die Bestände im Hessischen Ried einem sehr hohen Trockenstress ausgesetzt. Vitalitätseinbußen und erhöhte Mortalitätsraten wären die Folge.

- Unter den Klimabedingungen der trockenen Variante des A1B-Klimaszenarios (WETTREG (SPEKAT et al. 2007)) ist bis 2040 mit einer deutlichen Zunahme des Trockenstressrisikos zu rechnen. Ebenso wird die Grundwasserneubildung unter den Waldflächen signifikant abnehmen.

- Auf Standorten mit sicherem Grundwasseranschluss ist in Trockenjahren die reale Verdunstung der Bestände deutlich erhöht gegenüber Beständen, die nicht über einen gesicherten Grundwasseranschluss verfügen. Das 
Trockenstressrisiko wird abgemildert, sodass mit geringeren Vitalitätseinbußen und Mortalitätsraten gerechnet werden kann.

- Auf Böden mit einer hohen Wasserspeicherkapazität ist das Trockenstressrisiko grundsätzlich geringer. Dies setzt allerdings voraus, dass zu Beginn der Vegetationsperiode der Bodenwasserspeicher gefüllt ist. Gerade in extremen Trockenjahren ist dies jedoch nicht immer der Fall, sodass auch Bestände auf frischen und betont frischen Standorten von Wasserstress betroffen sein können.

Für die Bewirtschaftung der vorhandenen Waldbestände bedeutet dies, dass es unter Berücksichtigung der zu erwartenden Klimaänderungen dringend zu empfehlen ist, die Waldbehandlung auf eine Vermeidung bzw. Abmilderung von Trockenstresssituationen auszurichten und auf möglichst vielen Waldflächen den sicheren Grundwasseranschluss wieder herzustellen, um die Wälder zu erhalten und zu stabilisieren.

\subsection{Stoffhaushalt}

Im Rahmen dieses Teilprojektes ist es durch die Kombination mehrerer Modelle zur Rekonstruktion und Prognose der atmosphärischen Stoffeinträge, der bodenchemischen Prozesse und der Stoffausträge mit dem Sickerwasser gelungen, die bodenchemischen Kennwerte und damit auch indirekt die Trophiestufen der Standortskartierung zu dynamisieren. Durch die langfristigen Simulationen wurde deutlich, wie variabel und komplex die Wechselbeziehungen zwischen den Böden und den Austrägen mit dem Sickerwasser in Waldökosystemen sein können. Die Ergebnisse wurden erfolgreich genutzt, um die Veränderungen der StandortLeistungsbeziehungen modellgestützt zu quantifizieren.

Die Auswertungen haben zudem gezeigt, dass insbesondere in der Trockenperiode von 1989 - 1993 durch die Kombination von hohen atmosphärischen Schwefelbelastungen sowie schlechten Nährstoffverhältnissen die Bäume auf Standorten mit erheblichen Bodenversauerungen und Nährstoffauswaschungen einem starken Stress ausgesetzt waren. Mittlerweile haben nach den Modellrechnungen die erhöhten Stickstoffeinträge mit ihren Auswirkungen einen stärkeren Einfluss auf die Vitalität der Bestockungen. Aus den Simulationen ist weiterhin zu schließen, dass Grundwasserabsenkungen zu einer Verringerung der Kohlenstoffund Stickstoffvorräte im Oberboden führen. Dies ist wiederum mit erhöhten NAusträgen in die Atmosphäre und die Hydrosphäre verbunden. Die Auswirkungen der Klimaänderungen auf die Stickstoffausträge und eine Veränderung der Mineralisierungsleistungen bis zum Ende des Simulationszeitraumes 2039 sind als sehr gering einzuschätzen. Dieses ist jedoch im Wesentlichen darauf zurückzuführen, dass nach den meisten Klimaszenarien die Änderungen der einzelnen Parameter bis zu diesem Zeitpunkt noch relativ moderat ausfallen. 


\subsection{Waldschutz}

Mit dem Maikäfer-Mortalitätsmodell war es möglich, die mittleren Engerlingsdichten in den Waldbeständen in Abhängigkeit von den Grundwasserständen, den Bodensubstraten und von räumlichen Effekten relativ zuverlässig zu schätzen. Zur Einschätzung der Vitalitätsminderung von Einzelbäumen in Abhängigkeit von der Engerlingsdichte wurde zudem eine Schädigungsmatrix abgeleitet, die einen ersten wichtigen Schritt zur besseren Quantifizierung der Maikäferschäden darstellt. Über Grenzwerte legt diese Matrix fest, ab welchem Schädigungsgrad Bäumen der Ausfall droht.

Für das Untersuchungsgebiet zeigen die Auswertungen folgende Zusammenhänge auf:

- Populationsdichte:

Das Vorkommen der Waldmaikäfer ist im Hessischen Ried regional sehr unterschiedlich. In Darmstadt ist die Ausgangsdichte der Waldmaikäfer am höchsten, gefolgt von Jägersburg und Lampertheim. Die geringsten Ausgangsdichten sind in den Gebieten Frankfurt u. Langen, Kühkopf und Gernsheim zu verzeichnen. Die räumliche Lage der Waldgebiete hat somit einen großen Einfluss auf die Populationsdichte, was sich auch in den erklärenden Größen des generalisierten additiven Regressionsmodells (GAM) zur Einschätzung der zu erwartenden Engerlingsdichten widerspiegelt.

Die Grundwasser-Szenarien beeinflussen ebenfalls wesentlich die Populationsdichten der Maikäfer-Engerlinge. Für das gesamte Hessische Ried ist im Mittel die Populationsdichte bei dem Szenario GW+ am niedrigsten und bei dem Szenario GW- am höchsten. Hohe Ausgangsdichten kommen am häufigsten in Beständen ohne sicheren Grundwasseranschluss vor.

Hinsichtlich des Bodensubstrates wirkt sich insbesondere der Tongehalt auf die Engerlingsdichte aus. Mit steigendem Tonanteil sinkt die Dichte der Engerlinge. Hohe Dichten treten nur auf sandigen und lehmigen Standorten auf.

Die Dichteunterschiede zwischen den Szenarien sind innerhalb der jeweiligen Gebiete relativ gering. Die größten Unterschiede weist das Gebiet Jägersburg auf. Auch hier kommen die geringsten Ausgangsdichten beim Szenario GW+ und die höchsten beim Szenario GW- vor.

Die modellierten Ausgangsdichten liegen bei allen Szenarien unter den Werten der Engerlingsgrabungen, weil sie Mittelwerte für Bestände darstellen. Die Höchstwerte der Modellschätzungen belaufen sich bei den verschiedenen Szenarien auf ca. 20 Engerlinge pro Quadratmeter. Demgegenüber wurden bei den Grabungen Maximalwerte bis über 100 Engerlinge pro Quadratmeter festgestellt. Es kann somit unterstellt werden, dass die Bestände stellenweise einem wesentlich stärkeren Engerlingsfraß ausgesetzt 
sind, als es die Modellwerte erwarten lassen. Dementsprechend ist dort auch mit höheren Ausfällen zu rechnen.

- Einfluss der Populationsdichte auf die Mortalität der Waldbäume:

Die modellierten Absterberaten durch Engerlingsfraß fallen im Gesamtgebiet relativ gering aus. Sie liegen im Simulationszeitraum von 2007 bis 2039 bei allen Szenarien und für alle Altersklassen im Mittel bei nur ca. einem Prozent der Bäume pro Bestand. Dies schließt aber nicht aus, dass die Ausfälle in einzelnen Beständen sehr hoch sind.

Die Mortalitätsraten hängen sehr stark von den Ausgangsdichten ab. Gebiete mit hoher Ausgangsdichte weisen eine höhere Mortalität auf. Dementsprechend ist die höchste Mortalität im Gebiet Darmstadt zu verzeichnen, gefolgt von Lampertheim und Jägersburg. Die geringste Mortalität tritt in den Gebieten Gernsheim, Kühkopf sowie Frankfurt u. Langen auf.

- Gefäbrdung junger Waldbäume:

Dichten von fünf und mehr E3/ $\mathrm{m}^{2}$ führen sicher zum Absterben von Kulturen und natürlichen Verjüngungen. ALTENKIRCH et al. (2002), SCHWENKE (1974) und PUSTER (1910) gehen bereits bei einer Dichte von 1 bis $5 \mathrm{E} 3 / \mathrm{m}^{2}$ von einer letalen Wirkung aus. Die Modellierung der Engerlingsdichten zeigt, dass beim Szenario GW+ nur ca. 18 Prozent der Waldfläche Ausgangsdichten von über fünf $\mathrm{E} 3 / \mathrm{m}^{2}$ aufweisen und damit bei diesem Szenario mit der geringsten Gefährdung zu rechnen ist. Demgegenüber wären beim Szenario GW- ca. 25 Prozent der Waldfläche betroffen. Im Vergleich der Gebiete sind die Wälder in Darmstadt am stärksten gefährdet. Auf über der Hälfte der Waldfläche ist dort bei jedem Szenario eine Etablierung junger Bäume nicht mehr möglich. Ebenfalls einen hohen Anteil Waldflächen mit Engerlingsdichten über fünf $\mathrm{E} 3 / \mathrm{m}^{2}$ weisen die Gebiete Lampertheim und Jägersburg auf.

Während beim Szenario GW+ die Klimavarianten kaum einen Einfluss auf den Ausfall junger Bäume haben, zeigt sich, dass beim Szenario GW- und der trockenen Klimaausprägung deutlich mehr Jungpflanzen durch Engerlingsfraß ausfallen als bei den moderateren Klimavarianten.

- Gefährdung alter Waldbäume:

Die Anzahl der infolge von Waldmaikäferfraß abgestorbenen Bäume mit einem BHD über $7 \mathrm{~cm}$ ist im Simulationszeitraum von 2007 bis 2039 beim Szenario GW- mehr als doppelt so hoch wie beim Szenario GW+.

Ungeachtet der bisherigen politischen Diskussionen scheint somit eine wirksame Reduzierung der Engerlingsdichten in den Gradationsgebieten ökologisch wie ökonomisch dringend geboten. 


\subsection{Waldbau}

Erschwernisse, die sich aus der standörtlichen Ausstattung, Struktur, Vorschädigung und Gefährdung der Bestände ergeben, stellen den Waldbau im Hessischen Ried schon heute vor große Herausforderungen. Hinzukommen die Auflagen aus dem Wasser- und Naturschutz sowie die Anforderungen aus der Erholungsfunktion in den jeweiligen Waldgebieten. In den Teilprojekten 4 und 5 wurde versucht, die Entwicklungen der vorhandenen Bestände und die Veränderungen der waldbaulichen Potenziale unter den vorgegebenen Grundwasserstands- und Klimaszenarien abzuschätzen. Dabei berücksichtigten die waldbaulichen Behandlungsregeln, ob sich der Grundwasseranschluss für die Bestände verändert oder nicht. Diese mit der Praxis abgestimmte Anpassung führte aber gleichzeitig zu einer Nivellierung der Unterschiede zwischen den Szenarien.

Bereits in den nächsten dreißig Jahren wird das Klima in der Vegetationszeit deutlich trockener und wärmer. Die klimatischen Wasserbilanzen rutschen tiefer ins Minus, weil sich die Niederschläge verringern und die Verdunstung steigt. Die Grundwasserszenarien führen zu einer Halbierung (GW-) bzw. Verdoppelung $(\mathrm{GW}+)$ der Flächenanteile mit sicherem Grundwasseranschluss. Um den mit dem Klimawandel ohnehin zunehmenden Trockenstress für die Bestände nicht weiter zu erhöhen, sollte zumindest versucht werden, die Grundwasserstände auf dem Niveau des Grundwasserbewirtschaftungsplans Hessisches Ried (RP DARMSTADT, 1999) zu halten (GW0). Etwa 18 Prozent der Standorte hätten unter diesen Voraussetzungen weiterhin sicheren Grundwasseranschluss (mittlerer Grundwasserstand $\leq 250 \mathrm{~cm}$ unter Flur). Der Großteil der grundwasserfernen Standorte - dies werden mehr als 60 Prozent der Standorte sein - wird aufgrund der Klimaänderungen sehr sensitiv reagieren und gemessen am pflanzenverfügbaren Wasser nur noch in die schlechteren Frischestufen mäßig (F3), gering (F4) oder vielfach sogar sehr gering (F5) einzustufen sein. Dies betrifft besonders die Sandstandorte, aber auch Substrate mit geringen Lehm- bzw. Schluffanteilen.

Die Veränderungen der Frischestufen haben einen wesentlichen Einfluss auf die potenziellen Anbaumöglichkeiten der Baumarten. Eine den erwarteten Standortsveränderungen angepasste Planung der Waldentwicklungsziele hätte eine deutliche Verschiebung des Baumartenspektrums hin zu stärker an Trockenheit angepasste Baumarten wie vor allem Kiefer, aber auch Douglasie und Roteiche zur Folge. Unter Berücksichtigung der waldbaulichen Ausgangssituation fallen die Veränderungen bis zum Ende der dreißigjährigen Fortschreibung aber weitaus geringer aus. Dies ist darauf zurückzuführen, dass sich in vielen Beständen Buchennaturverjüngung etabliert hat bzw. Buchenunterstand und Buchenzwischenstand (einschließlich Hainbuche) vorhanden sind, die gemäß der derzeit gängigen waldbaulichen Praxis zunächst übernommen wurden. Dabei ist die wahrscheinlich realitätsnähere trockene Variante der Klimaprojektion mit erheblichen Risiken für den Buchenanbau verbunden. Betrachtet man die Bestände am Ende des Simulationszeitraumes im Jahre 2039, so werden bei weiterer Absenkung der 
Grundwasserstände und sich verstärkendem Klimawandel (Vegetationszeit trockener und wärmer) der Umfang der zu verjüngenden Waldfläche zunehmen, die Mortalitätsraten substratabhängig steigen, die Durchschnittsalter und die mittleren Vorräte sinken und die Bonitäten nachlassen.

Die verschiedenen simulierten Entwicklungsszenarien zeigen unterschiedlichen Handlungsbedarf auf. Während auf Standorten mit weiterhin sicherem Grundwasseranschluss oder hoher Bodenwasserspeicherkapazität die Veränderungen geringer ausfallen werden, besteht vor allem auf den künftig schlechter wasserversorgten Standorten Anpassungsbedarf. Dies macht ein differenziertes waldbauliches Vorgehen notwendig, bei dem die heutige und künftige Standortseignung der Bestockungen ebenso zu berücksichtigen ist wie der Grad ihrer Vorschädigung. Das Hauptaugenmerk der waldbaulichen Maßnahmen muss auf die Stabilisierung der vorhandenen Bestände, die Senkung bzw. Verteilung der Risiken und den Umbau der heute bzw. künftig nicht mehr standortsgemäßen Bestockungen gerichtet werden. Hierzu wird es notwendig sein, für jeden Bestand die Veränderungen seiner Standortsverhältnisse und seine waldbaulichen Entwicklungsmöglichkeiten perspektivisch einzuschätzen, um die Handlungsoptionen zielgerecht zu nutzen.

\subsubsection{Baumartenwahl und Waldentwicklungstypen (WET)-Planung auf standörtlicher Grundlage}

Die Dynamik der Standorte im Hessischen Ried wird in den nächsten Jahrzehnten vor allem durch die Veränderungen der Menge an pflanzenverfügbaren Wasser geprägt sein und einen wesentlichen Einfluss auf die Baumartenwahl und die Steuerung der Waldentwicklung haben. Der forstlichen Praxis stehen mit Abschluss dieser Untersuchung bessere Informationen zur heutigen bzw. künftigen Nährstoff- und Wasserversorgung der Standorte zur Verfügung, die es den Forstbetrieben mit Hilfe der im Projekt entwickelten WET-Matrizen ermöglichen, bestandesbezogen die heutige und künftige Standortseignung der vorhandenen Bestockungen einzuschätzen bzw. bei Verjüngungsmaßnahmen die Baumarten standortsgemäß auszuwählen.

Im vermehrt auftretenden Bereich der schlechteren Frischestufen F3 bis F5 führen die WET-Vorschläge (s. Tab. 67) zu folgenden Schwerpunktsetzungen bei der Baumartenwahl:

- Die heimischen Eichenarten kommen als führende Baumart fast ausschließlich nur noch in der Frischestufe F3 (mäßig frisch) bei gleichzeitig eutropher bzw. mindestens gut mesotropher Nährstoffversorgung in Betracht. Die Stieleiche hat sich bei Neukulturen unter den Bedingungen im Ried gegenüber der Traubeneiche häufig als robuster erwiesen.

- Bei mesotropher und schwach mesotropher Nährstoffversorgung erhalten die Douglasie und die Küstentanne in den Frischestufen mäßig frisch (F3) 
und gering wasserversorgt (F4) als führende Nadelbaumart gegenüber der Kiefer den Vorzug. Der Anbau der Roteiche erscheint hier ebenfalls Erfolg versprechend.

- Die Buche verliert unabhängig von der Nährstoffversorgung über alle drei Frischestufen hinweg grundsätzlich ihre Position als führende Baumart. Auf Standorten der Frischestufe F5 wird sie auch als Mischbaumart nicht mehr berücksichtigt. Bei den Frischestufen F3 und F4 nehmen die Mischungsanteile der Buche bei sich verschlechternder Nährstoffversorgung entsprechend der WET-Planung deutlich ab.

Tabelle 67: WET-Planung für den schlechter wasserversorgten Standortsbereich in Abhängigkeit von Trophie und Frischestufe (fett: vorrangige Waldentwicklungstypen)

\begin{tabular}{|c|c|c|c|}
\hline \multirow[b]{2}{*}{ Trophie } & \multicolumn{3}{|c|}{ Frischestufe (pflanzenverfügbares Wasser) } \\
\hline & mäßig (F3) & gering $(\mathrm{F} 4)$ & sehr gering (F5) \\
\hline \multirow{4}{*}{ eutroph } & Ei Hbu & Ei Hbu & $\mathbf{K i ~ L i ~}$ \\
\hline & Es Li HBu & Li Ah Kir Bu & Ki Ei \\
\hline & & Es Li Hbu & \\
\hline & $\begin{array}{l}\mathrm{Li} A \text { h Kir Bu } \\
\mathrm{Bu}\end{array}$ & $\mathrm{Ki} \mathrm{Li}$ & \\
\hline \multirow{7}{*}{ mesotroph } & Dgl Bu & Dgl Ki Bu & $\mathbf{K i}$ \\
\hline & REi HBu/Bu & REi HBu/Bu & $\mathbf{K i ~ B i}$ \\
\hline & Ei Hbu & Ki Bi Ei & \\
\hline & Ki Bu & Ki Dgl & \\
\hline & KTaBu & $\mathrm{KT} \mathrm{Ta} \mathrm{Bu}$ & $\mathrm{KTa} \mathrm{Bi}$ \\
\hline & $\mathrm{Bu} \mathrm{Dgl}$ & $\mathrm{Ki}$ & \\
\hline & $\mathrm{Bu}$ & $\mathrm{Ki} \mathrm{Bu}$ & \\
\hline \multirow{7}{*}{ oligotroph } & Dgl Ki Bi & Ki Bi Ei & $\mathbf{K i}$ \\
\hline & Ki Dgl Bi & Ki Dgl Bi & $\mathbf{K i ~ B i}$ \\
\hline & Ki Bi Ei & $\mathbf{K i}$ & \\
\hline & $\mathbf{K i}$ & KTa Bi & \\
\hline & KTa Bi & & \\
\hline & $\mathrm{Bi} \mathrm{Ki}$ & $\mathrm{Bi} \mathrm{Ki}$ & \\
\hline & $\mathrm{Ki} \mathrm{Ei}$ & & \\
\hline
\end{tabular}

- Die Hainbuche wird auf eutrophen und mesotrophen Standorten gegenüber der Buche als Mischbaumart in Eichen- und Roteichenbeständen favorisiert. In WET's mit führendem Nadelholz kann sie im mesotrophen Bereich ggf. 
alternativ zur Buche verwendet werden (entscheidend sind die örtlichen Erfahrungen).

- Auf den Standorten mit sehr geringem Anteil an pflanzenverfügbarem Wasser (F5) dominiert unabhängig von der Nährstoffversorgung die Kiefer.

- Auf oligotrophen Standorten spielen die Douglasie und die Küstentanne als führende Baumart oder Mischbaumart nur auf den Standorten der Frischestufen F3 und F4 eine größere Rolle. Die Birke ersetzt hier die Buche als Laubholzbeimischung.

- Zielgerechte Anteile an Begleitbaumarten (siehe Baumartenzusammensetzung der WET im Methodenteil) sind unter Berücksichtigung der standortabhängigen Konkurrenzverhältnisse grundsätzlich zu integrieren.

\subsubsection{Waldbauliche Maßnabmen}

Als Ergänzung zur bisherigen waldbaulichen Planung sollten künftig, trotz periodisch wieder notwendig werdender Anpassungen, die standortsabhängig anzustrebenden Waldentwicklungsziele (WET) bereits ab dem Kultur und Jungwuchsstadium festgelegt werden. So könnten von den Nachbesserungen in den Kulturen oder den Voranbauten in sich auflösenden Beständen über die Mischungsregulierung im Differenzierungsstadium, die Pflege im Auslese- und Ausreifestadium bis zu den Nutzungen im Reife- und Regenerationsstadium die Weichen so gestellt werden, dass die auch künftig standortsgemäßen Baumarten eingebracht, erhalten und gefördert bzw. deren Verjüngung über die Hiebsführung begünstigt werden. Die Handlungsoptionen der Forstpraxis werden dabei oftmals durch die Vorschädigung der Bestände, durch etablierte Verjüngungen oder durch die Konkurrenzkraft der Begleitvegetation eingeschränkt sein.

\subsubsection{Kultur-/Jungwuchsstadium}

Der Erfolg von Verjüngungsmaßnahmen hängt in weiten Bereichen des Hessischen Rieds entscheidend von der lokalen Maikäfersituation ab. Engerlingsdichten von 3-5 Individuen je $\mathrm{m}^{2}$ schränken den Kulturerfolg unabhängig von der Ausgangsbestockung und der Bodenvegetation von vornherein stark ein bzw. engen die Baumartenwahl auf die relativ unempfindliche Kiefer ein. In Maikäferschwerpunktgebieten sind flächige investive Waldverjüngungsmaßnahmen unabhängig von der Baumart mit dem Entwicklungszyklus des Maikäfers zu synchronisieren, d. h. die Hauptaktivitäten liegen im Flugjahr des Maikäfers.

Allgemein sind im Kultur-/Jungwuchsstadium folgende Grundsätze zu beachten:

- Technische Maßnahmen zur Bodenvorbereitung sind oftmals wegen der dichten Begleitvegetationsdecken unumgänglich.

- Standortsgemäße Naturverjüngungen haben Vorrang vor künstlichen Bestandesbegründungen. Die hohe Individuenzahl bietet ein höheres Anpassungspotenzial an sich verändernde Umweltbedingungen. Auf Fehl- 
stellen oder in lückigen Bereichen sind standortsgemäße Mischbaumarten (s. o.) einzubringen, um die Risken weiter zu verteilen.

- Bei sehr stammzahlreichen Kiefernnaturverjüngungen auf trockenen, nährstoffarmen Standorten kann bei verharrender Konkurrenz eine Stammzahlreduzierung auf rd. 10.000-15.000 je Hektar notwendig sein. Dabei sind standortsgemäße Mischbaumarten angemessen zu fördern.

- Bei flächigen Buchennaturverjüngungen, die künftig nicht mehr standortsgemäß sind, sollte die Buche zumindest auf Teilflächen zurückgedrängt werden (,auf den Stock setzen“), sofern keine Gefährdung durch die spätblühende Traubenkirsche zu erwarten ist. Hierzu bieten sich die qualitativ unbefriedigenden Bereiche an, die anschließend mit standortsgemäßen Baumarten zu bepflanzen sind.

- Bei der Kulturbegründung sind i. d. R. Reihenverbände mit Reihenabständen von ca. 2,5 m vorzuziehen. Ohne die Qualitätsentwicklung der Kulturen zu beeinträchtigen, bieten sie die Möglichkeit, starke Begleitvegetation zwischen den Pflanzreihen zu mulchen bzw. zu fräsen. Hierdurch gelangt der Niederschlag besser in den Boden, der Trockenstress für die Kulturpflanzen wird entspannt und die Lebensbedingungen für den Maikäfer verschlechtern sich.

- Kulturausfälle der Hauptbaumarten von über 30 Prozent machen in der Regel Nachbesserungen erforderlich. Größere Fehlstellen sollten zur Einbringung standortsgemäßer Mischbaumarten genutzt werden, während sich geringere Ausfälle häufig durch die Integration von Füll- und Treibhölzern kompensieren lassen. Hierbei ist zu beachten, dass die Konkurrenzkraft der Weichlaubbäume von der Salweide über die Birke bzw. Aspe bis zur Eberesche bzw. Roterle abnimmt, während die Toleranz der Hauptbaumarten gegenüber der Konkurrenz durch Weichlaubbäume von der Eiche bzw. Kiefer, über die Douglasie bzw. Küstentanne bis zur Buche steigt. Grundsätzlich ist von der Notwendigkeit einer intensiveren Jungbestandspflege auszugehen.

- Zunehmend haben sich im „Hessischen Ried“ auch Eichen (Roteichen)Saaten als eine erfolgreiche und kostengünstige Alternative zur Pflanzung erwiesen. Bei sachgerechter Durchführung liegt der Vorteil nicht nur in einer höheren Pflanzenzahl (Reserve), sondern vor allem auch in der Vermeidung pflanzungsbedingter Wurzeldeformationen. Bei Ausbildung eines natürlichen Wurzelsystems können die Pflanzen schneller tiefere Bodenschichten erschließen und dadurch ein höheres Maß an pflanzenverfügbarem Wasser ausnutzen (RUMPF 2007).

\subsubsection{Differenzierungsstadium}

In diesem Stadium erfolgen in der Regel keine Maßnahmen. Auf sie wird nicht zuletzt wegen der oft unsicheren Maikäferprognosen verzichtet. Gegebenenfalls kommt ein Protzenaushieb in Buchen-, Kiefern oder Eichen-Jungbeständen oder 
eine Mischungsregulierung (z. B. Weichlaubholz in Eichen-Jungbeständen) in Betracht.

\subsubsection{Auslese- und Ausreifungsstadium}

Aufgrund des insgesamt steigenden Gefährdungspotenzials und zur Verteilung der Risiken sollten die bisher angestrebten Z-Baumzahlen bei allen Baumarten um etwa 1/3 erhöht werden. Bei ihrer Auswahl ist zumindest bei durchschnittlicher Qualität die Vitalität des Einzelbaumes das wichtigste Auslesekriterium. Insbesondere in Beständen, deren Hauptbaumart künftig nicht mehr standortsgemäß ist, sind bleibend standortsgemäße Mischbaumarten bevorzugt als Z-Bäume auszuwählen und zu fördern bzw. eine angemessene Anzahl Bäume dieser Mischbaumarten auch bei nicht überzeugender Vitalität und Qualität als künftige Samenbäume zu erhalten.

Folgende allgemeine Empfehlungen können gegeben werden:

- Unter Beachtung der baumartenspezifischen Wachstumsgänge sollte grundsätzlich ein gestaffeltes Durchforstungskonzept mit 2 bis 3 stärkeren Eingriffen zu Beginn der Auslesephase (Entnahme von ein bis zwei Bedrängern) und einem anschließendem Übergang zu mäßig starken Durchforstungen umgesetzt werden, um anfangs die am besten veranlagten Bäume zu fördern und anschließend schonend mit der Baumzahlhaltung umzugehen. Gleichzeitig ermöglicht ein solches Vorgehen die Produktions- und Gefährdungszeiträume zu verkürzen. In stark geschädigten Beständen reduzieren sich die Eingriffe zwangsläufig auf Kalamitätsnutzungen.

- Als Durchforstungsart empfiehlt sich i. d. R. die Hochdurchforstung, die im Herrschenden eingreift und den Unter- und Zwischenstand erhält. Sie sollte grundsätzlich auf der gesamten Bestandesfläche durchgeführt werden, um die Vitalität und Stabilität der Bestände zu erhöhen. Dort, wo der Wasserhaushalt sehr angespannt ist, ist eine starke Niederdurchforstung $\mathrm{zu}$ empfehlen, bei der der Unter- und Zwischenstand entnommen wird, um den Trockenstress für die verbleibenden Bäume zu entlasten.

- In Kiefern-Jungbeständen werden bevorzugt vorwüchsige Bäume von der Kiefernmistel befallen. Sie sind bei den Durchforstungen möglichst frühzeitig zu entnehmen, um einer weiteren Ausbreitung entgegenzuwirken. Im anschließenden Ausreifestadium sind ebenfalls die befallenen Bäume vorrangig herauszuziehen bzw. es sollte in vollflächig von der Mistel „durchseuchten“ Beständen die Zielstärke abgesenkt und die Abnutzung vorzeitig erfolgen.

- Langfristige Unterbrechungen des Kronenschlusses sollten unbedingt vermieden werden, um die Verdunstung nicht noch zusätzlich anzustoßen und die den Wasserhaushalt belastende Vergrasung zu fördern (HEUER et al. 2005). 
- Nachträgliche Verdichtungen der Bestandeserschließung wirken im Ausreifestadium destabilisierend (erhöhte Verdunstung, Sonnenbrand, Prachtkäfer, Mistel, Förderung der Bodenvegetation) und sollten daher unterlassen werden.

\subsubsection{Reife- und Regenerationsstadium}

Zahlreiche Altbestände sind durch biotische und/oder abiotische Ursachen vorgeschädigt und erfordern ein schnelles betriebliches Handeln. Die waldbaulichen Spielräume werden durch Kronenschäden und Holzentwertungsgefahren, Bodenverwilderung und Vergrasung, Vorverjüngungen künftig nicht mehr standortsgemäßer Baumarten und drohende Maikäferschäden stark eingeschränkt. Unter diesen Rahmenbedingungen müssen die baumartenspezifischen Zielstärken unbedingt als variable Größen in Abhängigkeit von Vitalität, Qualität und Entwertungsgefahr gesehen werden. Dort wo Vorschädigungen und erhöhte Absterberaten vorliegen, sind die Mindestzielstärken gegenüber normalen Verhältnissen deutlich abzusenken, was jedoch nicht heißt, dass die in den jeweiligen Beständen noch vorhandenen vitalen und qualitativ guten Bäume nicht stärker werden dürfen.

Des Weiteren sollten bei stärkeren Bestockungsmängeln Störungslöcher außerhalb von Maikäferbefallszentren und gering überschirmte Teilflächen zügig zum Voranbau mit trockenstresstoleranten Baumarten genutzt werden. Die Mindestgröße der Bestandeslöcher beläuft sich für Schatt-/Halbschattbaumarten auf 0,2 Hektar, für Lichtbaumarten auf 0,3-0,5 Hektar. Die entsprechenden Grenzbestockungsgrade liegen bei $\mathrm{B}^{\circ} 0,4$ bzw. $\mathrm{B}^{\circ} 0,6$. Teilweise sind auch saumweise und teilflächige Endnutzungen notwendig, um so die Voraussetzungen für Erfolg versprechende Planzungen oder Saaten zu schaffen, für die eine Flächenräumung und Bodenbearbeitung notwendig ist (vgl. Huss u. KÜTHE 1974).

\subsection{Naturschutz}

\subsubsection{Schutzgebietsüberlagerungen und Nutzungseinschränkungen}

Im Hessischen Ried besteht eine komplexe Schutzgebietsüberlagerung mit bis zu vierfacher Abdeckung einzelner Flächen durch verschiedene Schutzgebietskategorien. Der Anteil des Waldes innerhalb der Netto-Schutzgebietskulisse (VSG, FFH und NSG) beträgt 48 Prozent. 13 Prozent der Waldfläche sind mit konkreten Auflagen für die Forstwirtschaft aus Naturschutzrecht belegt, darunter sechs Prozent, auf der die forstliche Nutzung eingestellt ist. Zusätzliche Einschränkungen wie Artenschutz, Eigenbindung oder betriebsinterne Regelungen erhöhen die Vielfalt der Auflagen und die Schwierigkeiten ihrer Einhaltung im laufenden Forstbetrieb.

Die rechtsverbindlichen Naturschutzauflagen im Hessischen Ried konzentrieren sich stark auf das Forstamt Groß-Gerau. In dessen Zuständigkeitsbereich 
liegen mit der „Kühkopf-Knoblochsaue“ und dem „Mönchbruch“ das größte und drittgrößte Naturschutzgebiet Hessens. Zusätzlich werden auf erheblichen Flächen dieses Forstamtes und des Kommunalforstamtes Frankfurt Kompensationsmaßnahmen für den Ausbau des Frankfurter Flughafens durchgeführt. Diese Situation ist für Hessen in diesem Umfang bisher einmalig.

Auffällig ist außerdem, dass nur 29 Prozent der im Rahmen der Hessischen Biotopkartierung flächenscharf kartierten Biotope innerhalb von Naturschutzgebieten liegen.

\subsubsection{Habitateignung}

Die mit der Software „Biomapper“ ermittelten Hotspots weisen zum Stichjahr 2007 einen hohen Anteil alter Eichenbestände auf. Der Anteil alter Eichenwälder ist eine Variable mit stark positivem Einfluss auf die Habitateignung. Es zeichnet sich ab, dass auf den identifizierten Hotspots in den niedrigeren Altersklassen ein deutliches Defizit an Eichennachwuchs besteht. Hieraus leitet sich die Notwendigkeit $\mathrm{ab}$, in dem direkten Umfeld der heutigen Hotspots nach Zukunftsflächen mit entsprechenden Anteilen an Eichen in den notwendigen Altersklassen sowie geeigneten Verjüngungsflächen zu suchen. Nur auf diese Weise kann ein dauerhafter Erhalt von Hotspots in der erforderlichen Qualität gewährleistet werden. Des Weiteren zeigt die Habitatmodellierung auch die wichtige Rolle der Laub- und Mischwaldkontinuität für den Erhalt geeigneter Lebensräume. Diese Methode kann wesentlich dazu beitragen, naturschutzfachliche Planungen zu unterstützen und die Wirksamkeit des Waldnaturschutzes bei begrenztem Flächenangebot zu erhöhen.

Bezüglich der Standortsbedingungen zeichnet sich ab, dass bei Eintritt des trockenen Klimaszenarios A1Bt die Flächen der Hotspots nur unter den Bedingungen des Grundwasserszenarios GW+ erhalten werden können. Bei einer Beibehaltung der derzeitigen Grundwasserstände (GW0) oder einer weiteren Grundwasserabsenkung (GW-) würde eine starke Veränderung hin zu trockeneren Standorten eintreten und negative Auswirkungen auf die Hotspots haben.

Auch bei den mit Hilfe eines verallgemeinerten additiven Modells (GAM) für das Jahr 2039 identifizierten Hotspotflächen zeigen sich deutliche Unterschiede zwischen den Grundwasserszenarien. Vor allem bei der Kombination des trockenen Klimaszenarios mit dem Grundwasserszenario GW- geht die Habitateignung vieler Flächen durch den dann erforderlichen Baumartenwechsel verloren.

\subsubsection{FFH-Gebiete und Lebensraumtypen}

Mit 23 Prozent der Waldfläche haben die FFH-Gebiete einen maßgeblichen Anteil an der Schutzgebietskulisse und deren Komplexität. 
Eine weitere Grundwasserabsenkung auf den Flächen der FFH-Gebiete bis zum Jahr 2039 würde zu einem deutlichen Verlust von feuchten und nassen Standorten führen. Diese Standorte gehören jedoch zu den naturschutzfachlich besonders wertvollen Bereichen. Im Falle des trockenen Klimaszenarios wäre dieser Verlust besonders groß, während die Grundwasseranhebung den negativen Einfluss der Klimaveränderungen deutlich abmildert.

Der Ausgangszustand und die Entwicklung der betrachteten Eichen-Lebensraumtypen „Stieleichen-Hainbuchenwälder“, „Alte bodensaure Eichenwälder" und „Eiche-/Ulmen-Eschen-Mischwälder am Ufer großer Flüsse“ (9160, 9190 und 91F0, Hartholzaue) sind bezüglich einzelner, aber ausschlaggebender Kriterien als kritisch zu bewerten.

- Der „Stieleichen-Hainbuchenwald“ ist laut „Interpretation Manual of European Union Habitats" und dem BfN-Handbuch zur Umsetzung der FFHRichtlinie über das Vorkommen auf zeitweilig oder dauerhaft feuchten Böden mit hohem Grundwasserstand definiert (SSYMANK et al. 1998). Die Ergebnisse der vorliegenden Studie zeigen, dass bereits der derzeitige Grundwasserstand im Hessischen Ried auf weniger als 20 Prozent der ausgewiesenen Flächen des LRT 9160 dieser Definition entspricht, es sich also bei 80 Prozent der Flächen de facto nicht um Lebensraumtypen in diesem strengen Sinne handelt. Das Grundwasserszenario GW+, welches auf den Grundwasserständen vor Beginn der erhöhten Grundwasserentnahme im Hessischen Ried basiert, führt zu einer leichten Verbesserung der Situation.

- Bei der Betrachtung der Anteile der lebensraumtypischen Baumarten auf den Flächen des LRT 9190 „Alte bodensaure Eichenwälder“ fällt der sehr hohe Anteil der nach dem Anspracheschlüssel der BWI3 nicht lebensraumtypischen Baumarten, vor allem von Buche und Hainbuche, auf. Sie sind nicht nur in der herrschenden Schicht, sondern ebenfalls mit hohen Anteilen im Nachwuchs und in der Verjüngung vertreten, was ihre starke Zunahme zum Ende der Simulationsrechnungen erklärt. Angesichts der deutlichen Präsenz der Buche stellt sich die Frage, ob sie nicht als lebensraumtypische Baumart berücksichtigt werden sollte.

- Auch auf den Flächen des Lebensraumtyps „Eichen-/Ulmen-EschenMischwälder am Ufer großer Flüsse" zeichnet sich ab, dass die Eiche sich dauerhaft nicht gegen die Konkurrenz anderer Baumarten behaupten kann. Eine gezielte Förderung der Eiche ist auf Flächen dieses Lebensraumtyps jedoch meist nicht möglich, da sie innerhalb von nutzungsfreien Wäldern (Naturschutzgebiete) liegen.

- In allen Lebensraumtypen mit der Hauptbaumart Eiche deutet sich weiterhin ein Mangel an Eichen in den jüngeren und mittleren Altersklassen an. Dieser kann in der Zukunft zu einem generellen Rückgang der Eiche auf den Flächen führen. 
- Die im Rahmen der Lebensraumtypanalyse getroffenen Aussagen zur Baumart Eiche können bedingt auch auf die Flächen der Vogelschutzgebiete übertragen werden, da in diesen häufig die Eiche eine wichtige Rolle spielt.

Zusammenfassend ist festzustellen, dass ein Erhalt der Eichengesellschaften nur durch aufwändige Verjüngungs- und Pflegemaßnahmen möglich sein wird (vgl. SIPKOVA et al. 2010). Dies erscheint angesichts der hohen naturschutzfachlichen Bedeutung der Eiche gerechtfertigt. Im Rahmen des Vorhabens konnten die Vorrangflächen für den Erhalt von Eichenwäldern im Sinne von Hotspots identifiziert werden.

\section{7 Ökonomie}

\subsubsection{Ertragswerte}

Der betriebswirtschaftliche Vergleich des Kalamitätsbetriebes und des Modellbetriebes von 1967 bis 2007 und die ökonomische Analysen für die auf die Zukunft gerichteten Waldentwicklungsszenarien von 2007 bis 2039 schließen zeitlich aneinander an. Die Methodik beider Teiluntersuchungen ist zwar nicht identisch, dennoch lassen sich die Ertragswerte miteinander vergleichen. Die realen Wälder im Projektgebiet („Kalamitätsbetrieb“) erbrachten in den vergangenen 40 Jahren einen Ertragswert, der bei identischer naturaler Ausgangssituation um ca. 70 Millionen Euro unter dem Ertragswert des „Modellbetriebes“ liegt. Die entgangenen Erträge der vergangenen 40 Jahre lassen sich den beiden Grundwasserszenarien GW0 und GW+ der 32-jährigen Waldentwicklungssimulationen gegenüberstellen. Hier betrug die maximale Differenz zwischen beiden Grundwasserszenarien nur ca. 5 Millionen Euro (trockenes Klimaszenario) bzw. vereinfacht auf einen 40-jährigen Zeitraum hochgerechnet 6,5 Millionen Euro. Selbst die Differenz zwischen den Grundwasserszenarien GW+ und GW- war mit 13 Millionen Euro (bezogen auf 40 Jahre) deutlich geringer als die Ertragswertdifferenz der Vergangenheit. Darin zeigt sich, dass bereits zu Beginn der Simulationen im Stichjahr 2007 durch Vorschädigungen ein Zustand erreicht war, der die Möglichkeiten der Einflussnahme auf die Ertragskraft der Wälder im Hessischen Ried stark einschränkte. Die Beeinträchtigungen der Wälder der vergangenen Jahrzehnte haben zu mittelfristig irreversiblen Schäden geführt. Selbst bei Anhebung des Grundwassers in Anlehnung an die Grundwasserstände von 1951 konnte die Ertragskraft im ca. 30-jährigen Simulationszeitraum nachhaltig längst nicht wieder hergestellt werden.

Bei der Betrachtung der erntekostenfreien Erlöse aus den Holzverkäufen, der Entwicklung der Bestandeswerte und der Kulturkosten wurden stets alle Annahmen sehr vorsichtig getroffen. Beispielsweise wurden für den Modellbetrieb die gleichen Kulturkosten pro Hektar unterstellt wie für den Kalamitätsbetrieb. Demgegenüber wies das Gutachten von FrIEDEL (2010) für die Hauptschad- 
gebiete des Hessischen Rieds erhöhte Kulturkosten von über 20 Euro pro Hektar und Jahr aus (FRIEDEL 2010). Außerdem gab er um ca. 40 Euro pro Hektar und Jahr erhöhte Verwaltungskosten für die Schadgebiete an. In der vorliegenden Untersuchung wurden diese Kosten bei der Berechnung von Aufwendungen und Erträgen nicht berücksichtigt. Die Ergebnisse beziehen sich ausschließlich auf die Bewirtschaftung und Entwicklung der Einzelbestände.

\subsubsection{Baumartenvergleich}

Der Vergleich der Baumarten im Kalamitäts- und Modellbetrieb zeigt bei der Kiefer höhere durchschnittliche Kalamitätsanteile an der Gesamtnutzung als bei der Eiche, die bei dieser wiederum höher liegen als bei der Buche. Die hohen Kalamitätsanteile bei der Kiefer verwundern auf den ersten Blick, da doch gerade die Kiefer allgemein als trockenstresstolerant angesehen wird. In die Kalamitätsanteile sind aber auch die Sturmschäden von 1984 und 1990 eingerechnet, von denen die Kiefer weitaus am stärksten betroffen war. Unter denjenigen Beständen, die den sicheren Grundwasseranschluss in der betrachteten Periode verloren hatten, wo sich also der Trockenstress erhöhte, weisen die Buchenbestände tatsächlich deutlich höhere Kalamitätsanteile an der Gesamtnutzung auf als die Kiefernbestände.

Die Ertragswerte der Baumarten unterscheiden sich naturgemäß. Da bei ihnen jeweils unterschiedliche Standorte und Altersverteilungen zugrunde liegen, ließen sich die durchschnittlichen absoluten Ertragswerte nicht unmittelbar vergleichen. Als Vergleichsmaßstab wurde die Relation zwischen dem Ertragswert im Kalamitätsbetrieb zum Ertragswert im Modellbetrieb verwendet. Die Kiefer erreicht hierbei die höchsten relativen Werte. Einzig auf Standorten, die bereits vor 1967 keinen sicheren Grundwasseranschluss aufwiesen, erreicht die Eiche eine höhere Ertragswertrelation als die Kiefer. Hierdurch wird bestätigt, was bereits die Kalamitätsanteile aufzeigen. Die Ertragswerte der Eichenbestände bleiben auf den konstant grundwasserfernen Standorten stabil. Bei Veränderungen der Grundwasserstände zeigen sie jedoch deutliche Reaktionen. Die Ertragswerte der Buche reagieren insgesamt am stärksten auf Grundwasserabsenkungen und sinken bei Verlust des Grundwasseranschlusses auf 50 Prozent der Modellbetriebswerte ab.

Für eine detaillierte Betrachtung sind die für eine größere Fläche geltenden Ertragswerte der Szenariensimulationen aussagefähiger. Als Vergleichswerte dienten die Verhältnisse bei der Kombination aus dem Grundwasserszenario GW0 und dem Klimaszenario „Referenz“. Zur Stratifizierung wurden die Bodenarten und die Veränderungen im Grundwasseranschluss gleichzeitig herangezogen. Erwartungsgemäß erwiesen sich die Sandstandorte als grundsätzlich problematischer im Vergleich zu den tonigen und (an)lehmigen Standorten. Die Ertragswerte der Buchenbestände sind unter Annahmen des Klimaszenarios A1B feucht und des Grundwasserszenarios GW0 relativ stabil. Sie nehmen jedoch bei dem Klima- 
szenarios A1B trocken vor allem auf den Sanden (bis 50 Prozent des Ertragswertes) deutlich ab. Die Einbußen erhöhen sich weiter bei fortschreitendem Grundwasserverlust (GW-) und können bis zu 70 Prozent der Vergleichswerte erreichen. Die Ertragswerte der Eichenbestände reagieren insgesamt weniger auf die unterschiedlichen Szenariokombinationen. Sie sinken auch bei trockenerer Klimaentwicklung kaum ab. Allerdings reagieren die Eichenbestände am empfindlichsten auf Grundwasserabsenkungen. Ein weiteres Absinken der Grundwasserstände würde bei denjenigen Eichenbeständen, die 2007 noch sicheren Grundwasseranschluss hatten, erhebliche Ertragsverluste verursachen. Ein Anbau auf Standorten ohne oder mit konstantem Grundwasseranschluss lässt hingegen annähernd gleiche Ertragswerte erwarten wie in der Referenzkombination. Die Kiefernbestände weisen die stabilsten Ertragswerte unter den neun Szenariokombinationen auf. Zwar führen Grundwasserabsenkungen auf Sandstandorten mit ursprünglich sicherem Grundwasseranschluss beim trockenen Klimaszenario zu erheblichen Einbußen bei den Ertragswerten, doch nehmen diese Flächen im Ried nur einen unbedeutenden Anteil an der Kieferngesamtfläche ein. Der Anbau der Kiefer verspricht daher ähnlich wie der der Eiche recht stabile Ertragswerte auch unter den Bedingungen des trockenen Klima-Szenarios, allerdings auf niedrigerem Niveau.

Abschließend wurden die minimalen Ertragswerte der verschiedenen Baumartengruppen auf den drei Substratgruppen miteinander verglichen. Die geringsten Ertragswerte werden jeweils für das Klimaszenario A1B trocken in Kombination mit dem Grundwasserszenario GW- berechnet. Die Edellaubbaumarten und die Douglasie zeigen sich dabei als vergleichsweise stabil. Dies trifft insbesondere für die Douglasie auf den Sandstandorten zu, sodass ihr verstärkter Anbau auf diesen „Problemstandorten“ empfehlenswert erscheint. Einschränkend ist hierzu aber anzumerken, dass die in die Berechnungen einbezogenen Douglasien- und auch Edellaubbaumbestände vergleichsweise jung waren und die Fläche der berücksichtigten Douglasienbestände sehr klein war. 



\section{Literatur}

Aber, J. D.; NAdelhoffer, K.J; Steudler, P. A. u. Melillo, J. M. (1989): Nitrogen saturation in northern forest ecosystems. BioScience, 39, 378-386

Aber, J. D.; Ollinger, S. V. u. Driscoll, C. T. (1997): Modelling nitrogen saturation in forest ecosystems in response to land use and atmospheric deposition. Ecological Modelling, 101, 61-78

AG BodEN (2005): Bodenkundliche Kartieranleitung. Bundesanstalt für Geowissenschaften und Rohstoffe (Hrsg.), Stuttgart, $438 \mathrm{~S}$.

Agren, G. I. u. Bosatta, E. (2002): Temperature response of soil organic matter. Soil Biol. Biochem., 34, 129-132

Ahrends, B. (2008): Dynamische Modellierung der Auswirkungen forstlicher Maßnahmen auf den Stoffhaushalt. Unveröffentlichter Abschlussbericht des WRRL-Pilotprojekts SILVAQUA Auswirkungen forstlicher Bewirtschaftung auf die Qualität von Sicker- und Oberflächengewässern in bewaldeten Einzugsgebieten, Göttingen, 364 S.

AHrENDS, B. (2010): Entwicklung eines dynamischen Standortmodells auf der Basis flächenhafter Standortsdaten. 3. Zwischenbericht des BMBF-Verbundprojekts „Anpassungsstrategien für eine nachhaltige Waldbewirtschaftung unter sich wandelnden Klimabedingungen - Decision Support System Wald und Klimawandel“, 10-19

Ahrends, B.; BötTCher, J. u. Dujjnisveld, W. H. M. (2005): Auswirkungen des Waldumbaus von Kiefernreinbeständen auf die Stoffdeposition und die Grundwasserqualität in Nordwestdeutschland. Freiburger Forstliche Forschung, 62, 221-234

Ahrends, B.; Döring, C.; JAnSEn, M.; MeESEnburg, H. u. BeEse, F. (2007): Kopplung dynamischer Modelle für die flächenhafte Abschätzung der Stoffdeposition im Wald. DBG, 110 (2), 421-422

Ahrends, B.; Döring, C.; JAnsen, M. u. MeEsenburg, H. (2008): Unterschiedliche Nutzungsszenarien und ihre Auswirkungen auf die Basensättigung im Wurzelraum - Ergebnisse von Szenarienvergleichen in Teileinzugsgebieten der Großen Bramke. Forst u. Holz, 63 (12), 32-36

Ahrends, B.; Meesendurg, H.; Döring, C. u. JANSEN, M. (2009): Assessment of forest management effects on N-cycling at three basins in the Upper Harz Mountains, Germany. Landschaftsökologie und Umweltforschung, 50, 3-7

Ahrends, B.; Meesenburg, H.; Döring, C. u. Jansen, M. (2010a): A spatio-temporal modelling approach for assessment of management effects in forest catchments. Status and Perspectives of Hydrology in Small Basins. IAHS Publ. 336, 32-37

Ahrends, B.; Penne, C. u. Panferov, O. (2010b): Impact of target diameter harvesting on spatial and temporal pattern of drought risk in forest ecosystems under climate change conditions. The Open Geography Journal, 3, 91-102

Akselsson, C., Sverdrup, H. u. HolmQvist, J. (2005): Estimating weathering rates of Swedish forest soils in different scales, using the PROFILE model and affiliated databases. Journal of Sustainable Forestry, 21 (2/3), 117-129

AlBERT, M. (2000): Ein funktionalisierter Höhenergänzungsalgorithmus für Einzelbaumwachstumsmodelle. Tagungsband der Jahrestagung der Sektion Ertragskunde des DVFFA vom 05. 07.06.2000 in Kaiserslautern, 32-43

Albert, M. u. HAnSEN, J. (2007): Ein Entscheidungsunterstützungssystem für die multifunktionale Forstplanung auf Landschaftsebene. Forst u. Holz, 62 (12), 14-18

Albert, M. u. SCHMidT, M. (2008): Erste Ergebnisse zur Modellierung des Standort-Leistungs-Bezuges unter Klimawandel. Tagungsband der Jahrestagung der Sektion Ertragskunde des DVFFA vom 05.-07.05.2008 in Trippstadt, 32-43 
AlBerT, M. u. SCHMidT, M. (2010a): Dynamik der Standort-Leistungs-Beziehungen von Buche, Eiche, Fichte, Kiefer und Douglasie unter Klimaveränderungen in Deutschland. Tagungsband der Jahrestagung der Sektion Ertragskunde im DVFFA vom 17.-19.05.2010 in Körbecke, 66-81

Albert, M. u. SCHMidT, M. (2010b): Climate-sensitive modelling of site-productivity relationships for Norway spruce (Picea abies (L.) Karst.) and common beech (Fagus sylvatica L.). Forest Ecology and Management, Vol. 259, Issue 4, 739-749

ALBRECHT, A. (2009): Sturmschadensanalysen langfristiger waldwachstumskundlicher Versuchsflächendaten in Baden-Württemberg. Schriftenreihe Freiburger Forstliche Forschung, Band 42, zugleich Freiburg i. Br., Univ., Diss., 2009, 174 S.

Altenkirch, W.; Majunke, C. u. Ohnesorge, B. (2002): Waldschutz auf ökologischer Grundlage. Verlag Eugen Ulmer, $434 \mathrm{~S}$.

Alveteg, M. (1998): Dynamics of forest soil chemistry. Department of Chemical Engineering II, Lund University, Lund, $77 \mathrm{~S}$.

Alveteg, M. u. Sverdrup, H. (2002): Manual for regional assessments using the SAFE model (draft version 8 April 2002). Department of Chemical Engineering II, Lund University, Lund, Sweden

Alveteg, M.; Walse, C. u. Warfvinge, P. (1997): Reconstructing historic atmospheric deposition and nutrient uptake from present day values using MAKEDEP. Water, Air, and Soil Pollution, $104,269-283$

Anders, S., Beck; W.; Bolte; A., Hofmann, G.; Jenssen, M.; Krakau, U.-K. u. Müller , J. (2002): Ökologie und Vegetation der Wälder Nordostdeutschlands. Verlag Kessel, Oberwinter, 283 S.

ANDERS, S.; BeCK; W.; HeYdeK, P.; FISCHER, R.; KÄTZEL, R.; KÖNIG, A.; KÜPPERS, J.-G.; LÖFfler, S.; LuX, W.; MÖlLer, K.; Müller, J. u. Thoroe, C. (2004): Auswirkung der Trockenheit 2003 auf Waldzustand und Waldbau. Arbeitsbericht d. Instituts für Forstökologie und Walderfassung der BFH 2, 109 S.

ARbeitSkreis StANDORTSKARTiERUNG (2003): Forstliche Standortsaufnahme. IHW-Verlag, Eching, $352 \mathrm{~S}$.

BAtjes, N. H. (2002): Carbon and nitrogen stocks in the soils of Central and Eastern Europe. Soil Use u. Management, 18, 324-329

BECK, W. (2001): Waldwachstum unter anhaltendem Fremdstoffeintrag. Ergebnisse aus waldwachstumskundlichen und dendroökologischen Untersuchungen. Beitr. f. Forstwirtsch. u. Landschaftsökologie, 35, 181-190

BECKER, R. (1999): Critical Load-Profile 4.2. Dokumentation (Deutsche Version). Modell und Handbuch unter: http://www.oekodata.com. Strausberg, $48 \mathrm{~S}$.

Becker, R.; Block, J.; SChimming, C.-G.; Spranger, T. u. Wellbrock, N. (2000): Critical Loads für Waldökosysteme - Methoden und Ergebnisse für Standorte des Level II-Programms. Bundesministerium für Ernährung, Landwirtschaft und Forsten (BML), Bonn, $71 \mathrm{~S}$.

BERG, B. u. LASKOWSKI, R. (2006): Litter decomposition: a guide to carbon and nutrient turnover. Advances in ecological research, 38, Elsevier, Amsterdam (u. a.), $428 \mathrm{~S}$.

BERGMANN, C. (1998): Stickstoff-Umsätze in der Humusauflage unterschiedlich immissionsbelasteter Kiefernbestände (Pinus sylvestris L.) im nordostdeutschen Tiefland - mit besonderer Berücksichtigung des gelösten organischen Stickstoffs. Cottbuser Schriften zu Bodenschutz und Rekultivierung, 1 , Cottbus, $128 \mathrm{~S}$.

Bierkens, M. F. P.; FinKe, P. A. u. DewiLlingen, P. (2000): Upscaling and downscaling methods for environmental research. Development in Plant and Soil Sciences, 88, Kluwer Academic Publishers, Dordrecht, 190 S.

Bleeker, A.; Reinds, G. J.; Vermeulen, A.; De Vries, W. u. Erisman, J. W. (2004): Critical loads and resent deposition thresholds of nitrogen and acidity and their exceedances at the level II and level I monitoring plots in Europe. ECN report ECN-C-04-117. Petten, The Netherlands

Blesson, (2006): Haas'sche Karte von 1803. Napoleon Online. Available at: http://www.napoleononline.de/phpBB2/viewtopic.php?p=7540u.highlight $=\mathrm{u} . \mathrm{sid}=\mathrm{e} 97 \mathrm{be} 472 \mathrm{ce} 23 \mathrm{e} 2 \mathrm{bf1} \mathrm{a} 84 \mathrm{c} 926 \mathrm{ba526463}$ [Accessed June 6, 2011] 
BLFW (1997): Grundwasserversauerung in Bayern. Informationsberichte des Bayerischen Landesamtes für Wasserwirtschaft, 97, $179 \mathrm{~S}$.

BLOCK, J. (2006): Stickstoffbelastung der rheinland-pfälzischen Wälder. Mitteilungen aus der Forschungsanstalt für Waldökologie und Forstwirtschaft, 60, 1-27

Bolte, A. (1999): Abschätzung von Trockensubstanz-, Kohlenstoff- und Nährelementvorräten der Waldbodenflora - Verfahren, Anwendung und Schätztafeln. Forstwiss. Beiträge Tharandt/ Contributions to Forest Science, 7

Bolte, A. u. WolfF, B. (2001): Validierung von Critical Load-Überschreitungen mit Indikatoren des aktuellen Wirkungsgeschehens - Teil 1: Waldökosysteme des Abschlussberichts des UBAForschungsvorhabens FKZ 298423 09. Bundesanstalt für Forst- und Holzwirtschaft, Eberswalde, $289 \mathrm{~S}$.

Bonten, L. T. C.; Mol-Dijkstra, J.; Wieggers, H. J. J.; De Vries, W.; Van Pul, A. u. Van Der HoEK, K. W. (2009): Linking nitrogen deposition to nitrate concentrations in groundwater below nature areas. Modelling approach and data requirements. Alterra-rapport 1881, Alterra, Wageningen, $41 \mathrm{~S}$.

Bonten, L.; Groenenberg, J. E.; Meesenburg, H. u. De Vries W. (2011a): Using advanced surface complexation models for modelling soil chemistry under forests: Solling forest, Germany. Environ. Pollut., 159 (10), 2831-2839

Bonten, L.; Posch, M. u. ReInds, G. J. (2011b): The VSD+ Soil Acidification Model. Model Description and User Manual Version 0.20. Alterra, Wageningen, 19 S.

BORKEN, W. u. MATZNER, E. (2004): Nitrate leaching in forest soils: an analysis of long-term monitoring sites in Germany. J. Plant Nutr. Soil Sci., 167(3), 277-283

Bormann, F. H. u. Likens, G. E. (1979): Pattern and Process in a Forested Ecosystem. SpringerVerlag, New York, $253 \mathrm{~S}$.

BötTCHER, J. u. SpRingob, G. (2001): A carbon balance model for organic layers of acid forest soils. J. Plant Nutr. Soil Sci., 164, 399-405

Braun, S.; Rihm, B.; SCHINDler, C. u. FlÜCKIGER, W. (1999): Growth of mature beech in relation to Ozone and nitrogen deposition: An epidemiological approach. Water, Air and Soil Pollution, $116,357-364$

Braun, S.; CAntaluppi, L. u. FlüCKIger, W. (2005): Fine roots in stands of Fagus sylvatica and Picea abies along a gradient of soil acidification. Environ. Pollut., 137, 574-579

BRÄUNIG, R. u. DiETER, M. (1999): Waldumbau, Kalamitätsrisiken und finanzielle Erfolgskennzahlen. In: Bergen, V. u. Brabänder, H.-D. (Hrsg.): Schriften zur Forstökonomie, 8, Sauerländer Verlag, Frankfurt, $148 \mathrm{~S}$.

Braunisch, V. u. Suchant, R. (2007): A Model for Evaluating the "Habitat Potential" of a Landscape for Capercaillie Tetrao urogallus: A Tool for Conservation Planning. Wildlife Biology, 13(sp1), 21-33

Brezger, A., (2005): Bayesian P-Splines in Structured Additive Regression Models. Dissertation an der Fakultät für Mathematik, Informatik und Statistik der LMU München, $183 \mathrm{~S}$.

BRINKMANN, S. u. NiEDER, R. (2002): Critical Loads für eutrophierenden Stickstoff - Weiterentwicklung des Ansatzes unter besonderer Berücksichtigung der Umsetzung im Boden (Humusschicht). Braunschweig, $116 \mathrm{~S}$.

BRUELHEIDE, H. u. UdELHOVEN, P. (2005): Correspondence of the fine-scale spatial variation in soil chemistry and the herb layer vegetation in beech forests. Forest Ecology and Management, 210, 205-223

Buberl, H. G.; v. Wilpert, K.; Trefz-Malcher, G.; Hildebrand, E. E. u. Wiebel, M. (1994): Der chemische Zustand der Waldböden in Baden-Württemberg. Ergebnisse der Bodenzustandserhebung im Wald 1989 - 1992 (BZE). Mitteilungen der Forstlichen Versuchs- und Forschungsanstalt Baden-Württemberg, 182, 104 S. 
Builtjes, P.; Hendriks, E.; Koenen, M.; SchaAp, M.; Banzhaf, S.; Kerschbaumer, A.; Gauger, T.; Nagel, H.-D; Scheuschner, T. u. Schlutow, A. (2011): Abschlussbericht zum UFOPLAN-Vorhaben FKZ 370764 200: Erfassung, Prognose und Bewertung von Stoffeinträgen und ihren Wirkungen in Deutschland (Modelling of Air Pollutants and Ecosystem Impact MAPESI). Im Auftrag des Umweltbundesamtes, gefördert vom BMU, Dessau-Rosslau

Bundesamt FÜR NATURSCHUTZ (BfN) (Hrsg.) (2010): Bewertung des Erhaltungszustandes der Lebensraumtypen nach Anhang I der Flora-Fauna-Habitat-Richtlinie in Deutschland. Überarbeitete Bewertungsbögen der Bund-Länder-Arbeitskreise als Grundlage für ein bundesweites FFHMonitoring. Bonn, $206 \mathrm{~S}$.

http://www.bfn.de/fileadmin/MDB/documents/themen/monitoring/Bewertungsschemata_A rten_2010.pdf

BundeSAMT FÜR UMWELT (BAFU) (2008): Entscheidungshilfe bei Sturmschäden im Wald. Vollzugshilfe für die Wahl der Schadensbehandlung im Einzelbestand.“ Sturmschaden-Handbuch 2008, Teil 3, Umwelt-Vollzug Nr. 0801

BundeSMINISTERIUM FÜR UMWELT, NATURSCHUTZ UND REAKTORSICHERHEIT (BMU) (2000): Hydrologischer Atlas von Deutschland. Freiburg

BundesnaturschutzGesetz (BNatschG) (2009): Bundesgesetzblatt Jahrgang 2009, Teil 1, Nr. 51, $2542 \mathrm{ff}$

Bytnerowicz, A.; Omasa, K. u. Paoletti, E. (2007): Integrated effects of air pollution and climate change on forests: A northern hemisphere perspective. Environmental Pollution, 147, 438-445

Chertov, O. G. u. Komarov, A. S. (1997): SOMM: A model of soil organic matter dynamics. Ecological Modelling, 94, 177-189

Chertov, O. G.; Komarov, A. S.; Nadporozhskaya, M.; Bykhovets; S. S. u. Zudin, S. L. (2001): ROMUL - a model of forest soil organic matter dynamics as a substantial tool for forest ecosystem modelling. Ecological Modelling, 138, 289-308

Choi, D. S.; Jin, H. O.; LeE, C. H.; Kim, Y. C. u. Kayama, M. (2005): Effect of soil acidification on the growth of Korean pine (Pinus koraiensis) seedlings in a granite-derived forest soil. Environ. Sci., $12(1), 33-47$

Coleman, K. u. Jenkinson, D. S. (1996): RothC-26.3. In: Powlson, D. S., Smith, P. u. Smith, J. U.: Evaluation of soil organic matter modells using existing long-term data sets. Springer-Verlag, Berlin, Heidelberg, New York, 237-246

Cosby, B. J.; Hornberger, G. M.; Galloway, J. N. u. Wright, R. F. (1985): Modeling the effects of acid deposition: assessment of a lumped-parameter model of soil water and streamwater chemistry. Water Resources Research, 21, 51-63

Couteaux, M. M.; McTiernan, K. B.; Berg, B.; Szuberla, D.; Dardenne, P. u. Pottner, P. (1998): Chemical composition and carbon mineralisation potential of Scots pine needles at different stages of decomposition. Soil Biol. Biochem., 30 (5), 583-593

Cox, D. R. (1972): Regression Models and Life Tables (with Discussion). Journal of the Royal Statistical Society, Series B 34, 187-220

Curtin, D. u. Rostad, H. P. W. (1997): Cation exchange and buffer potential of Saskatchewan soils estimated from texture, organic matter and pH. Canadian Journal of Soil Science, 621-626

Czajkowski, T.; Ahrends, B. u. Bolte, A. (2009): Critical limits of soil water availability (CL-SWA) for forest trees - an approach based on plant water status. Landbauforschung - v'TI Agriculture and Forestry Research 2 (59), 87-94

Dauber, E. u. Kreutzer, K. (1979): Die Ermittlung des Potentials forstlicher Reststoffe in der Bundesrepublik Deutschland. Forstw. Cbl., 98, 289-297

Davidson, E. A.; Trumbore, S. E. u. Amundson, R. (2000): Soil warming and organic carbon content. Nature, 408, 788-789

De MARTOnNe, E. 1926: Une nouvelle fonction climatologique: l'indice d'aridité. La Météorologie, 2, $449-458$ 
Deutschmann, G.; Rummenhohl, H. u. Tarrah, J. (1997): Die Bestimmung der effektiven Kationenaustauschkapazitiit von Gesteinen. Z. Pflanzenernähr. Bodenk., 160, 151-155

DE VRIES, W. (1991): Methodologies for the assessment and mapping of the critical loads and of the impact of abatement strategies on forest soils. Wageningen, $109 \mathrm{~S}$.

De VRIES, W. u. Posch, M. (2003): Derivation of cation exchange constants for sand, loess, clay and peat soils on the basis of field measurements in the Netherlands. Alterra-rapport 701, Alterra, Green World Research, Wageningen, $50 \mathrm{~S}$.

De Vries, W.; Posch, M. u. KämÄri, J. (1989): Simulation of the long-term soil response to acid deposition in various buffer ranges. Water, Air and Soil Pollution, 48, 349-390

Dijkstra, J. P. M.; Reinds, G.; Kros, J., H.; BerG, B. u. De Vries, W. (2009): Modelling soil carbon sequestration of intensively monitored forest plots in Europe by three different approaches. Forest Ecology and Management, 258, 1780-1793

Dise, N. u. Wright, R. F. (1995): Nitrogen leaching from European forests in relation to nitrogen deposition. Forest Ecology and Management, 71, (1-2), 153-161

Dise, N.; Matzner, E.; Armbruster, M. u. MacDonald, J. (2001): Aluminium output fluxes from forest ecosystems in Europe: A regional assessment. J. Environ. Qual. J. Environ. Qual., 30, (5), 1747-1756

DöbBELER, H. (2004): Simulation und Bewertung von Nutzungsstrategien unter heutigen und veränderten Klimabedingungen mit dem Wuchsmodell SILVA 2.2. Dissertation Univ. Göttingen, $231 \mathrm{~S}$.

DöbBeler, H. u. Spellmann, H. (2002): Methodological approach to simulate and evaluate silvicultural treatments under climate change. Forstwiss. Centralblatt, 121, Supplement 1, 52-69

DudA, H. (2006): Vergleich forstlicher Managementstrategien. Dissertation Universität Göttingen, 181 S. (http://webdoc.sub.gwdg.de/diss/2006/duda/)

DulTZ, S. (1993): Verwitterungsbilanzen an sauren Waldböden aus Geschiebedecksand. Fachbereich Geowissenschaften, Universität Hannover, 96 S.

ĎurskÝ, J. (1997): Modellierung der Absterbeprozesse in Rein- und Mischbeständen aus Fichte und Buche. AFJZ 168 (6/7), 131-134

ĎurskÝ, J. (2000): Einsatz von Waldwachstumssimulatoren für Bestand, Betrieb und Großregion, Habilitationsschrift, Lehrstuhl für Waldwachstumskunde, Technische Universität München, $223 \mathrm{~S}$.

DusCHL, C. (2001): Simulation forstbetrieblicher Sachverhalte auf der Basis gegenwärtiger Waldstrukturen. Hrsg.: Wissenschaftszentrum Weihenstephan für Ernährung, Landnutzung und Umwelt der Technischen Universität München und Bayerische Landesanstalt für Wald und Forstwirtschaft. Zugl.: München, Techn. Univ., Forstwiss. Diss. München. Forstliche Forschungsberichte München, 181

Duschl C. u. SudA, M. (2002): Simulation of Management Strategies in the Forest Estate Model "Germany". Forstwissenschaftliches Centralblatt 121, Supplement 1, 89-107

Dutch, J. u. Ineson, P. (1990): Denitrification of an Upland Forest Site. Forestry, 63 (4), 363-377

EBERL, C. (1998): Quantifizierung und Bewertung von Merkmalen forstlicher Standortstypen durch ökochemische Parameter im Westharz. Berichte des Forschungszentrums Waldökosysteme, Reihe A, Bd. 151, 1-156

EGNELL, G. u. VAlinger, E. (2003): Survival, growth and growth allocation of planted Scots pine trees after different levels of biomass removal in clear-felling. Forest Ecology and Management $177,65-74$

EichHORN, J. (Hrsg.) (1992): 10 Jahre Waldökosystemstudie Hessen: Ergebnisse und Perspektiven. Forschungsber. Hessische Forstliche Versuchsanstalt 15

EINERT, P. (2000): Depositionsuntersuchungen im Rahmen des Forschungsprogramms: „Langfristige waldbauliche Untersuchungen in Kiefernbeständen der Berliner Forsten“. Beitr. Forstwirtsch. u. Landsch.ökol., 34 (3), 109-112 
ELEND, C. (2000): Untersuchungen zum Einsatz von hemisphärischen Fotos zur Ermittlung von Bestandesstrukturparametern und deren Einfluss auf die Interception von Waldbeständen. Dipl.-Arb. Fachber. Forstwirtschaft und Umweltmanagement, Fachhochschule Hildesheim/ Holzminden/Göttingen

Elfying, B. u. Nyström, K., (1996): Stability of Site Index in Scots Pine (Pinus sylvestris L.) Plantations over Year of Planting in the Period 1900-1977 in Sweden. In: SPIECKER, H.; MIELIKÄINEN, K.; Köhl, M., u. SkovsgaArd, J.P. (Eds.): Growth Trends in European Forests. SpringerVerlag, Berlin Heidelberg New York, 71-78

Ellenberg, H. (1996): Vegetation Mitteleuropas mit den Alpen. Ulmer, Stuttgart, 1096 S.

Emmer, I. M. u. SEvinK, J. (1994): Temporal and vertical changes in the humus form profile during a primary succession of Pinus sylvestris. Plant and Soil, 167, 281-295

Erisman, J. W. u. DraAjers, G. P. J. (2003): Deposition to forests in Europe: most important factors influencing dry deposition and models used for generalisation. Environ. Pollut., 124, 379-388

Erisman, J. W.; v. Pul, A. u. WYers, P. (1994): Parametrization of surface resistance for the quantification of atmospheric deposition of acidifying pollutants and ozone. Atmos. Environ., 28, 2595 2607

Europäisches Parlament und Europäischer Rat (2000): Richtlinie 2000/60/EG des Europäischen Parlamentes und des Rates vom 23. Oktober 2000 zur Schaffung eines Ordnungsrahmens für Maßnahmen der Gemeinschaft im Bereich der Wasserpolitik (WRRL), ABl. L.327 der Europäischen Gemeinschaften vom 22.12.2000

FACELli, E. u. FACELli, J. M. (2002): Soil phosphorus heterogeneity and mycorrhizal symbiosis regulate plant intra-specific competition and size distribution. Oecologia, 133, 1, 54-61

FAHrmeir, L.; KNEIB, T. u. LANG, S. (2007): Regression. Springer, Berlin, 551 S.

FALK, W.; DieTZ, E.; GrÜnerT, S.; Schultze, B. u. Kölling, C. (2008): Wo hat die Fichte genügend Wasser? Neue überregional gültige Karten des Wasserhaushalts von Fichtenbeständen verbessern die Anbauentscheidung. LWF aktuell, 66, 21-25

Federer, C. A.; Vörösmarty, C. u. FekeTA, B. (2003): Sensitivity of annual evaporation to soil and root properties in two models of contrasting complexity. J. Hydrometeorology, 4, 1276-1290

FEGER, K. H. (1989): Hydrologische und chemische Wechselwirkungsprozesse in tieferen Bodenhorizonten und im Gestein in ihrer Bedeutung für den Chemismus von Waldgewässern. In: BRECHTEL, H.-M: Immissionsbelastung des Waldes und seiner Böden - Gefahr für die Gewässer? DVWK Mitteilungen, 17, 185-204

FEGER, K. H. (1993): Bedeutung von ökosysteminternen Umsätzen und Nutzungseingriffen für den Stoffhaushalt von Waldlandschaften. Freiburger Bodenkundliche Abhandlungen, 31, $237 \mathrm{~S}$.

Fiebiger, C.; Sutmöller, J.; Meesenburg, H. u. EichHorn, J. (2009): Auswirkungen von Klimaänderungen auf den Wasserhaushalt von Wäldern im Hessischen Ried. Berichte der DBG online Publikation, http://www.dbges.de

FÖLSTER, H. (1985): Proton consumption rates in holocene and present-day weathering of acid forest soils. In: Drever, J.I: The chemistry of weathering. D. Reidel Publ. Dordrecht, Holland, $197-$ 209

Fortmann, H.; Gundreben, M.; Kleefisch, B.; Meesenburg, H.; Meiwes, K. J.; Merkel, D.; SCHNEIDER, J. u. SEVERIN, K. (2007): Bodenqualitätszielkonzept Niedersachsen - Teil 2: Schwermetalle, organische Belastungen und Säurebildner. GeoBerichte, 7, 3-64

Fowler, H. J.; BlenKINSOP, S. u. TeBALDI, C. (2007): Linking climate change modelling to impacts studies: recent advances in downscaling techniques for hydrological modelling. International Journal of Climatology, 27 (12), 1547-1578

Fox, J. (2002): Cox Proportional-Hazards Regression for Survival Data. http://cran.rproject.org/doc/contrib/Fox-Companion/appendix-cox-regression.pdf

FRIEDEL, S. (2010): Grundwasserabsenkungen auf Waldstandorten des Hessischen Rieds - Kalkulation des Gesamtschadens. Im Auftrag der Projektgruppe Grundwasser des Landesbetriebes Hessen-Forst. $23 \mathrm{~S}$. 
GAFFREY, D. (1988): Forstamts- und bestandesindividuelles Sortimentierungsprogramm als Mittel zur Planung, Aushaltung und Simulation. Diplomarbeit Univ. Göttingen

Gasser, U.; STutz, H.-P. u. BouqueT, F. (2009): Bodenversauerung und Bodenfruchtbarkeit im Züricher Wald. Züricher Wald, 1, 4-9

Gauger, T.; KÖBle, R. u. SMiATEK, G. (1997): Kartierung kritischer Belastungskonzentrationen und -raten für empfindliche Ökosysteme in der Bundesrepublik Deutschland und anderer ECELänder. Teil 1: Deposition Loads. Institut für Navigation der Universität Stuttgart im Auftrag des Umweltbundesamtes, $126 \mathrm{~S}$.

Gauger, T.; Anshelm, F.; Schuster, H.; Draajjers, G. P. J.; Bleeker, A.; Erisman, J. W., Vermeulen, A. T. u. NAGEL, H.-D. (2002): Kartierung ökosystembezogener Langzeittrends atmosphärischer Stoffeinträge und Luftschadstoffkonzentrationen in Deutschland und deren Vergleich mit Critical Loads und Critical Levels. Forschungsvorhaben im Auftrag des BMU/ UBA, FE-Nr. 29942 210., Institut für Navigation, Univ. Stuttgart, 207 S.

Gauger, T.; Haenel, H.-D.; Rösemann, C.; Nagel, H.-D.; Becker, R.; Kraft, P.; Schlutow, A.; Schütze, G.; Weigelt-Kirchner, R. u. Anshelm, F. (2008): Nationale Umsetzung UNECELuftreinhaltekonvention (Wirkung). Abschlussbericht zum UFOPLAN-Vorhaben FKZ 20463 252. Im Auftrag des Umweltbundesamtes, gefördert vom Bundesministerium f. Umwelt, Naturschutz und Reaktorsicherheit, Dessau-Rosslau.

Gehrmann, J.; Andreae, H.; Fischer, U.; Lux, W. u. Spranger, T. (2001): Luftqualität und atmosphärische Stoffeinträge an Level II-Dauerbeobachtungsflächen in Deutschland. Bundesministerium für Verbraucherschutz, Ernährung und Landwirtschaft (BMVEL), $94 \mathrm{~S}$.

GiARdinA, G. P. u. RYAN, M. G. (2000): Evidence that decomposition rates of organic carbon in mineral soil do not vary with temperature. Nature, 404, 858-861

Glaser, F. F. u. HAuke, U. (2004): Historisch alte Waldstandorte und Hudewälder in Deutschland. Bundesamt für Naturschutz (Hrsg.), Reihe Angewandte Landschaftsökologie, 61, 194 S.

Glatzel, G.; KaZDA, M.; Grill, D.; Halbwachs, G. u. Katzensteiner, K. (1987): Ernährungsstörungen bei Fichte als Komplexwirkung von Nadelschäden und erhöhter Stickstoffdeposition ein Wirkungsmechanismus des Waldsterbens? Allg. Forst- u. J.-Ztg., 158 (5/6), 91-97

GlogNER, K.; GRÜNEKLEE, W. u. UlLRICH, T. (2009): Jahrestagung der AFSF. Wald im Klimawandel - Hess. Odenwald und Rhein-Main-Ebene. HESSEN-FORST - Forsteinrichtung und Naturschutz (FENA), Gießen, $86 \mathrm{~S}$.

Godbold, D.; Fritz, H.-W.; Jentschke, G.; Meesenburg, H. u. Rademacher, P. (2003): Root turnover and root necromass accumulation of Norway spruce (Picea abies) are affected by soil acidity. Tree Physiology, 23, 915-921

Göttlein, A.; Baumgarten, M.; Huber, C.; Weis, W.; Papen, H.; Butterbach-Bahl, K. u. GASCHE, R. (2003): Ökologie der Mischwaldbegründung in einem stickstoffbelasteten Fichtenbestand. LWF aktuell, 41, 6-8

Grigal, D. F.; McRoberts, R. E. u. Ohmann, L. F. (1991): Spatial Variation in Chemical Properties of Forest Floor and Surface Mineral Soil in the North Central United States. Soil Science, 151 (4), 282-290

Groenenberg, B. J.; Kros, H.; Van Der Salm, C. u. De Vries, W. (1995): Application of the NUCSAM model to the Solling spruce site. Ecological Modelling, 83 (1-2), 97-107

Gundersen, P. (1991): Nitrogen deposition and the forest nitrogen cycle: role of denitrification. Forest Ecology and Management, 44, 15-28

Gundersen, P.; Callesen, I. u. De VRIES, W. (1998): Nitrate leaching in forest ecosystems is related to forest floor $\mathrm{C} / \mathrm{N}$ ratios. Environmental Pollution, 102, 403-407

Gundersen, P.; Berg, B.; Currie, W. S.; Dise, N.; Emmett, B. A.; Gauci, V.; Holmberg, M.; KjonaAs, O. J.; Mol-Dijkstra, J.; Van Der Salm, C.; Schmidt, I. K.; Tietema, A., Wessel, W. Vestgarden, W., Akselsson, L. S. C., De Vries, W., Forsius, M.; Kros, H.; Matzner, E.; Moldan, F.; Nadelhoffer, K. J.; Nilsson, L.-O.; G. Reinds, J.; Rosengren, U.; Stuanes, A. O. u. Wright, R. F. (2006): Carbon - Nitrogen Interactions in Forest Ecosystems. Final Report. 
Danish Centre for Forest, Landscape and Planning, Denmark, 61 S., http://oro.open.ac.uk/32785/1/

Hammel, K. u. KEnNEL, M. (2001): Charakterisierung und Analyse der Wasserverfügbarkeit und des Wasserhaushalts von Waldstandorten in Bayern mit dem Simulationsmodell Brook90. Forstliche Forschungsberichte München, 185

Hanewinkel, M.; Hummel, S. u. Albrecht, A., (2010). Assessing natural hazards in forestry for risk management: a review. European Journal of Forest Research, 1-23

HANSEN, J. (2006): Der WaldPlaner - Ein System zur Entscheidungsunterstützung in einer nachhaltigen Forstwirtschaft. In: DEGENHARDT, A. u. WUNN, U.: Beiträge von der 18. Jahrestagung der Sektion Biometrie und Informatik des DVFFA in Trippstadt. Die Grüne Reihe, 112-119

HANSEN, J. u. NAGEL, J. (2011): Waldwachstumskundliche Softwaresysteme auf Basis von TreeGrOSS - Anwendung und theoretische Grundlagen. Nordwestdeutsche Forstliche Versuchsanstalt (Hrsg.), Göttingen, im Druck, $220 \mathrm{~S}$.

HASENAUER, H. (1994): Ein Einzelbaumwachstumssimulator für ungleichaltrige Fichten-Kiefern- und Buchen-Fichtenmischbestände. Forstliche Schriftenreihe der Universität für Bodenkultur, Österr. Ges. Waldökosystemforsch. experim. Baumforsch., Wien, 152 S.

Hasenauer, H. (2006): Sustainable Forest Management: Growth models for Europe. Springer, Berlin Heidelberg, $398 \mathrm{~S}$.

Hastie, T. J. u. Tibshirani, R. J. (1990): Generalized Additive Models. Monographs on Statistics and Applied Probability 43, Chapman u. Hall, London, 335 S.

HAub, H. (1997): Ein praxisorientiertes Verfahren zur Herleitung einer Entschädigung für erzwungenen Baumartenwechsel. Forst u. Holz, 52, 422-424

Heide, C. von der; Böttcher, J.; Deurer, M.; Weymann, D.; Well, R. u. Duijnisveld, W. H. M. (2008): Spatial variability of $\mathrm{N}_{2} \mathrm{O}$ concentrations and of denitrification-related factors in the surficial groundwater of a catchment in Northern Germany. J. Hydrol., 360, 230-241

Heinsdorf, D.; Kraub, H.-H. u. Tölle, H. (1986): Entwicklung der C- und N-Vorräte nach Kahlschlag auf ärmeren anhydromorphen Sandböden unter Kiefer. Beiträge für die Forstwirtschaft, $20(1), 8-13$

Helling, C. S.; Chesters, G. u. Corey, R. (1964): Contribution of organic matter and clay to soil cation exchange capacity as affected by the $\mathrm{pH}$ of the saturating solution. Soil Sci. Soc. Am. J., 28, 517-520

Helmisaari, H.; Holt Hanssen, K.; Jacobson, S.; Kukkola, M.; Luiro, J.; SaArsalmi, A.; Tamminen, P. u. Tveite, B. (2011): Logging residue removal after thinning in Nordic boreal forests: Long-term impact on tree growth. Forest Ecology and Management, 261, 1919-1927

Hennings, V. (2000): Auswertungsmethoden zur Beurteilung der Empfindlichkeit und Belastbarkeit von Böden. Sonderhefte Reihe G, Geol. Jahrb., (1), 1-232

Hessen-Forst (2008): Hessische Waldbaufibel. Kassel, 98 S.

Hessen-Forst (Hrsg.) (2011): Naturschutzleitlinie. Kassel, 93 S.

Hessen-Forst, FENA (2007): Natis-Homepage. http://www.natis.de/

HFORSTG (2002): Hessisches Forstgesetz. GVBl. I 2002, 582

Hessischer Landtag (2006): Antrag der Fraktionen der SPD, CDU, Bündnis 90/Die Grünen und der FDP betreffend Sanierung der südhessische Wälder. ULA/16/46

Heuer, E.; Anders, S.; Jenssen, M.; Münzenberger, B.; Oheimb v., G.; Härdtle, W.; KÄtzel, R.; Lockow, K.-W.; Bilke, G.; Majunke, C. u. Luthard, E. M. (Hrsg.) (2005): BMBF-Forschungsverbund „Zukunftsorientierte Waldwirtschaft“: Ökologischer Waldumbau im nordostdeutschen Tiefland. Eberswalder Forstliche Schriftenreihe, Bd. XXIII

Hirzel, A. H. (2011): Biomapper - Frequently Asked Questions. Biomapper - Frequently Asked Questions. Available at: http://www2.unil.ch/biomapper/ faq.html [Accessed June 16, 2011]

Hirzel, A. H.; Hausser J.; Chessel, D. u. Perrin, N. (2002): Ecological-niche factor analysis: How to compute habitat-suitability maps without absence data? Ecology, 83 (7), 2027-2036 
Hirzel, A.H.; Hausser, J. u. Perrin, N. (2008): Biomapper, Lausanne: Lab. for Conservation Biology. Available at: http://www2.unil.ch/biomapper

HMUlF (Hessisches Ministerium f. Umwelt, Landwirtschaft u. Forsten, Hrsg.) (1995): Hessische Biotopkartierung (HB), Kartieranleitung 3. Aufl., Wiesbaden.

HMUlF (Hessisches Ministerium f. Umwelt, LANDwirtschaft u. Forsten) (2002): Hessische Anweisung für Forsteinrichtungsarbeiten (HAFEA). Staatsanzeiger für das Land Hessen, 39, 3680-3728

HMUlf (Hessisches Ministerium f. Umwelt, Landwirtschaft u. Forsten) (2005): Das Hessische Ried zwischen Vernässung und Trockenheit. Wiesbaden

Hocke, R.; Haub, H.; Dumm, M.; Friedel, S.; Nowack, S. u. Rohde, M. (1997): Schäden durch Grundwasserabsenkung im Stadtwald Gernsheim. Gutachten der Hessischen Landesanstalt für Forsteinrichtung, Waldforschung und Waldökologie. $42 \mathrm{~S}$.

HöKE, S.; Rolf, M.; Dressler, H. v.; RÜCK, F. u. SCHNEIDER, J. (2009): Erweiterungen zur Kennwertermittlung für Böden mit technogenen Substraten. Berichte der DBG, 4 S.

Holecy, J. u. HANEWINKEL, M. (2006): A forest management risk insurance model and its application to coniferous stands in southwest Germany. Forest Policy and Economics, 8, 161-174

Holmberg, M.; Rankinen, K.; Johansson, M.; Forsius, M.; KleEmola, S.; Ahonen, J. u. Syri, S. (2000): Sensitivity of soil acidification model to deposition and forest growth. Ecological Modelling, 135, 311-325

Hörmann, G.; Scherzer, J.; Suckow, F.; Müller, J.; Wegehenkel, M.; Lukes, M.; Hammel, K.; Knieß, A. u. Meesenburg, H. (2003): Wasserhaushalt von Waldökosystemen: Methodenleitfaden zur Bestimmung der Wasserhaushaltskomponenten auf Level II-Flächen. Bundesministerium für Verbraucherschutz, Ernährung und Landwirtschaft (BMVEL) Referat 533. Bonn. 92 S.

Hornbeck, J. W.; Martin, C. W.; Pierce, R. S.; Bormann, F. H.; Likens, G. E. u. Eaton, J. S. (1987): The northern hardwood forest ecosystem: ten years of recovery from clearcutting NERP-596. Broomall, PA: U.S., Department of Agriculture, Forest Service, Northeastern Forest Experiment Station, $30 \mathrm{~S}$.

Huber, C.; Baumgarten, M.; Göttlein, A. u. Rotter, V. (2004): Nitrogen turnover and nitrate leaching after bark beetle attack in Mountainous Spruce Stands of the Bavarian Forest National Park. Water Air and Soil Pollution, Focus 4, 391-414

Huss, J. u. KÜTHE, K. (1974): Zur Pflege von Eichenkulturen. Ergebnisse eines Versuches im Forstamt Lampertheim. Forst- u. Holzwirt 29, 69-76

Hutchinson, G. E. (1957): Concluding Remarks. Cold Spring Harbor Symposia on Quantitative Biology, 22, 415-427

iPCC (Intergovernmental Panel on Climate Change) (2007): Climate Change 2007 - The Physical Science Basis. Contribution of Working Group 1 to the Fourth Assessment Report of the IPCC

IvEN, H. (1996): Die Grundwasseranreicherung im Hessischen Ried. Geol. Jb. Hessen, 124, 159-173

IvENS, W. P. M. F. (1990): Atmospheric deposition onto forests: an analysis of the deposition variability by means of throughfall measurements. Nederlandse geografische studies, 118, Utrecht, $151 \mathrm{~S}$.

Jackson, R. B.; Canadell, J.; Ehleringer, J. R.; Mooney, H. A.; Sala, O. E. u. Schulze, E. D. (1996): A global analysis of root distributions for terrestrial biomes. Oecologia, 108, 389-411

JacoB, D.; GÖTtel, H.; Kotlarski, S.; Lorenz, P. u. SieCK, K. (2008): Klimaauswirkungen und Anpassung in Deutschland - Phase 1: Erstellung regionaler Klimaszenarien für Deutschland. Umweltbundesamt, Dessau-Roßlau, $154 \mathrm{~S}$.

JACOBSEN, C. (2010): Forstökologische Beweissicherung Hessisches Ried - 4. Zwischenbericht. Landesbetrieb HESSEN-FORST, 285 S.

Jacobsen, C.; Rademacher, P.; Meesenburg, H. u. Meiwes, K.-J. (2003): Gehalte chemischer Elemente in Baumkompartimenten Literaturstudie und Datensammlung. Berichte des Forschungszentrums Waldökosysteme, Reihe B, Bd. 69, S. 81

Beiträge aus der NW-FVA, Band 10, 2013 
JANDL, R. (1998): Modeling processes in forest soils - problems, simplifications and caveats. Ecological Engineering, 10, 33-51

JANDL, R.; Lindner, M.; Vesterdal, L.; BAuwens, B.; BARitZ, R.; HAgedorn, F.; Johnson, D. W.; MinkKINEN, K. u. BYRne, K. A. (2007): How strongly can forest management influence soil carbon sequestration? Geoderma, 137, 253-268

Jansen, M.; Döring, C.; Ahrends, B.; Meesendburg, H.; Meiwes, K.-J. u. Beese, F. (2007): Kopplung dynamischer Modelle für die Bodenschutzkalkung im Wald. Mitteillungen der DBG, 110 (2), 483-484

JANSEN, M.; EberL, C. u. BeESE, F. (2002): Regionalization of soil chemical variables in the Harz mountains. In: JANSEN, M., JUdAS, M. u. SABOROWSKI, J.: Spatial modelling in forest ecology and management. Springer, Berlin u. a., 68-86

Johansson, M.; Alveteg, M.; Walse, C. u. Warfvinge, P. (1996): Derivation of Deposition and Uptake Scenarios. In: KNOflacher, M., SCHNEIDER, J. u. SojA, G.: Exceedance of critical loads and levels. Conference Papers, 15, Wien/Vienna, 318-324

Jönsson, C.; Warfvinge, P. u. Sverdrup, H. (1995): Application of the SAFE model to the Solling spruce site. Ecological Modelling, 83, 85-96

JRI (Lehrstuhl für Rechenorientierte Statistik und Datenanalyse, Universität Augsburg) (2011): http://www.rosuda.org/JRI/, 27.01.11

Jurgensen, M. F.; Harvey, A. E.; Graham, R. T.; Page-Dumroese, D. S.; Tonn, J. R.; Larsen, M. J. u. JAIN, T. B. (1997): Impact of timber harvesting on soil organic matter, nitrogen, productivity, and health of inland Northwest forests. For. Sci., 43 (2), 234-251

Kahn, M. u. Pretzsch, H. (1997): Das Wuchsmodell SILVA - Parametrisierung der Version 2.1 für Rein- und Mischbestände aus Fichte und Buche. AFJZ, 168, 115-123

Kelly, R. H.; Parton, W. J.; Crocker, G. J.; Grace, P. R.; Klir, J.; Körschens, M.; Poulton, P. R. u. RiChTER, D. D. (1997): Simulating trends in soil organic carbon in long-term experiments using the century model. Geoderma, 81, 75-90

KenK, G. u. Fischer, H. (1988): Evidence from nitrogen fertilisation in the forests of Germany. Environ. Pollut., 54, 199-218

Kern, K. G.; MOlL, W. u. Braun, H. J. (1961): Wurzeluntersuchungen in Rein- und Mischbeständen des Hochschwarzwaldes (Vfl. Todtmoos 2/I-IV). Allg. Forst- u. J.-Ztg., 132, 241-260

KLAMinder, J.; Lucas, R. W.; FutTer, M. N.; Bishop, K. H.; KÖHLER, S. J.; Egnell, G. u. LAudON, H. (2011): Silicat mineral weathering rate estimates: Are they precise enough to be useful when predicting the recovery of nutrient pools after harvesting? Forest Ecology and Management, $261,1-9$

KlincK, U.; MeIwes, K. J.; FrÖHlich, D.; RAdler, K. u. BeESE, F. (2010): Bilanz von Ein- und Austrag verschiedener Makronährstoffe nach Kleinkahlschlag und Zielstärkennutzung in einem Fichtenreinbestand. Forstwissenschaftliche Tagung, 22. bis 24. September 2010, 226-227

KNUTSSON, G. (1994): Acidification effects on groundwater - prognosis of the risks for the future. IAHS Publ., 222, 3-17

Kohlpainter, M. u. GötTlein, A. (2009): Mit dem Wald verschwindet auch der Humus. LWF aktuell, 71, 22-24

KonOpatZKi, A. u. Kirschner, G. (1997): Zum Standorts- und Vegetationswandel in den Wäldern der Länder Brandenburg, Mecklenburg-Vorpommern und des Tieflandteils von Sachsen-Anahlt. Berichte des Forschungszentrums Waldökosysteme, Reihe B, (56), S. 125

Kopp, D. (2004): Vorschlag für eine Rahmenklassifikation der Waldstandorte Deutschlands nach Ökotopgruppen. Waldökologie online, (1), 11-24

Kramer, H. (1976): Begriffe der Forsteinrichtung. Schriftenreihe der Forstlichen Fakultät der Universität Göttingen und Mitteilungen der Niedersächsischen Forstlichen Versuchsanstalt, Band 48, Frankfurt am Main, 88 S.

Kramer, H. (1982): Nutzungsplanung in der Forsteinrichtung, J. D. Sauerländer's Verlag, Frankfurt a. M., S. 128 
Kramer, H. (1988): Waldwachstumslehre: Ökologische u. anthropogene Einflüsse auf das Wachstum des Waldes, seine Massen- und Wertleistung und die Bestandessicherheit. Parey, Hamburg u. a., $374 \mathrm{~S}$.

Kros, J.; Reinds, G. J.; De VRIES, W.; LAtour, J. B. u. Bollen, M. (1995): Modelling the response of terrestrial ecosystems to acidification and desiccation scenarios. Water, Air and Soil Pollution, 85, 1101-1106

LACHAT, T. u. BütLeR, R. (2009): Identifying Conservation and Restoration Priorities for Saproxylic and Old-Growth Forest Species: A Case Study in Switzerland. Environmental Management, 44 (1), 105-118

LANDESFORSTVERWALTUNG NiEDERSACHSEN (2004): Langfristige ökologische Waldentwicklung Richtlinie zur Baumartenwahl. Aus dem Walde, 54, 145 S.

LANE, P. W. (2002): Generalized linear models in soil science. European Journal of Soil Science, 53, 241-251

LANGusch, J.-J. u. MATZnER, E. (2002): N fluxes in two nitrogen saturated forested catchments in Germany: dynamics and modelling with INCA. Hydrology and Earth System Science, 6 (3), 383394

Laubhann, D.; Sterba, H.; ReInds, G. J. u. De VRIES, W. (2009): The impact of atmospheric deposition and climate on forest growth in European monitoring plots: An individual tree growth model. Forest Ecology and Management, 258 (8), 1751-1761

Laubhann D.; Eckmüllner, O. u. STerba, H. (2010): Applicability of non-destructive substitutes for leaf area in different stands of Norway spruce (Picea abies [L.] Karst.) focusing on traditional forest crown measures. Forest Ecology and Management, 260, 1498-1506

LEHMANN (1981) Substratkartierung. unveröffentlicht

LEHNARDT, F. u. Brechtel, H.-M. (1983): Ergebnisse von Bodenwasserhaushalts-Untersuchungen auf grundwasserabgesenkten Waldstandorten des Lockersedimentbereiches in der Rhein-MainEbene, Hessisches Ried. Z. dt. geol. Ges., 134, 701-721

LehNARDT, F. u. Brechtel, H.-M. (1985): Schöpftiefe und effektiv nutzbare Bodenwasserspeicherung der wichtigsten Bodeneinheiten von grundwasserabgesenkten Waldstandorten im Hessischen Ried. Z. f. Kulturtechnik und Flurbereinigung, 26, 138-149

Lelong, F.; Dupraz, C.; Durand, P. u. Didon-Lescont, J. F. (1990): Effects of vegetation type on the biogeochemistry of small catchments (Mont Lozere, France). J. Hydrol., 116, 125-145

Leuschner, C. (1998): Water extraction by fine roots in the forest floor of a temperate FagusQuercus forest. Annals of Forest Science, 55, 141-157

Li, C.; Frolking, S. u. Harris, R. (1994): Modeling carbon biogeochemistry in agricultural soils. Global Biogeochem. Cycl., 8, 237-254

Li, C.; Aber, J. D.; Stange, F.; Butterbach-Bahl, K. u. Papen, H. (2000): A process-oriented model of $\mathrm{N}_{2} \mathrm{O}$ and $\mathrm{NO}$ emissions from forest soils: 1. Model development. Journal of Geophysical Research, 105, 4, 4369-4384

Likens, G. E.; Bormann, F. M.; Pierce, R. S.; Eaton, J. S. u. Johnson, N. M. (1977): Biochemistry of a Forest Ecosystem. Springer, New York, $146 \mathrm{~S}$.

Linkohr, B. I.; Williamson, L. C.; FitTer, A. H. u. Leyser, H. M. O. (2002): Nitrate and phosphate availability and distribution have different effects on root system architecture of Arabidopsis. The Plant Journal, 29, 6, 751-760

LISKI, J. (1995): Variation in soil organic carbon and thickness of soil horizons within a boreal forest stand - effect of trees and implications for sampling. Silva Fennica, 29 (4), 255-266

Liski, J.; Ilvesniemi, H.; Mäkelä, A. u. Westman, C. J. (1999): CO2 Emissons from Soil in response to climatic warming are overestimated - The decomposition of old soil organic matter is tolerant to temperature. Ambio, 28 (2), 171-174

Liski, J.; Perruchoud, D. u. Karjalainen, T. (2002): Increasing carbon stocks in the forest soils of Western Europe. Forest Ecology Management, 169, 159-175 
Liski, J.; Palosuo, T.; Peltoniemi, M. u. Sievänen, R. (2005): Carbon and decomposition model Yasso for forest soil. Ecological Modelling, 189, 168-182

MacDonald, J. A.; Dise, N. B.; Matzner, E.; ARMbruster, M. u. Gundersen, P. (2002): Nitrogen input together with ecosystem nitrogen enrichment predict nitrate leaching from European forests. Global Change Biology, 8, 1028-1033

MALESSA, V. u. AhrendS, B. (2001): Algorithmus der Silikatverwitterungsrate durch Implementierung des Modells "Profile" von Sverdrup u. Warfinge in das Verfahren AcidProgress. Arbeitshefte Boden, 2, 144-155

Malessa, V.; Ahrends, B. u. SCHAll, P. (2001): Erfassung des Tiefengradienten der physikalischchemischen Bodeneigenschaften, Lage der Versauerungsfront. Arbeitshefte Boden, (2), 53-68

MAtSon, P.; LOHSE, K. A. u. HALL, S. J. (2002): The globalisation of nitrogen exposition: Consequences for terrestrial ecosystems. Ambio, 31, 113-119

MCNulty, S. G. u. BogGs, J. L. (2010): A conceptual framework: Redefining forest soil's critical acid loads under a changing climate. Environ. Pollut., 158, 2053-2058

MeER, U. (2007): Methoden zur Beurteilung der Heterogenität und Disaggregierungsverfahren zur Verbesserung des Aussagegehaltes von Bodenbasisdaten. Geosynthesis - online, 144 S.

Mehtätalo, L. (2004): A longitudinal height-diameter model for Norway spruce in Finland. Can.J.For.Res., Vol. 34, 131-140

Meiwes, K. J.; Khanna, P. K. u. B. Ulrich (1986): Parameter for describing soil acidification and their relevance to the stability of forest ecosystems. Forest Ecology and Management, 15, 161 179

Meiwes, K. J. u. MeEsenburg, H. (2007): Säurebildner. GeoBerichte, 7, 34-48

Meiwes, K.-J.; MeEsenburg, H.; Bartens, H.; Rademacher, P. u. Khanna, P. K. (2002): Akkumulation von Auflagehumus im Solling. Mögliche Ursachen und Bedeutung für den Nährstoffkreislauf. Forst u. Holz, 57, 428-433

Meiwes, K. J.; Meesenburg, H.; EichHorn, J.; Jacobsen, C. u. Khanna, P. K. (2009): Changes in C and $\mathrm{N}$ contents of soils under beech forests over a period of 35 years. In: Brumme, R. u. KHANNA, P.: Functioning and Mangement of European Beech Ecosystems. Ecological Studies, 208, Springer Verlag, Berlin Heidelberg, 49-63

MellerT, K.-H.; KÖlling, C. u. Rehfuess, K. E. (1998): Vegetationsentwicklung und Nitrataustrag auf 13 Sturmkahlflächen in Bayern. Forstarchiv, 69, 3-11

Mellert, K.-H.; Gensior, A.; Göttlein, A. u. KÖlling, C. (2005): Risiko erhöhter Nitratkonzentrationen unter Wald in Bayern - Regionalisierung von Inventurergebnissen aus dem Raster des Level I. Waldökologie online, 2, 4-24

Mellert, K. H.; KÖlling, C.; RÜCKer, G. u. SChuberT, M. (2008): Kleinräumige Variabilität von Waldboden-Dauerbeobachtungsflächen in Bayern - Ein Beitrag zur Unsicherheitsabschätzung der BZE II. Waldökologie, Landschaftsforschung und Naturschutz, (6), 43-61

MenZel, A. (1997): Phänologie von Waldbäumen unter sich ändernden Klimabedingungen - Auswertung der Beobachtungen in den Internationalen Phänologischen Gärten und Möglichkeiten der Modellierung von Phänodaten. Forstliche Forschungsberichte München, Nr. 164, 147 S.

MenZel, A. u. Fabian, P. (1999): Growing season extended in Europe. Nature 397, S. 659

Meyer, P.; Menke, N.; Nagel, J.; Hansen, J.; Kawaletz, H.; Paar, U. u. Evers, J. (2009): Entwicklung eines Managementmoduls für Totholz im Forstbetrieb. Abschlussbericht DBU, $106 \mathrm{~S}$.

Mohr, K.; Meesendburg, H.; Horvath, B.; Meiwes, K. J.; SchaAf, S. u. Dämmgen, U. (2005): Bestimmung von Ammoniak-Einträgen aus der Luft und deren Wirkungen auf Waldökosysteme (ANSWER-Projekt). Landbauforschung Völkenrode, Sonderheft 279, Bundesforschungsanstalt für Landwirtschaft (FAL), Braunschweig, $113 \mathrm{~S}$.

MÖHRING, B. (2001): Nachhaltige Forstwirtschaft und Rentabilitätsrechnung - Ein Widerspruch? Allg. Forst- u. Jagdztg., 172 (4), 61-66 
MÖHRING, B. u. RÜPING, U. (2006): Bewertungskonzept für forstliche Nutzungsbeschränkungen. Schriften zur Forstökonomie 32, $48 \mathrm{~S}$.

Möhring, B.; RÜPInG, U.; LeEfKen, G. u. Ziegler, M. (2006): Die Annuität - ein „missing link“ der Forstökonomie. Allg. Forst- und Jagdztg., 177 (2), 21-29

Mol-Dijkstra, J. u. KROS, H. (2001): Modelling effects of acid deposition and climate change on soil and run-off chemistry at Risdalsheia, Norway. Hydrology and Earth System Science, 5, 487-498

Mol-Dijkstra, J.; Reinds, G. J.; Kros, H.; BJÖRn, B. u. De VRIES, W. (2009): Modelling soil carbon sequestration of intensively monitored forest plots in Europe by three different approaches. Forest Ecology and Management, 258 (8), 1780-1793

MonTEITH, J. L. (1965): Evaporation and environment. Symp. Soc. Exp. Biol., 19, 205-224

Monteith, J. L. (1985): Evaporation from land surfaces: Progress in analysis and prediction since 1948. In: Advances in Evapotranspiration, Proc. National Conference on Advances in Evapotranspiration, Dec. 16-17. Chicago, IL, Am. Soc. Agric. Eng., St. Joseph, MI. S.

Mudelsee, M.; Chirila, D.; Deutschländer, T.; Döring, C.; Haerter, J.; Hagemann, S.; Hoffmann, H.; Jacob, D.; P. Krahé, Lohmann, G.; Moseley, C.; Nilson, E.; Panferov, O.; Rath, T. u. Tinz, B. (2010): Climate Model Bias Correction und die Deutsche Anpassungsstrategie. Mitteilungen der DMG, 03, 2-7

MÜLLER, J. (2006): Effects of drought on the water balance of selected forest sites and the evaluation of a drought risk. Schriften aus der Forstlichen Fakultät der Universität Göttingen und der Niedersächsischen Forstlichen Versuchsanstalt, 142, 142-148

MÜLLER, J. (2007): Auswirkung von Trockenheit auf den Waldzustand - Ansätze zur Bewertung der Trockenheitsgefährdung von Waldstandorten. 12. Gumpensteiner Lysimetertagung 2007

MÜlleR, U. (2004): Auswertungsmethoden im Bodenschutz. Dokumentation zur Methodendatenbank des Niedersächsischen Bodeninformationssystems (NIBIS). Arbeitshefte Boden, 2004 (2), 409

MÜller-Using, B. (2005): Totholzdynamik eines Buchenbestandes im Solling, Berichte des Forschungszentrums Waldökosysteme, Reihe A, Bd. 193, Göttingen

Nagel, H.-D.; Becker, R.; Eitner, H.; Hübener, P.; Kunze, F.; Schlutow, A.; Schütze, G. u. WeigelT-KirChNER, R. (2004): Critical Loads für Säure und eutrophierenden Stickstoff. Förderkennzeichen 20085 212. Strausberg. 172 S.

NAGEL, J. (1999): Konzeptionelle Überlegungen zum schrittweisen Aufbau eines waldwachstumskundlichen Simulationssystems für Nordwestdeutschland. Schriften aus der Forstlichen Fakultät der Universität Göttingen und der Nieders. Forstl. Versuchsanstalt, Band 128, J.D. Sauerländer's Verlag, Frankfurt a. M., S. 122

NAGel, J. (2002): Das Open Source Entwicklungsmodell - eine Chance für Waldwachstumssimulatoren. Deutscher Verband Forstlicher Forschungsanstalten - Sektion Ertragskunde, Jahrestagung Schwarzburg 13-15. Mai 2002, 1-6

NAGEL, J. (2008): Schätzung der Holznutzung und der Totholzmengen im Hinblick auf Quantifizierung der korrespondierenden Nährstoffmengen. Themenschwerpunkt Energieholz und standörtliche Nachhaltigkeit, Teil 1, Forst u. Holz, 63. Jg., 23-25

Nagel, J. (2009): Waldwachstumssimulation mit dem Softwarepaket TreeGrOSS - Neuerungen, Erweiterungsmöglichkeiten und Qualitätsmanagement. In: RÖMISCH, K.; NothduRFT, A. u. WunN, U. (Hrsg.): Tagungsband der gemeinsamen Jahrestagung der Sektion Forstliche Biometrie und Informatik im DVFFA (20. Tagung) und der AG Ökologie u. Umwelt in der Intern. Biometr. Gesell., 22.-24.09.2008 in Freiburg. Die Grüne Reihe, 174-178

Nagel, J.u. Biging, G.S. (1995): Schätzung der Parameter der Weibullfunktion zur Generierung von Durchmesserverteilungen. Allg. Forst- u. J. Ztg., 166 (9/10), 185-189

Nagel, J.; Albert, M. u. Schmidt, M. (2002): Das waldbauliche Prognose- und Entscheidungsmodell BWINPro 6.1. Forst u. Holz 57 (15/16), 486-493

Nagel, J.; Duda, H. u. Hansen, J. (2006): Forest Simulator BWINPro7. Forst u. Holz 61 (10), 427429

Beiträge aus der NW-FVA, Band 10, 2013 
NAGEL, H.-D. u. Gregor, H.-D. (1999): Ökologische Belastungsgrenzen - Critical Loads u. Levels. Ein internationales Konzept für die Luftreinhaltepolitik. Springer. Berlin. 259 S.

Nagel, H.-D.; Schlutow, A.; Kraft, P.; SCheusner, T. u. Weigelt-Kirchner, R. (2010): Modellierung und Kartierung räumlich differenzierter Wirkungen von Stickstoffeinträgen in Ökosysteme im Rahmen der UNECE-Luftreinhaltekonvention. Teilbericht II: Das BERN-Modell ein Bewertungsmodell für die oberirdische Biodiversität. Texte Umweltbundesamt, 08/2010, 123

Nebe, W. u. Herrmann, U. J. (1987): Das ökologische Messfeld der Sektion Forstwirtschaft der TU Dresden VI. Zur Verteilung der Nährelemente in der oberirdischen Dendromasse eines 100jährigen Fichtenbaumholzes. Wissenschaftliche Zeitschrift der Technischen Universität Dresden, 36 (6), 235-241

NFP (Niedersächsisches Forstplanungsamt) (2002): Forstliche Standortsaufnahme - Geländeökologischer Schätzrahmen. Anwendungsbereich: Pleistozänes (Diluviales) Flachland

NiLSEN, P. (1990): Effect of nitrogen on drought of Norway spruce and Scots pine. Sci. Total Environ., 96, 189-198

NiLsSON, L.-O. u. WikLund, K. (1992): Influence of nutrient and water stress on Norway spruce production in south Sweden - the role of air pollutants. Plant and Soil, 147, 251-265

Nilsson, S. I.; Miller, H. G. u. Miller, J. D. (1982): Forest growth as a possible cause of soil and water acidification: an examination of the concepts. Oikos, 39, 40-49

NORD-LARSEN, T. (2002): Stand and site productivity response follwing whole tree harvesting in early thinnings of Norway spruce (Picea abies (L.) karst.). Biomass and Bioenergy, 23, 1-12

Norman, J.; Jansson, P. E.; Farahbakhshazad, N.; Butterbach-BAhl, K.; Li, C. u. KLemedtsSON, L. (2008): Simulation of $\mathrm{NO}$ and $\mathrm{N}_{2} \mathrm{O}$ emissions from a spruce forest during a freeze/thaw event using an $\mathrm{N}$-flux submodel from the PnET-N-DNDC model integrated to CoupModel. Ecological Modelling, 216, 18-30

NW-FVA (Hrsg.) (2007): Waldzustandsbericht Hessen 2007. Göttingen, 32 S.

NW-FVA (Hrsg.) (2011): Waldzustandsbericht Hessen 2011. Göttingen, 32 S.

OfFer, A. u. STAUPENDAHL, K. (2009): Neue Bestandessortentafeln für die Waldbewertung und ihr Einsatz in der Bewertungspraxis. Forst u. Holz, 64 (5), 16-25

Overbeck, M.; Schmidt, M.; Fischer, C.; Evers. J.; Schulze, A.; Höveldann, T. u. Spellmann, H. (2011): Ein statistisches Modell zur Regionalisierung der nutzbaren Feldkapazität von Waldstandorten in Niedersachsen. Forstarchiv, 82, 92-100

Pardo, L. H.; Driscoll, C. T. u. Likens, G. E. (1995): Patterns of nitrate loss from a chronosequence of clear-cut watersheds. Water, Air and Soil Pollution, 85, 1659-1664

Penman, H.L. (1948): Natural evaporation from open water, bar soils and grass. Proc. Royal Meteorologic Society, 193, 120-145

Penne, C.; Ahrends, B.; Deurer, M. u. BötTCher, J. (2010): The impact of the canopy structure on the spatial variability in forest floor carbon stocks. Geoderma, 158 (3-4), 282-297

Peters, K. (1995): Methoden zur Bestimmung der trockenen Deposition auf Pflanzenoberflächen. Z. Umweltchemi. Ökotox., 7 (6), 337-352

Piani, C.; HAerter, J. O. u. Coppola, E. (2010): Statistical bias correction for daily precipitation in regional climate models over Europe. Theor. Appl. Climatol., 99, 187-192

Posch, M. u. KuRZ, D. (2007): A2M - A program to compute all possible mineral modes from geochemical analyses. Computers \& Geosciences, 33, 563-572

Posch, M. u. ReINDS, G. J. (2009): A very simple dynamic soil acidification model for scenario analyses and target load calculations. Environmental Modelling u. Software, 24 (3), 329-340

Posch, M.; Hettelingh, J.-P. u. Slootweg, J. (2003): Manual for Dynamic Modelling of Soil Response to Atmospheric Deposition. RIVM Report 259101012, Bilthoven, The Netherlands, $69 \mathrm{~S}$. 
Pries, L.; Altstädt, N. u. VelBeCKer, K. (1999): Gefährdung der Wälder im Rhein-Main-Gebiet Konzepte zur Walderhaltung und Waldstabilisierung. Mitteilungen der Hessischen Landesforstverwaltung, Band 35, $243 \mathrm{~S}$.

Prietzel, J.; Stetter, U.; Klemmt, H.-J. u. Rehfuess, K. E. (2006): Recent carbon and nitrogen accumulation and acidification in soils of two Scots pine ecosystems in Southern Germany. Plant and Soil, 289, 153-170

Puhe, J. u. Ulrich, B. (2001): Globale Climate Change and Human Impacts on Forest Ecosystems. Postglacial Development, Present Situation, and Future Trends in Central Europe. Ecological Studies, Springer. Berlin u. a. $592 \mathrm{~S}$.

PUSTER (1910): Ein Jahrzehnt im Kampfe mit dem Maikäfer. Forstw. Zbl., 633-649

R Development Core Team (2010): R: A language and environment for statistical computing. R Foundation for Statistical Computing, Vienna, Austria. ISBN 3-900051-07-0, URL http://www.R-project.org

Raissi, F.; MÜller, U. u. Meesenburg, H. (2009): Ermittlung der effektiven Durchwurzelungstiefe von Forststandorten. GeoFakten, 9, 1-7

REGIERUNGSPRÄSIDIUM DARMSTADT (1999): Grundwasserbewirtschaftungsplan Hessisches Ried. Darmstadt, $136 \mathrm{~S}$.

Reinds, G. J.; Posch, M. u. Leemans, R. (2009): Modelling recovery from soil acidification in European forests under climate change. Science of the Total Environment, 407, 5663-5673

Renger, M.; Bohne, K.; Facklam, M.; Harrach, T.; RieK, W.; SchäFer, W.; Wessolek, G. u. ZACHARIAS, S. (2008): Ergebnisse und Vorschläge der DBG-Arbeitsgruppe „Kennwerte des Bodengefüges" zur Schätzung bodenphysikalischer Kennwerte. Berlin, 51 S.

Reuss, J. O. (1983): Implications of the calcium-aluminum exchange system for the effect of acid precipitation on soils. J. Environ. Qual., 12, (4), 591-595

RiCHARDS, L.A. (1931): Capillary conduction of liquids through porous mediums. Physics, 1 (5), 318333

Richter, A. K.; Hirano, Y.; Luster, J.; Forssard, E. u. Brunner, I. (2010): Soil base saturation affects root growth of European beech seedlings. J. Plant Nutr. Soil Sci., doi: 10.1002/jppln.200900351

RiCHTER, D. (1995): Ergebnisse methodischer Untersuchungen zur Korrektur des systematischen Messfehlers des Hellmann-Niederschlagsmessers. Berichte des Deutschen Wetterdienstes 194

RichtLinien für die Ermittlung und Prüfung des Verkehrswertes von Waldflächen und Nebenentschädigungen (Waldwertermittlungstichtlinien - WaldR 2000) vom 12.07.2000, Bundesanzeiger, Jg. 52, Nr. $168 \mathrm{a}$

Riebeling, R. (1989a): Abschließende Stellungnahme über Mindererlöse und Hiebsunreifeverluste durch erhöhte Trocknisanfälle nach Grundwasserabsenkungen im Stadtwald Gernsheim. 12 S.

Riebeling, R. (1989b): Forstlich-ökologische Untersuchungen im Hess. Ried - Gutachterliche Stellungnahme über bereinigte Mindererlöse, Mehrkosten und Hiebsunreifeverluste im Gemeindewald Biblis. $11 \mathrm{~S}$.

Riebeling, R. (1990): Gutachterliche Stellungnahme über bereinigte Mindererlöse, Mehrkosten und Hiebsunreifeverluste im Gemeindewald Rohrheim. $11 \mathrm{~S}$.

Riebeling, R. u. Hocke, R. (1988): Forstlich-ökologische Stellungnahme zu den Infiltrationsanlagen Allmendfeld und Jägersburger Wald. 14 S. und Anlagen. AZ.: Z 81.946

RIEK, W. (1998): Verfahren zur Bestimmung des effektiv nutzbaren Bodenwassers von Kiefernstandorten im pleistozänen Tiefland. Beiträge für Forstwirtschaft und Landschaftsökologie, 32 (1), 28-33

RieK, W. u. WolfF, B. (2007): Bodenkundliche Indikatoren für die Auswertung der Bodenzustandserhebung im Wald (BZE II). Berichte des Forschungszentrums Waldökosysteme, Reihe B, 74, 1132

Rockel, B.; Will, A. u. Hense, A. (2008): The regional climate model COSMO-CLM (CCLM). Editorial. Meteorol. Z., 17 (4), 347-348

Beiträge aus der NW-FVA, Band 10, 2013 
Roeckner, E.; Bäuml, G.; Bonaventura, L.; Brokopf, R.; Esch, M.; Giorgetta, M.; Hagemann, S.; Kirchner, I.; Kornblueh, L.; Manzini, E.; Rhodin, A.; Schlese, U.; SCHUlZWEIDA, U. u. TOMPKINS, A. (2003): The atmospheric general circulation model ECHAM5 - Part 1: Model Description. MPI-Berichte, Max-Planck-Institut für Meteorologie, Bd. 349

RÖHLE, H. (1995): Zum Wachstum der Fichte auf Hochleistungsstandorten in Südbayern. Mitt. aus der Staatsforstverwaltung Bayerns, 48. Heft, $272 \mathrm{~S}$.

Romanyá, J.; Cortina, J.; FAlloon, P.; Coleman, K. u. SMith, P. (2000): Modelling changes in soil organic matter after planting fast-growing Pinus radiata on mediterranean agricultural soils. European Journal of Soil Science, 51, 627-641

Rothe, A. u. Mellert, K. H. (2004): Effects of forest management on nitrate concentrations in seepage water of forests in southern Bavaria, Germany. Water, Air, and Soil Pollution, 156, 337 355

RÜPING, U. (2009): Wasserschutz im Wald: Betriebswirtschaftliches Bewertungskonzept und institutionelle Umsetzungsinstrumente. Schriften zur Forst- und Umweltökonomie, 34. J.D. Sauerländer's Verlag, Frankfurt am Main, 256 S.

RumpF, H. (2007): Erste Ergebnisse eines Freisaatversuches mit Traubeneiche im Nordwestdeutschen Flachland. Forst u. Holz 62, 13-18

SACHS, L. u. HedDERICH, J. (2006): Angewandte Statistik. Methodensammlung mit R. Springer, Berlin, $702 \mathrm{~S}$.

SAINJu, U. M. u. Good, R. E. (1993): Vertical root distribution in relation to soil properties in New Jersey Pinelands forest. Plant and Soil, 150, 87-97

SCHADAUER, K., (1999): Oberhöhenbonität und Standort der Fichte nach Daten der Österreichischen Forstinventur. Mitteilungen der Forstl. Bundesversuchsanstalt Wien, 171, 135 S.

Schär, C.; Vidale, P. L.; Luthi, D.; Frei, C.; Haberli, C.; Liniger, M. A. u. Appenzeller, C. (2004): The role of increasing temperature variability in European summer heatwaves. Nature, 427 (6972), 332-336

SChlutow, A. I.; Profft, I. u. Frischbier, N. (2009): Das BERN-Modell als Instrument zur Einschätzung der Angepasstheit von Waldgesellschaften und Baumarten an den Klimawandel in Thüringen. Forst u. Holz, 64 (4), 31-39

SCHMiDT, M. (2008): Ein longitudinales Höhen-Durchmesser Modell für Fichte in Nordwestdeutschland. Tagungsband der Jahrestagung der Sektion Ertragskunde des DVFFA vom 05. bis 07. Mai 2008 in Trippstadt, 22-31

SCHмidT, M., (2009): Ein longitudinales Höhen-Durchmesser Modell für Fichte in Deutschland. Tagungsband der Jahrestagung der Sektion Ertragskunde im DVFFA vom 25.-27.05.2009 in Ascona/Schweiz, 69-82

Schmidt, M.; HanewinKel, M.; Kublin, E.; KÄndler, G. und Kohnle, U. (2010): An inventorybased approach for modeling single tree storm damage - experiences with the winter storm 1999 in southwestern Germany. Can. J. For. Res., 40 (8), 1636-1652

SCHOBER, R. (1987): Ertragstafeln wichtiger Baumarten. J. D. Sauerländer's Verlag, Frankfurt a. M.

SCHÖNING, I.; TOTSCHE, K. U. u. KÖGEL-KNABER, I. (2006): Small scale spatial variability of organic carbon stocks in litter and solum of a forested Luvisol. Geoderma, 136, 631-642

SCHÖPFER, W. u. DAubER, E. (1989): Bestandessortentafeln 82/85. Forstliche Versuchs- und Forschungsanstalt Baden-Württemberg, $51 \mathrm{~S}$. http://books. google.de/books?id=IBruGwAACAAJ\&hl=de\&sitesec=reviews

SCHÖPp, W.; POSCH, M.; MYLONA, S. u. JohANSSON, M. (2003): Long-term development of acid deposition $(1880-2030)$ in sensitive freshwater regions in Europe. Hydrology and Earth System Science, 7 (4), 436-446

Schrijver, D. A.; Staelens, J.; Wuyts, K.; Hoydonck, V. G.; JAnssen, N.; Mertens, J.; Gielis, L.; Geudens, G.; Augusto, L. u. Verheyen, K. (2008): Effect of vegetation type on throughfall deposition and seepage flux. Environ. Pollut., 153 (2), 295-303 
SCHULLA, J. (1997): Hydrologische Modellierung von Flussgebieten zur Abschätzung der Folgen von Klimaänderung. Diss. 12018, ETH Zürich, 163 S.

Schulla, J. u. JASPER, K. (2007): Model Description WaSiM-ETH. Technical Report, unveröff.; http://www.wasim.ch/downloads/doku/wasim/wasim_2007_en.pdf

Schulp, C. J. E.; NAbuUrs, G. J.; Verburg, P. H. u. WAal, R. W. D. (2008): Effects of tree species on carbon stocks in forest floor and mineral soil and implications for soil carbon inventories. Forest Ecology and Management, 256, 482-490

Schulte-Bisping, H.; Bredemeier, M. u. Beese, F. (2001): Nachhaltigkeit der Regelungsfunktion von Waldökosystemen: Bodeneigenschaften und Stoffhaushalt. Forst u. Holz, 56 (15), 479-482

SChulze, K.; Borken, W.; Muhr, J. u. MATZNer, E. (2009): Stock, turnover time and accumulation of organic matter in bulk and density fractions of a Podzol soil. European Journal of Soil Science, 60, 567-577

Schwenke, W. (1974): Die Forstschädlinge Europas. Band 2, Verlag Paul Parey, Hamburg und Berlin, $500 \mathrm{~S}$.

Schwerdtfeger, F. (1981): Die Waldkrankheiten. Verlag Paul Parey, Hamburg und Berlin, 486 S.

SIMEK, M. u. COOPER, J. E. (2002): The influence of soil pH on denitrification: progress towards the understanding of this interaction over the last 50 years. European Journal of Soil Science, 53, 345-354

Sipkova, Z.; Balzer, S.; Evans, D. u. Ssymank, A. (2010): Assessing the conservation status of European Union habitats - Results of the community report with a case study of the German national report. Ann. Bot. (Roma), 19-37

SpeKat, A.; ENKE, W. u. KReIENKAMP, F. (2007): Neuentwicklung von regional hoch aufgelösten Wetterlagen für Deutschland und Bereitstellung regionaler Klimaszenarios auf der Basis von globalen Klimasimulationen mit dem Regionalisierungsmodell WETTREG auf der Basis von globalen Klimasimulationen mit ECHAM5/MPI-OM T63L31 2010 bis 2100 für die SRESSzenarios B1, A1B und A2. Endbericht im Rahmen des FuE-Vorhabens „Klimaauswirkungen und Anpassung in Deutschland - Phase 1: Erstellung regionaler Klimaszenarios für Deutschland" des Umweltbundesamtes, Förderkennzeichen 20441 138. Publikationen des Umweltbundesamtes, $149 \mathrm{~S}$.

Spellmann, H.; SutMÖlleR, J. u. MeEsenburg, H. (2007): Risikovorsorge im Zeichen des Klimawandels. AFZ/Der Wald, 23, 1246-1249

Spieker, H.; Mielikäinen, K.; KÖHL, M. u. SkOvsgaArd, J. P. (1996): Growth Trends in European Forests. European Forest Institute Research Report No. 5, Springer, 368 S.

SPRANGER, T. (2000): Methodische Ansätze zur Ermittlung der Gesamtdeposition in Waldbestände. Forstarchiv, 71, 39-41

Spranger, T.; Lorenz, K. u. Gregor, H.-D. (2004): Manual on methodologies and criteria for Modelling and Mapping Critical Loads u. Levels and Air Pollution Effects, Risks and Trends. Texte Umweltbundesamt, Federal Environmental Agency (Umweltbundesamt), Berlin, 266 S.

SsymanK, A.; HAUKe, U.; RÜCKRIEM, C. u. SChrÖDER, E. (1998): Das europäische Schutzgebietssystem Natura 2000. BfN-Handbuch zur Umsetzung der Fauna-Flora-Habitat-Richtlinie und der Vogelschutz-Richtlinie. Schr.R. f. Landschaftspfl. u. Natursch., 53, 560 S.

STAUPENDAHL, K. (2011): Modellierung der Überlebenswahrscheinlichkeit von Waldbeständen mit Hilfe der neu parametrisierten Weibull-Funktion. Forstarchiv, 82 (1), 10-19

STERBA, H. (1981): Natürlicher Bestockungsgrad und Reinekes SDI. Centralblatt f. d. ges. Forstwesen, 98 (2), 101-116

STERBA, H. (1987): Estimating potential density from thinning experiments and inventory data. Forest Science, 33 (4), 1022-1034

STERBA, H. (1995): Forest decline and increasing increments: a simulation study. Forestry, Vol. 68 (2) $153-163$

Beiträge aus der NW-FVA, Band 10, 2013 
STOCK, R. (Hrsg.) (2004): Nachhaltige und multifunktionale Forstwirtschaft - Ein Verfahrens- und Zustandsvergleich für verschiedene Testregionen. Initiativen zum Umweltschutz, Bd. 58, Erich Schmidt Verlag, Berlin, 283 S.

STORCH, M. (1995): Qualitative und quantitative Aufnahme des Befalls durch kernholzentwertende Insekten an 113 eingeschnittenen Eichenstammabschnitten (Stadtwald Gernsheim). Internes Gutachten für die Stadt Gernsheim, unveröffentlicht, $13 \mathrm{~S}$.

SuN (2009): http://www.sun.com/software/products/appsrvr/index.jsp, 15.05.09

Sverdrup, H. (1990): The kinetics of base cation release due to chemical weathering. Lund University Press, Lund/Sweden, 246 S.

SVERDRUp, H. (1996): Geochemistry, the key to understanding the environmental chemistry. The Science of the Total Environment, 183, 67-87

Sverdrup, H. u. WARFvinge, P. (1993): Calculating field weathering rates using a mechanistic geochemical model PROFILE. Applied Geochemistry, 8, 273-283

SVERDRUP, H. u. WARFVINGE, P. (1995): Estimating field weathering rates using laboratory kinetics. In: White, A. F. u. BrantLY, S. L.: Chemical Weathering of Silicate Minerals. 31. Mineralogical Society of America. Washingston, DC, 485-541

Sverdrup, H.; De Vries, W. u. Hendriksen, A. (1990): Mapping Critical Loads: A guidance to the criteria, calculations, data collection and mapping of critical loads. Nordic Council of Ministers, Copenhagen, Miljorapport (Enviromental Report) 1990:14, 124 S.

Sverdrup, H.; Warfvinge, P. u. Nihlgard, B. (1994): Assessment of soil acidification effects on forest growth in Sweden. Water, Air and Soil Pollution, 78, 1-36

Tebaldi, C.; Hayhoe, K.; Arblaster, J. M. u. Meehl, G. A. (2006): Going to the extremes: an intercomparsion of model-simulated historical and future changes in extreme events. Climate Change, 79, 185-211

TeEPe, R.; Dilling, H. u. BeESE, F. (2003): Estimating water retention curves of forest soils from soil texture and bulk density. J. Plant Nutr. Soil Sci., 166, 111-119

Therneau, T. M. u. Grambsch, P.M. (2000): Modelling Survival Data - Extending the Cox Model. Springer, New York, Berlin, Heidelberg

TherneAu, T.M. u. Lumley, T. (2009): Survival analysis, including penalised likelihood. R package version 2.35-8. http://CRAN.R-project.org/package= survival

Thornley, J. H. M. u. CAnNell, M. G. R. (2001): Soil Carbon Storage Response to Temperature: an Hypothesis. Annals of Botany, 87, 591-598

TieTEMA, A. (2004): WANDA, a regional dynamic nitrogen model (With Aggregated Nitrogen DynAmics) for nitrate leaching from forests. Hydrology and Earth System Sciences, 8, 803-813

Tietema, A.; Bounten, W. u. WARTENBergh, P. E. (1991): Nitrous oxide dynamics in an oak-beech forest ecosystem in the Netherlands. For. Ecol. Manage., 44, 53-61

TikTAK, A. u. van Grinsven, H. J. M. (1995): Review of sixteen forest-soil-atmosphere models. Ecological Modelling, 83, 35-53

UlRICH, B. (1995): Der ökologische Bodenzustand - seine Veränderungen in der Nacheiszeit, Ansprüche der Baumarten. Forstarchiv, 66, 117-127

Ulrich, B. u. Shrivastava, M. B. (1978): Schätzung quantitativer Bodenparameter bei der forstlichen Standortskartierung am Beispiel des hessischen Berglands. Forstw. Cbl., 97, 41-50

UmweltBundesamt (2010): Nationale Trendtabellen für die deutsche Berichterstattung atmosphärischer Emissionen $1990-2008$ (Fassung zur EU-Submission 15.01.2010). http://www.umweltbundesamt.de, Umweltbundesamt, Dessau

UN/ECE (2004): Handbook for the 1979 Convention on Longe-range Transboundary Air Pollution and its Protocols. UN, New York, Geneva, $341 \mathrm{~S}$.

UN/ECE (2006): Strategies and Policies for air pollution abatement. 2006 review prepared under The Convention on Long-range Transboundary Air Pollution. United Nations, New York and Geneva, 78 S. 
van Breemen, N.; C. T. Driscoll u. J. Mulder (1983): Acidification and alkalinization of soils. Plant and Soil, 75, 283-308

VAN DER SALM, C. (2001): Assessment of the regional variation in weathering rates of loess and clay soils in the Netherlands. Water, Air and Soil Pollution, 131, 217-243

VAn Der Salm, C.; KÖHLEnberg, L. u. DE VRIES, W. (1998): Assessment of weathering rates in Dutch loess and river-clay soils at $\mathrm{pH} 3.5$, using laboratory experiments. Geoderma, 85, 41-62

VAN GENUCHTEN, M.T. (1980): A closed-form equation for predicting the hydraulic conductivity of unsaturated soils. Soil Sci. Soc. Am. J. 44, 892-898

Vanmechelen, L.; Groenemans, R. U. u. Vanranst, E. (1997): Forest soil conditions in Europe. Results of a large-scale soil survey. Technical Report. - EC, UN/ECE. Ministry of the Flemish Community, Brüssel/Genv., 259 S.

Velbel, M. (1986): The mathematical basis for determining rates of geochemical and geomorphic processes in small forest watersheds by mass balance. Examples and implications. In: COLEMAN, S. u. Dethier, D.: Rates of Chemical Weathering of Rocks and Minerals. Academy Press, 439451

Vleeshouwes, L. M. u. Verhagen, A. (2002): Carbon emission and sequestration by agricultural land use: a model study for Europe. Global Change Biology, 8, 519-530

WAGENFÜHR, R. (2000): Holzatlas. Fachbuchverl. im Hanser Verlag, Leipzig, 707 S.

Wallman, P.; Belyazid, S.; Svensson, M. G. E. u. Sverdrup, H. (2006): DECOMP - a semimechanistic model of litter decomposition. Environmental Modelling u. Software, 21, 33-44

Walse, C.; Berg, B. u. Sverdrup, H. (1998): Review and synthesis of experimental data on organic matter decomposition with respect to the effect of temperature, moisture, and acidity. Environ. Res., 6, 25-40

Warfvinge, P.; Falkengren-Grerup, U. u. Sverdrup, H. (1993): Modelling long-term cation supply in acidified forest stands. Environ. Pollut., 80, 1-14

WeBer, G. u. BAHR, B. (2000): Wachstum und Ernährungszustand junger Eschen (Fraxinus excelsior L.) und Bergahorne (Acer pseudoplatanus L.) auf Sturmwurfflächen in Bayern in Abhängigkeit vom Standort. Forstw. Cbl., 119, 177-192

Weber-BlasschKe, G.; Claus, M. u. Rehfuess, K. E. (2002): Growth and nutrition of ash (Fraxinus exelsior L.) and sycamore (Acer pseudoplatanus L.) on soils of different base saturation in pot experiments. For. Ecol. Manage., 167, 43-56

WeIs, W.; HubER, C. u. GÖTtLEIN, A. (2008): Waldverjüngung und Wasserqualität. LWF aktuell, 66, $9-12$

Wendling, U. (1995): Berechnung der Gras-Referenzverdunstung mit der FAO Penman-MonteithBeziehung. Wasserwirtschaft, 85, 12, 602-604

Wessolek, G.; Dujjnisveld, W. H. M. u. Trinks, S. (2004): Ein neues Verfahren zur Berechnung der Sickerwasserrate aus dem Boden: das TUB-BGR-Verfahren. In: Bronstert, A.; THIEKEN, A; Merz, B.; Rohde, M. u. Menzel, L. (Hrsg.): Wasser- und Stofftransport in heterogenen Einzugsgebieten. Forum für Hydrologie und Wasserbewirtschaftung, Heft 05.04, Beiträge zum Tag der Hydrologie, Band 1, 135-145

Wessolek G.; Kaupenjohann, M. u. Renger, M. (2009): Bodenphysikalische Kennwerte und Berechnungsverfahren für die Praxis. Bodenökologie und Bodengenese 40

Wijesinghe, D. K. u. Hutchings, M. J. (1997): The Effects of Spatial Scale of Environmental Heterogeneity on the Growth of a Clonal Plant: An Experimental Study with Glechoma hederacea. Journal of Ecology, 85, 1, 17-28

WILPERT, K. VON (1990): Die Jahrringstruktur von Fichten in Abhängigkeit vom Bodenwasserhaushalt auf Pseudogley und Parabraunerde : ein Methodenkonzept zur Erfassung standortsspezifischer Wasserstreßdisposition. Freiburger bodenkundl. Abhandlungen, 24, 184 S.

WOLLBORn, P. u. BöCKMANN, T. (1998): Ein praktikables Modell zur Strukturierung des Vorrates aus Ertragstafelschätzung. Forst u. Holz, 53 (18), 547-550 
WoOD, S.N. (2006): Generalized additive models: an introduction with R. Chapman u. Hall/CRC, Boca Raton, $391 \mathrm{~S}$.

Worrell, R. u. HAMPSON, A. (1997): The influence of some forest operations on the sustainable management of forest soils-review. Forestry, 70 (1), 61-85

WuLF, M. (1994): Überblick zur Bedeutung des Alters von Lebensgemeinschaften, dargestellt am Beispiel „historisch alter Wälder“. In: NordDeutsche NaturschutZakademie (Hrsg.): Bedeutung historich alter Wälder für den Naturschutz. NNA-Ber., 7 (3), 3-14

Zanger (1998): Die Geschichte des Hessischen Rieds. Ökologie und Landschaft Nr. 8

ZEZsChwiTZ, E. V. vON (1980): Analytische Kennwerte typischer Humusformen westfälischer Bergländer. Z.Pflanzenernähr. Bodenk., 143, 692-700

ZEZsCHWITZ, E. V. VON (1985): Qualitätsänderungen des Waldhumus. Forstwissenschaftliches Centralblatt, 104, 205-220

ZimMERMANN, H. (1953/54): Substratkartierung. Unveröffentlicht

ZimmermanN, H. (1956): Die Waldstandorte im Wuchsbezirk Rhein-Main-Ebene. 133 S.

ZimmermanN, H. (1989): Die Waldstandorte in Hessen und ihre Bestockung. Waldbauliche Leitlinien und Empfehlungen für den öffentlichen Wald. Mitteilungen der Hessischen Landesforstverwaltung, Band 20, J.D. Sauerländer's, Frankfurt a. M.

ZirLeWagen, D. (2009): Regionalisierung der bodenchemischen Drift in der Dübener Heide im Zeitraum 1995 - 2006. Waldökologie, Landschaftsforschung und Naturschutz, 8, 21-30 


\section{Autoren}

Jörg Ahner

ehem.: Nordwestdeutsche Forstliche Versuchsanstalt

Abt. Waldwachstum

joerg.ahner@forst.hessen.de

Falko Engel

Nordwestdeutsche Forstliche Versuchsanstalt

Abt. Waldwachstum

Grätzelstraße 2

D-37079 Göttingen

falko.engel@nw-fva.de

\section{Dr. Swen Hentschel}

Nordwestdeutsche Forstliche

Versuchsanstalt

ehem.: Abt. Waldwachstum /

aktuell: Abt. Waldschutz

Grätzelstraße 2

D-37079 Göttingen

swen.hentschel@nw-fva.de

\section{Dr. Henning Meesenburg}

Nordwestdeutsche Forstliche

Versuchsanstalt

Abt. Umweltkontrolle

Grätzelstraße 2

D-37079 Göttingen

henning.meesenburg@nw-fva.de

\section{Dr. Bernd Ahrends}

Nordwestdeutsche Forstliche

Versuchsanstalt

Abt. Umweltkontrolle

Grätzelstraße 2

D-37079 Göttingen

bernd.ahrends@nw-fva.de

\section{Dr. Jan Hansen}

Nordwestdeutsche Forstliche

Versuchsanstalt

Abt. Waldwachstum

Grätzelstraße 2

D-37079 Göttingen

jan.hansen@nw-fva.de

\section{Dr. Rainer Hurling}

Nordwestdeutsche Forstliche

Versuchsanstalt

Abt. Waldschutz

Grätzelstraße 2

D-37079 Göttingen

rainer.hurling@nw-fva.de

\section{Uwe Mestemacher}

ehem. Georg-August-Universität

Göttingen

Abt. für Forstökonomie und

Forsteinrichtung

uwe.mestemacher@nfp.niedersachsen.de 
Dr. Peter Meyer

Nordwestdeutsche Forstliche

Versuchsanstalt

Abt. Waldwachstum

Grätzelstraße 2

D-37079 Göttingen

peter.meyer@nw-fva.de

\section{Prof. Dr. Jürgen Nagel}

Nordwestdeutsche Forstliche

Versuchsanstalt

Abt. Waldwachstum

Grätzelstraße 2

D-37079 Göttingen

juergen.nagel@nw-fva.de

\section{Bianca Pape}

ehem: Nordwestdeutsche Forstliche Versuchsanstalt

Abt. Waldschutz

\section{Prof. Dr. Bernhard Möhring}

Georg-August-Universität Göttingen

Abt. für Forstökonomie und

Forsteinrichtung

Büsgenweg 5

D-37077 Göttingen

bmoehri@uni-forst.gwdg.de

\section{Ralf Nagel}

Nordwestdeutsche Forstliche

Versuchsanstalt

Abt. Waldwachstum

Grätzelstraße 2

D-37079 Göttingen

ralf.nagel@nw-fva.de

\section{Dr. Martin Rohde}

Nordwestdeutsche Forstliche

Versuchsanstalt

Koordination, Projekte, Öffentlich-

keitsarbeit

Grätzelstraße 2

D-37079 Göttingen

martin.rohde@nw-fva.de

\section{Dr. Marcus Schmidt}

Nordwestdeutsche Forstliche

Versuchsanstalt

Abt. Waldwachstum

Grätzelstraße 2

D-37079 Göttingen

marcus.schmidt@nw-fva.de 


\section{Dr. Matthias Schmidt}

Nordwestdeutsche Forstliche

Versuchsanstalt

Abt. Waldwachstum

Grätzelstraße 2

D-37079 Göttingen

matthias.schmidt@nw-fva.de

\section{Prof. Dr. Hermann Spellmann}

Direktor

Nordwestdeutsche Forstliche

Versuchsanstalt

Grätzelstraße 2

D-37079 Göttingen

hermann.spellmann@nw-fva.de

\section{Johannes Sutmöller}

Nordwestdeutsche Forstliche

Versuchsanstalt

Abt. Umweltkontrolle

Grätzelstraße 2

D-37079 Göttingen

johannes.sutmöller@nw-fva.de 



\section{Anhang}

Anhang 1: Niederschlags- und Klimastationen

Tabelle A1: Verwendete Niederschlags- und Klimastationen (WETTREG-Klimaszenarien) $(\mathrm{N}=$ Niederschlag, $T=$ Temperatur, $R F=$ Relative Feuchte, $W=W$ indgeschwindigkeit, $S=$ Sonnenscheindauer)

\begin{tabular}{|c|c|c|c|c|c|}
\hline Station & $\mathrm{N}$ & $\mathrm{T}$ & $\mathrm{RF}$ & W & $\mathrm{S}$ \\
\hline Alzey & $\mathrm{X}$ & $\mathrm{X}$ & $\mathrm{X}$ & $\mathrm{X}$ & $\mathrm{X}$ \\
\hline Bammental & $\mathrm{X}$ & - & - & - & - \\
\hline Beerfelden & $\mathrm{X}$ & $\mathrm{X}$ & $\mathrm{X}$ & $\mathrm{X}$ & $\mathrm{X}$ \\
\hline Biblis & $\mathrm{X}$ & - & - & - & - \\
\hline Dieburg & $\mathrm{X}$ & - & - & - & - \\
\hline Frankfurt/Flughafen & $\mathrm{X}$ & - & - & - & - \\
\hline Frankfurt/Praunheim & $\mathrm{X}$ & - & - & - & - \\
\hline Frankfurt/Sindlingen & $\mathrm{X}$ & - & - & - & - \\
\hline Gernsheim & $\mathrm{X}$ & - & - & - & - \\
\hline Gross-Gerau & $\mathrm{X}$ & - & - & - & - \\
\hline Hattersheim & $\mathrm{X}$ & - & - & - & - \\
\hline Hemsbach & $\mathrm{X}$ & - & - & - & - \\
\hline Heusenstamm & $\mathrm{X}$ & - & - & - & - \\
\hline Hochheim & $\mathrm{X}$ & - & - & - & - \\
\hline Hofheim & $\mathrm{X}$ & - & - & - & - \\
\hline Kahl & $\mathrm{X}$ & $\mathrm{X}$ & $\mathrm{X}$ & $\mathrm{X}$ & $\mathrm{X}$ \\
\hline Lampertheim & $\mathrm{X}$ & - & - & - & - \\
\hline Langen & $\mathrm{X}$ & - & - & - & - \\
\hline Lindenfels & $\mathrm{X}$ & - & - & - & - \\
\hline Mainz & $\mathrm{X}$ & $\mathrm{X}$ & $\mathrm{X}$ & $\mathrm{X}$ & $\mathrm{X}$ \\
\hline Mannheim & $\mathrm{X}$ & $\mathrm{X}$ & $\mathrm{X}$ & $\mathrm{X}$ & $\mathrm{X}$ \\
\hline Messel & $\mathrm{X}$ & - & - & - & - \\
\hline Mettenheim & $\mathrm{X}$ & - & - & - & - \\
\hline Moerlenbach & $\mathrm{X}$ & - & - & - & - \\
\hline Neu-Isenburg & $\mathrm{X}$ & - & - & - & - \\
\hline Oppenheim & $\mathrm{X}$ & - & - & - & - \\
\hline Reichelsheim & $\mathrm{X}$ & - & - & - & - \\
\hline Reinheim & $\mathrm{X}$ & - & - & - & - \\
\hline Roedermark & $\mathrm{X}$ & - & - & - & - \\
\hline Seeheim & $\mathrm{X}$ & - & - & - & - \\
\hline Viernheim & $\mathrm{X}$ & - & - & - & - \\
\hline Weiterstadt & $\mathrm{X}$ & - & - & - & - \\
\hline Wiesbaden & $\mathrm{X}$ & $\mathrm{X}$ & $\mathrm{X}$ & $\mathrm{X}$ & $\mathrm{X}$ \\
\hline Worms & $\mathrm{X}$ & - & - & - & - \\
\hline
\end{tabular}

Beiträge aus der NW-FVA, Band 10, 2013 
Tabelle A2: Deskriptive Statistik der Mächtigkeiten des Auflagehumus in Abhängigkeit von der Humusform (mut $=$ L-Mull, muf $=$ F-Mull, mou $=$ mullartiger Moder, mota $=$ feinbumusarmer Moder, mot = typischer Moder, motr $=$ feinbumusreicher Moder, mor $=$ robhumusartiger Moder, rota $=$ feinhumusarmer Rohbumus, rot $=$ typischer Robbumus, rotr $=$ feinhumusreicher Robhumus)

\begin{tabular}{lcccccccccc}
\hline & mut & muf & mou & mota & mot & motr & mor & rota & rot & rotr \\
\hline Minimum & 1 & 1 & 0 & 0 & 1 & 1 & 3 & 3 & 5 & 4 \\
Q1 & 1 & 2 & 2 & 3 & 4 & 5 & 6 & 6 & 10 & 8 \\
Median & 1 & 3 & 4 & 5 & 4 & 7 & 8 & 8 & 24 & 9.5 \\
Mittelwert & 1,5 & 3,12 & 3,9 & 4,8 & 4,2 & 6,9 & 7,8 & 8,8 & 18,6 & 11,4 \\
Q3 & 2 & 4 & 5 & 6 & 4 & 8 & 9 & 10 & 28 & 11 \\
Maximum & 3 & 10 & 13 & 14 & 9 & 18 & 19 & 21 & 29 & 34 \\
Anzahl & 24 & 133 & 110 & 176 & 11 & 125 & 78 & 39 & 9 & 42 \\
\hline
\end{tabular}




\section{Anhang 2: Stoffhaushaltsmodell}

\section{Anbang 2.1: Modellauswabl und-anpassung: Very Simple Dynamic Model (VSD)}

Konzeptionell ist VSD die dynamische Erweiterung der einfachen Massenbilanzmodelle nach dem Critical Load-Ansatz (SPRANGER et al. 2004) mit Prozessen wie Kationenaustausch und Stickstoffimmobilisierung. Somit besteht VSD aus zahlreichen Massenbilanzgleichungen, die die Eintragssituation in den Boden und die Stoffausträge in das Gewässer beschreiben. Ausgangspunkt ist das IonenGleichgewicht in der Bodenlösung unterhalb des Wurzelraumes:

$$
\begin{aligned}
{\left[\mathrm{H}^{+}\right]+\left[\mathrm{BC}^{2+}\right]+\left[\mathrm{Na}^{+}\right]+\left[\mathrm{Al}^{3+}\right]+\left[\mathrm{NH}_{4}^{+}\right]=\left[\mathrm{SO}_{4}^{2-}\right]+\left[\mathrm{NO}_{3}^{-}\right]+\left[\mathrm{Cl}^{-}\right]+\left[\mathrm{HCO}_{3}^{-}\right]+\left[\mathrm{Org}^{-}\right](41) } \\
\text { mit: } \quad \mathrm{B}_{\mathrm{C}}=\text { Konzentrationen von } \mathrm{Ca}+\mathrm{Mg}+\mathrm{K}\left[\mathrm{eq} \mathrm{m}^{-3}\right] \\
\mathrm{Org}^{-}=\text {Konzentration organischer Anionen }\left[\mathrm{eq} \mathrm{m}^{-3}\right]
\end{aligned}
$$

Folgende chemische Gleichgewichtsreaktionen werden im VSD-Modell berücksichtigt:

- die Auflösung von Aluminiumoxiden,

- die Dissoziation von Hydrogencarbonat,

- die Dissoziation von organischen Säuren

- und der Kationenaustausch zwischen den festen Bodenpartikeln und der Bodenlösung. Berücksichtigt wird hierbei $\mathrm{Al}^{3+}, \mathrm{H}^{+}$und die basischen Kationen $(\mathrm{Ca}, \mathrm{Mg}, \mathrm{K})$.

Die Ermittlung der Gleichgewichtsreaktionen ergibt sich wie folgt: die Auflösung von Aluminiumoxiden:

$$
[A l]=K_{\text {Alox }} \cdot[H]^{a}
$$

mit: $\quad \mathrm{K}_{\text {AlOx }}=$ Lösungskonstante

$$
\mathrm{a} \quad=\text { Steigung der } \mathrm{pH}-\mathrm{pAl} \text { Beziehung }(\mathrm{a}<3)
$$

Der Einfluss der Temperatur auf die Lösungskonstante $\left(\mathrm{K}_{\mathrm{AlO}}\right)$ wird mit einer Arrhenius-Funktion nach MOL-DiJKSTRA u. KROS (2001) modelliert:

$$
K_{\text {Alox }}(T)=K_{\text {Alox }}\left(T_{1}\right) \cdot \exp \left(-\frac{95490}{R}\left(\frac{1}{T_{1}}-\frac{1}{T}\right)\right), \quad T_{1}=283 \mathrm{~K}
$$

mit: $\quad \mathrm{R}=8.314 \mathrm{~J} \mathrm{~mol}^{-1} \mathrm{~K}^{-1}$ als allgemeine Gaskonstante

die Dissoziation von Hydrogencarbonat $\mathrm{HCO}_{3}$ :

$$
\left[\mathrm{HCO}_{3}\right]=\frac{K_{\mathrm{HCO} 3} \cdot p_{\mathrm{CO} 2}}{[\mathrm{H}]}
$$

mit: $\quad \mathrm{K}_{\mathrm{HCO} 3}=$ Dissoziationskonstante

pCO2 = Partialdruck von $\mathrm{CO}_{2}$ in der Bodenlösung 
Nach REINDS et al. (2009) kann die Dissoziationskonstante ( $\left.\mathrm{K}_{\mathrm{HCO}}\right)$ ebenfalls in Abhängigkeit von der Temperatur ermittelt werden:

$$
\log _{10} K_{\text {HCO3 }}=-\frac{1018}{T}-0.0175 \cdot T+0.826
$$

mit: $\quad \mathrm{T}=$ Temperatur $[\mathrm{K}]$

die Dissoziation von organischen Säuren RCOO:

$$
\left[\mathrm{RCOO}^{-}\right]=\frac{m \cdot \mathrm{DOC} \cdot K_{1}}{K_{1} \cdot[H]}
$$

mit: $\quad$ DOC $=$ Konzentration von gelöstem organischem Kohlenstoff $\left[\mathrm{molC} \mathrm{m}^{-3}\right]$

$\mathrm{m} \quad=$ Konzentration der funktionalen Gruppen [molC $\mathrm{molC}^{-1}$ ]

$\mathrm{K} 1=1$. Dissoziations-Konstante

Die Berechnung des Kationenaustausches zwischen den festen Bodenpartikeln und der Bodenlösung erfolgt mit Hilfe der Gapon-Austausch-Gleichungen. Berücksichtigt werden hierbei $\mathrm{Al}^{3+}, \mathrm{H}^{+}$und die basischen Kationen $(\mathrm{Ca}, \mathrm{Mg}, \mathrm{K})$ :

$$
\begin{aligned}
& \frac{E_{A l}}{E_{B C}}=k_{A l B C} \cdot \frac{\left[A l^{3+}\right]^{1 / 3}}{\left[B C^{2+}\right]^{1 / 2}} \\
& \frac{E_{H}}{E_{B C}}=k_{H B C} \cdot \frac{\left[H^{+}\right]}{\left[B C^{2+}\right]^{1 / 2}}
\end{aligned}
$$

mit: $\quad \mathrm{k}_{\mathrm{AlBc}} \quad=$ Gapon-Austausch-Koeffizient $\mathrm{Al}$ gegen $\mathrm{Ca}+\mathrm{Mg}+\mathrm{K}$

$$
\mathrm{k}_{\mathrm{HBc}}=\text { Gapon-Austausch-Koeffizient } \mathrm{H} \text { gegen } \mathrm{Ca}+\mathrm{Mg}+\mathrm{K}
$$

Die dargestellten Gapon-Gleichungen für den Austausch von $\mathrm{Al}^{3+}, \mathrm{H}^{+}$und den Austausch basischer Kationen werden z. B. auch im SAFE Modell (ALVETEG 1998) verwendet. Aber anstatt des Al-Bc Austausches wird die Gleichung für den $\mathrm{H}-\mathrm{Al}$ Austausch benutzt. Diese ergibt sich aus den oben genannten Gleichungen durch einfache Division $\left(k_{H A l}=k_{H B} / k_{A I B c}\right)$.

Die Gleichgewichtsbedingungen für beide Modelle erfordern, dass:

$$
E_{B C}+E_{A l}+E_{H}=1
$$

Für alle Kationen $\left(\mathrm{Ca}, \mathrm{Mg}, \mathrm{K}, \mathrm{Na}\right.$ ) und Anionen $\left(\mathrm{SO}_{4}, \mathrm{NO}_{3}, \mathrm{Cl}\right)$, die im Modell betrachtet werden, gilt die folgende Massenbilanzgleichung:

$$
\frac{d X_{t o t}}{d t}=X_{\text {in }}-Q \cdot[X]
$$

mit: $\quad \mathrm{X}_{\text {tot }} \quad=$ Ionen-Gehalte im Boden [eq $\left.\mathrm{m}^{-2}\right]$

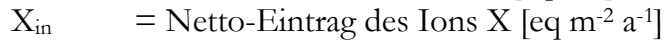

$\mathrm{Q}=$ Grundwasserneubildungsmenge $\left[\mathrm{m} \mathrm{a}^{-1}\right]$ 
Diese Differentialgleichung beschreibt mathematisch für alle Kationen und Anionen den Übergang von der Staedy state-Massenbilanz zur dynamischen Berechnung der Veränderung der Ionen-Gehalte in der Bodenlösung über die Zeit.

Für $\mathrm{H}, \mathrm{Al}, \mathrm{CO}_{2}$ und organische Säuren wird keine Massenbilanz berücksichtigt. Ihre Nachlieferung wird als unbegrenzt angenommen.

Für Sulfat, Stickstoff, Natrium und Chlorid werden keine Interaktionen mit der Bodenmatrix modelliert, sodass der Gesamtgehalt im Boden $\left(\mathrm{X}_{\text {tot }}\right)$ gleich dem Gehalt im Bodenwasser ist:

$$
X_{\text {tot }}=\Theta \cdot \mathrm{Z} \cdot[\mathrm{X}] \text { mit } \mathrm{X}=\mathrm{SO}_{4}, \mathrm{NO}_{3}, \mathrm{Na}, \mathrm{Cl}
$$

mit: $\quad \Theta=$ volumetrischer Wassergehalt im Boden $\left[\mathrm{m}^{3} \mathrm{~m}^{-3}\right]$

$\mathrm{Z}=$ Mächtigkeit des Wurzelraumes [m]

$[\mathrm{X}]=$ Konzentration von Stoff $\mathrm{X}$ in der Bodenlösung [eq $\left.\mathrm{m}^{-3}\right]$

Für alle basischen Kationen Bc, die am Kationenaustausch beteiligt sind, ergibt sich der Gesamtgehalt aus der Summe der Kationen in der Bodenlösung und an den Austauscherplätzen

$$
\begin{aligned}
& B c_{\text {tot }}=\Theta \cdot Z \cdot[B c]+p \cdot Z \cdot K A K \cdot E_{B c} \\
& \text { mit: } \quad \mathrm{p}=\text { Rohdichte des Bodens }\left[\mathrm{g} / \mathrm{cm}^{3}\right] \\
& \mathrm{KAK}=\text { Kationenaustauschkapazität [meq kg-1] } \\
& \mathrm{E}_{\mathrm{Bc}} \quad=\text { austauschbarer Anteil der basischen Kationen [0-1] }
\end{aligned}
$$

\section{Anhang 2.2: Modellmodifikationen \\ Nährstoffaufnahme}

Im Modell VSD (Version 3.1.2 - POsCH u. REINDS 2009) werden die Nährstoffentzüge bei der Bilanzierung wie folgt berücksichtigt:

$$
X_{A}=\left\{\begin{array}{ccc}
X_{A} & \text { für } & X_{\text {dep }}+X_{V} \geq X_{A} \\
X_{\text {dep }}+X_{V} & \text { für } & X_{\text {dep }}+X_{V}<X_{A}
\end{array}\right.
$$

mit: $\quad X_{\mathrm{A}} \quad=$ Aufnahme von Stoff $\mathrm{X}(\mathrm{Ca}, \mathrm{Mg}$ und $\mathrm{K})$ in die Vegetation [eq $\mathrm{m}^{-2} \mathrm{a}^{-1}$ ]

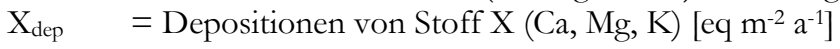

$\mathrm{X}_{\mathrm{V}} \quad=$ Verwitterungsraten von Stoff $\mathrm{X}(\mathrm{Ca}, \mathrm{Mg}, \mathrm{K})\left[\mathrm{eq} \mathrm{m}^{-2} \mathrm{a}^{-1}\right]$

Mit dieser Modellformulierung können z. B. bei niedrigen Verwitterungsraten und Depositionen basischer Kationen die Effekte einer erhöhten Nutzungsintensität auf die Basensättigung im Wurzelraum nur unzureichend beschrieben werden. Entsprechend wurde die Bedingung wie folgt modifiziert: 


$$
X_{A}=\left\{\begin{array}{ccc}
X_{A} & \text { für } & X_{d e p}+X_{V} \geq X_{A} \\
X_{A} & \text { für } & X_{d e p}+X_{V}+B C_{E} \geq X_{A} \\
X_{\text {dep }}+X_{V}+B C_{E} & \text { für } & X_{\text {dep }}+X_{V}+B C_{E}<X_{A}
\end{array}\right.
$$

mit: $\quad$ BCE $=$ Basenvorrat am Austauscher $\left[\mathrm{eq} \mathrm{m}^{-2}\right]$

Der Basenvorrat ergibt sich aus:

$$
B C_{E}=R D \cdot M \cdot C E C \cdot E_{B C}
$$

$$
\begin{aligned}
& \text { mit: } \quad \mathrm{RD} \quad=\text { Rohdichte }\left[\mathrm{g} \mathrm{cm}^{-3}\right] \\
& \mathrm{M} \quad=\text { Mächtigkeit [m] } \\
& \text { CEC = Kationenaustauschkapazität [meq kg-1 }] \\
& \mathrm{EBC}=\text { Basensättigung [0-1] }
\end{aligned}
$$

\section{Mebrschichtmodell}

In der vorab beschriebenen Version ist VSD ein Einschichtmodell. Somit wird die vertikale Heterogenität des Bodens vernachlässigt. Insbesondere bei Kalkungen und Böden mit hinsichtlich der Basensättigung sehr inhomogen Schichten führt die Annahme einer gleichmäßigen Verteilung der Elementeinträge in dem betrachteten Bilanzierungsraum (Durchwurzelungszone) zu Problemen bei einer Berechnung der Silikatverwitterungsrate anhand von schichtbezogenen bodenchemischen Daten. Daher wurde das Modell so umprogrammiert, dass optional auch Mehrschichtsimulationen von bis zu 25 Schichten möglich sind. Hierbei wird der Nettoeintrag der ersten Schicht entsprechend dem Einschichtmodel berechnet. Für die folgenden Schichten wird der Input jeweils aus dem Austrag der vorangegangenen Schicht ermittelt. Der Anteil der jeweiligen Bodenschicht an der Gesamtaufnahme der basischen Kationen und des Stickstoffs wird über die Feinwurzelverteilung (s. Kap. 2.2.4.3.1) gesteuert. Somit ergibt sich der Netto-Eintrag in die jeweilige Bodenschicht anhand der folgenden Massenbilanzgleichungen:

$$
\begin{aligned}
& {[\mathrm{SO} 4]_{i}=\frac{1}{Q_{i}} \cdot\left(Q_{i-1} \cdot[\mathrm{SO} 4]_{i-1}\right)} \\
& {[\mathrm{CL}]_{i}=\frac{1}{Q_{i}} \cdot\left(Q_{i-1} \cdot[\mathrm{CL}]_{i-1}\right)} \\
& {[N]_{i}=\frac{1}{Q_{i}} \cdot\left(Q_{i-1} \cdot[N]_{i-1}-R_{A, i}\right)} \\
& {[N a]_{i}=\frac{1}{Q_{i}} \cdot\left(Q_{i-1} \cdot[C L]_{i-1}+R w_{N a, i}\right)} \\
& {[B C]_{i}=\frac{1}{Q_{i}} \cdot\left(Q_{i-1} \cdot[B C]_{i-1}+R w_{B c, i}-R_{A, i}\right)}
\end{aligned}
$$


mit: $\quad[\mathrm{X}]_{\mathrm{i}} \quad=$ Konzentration von Stoff $\mathrm{X}$ in der Bodenlösung unterhalb der Boden schicht i $\left[\right.$ eq $\left.\mathrm{m}^{-3}\right]$

$\mathrm{Q}_{\mathrm{i}} \quad=$ Wasserfluss $\left[\mathrm{m}^{3} \mathrm{~m}^{-2} \mathrm{a}^{-1}\right]$

$\mathrm{i}=$ Index der Bodenschicht $[-]$

$\mathrm{R}_{\mathrm{wx}, \mathrm{i}}=$ Verwitterungsrate des Stoffes $\mathrm{X}$ in der Bodenschicht $\mathrm{i}\left[\mathrm{eq} \mathrm{a} \mathrm{a}^{-1}\right]$

$\mathrm{R}_{\mathrm{X}, \mathrm{i}} \quad=$ Rate der Aufnahme des Stoffes X aus der Bodenschicht $\mathrm{i}\left[\mathrm{eq} \mathrm{a}^{-1}\right]$

$\mathrm{R}_{\mathrm{A}, \mathrm{i}} \quad=$ Rate der Stickstoffaufnahme aus der Bodenschicht $\mathrm{i}\left[\mathrm{eq} \mathrm{a}^{-1}\right]$

\section{Koblenstoff- und Stickstoffhaushalt}

Bei den Modellsimulationen wurde die von BONTEN et al. (2009) entwickelte und dokumentierte vereinfachte Version des Modells DNDC (LI et al. 1994) verwendet, die auch in die Modelle VSD+ (BONTEN et al. 2011b) und SMARTml (BONTEN et al. 2011a) implementiert ist. In dieser Modellversion sind die wesentlichen Prozesse des C- und N-Kreislaufes (Immobilisation, Denitrifikation, Nitrifikation, Stickstoffausträge) berücksichtigt und eng miteinander verknüpft.

Das Kohlenstoffmodell verwendet die folgenden 4 Pools:

- leicht abbaubare frische Streu $\left(\mathrm{C}_{\mathrm{fe}}\right)$

- schwer abbaubare frische Streu $\left(\mathrm{C}_{\mathrm{fs}}\right)$

- mikrobielle Biomasse $\left(\mathrm{C}_{\mathrm{mb}}\right)$

- langsam abbaubare organische Substanz $\left(\mathrm{C}_{\mathrm{hm}}\right)$

Jeder Pool hat seinen eigenen Abbaukoeffizienten und ein festes C/N-Verhältnis. Die ersten drei C-Pools können jeweils in einen anderen umgewandelt werden (s. Abb. A1). Der Kohlenstoffverlust aus allen Pools erfolgt in Form von $\mathrm{CO}_{2}$.

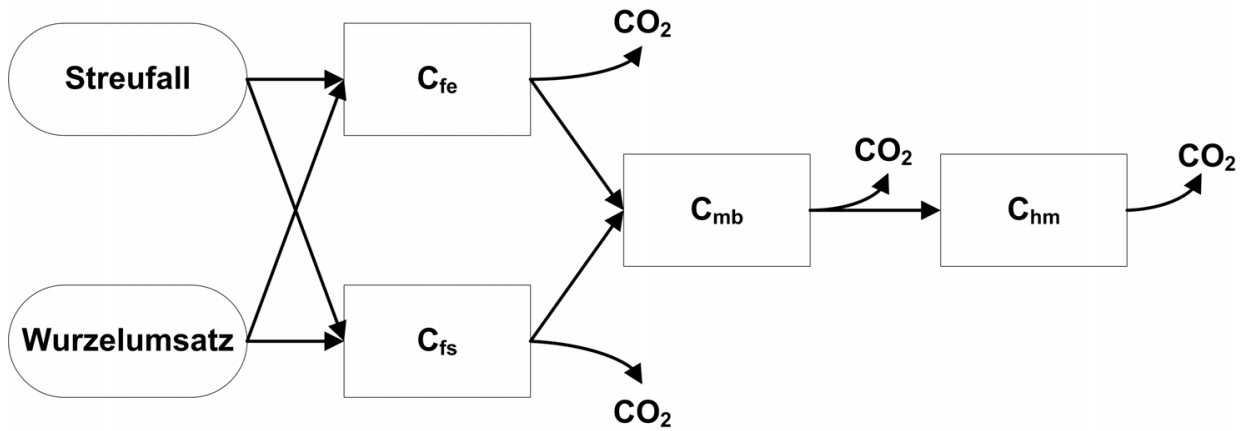

Abbildung A1: Strukturdiagramm der vier Koblenstoffpools, ibre Interaktionen sowie die Input-(Streufall und Wurzelumsatz) und Outputflüsse $\left(\mathrm{CO}_{2}\right)$ des Modellansatzes (verändert nach BONTEN et al. 2011b).

Mathematisch lassen sich die Vorratsänderungen in den jeweiligen Pools mit Hilfe der folgenden Differenzialgleichungen beschreiben:

$$
\frac{d}{d t} C_{f e}=\left(a m_{l f} \cdot f r_{f e, l f}+a m_{l f} \cdot f r_{f e, r t}\right) \cdot 500-k_{f e} \cdot C_{f e}
$$




$$
\begin{aligned}
& \frac{d}{d t} C_{f s}=\left(a m_{l f} \cdot f r_{f s, l f}+a m_{l f} \cdot f r_{f s, r t}\right) \cdot 500-k_{f s} \cdot C_{f s} \\
& \frac{d}{d t} C_{m b}=k_{f e} \cdot f r_{h u, f e} \cdot C_{f e}+k_{f s} \cdot f r_{h u, f s} \cdot C_{f s}-k_{m b} \cdot C_{m b} \\
& \frac{d}{d t} C_{h m}=k_{m b} \cdot f r_{h u, m b} \cdot C_{m b}-k_{h m} \cdot C_{h m}
\end{aligned}
$$

mit: $\quad a_{1 \mathrm{f}} \quad=$ Streufall $\left[\mathrm{kg} \mathrm{m}^{-2} \mathrm{a}^{-1}\right]$

$\mathrm{fr}_{\mathrm{fe}, \mathrm{lf}} \quad=$ leicht abbaubarer Anteil des Streufalls [-]

$\mathrm{fr}_{\mathrm{f}_{\mathrm{s}, \mathrm{ff}}} \quad=$ schwer abbaubarer Anteil des Streufalls [-]

$\mathrm{fr}_{\mathrm{fe}, \mathrm{rt}} \quad=$ leicht abbaubarer Anteil des Wurzelumsatzes [-]

$\mathrm{fr}_{\mathrm{fs}, \mathrm{rt}} \quad=$ schwer abbaubarer Anteil des Wurzelumsatzes [-]

$\mathrm{k}_{\mathrm{x}} \quad=$ Abbaukonstante von Pool $\mathrm{x}=\mathrm{fe}, \mathrm{fs}, \mathrm{mb}, \mathrm{hm}\left[\mathrm{a}^{-1}\right]$

$\mathrm{fr}_{\mathrm{hu}, \mathrm{x}}=$ Anteil der Mineralisierung eines C-Pools, der an einen anderen übergeben wird [-]

Der Streufall und der Wurzelumsatz werden in Abhängigkeit vom C/N-Verhältnis in die leicht und schwer abbaubaren Anteile aufgeteilt.

$$
\left.\begin{array}{c}
\frac{f r_{f e, l f} \cdot C N_{f e}+f r_{f s, l f} \cdot C N_{f s}=C N_{l f}}{f r_{f e, l f}+f r_{f s, l f}=1} \\
\frac{f r_{f e, r t} \cdot C N_{f e}+f r_{f s, r t} \cdot C N_{f s}=C N_{r t}}{f r_{f e, r t}+f r_{f s, r t}=1}
\end{array}\right\}
$$

Die Abbaukoeffizienten werden anhand eines Standardwertes $\left(k_{\mathrm{x}, \max }\right)$ in Abhängigkeit von der Temperatur, dem pH-Wert, dem Wassergehalt und der Austrocknung des Bodens berechnet,

$$
\begin{aligned}
& k_{x}=k_{x, \max } \cdot r f_{\min , p H} \cdot r f_{m i} \\
& f_{x}=1-\exp \left(-k_{x}\right)
\end{aligned}
$$

wobei $\mathrm{rf}_{\mathrm{min}, \mathrm{pH}}$ und $\mathrm{rf}_{\mathrm{mi}}$ (Abhängig von der Temperatur, dem Wassergehalt und der Austrocknungsrate) wie folgt berechnet werden:

$$
\begin{aligned}
r f_{\text {min }, p H} & =\frac{1}{1+\exp (2 \cdot(3,8-p H))} \\
r f_{n i, p H} & =\frac{1}{1+\exp (4 \cdot(2,75-p H))} \\
r f_{d e, p H} & =\frac{1}{1+\exp (2,5 \cdot(5-p H))}
\end{aligned}
$$

(pH ist der $\mathrm{pH}-$ Wert in der Bodenlösung) 
Die Modifikation der Mineralisierung aufgrund von Temperaturveränderungen wird wie folgt berücksichtigt,

$$
r f_{\min , T}=\exp \left[3.36\left(\frac{T-40}{T+31,79}-\frac{T_{0}-40}{T_{0}+31,79}\right)\right], T_{0}=10^{\circ} \mathrm{C}
$$

wobei $\mathrm{T}\left({ }^{\circ} \mathrm{C}\right)$ die Bodentemperatur beschreibt. Für die Nitrifikation und die Denitrifikation werden entsprechende Reduktionsfunktionen verwendet.

$$
r f_{n i, T}=r f_{d e, T}=r f_{m i, T}
$$

Die Abhängigkeit der Mineralisierungsrate von der Bodenfeuchte erfolgt auf Grundlage des Konzeptes von aeroben und anaeroben Zonen. Hierbei ist die Mineralisierung proportional zur relativen Größe der aeroben Zone im Boden. Diese Größe kann anhand der Abhängigkeit der Denitrifikation von dem wassergefüllten Porenraum $\left(=\theta / \theta_{\text {sat }}\right)$ ermittelt werden. Hier liegt die Annahme zugrunde, dass die Denitrifikation nur unter anaeroben Bedingungen stattfindet. Die Reduktionsfunktion der Denitrifikation aufgrund der Bodenfeuchte wird wie folgt beschrieben,

$$
r f_{d e, \theta}=\left\{\begin{array}{ccc}
0 & \text { für } & \frac{\theta}{\theta_{\text {sat }}}<0,62 \\
\left(\frac{\theta / \theta_{\text {sat }}-0,62}{1-0,62}\right)^{1.74} & \text { für } & 0,62 \leq \frac{\theta}{\theta_{\text {sat }}} \leq 1
\end{array}\right.
$$

wobei $\theta\left(\mathrm{m}^{3} / \mathrm{m}^{3}\right)$ den Bodenwassergehalt und $\theta_{\text {sat }}\left(\mathrm{m}^{3} / \mathrm{m}^{3}\right)$ den gesamten Porenraum (Wassergehalt bei Sättigung) beschreibt. Die Reduktionsfunktionen für die Mineralisierung und Nitrifikation aufgrund der Bodenfeuchte sind definiert als minus 1 der Reduktion für die Denitrifikation (z. B. der Größe von der aeroben Zone):

$$
\begin{aligned}
& r f_{m i, \theta}=1-r f_{d e, \theta} \\
& r f_{n i, \theta}=1-r f_{d e, \theta}
\end{aligned}
$$

Die Korrektur der Mineralisierung aufgrund von Trockenstress ( $\mathrm{rf}_{\mathrm{min}, \mathrm{dr}}$ ) wird in Anlehnung an VLEESHOUWERS u. VERHAGEN (2002) beschrieben,

$$
\begin{array}{ccc}
r f_{m i, d r}=2 \cdot \frac{\theta-\theta_{w p}}{\theta_{f c}-\theta_{w p}} & \text { für } & \theta_{w p}<\theta<\frac{\theta_{w p}}{2} \\
1 & \text { für } & \theta \geq \frac{\theta_{f c}+\theta_{w p}}{2}
\end{array}
$$


wobei $\theta_{\text {fc }}\left(\mathrm{m}^{3} / \mathrm{m}^{3}\right)$ den Feuchteanteil bei Feldkapazität und $\theta_{\mathrm{wp}}\left(\mathrm{m}^{3} / \mathrm{m}^{3}\right)$ beim permanenten Welkepunkt beschreibt. Für die Denitrifikation und Nitrifikation werden die gleichen Reduktionsfunktionen wie für die Mineralisierung verwendet.

$$
r f_{n i, d r}=r f_{d e, d r}=r f_{m i, d r}
$$

Die berücksichtigten Prozesse des Stickstoffhaushaltes sind in der Abbildung A2 dargestellt. Die Nummern beschreiben die Reihenfolge der Berechnungsschritte. Als Inputgrößen werden die Deposition von $\mathrm{NH}_{4}$ und $\mathrm{NO}_{3}$, der Streufall, der Wurzelumsatz und die N-Fixierung betrachtet.

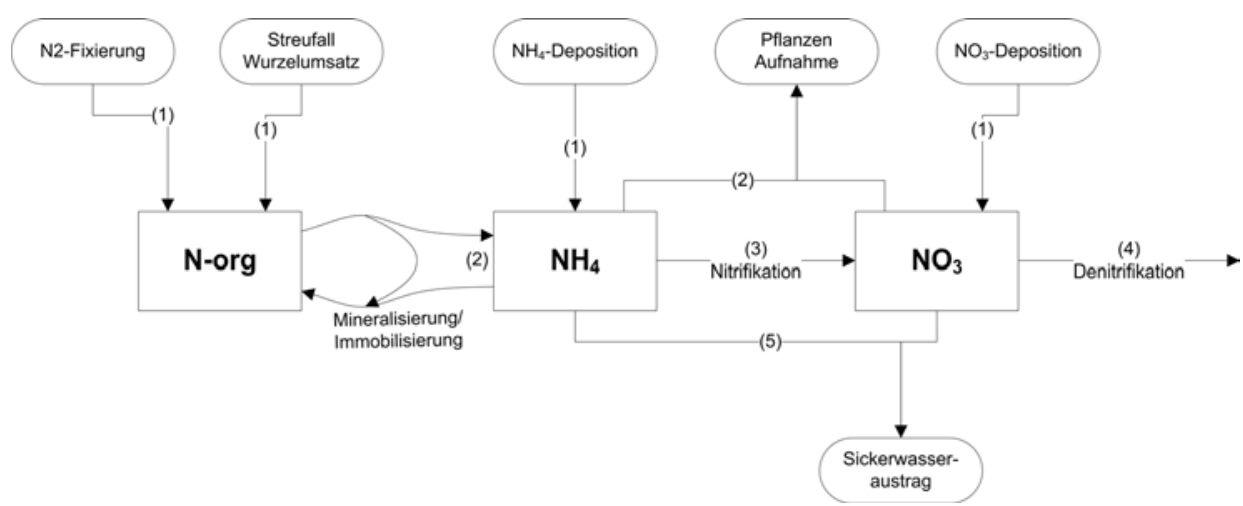

Abbildung A2: Strukturdiagramm der berücksichtigten Prozesse des Stickstoffhaushaltes. Die Nummern beschreiben die Reihenfolge der Berechnungsschritte (verändert nach BONTEN et al. 2011b).

Der Stickstoffinput mit dem Streufall, $\mathrm{N}_{\mathrm{lf}}\left(\mathrm{eq} / \mathrm{m}^{2} / \mathrm{a}\right)$, ist abhängig von der Gesamtstickstoffdeposition,

$\mathrm{N}_{\mathrm{dep}}=\mathrm{NH}_{4, \text { dep }}+\mathrm{NO}_{3, \mathrm{dep}}\left(\mathrm{eq} / \mathrm{m}^{2} / \mathrm{a}\right)$.

$$
N_{l f}=\frac{a m_{l f}}{1,4} \cdot\left(c t N_{l f, \min }+\left(c t N_{l f, \text { max }}-c t N_{l f, \min }\right) \cdot\left(1-e^{-\exp N l f d e p \cdot N_{\text {dep }}}\right)\right)
$$

wobei $\operatorname{am}_{\mathrm{lf}}\left(\mathrm{kg} / \mathrm{m}^{2} / \mathrm{a}\right)$ den Streufall beschreibt, $\mathrm{ctN} \mathrm{N}_{\mathrm{lf} \text {,min }} / \mathrm{ctN}_{\mathrm{lf} \text {,max }}(\%)$ sind die minimalen/maximalen N-Gehalte im Streufall, expNlfdep $\left(\mathrm{m}^{2} / \mathrm{a} / \mathrm{eq}\right)$ ist der Exponent, der die Beziehung zwischen der N-Deposition und dem N-Gehalt des Streufalls beschreibt. Der Divisor von 1,4 sorgt für die Umrechnung von Prozent in Mol (= eq) von N. Die Stickstofffixierung $\left(\mathrm{N}_{\mathrm{fix}}\right)$ ist ein konstanter Modellinput.

Die Immobilisierung/Mineralisierung von Stickstoff erfolgt in Abhängigkeit vom Umsatz der jeweiligen C-Pools,

$$
N_{i m, x}=\frac{1}{14 \cdot C N_{x}} \Delta C_{x, t} \quad \text { mit } \quad x=f e, f s, m b, h m
$$


wobei $\mathrm{N}_{\mathrm{im}, \mathrm{x}}\left(\mathrm{eq} / \mathrm{m}^{2} / \mathrm{a}\right)$ die Stickstoffimmobilisation im Pool $\mathrm{x}$ ist und $\Delta \mathrm{C}_{\mathrm{x}, \mathrm{t}}=\mathrm{C}_{\mathrm{x}, \mathrm{t}}-$

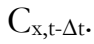

Die gesamte N-Nettoimmobilisierung berechnet sich wie folgt:

$$
N_{i m}=N_{i m, f e}+N_{i m, f s}+N_{i m, m b}+N_{i m, h m}+N_{f i x}+N_{l f}-N_{r t}
$$

Wenn $\mathrm{N}_{\text {im }}>0$, liegt eine Nettoimmobilisierung vor, andernfalls eine Nettomineralisierung.

Die Berechnung der Stickstoffaufnahme erfolgt wie in Kapitel 2.1.4.7 beschrieben.

Wenn $\mathrm{N}_{\mathrm{dep}}-\mathrm{N}_{\mathrm{im}}-\mathrm{N}_{\mathrm{u}}<0$ sind, steht nicht genügend $\mathrm{N}$ für die Immobilisation und die Pflanzenaufnahme zur Verfügung. In diesen Fall wird die Umsatzrate $\left(\mathrm{k}_{\mathrm{fs}}\right)$ des Pools $\mathrm{C}_{\mathrm{fs}}$ soweit reduziert, dass gilt: $\mathrm{N}_{\mathrm{dep}}-\mathrm{N}_{\mathrm{im}}-\mathrm{N}_{\mathrm{u}}=0$. Die gesamte $\mathrm{N}$ Aufnahme wird in $\mathrm{NH}_{4, \mathrm{u}}$ und $\mathrm{NO}_{3, \mathrm{u}}$ aufgeteilt, wobei die $\mathrm{NH}_{4, \mathrm{u}}$ bevorzugt stattfindet.

$$
\begin{aligned}
& N H_{4, u}=\min \left\{N H_{4, d e p}-N_{i m}, N_{u}\right\} \\
& N O_{3, u}=N_{u}-N H_{4, u}
\end{aligned}
$$

Es wird angenommen, dass die gesamte $\mathrm{N}_{\mathrm{im}}$ in Form von Ammonium stattfindet. Der nächste Schritt ist die Nitrifikation, $\mathrm{N}_{\mathrm{ni}}\left(\mathrm{eq} / \mathrm{m}^{2} / \mathrm{a}\right)$ :

$$
N_{n i}=f r_{n i} \cdot\left(N H_{4, d e p}-N_{i m}-N H_{4, u}\right)
$$

$\mathrm{fr}_{\text {ni }}$ beschreibt den Anteil des verfügbaren $\mathrm{NH}_{4}$, der jährlich nitrifiziert wird. Anschließend erfolgt die Berechnung der Denitrifikation, $\mathrm{N}_{\mathrm{de}}\left(\mathrm{eq} / \mathrm{m}^{2} / \mathrm{a}\right)$ :

$$
N_{d e}=f r_{d e} \cdot\left(N O_{3, \text { dep }}+N_{n i}-N O_{3, u}\right)
$$

$\mathrm{fr}_{\mathrm{de}}$ beschreibt den Anteil des verfügbaren $\mathrm{NO}_{3}$, der jährlich denitrifiziert wird. Die jährlichen Nitrifikations-/Denitrifikationsanteile werden wie folgt berechnet:

$$
f r_{y}=1-\exp \left(-k_{y} \cdot r f_{y, p H} \cdot r f_{y}\right) \quad \text { mit } \quad y=n i, d e
$$

$\mathrm{k}_{\mathrm{y}}$ ist eine benutzerspezifische Konstante und $\mathrm{rf}_{\mathrm{y}}$ und $\mathrm{rf}_{\mathrm{y}, \mathrm{pH}}$ sind Reduktionsfunktionen.

Die verbleibenden Mengen an $\mathrm{NH}_{4}$ und $\mathrm{NO}_{3}$ werden aus der Wurzelzone ausgewaschen $\left(\mathrm{NH}_{4, \text { le }}\right.$ und $\left.\mathrm{NO}_{3, \text { le in eq }} / \mathrm{m}^{2} / \mathrm{a}\right)$ :

$$
\begin{aligned}
& N H_{4, l e}=N H_{4, d e p}-N_{i m}-N H_{4, u}-N_{n i} \\
& N O_{3, l e}=N O_{3, d e p}-N O_{3, u}+N_{n i}-N_{d e}
\end{aligned}
$$




\section{Anhang 2.3: Parametrisierung und Transferfunktionen}

Zur flächenhaften Anwendung des Modellsystems sind zahlreiche Eingangsdaten notwendig. Tabelle A3 liefert einen Überblick über die Quellen bzw. die Methoden, mit deren Hilfe sie abgeleitet wurden. Die Parametrisierung der Eingangsgrößen Durchwurzelungstiefe und -verteilung, Kationenaustauschkapazität, $\mathrm{CO}_{2^{-}}$ Partialdruck, Verwitterungsoberfläche, Bodenwassergehalt, nutzbare Feldkapazität, und Sickerwasserrate sind weiter unten im Anhang detailliert beschrieben. Daher wird im Folgenden verstärkt auf die Hauptkomponenten des Stoffhaushaltes (Deposition, Verwitterung und Nährstoffentzüge) eingegangen.

Tabelle A3: Eingangsdaten und ibre Quellen für die Modellrechnungen mit dem modifizierten Versauerungsmodell VSD (very simple dynamic soil acidification model)

\begin{tabular}{|c|c|c|c|c|}
\hline Kürzel & Beschreibung & Wert & Einheit & Quelle \\
\hline SiteNum & Standortsnummer & - & - & GIS \\
\hline START & Start der Simulation & 1900 & $\mathrm{a}$ & User \\
\hline END & Ende der Simulation & 2040 & a & User \\
\hline thick & Horizontmächtigkeit & konstant & $\mathrm{m}$ & Bodenkarte \\
\hline bulkdens & Lagerungsdichte & konstant & $\mathrm{g} / \mathrm{cm}^{3}$ & Bodenkarte \\
\hline Theta & Wassergehalt & dynamisch & $\mathrm{m} / \mathrm{m}$ & Anhang 2.3, Text \\
\hline $\mathrm{pCO}_{2} \mathrm{fac}$ & $\mathrm{CO}_{2}$-Partialdruck & kostant/dyn. & $\mathrm{x}$ atm & Anhang 2.3, Text \\
\hline CEC & $\begin{array}{l}\text { Kationenaustausch- } \\
\text { kapazität }\end{array}$ & konstant & $\mathrm{meq} / \mathrm{kg}$ & Anhang 2.3, Text \\
\hline bsat_0 & Initiale Basensättigung & konstant & $0-1$ & Kapitel 2.2.4.9 \\
\hline Excmod & $\begin{array}{l}\text { Modell des } \\
\text { Kationenaustausches }\end{array}$ & Gapon & - & User \\
\hline $\lg \mathrm{KAlBC}$ & $\begin{array}{l}\text { Gapon-Austausch- } \\
\text { Koeffizienten von } \mathrm{Al} z u \\
\mathrm{Ca}+\mathrm{Mg}+\mathrm{K}\end{array}$ & konstant & - & Anhang Tab. A4 \\
\hline $\operatorname{lgKHBC}$ & $\begin{array}{l}\text { Gapon-Austausch- } \\
\text { Koeffizienten von } \mathrm{H} z u \\
\mathrm{Ca}+\mathrm{Mg}+\mathrm{K}\end{array}$ & konstant & - & Anhang Tab. A4 \\
\hline $\operatorname{expAl}$ & $\begin{array}{l}\text { Exponent in der } \\
\text { Gleichung }[\mathrm{Al}]= \\
\text { KAlox }[\mathrm{H}]^{\mathrm{a}}\end{array}$ & 3 & - & $\begin{array}{l}\text { SPRANGER et al. } \\
(2004)\end{array}$ \\
\hline $\lg$ KAlox & $\begin{array}{l}\text { log10 der Aluminium- } \\
\text { lösungskonstanten }\end{array}$ & 8 & - & $\begin{array}{l}\text { SPRANGER et al. } \\
(2004)\end{array}$ \\
\hline Cpool_0 & $\begin{array}{l}\text { initialer Kohlenstoffvorrat } \\
\text { im Oberboden }\end{array}$ & konstant & $\mathrm{g} / \mathrm{m}^{2}$ & Kapitel 2.2.4.9 \\
\hline CNrat_0 & $\begin{array}{l}\text { initiales } \mathrm{C} / \mathrm{N}-\text { Verhältnis } \\
\text { im Oberboden }\end{array}$ & konstant & $\mathrm{g} / \mathrm{g}$ & Kapitel 2.2.4.9 \\
\hline RCOOmod & $\begin{array}{l}\text { Dissoziation organischer } \\
\text { Säure }\end{array}$ & konstant & - & nicht berücksichtigt \\
\hline
\end{tabular}




\begin{tabular}{|c|c|c|c|c|}
\hline Kürzel & Beschreibung & Wert & Einheit & Quelle \\
\hline cRCOO & $\begin{array}{l}\text { Konzentration } \\
\text { organischer Säure }\end{array}$ & 0 & $\mathrm{~mol} / \mathrm{m}^{3}$ & User \\
\hline TempC & Jahresmitteltemperatur & Szenario & ${ }^{\circ} \mathrm{C}$ & Klimadaten \\
\hline percol & $\begin{array}{l}\text { Grundwasserneubildungs- } \\
\text { menge }\end{array}$ & Szenario & $\mathrm{mm}$ & $\begin{array}{l}\text { Anhang Kap. 2.3, } \\
\text { Text }\end{array}$ \\
\hline Ca_we & $\begin{array}{l}\text { Calcium- } \\
\text { Verwitterungsrate }\end{array}$ & dynamisch & $\mathrm{eq} / \mathrm{m}^{2} / \mathrm{a}$ & Kapitel 2.2.4.5 \\
\hline Mg_we & $\begin{array}{l}\text { Magnesium- } \\
\text { Verwitterungsrate }\end{array}$ & dynamisch & $\mathrm{eq} / \mathrm{m}^{2} / \mathrm{a}$ & Kapitel 2.2.4.5 \\
\hline K_we & Kalium-Verwitterungsrate & dynamisch & $\mathrm{eq} / \mathrm{m}^{2} / \mathrm{a}$ & Kapitel 2.2.4.5 \\
\hline Na_we & $\begin{array}{l}\text { Natrium- } \\
\text { Verwitterungsrate }\end{array}$ & dynamisch & $\mathrm{eq} / \mathrm{m}^{2} / \mathrm{a}$ & Kapitel 2.2.4.5 \\
\hline N_upt & Stickstoff-Aufnahmerate & dynamisch & $\mathrm{eq} / \mathrm{m}^{2} / \mathrm{a}$ & Kapitel 2.2.4.6 \\
\hline Ca_upt & Calcium-Aufnahmerate & dynamisch & $\mathrm{eq} / \mathrm{m}^{2} / \mathrm{a}$ & Kapitel 2.2.4.6 \\
\hline Mg_upt & $\begin{array}{l}\text { Magnesium- } \\
\text { Aufnahmerate }\end{array}$ & dynamisch & $\mathrm{eq} / \mathrm{m}^{2} / \mathrm{a}$ & Kapitel 2.2.4.6 \\
\hline K_upt & Kalium-Aufnahmerate & dynamisch & $\mathrm{eq} / \mathrm{m}^{2} / \mathrm{a}$ & Kapitel 2.2.4.6 \\
\hline $\mathrm{SO}_{2} \_\mathrm{dep}$ & $\mathrm{SO}_{2}$-Deposition & dynamisch & $\mathrm{eq} / \mathrm{m}^{2} / \mathrm{a}$ & Kapitel 2.2.4.5 \\
\hline NOx_dep & $\mathrm{NO}_{\mathrm{X}}$-Deposition & dynamisch & $\mathrm{eq} / \mathrm{m}^{2} / \mathrm{a}$ & Kapitel 2.2.4.5 \\
\hline $\mathrm{NH}_{3 \_ \text {dep }}$ & $\mathrm{NH}_{3}$-Deposition & dynamisch & $\mathrm{eq} / \mathrm{m}^{2} / \mathrm{a}$ & Kapitel 2.2.4.5 \\
\hline Ca_dep & Calcium-Deposition & dynamisch & $\mathrm{eq} / \mathrm{m}^{2} / \mathrm{a}$ & Kapitel 2.2.4.5 \\
\hline Mg_dep & Mg-Deposition & dynamisch & $\mathrm{eq} / \mathrm{m}^{2} / \mathrm{a}$ & Kapitel 2.2.4.5 \\
\hline K_dep & Kalium-Deposition & dynamisch & $\mathrm{eq} / \mathrm{m}^{2} / \mathrm{a}$ & Kapitel 2.2.4.5 \\
\hline $\mathrm{Na}$ dep & Natrium-Deposition & dynamisch & $\mathrm{eq} / \mathrm{m}^{2} / \mathrm{a}$ & Kapitel 2.2.4.5 \\
\hline Cl_dep & Chlorid-Deposition & dynamisch & $\mathrm{eq} / \mathrm{m}^{2} / \mathrm{a}$ & Kapitel 2.2.4.5 \\
\hline kmin_fe & $\begin{array}{l}\text { Abbaukoeffizient leicht } \\
\text { abbaubare frische Streu }\end{array}$ & 8,7 & $a^{-1}$ & BONTEN et al. (2011b) \\
\hline kmin_fs & $\begin{array}{l}\text { Abbaukoeffizient schwer } \\
\text { abbaubare frische Streu }\end{array}$ & 0,06 & $\mathrm{a}^{-1}$ & BONTEN et al. (2011b) \\
\hline kmin_mb & $\begin{array}{l}\text { Abbaukoeffizient } \\
\text { mikrobielle organische } \\
\text { Substanz }\end{array}$ & 1,0 & $a^{-1}$ & BONTEN et al. (2011b) \\
\hline kmin_hu & $\begin{array}{l}\text { Abbaukoeffizient humifi- } \\
\text { zierte organische Substanz }\end{array}$ & 0,0013 & $a^{-1}$ & BONTEN et al. (2011b) \\
\hline frhu_fe & $\begin{array}{l}\text { Tranferanteil der leicht } \\
\text { abbaubaren Streu }\end{array}$ & 0,0002 & - & BONTEN et al. (2011b) \\
\hline frhu_fs & $\begin{array}{l}\text { Tranferanteil der schwer } \\
\text { abbaubaren Streu }\end{array}$ & 0,28 & - & BONTEN et al. (2011b) \\
\hline frhu_mb & $\begin{array}{l}\text { Tranferanteil der mikrbi- } \\
\text { ellen organischen Sustanz }\end{array}$ & 0,95 & - & BONTEN et al. (2011b) \\
\hline CN_fe & $\mathrm{C} / \mathrm{N}-$ Verhältnis fe & 17 & $\mathrm{~g} / \mathrm{g}$ & BONTEN et al. (2011b) \\
\hline
\end{tabular}




\begin{tabular}{|c|c|c|c|c|}
\hline Kürzel & Beschreibung & Wert & Einheit & Quelle \\
\hline CN_fs & $\mathrm{C} / \mathrm{N}-$ Verhältnis fs & 295 & $g / g$ & BONTEN et al. (2011b) \\
\hline CN_mb & $\mathrm{C} / \mathrm{N}-$ Verhältnis mb & 9,5 & $\mathrm{~g} / \mathrm{g}$ & BONTEN et al. (2011b) \\
\hline CN_hu & C/N-Verhältnis hu & 9,5 & $\mathrm{~g} / \mathrm{g}$ & BONTEN et al. (2011b) \\
\hline CN_rt & $\begin{array}{l}\text { C/N-Verhältnis } \\
\text { Wurzelumsatz }\end{array}$ & 40 & $\mathrm{~g} / \mathrm{g}$ & BONTEN et al. (2011b) \\
\hline knit & $\begin{array}{l}\text { maximale Nitrifikations- } \\
\text { rate1 }\end{array}$ & 4 & $a^{-1}$ & BONTEN et al. (2011b) \\
\hline kdenit & $\begin{array}{l}\text { maximale } \\
\text { Denitrifikationsrate1 }\end{array}$ & 4 & $a^{-1}$ & BONTEN et al. (2011b) \\
\hline Nfix & Stickstofffixierung & 0 & $\mathrm{eq} / \mathrm{m}^{2} / \mathrm{a}$ & BONTEN et al. (2011b) \\
\hline Nlfmin & $\begin{array}{l}\text { Minimaler Stickstoffgehalt } \\
\text { im Streufall }\end{array}$ & dynamisch & $\%$ & Anhang, Tab. A6 \\
\hline Nlfmax & $\begin{array}{l}\text { Maximaler } \\
\text { Stickstoffgehalt im } \\
\text { Streufall }\end{array}$ & dynamisch & $\%$ & Anhang, Tab. A6 \\
\hline Ncf & $\begin{array}{l}\text { Verhältnis zwischen } \\
\text { Streufall und } \\
\text { Wurzelumsatz }\end{array}$ & dynamisch & - & Anhang, Tab. A6 \\
\hline expNlfdep & $\begin{array}{l}\text { Exponent der Beziehung } \\
\text { zwischen Deposition und } \\
\text { N-Gehalt im Streufall }\end{array}$ & dynamisch & $\mathrm{eq} / \mathrm{m}^{2} / \mathrm{a}$ & Anhang, Tab. A6 \\
\hline
\end{tabular}

${ }^{1}$ : bei einer Referenztemperatur von $10^{\circ} \mathrm{C}$

\section{Durchwurzelungstiefe und -verteilung}

Die Bilanzierung der Nährstoffe im Boden erfordert eine möglichst genaue Abschätzung des Wurzelraumes und der relativen Verteilung der Wurzeln innerhalb des Bodenprofils, da über die Wurzelverteilung die Nährstoffentzüge der jeweiligen Bodenhorizonte gesteuert werden. Ein häufiger Ansatz, um die gesamte Nährstoffaufnahme auf die einzelnen Bodenschichten zu verteilen, ist die Aufteilung der Nährstoffaufnahme auf die jeweiligen Bodenhorizonte anhand der Wurzelverteilung (JANDL 1998).

Zur Bestimmung der effektiven Durchwurzelungstiefe haben RAISSI et al. (2009) die 13 wichtigsten Verfahren zusammengefasst. Auch MüLLER (2004) und CZAJKOWSKI et al. (2009) (basierend auf RAISSI et al. 2009) haben ebenfalls Zusammenstellungen von effektiven Durchwurzelungstiefen in Forstböden vorgeschlagen. Da bei den Untersuchungen von LEHNARDT u. BRECHTEL (1983, 1985) in der Rhein-Main-Ebene (Hessisches Ried) keine eindeutigen Unterschiede zwischen den Baumarten ermittelt werden konnten, wurde als Grundlage für die Modellierungen das Verfahren von MüLLER (2004) für die Regionalisierung der Durchwurzelungstiefe ausgewählt, wobei die Baumartenunterschiede nicht beachtet wurden. Als Eingangsdaten finden bei dieser Regel Bodenart, Festgestein, 
Bodentyp, Niederschlag und das Bestandesalter Berücksichtigung. Diese sogenannte potenzielle Wurzeltiefe kann durch das jeweilige Bodenprofil eines Standortes abgeschnitten werden, wenn die Tiefe größer ist als die obere Tiefe eines nicht durchwurzelbaren Horizontes. Als Kriterien fungieren hierbei terrestrische Unterbodenhorizonte (C-Horizonte), sauerstofffreie Horizonte (Gr/Sr-Horizonte) oder Horizonte, die durch Reduktgase geprägt sind (Y-Horizonte). Entsprechend führen auch unterschiedliche Grundwasserstände zu unterschiedlichen Durchwurzelungstiefen an grundwasserbeeinflussten Standorten. Bei Grundwassereinfluss ist die unterste Grenze der Durchwurzelungstiefe der Grundwasserstand (RAISSI et al. 2009).

Die relative Wurzelintensität wird in Abhängigkeit von der Durchwurzelungstiefe modelliert. Hierfür wurde die Funktion aus FEDERER et al. (2003) von AHRENDS et al. (2010b) leicht modifiziert,

$$
f_{W}=1-0,5^{z / h}
$$

wobei $\mathrm{f}_{\mathrm{W}}$ der Anteil der Wurzeln über der Tiefe $\mathrm{z}$ ist und $\mathrm{h}$ beschreibt die Tiefe, in $\operatorname{der} \mathrm{f}=0,5$ ist. Der Parameter h berechnet sich aus der Durchwurzelungstiefe (RD) und einer Konstanten (k) wie folgt:

$$
h=\frac{R D}{k}
$$

Die Konstante $\mathrm{k}$ wurde als baumartenunabhängiger Wert aus dem Parameter $\mathrm{h}$ (nach JACKSON et al. 1996) und der Tiefe nach FEDERER et al. (2003) berechnet.

Verschiedene Untersuchungen (FACELLI u. FACELLI 2002, LINKOHR et al. 2002, WiJESINGHE u. HuTCHINGS 1997) haben gezeigt, dass sich Feinwurzeln vermehrt in Zonen mit hoher Nährstoff- und Wasserverfügbarkeit anreichern. Entsprechend zeigten die Untersuchungen von BRAUN et al. (2005) Effekte der Basensättigung auf die relative Feinwurzellänge und SAINJU u. GOOD (1993) ermittelten enge positive Beziehungen zwischen Wurzeldichte, effektiver Austauschkapazität und den austauschbar gebundenen Kationen. In einem Wurzelwachstumsexperiment mit Buchenjungpflanzen nahm ab einer Basensättigung $<3 \%$ der Sauerstoffverbrauch ab und die Callose-Konzentration zu (RICHTER et al. 2010). Entsprechend wird im Modell bei einer Basensättigung von $<3 \%$ der Entzug von basischen Kationen aus der jeweiligen Bodenschicht eingestellt (d. h. die Durchwurzelungsintensität wird auf Null gesetzt). So wird verhindert, dass aus einem Bodenhorizont Nährstoffentzüge erfolgen, obwohl keine Vorräte mehr vorhanden sind. Der fehlende Anteil an der Gesamtaufnahme des Bestandes wird dem ersten Horizont (von unten nach oben zählend) zugeschlagen, der eine Basensättigung $>5 \%$ besitzt. Die Zuordnung von unten nach oben folgt der Hypothese, dass sich der Grad der Zu- oder Abnahme der Feinwurzelintensität mit zunehmender Profiltiefe danach richtet, inwieweit bereits die Nährstoffansprüche der betreffenden Pflanzen gedeckt werden konnten (KERN et al. 1961). Um den Übergang an der $3 \%$-Grenze fließender zu gestalten und zu berücksichtigen, dass innerhalb eines 
Profils die Feinwurzelintensität wahrscheinlich dort am größten ist, wo die Verhältnisse einen hohen Nutzungsgrad zulassen (KERN et al. 1961), wird das asymptotische Tiefenprofil in Abhängigkeit von der Basensättigung in der jeweiligen Bodenschicht wie folgt korrigiert. Hierfür wird zunächst die Differenz (DIF) der Basensättigung der jeweiligen Bodenschicht $\left(\mathrm{BS}_{\mathrm{i}}\right)$ zur tiefenstufengewichteten mittleren Basensättigung der Wurzelzone $\left(\mathrm{X}_{\mathrm{TG}} \mathrm{BS}_{\mathrm{W}}\right)$ berechnet

$$
D I F=B S-X_{T G} B S_{W}
$$

und anschließend mit Hilfe der prozentualen Differenz - unter Berücksichtigung des Anteiles der Horizontmächtigkeit (Z) am Gesamtwurzelraum (WR) - der Wurzelanteil in der jeweiligen Schicht $\left(f_{\mathrm{WW}}\right)$ korrigiert:

$$
f_{W, t}=f_{W, t-1}+D I F \cdot \frac{Z}{W R}
$$

$\mathrm{Da}$ in VSD keine Differenzierung zwischen den basischen Kationen möglich ist, bleibt bei diesem Ansatz jedoch die Zusammensetzung des Nährstoffangebots (Antagonismen) unberücksichtigt und die Wurzelintensität reagiert nicht auf einseitige Angebote von $\mathrm{Ca}, \mathrm{Mg}$ oder $\mathrm{K}$.

\section{Kationenaustauschkaparität}

Die effektive Kationenaustauschkapazität $\left(\mathrm{KAK}_{\text {eff }}\right)$ ist abhängig vom bei den Messungen gegebenen $\mathrm{pH}$-Wert. Folglich ergibt sich eine Differenz zwischen Kationenaustauschkapazitäten, die beim gegebenen $\mathrm{pH}-$ Wert gemessen wurden, und denen, die bei einem Standard-pH $(6,5$ oder 8,2) ermittelt wurden. Daher werden in VSD (wie auch in vielen anderen Modellen) die Austauschkonstanten in Beziehung zu einem pH-Wert in einer gepufferten Lösung in Beziehung gesetzt, damit ein einheitliches Niveau vorliegt. Liegen für einen Standort die gemessenen Kationenaustauschkapazitäten für einen bestimmten $\mathrm{pH}$-Wert vor, dann kann mit Hilfe der Schätzmodelle (z. B. MÜLLER 2004, CURTIN u. ROSTAD 1997, HELLING et al. 1964) die gemessenen KAK auf den standardisierten Wert skaliert werden. Die folgenden Gleichung zeigt hierfür die Berechungen nach SPRANGER et al. (2004):

$$
K A K_{p H=6,5}=K A K_{\text {gemessen }} \cdot \frac{M K A K(p H=6,5)}{M K A K(p H=\text { gemessen })}
$$

mit: MKAK = mit Schätzmodell berechnete KAK zum jeweiligem $\mathrm{pH}-$ Wert

Zur Ableitung der potenziellen und/oder der effektiven Kationenaustauschkapazität liegt in der Literatur eine Vielzahl von Pedotransferfunktionen vor (AG BODEN 2005, MÜLler 2004, Helling et al. 1984, CurTiN u. Rostad 1997). Verwendet wurde letztendlich die Funktion des NIBIS (Niedersächsischen Bodeninformationssystems - MÜLLER 2004), da diese wahrscheinlich eine maximale Übertragbarkeit erlaubt. Neben dieser Schätzfunktion wurden auch andere Modelle getestet. In MÜLLER (2004) wird für die $\mathrm{KAK}_{\text {pot }}$ des Bodenskeletts eine KAK von $1 \mathrm{cmol}_{\mathrm{c}} \mathrm{kg}^{-1}$ zugewiesen, wobei die KAK natürlicher Bodenskelette durchaus 
höher liegen kann (DEUTSCHMANN et al. 1997, HÖKE et al. 2009). Mit dem Bewertungsschlüssel bei MÜLLER (2004) kann die KAK der organischen Auflage nur stark vereinfacht abgeschätzt werden. In Nordrhein-Westfalen ist im Rahmen der Bodenzustandserhebung für L+Of-Auflagen im Mittel eine $\mathrm{KAK}_{\text {eff }}$ von $45 \mathrm{cmol}_{\mathrm{c}} \mathrm{kg}^{-1}(\mathrm{n}=122)$ und für die Oh-Auflagen von $35 \mathrm{cmol}_{\mathrm{c}} \mathrm{kg}^{-1} \quad(\mathrm{n}=87)$ (HÖKE et al. 2009) ermittelt worden. Entsprechend wird von den Autoren vorgeschlagen, eine $\mathrm{KAK}_{\text {eff }}$ von $40 \mathrm{cmol}_{\mathrm{c}} \mathrm{kg}^{-1}$ für die organischen Auflagen zu verwenden, bis genauere Werte vorliegen. Daher wurde die $\mathrm{KAK}_{\text {pot }}$ für die Humusstufe $\mathrm{H}$ von 125 auf $100 \mathrm{cmol}_{\mathrm{c}} \mathrm{kg}^{-1}$ herabgesetzt.

\section{Austauschkoeffizienten}

Bei den Modellsimulationen wurden die folgenden Gapon-Austausch-Koeffizienten hinterlegt. Bei den hier dargestellten Koeffizienten ist zu beachten, dass sie empirisch an Standorten in den Niederlanden ermittelt worden sind.

Tabelle A 4: Gapon-Austausch-Koeffizienten von Al zu Ca+Mg+K (DE VRIES u. POSCH 2003)

\begin{tabular}{ccccc}
\hline \multirow{2}{*}{ Tiefe $[\mathrm{cm}]$} & Sand & Löss & TAlBc $\left[\mathrm{eq} / \mathrm{m}^{3}\right]^{1 / 6}$ & Torf \\
\hline $0-10$ & 6,2729898 & 4,8025797 & 1,5117312 & 1,3136346 \\
$10-30$ & 15,292362 & 7,4726489 & 1,0677623 & 1,1155129 \\
$30-60$ & 20,439703 & 7,5417925 & 0,1036274 & 0,5642539 \\
$60-100$ & 40,315735 & 7,6115759 & 0,0497135 & 0,4211866 \\
\hline
\end{tabular}

Tabelle A5: Gapon-Austausch-Koeffizienten von $H$ qu Ca+Mg+K (DE VRIES u. POSCH 2003)

\begin{tabular}{ccccc}
\hline \multirow{2}{*}{ Tiefe $[\mathrm{cm}]$} & Sand & Löss & THBc $\left[\mathrm{eq} / \mathrm{m}^{3}\right]^{-1 / 2}$ & Torf \\
\hline $0-10$ & 67,377516 & 61,449025 & 216,03046 & 29,411353 \\
$10-30$ & 150,49255 & 77,716816 & 86,599423 & 24,519691 \\
$30-60$ & 205,35959 & 77,004304 & 148,42771 & 39,311082 \\
$60-100$ & 328,48459 & 76,298324 & 212,08746 & 47,589923 \\
\hline
\end{tabular}

In anderen Regionen müssen solche Koeffizienten erst noch entwickelt werden und mit regional ermittelten Koeffizienten überprüft werden (NAGEL et al. 2004).

\section{$\mathrm{CO}_{2}$-Partialdruck}

Benötigt wird der $\mathrm{CO}_{2}$-Partialdruck als Vielfaches des atmosphärischen Druckes. Dieser kann vereinfacht anhand der Horizontsymbole abgeschätzt werden. Humusauflagen 5-10, A-Horizonte 5-15, B-Horizonte 15-20 und C-Horizonte 1530 [x atm]. Für den Partialdruck der freien Atmosphäre ist ein Standardwert von 370 ppm oder 3,7·10-4 atm hinterlegt (SPRANGER et al. 2004). 


\section{Verwitterungsoberfläche}

Als Grundlage für die Berechnung der Verwitterungsoberfläche nach SVERDRUP u. WARFVINGE (1993) dienen die Informationen zur Bodenart, zur Lagerungsdichte und zum Skelettgehalt aus den Bodenprofilen.

$$
\begin{aligned}
& A_{W}=\left(8,0 \cdot \frac{\% \text { Ton }}{100}+2,2 \cdot \frac{\% \text { Schluff }}{100}+0,3 \cdot \frac{\% \text { Sand }}{100}\right) \cdot\left(1,0-\frac{\% \text { Skelett }}{100}\right) \cdot \frac{p}{1000} \cdot 10^{6} \\
& \text { mit: } \begin{aligned}
A_{W} \quad & =\text { chemisch wirksame Mineraloberfläche }\left[\mathrm{m}^{2} \mathrm{~m}^{-3}\right] \\
\% \mathrm{X} & =\text { Gehalt an Ton, Schluff und Sand sowie Skelettanteil }[\%] \\
p \quad & =\text { Trockenraumdichte der Bodenschicht }\left[\mathrm{kg} \mathrm{m}^{-3}\right]
\end{aligned}
\end{aligned}
$$

\section{Bodenwassergehalt}

Sowohl VSD als auch das Modell PROFILE benötigen den volumetrischen Wassergehalt als Jahresmittel $\left(\mathrm{m}^{3} \mathrm{~m}^{-3}\right)$. Als erste Näherung kann für die Abschätzung ein Standardwert von 0,2 $\left(\mathrm{m}^{3} \mathrm{~m}^{-3}\right)$ für Waldböden verwendet werden (SVERDRUP et al. 1990). Um bodenartenspezifische Unterschiede stärker zu berücksichtigen, kann auch der Wassergehalt im Bereich von $\mathrm{pF}$ 1,8 bis 4,2 verwendet werden (BECKER 1999). Zur Abschätzung der nutzbaren Feldkapazität siehe folgendes Kapitel. Die Korrektur der Bodenwassergehalte in Abhängigkeit vom Grundwasserstand erfolgte anhand einer modifizierten Version der Zuordnungsmatrix zur Ermittlung des volumetrischen Wassergehaltes nach NAGEL et al. (2010).

Neben dem Bodenwassergehalt wird auch die Bodenfeuchtesättigung benötigt. Bei zu geringen Feuchtegehalten an den Mineraloberflächen sinkt die Verwitterungsrate ab. Demgegenüber führen sehr hohe Feuchtegehalte im Boden zu einer Erhöhung der Denitrifikation. Die hierfür entscheidende Bodenfeuchtesättigung lässt sich wie folgt berechnen (SVERDRUP u. WARFVINGE 1993):

$$
\theta=\frac{p_{\text {solids }} \cdot \Theta}{p_{\text {solids }}+1000 \cdot \Theta-p_{\text {bulk }}}
$$

$$
\begin{aligned}
& \text { mit: } \quad \theta \quad=\text { Bodenfeuchtesättigung [0-1] } \\
& \Theta \quad=\text { Bodenwassergehalt }\left[\mathrm{m}^{3} \mathrm{~m}^{-3}\right] \\
& \text { psolids }=\text { Dichte der Bodenpartikel }\left[\mathrm{kg} \mathrm{m}^{-3}\right] \\
& \text { pbulk = Trockenraumdichte }\left[\mathrm{kg} \mathrm{m}^{-3}\right]
\end{aligned}
$$

\section{Nutzbare Feldkapazität}

Die in der KA5 (AG-BODEN 2005) aufgeführten Tabellen für die Schätzung der bodenphysikalischen Kennwerte (FK, $\mathrm{nFK}$, LK und $\mathrm{kf}$ ) weisen gravierende Mängel auf (RENGER et al. 2008). Daher hat die Arbeitsgruppe der DBG „Kennwerte des Bodengefüges“ die bestehenden Schätztabellen verbessert. Das betrifft insbesondere die $\mathrm{Zu}$ - und Abschläge für hydromorphe Böden in Abhängigkeit vom Grundwasserflurabstand und Stauwassereinfluss. Der Einfluss des Grundwassers und der Staunässe wurde bisher bei der Schätzung der nFK-Werte nicht berücksichtigt (AG-BODEN 2005). Die Ableitung der nFK für die Humusauflage 
erfolgt nach LEUSCHNER (1998) mit einer nFK von 26 mm/dm. Extrem humosen Horizonten (15-30\% organische Substanz) wird pauschal eine $\mathrm{nFK}$ von $37 \mathrm{~mm} / \mathrm{dm}$ zugewiesen (MÜLLER 2004).

Vegetationspezifische Parameter im C- und N-Modell

Tabelle A6: $\quad$ Standardwerte für Nlfmin, Nlfmax, expNlfdep, nof und Nst bei unterschiedlichen Vegetationstypen (BONTEN et al. 2011b)

\begin{tabular}{lccccc}
\hline Vegetationstyp & Nlfmin & Nlfmax & expNlfd & ncf & Nst \\
\hline Fichte & 1,07 & 1,51 & 10,8 & 0,8 & 0,11 \\
Kiefer & 1,01 & 2,13 & 7,4 & 0,6 & 0,11 \\
$\begin{array}{l}\text { Laubbäume Weichholz } \\
\text { (z. B. Weide Pappel) }\end{array}$ & 1,52 & 2,90 & 8,2 & 0,5 & 0,13 \\
$\begin{array}{l}\text { Laubbäume Hartholz } \\
\text { (z. B. Eiche, Buche) }\end{array}$ & 1,52 & 2,90 & 8,2 & 0,5 & 0,13 \\
$\begin{array}{l}\text { Immergrüne Laubbäume } \\
\text { Grasland }\end{array}$ & 1,52 & 2,90 & 8,2 & 0,5 & 0,13 \\
Tundra, Heide & 0,85 & 2,30 & 9,0 & 0,5 & 0,11 \\
& 0,85 & 1,80 & 9,0 & 0,5 & 0,11 \\
\hline
\end{tabular}

Sickerwasserrate (TUB_BGR-Verfahren)

Zur Abschätzung der Sickerwasserrate an der unteren Grenze des Wurzelraumes wurde das Verfahren TUB-BGR eingesetzt (WESSOLEK et al. 2004), da dieses eine Untergliederung in grundwasserbeeinflusste und grundwasserferne Areale vornimmt. Die hierfür notwendige potenzielle Evapotranspiration wurde nach WENDLING (1995) ermittelt und die nFK im effektiven Wurzelraum nach der oben beschriebenen Methode. Der kapillare Aufstieg wurde nach MÜLLER (2004) berechnet.

\section{Deposition}

Die Zuordnung der Bestandestypen zu Landnutzungstypen der atmosphärischen Stoffeinträge erfolgte gemäß Tabelle A7. 
Tabelle A7: Zuordnung der Bestandestypen zu Landnutzungstypen (2: landwirtschaftliche Flächen, 3: Laubwald, 4: Nadelwald, 5: Mischwald) der atmosphärischen Stoffeinträge; aus: LANDESFORSTVERW ALTUNG NIEDERSACHSEN (2004)

\begin{tabular}{|c|c|c|}
\hline Ziffer & Bestandestyp & Landnutzungstyp \\
\hline 0 & Blöße & 2 \\
\hline 10 & TEi rein & 3 \\
\hline 11 & SEi rein & 3 \\
\hline 12 & TEi/Bu mit sonst. Laubbäumen & 3 \\
\hline 13 & SEi mit Edellaubbäumen & 3 \\
\hline 14 & SEi/Bu mit sonst. Laubbäumen & 3 \\
\hline 16 & Ei mit Nadelbäumen & 5 \\
\hline 17 & Ei mit sonst. Laub- u./o. Nadelbäumen & 3 \\
\hline 18 & REi rein u. gemischt & 3 \\
\hline 19 & sonst. Bestände der Baumartengruppe Eiche & 3 \\
\hline 20 & $\mathrm{Bu}$ rein & 3 \\
\hline 21 & Bu mit Ei & 3 \\
\hline 22 & Bu mit BAh & 3 \\
\hline 23 & Bu mit Edellaubbäumen & 3 \\
\hline 25 & $\mathrm{Bu}$ mit $\mathrm{Fi}$ & 5 \\
\hline 26 & Bu mit Dgl & 5 \\
\hline 27 & $\mathrm{Bu}$ mit Ta & 5 \\
\hline 28 & Bu mit Lä & 3 \\
\hline 29 & $\mathrm{Bu}(\mathrm{HBu})$ mit sonst. Baumarten & 3 \\
\hline 30 & BAh rein & 3 \\
\hline 31 & Es rein & 3 \\
\hline 32 & Es gemischt & 3 \\
\hline 33 & Es mit RErl & 3 \\
\hline 34 & BAh gemischt & 3 \\
\hline 35 & Li rein u. gemischt & 3 \\
\hline 36 & Kir rein u. gemischt & 3 \\
\hline 39 & Sonst. Bestände der Baumartengruppe ALh & 3 \\
\hline 40 & Erl rein u. gemischt & 3 \\
\hline 42 & $\mathrm{~Pa} / \mathrm{As}$ rein $\mathrm{u}$. gemischt & 3 \\
\hline 43 & RErl mit Es & 3 \\
\hline 44 & Bi rein u. gemischt & 3 \\
\hline 49 & Sonst. Bestände der Baumartengruppe ALn & 3 \\
\hline 50 & Fi rein & 4 \\
\hline
\end{tabular}




\begin{tabular}{|c|c|c|}
\hline Ziffer & Bestandestyp & Landnutzungstyp \\
\hline 51 & Hochlagenfichte & 4 \\
\hline 52 & Fi mit Bu & 5 \\
\hline 53 & Fi mit ALn & 5 \\
\hline 54 & Fi mit sonst. Laubbäumen & 5 \\
\hline 55 & W'Ta rein u. gemischt & 4 \\
\hline 56 & Sonst. Ta rein u gemischt & 4 \\
\hline 57 & Fi mit sonst. Nadelbäumen & 4 \\
\hline 58 & Fi mit Laub- und Nadelbäumen & 4 \\
\hline 59 & Sonst. Bestände der Baumartengruppe Fichte & 4 \\
\hline 60 & Dgl rein & 4 \\
\hline 62 & $\mathrm{Dgl}$ mit $\mathrm{Bu}$ & 5 \\
\hline 64 & Dgl mit sonst. Laubbäumen & 5 \\
\hline 65 & Dgl mit Fi & 4 \\
\hline 66 & Dgl mit Ta & 4 \\
\hline 67 & Dgl mit Ki & 4 \\
\hline 68 & Dgl mit Laub- u./o. Nadelbäumen & 4 \\
\hline 70 & Ki rein & 4 \\
\hline 71 & Ki mit Ei u. sonst. Baumarten & 5 \\
\hline 72 & Ki mit Bu u. sonst. Baumarten & 5 \\
\hline 74 & Ki mit sonst. Laub- u./o. Nadelbäumen & 5 \\
\hline 75 & Ki mit Fi & 4 \\
\hline 76 & Ki mit Dgl & 4 \\
\hline 77 & SKi rein u. gemischt & 4 \\
\hline 78 & Stro rein u. gemischt & 4 \\
\hline 79 & Sonst. Bestände der Baumartengruppe Kiefer & 4 \\
\hline 81 & ELä rein & 4 \\
\hline 82 & JLä rein & 4 \\
\hline 83 & JLä mit Bu u. sonst. Laubbäumen & 5 \\
\hline 84 & JLä mit sonst. Laub- u./o. Nadelbäumen & 4 \\
\hline 85 & ELä mit Bu u. sonst. Laubbäumen & 5 \\
\hline 86 & ELä mit sonst. Laub- u./o .Nadelbäumen & 4 \\
\hline 89 & Sonst. Bestände der Baumartengruppe Lärche & 4 \\
\hline
\end{tabular}


Tabelle A8: $\quad$ Parameter der Höhenkorrekturfunktionen (vgl. Gl. 2) in Abhängigkeit von der Landnutzungsform und dem jeweiligen Element für den Datensatz in Hessen (GAUGER et al. 2008)

\begin{tabular}{|c|c|c|c|}
\hline Landnutzung & Element & $\mathrm{m}$ & b2 \\
\hline Laubwald & $\mathrm{Ca}$ & 0,007204424 & 0,848167432 \\
\hline Laubwald & $\mathrm{Cl}$ & 0,007204424 & 0,848167432 \\
\hline Laubwald & $\mathrm{K}$ & 0,007204424 & 0,848167432 \\
\hline Laubwald & $\mathrm{Mg}$ & 0,007204424 & 0,848167432 \\
\hline Laubwald & $\mathrm{Na}$ & 0,007204424 & 0,848167432 \\
\hline Laubwald & $\mathrm{NH}_{\mathrm{X}}$ & 0,00785595 & 0,833017266 \\
\hline Laubwald & $\mathrm{NO}_{\mathrm{Y}}$ & 0,006351242 & 0,865623601 \\
\hline Laubwald & $\mathrm{SO}_{\mathrm{x}}$ & 0,007204424 & 0,848167432 \\
\hline Mischwald & $\mathrm{Ca}$ & 0,007274179 & 0,852502335 \\
\hline Mischwald & $\mathrm{Cl}$ & 0,007274179 & 0,852502335 \\
\hline Mischwald & $\mathrm{K}$ & 0,007274179 & 0,852502335 \\
\hline Mischwald & $\mathrm{Mg}$ & 0,007274179 & 0,852502335 \\
\hline Mischwald & $\mathrm{Na}$ & 0,007274179 & 0,852502335 \\
\hline Mischwald & $\mathrm{NH}_{\mathrm{X}}$ & 0,008001257 & 0,836516263 \\
\hline Mischwald & $\mathrm{NO}_{Y}$ & 0,006560694 & 0,866272886 \\
\hline Mischwald & $\mathrm{SO}_{\mathrm{x}}$ & 0,007274179 & 0,852502335 \\
\hline Nadelwald & $\mathrm{Ca}$ & 0,006103321 & 0,878578405 \\
\hline Nadelwald & $\mathrm{Cl}$ & 0,006103321 & 0,878578405 \\
\hline Nadelwald & $\mathrm{K}$ & 0,006103321 & 0,878578405 \\
\hline Nadelwald & $\mathrm{Mg}$ & 0,006103321 & 0,878578405 \\
\hline Nadelwald & $\mathrm{Na}$ & 0,006103321 & 0,878578405 \\
\hline Nadelwald & $\mathrm{NH}_{\mathrm{X}}$ & 0,006776774 & 0,864081056 \\
\hline Nadelwald & $\mathrm{NO}_{Y}$ & 0,005648321 & 0,886850479 \\
\hline Nadelwald & $\mathrm{SO}_{\mathrm{X}}$ & 0,006103321 & 0,878578405 \\
\hline
\end{tabular}




\section{Silikatverwitterungsrate}

Für den Prozess der Verwitterung werden die folgenden vier Prozesse betrachtet:

- Reaktion mit H+

- Reaktion mit $\mathrm{H}_{2} \mathrm{O}$

- Reaktion mit $\mathrm{CO}_{2}$

- Reaktion mit organischen Säuren (R)

Die Lösungsrate für jedes Mineral im Boden ergibt sich somit aus der Summe der vier Teilprozesse (SVERDRUP u. WARFVINGE 1993):

$$
r_{j}=k_{H^{+}} \cdot \frac{\left[H^{+}\right]^{n_{H}}}{f_{H}}+\frac{k_{\mathrm{H}_{2} \mathrm{O}}}{f_{\mathrm{H}_{2} \mathrm{O}}}+k_{\mathrm{CO}_{2}} \cdot p_{\mathrm{CO}_{2}}^{n_{\mathrm{CO}}}+k_{R} \cdot \frac{\left[R^{-}\right]^{n_{R}}}{f_{R}}
$$

wobei: $\mathrm{r} \quad=$ Lösungsrate eines Minerals $\left[\mathrm{kmol}_{\mathrm{c}} \mathrm{m}^{-3} \mathrm{a}^{-1}\right]$

$\mathrm{k}_{\mathrm{y}} \quad=$ Reaktionsgeschwindigkeitskonstante $\mathrm{k}$ der Reaktion $\mathrm{y}$

$\mathrm{f}_{\mathrm{y}} \quad=$ Reduktionsfaktor der Mineralverwitterung $\mathrm{f}$ der Reaktion $\mathrm{y}$

$\left[\mathrm{H}^{+}\right]=$Konzentration von Protonen in der Bodenlösung $\left[\mathrm{kmol}_{\mathrm{c}} \mathrm{m}^{-3}\right]$

$\left[\mathrm{R}^{-}\right] \quad=$ Konzentration von organ. Säuren in der Bodenlösung $\left[\mathrm{kmol}_{\mathrm{c}} \mathrm{m}^{-3}\right]$

$\mathrm{PCO}_{\mathrm{C}}=\mathrm{CO}_{2}^{-}[\mathrm{x}$ atm $]$

$\mathrm{n}_{\mathrm{y}} \quad=$ Reaktionsordnung $\mathrm{n}$ der Reaktion $\mathrm{y}$

j $\quad=$ Mineral-Index

Die Reduktionsfaktoren $\left(f_{\mathrm{y}}\right)$ berechnen sich aus den Konzentrationen basischer Kationen, von Aluminium und organischen Säuren in der Bodenlösung.

$$
\begin{aligned}
& f_{H}=\left(1+\frac{\left[B C^{2+}\right]}{C_{B C}}\right)^{x_{B C}} \cdot\left(1+\frac{\left[A l^{3+}\right]}{C_{A l}}\right)^{X_{A l}} \\
& f_{\mathrm{H}_{2} \mathrm{O}}=\left(1+\frac{\left[B C^{2+}\right]}{C_{B C}}\right)^{z_{B C}} \cdot\left(1+\frac{\left[A l^{3+}\right]}{C_{A l}}\right)^{z_{A l}} \\
& f_{R}=\left(1+\left(\frac{[R]}{C_{R}}\right)^{0.5}\right) \\
& f_{\mathrm{CO}_{2}}=1
\end{aligned}
$$

wobei: fy $\quad=$ Reduktionsfaktor der Mineralverwitterung $f$ der Reaktion $y$

$[\mathrm{x}] \quad=$ Konzentration von basischen Kationen, organischen Säuren oder von Aluminium in der Bodenlösung [ $\mathrm{kmolc}^{-3}$ ]

$\mathrm{C}_{\mathrm{x}}=$ Referenz-Konzentration von basischen Kationen, Aluminium oder organischen Säuren in der Bodenlösung zur Begrenzung der MineralLöslichkeit $\left[\mathrm{kmolc} \mathrm{m}^{-3}\right]$

$\mathrm{x} / \mathrm{z}=$ Reaktionsordnung für basische Kationen oder Aluminium 
Die auf eine Bodentemperatur von $8{ }^{\circ} \mathrm{C}$ standardisierten Reaktionsgeschwindigkeitskonstanten werden mit folgender Arrhenius-Funktion (SVERDRUP u. WARFVINGE 1993) an die Temperaturverhältnisse des jeweiligen Standortes angepasst.

$$
\log _{10}=\left(\frac{k_{T}}{k_{8^{\circ} \mathrm{C}}}\right)=\frac{E_{\mathrm{A}}}{R} \cdot\left(\frac{1}{281}-\frac{1}{T}\right)
$$

wobei: $\mathrm{E}_{\mathrm{A}}=$ Aktivierungsenergie $\left[\mathrm{kJ} \mathrm{kmol}^{-1}\right]$

$\mathrm{R}=$ allgemeine Gaskonstante $\left[\mathrm{kJ} \mathrm{kmol}^{-1} \mathrm{~K}^{-1}\right]$

$\mathrm{k}=$ Reaktionsgeschwindigkeitskonstante $\left[\mathrm{kmol}_{\mathrm{c}} \mathrm{m}^{-2} \mathrm{~s}^{-1}\right]$

$\mathrm{T} \quad=$ absolute Temperatur $[\mathrm{K}]$

Die gesamte Verwitterungsrate eines Bodenhorizontes ergibt sich dann aus der Summe des Produktes der Lösungsraten mit den Mineralanteilen im Boden.

$$
R_{w, i}=\sum_{j=1}^{\text {minerals }} r_{j} \cdot A_{i} \cdot x_{j} \cdot \theta_{i} \cdot z_{i}
$$

wobei: $\quad \mathrm{Rw} \quad=$ Raten der Verwitterung basischer Kationen $\left[\mathrm{kmolc}^{-3} \mathrm{a}^{-1}\right]$

$\mathrm{r} \quad=$ Lösungsrate des Minerals $\left[\mathrm{kmolc} \mathrm{m}^{-3} \mathrm{a}^{-1}\right]$

A = für die Verwitterung wirksame Mineraloberfläche $\left[\mathrm{m}^{2} \mathrm{~m}^{-3}\right]$

$\mathrm{x}=$ Anteil des Minerals nach Mineralanalyse [0-1]

$\theta=$ Bodenfeuchtesättigung, abgeleitet aus dem volumetrischem Wassergehalt [0-1]

$\mathrm{z}=$ Mächtigkeit des Horizontes [m]

j $\quad=$ Mineralindex

i $\quad=$ Horizont-Index

Um die korrekte Implementierung der Gleichungen und ihrer Parameterisierung zu prüfen, wurden die eingebauten Funktionen unter „kontrollierten Randbedingungen“ mit dem Modell CL-Profile Version 4.2 (BECKER 1999) verglichen. Beide Programme lösen im Kern exakt dasselbe Problem. Daher können unterschiedliche Ergebnisse nur aufgrund von Programmierfehlern oder unterschiedlichen Parametrisierungen auftreten. Die gute Übereinstimmung für alle vier Teilprozesse der Minerallösung zeigt, dass die Gleichungen korrekt implementiert wurden. 

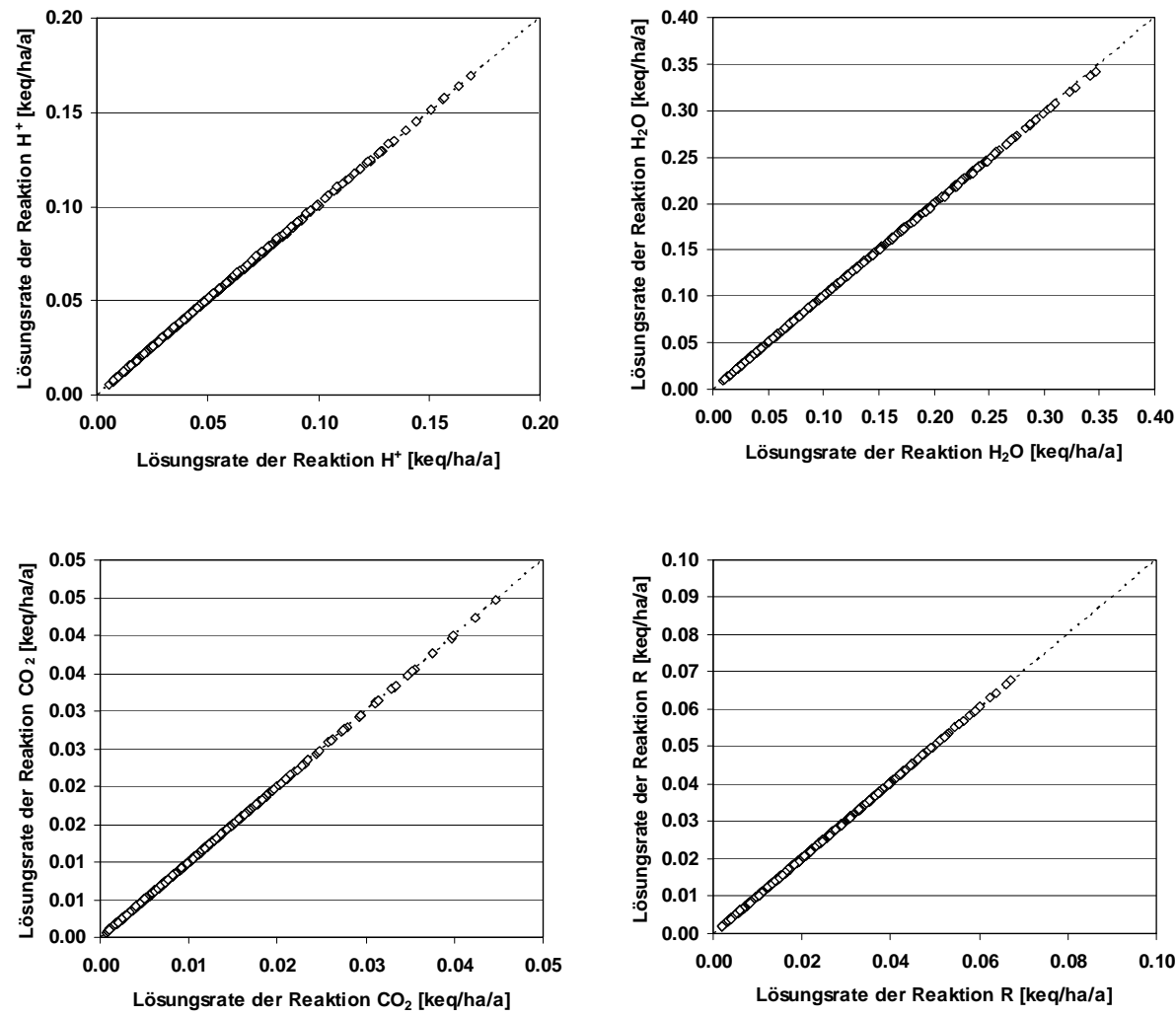

Abbildung A3: Vergleich der Lösungsrate [keq/ha/a] für die vier Teilprozesse der Mineralverwitterung im Boden zwischen dem Modell CL-Profil und den Gleichungen in DSS-RM unter kontrollierten Rahmenbedingungen 
Zur flächenhaften Abschätzung der Verwitterungsrate sind weitere Eingangsdaten notwendig. Tabelle A9 liefert einen Überblick über die Quellen bzw. die Methoden, mit deren Hilfe sie abgeleitet wurden.

Tabelle A9: Eingangsdaten und ihre Quellen für die Berechnung der Silikatverwitterungsrate

\begin{tabular}{|c|c|c|c|c|}
\hline Kürzel & Beschreibung & Wert & Einheit & Quelle \\
\hline $\mathrm{k}_{\mathrm{y}}$ & $\begin{array}{l}\text { Reaktionsgeschwindig- } \\
\text { keitskonstanten der } \\
\text { Reaktion y }\end{array}$ & dynamisch & $\mathrm{kmol}_{\mathrm{c}} \mathrm{m}^{-2} \mathrm{~s}^{-1}$ & Tabelle A9 \\
\hline $\mathrm{n}_{\mathrm{y}}$ & $\begin{array}{l}\text { Reaktionsordnung } \mathrm{n} \text { der } \\
\text { Reaktion y }\end{array}$ & konstant & - & Tabelle A9 \\
\hline $\mathrm{x}$ & $\begin{array}{l}\text { Stoffkonzentrationen in } \\
\text { der Bodenlösung }\end{array}$ & dynamisch & $\mathrm{kmol}_{\mathrm{c}} \mathrm{m}^{-3}$ & VSD-Modell \\
\hline $\mathrm{p}_{\mathrm{CO} 2}$ & $\mathrm{CO}_{2}$-Partialdruck & konstant & $\mathrm{x}$ atm & Anhang s.o. \\
\hline $\mathrm{C}_{\mathrm{X}}$ & Referenzkonzentrationen & konstant & $\mathrm{kmol}_{\mathrm{c}} \mathrm{m}^{-3}$ & Tabelle A10 \\
\hline $\mathrm{X}_{\mathrm{X}} / \mathrm{Z}_{\mathrm{X}}$ & $\begin{array}{l}\text { Reaktionsordnung für } \\
\text { basische Kationen und } \mathrm{Al}\end{array}$ & konstant & & Tabelle A10 \\
\hline $\mathrm{E}_{\mathrm{A}}$ & Aktivierungsenergie & konstant & $\mathrm{kJ} \mathrm{kmol}^{-1}$ & Tabelle A11 \\
\hline $\mathrm{R}$ & Allgemeine Gaskonstante & konstant & $\mathrm{kJ} \mathrm{kmol}{ }^{-1} \mathrm{~K}^{-1}$ & Tabelle A11 \\
\hline $\mathrm{k}$ & $\begin{array}{l}\text { Reaktionsgeschwindigkeit } \\
\text { skonstante }\end{array}$ & konstant & & Tabelle A11 \\
\hline A & Verwitterungsoberfläche & konstant & $m^{2} m^{-3}$ & Anhang s.o. \\
\hline $\mathrm{x}$ & $\begin{array}{l}\text { Anteil des Minerals nach } \\
\text { Mineralanalyse }\end{array}$ & konstant & $0-1$ & Tabelle A12 \\
\hline$\theta$ & Bodenfeuchtesättigung & dynamisch & $0-1$ & Anhang s.o. \\
\hline z & Horizontmächtigkeit & konstant & $\mathrm{m}$ & Bodenkarte \\
\hline SB & $\begin{array}{l}\text { Substrat der } \\
\text { Bodenbildung }\end{array}$ & konstant & - & Bodenkarte \\
\hline M & Mineralogie & konstant & - & $\begin{array}{l}\text { modifiziert nach } \\
\text { MALESSA u. } \\
\text { AHRENDS } 2001 \text {, } \\
\text { POSCH et al. } \\
2007 \text {, AHRENDS } \\
2008\end{array}$ \\
\hline
\end{tabular}


Tabelle A10: Mineralkinetische Modellparameter zur Berechnung der Verwitterungsrate (Angaben in kmol $m^{-2} s^{-1}$ bei einer Temperatur von $8{ }^{\circ} \mathrm{C}$ (BECKER 1999))

\begin{tabular}{|c|c|c|c|c|c|c|}
\hline Mineral & $\mathrm{pk}_{\mathrm{H}}$ & $\mathrm{pk}_{\mathrm{H} 2 \mathrm{O}}$ & $\mathrm{pk}_{\mathrm{CO} 2}$ & $\mathrm{pkR}$ & $\mathrm{nH}$ & $\mathrm{nCO}_{2}$ \\
\hline K-Feldspat & 14,7 & 17,2 & 16,8 & 15 & 0,5 & 0,6 \\
\hline Plagioklas & 14,6 & 16,8 & 15,9 & 14,7 & 0,5 & 0,6 \\
\hline Pyroxen & 12,8 & 16,9 & 15,8 & 14,4 & 0,7 & 0,6 \\
\hline Amphibol & 12,8 & 16,9 & 15,8 & 14,4 & 0,7 & 0,6 \\
\hline Calcit & 13,6 & 15,2 & 13,2 & 13,2 & 1,0 & 1,0 \\
\hline Dolomit & 13,6 & 15,2 & 13,2 & 13,2 & 1,0 & 1,0 \\
\hline Fe-Al-Chlorit & 14,8 & 17,0 & 16,2 & 15,0 & 0,7 & 0,5 \\
\hline Fe-Mg-Chlorit & 14,8 & 17,0 & 16,2 & 15,0 & 0,7 & 0,5 \\
\hline Mg-Chlorit & 14,8 & 17,0 & 16,2 & 15,0 & 0,7 & 0,5 \\
\hline Kaolinit & 15,1 & 17,6 & 16,5 & 15,2 & 0,8 & 0,5 \\
\hline Al-Vermiculit & 15,2 & 17,5 & 16,5 & 15,3 & 0,5 & 0,5 \\
\hline K-Illit1 & 15,2 & 17,5 & 16,5 & 15,3 & 0,5 & 0,5 \\
\hline K-Illit2 & 15,2 & 17,5 & 16,5 & 15,3 & 0,5 & 0,5 \\
\hline K-Illit3 & 15,2 & 17,5 & 16,5 & 15,3 & 0,5 & 0,5 \\
\hline Illit1 & 15,2 & 17,5 & 16,5 & 15,3 & 0,5 & 0,5 \\
\hline Illit2 & 15,2 & 17,5 & 16,5 & 15,3 & 0,5 & 0,5 \\
\hline Illit3 & 15,2 & 17,5 & 16,5 & 15,3 & 0,5 & 0,5 \\
\hline WL-Illit-Vermiculit & 15,1 & 17,5 & 16,5 & 15,3 & 0,5 & 0,6 \\
\hline WL-Chlorit-Vermiculit & 14,9 & 17,3 & 16,3 & 15,3 & 0,6 & 0,5 \\
\hline K-Vermiculit & 15 & 17,4 & 16,5 & 15,3 & 0,6 & 0,5 \\
\hline Mg-Vermiculit & 15 & 17,4 & 16,5 & 15,3 & 0,6 & 0,5 \\
\hline Ca-Vermiculit & 15 & 17,4 & 16,5 & 15,3 & 0,6 & 0,5 \\
\hline Vermiculit1 & 15 & 17,4 & 16,5 & 15,3 & 0,6 & 0,5 \\
\hline Vermiculit2 & 15 & 17,4 & 16,5 & 15,3 & 0,6 & 0,5 \\
\hline Smektit(basenreich) & 14,8 & 17,0 & 16,0 & 15,0 & 0,6 & 0,5 \\
\hline Smektit(basenarm) & 14,8 & 17,0 & 16,0 & 15,0 & 0,6 & 0,5 \\
\hline Al-Vermiculit & 14,8 & 17,0 & 16,0 & 15,0 & 0,6 & 0,5 \\
\hline labileTonminerale & 15,2 & 17,5 & 16,5 & 15,3 & 0,5 & 0,5 \\
\hline Pyrobol & 12,8 & 16,9 & 15,8 & 14,4 & 0,7 & 0,6 \\
\hline Illit & 15,2 & 17,5 & 16,5 & 15,3 & 0,5 & 0,5 \\
\hline $\mathrm{Mg}$-Vermiculit & 15 & 17,4 & 16,5 & 15,3 & 0,6 & 0,5 \\
\hline Ca-Vermiculit & 15 & 17,4 & 16,5 & 15,3 & 0,6 & 0,5 \\
\hline Al-Vermiculit & 15,2 & 17,5 & 16,5 & 15,3 & 0,5 & 0,5 \\
\hline Mg-Smektit & 14,8 & 17,0 & 16,0 & 15,0 & 0,6 & 0,5 \\
\hline Ca-Smektit & 14,8 & 17,0 & 16,0 & 15,0 & 0,6 & 0,5 \\
\hline
\end{tabular}


Tabelle A11: Mineralkinetische Modellparameter zur Berechnung der Verwitterungsrate (Angaben in kmol $m^{-2} s^{-1}$ bei einer Temperatur von $8{ }^{\circ} \mathrm{C}$ (BECKER 1999))

\begin{tabular}{|c|c|c|c|c|c|c|c|}
\hline Mineral & $\mathrm{x}_{\mathrm{Al}}$ & $\mathrm{x}_{\mathrm{BC}}$ & $\mathrm{z}_{\mathrm{Al}}$ & $\mathrm{Z}_{\mathrm{Ca}}$ & $\mathrm{C}_{\mathrm{Al}}$ & $\mathrm{C}_{\mathrm{R}}$ & $\mathrm{C}_{\mathrm{Bc}}$ \\
\hline K-Feldspat & 0,4 & 0,15 & 0,14 & 0,15 & $510^{-7}$ & $510^{-6}$ & $210^{-4}$ \\
\hline Plagioklas & 0,4 & 0,20 & 0,14 & 0,15 & $510^{-7}$ & $510^{-6}$ & $210^{-4}$ \\
\hline Pyroxen & 0,3 & 0,30 & 0,20 & 0,30 & $510^{-5}$ & $510^{-6}$ & $210^{-4}$ \\
\hline Amphibol & 0,3 & 0,30 & 0,20 & 0,30 & $510^{-5}$ & $510^{-6}$ & $210^{-4}$ \\
\hline Calcit & 0,4 & 0,40 & 0,00 & 0,20 & $510^{-3}$ & $510^{-6}$ & $110^{-3}$ \\
\hline Dolomit & 0,4 & 0,40 & 0,00 & 0,20 & $510^{-3}$ & $510^{-6}$ & $110^{-3}$ \\
\hline Fe-Al-Chlorit & 0,2 & 0,20 & 0,10 & 0,10 & $510^{-5}$ & $510^{-6}$ & $210^{-4}$ \\
\hline $\mathrm{Fe}-\mathrm{Mg}$-Chlorit & 0,2 & 0,20 & 0,10 & 0,10 & $510^{-5}$ & $510^{-6}$ & $210^{-4}$ \\
\hline Mg-Chlorit & 0,2 & 0,20 & 0,10 & 0,10 & $510^{-5}$ & $510^{-6}$ & $210^{-4}$ \\
\hline Kaolinit & 0,4 & 0,20 & 0,10 & 0,10 & $510^{-6}$ & $510^{-6}$ & $210^{-4}$ \\
\hline Al-Vermiculit & 0,4 & 0,10 & 0,20 & 0,10 & $410^{-6}$ & $510^{-6}$ & $510^{-4}$ \\
\hline K-Illit1 & 0,4 & 0,10 & 0,20 & 0,10 & $410^{-6}$ & $510^{-6}$ & $510^{-4}$ \\
\hline K-Illit2 & 0,4 & 0,10 & 0,20 & 0,10 & $410^{-6}$ & $510^{-6}$ & $510^{-4}$ \\
\hline K-Illit3 & 0,4 & 0,10 & 0,20 & 0,10 & $410^{-6}$ & $510^{-6}$ & $510^{-4}$ \\
\hline Illit1 & 0,4 & 0,10 & 0,20 & 0,10 & $410^{-6}$ & $510^{-6}$ & $510^{-4}$ \\
\hline Illit2 & 0,4 & 0,10 & 0,20 & 0,10 & $410^{-6}$ & $510^{-6}$ & $510^{-4}$ \\
\hline Illit3 & 0,4 & 0,10 & 0,20 & 0,10 & $410^{-6}$ & $510^{-6}$ & $510^{-4}$ \\
\hline WL-Illit-Vermiculit & 0,4 & 0,20 & 0,14 & 0,15 & $410^{-6}$ & $510^{-6}$ & $510^{-4}$ \\
\hline WL-Chlorit-Vermiculit & 0,3 & 0,20 & 0,10 & 0,10 & $510^{-3}$ & $510^{-6}$ & $510^{-4}$ \\
\hline K-Vermiculit & 0,4 & 0,20 & 0,10 & 0,10 & $410^{-6}$ & $510^{-6}$ & $510^{-4}$ \\
\hline Mg-Vermiculit & 0,4 & 0,20 & 0,10 & 0,10 & $410^{-6}$ & $510^{-6}$ & $510^{-4}$ \\
\hline Ca-Vermiculit & 0,4 & 0,20 & 0,10 & 0,10 & $410^{-6}$ & $510^{-6}$ & $510^{-4}$ \\
\hline Vermiculit1 & 0,4 & 0,20 & 0,10 & 0,10 & $410^{-6}$ & $510^{-6}$ & $510^{-4}$ \\
\hline Vermiculit2 & 0,4 & 0,20 & 0,10 & 0,10 & $410^{-6}$ & $510^{-6}$ & $510^{-4}$ \\
\hline Smektit(basenreich) & 0,3 & 0,20 & 0,20 & 0,20 & $410^{-6}$ & $510^{-6}$ & $210^{-4}$ \\
\hline Smektit(basenarm) & 0,3 & 0,20 & 0,20 & 0,20 & $410^{-6}$ & $510^{-6}$ & $210^{-4}$ \\
\hline Al-Vermiculit & 0,3 & 0,20 & 0,20 & 0,20 & $410^{-6}$ & $510^{-6}$ & $210^{-4}$ \\
\hline labile'Tonminerale & 0,4 & 0,10 & 0,20 & 0,10 & $410^{-6}$ & $510^{-6}$ & $510^{-4}$ \\
\hline Pyrobol & 0,3 & 0,30 & 0,20 & 0,30 & $510^{-6}$ & $510^{-6}$ & $210^{-4}$ \\
\hline Illit & 0,4 & 0,10 & 0,20 & 0,10 & $410^{-6}$ & $510^{-6}$ & $510^{-4}$ \\
\hline Mg-Vermiculit & 0,4 & 0,20 & 0,10 & 0,10 & $410^{-6}$ & $510^{-6}$ & $510^{-4}$ \\
\hline $\mathrm{Ca}-$ Vermiculit & 0,4 & 0,20 & 0,10 & 0,10 & $410^{-6}$ & $510^{-6}$ & $510^{-4}$ \\
\hline Al-Vermiculit & 0,4 & 0,10 & 0,20 & 0,10 & $410^{-6}$ & $510^{-6}$ & $510^{-4}$ \\
\hline Mg-Smektit & 0,3 & 0,20 & 0,20 & 0,20 & $410^{-6}$ & $510^{-6}$ & $210^{-4}$ \\
\hline Ca-Smektit & 0,3 & 0,20 & 0,20 & 0,20 & $410^{-6}$ & $510^{-6}$ & $210^{-4}$ \\
\hline
\end{tabular}


Tabelle A12: Aktivierungsenergie zur Berechnung der temperaturabhängigen Reaktionsgeschwindigkeitskonstanten (BECKER 1999)

\begin{tabular}{|c|c|c|c|c|}
\hline \multirow{2}{*}{ Mineral } & \multicolumn{4}{|c|}{$\mathrm{EA} \mathrm{R}^{-1}$} \\
\hline & $\mathrm{pk}_{\mathrm{H}}$ & $\mathrm{pk}_{\mathrm{H} 2 \mathrm{O}}$ & $\mathrm{pk}_{\mathrm{CO} 2}$ & $\mathrm{pk}_{\mathrm{R}}$ \\
\hline K-Feldspat & 3500 & 2000 & 1700 & 1200 \\
\hline Plagioklas & 4200 & 2500 & 1700 & 1200 \\
\hline Pyroxen & 3500 & 3800 & 1700 & 2000 \\
\hline Amphibol & 3500 & 3800 & 1700 & 2000 \\
\hline Calcit & 1000 & 2800 & 2180 & 2200 \\
\hline Dolomit & 1880 & 2700 & 1800 & 2200 \\
\hline Fe-Al-Chlorit & 4500 & 3500 & 1700 & 1800 \\
\hline Fe-Mg-Chlorit & 4500 & 3500 & 1700 & 1800 \\
\hline Mg-Chlorit & 4500 & 3500 & 1700 & 1800 \\
\hline Kaolinit & 4300 & 3800 & 1700 & 3000 \\
\hline Al-Vermiculit & 4400 & 3800 & 1700 & 2000 \\
\hline K-Illit1 & 4500 & 3800 & 1700 & 2000 \\
\hline K-Illit2 & 4500 & 3800 & 1700 & 2000 \\
\hline K-Illit3 & 4500 & 3800 & 1700 & 2000 \\
\hline Illit1 & 4500 & 3800 & 1700 & 2000 \\
\hline Illit2 & 4500 & 3800 & 1700 & 2000 \\
\hline Illit3 & 4500 & 3800 & 1700 & 2000 \\
\hline WL-Illit-Vermiculit & 4400 & 3800 & 1700 & 2000 \\
\hline WL-Chlorit-Vermiculit & 4400 & 3600 & 1700 & 1900 \\
\hline K-Vermiculit & 4300 & 3800 & 1700 & 2000 \\
\hline Mg-Vermiculit & 4300 & 3800 & 1700 & 2000 \\
\hline Ca-Vermiculit & 4300 & 3800 & 1700 & 2000 \\
\hline Vermiculit1 & 4300 & 3800 & 1700 & 2000 \\
\hline Vermiculit2 & 4300 & 3800 & 1700 & 2000 \\
\hline Smektit(basenreich) & 4500 & 3500 & 1700 & 1800 \\
\hline Smektit(basenarm) & 4500 & 4000 & 2100 & 3000 \\
\hline Al-Vermiculit & 4500 & 4000 & 2100 & 3000 \\
\hline labile'Tonminerale & 4500 & 3800 & 1700 & 2000 \\
\hline Pyrobol & 3500 & 3800 & 1700 & 2000 \\
\hline Illit & 4500 & 3800 & 1700 & 2000 \\
\hline Mg-Vermiculit & 4300 & 3800 & 1700 & 2000 \\
\hline Ca-Vermiculit & 4300 & 3800 & 1700 & 2000 \\
\hline Al-Vermiculit & 4400 & 3800 & 1700 & 2000 \\
\hline Mg-Smektit & 4500 & 3500 & 1700 & 1800 \\
\hline Ca-Smektit & 4500 & 3500 & 1700 & 1800 \\
\hline
\end{tabular}


Tabelle A13: Stöchiometrie der im Modellsystem hinterlegten Minerale (BECKER 1999)

\begin{tabular}{|c|c|c|c|c|c|c|c|}
\hline Mineral & $\mathrm{Ca}$ & $\mathrm{Mg}$ & K & $\mathrm{Na}$ & $\mathrm{Al}$ & $\mathrm{Si}$ & $\mathrm{PO}_{4}$ \\
\hline K-Feldspat & 0 & 0 & 0,9 & 0,1 & 1 & 3 & 0 \\
\hline Plagioklas & 0,15 & 0 & 0 & 0,7 & 1 & 3 & 0 \\
\hline Pyroxen & 0,25 & 0,25 & 0 & 0 & 0,033 & 1,125 & 0 \\
\hline Amphibol & 0,165 & 0,335 & 0 & 0 & 0,167 & 0,55 & 0 \\
\hline Calcit & 0,975 & 0,02 & 0 & 0 & 0 & 0 & 0,05 \\
\hline Dolomit & 0,61 & 0,36 & 0 & 0 & 0 & 0 & 0,005 \\
\hline Fe-Al-Chlorit & 0 & 0,2 & 0 & 0 & 2,58 & 2,28 & 0 \\
\hline Fe-Mg-Chlorit & 0 & 2,12 & 0 & 0 & 2,58 & 2,28 & 0 \\
\hline Mg-Chlorit & 0 & 4,28 & 0 & 0 & 2,58 & 2,28 & 0 \\
\hline Kaolinit & 0 & 0 & 0 & 0 & 1 & 1 & 0 \\
\hline Al-Vermiculit & 0,12 & 0,33 & 0,1 & 0 & 3,773 & 3,24 & 0 \\
\hline K-Illit1 & 0 & 0,07 & 0,57 & 0,01 & 2,04 & 3,5 & 0 \\
\hline K-Illit2 & 0 & 0,06 & 0,53 & 0,01 & 2,06 & 3,5 & 0 \\
\hline K-Illit3 & 0 & 0,05 & 0,49 & 0,01 & 2,08 & 3,5 & 0 \\
\hline Illit1 & 0,02 & 0,23 & 0,7 & 0 & 2 & 3,5 & 0 \\
\hline Illit2 & 0,02 & 0,18 & 0,6 & 0 & 2,05 & 3,5 & 0 \\
\hline Illit3 & 0,025 & 0,14 & 0,5 & 0 & 2,1 & 3,5 & 0 \\
\hline WL-Illit-Vermiculit & 0,05 & 0,15 & 0,4 & 0 & 2,1 & 3,5 & 0 \\
\hline $\begin{array}{l}\text { WL-Chlorit- } \\
\text { Vermiculit }\end{array}$ & 0,085 & 0,385 & 0,025 & 0 & 1,66 & 2,06 & 0 \\
\hline K-Vermiculit & 0,01 & 0,2 & 0,33 & 0 & 2,15 & 3,4 & 0 \\
\hline Mg-Vermiculit & 0 & 0,47 & 0 & 0 & 2,32 & 2,92 & 0 \\
\hline Ca-Vermiculit & 0,37 & 0,1 & 0 & 0 & 2,32 & 2,92 & 0 \\
\hline Vermiculit1 & 0,17 & 0,27 & 0,05 & 0 & 2,32 & 2,92 & 0 \\
\hline Vermiculit2 & 0,14 & 0,21 & 0,04 & 0 & 2,82 & 3 & 0 \\
\hline Smektit(basenreich) & 0,08 & 0,47 & 0,02 & 0,02 & 1,56 & 3,95 & 0 \\
\hline Smektit(basenarm) & 0,04 & 0,24 & 0,01 & 0,02 & 1,7 & 3,95 & 0 \\
\hline Al-Vermiculit & 0,06 & 0,14 & 0,07 & 0,01 & 2,92 & 3,24 & 0 \\
\hline labile'Tonminerale & 0,025 & 0,125 & 0,01 & 0,01 & 1,68 & 3,95 & 0 \\
\hline Pyrobol & 0,21 & 0,29 & 0 & 0 & 0,1 & 0,84 & 0 \\
\hline Illit & 0 & 0 & 0,71 & 0 & 2,23 & 3,5 & 0 \\
\hline Mg-Vermiculit & 0 & 0,3 & 0 & 0 & 2,6 & 3,4 & 0 \\
\hline $\mathrm{Ca}-$ Vermiculit & 0,3 & 0 & 0 & 0 & 2,6 & 3,4 & 0 \\
\hline Al-Vermiculit & 0 & 0 & 0 & 0 & 4,35 & 3,24 & 0 \\
\hline Mg-Smektit & 0 & 0,19 & 0 & 0 & 1,94 & 3,95 & 0 \\
\hline Ca-Smektit & 0,19 & 0 & 0 & 0 & 1,94 & 3,95 & 0 \\
\hline
\end{tabular}


Tabelle A14: Rohdichte $\left[\mathrm{kg} \mathrm{fm}^{-1}\right]$ von trockenem Derbholz und Derbrinde (zugeordnet auf Grundlage der Angaben aus WAGENFÜHR 2000 und KRAMER 1988)

\begin{tabular}{|c|c|c|c|c|c|}
\hline Baumart & Derbholz & Derbrinde & Baumart & Derbholz & Derbrinde \\
\hline $\mathrm{Ei}$ & 650 & 440 & $\mathrm{JBi}$ & 610 & 420 \\
\hline Sei & 650 & 440 & Erl & 510 & 330 \\
\hline Tei & 650 & 440 & Rerl & 510 & 330 \\
\hline Rei & 660 & 440 & WErl & 510 & 330 \\
\hline Zei & 630 & 440 & GErl & 510 & 330 \\
\hline $\mathrm{Bu}$ & 680 & 430 & $\mathrm{~Pa}$ & 410 & 230 \\
\hline $\mathrm{Hbu}$ & 790 & 430 & As & 450 & 230 \\
\hline Es & 650 & 435 & Spa & 410 & 230 \\
\hline $\mathrm{Ah}$ & 590 & 410 & $\mathrm{GPa}$ & 410 & 230 \\
\hline $\mathrm{Bah}$ & 590 & 410 & $\mathrm{BPa}$ & 410 & 230 \\
\hline SAh & 590 & 410 & Wei & 330 & 230 \\
\hline Fah & 590 & 410 & RKast & 510 & 230 \\
\hline Rü & 640 & 430 & EbEs & 730 & 435 \\
\hline BRü & 640 & 430 & TKir & 545 & 435 \\
\hline FlaRü & 640 & 430 & $\mathrm{Fi}$ & 430 & 275 \\
\hline FRü & 640 & 430 & $\mathrm{SFi}$ & 430 & 275 \\
\hline $\mathrm{Li}$ & 490 & 330 & $\mathrm{OFi}$ & 430 & 275 \\
\hline Sli & 490 & 330 & SteFi & 430 & 275 \\
\hline WLi & 490 & 330 & $\mathrm{Ta}$ & 410 & 360 \\
\hline Rob & 740 & 435 & WTa & 410 & 360 \\
\hline Kast & 560 & 435 & NTa & 410 & 360 \\
\hline $\mathrm{Nuß}$ & 640 & 435 & $\mathrm{KTa}$ & 370 & 360 \\
\hline Kir & 550 & 435 & KolTa & 410 & 360 \\
\hline Apf & 700 & 435 & ETa & 410 & 360 \\
\hline $\mathrm{Bir}$ & 700 & 435 & $\mathrm{JTa}$ & 410 & 360 \\
\hline Els & 710 & 435 & $\mathrm{VTa}$ & 410 & 360 \\
\hline Mehl & 710 & 435 & $\mathrm{PTa}$ & 410 & 360 \\
\hline Zwe & 700 & 435 & Ts & 440 & 360 \\
\hline $\mathrm{Bi}$ & 610 & 420 & Th & 350 & 360 \\
\hline Sbi & 610 & 420 & $\mathrm{Ch}$ & 460 & 360 \\
\hline Mbi & 610 & 420 & Seqg & 370 & 360 \\
\hline Eibe & 640 & 360 & Pcont & 490 & 320 \\
\hline $\mathrm{Dgl}$ & 470 & 360 & Stro & 370 & 320 \\
\hline $\mathrm{Ki}$ & 490 & 320 & Lä & 550 & 360 \\
\hline Ski & 490 & 320 & ELa & 550 & 360 \\
\hline Bki & 490 & 320 & JLä & 550 & 360 \\
\hline
\end{tabular}


Anhang 3: Fragebogen Waldbewirtschaftung

\section{Waldbestände}

Bitte geben Sie für die Baumarten Eiche, Buche und Kiefer jeweils 2-3 Beispielbestände an!

Welche der älteren Bestände (> 60 Jahre) sind besonders stark geschädigt?

Welche der älteren Bestände präsentieren sich noch vital?

Wie reagieren jüngere Bestände (<60 Jahre)? Zum Beispiel: Wird ein massives Absterben im Alter von 30-40 Jahren beobachtet?

\section{Verjüngung}

Wenn möglich, bitte für den Zeitraum ab 1993 in beiliegendem Formular eintragen.

Bitte nur Flächen auffübren, bei denen eine freie Wabl der Baumarten bestand (also keine Einschränkungen vorlagen, wie sie ₹. B. bei Kompensationsmaßnahmen bäufig vorkommen).

Welche Baumarten wurden versucht?

Standortheimische: Eiche, Buche, Kiefer (wenn möglich jeweils 2-3 Bsp.)

Andere Baumarten: Roteiche, Douglasie, Robinie... (möglichst alle Verjüngungsversuche)

Welche Verfahren kamen zum Einsatz?

Waldbauliche Verfahren: Saat, Voranbau, Naturverjüngung, Pflanzung

Technische Umsetzung: Pflanzverband, Bodenbearbeitung, Pflanzverfabren...

Wie ist Ihre bisherige Einschätzung?

\section{Sonstige Beobachtungen}

Wann setzten die massiven Schädigungen (bzw. Erholungen) ein?

Stichpunkte:

Baumaßnahmen, Windwurf, neue/verstärkte Immissionen

Insektenkalamitäten, Trockenjahre (wie der Sommer 2003)

besonders betroffene Expositionen, Schäden trotz intakter Waldränder etc. 
Anhang 4: Sortimentierungsschlüssel
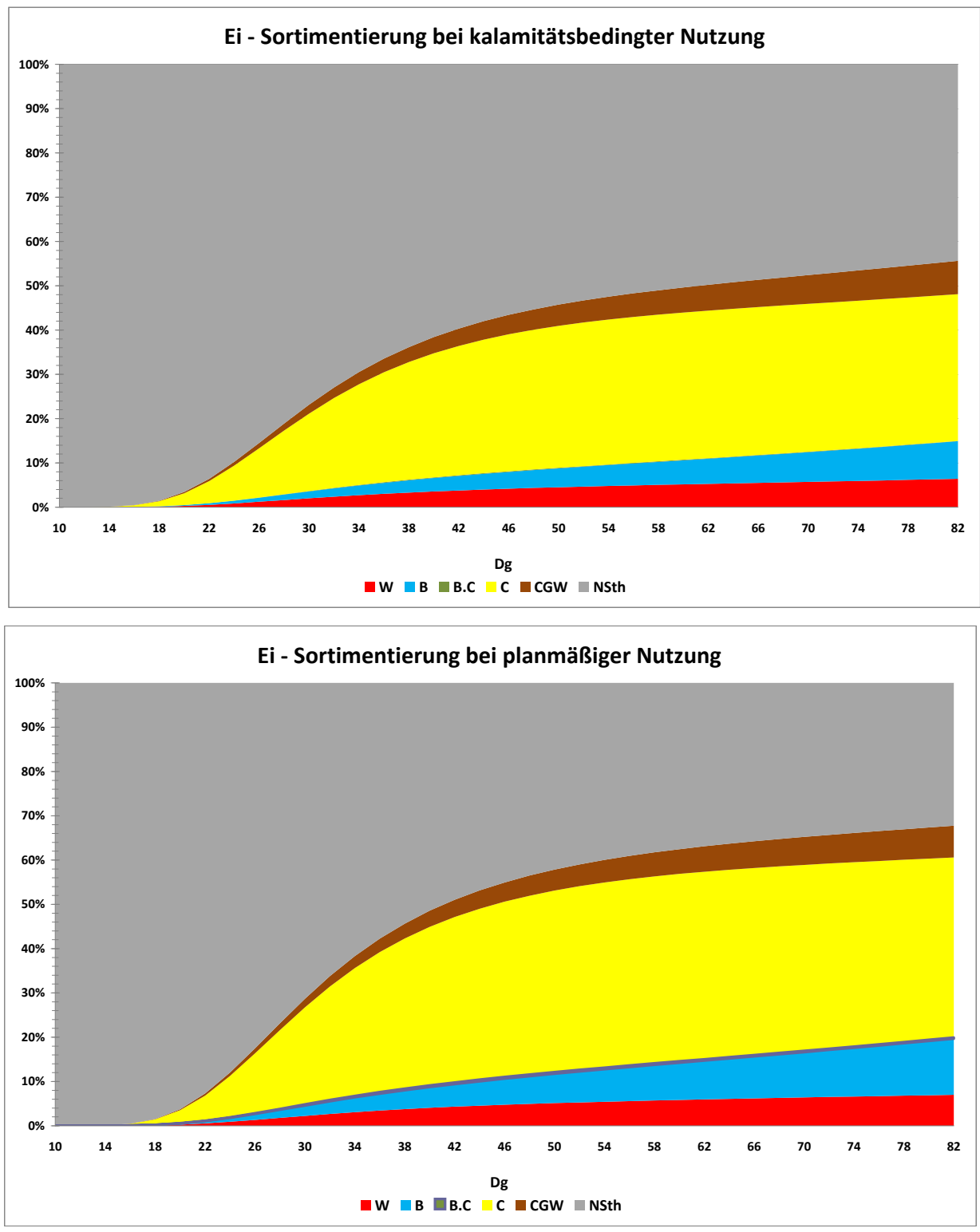

Abbildung A4: Sortimentierungsfächer für die Baumartengruppe Eiche bei kalamitätsbedingter (oben) und planmäßiger Nutzung (unten)

Beiträge aus der NW-FVA, Band 10, 2013 

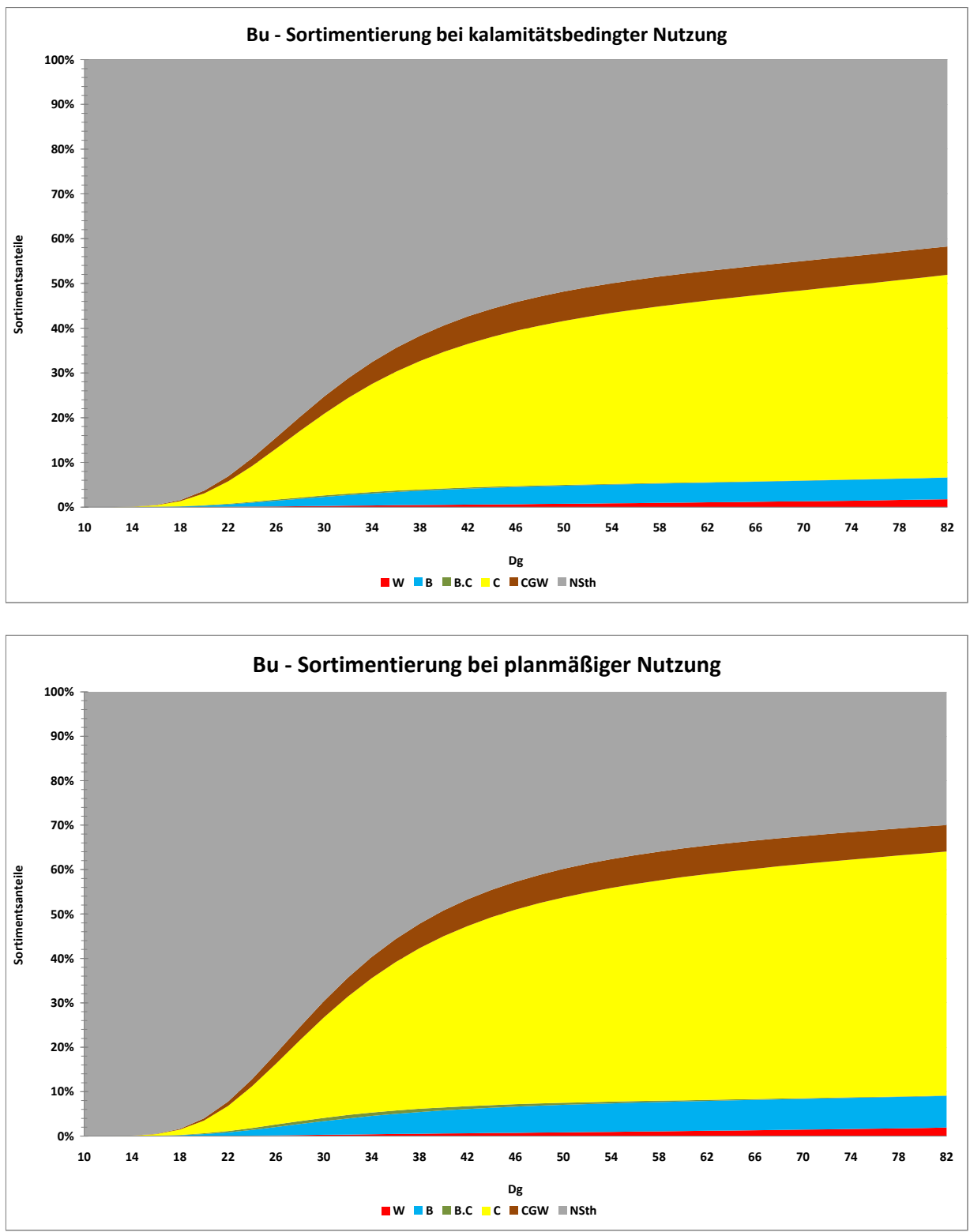

Abbildung A5: Sortimentierungsfächer für die Baumartengruppe Buche bei kalamitätsbedingter (oben) und planmäßiger Nutzung (unten) 

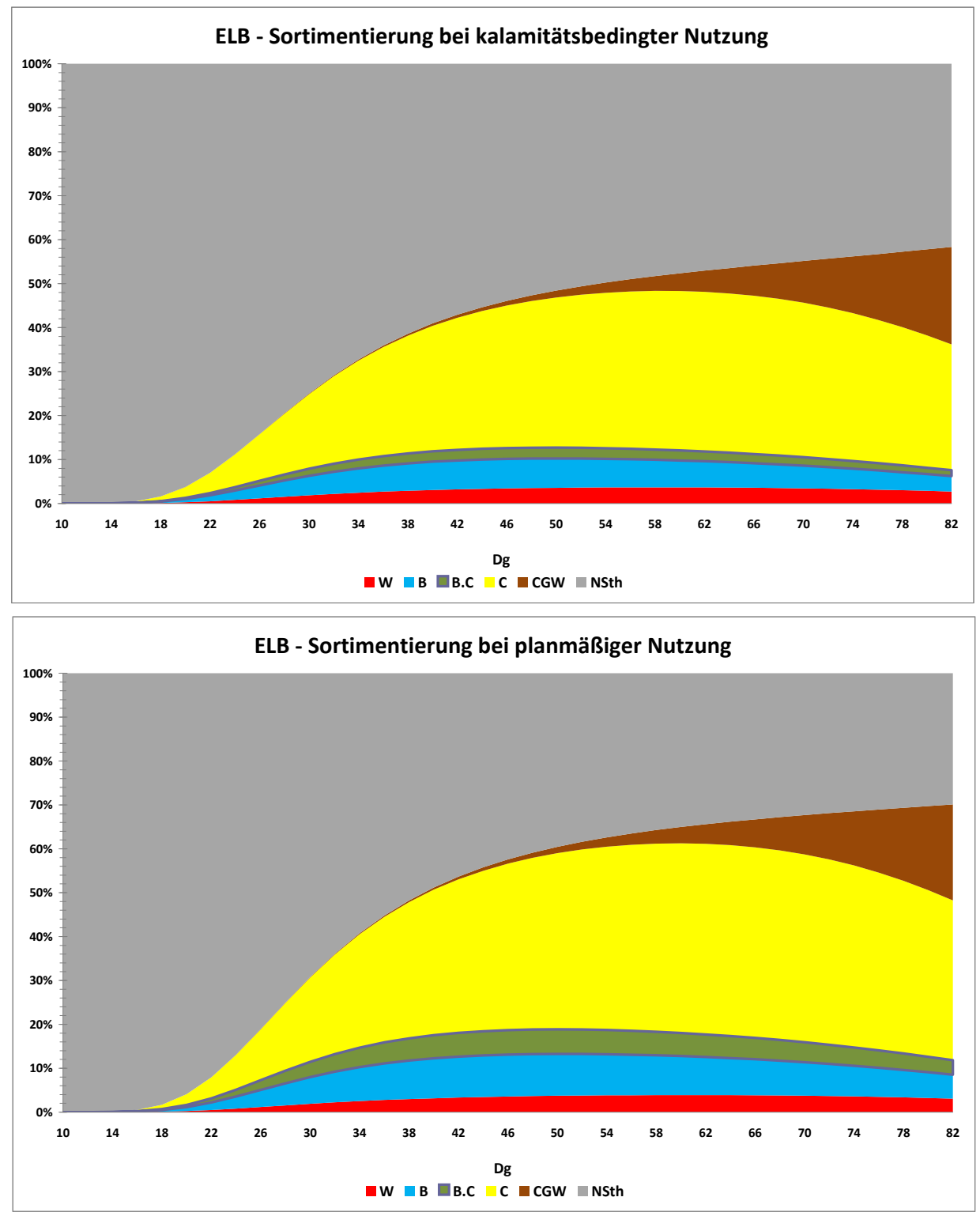

Abbildung A6: Sortimentierungsfächer für die Baumartengruppe Edellaubbäume bei kalamitätsbedingter (oben) und planmäßiger Nutzung (unten)

Beiträge aus der NW-FVA, Band 10, 2013 

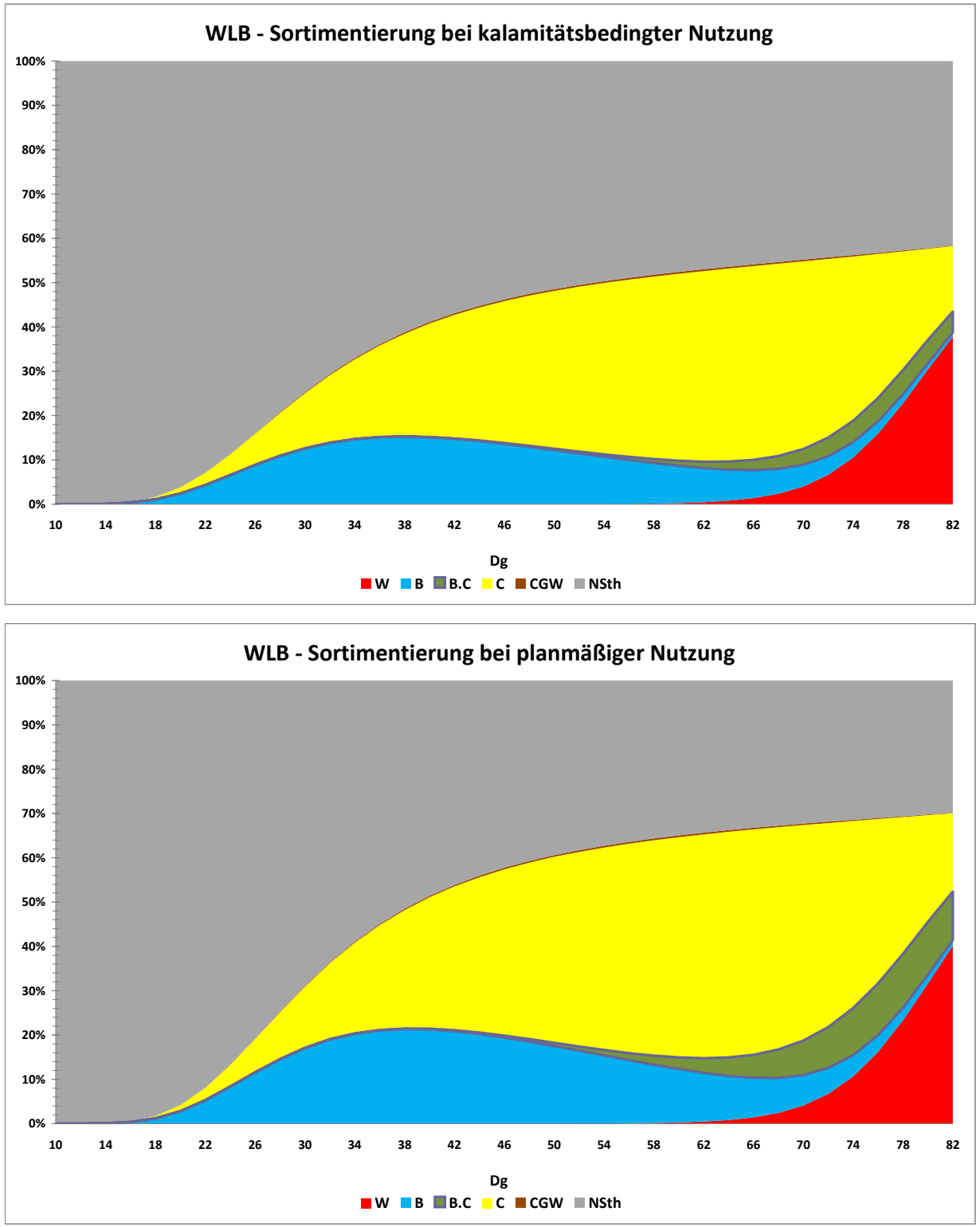

Abbildung A7: Sortimentierungsfächer für die Baumartengruppe Weichlaubbäume bei kalamitätsbedingter (oben) und planmäßiger Nutzung (unten) 

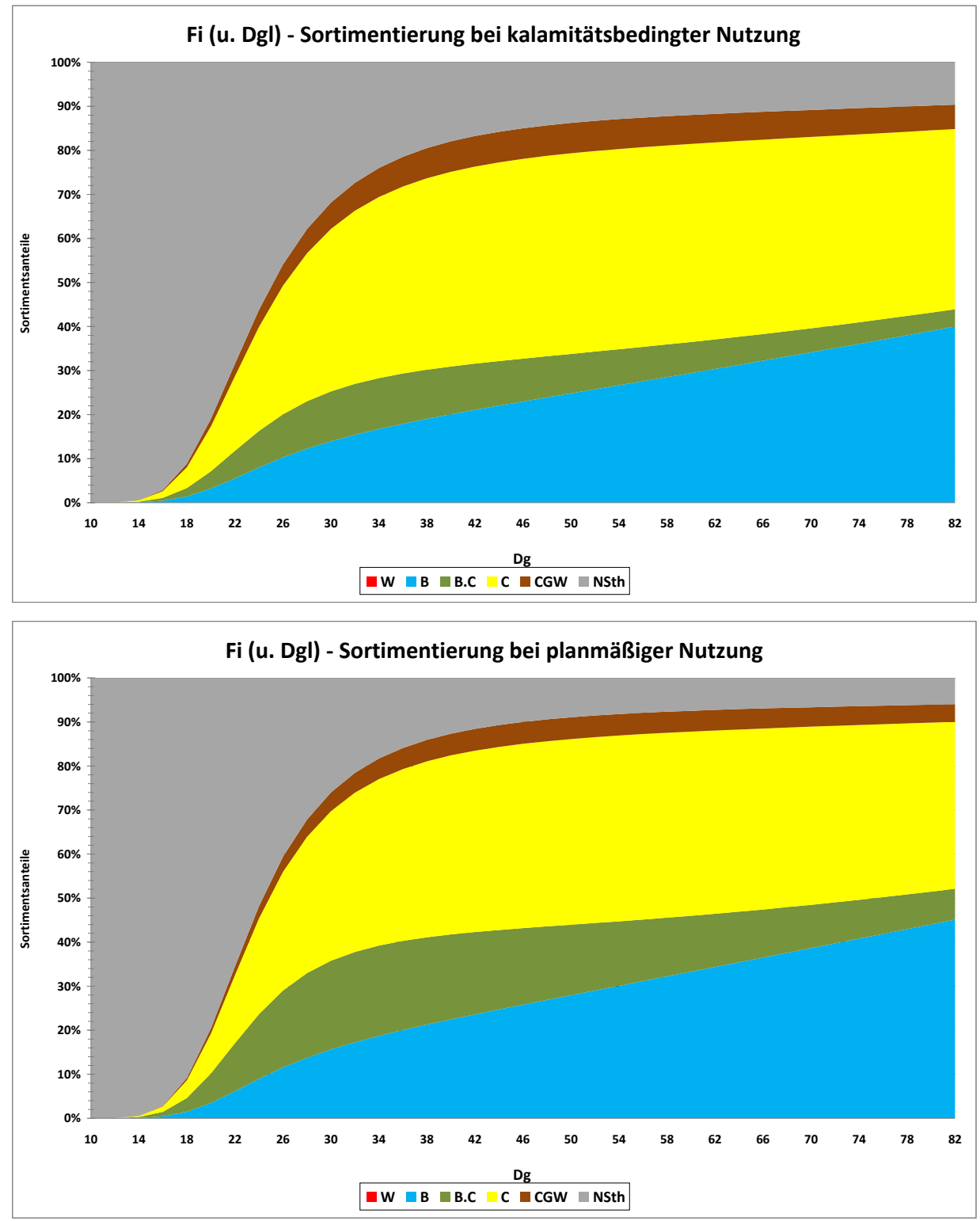

Abbildung A8: Sortimentierungsfächer für die Baumartengruppe Fichte bei kalamitätsbedingter (oben) und planmäßiger Nutzung (unten) 
Anhang 5: Ertragswertdifferenzen

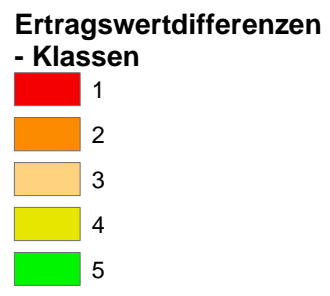

\section{Grundwasserstraten}

Ull/ vGw
IIIA gGw
nGw
Gw

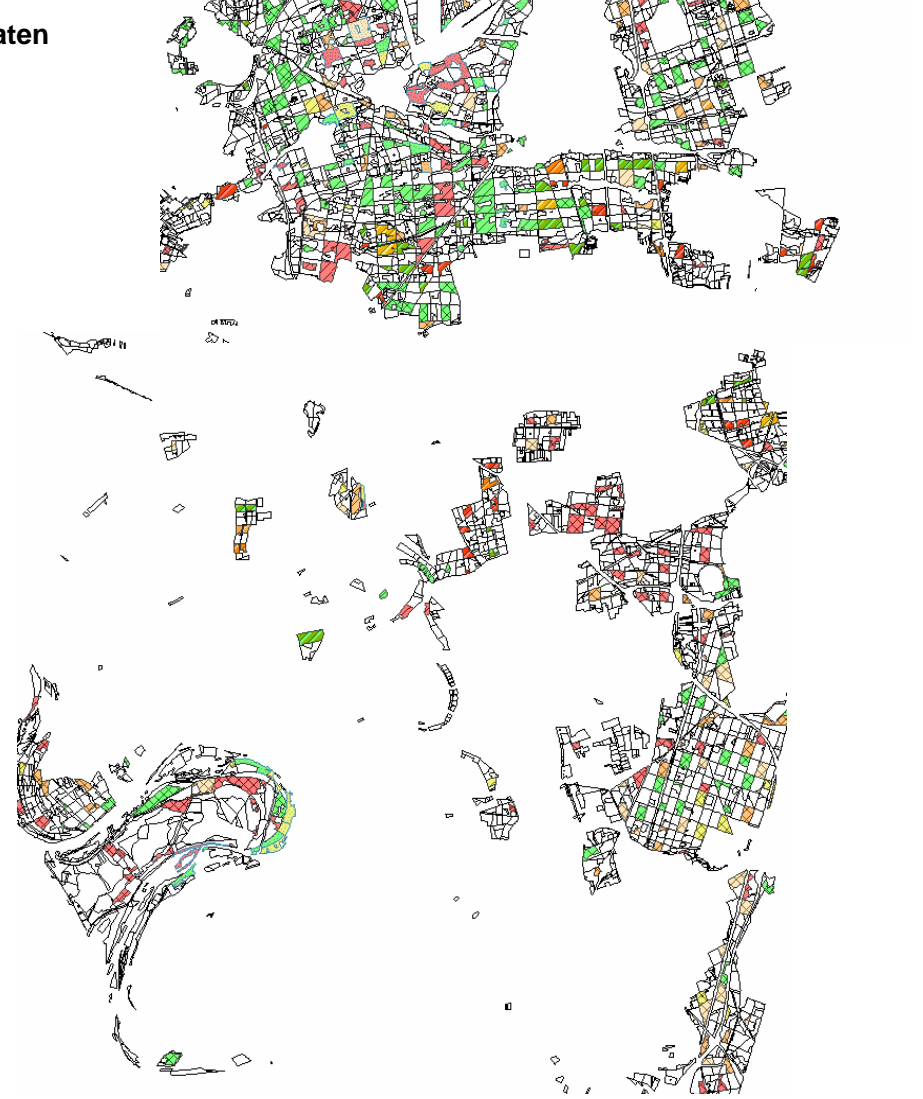

Abbildung A9: Ertragswertdifferenzen zwischen Kalamitätsbetrieb und Modellbetrieb und Grundwassersituation in den ausgewäblten Beständen (Nordteil: Frankfurt, Langen, Darmstadt, Groß Gerau Nord) (1 = Ertragswertminderung $>5000 € /$ ha, $2=$ Ertragswertminderung $2501 € /$ ha bis $5000 € /$ ha, $3=$ Ertragswertminderung $1001 € /$ ha bis $2500 € /$ ha, $4=$ Ertragswertminderung $1 € /$ ha bis $1000 € /$ ha, $5=$ Ertragswertminderung $<1 € /$ ha; $v G W=$ Grundwasseranschluss verloren, $g G W=$ Grundwasserstand gesunken, aber Anschluss vorhanden, $n G W=$ bereits 1967 kein Grundwasseranschluss vorbanden, $G W=$ Grundwasseranschluss 1967 und 2007 vorbanden) 


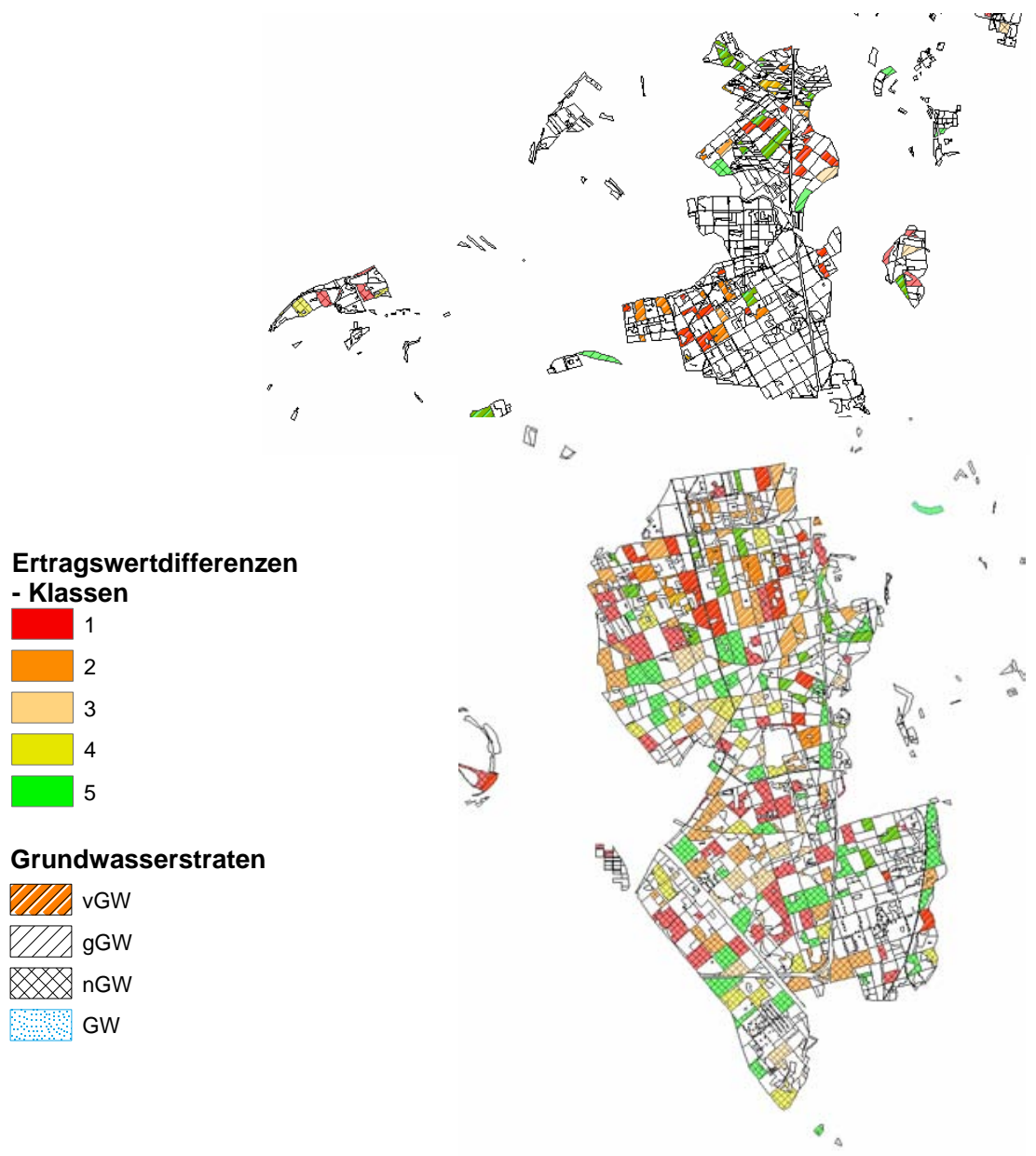

Abbildung A10: Ertragswertdifferenzen zwischen Kalamitätsbetrieb und Modellbetrieb und Grundwassersituation in den ausgewählten Beständen (Südteil: Groß-Gerau Süd, Lampertheim $) \quad(1=$ Ertragswertminderung $>5000 € /$ ha,$\quad 2=$ Ertragswertminderung $2501 € /$ ha bis $5000 € /$ ha, $3=$ Ertragswertminderung $1001 € /$ ha bis $2500 € /$ ha, $4=$ Ertragswertminderung $1 € /$ ha bis $1000 € /$ ha,$\quad 5=$ Ertragswertminderung $<1 € /$ ha; $\nu G W=$ Grundwasseranschluss verloren, $g G W=$ Grundwasserstand gesunken, aber Anschluss vorbanden, $n G W=$ bereits 1967 kein Grundwasseranschluss vorhanden, $G W=$ Grundwasseranschluss 1967 und 2007 vorhanden) 



\section{Beiträge aus der Nordwestdeutschen Forstlichen Versuchsanstalt}

Band

1 (2007) Clusterstudie Forst und Holz Niedersachsen. Burkhard Rüther, Jan Hansen, Agatha Ludwig, Hermann Spellmann, Jürgen Nagel, Bernhard Möhring, Matthias Dieter. 92 S.

2 (2008) Die Waldkiefer - Fachtagung zum Baum des Jahres 2007. Nordwestdeutsche Forstliche Versuchsanstalt (Hrsg.). 98 S.

3 (2008) Ergebnisse angewandter Forschung zur Buche. Nordwestdeutsche Forstliche Versuchsanstalt (Hrsg.). 343 S.

4 (2008) Ergebnisse des westdeutschen IUFRO-Küstentannen-Provenienzversuches im Alter 27. Hans-Martin Rau, Armin König, Wolfhard Ruetz, Hendrik Rumpf, Egbert Schönfelder. $62 \mathrm{~S}$.

5 (2010) Fichtenherkunftsversuch von 1962 und IUFRO-Fichtenherkunftsversuch von 1972. Ergebnisse von mehr als 30jähriger Beobachtung in Deutschland. Mirko Liesebach, Hans-Martin Rau, Armin O. König. 467 S.

6 (2011) Kohlenstoffstudie Forst und Holz Niedersachsen. René Wördehoff, Hermann Spellmann, Jan Evers, Jürgen Nagel. 92 S.

7 (2012) Das digitale Luftbild. Ein Praxisleitfaden für Anwender im Forst- und Umweltbereich. Arbeitsgruppe Forstlicher Luftbildinterpreten (Hrsg.). $84 \mathrm{~S}$.

8 (2012) Züchtung und Ertragsleistung schnellwachsender Baumarten im Kurzumtrieb. Erkenntnisse aus drei Jahren FastWood, ProLoc und Weidenzüchtung. Fachtagung vom 21. bis 22.09.2011 in Hann. Münden. Nordwestdeutsche Forstliche Versuchsanstalt (Hrsg.). $430 \mathrm{~S}$.

9 (2012) SILVAQUA - Auswirkungen forstlicher Bewirtschaftsungsmaßnahmen auf den Zustand von Gewässern in bewaldeten Einzugsgebieten am Beispiel der Oker im Nordharz. Nordwestdeutsche Forstliche Versuchsanstalt (Hrsg.). 226 S.

10 (2013) Waldentwicklungsszenarien für das Hessische Ried. Entscheidungsunterstützung vor dem Hintergrund sich beschleunigt ändernder Wasserhaushalts- und Klimabedingungen und den Anforderungen aus dem europäischen Schutzgebietssystem Natura 2000. Nordwestdeutsche Forstliche Versuchsanstalt (Hrsg.). 397 S. 
Alle Bände der „Beiträge aus der NW-FVA“ sind auch als freie Onlineversion über die Homepage der NW-FVA (www.nw-fva.de), des Verlages sowie über den OPAC der Niedersächsischen Staats- und Universitätsbibliothek (http://www.sub.uni-goettingen.de) erreichbar und dürfen gelesen, heruntergeladen sowie als Privatkopie ausgedruckt werden. Es gelten die Lizenzbestimmungen der Onlineversion. Es ist nicht gestattet, Kopien oder gedruckte Fassungen der freien Onlineversion zu veräußern. 
Die Wälder im Ballungsraum Rhein-Main gehören zu den forstlichen Brennpunkten in Mitteleuropa. Flächenverbrauch, Zerschneidung, Stoffeinträge aus der Luft, steigender Wasserbedarf sowie eine Vielzahl biotischer Schaderreger führen zur Destabilisierung der Wälder. Die ökologischen Rahmenbedingungen werden sich in Zukunft durch den Klimawandel weiter verschlechtern. In der vorliegenden Untersuchung wurden mit einem modellorientierten Ansatz die Auswirkungen der sich ändernden Umweltbedingungen auf die Leistungen und Wirkungen der Wälder sowie auf die Handlungsspielräume der Forstbetriebe im Hessischen Ried für einen 30-jährigen Prognosezeitraum abgebildet. Hierdurch erhalten Politik, Fachverwaltungen und Waldbesitzer eine raumbezogene Wissens- und Entscheidungsbasis, um die Waldfunktionen bzw. die gesellschaftlichen Ansprüche an den Wald in der Fläche neu zu gewichten, Vermeidungs- bzw. Anpassungsstrategien zu entwickeln und gezielte Maßnahmen zur Sanierung der bereits stark geschädigten Waldgebiete einzuleiten.

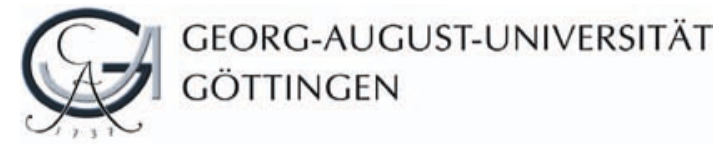

ISBN: $978-3-86395-110-8$

ISSN: $1865-6994$

\section{Universitätsdrucke Göttingen}

